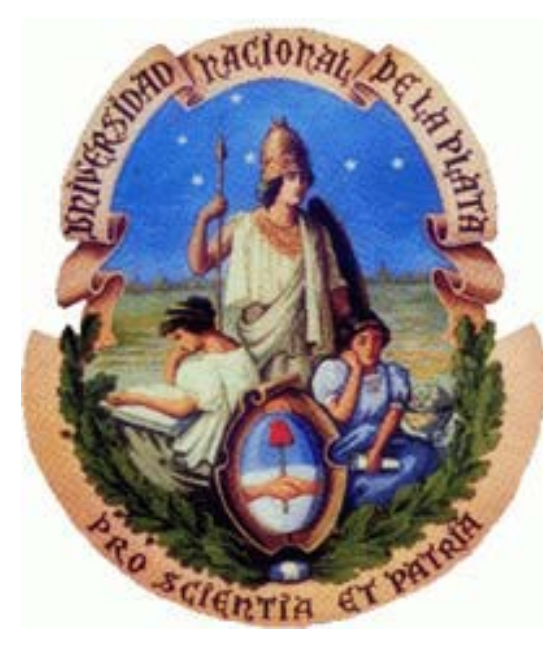

Universidad Nacional de La Plata

Facultad de Ciencias Exactas

Departamento de Química

\title{
Aprovechamiento integral de raíces de ahipa \\ (Pachyrhizus ahipa) y sus productos derivados con fines alimentarios
}

\author{
Tesis Doctoral \\ María Cecilia Doporto \\ Directora: Dra. Sonia Z. Viña \\ Co-Directora: Dra. María Alejandra García
}


El presente trabajo de Tesis para optar al título de Doctor de la Facultad de Ciencias Exactas fue realizado en el Centro de Investigación y Desarrollo en Criotecnología de Alimentos (CIDCA), de la Facultad de Ciencias Exactas, Universidad Nacional de La Plata y el CONICET-La Pata, bajo la dirección de la Dra. Sonia Zulma Viña y la Dra. María Alejandra García. 
A Juan Ignacio y María Emilia

A Gonzalo 


\section{AGRADECIMIENTOS}

Deseo expresar mi agradecimiento a todas aquellas personas que de una manera $u$ otra hicieron posible la realización de este trabajo de Tesis, y muy especialmente:

A la Dra. Sonia Viña, mi directora de Tesis, por su participación y constante apoyo; por sus apreciados y relevantes aportes, además por sus críticas, comentarios y sugerencias durante el desarrollo de esta investigación.

A la Dra. Maria Alejandra García, mi co-directora de Tesis, por su incondicionalidad, y apoyo; por su experiencia, aportes y sugerencias acertadas. Además por su ejemplo docente y dedicación a lo largo de todos estos años.

A la Dra. Alicia Chaves, por haberme recibido tan amablemente en el CIDCA. También por darme un lugar en su grupo de trabajo y a las personas del mismo que hicieron posible esta Tesis.

A la Agencia Nacional de Promoción de la Ciencia y Tecnología (ANPCyT), al Consejo Nacional de Investigaciones Científicas y Técnicas (CONICET) y a la Universidad Nacional de La Plata (UNLP) por permitir financiar el presente trabajo.

Al personal de la Estación Experimental del INTA (Montecarlo, Misiones) por suministrarme las raíces de ahipa y mandioca.

A Alicia Mugridge por su comprensión, incondicionalidad, dedicación, charlas y mates.

A Cecilia Dini por su incondicionalidad, amistad, mates y charlas. Además de su ayuda y colaboración en el laboratorio, especialmente en la determinación de antinutrientes en las raíces de ahipa.

A Olivia López por su agradable compañía en el laboratorio, apoyo, mates y charlas. También por las determinaciones realizadas en el PLAPIQUI (CONICET) de Bahía Blanca.

A Fernanda Sacco por su colaboración en la elaboración de las galletitas.

A Eduardo Denisenia y Florencia Versino por la ayuda en el rallado y procesamiento de las raíces.

A Daniela Olivera, por su comprensión y colaboración en la aplicación de los modelos matemáticos para ajustar las isotermas de sorción. A Micaela Ureta y Viviana Salvadori por su buena predisposición y uso del horno.

A Marina Urriza por su agradable compañía y ayuda con el Kjeldahl.

A Javier Lecot y Daniel Russo por haberme ayudado con las experiencias del DSC.

A Arturo Colavita por la determinación de fósforo realizada. 
Al grupo de Cristina Ferrero (CIDCA) por los materiales compartidos para la determinación de Fibra Dietaria Total.

A Diana Velasco por su eficiente búsqueda del material bibliográfico solicitado a lo largo de la Tesis.

Al Dr. Fernando Chirdo del LISIN de la Facultad de Ciencias Exactas (UNLP) por la determinación de prolaminas en muestras de ahipa.

A las Cátedras de Química Analítica I y Bromatología de la Facultad de Ciencias Exactas por facilitarme la mufla.

A la Prof. María Rosa Simón y la Sra. Mirta Castaño del Curso Cereales de la Facultad de Ciencias Agrarias y Forestales (UNLP), por habernos facilitado el uso del cernidor de laboratorio.

A la Ing. Agr. Marina Sisterna de la Facultad de Ciencias Agrarias y Forestales (UNLP), por la conducción de los ensayos microbiológicos.

A la Ing. Agr. Adriana Chamorro del Curso Oleaginosas de la Facultad de Ciencias Agrarias Forestales (UNLP) por las semillas de colza suministradas.

A mis compañeros del CIDCA, especialmente a mis compañeros de laboratorio y de box por brindarme su apoyo y compañerismo en todo momento.

A mis compañeros de las cátedras de Química de Ingeniería Industrial y Química Analítica I, por su comprensión a lo largo de la Tesis.

A mis amigos por su paciencia, comprensión y apoyo.

A mi familia, por apoyarme y acompañarme siempre. 


\section{PUBLICACIONES}

Durante el desarrollo de la presente Tesis Doctoral se publicaron los siguientes artículos en Congresos:

1. "Pachyrhizus ahipa (ahipa): cultivo de uso hortícola y fuente de almidón". Resumen. O. López, A. Pachas, M. C. Doporto, P. Rohatsch, H. Fassola, A. Mugridge, A. R. Chaves, N. E. Zaritzky, S. Z. Viña, M. A. García. Jornadas de Amaranto. Proyecto Amaranth: Future Food. La Plata, Buenos Aires, Argentina, 22 y 23 de octubre de 2009.

2. "Valor nutritivo y parámetros fisiológicos relativos a la conservación poscosecha de raíces de ahipa (Pachyrhizus ahipa)". M. C. Doporto, A. Mugridge, A. R. Chaves, M. A. García, S. Z. Viña. VI Congreso Iberoamericano de Tecnología Postcosecha y Agroexportaciones. Trabajo completo publicado en Revista Iberoamericana de Tecnología Postcosecha, Vol 11, № 1 (edición especial), pp 32. Mérida, Yucatán, México del 22 al 26 de junio de 2010.

3. “Componentes nutricionalmente relevantes de raíces de ahipa (Pachyrhizus ahipa)". Resumen. M.C. Doporto, A. Mugridge, S.Z. Viña y M.A. García. Congreso Internacional de Nutrición y Tecnología de los Alimentos. CINTA. San Rafael, Mendoza, Argentina, del 20 al 21 de agosto de 2010.

4. "Incidencia del método de obtención en la composición química y propiedades funcionales de harina de ahipa". Trabajo completo. M.C. Doporto, A. Mugridge, S.Z. Viña y M.A. García. VI Congreso Argentino de Ingeniería Química (CAIQ). Asociación Argentina de Ingenieros Químicos (AAIQ).ISSN: 1850-3500 ISSN: 1850-3519. Mar del Plata, Buenos Aires, Argentina, del 26 al 29 de septiembre de 2010.

5. "Almacenamiento poscosecha de raíces de Pachyrhizus ahipa (ahipa, Andean yam bean)". Resumen. Doporto, M. C., Mugridge, A., Chaves, A. R., García, M. A., Viña, S. Z.XXXIII Congreso Argentino de Horticultura. Asociación Argentina de Horticultura (ASAHO). ISBN 978-987-97812-6-5. Rosario, Santa Fe, Argentina, del 28 de septiembre al 1 de octubre de 2010.

6. "Calidad nutricional de raíces de ahipa (Pachyrhizus ahipa) y su potencialidad como alimento libre de gluten”. Resumen. Dini, Cecilia; Doporto, María C.; Viña, Sonia Z. y García María A. V Simposio Internacional de Innovación y Desarrollo de Alimentos (INNOVA). Ciudad de Montevideo, Uruguay del 11 al 13 de octubre de 2011. 
7. "Harinas libres de gluten: propiedades fisicoquímicas que influyen en su estabilidad". Resumen. Doporto, María C., Mugridge, Alicia, Viña, Sonia Z. y García María A. XIII Congreso Argentino de Ciencia y Tecnología de Alimentos-CYTAL-AATA. Ciudad de Buenos Aires, Argentina, del 19 al 21 de octubre de 2011.

8. "Propiedades físico-químicas y térmicas de harinas nutricionalmente diferenciadas." Trabajo completo. Doporto, María C., Mugridge, Alicia, Viña, Sonia Z. y García María A. VIII Congreso Iberoamericano de Ingeniería de Alimentos-CIBIA 8. Lima, Perú del 23 al 26 de octubre de 2011.

9. "Estabilidad de ingredientes funcionales obtenidos de raíces tuberosas." Trabajo completo. Doporto M. C., Dini C., Mugridge A., Viña S. Z., García M. A. Congreso Latinoamericano en Ingeniería y Ciencias Aplicadas CLICAP 2012. San Rafael, Mendoza, Argentina del 28 al 30 de marzo de 2012.

10. "Revalorización del cultivo de ahipa (Pachyrhizus ahipa): análisis de su calidad nutricional y su potencialidad como alimento libre de gluten". C. Dini, M.C. Doporto, S.Z. Viña y M.A. García. III Congreso Internacional sobre Nutrición, Ciencia y Tecnología de los Alimentos (CINTA). Mendoza, Mendoza, Argentina del 9 al 11 de agosto de 2012.

11. "Digestibilidad y propiedades funcionales relevantes del almidón de Pachyrhizus ahipa." Trabajo completo. Doporto M.C., Dini C., Viña S.Z., García M.A. IV Congreso Internacional Ciencia y Tecnología de los Alimentos. Córdoba, Córdoba, Argentina, del 14 al 16 de noviembre de 2012.

12. "Variaciones en el perfil nutricional de raíces de Pachyrhizus ahipa (ahipa) según la accesión de origen". Trabajo completo. Dini C., Doporto M.C., Mugridge, A., Viña S.Z. y García M.A. XIV Congreso Argentino de Ciencia y Tecnología de Alimentos CYTAL. Rosario, Santa Fe, Argentina, del 23 al 25 de octubre de 2013.

En Revistas Científicas Internacionales y otros medios de divulgación se publicaron los siguientes artículos y capítulos de libro:

1. "Pachyrhizus ahipa roots and flour: biochemical and functional characteristics". Doporto, María C; Mugridge, A; García, María A.; Viña, Sonia Z. Food Chemistry. Vol 126, 1670-1678. 2011. 
2. "Raíces de ahipa (Pachyrhizus ahipa): calidad nutricional y usos potenciales como alimento diferenciado". Dini, Cecilia; Doporto, María C.; García, María A.; Viña, Sonia Z.Revista: La Alimentación Latinoamericana. Editorial Publitec. ISSN: 0325-3384. Número 296, 48-52. 2011.

3. "Physicochemical, thermal and sorption properties of nutritionally differentiated flours and starches". Doporto, María C; Dini, Cecilia; Mugridge, A; Viña, Sonia Z., García, María A. Journal of Food Engineering. Vol 113, 569-576. 2012.

4. Capítulo IV “Obtención y caracterización de harina a partir de raíces de Pachyrhizus ahipa" del libro "Pachyrhizus ahipa: Revalorización de un cultivo ancestral". Doporto, María C; Viña, Sonia Z.; García, María A.Editorial Académica Española. ISBN 978-3-659-03826-6. 2012.

5. "Nutritional profile and anti-nutrient analyses of Pachyrhizus ahipa roots from different accessions". Dini, Cecilia; Doporto, María C; García, María A.; Viña, Sonia Z. Food Research Internacional. Vol 54 (1), 255-261. 2013.

6. "Pachyrhizus ahipa roots and starches: composition and functional properties related to their food uses". Doporto, María C; Dini, Cecilia; Viña, Sonia Z.; García, María A. Starch-Stärke. Artículo publicado online: 27-12-2013. DOI: 10.1002/star.201300196. 2013. 


\section{RESUMEN}

El objetivo general del presente trabajo de Tesis fue evaluar las potencialidades de la especie vegetal Pachyrhizus ahipa (ahipa) como cultivo alternativo nativo de América, y contribuir a ampliar sus posibilidades de uso e incorporación como fuente de materia prima de agroindustrias generadoras de valor agregado. El estudio de esta especie y sus principales productos derivados (almidón, fibra y harina) permitirá identificar y desarrollar las aplicaciones industriales más adecuadas, conduciendo a un aprovechamiento integral de la misma.

Las raíces y tubérculos (R\&T) son fuentes de energía en la dieta y algunos de ellos aportan minerales, vitaminas y aminoácidos esenciales. El conocimiento de las propiedades nutricionales y físico-químicas de las R\&T y sus productos derivados es vital en la formulación de alimentos.

Entre los cultivos de R\&T se encuentran ciertas especies de origen andino, siendo la ahipa (Pachyrhizus ahipa (Wed) Parodi) una de las menos estudiadas. El rescate de este cultivo implicaría potenciales beneficios económicos y agroecológicos, relacionados con la diversificación productiva y la generación de materias primas y productos elaborados alternativos. Así, las raíces tuberosas de ahipa podrían destinarse a propósitos múltiples tales como obtención de harina, almidón y fibras naturales a escala industrial, además de su comercialización como hortaliza fresca.

En comparación con otras R\&T tropicales y subtropicales, las raíces de ahipa mostraron una composición química más equilibrada desde el punto de vista nutricional, realizando un aporte significativo de proteínas, fibra dietaria y minerales tales como potasio, calcio, hierro, junto con el componente mayoritario (almidón). Las raíces se pueden considerar una buena fuente de hidratos de carbono (principalmente almidón y sacarosa) y fibra dietaria total. La composición química de las raíces de ahipa varió con la accesión de origen. Las accesiones Local e IRNAS 11 se destacaron por su alto contenido de almidón, un nivel de proteína intermedio, bajo contenido de fibra dietaria total y de sodio, niveles más reducidos de antinutrientes (oxalatos, ácido fítico y taninos), lo que representa una ventaja desde el punto de vista nutricional. Al analizar las propiedades térmicas, las accesiones Local e IRNAS 11 mostraron los valores más altos de entalpía. Por lo tanto, estas dos accesiones presentaron propiedades interesantes a tener en cuenta en un programa de mejoramiento genético.

El almidón de Pachyrhizus ahipa se obtuvo a escala de laboratorio empleando un proceso de extracción optimizado, simple y con un bajo costo asociado. Esta técnica resultó eficiente permitiendo conseguir muestras representativas, con buenos rendimientos y alta pureza. El almidón obtenido presentó bajo contenido de amilosa, por lo que podría considerarse un aditivo alternativo al almidón de maíz para la industria alimentaria. Además, sus pastas también presentaron una mejor aptitud para la cocción ya que gelatinizaron a una temperatura significativamente más baja que las del almidón de maíz. Sus gránulos exhibieron buena capacidad de hinchamiento, pudiendo emplearse como agente espesante dado su comportamiento reológico. Una de las principales ventajas de este almidón fue la baja tendencia a la retrogradación de sus pastas cuando se almacenaron bajo condiciones de refrigeración.

De las isotermas de sorción de los almidones de ahipa y mandioca se obtuvieron los parámetros termodinámicos que caracterizaron la estabilidad de estos productos en las diferentes condiciones de almacenamiento ensayadas. Se estudiaron las características microestructurales de ambos almidones mediante estudios morfológicos al SEM, estableciendo el patrón de difracción de rayos $\mathrm{X}$ y asignando los picos característicos de los espectros FTIR.

La digestibilidad del almidón de ahipa fue similar a la de los almidones de otras leguminosas. La accesión IRNAS 11 de ahipa mostró mayor proporción de almidón rápidamente digestible y 
resistente, mientras que el almidón de mandioca tuvo una baja proporción de almidón lentamente digerible. El almidón de ahipa proveniente de la accesión Local presentó valores de estas fracciones intermedios entre la accesión IRNAS 11 y mandioca. Desde un punto de vista nutricional, estos resultados podrían indicar cierta versatilidad del almidón de ahipa con el fin de ser utilizado como un ingrediente para alimentos con alto contenido de energía.

Por otra parte, se caracterizó el residuo remanente de la extracción de almidón de ahipa morfológicamente a través de SEM y se determinó que tanto la fibra como el almidón eran los componentes mayoritarios del mismo. La capacidad de hinchamiento y de retención de solventes del residuo fue mayor que la del almidón y la raíz parcialmente deshidratada, respectivamente, debido al carácter altamente hidrofílico de sus componentes.

Las harinas de ahipa y mandioca se obtuvieron a través de procedimientos relativamente simples que permitieron conservar un buen nivel de integridad de los gránulos de almidón.

La harina de ahipa es un producto que podría ser utilizado en la preparación alimentos para celíacos ya que por enzimo-inmunoensayos se verificó la ausencia de gliadinas. La característica diferencial de la harina de ahipa fue su aporte de proteínas, fibra y minerales tales como potasio, hierro y calcio, reflejando una composición nutricionalmente más equilibrada que la correspondiente harina de mandioca y que otras harinas provenientes de R\&T.

Se realizó la caracterización microestructural de las harinas obtenidas a través de los patrones de difracción de rayos $X$ para evaluar el grado de cristalinidad y de los espectros de FTIR para analizar la interacción entre los componentes principales de las harinas obtenidas. Las mismas presentaron un patrón de difracción Tipo $\mathrm{C}$ y el origen botánico de la muestra afectó el grado de cristalinidad de los gránulos. Los espectros FTIR de las harinas fueron similares, independientemente de su origen.

Las isotermas de sorción permitieron evaluar el contenido de humedad que garantizaría la estabilidad de las harinas bajo diferentes condiciones de almacenamiento. La harina de ahipa gelatinizó a temperatura más baja que la de mandioca, lo que indica una mejor aptitud para la cocción. En general, las temperaturas de gelatinización de ambas harinas fueron más altas que las de sus respectivos almidones, debido a su composición química.

Las diferencias observadas en la capacidad de hinchamiento y de retención de solventes de ambas harinas deberán ser consideradas en relación a las aplicaciones específicas, tales como la incorporación de las mismas como ingredientes en alimentos funcionales libres de gluten.

Por último, se demostró la factibilidad de elaborar una galletita de alta calidad sensorial a base de harina de ahipa y almidón de maíz, ambas materias primas exentas de gluten destinadas a la población celíaca.

Las galletitas elaboradas con $25 \%$ de harina de ahipa y horneadas a $200^{\circ} \mathrm{C}$ durante 7,5 minutos obtuvieron el mayor puntaje en cuanto a aceptabilidad general, sabor y color. Teniendo en cuenta asimismo el menor requerimiento energético para la preparación del producto, ésta fue la condición de cocción seleccionada.

La harina obtenida de la raíz tuberosa de Pachyrhizus ahipa podría sustituir al almidón de maíz en futuras formulaciones para la preparación de productos horneados libres de gluten, lo que contribuiría a obtener un producto nutricionalmente balanceado y con buena aceptación por parte de los consumidores. 


\section{INDICE}

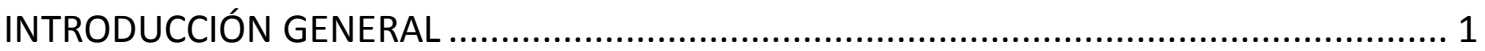

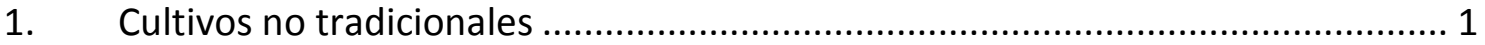

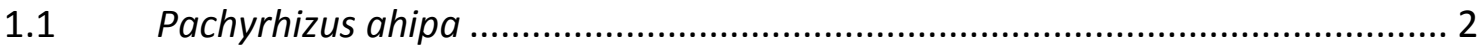

2. Ingredientes alimentarios: propiedades funcionales ......................................... 5

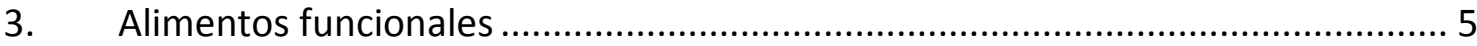

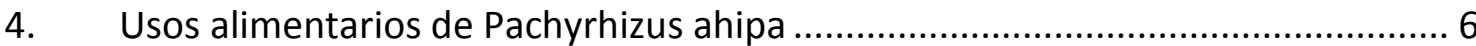

5. La Celiaquía y los productos libres de gluten .................................................... 7

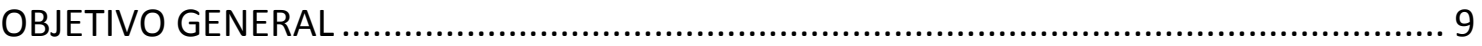

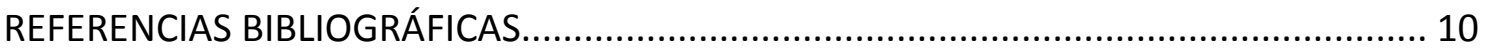

CAPÍTULO 1. Caracterización de las raíces de Pachyrhizus ahipa .................................. 12

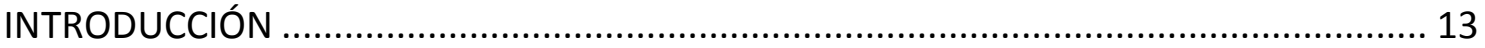

1. Principales cultivos de raíces y tubérculos (R\&T): generalidades ....................... 13

2. Composición química de las principales R\&T .................................................. 15

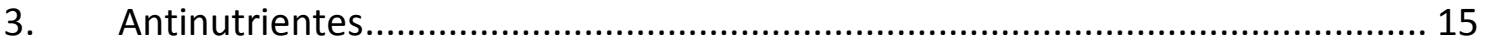

4. Generalidades sobre la poscosecha de R\&T ................................................ 17

5. Tratamientos físicos de poscosecha ............................................................... 18

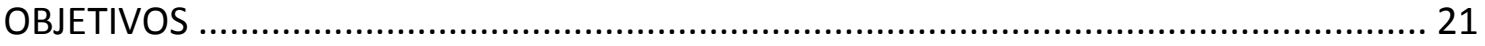

CAPÍTULO 1. SECCIÓN 1. Composición química de raíces de Pachyrhizus ahipa accesión

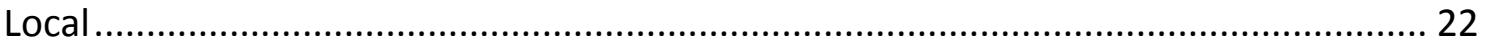

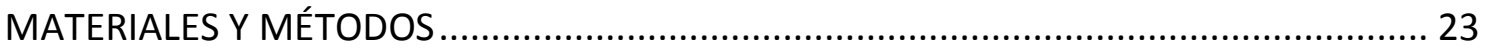

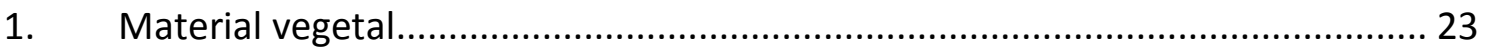

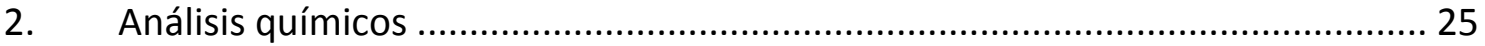

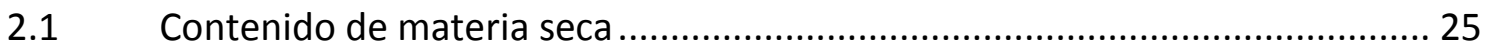

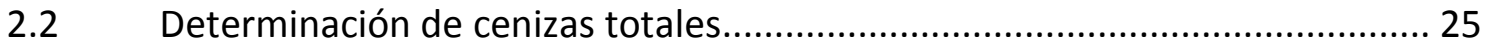

2.3 Cuantificación de sodio, potasio, calcio, hierro y magnesio ........................... 26

2.4 Determinación del contenido de fósforo ......................................................... 26

2.5 Extracción y cuantificación de lípidos totales............................................... 26

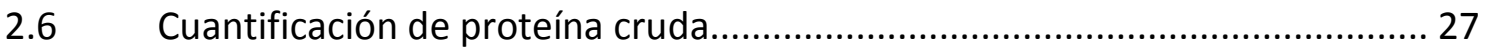

2.7 Cuantificación de fibra detergente ácido ....................................................... 28 


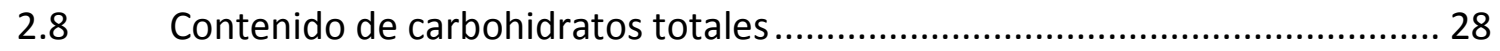

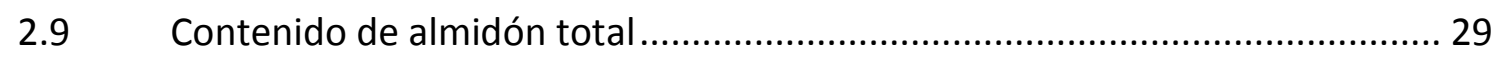

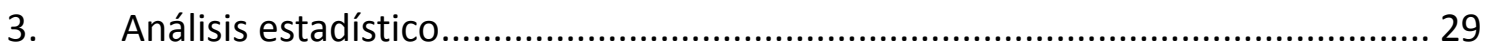

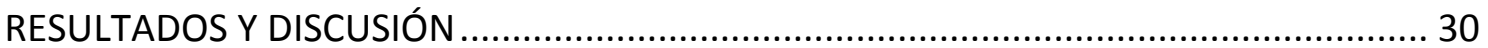

1. Composición química de las raíces de Pachyrhizus ahipa accesión Local........... 30

CAPÍTULO 1. SECCIÓN 2. Poscosecha de raíces de Pachyrhizus ahipa ........................... 33

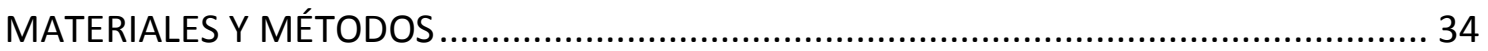

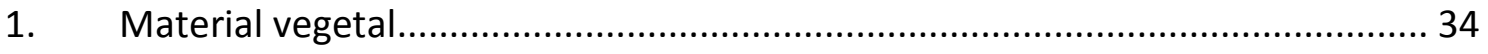

2. Poscosecha de raíces de Pachyrhizus ahipa ....................................................... 34

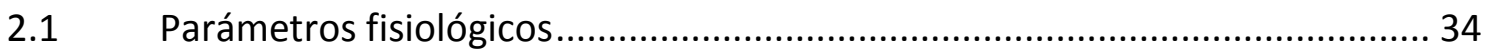

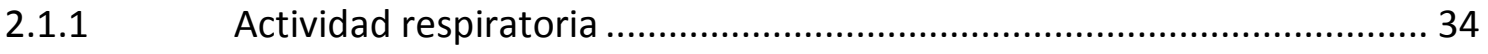

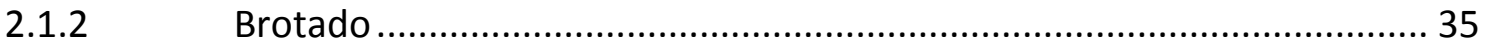

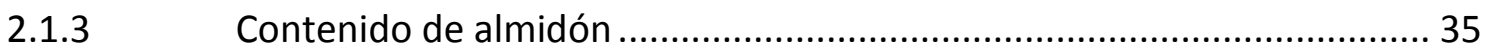

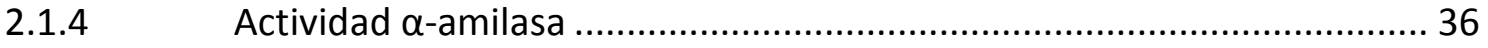

2.2 Almacenamiento de raíces de Pachyrhizus ahipa a diferentes temperaturas 36

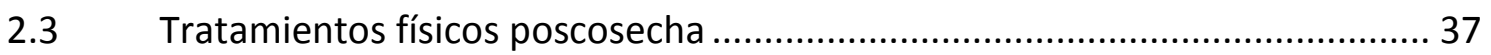

2.4 Atributos de calidad en raíces almacenadas ................................................ 38

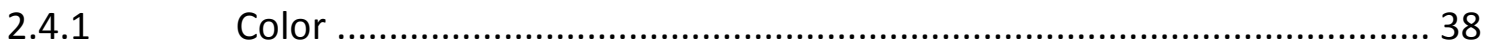

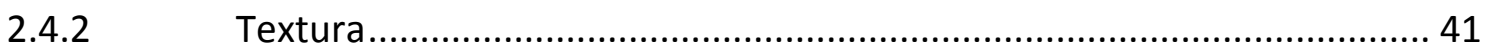

2.5 Análisis de la población fúngica predominante............................................ 43

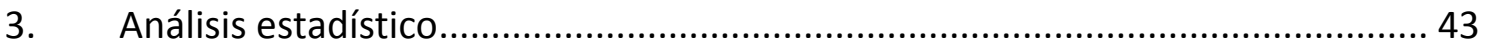

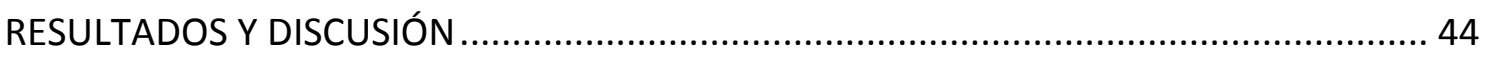

1. Conservación de las raíces de ahipa a distintas temperaturas .......................... 44

2. Parámetros fisiológicos asociados a la degradación de las reservas de almidón 44

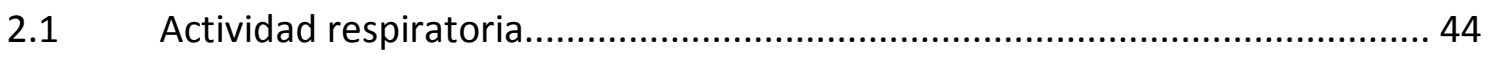

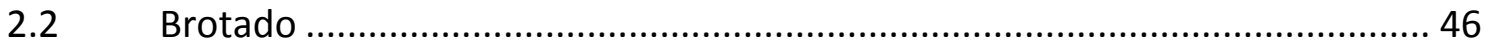

2.3 Contenido de almidón total y actividad $\alpha$-amilasa ...................................... 47

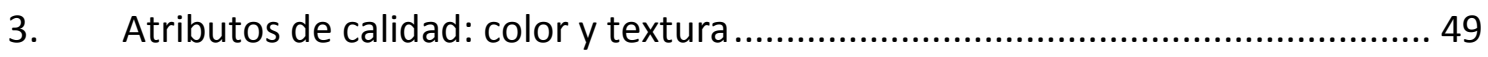

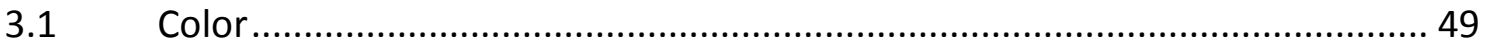

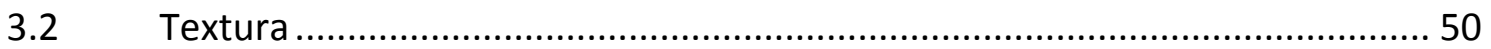

4. Análisis de la población fúngica predominante ............................................ 52 
CAPÍTULO 1. SECCIÓN 3. Composición química y propiedades funcionales de raíces de Pachyrhizus ahipa pertenecientes a diferentes accesiones ........................................ 55

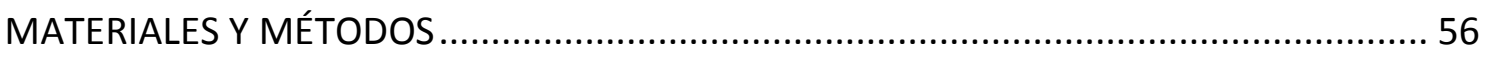

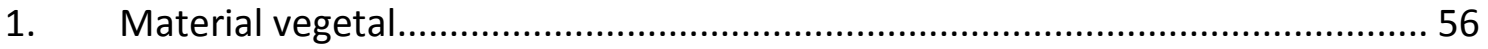

2. Análisis químico de macro y microcomponentes........................................... 56

2.1 Cuantificación de sodio, potasio, calcio, hierro y magnesio ............................ 56

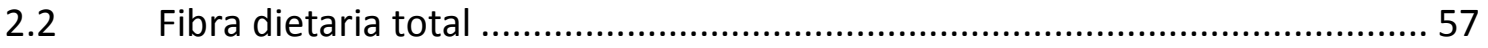

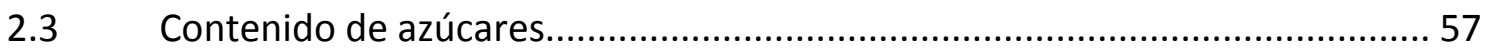

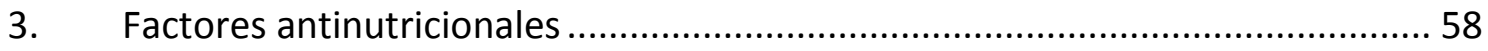

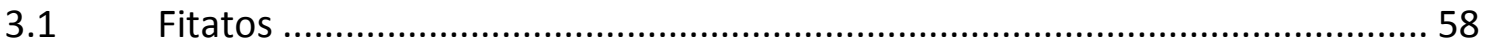

3.2 Compuestos fenólicos totales y taninos .................................................. 58

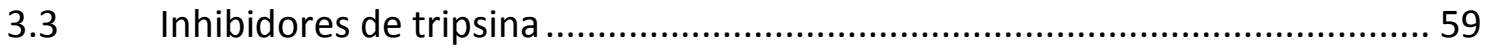

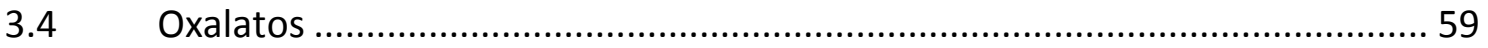

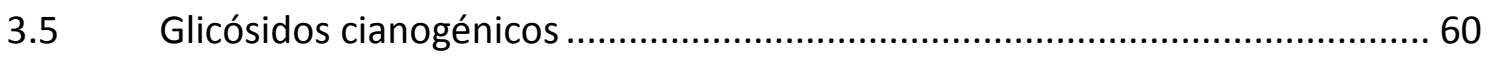

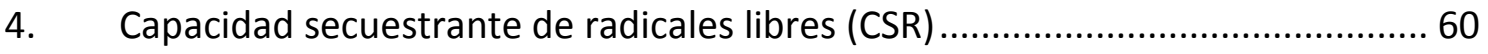

5. Propiedades funcionales asociadas a la composición química .........................6 60

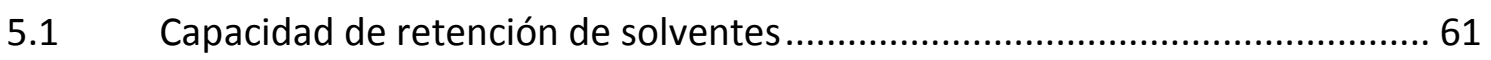

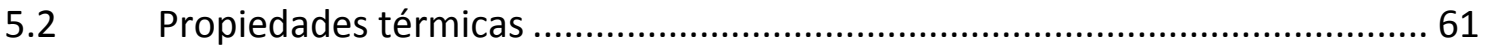

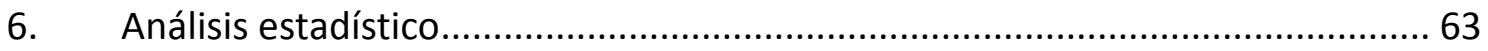

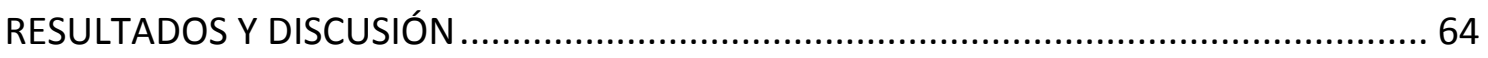

1. Composición química de raíces de ahipa pertenecientes a las diferentes

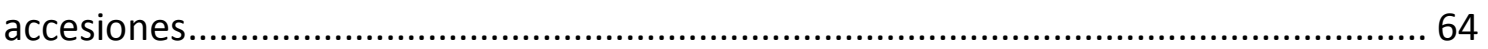

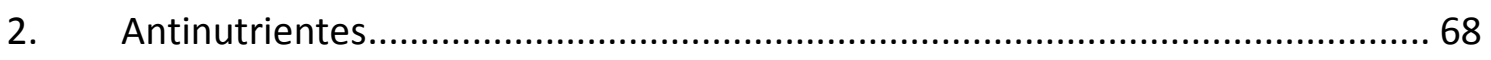

3. Actividad secuestrante de radicales libres .................................................. 71

4. Capacidad de retención de solventes.............................................................. 72

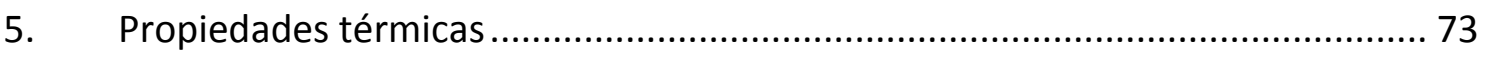

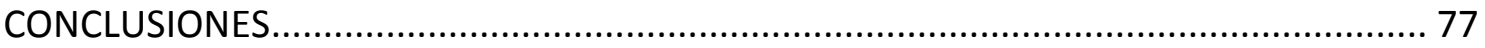

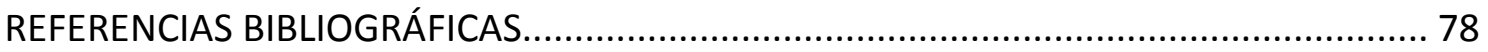

CAPÍTULO 2. Características físico-químicas, morfológicas y funcionales del almidón de

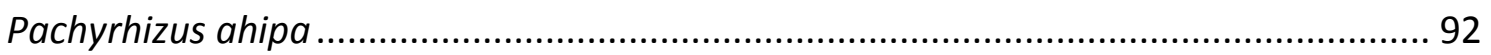

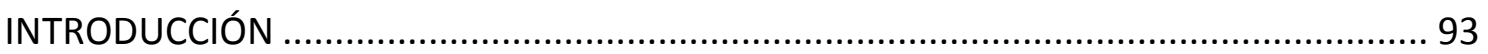


1. El almidón

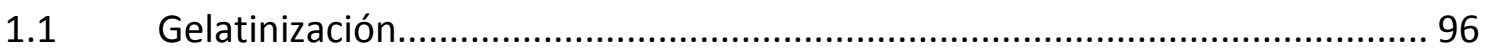

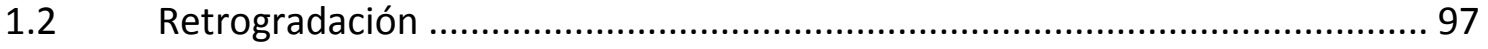

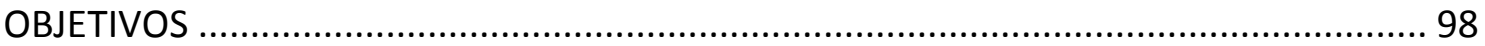

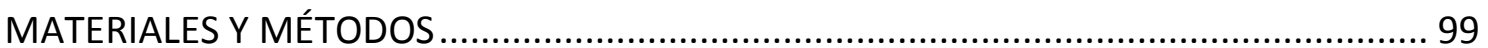

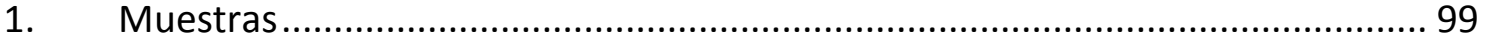

2. Extracción del almidón de ahipa y mandioca .................................................... 99

3. Caracterización de los almidones extraídos ..................................................... 101

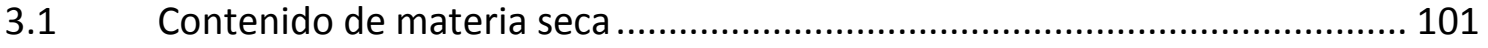

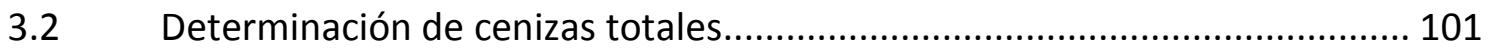

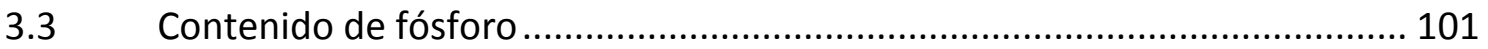

3.4 Extracción y cuantificación de lípidos totales................................................. 101

3.5 Determinación del contenido de nitrógeno total....................................... 102

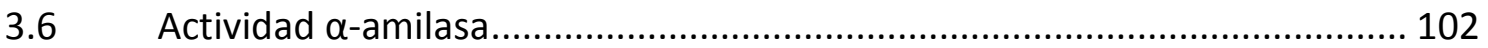

4. Caracterización fisicoquímica y microestructural de los almidones .................. 102

4.1 Determinación de la concentración de amilosa en almidón de ahipa y

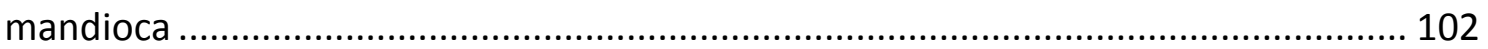

4.2 Medidas de color superficial de los almidones........................................... 103

4.3 Morfología y distribución de tamaño de los gránulos................................. 103

4.4 Espectroscopía de difracción de rayos X ..................................................... 104

4.5 Análisis por Espectroscopía Infrarroja con Transformada de Fourier ............ 105

4.6 Estudio de la estabilidad de los almidones: isotermas de sorción ................ 105

4.7 Modelado matemático de las isotermas de sorción de los almidones .......... 108

4.8 Parámetros termodinámicos derivados de las isotermas de sorción ............ 109

5. Propiedades funcionales de los almidones .................................................. 110

5.1 Determinación de la capacidad de retención de agua del almidón ................ 110

5.2 Transiciones térmicas de los almidones de ahipa y mandioca. Estudio de la

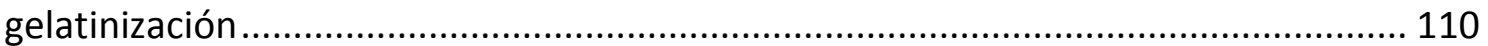

5.3 Capacidad de hinchamiento de los gránulos de almidón.............................. 111

5.4 Caracterización reológica de las pastas de almidón ...................................... 111

5.5 Retrogradación de las pastas de almidón de ahipa y mandioca bajo condiciones de refrigeración 


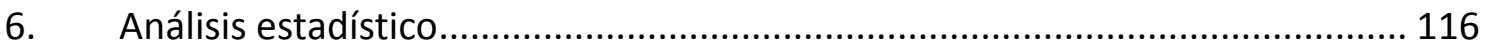

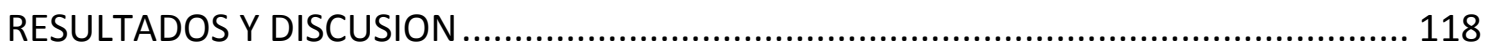

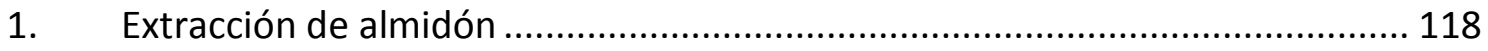

2. Caracterización de los almidones extraídos ................................................... 119

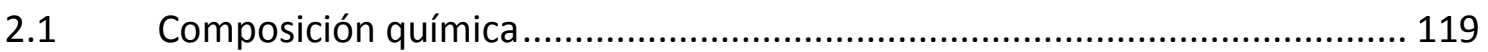

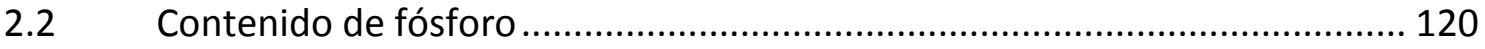

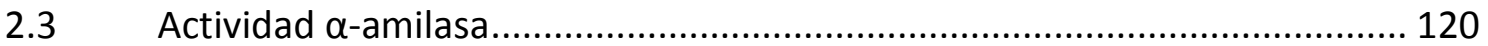

3. Caracterización fisicoquímica y microestructural de los almidones ..................120

3.1 Relación amilosa/amilopectina.............................................................. 120

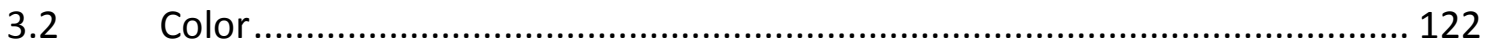

3.3 Morfología y distribución de tamaños de gránulos....................................... 123

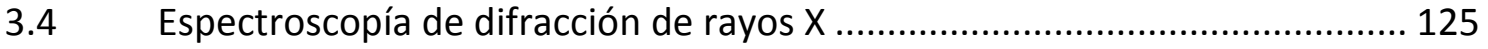

3.5 Análisis por Espectroscopía Infrarroja con Transformada de Fourier ........... 127

3.6 Estudio de la estabilidad de los almidones extraídos (Isotermas de sorción)129

3.7 Parámetros termodinámicos de las isotermas de sorción ............................. 132

4. Propiedades funcionales de los almidones extraídos ................................... 135

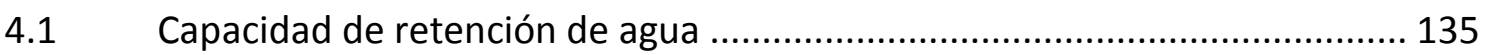

4.2 Gelatinización de las suspensiones de almidón. Transiciones térmicas ........ 136

4.3 Capacidad de hinchamiento de los gránulos ............................................ 138

4.4 Comportamiento reológico de las pastas de almidón.................................. 140

4.5 Retrogradación de las pastas de almidón bajo condiciones de refrigeración146

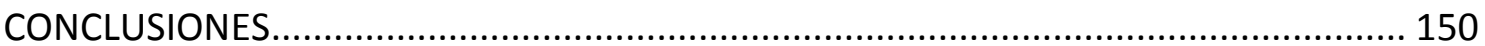

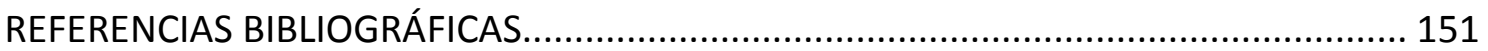

CAPÍTULO 3. Digestibilidad del almidón de Pachyrhizus ahipa. Caracterización del residuo de la extracción de almidón .......................................................................... 160

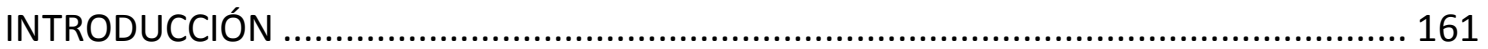

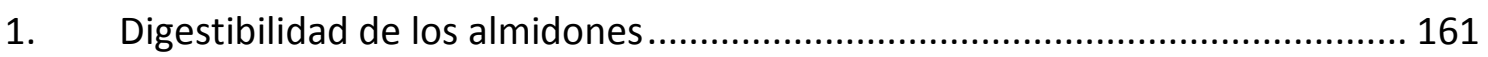

1.1 Digestión in vivo del almidón ...................................................................... 163

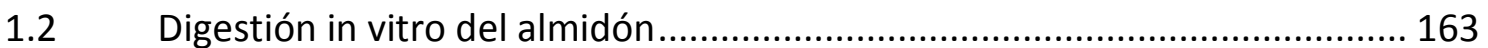

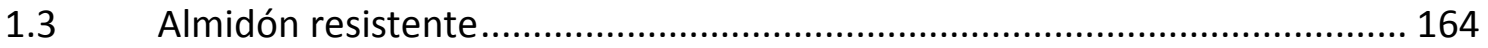

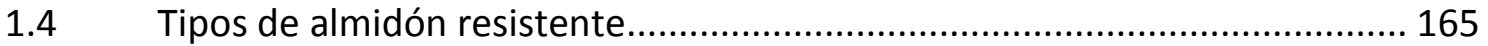


1.5 Efectos fisiológicos del almidón resistente.

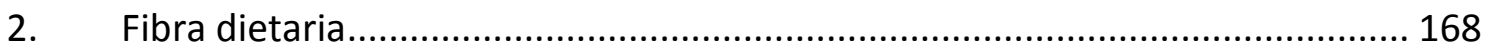

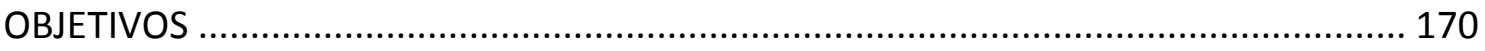

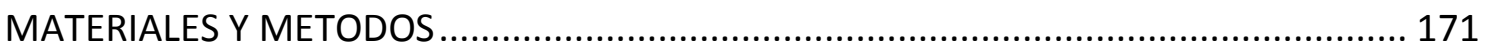

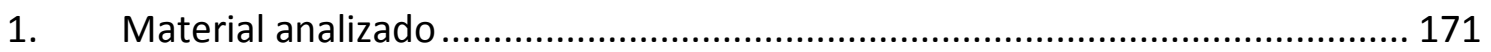

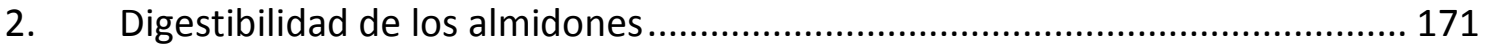

2.1 Cuantificación de las fracciones de almidón digerible en forma rápida, lenta y almidón resistente en muestras gelatinizadas

2.2 Digestibilidad de los almidones de ahipa y mandioca ................................ 172

2.3 Índice de hidrólisis e índice glicémico de los almidones .............................. 173

2.4 Cinética de hidrólisis a largo plazo de los almidones nativos de ahipa y mandioca

3. Obtención del residuo sólido de la extracción del almidón de ahipa ................ 174

4. Composición química del residuo de la extracción del almidón de ahipa ......... 175

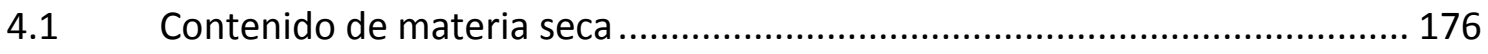

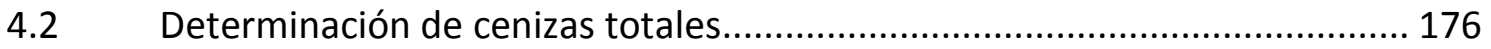

4.3 Extracción y cuantificación de lípidos totales.............................................. 176

4.4 Determinación del contenido de nitrógeno total........................................ 176

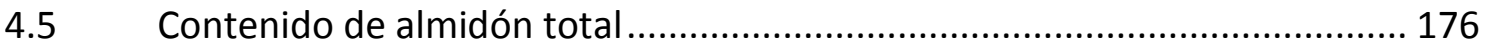

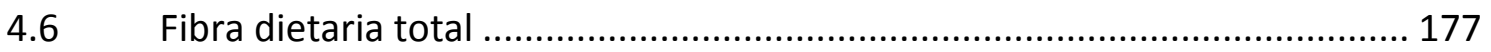

5. Caracterización microestructural: morfología de las partículas del residuo .... 177

6. Propiedades funcionales del residuo de la extracción del almidón de ahipa ... 177

6.1 Determinación de la capacidad de retención de agua ................................. 177

6.2 Determinación de la capacidad de hinchamiento ..................................... 177

6.2.1 Contenido de amilosa y amilopectina .............................................. 178

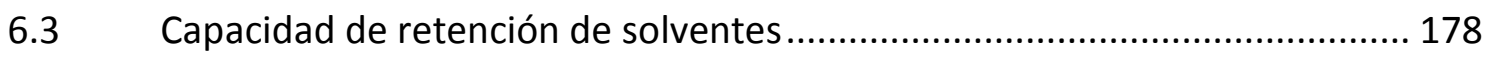

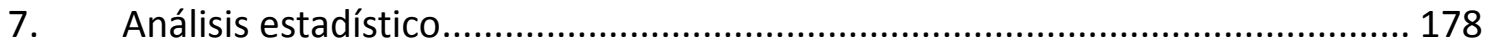

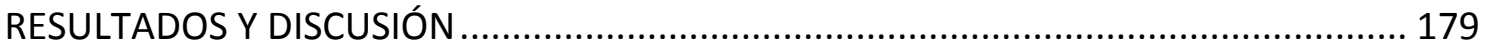

1. Digestibilidad de los almidones de ahipa y mandioca ................................... 179

2. Composición química del residuo de la extracción del almidón de ahipa ......... 187

3. Morfología del residuo remanente de la extracción del almidón de ahipa....... 188

4. Propiedades funcionales del residuo de la extracción del almidón de ahipa ... 190 


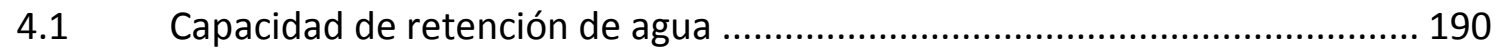

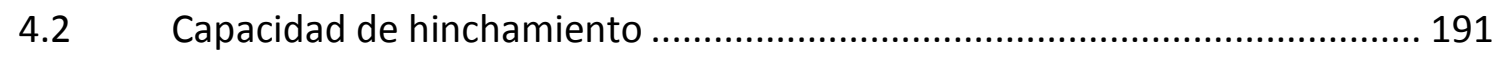

4.3 Capacidad de retención de solventes ....................................................... 193

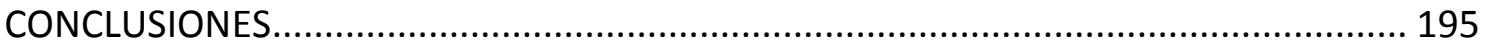

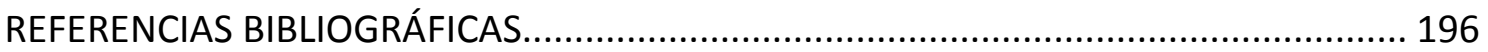

CAPÍTULO 4. Obtención y caracterización de harinas de Pachyrhizus ahipa y Manihot

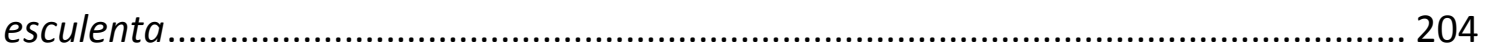

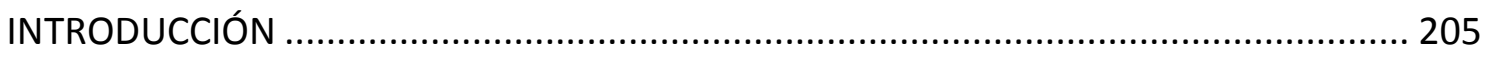

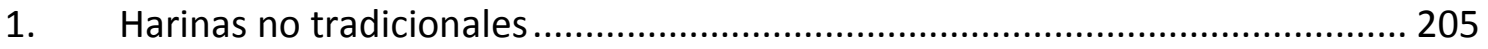

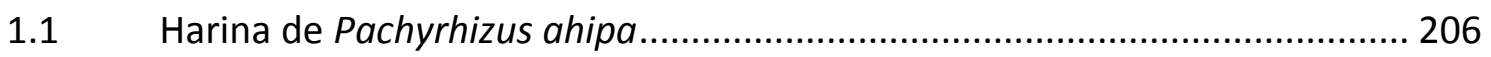

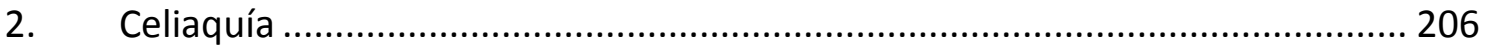

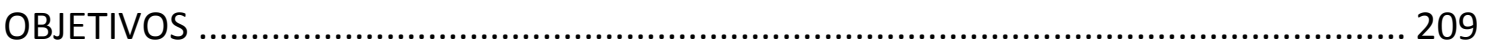

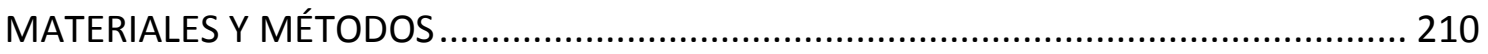

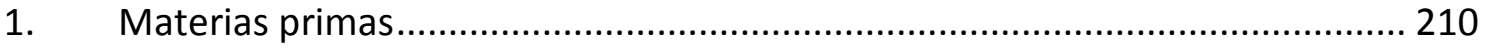

2. Procesamiento de las raíces y obtención de harina de Pachyrhizus ahipa y

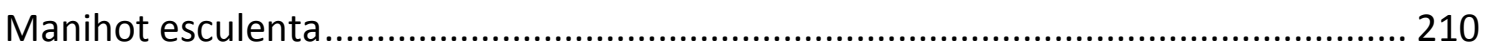

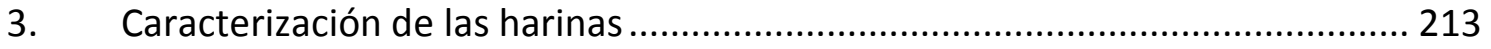

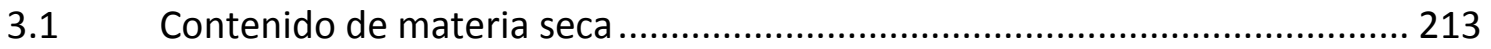

3.2 Determinación de cenizas totales en harina de ahipa................................. 213

3.3 Extracción y cuantificación de lípidos totales............................................... 214

3.4 Determinación del contenido de nitrógeno total......................................... 214

3.5 Contenido de prolaminas en harina de ahipa ............................................ 214

3.6 Determinación de fibra detergente ácido ................................................ 214

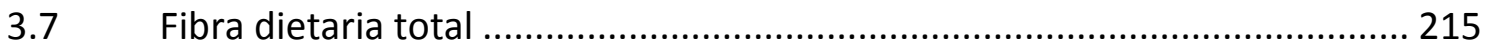

3.8 Contenido de carbohidratos totales ........................................................... 215

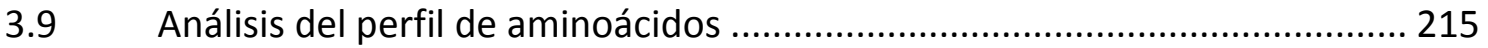

3.10 Cuantificación de sodio, potasio, calcio, hierro y magnesio ......................... 216

3.11 Contenido de fósforo en harina de ahipa .................................................... 216

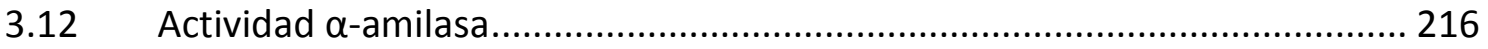

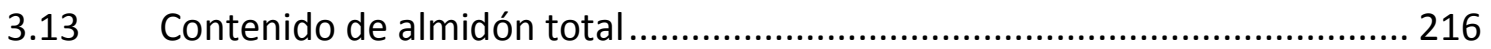

4. Caracterización fisicoquímica y microestructural de las harinas ...................... 216 


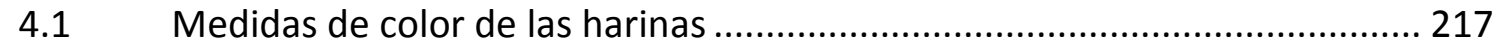

4.2 Estudio de la estabilidad de las harinas: isotermas de sorción ...................... 217

4.3 Modelado matemático de las isotermas de sorción de las harinas .............. 217

4.4 Parámetros termodinámicos de las isotermas de sorción ........................... 218

4.5 Morfología y distribución de tamaño de partículas de las harinas ................ 218

4.6 Espectroscopía de difracción de rayos X de las harinas .............................. 218

4.7 Análisis por Espectroscopía Infrarroja con Transformada de Fourier ........... 219

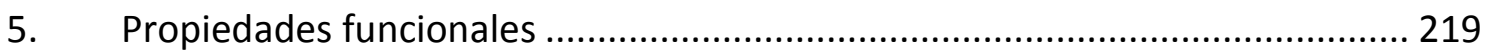

5.1 Determinación de la capacidad de retención de agua de las harinas ............ 219

5.2 Transiciones térmicas de las harinas de ahipa y mandioca........................... 219

5.3 Capacidad de hinchamiento de la harina de ahipa ................................... 220

5.4 Capacidad de retención de solventes ............................................................ 220

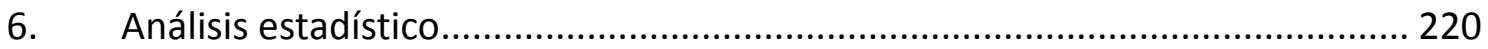

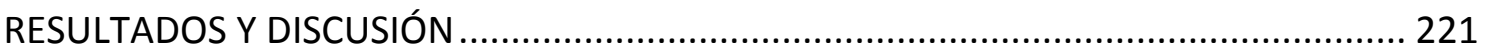

1. Procesamiento de las raíces y obtención de harinas ........................................ 221

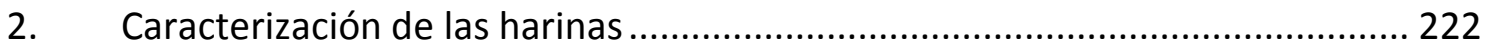

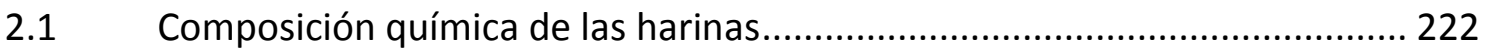

2.2 Análisis del perfil de aminoácidos de la harina de ahipa............................... 225

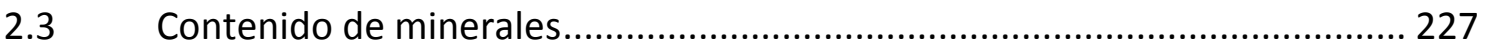

2.4 Actividad $\alpha$-amilasa y contenido de almidón total .......................................2229

3. Caracterización fisicoquímica y microestructural de las harinas ...................... 231

3.1 Medidas de color de las harinas de ahipa y mandioca.................................. 231

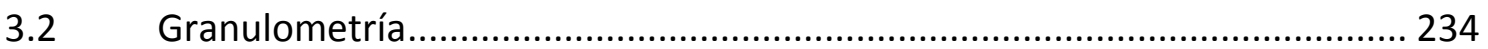

3.3 Espectroscopía de difracción de rayos X de la harina de ahipa..................... 239

3.4 Espectroscopía infrarroja con transformada de Fourier .............................. 240

3.5 Estabilidad de las harinas de ahipa y mandioca ........................................ 245

3.6 Parámetros termodinámicos de las isotermas de sorción ............................250

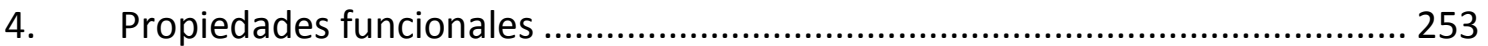

4.1 Determinación de la capacidad de retención de agua de las harinas ........... 253

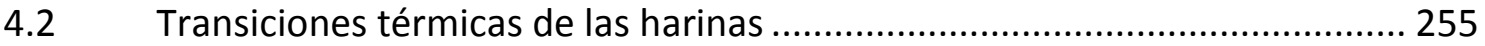

4.3 Capacidad de hinchamiento de la harina de ahipa ....................................... 259

4.4 Capacidad de retención de solventes ......................................................... 261 
CAPÍTULO 5. Aplicaciones tecnológicas: productos horneados elaborados con harina de Pachyrhizus ahipa 276

INTRODUCCIÓN 277

1. Alimentos para celíacos 277

2. Legislación en la Argentina. 278

3. Incidencia de la enfermedad celíaca en nuestro país 281

4. Galletitas aptas para celíacos 281

OBJETIVOS 283

MATERIALES Y MÉTODOS 284

1. Elaboración de las galletitas 284

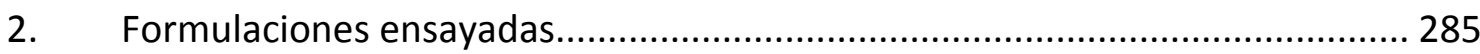

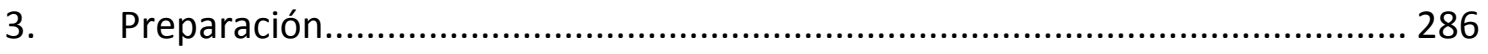

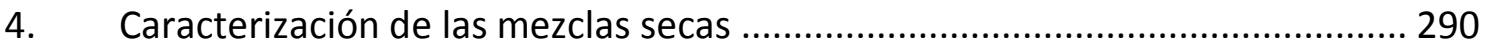

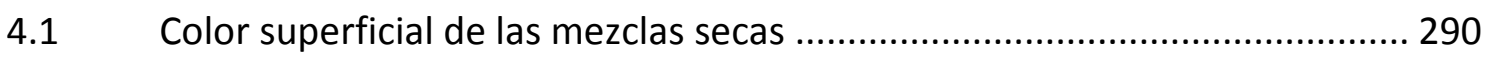

4.2 Capacidad de retención de solventes......................................................... 290

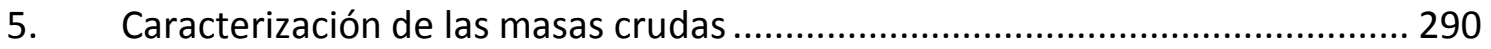

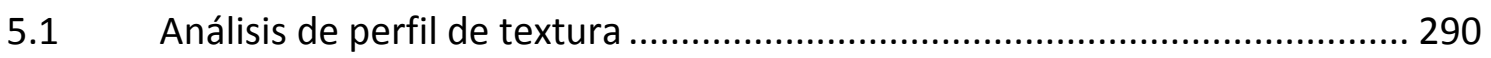

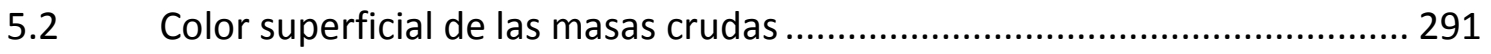

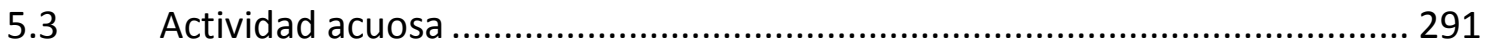

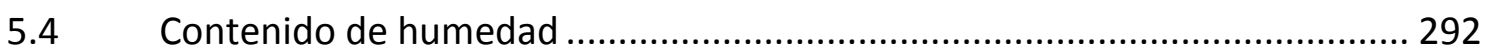

6. Atributos de calidad y composición química de las galletitas.......................... 292

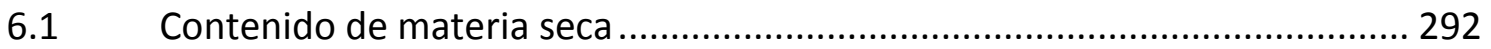

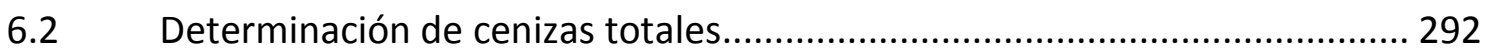

6.3 Extracción y cuantificación de lípidos totales.............................................. 293

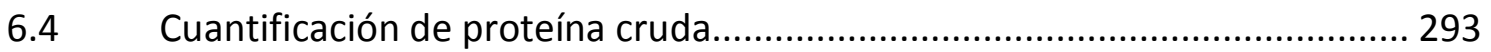

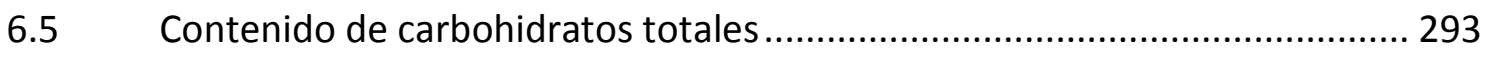

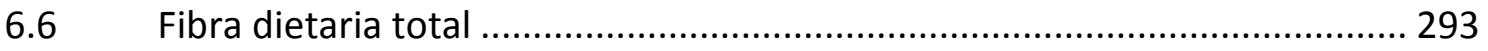

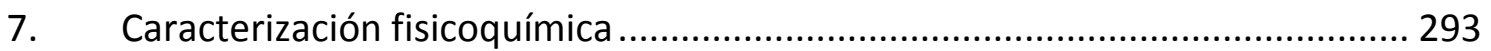

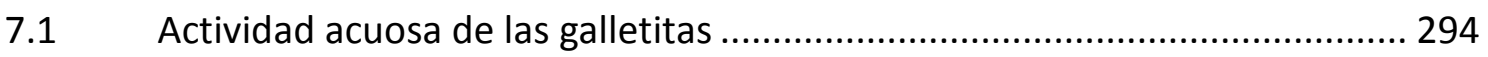


7.2 Propiedades ópticas: color superficial de las galletitas ................................. 294

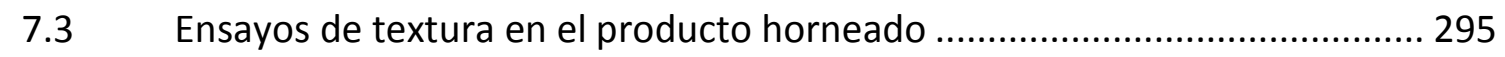

7.4 Medida del volumen del producto horneado ............................................ 296

8. Evaluación de la aceptabilidad del producto mediante panel sensorial........... 296

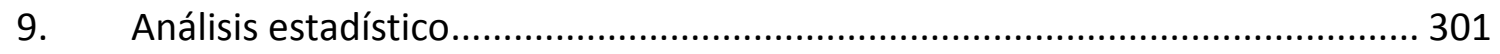

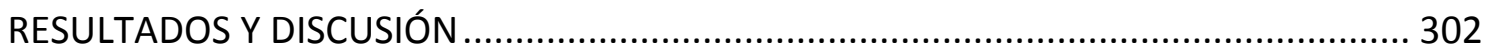

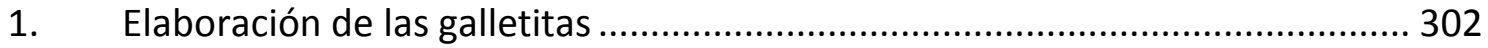

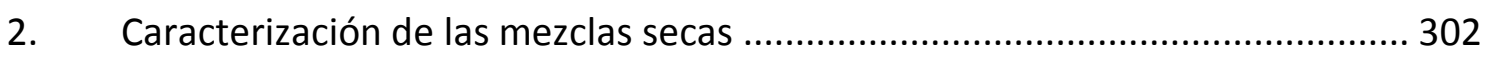

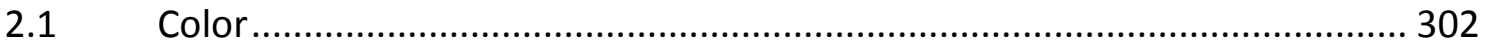

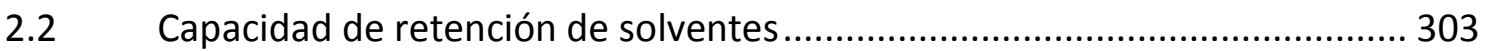

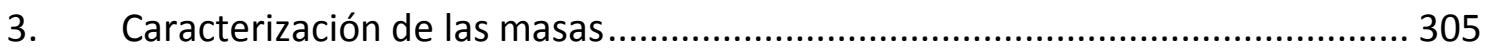

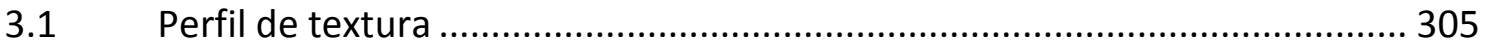

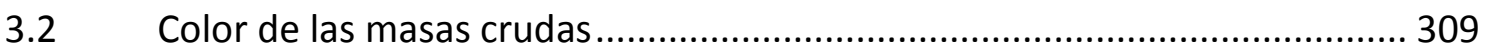

3.3 Actividad acuosa y contenido de humedad de las masas crudas.................. 310

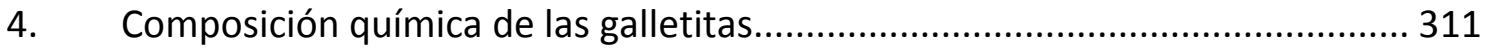

5. Caracterización fisicoquímica del producto horneado ................................... 313

5.1 Actividad acuosa y contenido de humedad................................................ 313

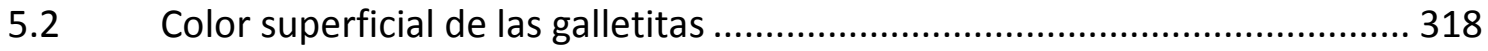

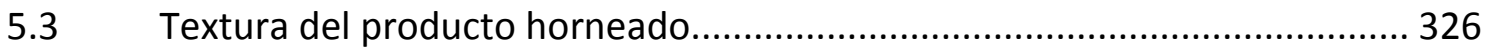

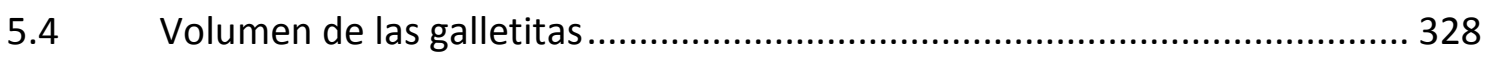

6. Evaluación sensorial del producto................................................................. 329

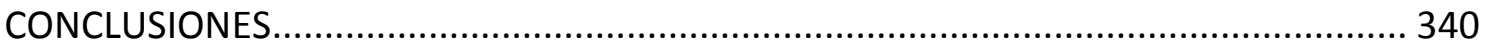

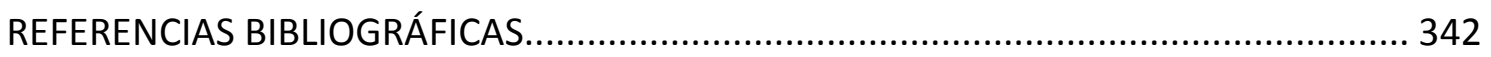

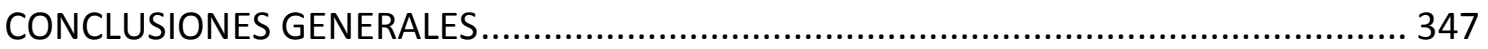




\section{INTRODUCCIÓN GENERAL}

\section{Cultivos no tradicionales}

El rescate de especies vegetales nativas, tanto para la conservación de la biodiversidad como para su uso racional como nuevas fuentes de alimentos y aditivos alimentarios, fibras, colorantes, fármacos e incluso biocombustibles, ha impulsado numerosas líneas de investigación en los últimos años.

El estudio de especies que podrían ser cultivadas con propósitos múltiples (uso alimentario, agroindustrialización, recuperación de suelos, etc.) implica potenciales beneficios económicos y agroecológicos, relacionados con la diversificación de cultivos y la generación de materias primas y productos elaborados alternativos.

En tiempos de la conquista española, los Incas cultivaban un número de diferentes especies vegetales que equiparaba prácticamente al de los cultivos de toda Asia o Europa en aquel entonces. Sobre las laderas de las montañas, hasta los $4000 \mathrm{~m}$ de altura y a lo largo de la columna vertebral de América del Sur se producían raíces, granos, legumbres, frutas y hortalizas (NRC, 1989).

Sin embargo, muchos de estos cultivos fueron reemplazados por especies europeas. De esta manera, al menos treinta especies vegetales distintas fueron relegadas, entre ellas: oca, maca, tarwi, nuñas y lucuma, las cuales permanecieron confinadas en el Altiplano (NRC, 1989). Lamentablemente, muchas de estas especies han recibido escasa atención y no han sido objeto de promoción comercial ni de investigación científica, aunque algunas resultan ampliamente adaptables, nutritivas y de alta aceptabilidad por parte de los consumidores.

El Centro Internacional de la Papa (CIP) y otras organizaciones vinculadas han implementado diversos programas para rescatar especies vegetales andinas amenazadas de extinción biológica y/o debilitamiento genético. Al respecto, ha sido mencionado que en la región Andina, al menos nueve especies productoras de raíces y tubérculos comestibles revisten importancia en sistemas agrícolas basados en la producción de papa. Estos cultivos son relevantes desde el punto de vista económico y nutricional para la subsistencia de agricultores de la región, que frecuentemente los usan sustituyendo en la dieta a ciertas frutas y hortalizas de mayor costo.

Las especies correspondientes son: ahipa (Pachyrhizus ahipa), achira (Canna edulis), arracacha (Arracacia xanthorrhiza), maca (Lepidium meyenii), mashua (Tropaeolum 
tuberosum), mauka (Mirabilis expansa), oca (Oxalis tuberosa), ulluco (Ullucus tuberosus) y yacón (Smallanthus sonchifolius). Se ha mencionado que, muy posiblemente, encontrando nuevos usos para las mismas se estimularía su demanda, el intercambio comercial y se crearían nuevas oportunidades económicas.

\subsection{Pachyrhizus ahipa}

Con referencia a la ahipa (Pachyrhizus ahipa (Wedd.) Parodi) (Figuras I y II), se trata de una planta perteneciente a la Familia Leguminosas, productora de raíces tuberosas, nativa de América del Sur y cultivada en pequeña escala en los Andes bolivianos, Sur de Perú y el Noroeste de Argentina (provincias de Jujuy y Salta) (Forsyth y col., 2002; Fassola y col., 2006; Ramos de la Peña y col., 2013). Esta especie, acumula almidón como principal compuesto de reserva (Grau, 1997), produce semillas (a partir de las cuales se propaga su cultivo) y tiene hojas y tallos en los que se acumula rotenona, una sustancia con propiedades insecticidas, presentando así alta tolerancia al ataque de plagas. La rotenona se encuentra asimismo en las semillas maduras, aunque la raíz está normalmente libre de este compuesto (Viña, 2012; López y García, 2012).

El ciclo de crecimiento de la ahipa es de 6-8 meses (Ramos de la Peña y col., 2013) pero presenta algunas dificultades biológico-agronómicas ya que una producción eficiente requiere un manejo cuidadoso del cultivo que incluye la poda sistemática de flores y frutos jóvenes durante el ciclo (Matos y col., 1998; Grau, 1997).

Estudios previos han señalado que el contenido de materia seca de las raíces frescas de ahipa es aproximadamente $25 \%$, correspondiendo un $20-50 \%$ a almidón y un $8-14 \%$ a proteínas (Grau, 1997). El elevado contenido de proteínas se debe a la simbiosis con bacterias que posibilitan la fijación de $\mathrm{N}_{2}$ atmosférico. Se ha mencionado también una alta proporción de azúcares presentes (Sørensen y col., 1997). Esta raíz es valorada por su alto contenido en agua, fibra, hidratos de carbono y niveles reducidos de lípidos (López y García, 2012). Por lo tanto, en base a su composición química, se puede decir que las raíces tuberosas de ahipa son alimentos saludables. 


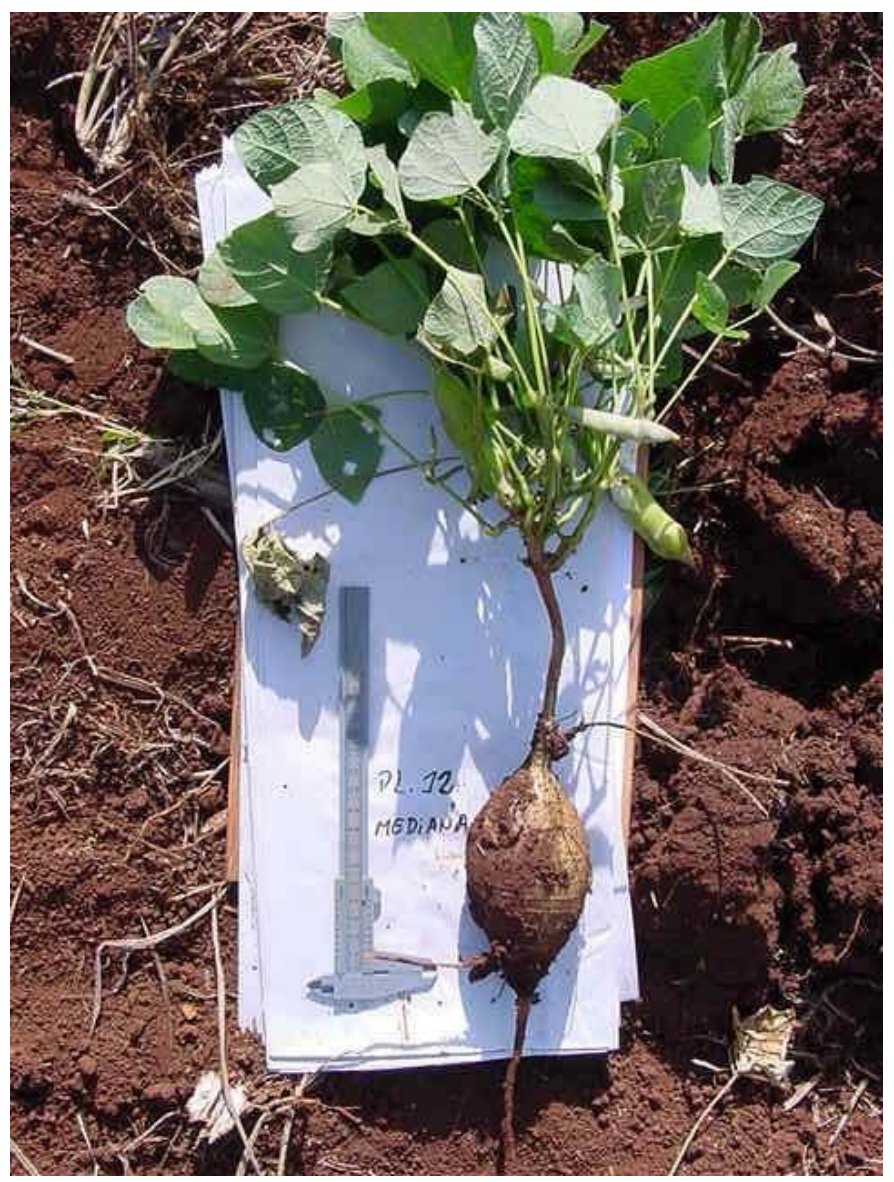

Figura I. Planta descalzada de Pachyrhizus ahipa (ahipa). Estación Experimental Agropecuaria INTA Montecarlo (Misiones, Argentina).

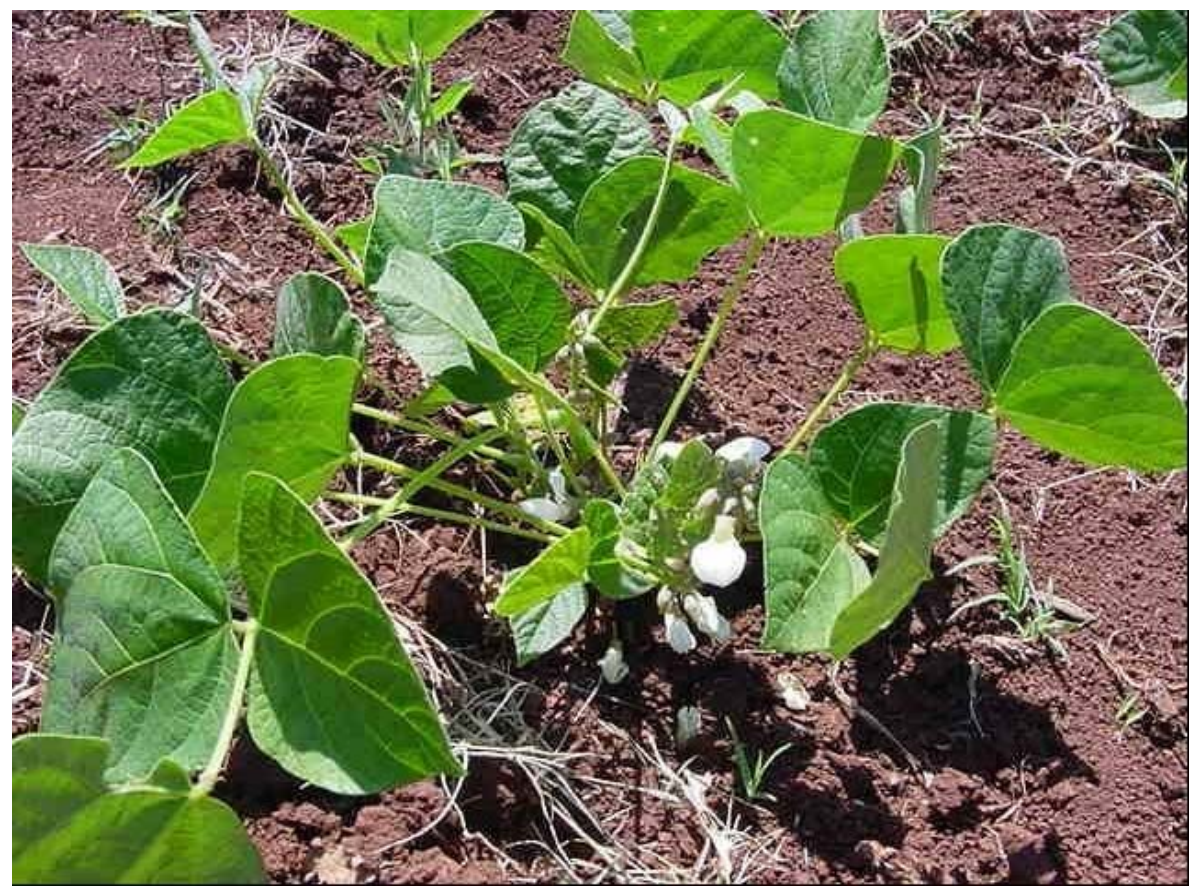

Figura II. Plantas de Pachyrhizus ahipa cultivadas en la Estación Experimental Agropecuaria INTA Montecarlo (Misiones, Argentina) (parte aérea). 
Desde el punto de vista agroindustrial, en Misiones existen establecimientos productores de almidón, siendo el cultivo de mandioca (Manihot esculenta, Crantz) (Figura III) la principal fuente regional de abastecimiento. En la cuenca industrial de la zona agroeconómica Oeste, el cultivo de mandioca es particularmente intensivo en los departamentos Eldorado, Montecarlo, Libertador General San Martín, Cainguàs y San Ignacio, donde se asientan industrias almidoneras que procesan 8.500 toneladas anuales de almidón y que representan el 59\% del consumo nacional (PTR 2005-2007, INTA). En diversas oportunidades, los industriales de la provincia han coincidido en señalar como mayor obstáculo de las empresas almidoneras la falta de materia prima para reactivar el sector productivo. Sumado a ello, existe un problema derivado de la baja producción de almidón de mandioca en el período comprendido entre octubre y marzo de cada año, que obliga a la industria local a entrar en un receso.

Las características mencionadas de la ahipa le otorgarían potencialidades como cultivo alternativo y/o complementario al de mandioca, factible de incorporar a los planteos rotacionales o como cultivo intercalar en forestaciones, favoreciéndose así la diversificación productiva.

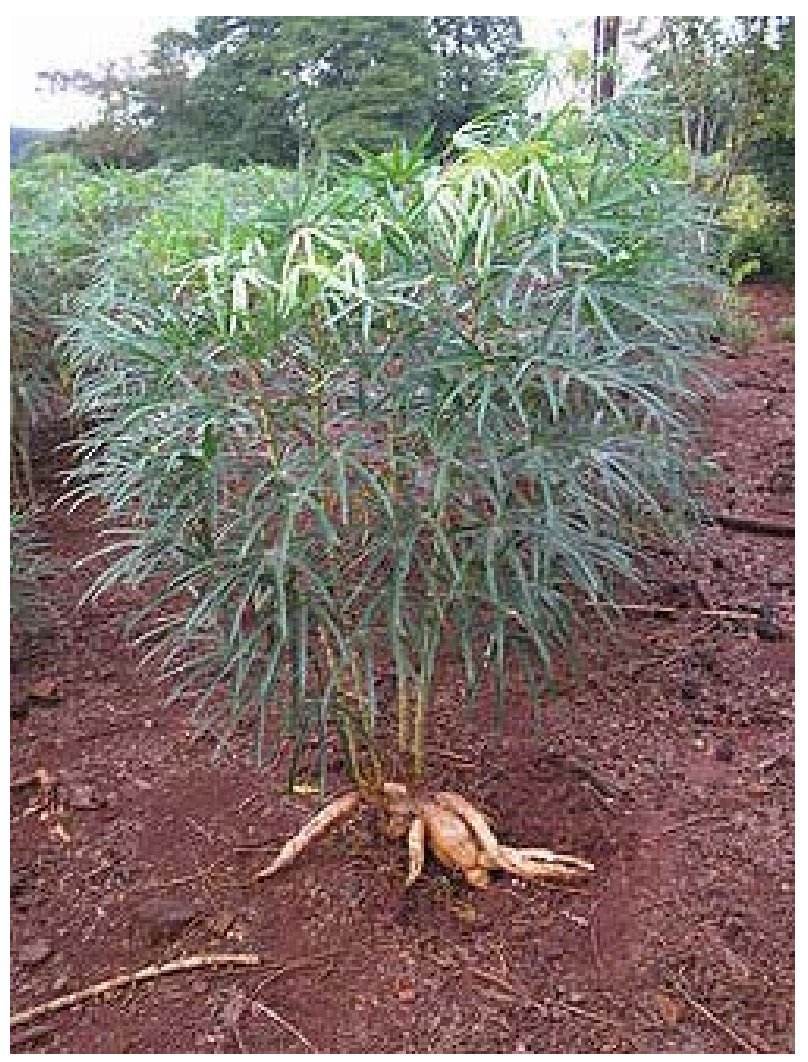

Figura III. Planta de Manihot esculenta (mandioca). Estación Experimental Agropecuaria INTA Montecarlo (Misiones, Argentina). 


\section{Ingredientes alimentarios: propiedades funcionales}

De acuerdo con Mínguez Mosquera y Pérez Gálvez (2013), existen dos acepciones del término "funcional", y que incluyen un significado "tecnológico" y un aspecto "fisiológico". Ambas acepciones, junto con las propiedades nutricionales, surgen a partir de las características químicas de los ingredientes que componen los alimentos, principalmente por la presencia y estructura de grupos reactivos característicos de dichos componentes.

De las características químicas dependerán el valor nutricional del producto y su atractivo sensorial, y son el origen del desarrollo, durante y después del procesado del alimento, de cambios tanto convenientes como indeseables. Posteriormente, cuando dichos ingredientes son ingeridos, éstos participarán en las actividades metabólicas del organismo, atribuyéndole al producto un valor nutricional determinado $y$, en ocasiones, un beneficio adicional del cual se deriva su carácter funcional en el sentido fisiológico.

El concepto de funcionalidad tecnológica de un alimento (propiedades tecnofuncionales), implica que a partir de la interacción entre sus constituyentes, que puede ser propiciada o acentuada por las condiciones de procesamiento, surgen las características, tanto organolépticas como nutricionales, adecuadas para satisfacer las demandas del consumidor. Sin embargo, también se puede dar lugar a cambios detrimentales o negativos.

El análisis y aplicación de la funcionalidad tecnológica hace posible el desarrollo de técnicas que favorezcan los cambios positivos inducidos en los alimentos y que se minimicen las modificaciones indeseadas.

\section{Alimentos funcionales}

La nueva nutrición centra su interés en la relación entre la alimentación y la promoción de la salud. En tal sentido, la nutrición actual se orienta a proveer de alimentos que, además de los nutrientes, contienen otros compuestos biológicamente activos que aportan un beneficio adicional. Así nació el concepto de "alimentos funcionales", cuya elaboración no sólo contempla la calidad nutricional, tecnológica y sensorial, sino que también contienen naturalmente o se han incluido en ellos componentes bioactivos. Estos compuestos, en su mayoría, se encuentran presentes en los alimentos vegetales. 
La tendencia del consumidor actual es la de escoger alimentos que, además de ser inocuos, produzcan beneficios para su salud y bienestar, propiedades que otorgan los elementos bioactivos presentes en los alimentos funcionales.

Los alimentos que contienen cereales, y en particular los productos de panificación, representan una alternativa interesante como productos saludables y/o funcionales ya que, fuera de las propiedades nutricionales propias de los cereales y sus derivados (harinas, salvado, germen o mezclas de ellos), cabe la posibilidad de transformarlos en alimentos funcionales al adicionarles compuestos bioactivos de efecto reconocido. Entre éstos compuestos se destacan ciertos tipos de fibra dietética, prebióticos, ácidos grasos omega, antioxidantes u otros. Además, otras alternativas consisten en el reemplazo de parte de las grasas saturadas por otras más saludables, la reducción del aporte de sodio, la adición de almidones resistentes a la digestión o el incremento de su porcentaje por modificaciones en la tecnología de elaboración, entre otras. Los productos de panificación son económicos, fáciles de envasar y transportar, de prolongada conservación y de amplia aceptación. Estas características, sumadas al gran volumen de producción, abren inmensas posibilidades de elaboración de alimentos funcionales (Lutz y Edel León, 2009).

Sin embargo, hay poblaciones como la de los pacientes celíacos, que no pueden acceder a los beneficios de estos alimentos que contienen los cereales trigo, avena, cebada y centeno, dada la intolerancia al gluten que padecen. Por tal motivo, es necesario el desarrollo de alimentos que reúnan las mismas características nutritivas, funcionales, pero que sean libres de gluten.

\section{Usos alimentarios de Pachyrhizus ahipa}

La ahipa se consume principalmente como un vegetal crudo con limón en ensaladas, en sopas, frito salteado o conservado en vinagre, con cebolla. Esta raíz tiene un perfil de textura similar a la papa blanca (Ramos de la Peña y col., 2013). La ahipa se considera una raíz rica en energía y de fácil digestión (Noman y col., 2007).

Si bien las raíces de ahipa pueden ser utilizadas directamente como hortaliza fresca, es posible considerar también que tanto el cultivo como el consumo de esta especie se favorecerían si hubiera opciones de transformación de las raíces. Las mismas constituirían una materia prima potencial para la obtención de diversos productos de 
alto valor agregado, principalmente almidón y fibra. El aprovechamiento integral de esta raíz supone la producción y caracterización de estos productos.

Con respecto a la caracterización del almidón que esta especie produce, los resultados hallados en la bibliografía son diversos. Algunos informes (Sørensen y col., 1997; Forsyth y col., 2002) mencionan niveles relativamente bajos de amilosa, menores que el $17 \%$, resultando más bajos que los de almidones de cereales.

El almidón de ahipa presenta un tamaño de gránulo homogéneo respecto de otros almidones de diferente origen botánico (Leonel, 2007), teniendo una aplicación potencial en la industria del papel y también en los alimentos que requieren baja retrogradación después del procesamiento.

Asimismo, la bibliografía relacionada a estudios de gelatinización y retrogradación de este almidón o del proveniente de otras especies de Pachyrhizus es relativamente escasa (Mélo y col., 2003).

Desde el punto de vista nutricional, los almidones pueden clasificarse en base a la velocidad y la extensión en que son digeridos en el intestino delgado humano. De esta manera tenemos almidones rápidamente digestibles, lentamente digestibles y almidones resistentes (Englyst y col., 1992). La digestibilidad del almidón se ha vinculado con la especie vegetal de origen y depende en gran medida de las propiedades fisicoquímicas del mismo. También resulta influenciada por las condiciones de procesamiento y conservación. Dado que la mayoría de los alimentos ricos en almidón se consumen cocidos, la digestibilidad enzimática del almidón gelatinizado es una propiedad crítica en la industria alimentaria.

\section{La Celiaquía y los productos libres de gluten}

La Celiaquía es una enfermedad o trastorno crónico causado por la intolerancia permanente a la ingestión de gluten, conjunto de proteínas presentes en el trigo, avena, cebada y centeno (TACC) y productos derivados de estos cuatro cereales. El único tratamiento eficaz es el cambio a una dieta libre de gluten de por vida, lo que permite la regeneración de las vellosidades intestinales y la disminución de los síntomas asociados a la enfermedad.

La mayoría de los alimentos procesados contienen gluten. En muchos casos la dieta necesaria no es bien aceptada ya que se suprimen alimentos básicos cotidianos, 
manifestándose frecuentemente carencias desde el punto de vista nutricional. Los resultados de un número de estudios indican un consumo desequilibrado de carbohidratos, proteínas y lípidos, como así también una ingesta limitada de ciertos nutrientes esenciales en los sujetos celíacos, en relación a los controles (Álvarez-Jubete y col., 2010).

Entre las alternativas alimentarias, las galletitas son productos cuyo consumo se distribuye a lo largo del mundo y es realizado tanto por niños como adultos. Sus principales ingredientes son la harina de trigo, el azúcar y la materia grasa que, combinados en diferentes proporciones, dan lugar a una amplia gama de texturas y sabores. Existen en el mercado galletitas dulces (cookies) sin gluten, aptas para el consumo de personas celíacas, aunque son, en general, productos de baja calidad debido a su textura arenosa y seca. En ellas se reemplaza la harina de trigo por mezclas de almidones o harinas libres de gluten (Lutz y Edel León, 2009).

La harina obtenida de las raíces tuberosas de ahipa sería en principio un producto libre de gluten, por lo cual podría ser considerada como ingrediente en la elaboración de mezclas para la obtención de productos horneados (entre ellos galletitas) destinados a la población celíaca, como alternativa a los productos convencionales.

El estudio de la especie vegetal Pachyrhizus ahipa y sus principales productos (almidón, fibra y harina) contribuirán a identificar y desarrollar las aplicaciones industriales más adecuadas y conducirían a un aprovechamiento integral de la misma. 


\section{OBJETIVO GENERAL}

El objetivo general del presente trabajo de Tesis fue evaluar las potencialidades de la ahipa (Pachyrhizus ahipa) como cultivo nativo alternativo y contribuir a ampliar sus posibilidades de uso e incorporación como fuente de materia prima de agroindustrias generadoras de valor agregado. 


\section{REFERENCIAS BIBLIOGRÁFICAS}

Álvarez-Jubete, L., Arendt, E. K., Gallagher, E. (2010). Nutritive value of pseudocereals and their increasing use as functional gluten free ingredients. Trends Food Sci. Technol. 21, 106-113.

Englyst, H. N., Kingman, S. M., Cummings, J. H. (1992). Classification and measurement of nutritionally important starch fractions. European Journal of Clinical Nutrition, 46, S30-S50.

Fassola, H.E.; Pachas, A.N.; Rohatsch, P.E.; Rodríguez, D.N. y Leidi, E.O. (2006). Valorización y recuperación de la ajipa como cultivo alternativo para sistemas agrícolas sostenibles. 52 Congreso Internacional de Americanistas, Pueblos y Culturas de América, 17-21/7/06, Sevilla.

Forsyth, J.L., Ring, S.G., Noel, T.R. (2002). Characterization of Starch from Tubers of Yam Bean (Pachyrhizus ahipa). Journal of Agricultural and Food Chemistry, 50, 361-367.

Grau, A. (1997). Ahipa, la legumbre tuberosa de los Andes. Ciencia Hoy, 7(42). Disponible en http://www.ciencia-hoy.retina.ar/hoy42/ahipa2.htm.

Leonel, M. (2007). Analysis of the shape and size of starch grains from different botanical species. Ciência e Tecnologia de Alimentos, Campinas, 27, 579-588.

López, O. V., García, M. A. (2012). Starch films from a novel (Pachyrhizus ahipa) and conventional sources: Development and characterization. Materials Science and Engineering C 32, 1931-1940.

Lutz, M., Edel León, A. (Editores). (2009). Aspectos nutricionales y saludables de los productos de panificación. Universidad de Valparaíso-Editorial.

Matos, M.C.; Matos, A. A. y Vieira da Silva, J.B. (1998). Effect of manual and chemical flower.

Mínguez Mosquera, M. I., Pérez Gálvez, A. (2013). Características químicas nutricionales y funcionales de los alimentos. IG_AgroCSIC_5. Instituto de la grasa (CSIC). Sevilla, España.

Mélo, E.A.; Stamford, T.L.; Silva, M.P., Krieger, N. y Stamford, N.P. (2003). Functional properties of yam bean (Pachyrhizus erosus) starch. Bioresource Technology 89, 103-106. 
N.R.C. (1989). Lost crops of the Incas: little-known plants of the Andes with promise for worldwide cultivation. Washington DC: National Academy Press.

Noman, A. S. M., Hoque, M. A., Haque, M. M., Pervin, F., Karim, M. R. (2007). Food Chem. 102, 1112-1118.

PTR Plan Tecnológico Regional. (2005-2007). Centro Regional Misiones INTA.

Ramos de la Peña, A. M., Renard, C. M. G. C., Wicker, L., Contreras-Esquivel, J. C. (2013). Advances and perspectives of Pachyrhizus spp. in food science and biotechnology. Trends in Food Science \& Technology 29, 44-54.

Sørensen, M., Døygaard, S., Estrella, J., Kvist, L. P., Nielsen, P. E. (1997). Status of the South American tuberous legume Pachyrhizus tuberosus (Lam.) Spreng. Biodiversity and Conservation 6, 1581-1625.

Viña, S. Z. (2012). Introducción. Pachyrhizus ahipa. Revalorización de un cultivo ancestral. Editores López, O. V., García, M. A., Viña, S. Z. Editorial Académica Española. 
CAPÍTULO 1.

Caracterización de las raíces de

Pachyrhizus ahipa 


\section{INTRODUCCIÓN}

\section{Principales cultivos de raíces y tubérculos (R\&T): generalidades}

Los órganos subterráneos comestibles provenientes de diversas especies vegetales son denominados comúnmente "hortalizas pesadas". Comprenden distintas estructuras botánicas, tales como raíces (remolacha, zanahoria, batata, mandioca, por ejemplo); tubérculos, como es el caso de la papa, el topinambur o el ñame; bulbos (cebolla, ajo, echalote y otras especies de Allium relacionadas); o rizomas, como los del jengibre (Cantwell y Kasmire, 2002).

Se los puede agrupar de la siguiente manera:

a) Productos cultivados típicamente en zonas templadas, como es el caso de la papa (Solanum tuberosum) que representó una producción de 374.382.274 toneladas a nivel mundial, en el año 2011 (FAOSTAT, 2013), lo que la ubica como el cuarto cultivo más importante en el mundo. Aunque comúnmente se la describe como un alimento básico en regiones templadas, es en realidad una especie originaria de las tierras altas de los Andes sudamericanos (Tay, 2013).

b) Productos cultivados mayormente en regiones tropicales y subtropicales, como batata, ñame y mandioca, entre otros.

Este tipo de commodities se caracterizan por constituir órganos de almacenamiento (principalmente de carbohidratos), presentar generalmente baja actividad respiratoria dependiendo del estado de desarrollo, ser relativamente poco perecederos y permitir por lo tanto su almacenamiento por períodos más prolongados. Sin embargo, pueden continuar su crecimiento luego de recolectados, desarrollando raicillas o brotes, por ejemplo.

Tay (2013) realizó una reseña de los principales cultivos de raíces y tubérculos, indicando que casi todos ellos son de origen tropical y subtropical, incluyendo papa (Solanum tuberosum L. y otras especies diploides, triploides y pentaploides), mandioca (Manihot esculenta Crantz), batata (Ipomoea batatas (L.) Lam.), yams o ñames (Dioscorea spp.), los Aroides, que comprenden a su vez al taro (Colocasia spp.), cocoyam (Xanthosoma spp.), y otros géneros como Alocasia, Amorphophallus y Cyrtosperma (taro gigante de los pantanos). A estas especies se suma un grupo de nueve raíces y tubérculos "menores", de origen andino. Este último conjunto reúne a: ahipa (Pachyrhizus ahipa (Weddell) Parodi), achira (Canna indica L.), arracacha 
(Arracacia xanthorrhiza Bancroft), maca (Lepidium meyenii Walpers), mashua (Tropaeolum tuberosum Ruiz y Pavón), mauka (Mirabilis expansa Ruiz y Pavón), oca (Oxalis tuberosa Mol.), ulluco (Ullucus tuberosus Caldas) y yacón (Smallanthus sonchifolius).

Esta clase de cultivos no es por lo común ampliamente comercializada a nivel internacional. Sus precios no muestran generalmente grandes incrementos o fluctuaciones durante las crisis mundiales de los mercados como sí ha ocurrido con los cultivos de granos, tales como las que se verificaron en años recientes en el caso del arroz, el trigo y el maíz (Tay, 2013).

El origen tropical de estas materias primas posibilita que puedan ser cultivadas en un amplio período del año siempre que cuenten con disponibilidad de agua y con temperaturas apropiadas para su crecimiento. Pueden complementar a los cultivos de cereales, incorporándose a las rotaciones agrícolas. Algunos se producen en tierras marginales, con limitantes tales como sequía, anegamiento, salinidad y condiciones deficientes de fertilidad del suelo.

En muchos casos se señala que este tipo de cultivos desempeñan un papel importante en la estabilización de la seguridad y los precios de los alimentos a nivel local o regional.

Presentan un alto potencial para incrementar sus rendimientos, aún con un relativamente escaso número de mejoras a nivel productivo y/o agronómico.

La mandioca, en particular, es predominantemente cultivada en países en vías de desarrollo de Asia, África y Latinoamérica. Se ubica en el quinto lugar en términos de su producción total a nivel mundial. Se trata de una fuente importante de energía en los trópicos y sub-trópicos. Su vida postcosecha es relativamente corta por tal motivo es utilizada y comercializada localmente. Una parte considerable de la producción es procesada para la obtención de almidón.

En lo que respecta a la producción de mandioca en nuestro país, según Bongiovanni y Giletta (2012) se cultivaron 40.000 hectáreas en el año 2009. La Provincia de Misiones reúne una superficie de aproximadamente 30.000 ha destinada al cultivo de esta especie, con una producción total de alrededor de 260.000 toneladas. De este total, un $25 \%$ se destina a uso industrial, mayoritariamente a la producción de almidón (fécula) y en menor proporción a la producción de harina de mandioca. Dicha provincia 
concentra alrededor del $70 \%$ de la superficie cultivada a nivel nacional y prácticamente la totalidad de la producción nacional de almidón de mandioca (Morandi y Pirker, 2012).

\section{Composición química de las principales R\&T}

Las raíces y tubérculos son fuentes de energía en la dieta y algunos de ellos aportan minerales, vitaminas y aminoácidos esenciales. En general estos cultivos representan más del $5 \%$ de la ingesta calórica humana. El conocimiento de las propiedades nutricionales y físico-químicas de los cultivos de R\&T es vital en la formulación de alimentos. Todas las raíces y tubérculos tienen alto contenido de humedad, generalmente inferior o igual al $65 \%$ de la parte comestible (Opara, 2003). La composición química de las principales R\&T (aroides, mandioca, batata, papa, yams) presentan un contenido de proteínas y fibra entre 0,5-3,0\%. En cuanto al contenido de almidón, se hallaron valores entre $13-36 \%$, siendo mayor en mandioca (27-36\%). La cantidad de lípidos y cenizas totales en R\&T es relativamente baja (inferior a 6,5\% y 1,5\%, respectivamente). El contenido de materia seca va desde 20 hasta $40 \%$, siendo mandioca (30-40\%) y yam (20-42\%) los cultivos con mayores rangos hallados. La batata contiene el mayor nivel de azúcares (1,5-5\%) determinado en R\&T (Opara, 2003).

Además de los componentes mayoritarios (carbohidratos, proteínas, lípidos, minerales), los órganos vegetales pueden contener ciertos factores, que aún a muy bajas concentraciones, pueden interferir con la asimilación de uno o varios nutrientes; a estos constituyentes se los denomina genéricamente factores antinutricionales o antinutrientes.

\section{Antinutrientes}

Los compuestos naturales o sintéticos que interfieren con la absorción de un nutriente son denominados factores antinutricionales o antinutrientes (Cammack, 2006). La mayoría de estos factores son metabolitos secundarios de las plantas, que actúan como pesticidas naturales para proteger al vegetal de herbívoros y microorganismos patógenos (Heldt y Piechulla, 2011).

Los antinutrientes se pueden clasificar en tres grandes grupos (Janssen, 1997):

1) antiproteínas, que interfieren en la utilización de proteínas o aminoácidos, 
2) antiminerales, que impiden o reducen la absorción de minerales, y

3) antivitaminas, que hidrolizan o disminuyen la disponibilidad de las vitaminas.

Entre las antiproteínas más comunes en los alimentos se encuentran las lectinas y los inhibidores de proteasas. Las lectinas son glicoproteínas que pueden alterar el metabolismo de lípidos, carbohidratos y proteínas (Dini y col., 2012).

Los inhibidores de proteasas son proteínas capaces de interferir con la actividad de algunas proteasas digestivas. Se pueden dividir en dos categorías principales: aquéllos con alto peso molecular (20-25 kDa) interfiriendo principalmente con la actividad de la tripsina y los de bajo peso molecular (6-10 kDa) inhibiendo la quimotripsina, principalmente. Los inhibidores de tripsina pueden inducir hipertrofia y/o hiperplasia pancreática (Dini y col., 2012). Según Opara (2003), la batata tiene actividad inhibitoria de la tripsina.

Los glicósidos cianogénicos son compuestos que también se pueden incluir dentro de las antiproteínas. Su hidrólisis conduce a la producción de HCN, que interfiere con la cadena respiratoria mediante la inhibición de la enzima citocromo oxidasa, actuando como un veneno muy potente (Dini y col., 2012). La mandioca es una de las principales R\&T que contiene glicósidos cianogénicos (Opara, 2003), principalmente linamarina y en menor proporción, lotaustralina.

El grupo de antiminerales comprende entre otros al ácido fítico y al ácido oxálico. Estos compuestos interactúan con algún catión presente reduciendo así la biodisponibilidad de muchos minerales, pero su presencia rara vez tiene consecuencias graves en la salud de los consumidores. El fitato, anión resultante de la disociación del ácido fítico, está relacionado a menudo con la reducción de la disponibilidad del hierro, magnesio, zinc, cobre, calcio y manganeso (Dini y col., 2012).

El ácido oxálico presente en ciertos alimentos reduce la biodisponibilidad del calcio produciendo bloqueo de los túbulos renales y desarrollo de cálculos. Los Aroides son el principal grupo de R\&T donde se presentan niveles elevados de este compuesto (Opara, 2003).

El tercer grupo de antinutrientes, llamado antivitaminas, incluye a la enzima oxidasa del ácido ascórbico, a las catequinas y a los taninos, entre otros compuestos. Además de su actividad antinutritiva, los taninos pueden reducir la palatabilidad de los alimentos por la astringencia asociada con su interacción con las proteínas salivales 
(Dini y col., 2012). Opara (2003) informó que entre las R\&T más conocidas, los yams o ñames contienen estos compuestos en cantidades considerables.

\section{Generalidades sobre la poscosecha de R\&T}

Como se señaló anteriormente, a excepción de la papa y algunas otras especies, las raíces y tubérculos se cultivan en zonas más cálidas y tienen un período de crecimiento relativamente largo. Son fuentes de carbohidratos en la ingesta; constituyen órganos de almacenamiento y por ello, en general, presentan baja tasa respiratoria (Mugridge y col., 2012).

Sin embargo, ciertas R\&T son productos muy perecederos $y$, en consecuencia, las pérdidas poscosecha pueden ser considerables; por lo tanto requieren técnicas especializadas de manipulación, almacenamiento y conservación, para reducir al mínimo las pérdidas, prolongar la duración de los productos y mantener su calidad.

La promoción de tecnologías mejoradas de conservación y procesamiento se respalda en la capacitación para la manipulación poscosecha correcta, la gestión de calidad, el acopio y la comercialización, que resultan ser elementos básicos requeridos por los procesadores.

Es sabido que las frutas y hortalizas (incluyendo a las raíces comestibles, entre estas últimas) son órganos vegetales cuyo contenido en agua varía entre 65-95\% y cuyos procesos metabólicos continúan activos después de la recolección. Su vida poscosecha depende del ritmo de consumo de sus reservas almacenadas y de la velocidad con que se produce la pérdida de agua.

Las pérdidas causadas por los procesos fisiológicos normales se intensifican cuando se dan condiciones que aceleran el deterioro natural. Cuando el producto se expone a temperaturas extremas, a modificaciones inapropiadas de la composición de la atmósfera y/o a contaminación, sufre un deterioro fisiológico acelerado, que puede causar la producción de sabores desagradables, la detención del proceso de desarrollo $\mathrm{u}$ otras modificaciones de los procesos vitales, y puede dejar de ser apto para el consumo.

La manipulación descuidada del producto fresco es causa de daños internos que aceleran el deterioro o bien ocasiona lesiones en las estructuras y tejidos de protección, que aumentan rápidamente la pérdida de agua. Dichas lesiones también 
propician el ingreso de microorganismos patógenos causantes de diversas enfermedades.

No existe prácticamente información sistematizada referida a cuáles serían las mejores condiciones de conservación poscosecha para las raíces de Pachyrhizus ahipa (ahipa) en particular. Actualmente se trata de un cultivo producido a escala muy reducida en nuestro país y para, eventualmente, ampliar su distribución hacia zonas más alejadas de los centros de producción (circunscriptos principalmente a las provincias de Jujuy y Salta) resulta crítica a nivel comercial la falta de canales fluidos de distribución.

Es factible que el consumo y el cultivo de esta especie como fuente de materias primas se vean favorecidos si hubiera un mayor número de opciones de utilización y obtención de productos de transformación, que permitirían su uso más difundido como alimento.

Para aportar soluciones a este problema e incrementar con ellas la demanda y las opciones de comercialización se han propuesto métodos de conservación de las raíces en poscosecha, de bajo costo, que permitan almacenarlas durante períodos más prolongados.

De acuerdo a sus requerimientos térmicos poscosecha, las raíces de ahipa se clasifican como sensibles al daño por frío, junto con batata (Ipomoea batatas), cará (Dioscorea alata L.), mandioca (Manihot esculenta), jengibre (Zingiber officinale), taro (Colocasia esculenta), entre otras especies (Mugridge y col., 2012).

\section{Tratamientos físicos de poscosecha}

Entre las tecnologías poscosecha disponibles para prolongar la vida útil y reducir los efectos del daño en productos vegetales es importante destacar el beneficio de los llamados tratamientos físicos, considerados tecnologías limpias. Estos tratamientos implican la reducción del uso de aditivos y preservantes químicos en los alimentos, evitando algún efecto residual y/o secundario.

Dentro de los métodos físicos, se encuentran incluidos los tratamientos térmicos; este tipo de tratamientos implica el empleo de temperaturas más bajas y tiempos más reducidos que en el caso de los tratamientos tradicionales de escaldado, pasteurización, cocción o esterilización utilizados en otros tipos de alimentos (Hoover, 
1997). Ello es debido a la necesidad de no alterar la calidad sensorial y nutricional de los productos frescos.

De esta forma se han desarrollado para productos hortofrutícolas tratamientos térmicos que, en un principio, se clasificaron en cortos (hasta 60 minutos en agua a 45$60^{\circ} \mathrm{C}$ ) o largos ( 12 horas a 4 días en aire a $38-46^{\circ} \mathrm{C}$ ) (Schirra y col., 2000). Así, diversos autores han informado tratamientos en cítricos por inmersión en agua caliente (44 a $50^{\circ} \mathrm{C}$ ) durante un período corto de tiempo (1 a 4 minutos) (Smilanick y col., 2006) o mediante la técnica conocida como curado, tratando los productos en cámara con aire a temperaturas de $35-40^{\circ} \mathrm{C}$ y humedad relativa del $90 \%$, durante 2 ó 3 días (Stange y Eckert, 1994; Lanza, 1997; Torres y col., 2002) obteniendo buenos controles inclusive con 24 horas de curado o menos (Stange y Eckert, 1994; Lanza, 1997, Meier y col., 2004a y b).

El mecanismo mediante el cual un tratamiento térmico induce cambios fisiológicos en los tejidos, tales como la inhibición de las enzimas que degradan las paredes celulares, estaría asociado a modificaciones en la expresión de genes y en la síntesis de proteínas (Lurie, 1998). Por acción de las altas temperaturas el ácido ribonucleico mensajero (mRNA) de los genes involucrados en ciertos procesos normales del crecimiento y desarrollo desaparece, mientras que se acumula el relacionado a la síntesis de proteínas de estrés térmico (PET) (Mugridge y col., 2012).

Una de las respuestas inmediatas a temperaturas por encima de $35^{\circ} \mathrm{C}$ es la disociación y reorganización de polirribosomas existentes, originando estructuras que traducen preferencialmente el mRNA que codifica para la síntesis de PET. Este proceso forma parte de las respuestas de los organismos al estrés térmico (Lurie, 1998).

Se ha mencionado que los tratamientos térmicos estimulan los mecanismos de defensa del propio producto a la colonización e infección por parte de microorganismos. El tratamiento es capaz de activar en los tejidos la biosíntesis de lignina, así como de diferentes sustancias endógenas (fitoalexinas) que inhiben el desarrollo fúngico (Tuset y col., 1997).

Por lo tanto, el fundamento de utilizar los tratamientos térmicos reside en someter a los tejidos vegetales a un estrés controlado que los preparará o acondicionará para tolerar otros tipos de estrés. 
Otro tipo de tratamiento físico utilizado es la aplicación de radiación ultravioleta (UV). Dicha radiación corresponde a una parte de la región no ionizante del espectro electromagnético. Se la divide tradicionalmente en tres rangos de longitud de onda: UV-C (200-280 nm), que es extremadamente nociva para los organismos, pero no relevante bajo condiciones naturales de irradiación solar; UV-B (280-320 nm), de interés particular debido a que puede inducir diversos efectos de daño en las plantas; $y$ UV-A (320-400 nm), que es la porción menos peligrosa de la radiación UV (Hollósy, 2002).

Se ha informado que la radiación UV-C afecta varios procesos fisiológicos en tejidos vegetales, y que más relevante aún es el hecho de ocasionar daños en el ácido desoxirribonucleico (ADN) microbiano (Allende y Artés, 2003). Por ello, la radiación UV ha sido empleada principalmente debido a sus efectos germicidas, induciendo modificaciones en diversas biomoléculas. Tanto las regiones UV-B como UV-C pueden generar una multitud de fotoproductos derivados del ADN, capaces de producir mutaciones durante la replicación (Hollósy, 2002). La radiación UV-C es usada principalmente como un tratamiento de superficie debido a que penetra sólo 50-300 $\mathrm{nm}$ dentro de los tejidos (Maharaj y col., 1999).

Asimismo, esta radiación afecta a las proteínas y a los fosfo- y glicolípidos, que son los principales componentes de las membranas celulares. Los lípidos contienen ácidos grasos insaturados que pueden ser destruidos por la radiación UV en presencia de oxígeno (Hollósy, 2002).

Por otra parte, diversos estudios han señalado que la luz UV-C es un estímulo a la síntesis y acumulación de fitoalexinas. Estos compuestos están asociados con la resistencia a enfermedades en muchas especies vegetales (Langcake y Pryce, 1977; Bridge y Klarman, 1973).

Como se ha señalado, la radiación UV-C es generalmente perjudicial para los tejidos vegetales. Sin embargo, a dosis bajas puede producir efectos provechosos. Este fenómeno es conocido como hormesis (estimulación de respuestas positivas mediante niveles bajos o controlados de factores de estrés) (Calabrese y col., 1987) y constituye el fundamento de la aplicación de radiación UV-C como tratamiento físico postcosecha. 


\section{OBJETIVOS}

Los objetivos planteados para este capítulo son los siguientes:

1. Analizar la composición química de las raíces de Pachyrhizus ahipa, cuantificando los componentes mayoritarios (humedad, cenizas, lípidos totales, proteína cruda, fibra, almidón) y aquellos compuestos minoritarios que guardan relevancia nutricional.

2. Analizar los principales procesos fisiológicos (actividad respiratoria, brotado, actividad de la enzima $\alpha$-amilasa) relacionados con la degradación del almidón, principal compuesto de reserva de las raíces.

3. Evaluar la incidencia de distintas temperaturas de almacenamiento y de la aplicación de tecnologías limpias (tratamientos térmicos moderados, irradiación UV-C) sobre atributos de calidad tales como la textura y el color interno de las raíces y sobre el desarrollo de hongos.

4. Comparar la composición química (análisis proximal, elementos minerales, antinutrientes) de raíces de ahipa pertenecientes a distintas accesiones.

Para un mejor ordenamiento, el presente Capítulo se ha dividido en tres secciones:

Sección 1. Composición química de raíces de Pachyrhizus ahipa pertenecientes a la denominada "accesión Local".

Sección 2. Poscosecha de raíces de Pachyrhizus ahipa.

Sección 3. Composición química y propiedades funcionales de raíces pertenecientes a distintas accesiones de Pachyrhizus ahipa. 


\section{CAPÍTULO 1. SECCIÓN 1.}

\section{Composición química de raíces de}

\section{Pachyrhizus ahipa pertenecientes a la accesión Local}




\section{Material vegetal}

\section{MATERIALES Y MÉTODOS}

Se trabajó con plantas de Pachyrhizus ahipa (Wedd.) Parodi cultivadas en la Estación Experimental Montecarlo del Instituto Nacional de Tecnología Agropecuaria (INTA),

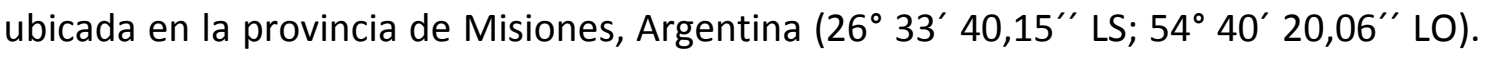
Las raíces fueron cosechadas en el mes de abril (años 2009 a 2012 inclusive), cuando se produjo la senescencia de la parte aérea de las plantas.

Las raíces de ahipa se recibieron en el laboratorio del CIDCA (La Plata, Buenos Aires) y se procesaron inmediatamente. Aquellas que se encontraban dañadas o con síntomas y/o signos de enfermedades fueron descartadas. Las raíces seleccionadas fueron lavadas exhaustivamente con agua corriente, removiendo los restos de tierra. A continuación se implementó un tratamiento de sanitización, que consistió en una inmersión de las raíces en una solución de hipoclorito de sodio ( $\mathrm{NaClO}, 250$ ppm de cloro activo, $10 \mathrm{~min}$ ). Finalmente las raíces se dejaron secar a temperatura ambiente.

Las determinaciones químicas se realizaron primeramente sobre raíces de ahipa pertenecientes a la denominada "accesión Local" (Figura 1.1). Este material proviene en su origen de semillas recolectadas en la Localidad Perico (Jujuy), suministradas en el año 2004 por el Dr. Alfredo Grau al Ing. Hugo Fassola de la EEA Montecarlo INTA. En la mencionada Estación se lleva a cabo la evaluación de este material en base a sus características agronómicas, realizándose anualmente la multiplicación del mismo. Este material estuvo disponible para su evaluación en el CIDCA a partir del año 2007. En una segunda etapa (2010-2012), se procedió a analizar la composición química de raíces de ahipa pertenecientes a otras accesiones, las cuales provenían en su origen del IRNAS-CSIC (Instituto de Recursos Naturales y Agrobiología - Consejo Superior de Investigaciones Científicas, Sevilla, España) provistas por el Dr Eduardo Leidi. Dichas accesiones fueron designadas en la EEA Montecarlo de la siguiente manera: IRNAS 4, 5, 9 y 11 , y allí se procedió a su evaluación y multiplicación.

Con fines comparativos, las mismas determinaciones llevadas a cabo en raíces de ahipa se realizaron también en raíces de mandioca "cultivar Pomberi" cultivadas en Colonia Guatambú en la zona de influencia de la EEA Montecarlo; el material correspondía a raíces de un año (Figura 1.2). 


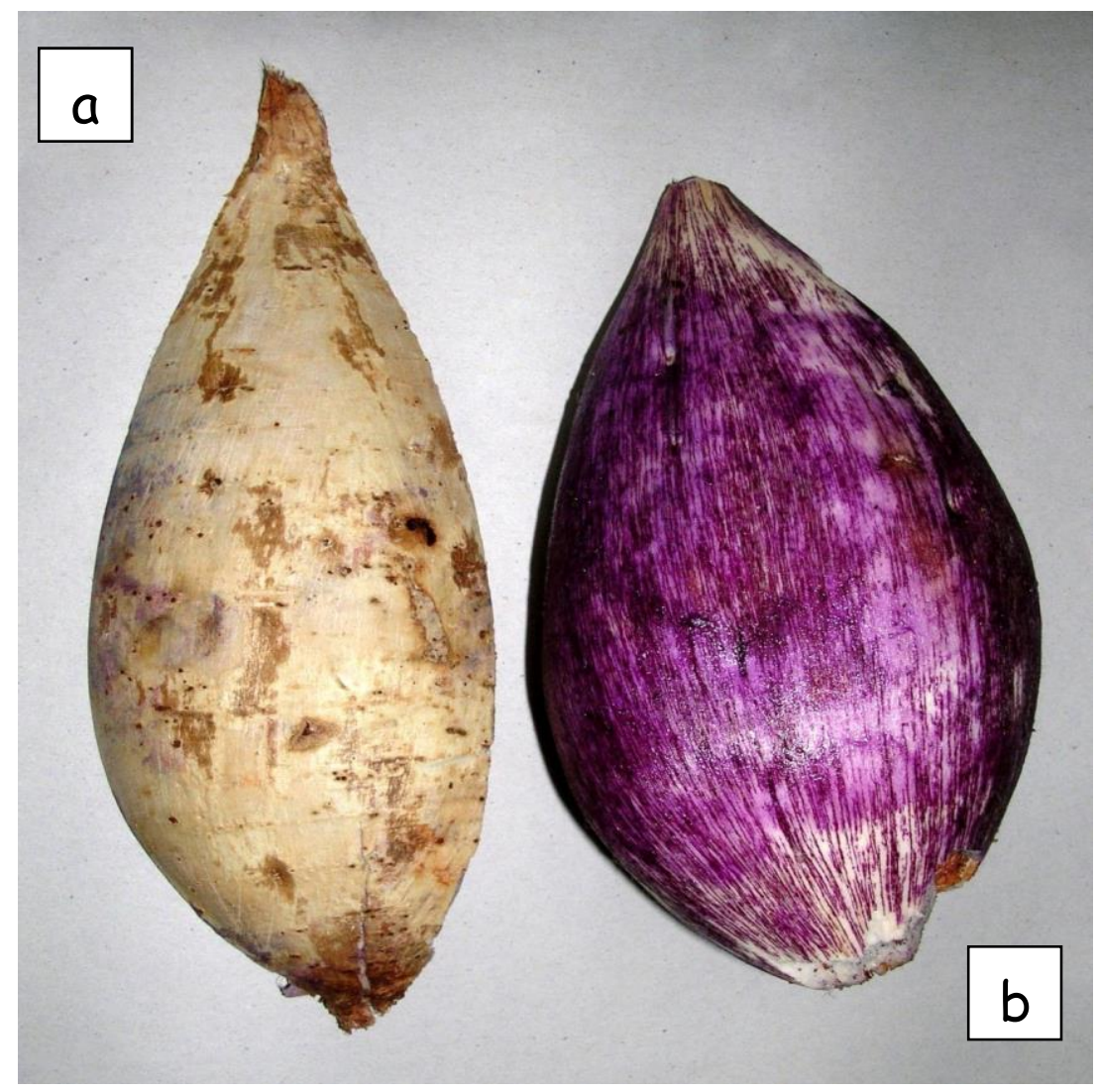

Figura 1.1. Raíces de Pachyrhizus ahipa (ahipa) provenientes de la EEA MontecarloINTA (Misiones, Argentina). a) raíz sin pelar (entera) b) raíz pelada (sin cáscara)

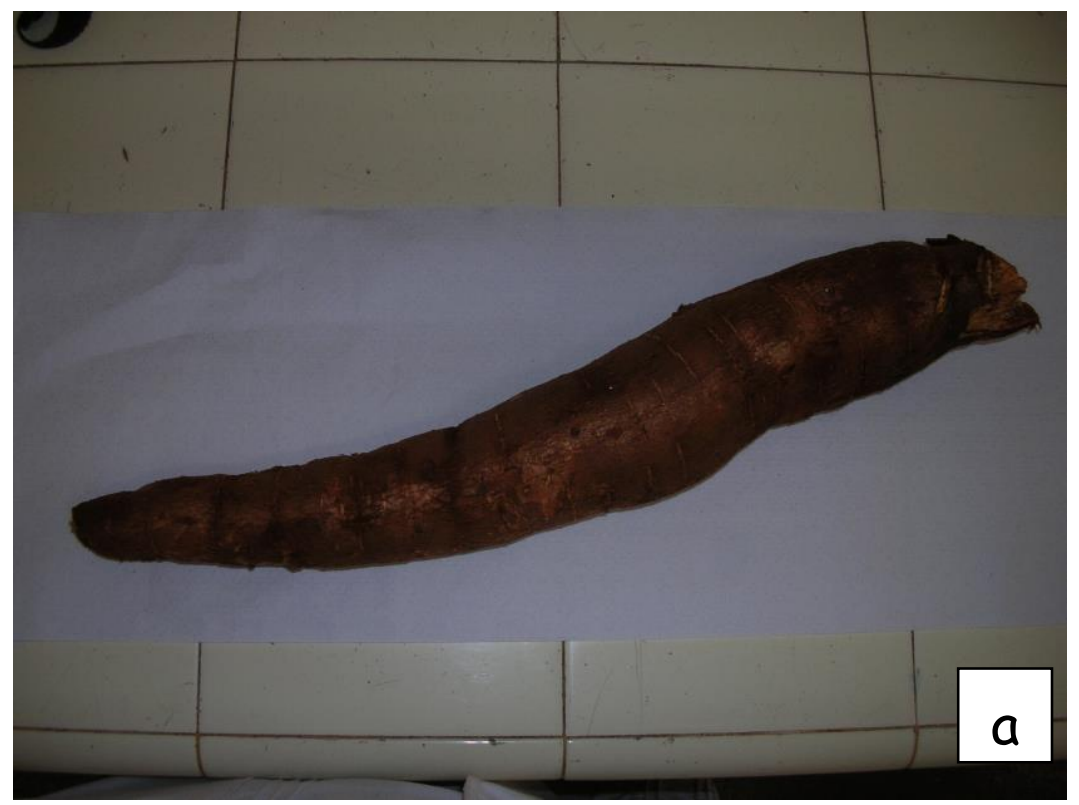




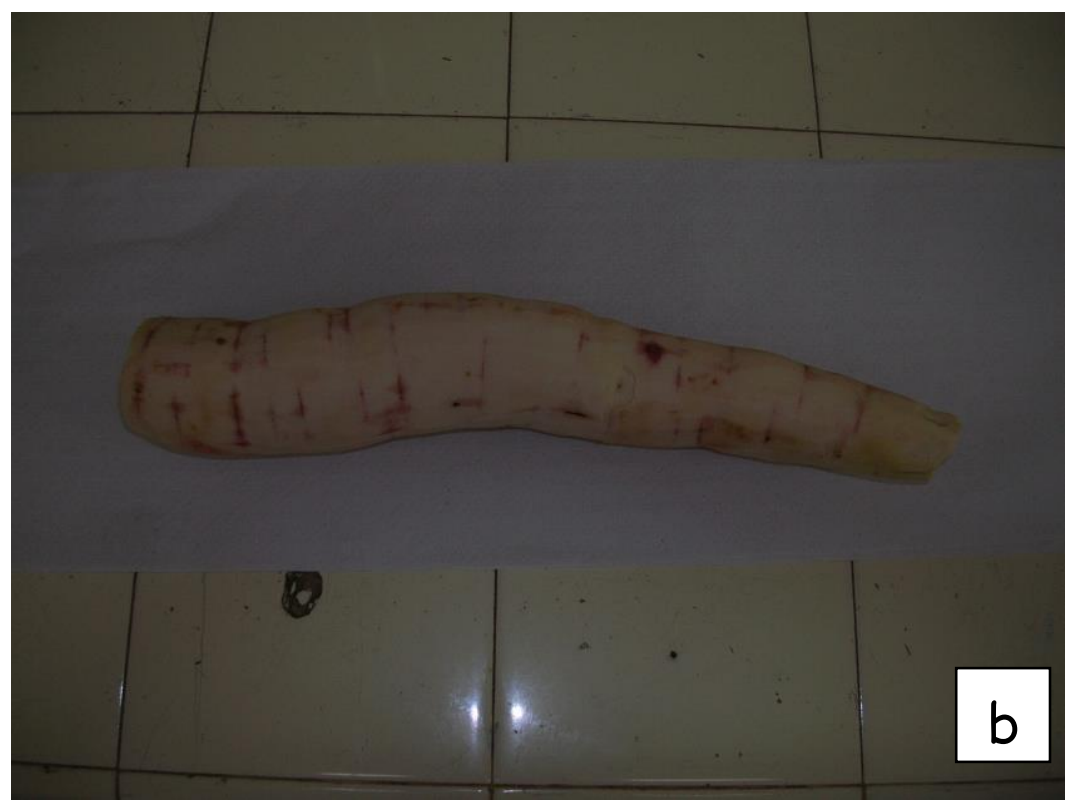

Figura 1.2. Raíces de Manihot esculenta provenientes de la EEA Montecarlo-INTA

(Misiones, Argentina). a) raíz sin pelar (entera) b) raíz pelada (sin cáscara)

\section{Análisis químicos}

Las raíces de ahipa acondicionadas como se describió anteriormente fueron cortadas en rebanadas y secadas en estufa a $60^{\circ} \mathrm{C}$, hasta alcanzar peso constante. Las muestras deshidratadas fueron finamente molidas y conservadas en frascos herméticamente cerrados hasta el momento de su análisis. Al material así tratado (estabilizado) se lo denominará de aquí en más "raíces parcialmente deshidratadas".

\subsection{Contenido de materia seca}

Se cuantificó el contenido de materia seca y humedad residual, siguiendo el método de referencia (AOAC, 1990). Las muestras (2,0 g) fueron sometidas a deshidratación en estufa (San Jor H701P, Argentina) a $105^{\circ} \mathrm{C}$ hasta alcanzar peso constante. Luego, se dejaron enfriar en un desecador y se pesaron. Los resultados finales se expresaron como porcentaje (\%) en relación al peso inicial de la muestra.

\subsection{Determinación de cenizas totales}

Las muestras ( $2 \mathrm{~g}$ ) parcialmente deshidratadas de raíces de ahipa se colocaron en crisoles tarados, previamente incinerados $\left(900^{\circ} \mathrm{C}\right)$. Luego fueron pesadas en balanza 
analítica y se carbonizaron lentamente a la llama de un mechero Bunsen, según el método de referencia (AOAC, 1990). Posteriormente se llevaron a una mufla (Indef 331, Córdoba, Argentina) a $550^{\circ} \mathrm{C}$ durante aproximadamente 5 horas, hasta obtención de cenizas blancas. Los crisoles conteniendo las cenizas se pesaron. Se calculó el porcentaje (\%) de cenizas totales.

\subsection{Cuantificación de sodio, potasio, calcio, hierro y magnesio}

Las determinaciones respectivas fueron llevadas a cabo en el CINDEFI (Centro de Investigación y Desarrollo en Fermentaciones Industriales, Facultad de Ciencias Exactas UNLP - CONICET La Plata). Muestras de cenizas (0,03-0,05 g) se pesaron en una balanza analítica y se disolvieron en una solución de ácido nítrico $\left(\mathrm{HNO}_{3}\right)$ al $50 \% \mathrm{v} / \mathrm{v}$. Para la determinación del contenido de calcio, a las muestras disueltas (concentración final de $0,5 \% \mathrm{v} / \mathrm{v})$ se les agregó óxido de lantano ( $5 \% \mathrm{p} / \mathrm{v})$ para evitar interferencias de radiación. Los análisis de hierro $(\lambda=248,3 \mathrm{~nm})$, calcio $(\lambda=422,7 \mathrm{~nm})$ y magnesio $(\lambda=$ $285,2 \mathrm{~nm}$ ) fueron realizados mediante espectroscopía de absorción atómica y la cuantificación de sodio $(\lambda=589,0 \mathrm{~nm})$ y potasio $(\lambda=766,5 \mathrm{~nm})$ por espectroscopía de emisión atómica. Las mediciones se efectuaron en un espectrofotómetro Shimadzu AA-6650 (Japón). Los resultados finales se expresaron como $\mathrm{mg} / 100 \mathrm{~g}$ de raíces parcialmente deshidratadas.

\subsection{Determinación del contenido de fósforo}

La cuantificación de fósforo se realizó por el método espectrofotométrico 965.17 (AOAC, 1990). La misma se llevó a cabo por cuadruplicado, utilizando el complejo vanado-molibdato como reactivo. Los resultados finales se expresaron como $\mathrm{mg} / 100 \mathrm{~g}$ de raíces parcialmente deshidratadas.

\subsection{Extracción y cuantificación de lípidos totales}

Para la determinación del contenido de lípidos, las muestras de ahipa (raíces parcialmente deshidratadas) se pesaron (12 g) por duplicado y se colocaron en cartuchos realizados con papel de filtro. Los mismos se dispusieron en un equipo Soxhlet durante 2 horas (aproximadamente siete ciclos de extracción). El solvente empleado fue n-hexano. Se pesaron los balones conteniendo los residuos sólidos 
(grasa cruda), después de la recuperación del solvente y posterior evaporación del mismo. Los resultados se expresaron como porcentaje (\%).

\subsection{Cuantificación de proteína cruda}

Se determinó el contenido de proteínas presente mediante el método de Kjeldahl. Este método cuantifica el nitrógeno total, proveniente principalmente de las proteínas y otras fuentes de nitrógeno no proteico (ácidos nucleicos, por ejemplo) y mediante un factor de conversión se estima la cantidad de las mismas presentes en la muestra.

Se colocaron $0,8 \mathrm{~g}$ de la muestra en tubos de vidrio del digestor A-435 K Büchi (Flawil, Suiza). Se agregaron aproximadamente $10 \mathrm{~g}$ de la mezcla catalizadora formada por sulfato cúprico y sulfato de sodio (1:10), junto con $15 \mathrm{~mL}$ de $\mathrm{H}_{2} \mathrm{SO}_{4}$ concentrado. El proceso de digestión comenzó con un calentamiento suave elevando luego la temperatura hasta que no se observaron partículas carbonosas sin oxidar; una vez finalizado el proceso, el líquido quedó translúcido, considerándose así que se completó la digestión de la materia orgánica. La solución resultante se dejó enfriar para luego comenzar la destilación de cada tubo.

En el Erlenmeyer sobre el cual se recogió el $\mathrm{NH}_{3}$ destilado, se colocaron $50 \mathrm{~mL}$ de solución de $\mathrm{H}_{3} \mathrm{BO}_{3}$ al $4 \%$ p/v y 5 gotas del indicador Mortimer (cuya composición es 20 $\mathrm{mg}$ rojo metilo $+100 \mathrm{mg}$ de verde de bromocresol $+100 \mathrm{~mL}$ etanol) que presenta un viraje a pH cercano a 5,0 (que es el pH del ácido bórico al 4-5\%). El indicador es rojo a dicho $\mathrm{pH}$ y se vuelve azul cuando se le agrega $\mathrm{NH}_{3}$ que alcaliniza el medio.

El tubo con el digerido se colocó en el destilador K-350 Büchi (Flawil, Suiza) y se adicionó solución de $\mathrm{NaOH}$ al $32 \% \mathrm{p} / \mathrm{v}$ para neutralizar el $\mathrm{H}_{2} \mathrm{SO}_{4}$ más un exceso (el volumen de $\mathrm{NaOH} 32 \%$ debe neutralizar los $15 \mathrm{~mL}$ de $\mathrm{H}_{2} \mathrm{SO}_{4}$ concentrado y además adicionar $5 \mathrm{~mL}$ en exceso para alcalinizar la muestra), para que el medio se torne fuertemente alcalino (aparición de un color pardo oscuro).

Se realizó la destilación $\left(250 \mathrm{~mL}\right.$ ) hasta que el color de la solución de $\mathrm{H}_{3} \mathrm{BO}_{3}$ viró al verde-azulado. El destilado recogido se tituló con una solución de $\mathrm{H}_{2} \mathrm{SO}_{4}$ valorada hasta que el color del mismo viró nuevamente al rojo claro.

Se realizó un ensayo en blanco para descartar el nitrógeno que podrían aportar los reactivos. 
A partir de los datos obtenidos se calculó el contenido de proteínas, expresado en porcentaje $(\% \mathrm{p} / \mathrm{p})$, a partir de la siguiente ecuación:

$$
\text { Proteína }(\% \mathrm{p} / \mathrm{p})=\frac{\left(\mathrm{V}_{\text {muestra }}-\mathrm{V}_{\text {blanco }}\right) * \mathrm{~N}_{\mathrm{H}_{2} \mathrm{SO}_{4}} * 0,014 * \text { factordeconversión }}{\text { pesodelamuestralg })} * 100
$$

Donde:

$\mathrm{V}_{\text {muestra }}=$ volumen de ácido sulfúrico gastado para valorar la muestra $(\mathrm{mL})$,

$\mathrm{V}_{\text {blanco }}=$ volumen de ácido sulfúrico gastado para valorar el blanco $(\mathrm{mL})$,

0,014 = peso de un miliequivalente de nitrógeno,

Factor de conversión = 6,25.

El factor de conversión depende de la muestra que se analiza. En los alimentos en general, como consecuencia de la estructura a base de aminoácidos individuales, el contenido en nitrógeno de las proteínas varía sólo entre unos límites muy estrechos (15 a 18\%; en promedio 16\%). Es decir que en $100 \mathrm{~g}$ de proteína promedio hay $16 \mathrm{~g}$ de nitrógeno $\left(\mathrm{N}_{2}\right)$, entonces $1 \mathrm{~g}$ de nitrógeno corresponderá a 6,25 g de proteína.

Los resultados se expresaron como porcentaje (\%).

\subsection{Cuantificación de fibra detergente ácido}

Esta determinación se llevó a cabo a partir de 1,0 g de raíces de ahipa, por duplicado. La cuantificación fue realizada por el sistema de detergentes de Van Soest (Robertson y Van Soest, 1981), siguiendo el método 973.18c (AOAC, 1990). Las muestras se trataron durante 1 hora a ebullición con una solución conteniendo bromuro de cetiltrimetilamonio en $\mathrm{H}_{2} \mathrm{SO}_{4} 1 \mathrm{~N}$. El residuo obtenido luego de filtrar al vacío se cuantificó gravimétricamente. La fracción fibra detergente ácido (FDA) correspondería a los componentes menos digeribles de la muestra, incluyendo lignina, celulosa, sílice y formas insolubles de nitrógeno. Los resultados se expresaron como porcentaje (\%).

\subsection{Contenido de carbohidratos totales}

El contenido de carbohidratos totales se calculó por diferencia, después de la cuantificación de los otros componentes del análisis centesimal (cenizas, proteínas y lípidos totales). Este valor se corresponde con el contenido de azúcares solubles, 
almidón y carbohidratos estructurales (celulosas, hemicelulosas), tomados conjuntamente. Los resultados se expresaron como porcentaje (\%).

\subsection{Contenido de almidón total}

Se determinó a partir de 0,10-0,15 g de muestra, empleando el kit enzimático K-TSTA 05/06 (Megazyme@, Irlanda). El método consiste en la conversión de almidón a glucosa y la determinación colorimétrica de ésta mediante una reacción enzimática específica acoplada a un sistema cromógeno (4-amino antipirina). Se empleó una solución patrón de D-glucosa $\left(1,0 \mathrm{mg} \mathrm{mL}^{-1}\right)$ con $0,2 \%(\mathrm{p} / \mathrm{v})$ de ácido benzoico. Las lecturas de absorbancia se realizaron a $510 \mathrm{~nm}$ en un espectrofotómetro Shimadzu UV mini 1240 UV-VIS (Japón). Los resultados se expresaron en porcentaje (\%).

\section{Análisis estadístico}

Se realizó el correspondiente análisis de varianza mediante el uso del software Systat (SYSTAT, Inc., Estados Unidos) versión 10.0. Las diferencias se compararon mediante el test de la diferencia mínima significativa de Fisher (LSD) usando un nivel de significación $p=0,05$. 


\section{RESULTADOS Y DISCUSIÓN}

\section{Composición química de las raíces de Pachyrhizus ahipa pertenecientes a la} accesión Local

La Tabla 1.1 muestra los resultados del análisis de macrocomponentes realizado sobre las raíces de ahipa Local.

Tabla 1.1. Macrocomponentes (\% p/p) de raíces de Pachyrhizus ahipa (ahipa) accesión Local.

\begin{tabular}{ccccccc} 
Materia seca & $\begin{array}{c}\text { Cenizas } \\
\text { totales }\end{array}$ & $\begin{array}{c}\text { Lípidos } \\
\text { totales }\end{array}$ & $\begin{array}{c}\text { Proteína } \\
\text { cruda }\end{array}$ & $\begin{array}{c}\text { Fibra detergente } \\
\text { ácido }\end{array}$ & $\begin{array}{c}\text { Carbohidratos } \\
\text { totales }\end{array}$ & $\begin{array}{c}\text { Almidón } \\
\text { total }\end{array}$ \\
\hline $87,1 \pm 0,2$ & $3,50 \pm 0,02$ & $0,65 \pm 0,04$ & $8,6 \pm 0,3$ & $12,8 \pm 0,6$ & $87,2 \pm 0,3$ & $37,0 \pm 2,7$
\end{tabular}

Nota: Los valores informados corresponden a la media \pm las desviaciones estándar.

Cuando las raíces de ahipa frescas fueron sometidas al proceso de estabilización (llevado a cabo a $60^{\circ} \mathrm{C}$ ) perdieron $76,4 \pm 0,3 \%$ de humedad.

El contenido de agua residual de las raíces parcialmente deshidratadas (determinado a $105^{\circ} \mathrm{C}$ ) fue $12,9 \pm 0,2 \%$.

En cuanto al contenido de materia seca, estos resultados son superiores a los informados por Noman y col. (2007) para Pachyrhizus erosus L. $(82,0 \pm 2,2 \%)$, papa $(77,3 \pm 0,2 \%)$ y batata $(68,7 \pm 0,1 \%)$.

Los niveles de cenizas totales hallados en ahipa Local fueron ligeramente inferiores a los informados para rizomas de distintas variedades de Canna edulis $(5,1-5,7 \%)$ pero superiores a los correspondientes a mandioca (1,9\%) (Piyachomkwan y col., 2002). El contenido de cenizas totales se relaciona directamente con el de los minerales presentes en la muestra.

En la Tabla 1.2 se observan los valores de los elementos minerales analizados (sodio, potasio, calcio, magnesio, hierro y fósforo) de las raíces de ahipa. El fósforo y el potasio fueron los minerales mayoritarios en tanto que, por tratarse de un micronutriente, los tenores más bajos correspondieron al hierro. Ogbuagu (2008) también halló que el potasio fue el principal componente mineral en Dioscorea bulbifera ("potato yam") y Dioscorea dumentorum ("bitter yam"). 
Tabla 1.2. Contenido de elementos minerales (mg/100g) en raíces de Pachyrhizus ahipa (accesión Local) parcialmente deshidratadas.

\begin{tabular}{cccccc} 
Sodio & Potasio & Calcio & Magnesio & Hierro & Fósforo \\
\hline $12 \pm 2$ & $773 \pm 15$ & $210 \pm 15$ & $64 \pm 1$ & $37 \pm 2$ & $849 \pm 92$
\end{tabular}

Nota: Los valores informados corresponden a la media \pm las desviaciones estándar.

El contenido de lípidos totales de las raíces de ahipa $(0,65 \%)$ fue significativamente más elevado que el informado para otras raíces y tubérculos (R\&T). Afoakwa y SefaDedeh (2001) hallaron que los valores medios de grasa cruda de distintas líneas de Dioscorea dumetorum estuvieron comprendidos entre $0,35-0,38 \%$. Los autores señalaron que dichos niveles eran considerablemente bajos y similares a los de otras $R \& T$, tales como papa $(0,4 \mathrm{~g} / 100 \mathrm{~g})$ y ciertas Aráceas comestibles $(0,2 \mathrm{~g} / 100 \mathrm{~g})$. Sin embargo, Padonou y col. (2005) informaron un contenido promedio de lípidos igual a 0,56\% (base seca) para raíces de mandioca deshidratadas.

En relación al contenido de proteína cruda, Zanklan y col. (2007) han mencionado que las especies de Pachyrhizus spp (yam bean) producen relativamente altos niveles de proteína, de 3 a 5 veces mayores que los de R\&T tropicales comúnmente cultivados, tales como mandioca (Manihot esculenta), batata (Ipomoea batatas) y yam o ñame (Dioscorea spp). Dichos autores han informado un contenido de proteína cruda de raíces de Pachyrhizus ahipa igual a 9,0\%, cercano al hallado en el presente estudio (Tabla 1.1). En un trabajo anterior del grupo de investigación (López y col., 2010), se informó un contenido de 6,5 \pm 0,7\% de proteína cruda para las raíces enteras de ahipa. Dado que las determinaciones corresponden a ciclos de cultivo diferentes, las diferencias en el contenido de proteína cruda pueden ser probablemente atribuidas a un mejor estado de fertilidad del suelo en el segundo ciclo, entre otros factores.

Forsyth y Shewry (2002) estudiaron las proteínas presentes en raíces de Pachyrhizus ahipa y señalaron que la fracción de proteínas solubles en sales comprendía cerca del $60 \%$ del nitrógeno total de las raíces, en tanto que los componentes nitrogenados de baja masa molecular representaban alrededor del 30\%. Indicaron también que los análisis electroforéticos de la fracción proteica demostraron que ninguno de los constituyentes presentes en seis accesiones diferentes de Pachyrhizus ahipa se hallaba 
en cantidades suficientemente altas como para sugerir una función como proteínas de almacenamiento. Se concluyó que el rol primario de dichas proteínas estaría probablemente relacionado a aspectos del metabolismo y desarrollo de las raíces, confiriendo en ciertos casos protección contra plagas y enfermedades.

Se determinó, como primera aproximación a la cuantificación del contenido de fibra de la raíz, el nivel de fibra detergente ácido (FDA) presente en muestras de raíces de ahipa (Tabla 1.1). Los resultados hallados fueron significativamente más elevados que los informados por Agbor-Egbe y Treche, (1995) para tubérculos de distintas especies de Dioscorea spp. Los mencionados autores señalaron valores variables de FDA, comprendidos entre 2,0\% (D. liebrechtaiana) y 5,5\% (D. dumetorum).

El contenido de almidón de las raíces de ahipa (Tabla 1.1) resultó comparativamente más bajo que el de mandioca y batata referidos a base seca (Opara, 2003).

En relación a otras R\&T tropicales y subtropicales, las raíces de ahipa de la accesión Local mostraron una composición química más equilibrada desde el punto de vista nutricional, realizando un aporte de proteínas, fibra y minerales esenciales tales como potasio, calcio y hierro, junto con el almidón, uno de los componentes mayoritarios. Así, la incorporación de raíces de ahipa Local a la dieta constituiría una alternativa de interés desde el punto de vista nutricional. 


\section{CAPÍTULO 1. SECCIÓN 2.}

\section{Poscosecha de raíces de Pachyrhizus ahipa}




\section{Material vegetal}

\section{MATERIALES Y MÉTODOS}

Se utilizaron raíces frescas de ahipa cuya procedencia y forma de acondicionamiento correspondieron a las descriptas en la Sección 1 del presente Capítulo.

Las raíces seleccionadas, lavadas y desinfectadas se colocaron en el interior de bandejas ranuradas de plástico $(43 \mathrm{~cm} \times 33 \mathrm{~cm} \times 10 \mathrm{~cm})$ y posteriormente fueron cubiertas con film PY ${ }^{\circledR}$ (Figura 1.3). La película $P Y 8^{\circledR}$ es una poliolefina multiperforada ( 3\% de la superficie total perforada), su espesor es $15 \mu \mathrm{m}$ y su velocidad de transferencia de vapor de agua es $300 \mathrm{~g} \mathrm{~m}^{-2}$ día $^{-1}$.

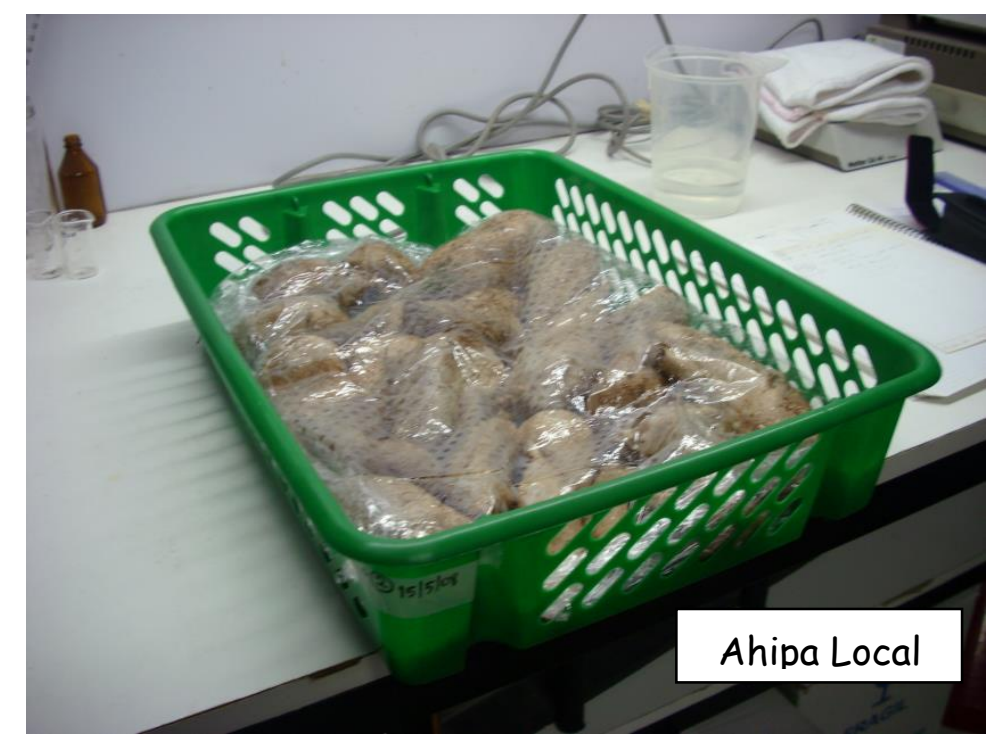

Figura 1.3. Bandeja conteniendo raíces de Pachyrhizus ahipa (ahipa) envasadas con película $\mathrm{PY} 8^{\circledR}$.

\section{Poscosecha de raíces de Pachyrhizus ahipa}

\subsection{Parámetros fisiológicos asociados a la degradación de las reservas de almidón}

\subsubsection{Actividad respiratoria}

El deterioro de un producto vegetal es proporcional a la actividad respiratoria. Se determinó la misma en raíces de ahipa de peso y volumen conocidos que se ubicaron en el interior de frascos de vidrio herméticamente cerrados de $2 \mathrm{~L}$ de capacidad. $\mathrm{El} \mathrm{CO}_{2}$ acumulado se midió usando un sensor Compuflow 8650 Indoor Air Quality Meter (Estados Unidos) incorporado dentro del frasco (Figura 1.4). Se graficó la concentración 
de $\mathrm{CO}_{2}$ en función del tiempo. A partir de la pendiente de la línea, se calculó la producción de $\mathrm{CO}_{2}$ expresada en $\mathrm{mL} \mathrm{kg}^{-1} \mathrm{~h}^{-1}$.

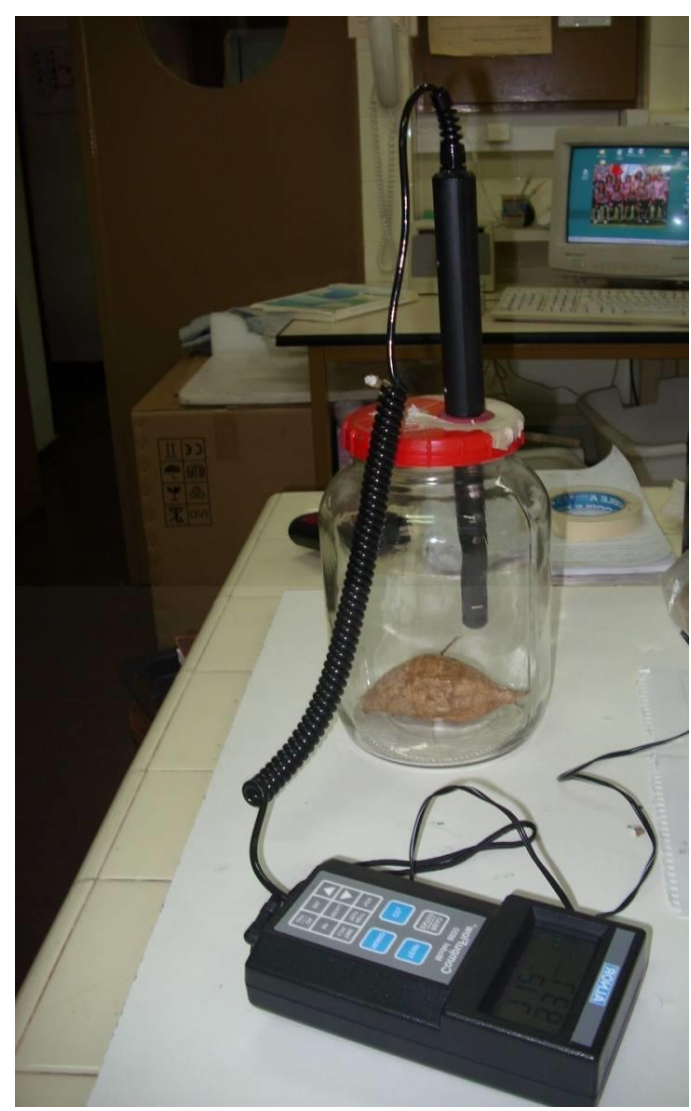

Figura 1.4. Sensor Compuflow 8650 Indoor Air Quality Meter empleado en la medición de la actividad respiratoria de raíces de Pachyrhizus ahipa (ahipa).

\subsubsection{Brotado}

Este parámetro fisiológico fue determinado observando la aparición de brotes y realizando el correspondiente recuento (número de raíces brotadas). Los resultados se expresaron como porcentaje (\%) de raíces brotadas.

\subsubsection{Contenido de almidón}

Se determinó a partir de 0,10-0,15 g de muestra, empleando el kit enzimático KTSTA 05/06 (Megazyme@, Irlanda). El método empleado se detalló en la sección anterior del presente Capítulo. Los resultados se expresaron en porcentaje (\%). 


\subsubsection{Actividad $\alpha$-amilasa}

Se midió empleando el kit enzimático Ceralpha (K-CERA 08/05 Megazyme@), Irlanda), que utiliza como sustrato el reactivo $p$-nitrofenil maltoheptaósido con su extremo no reductor bloqueado, en presencia de exceso de $\alpha$-glucosidasa termoestable que genera glucosa y $p$-nitrofenol (Figura 1.5). Una vez que se detuvo la reacción mediante el agregado de una solución de hidróxido de potasio de baja concentración, se midió la absorbancia a $400 \mathrm{~nm}$. Los resultados se expresaron como Unidades Ceralpha $\mathrm{g}^{-1} \mathrm{de}$ muestra.

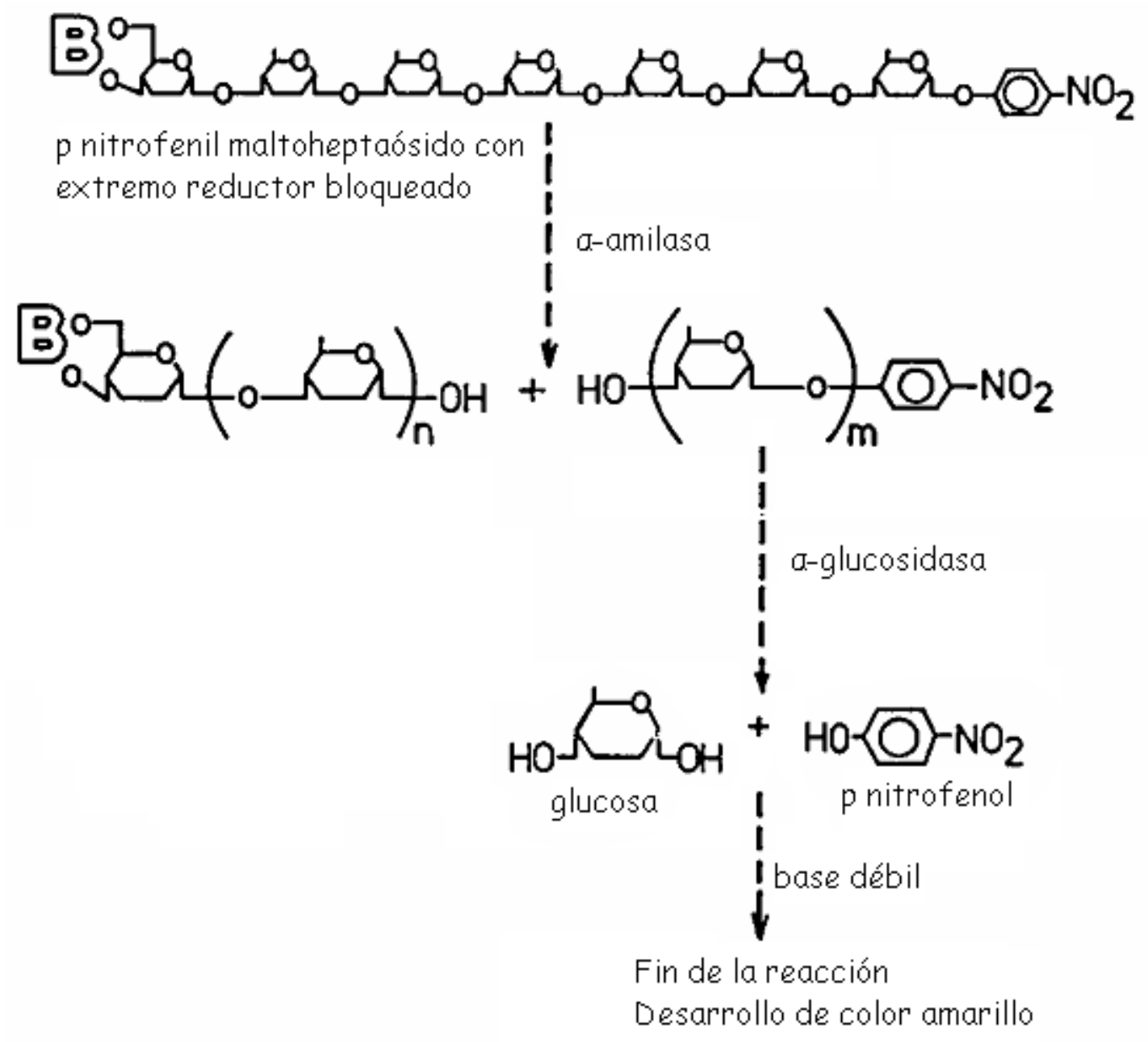

Figura 1.5. Fundamento del método enzimático para determinar la actividad $\alpha$ amilasa. 


\subsection{Almacenamiento de raíces de Pachyrhizus ahipa a diferentes temperaturas}

Las raíces de ahipa acondicionadas como se describió anteriormente se almacenaron a distintas temperaturas: 4,10 y $25^{\circ} \mathrm{C}$. En base a la inspección visual de las muestras y teniendo en cuenta principalmente el desarrollo de daños (básicamente la incidencia de microorganismos) se determinó la vida útil de las raíces bajo las condiciones ensayadas, seleccionando la temperatura más adecuada de conservación.

\subsection{Tratamientos físicos poscosecha}

Con el fin de evaluar la incidencia de distintos tratamientos físicos sobre aspectos de la calidad de las raíces de ahipa, algunas muestras fueron sometidas a un tratamiento térmico (HS, heat shock) y otras se irradiaron con UV-C.

Para la aplicación del tratamiento térmico, el producto fue calentado en estufa a $60^{\circ} \mathrm{C}$ durante 35 minutos. Una vez retiradas de la estufa, las raíces se dejaron enfriar a temperatura ambiente y se envasaron.

En el caso del tratamiento UV-C, ambas caras de las raíces fueron expuestas a la radiación (longitud de onda de $254 \mathrm{~nm}$ ) bajo cuatro lámparas UV-C (TUV G30T8, 30W, Philips, Estados Unidos), a una dosis de $15 \mathrm{~kJ} \mathrm{~m}^{-2}$. La intensidad de flujo de las lámparas se midió con un radiómetro (Cole-Parmer Instrument Company, Vernon Hills, IL, Estados Unidos). En la Figura 1.6 se muestra la aplicación del tratamiento UV-C a raíces de ahipa.

En ambos casos, después de la aplicación del tratamiento, 25 raíces fueron envasadas tal como se indicó anteriormente (Figura 1.3).

Las bandejas fueron almacenadas en estufa a $25^{\circ} \mathrm{C}$, con humedad relativa variable (60\% en promedio) durante 4 meses. Para cada tratamiento se utilizaron tres bandejas. Como control se almacenaron, en iguales condiciones, el mismo número de bandejas conteniendo raíces de Pachyrhizus ahipa sin ningún tratamiento.

En resumen, los tratamientos ensayados fueron:

a) control (raíces lavadas con agua corriente);

b) raíces lavadas y tratadas térmicamente en estufa $\left(60^{\circ} \mathrm{C}\right)$ durante 35 minutos;

c) raíces lavadas e irradiadas con UV-C $\left(15 \mathrm{~kJ} / \mathrm{m}^{2}\right)$. 

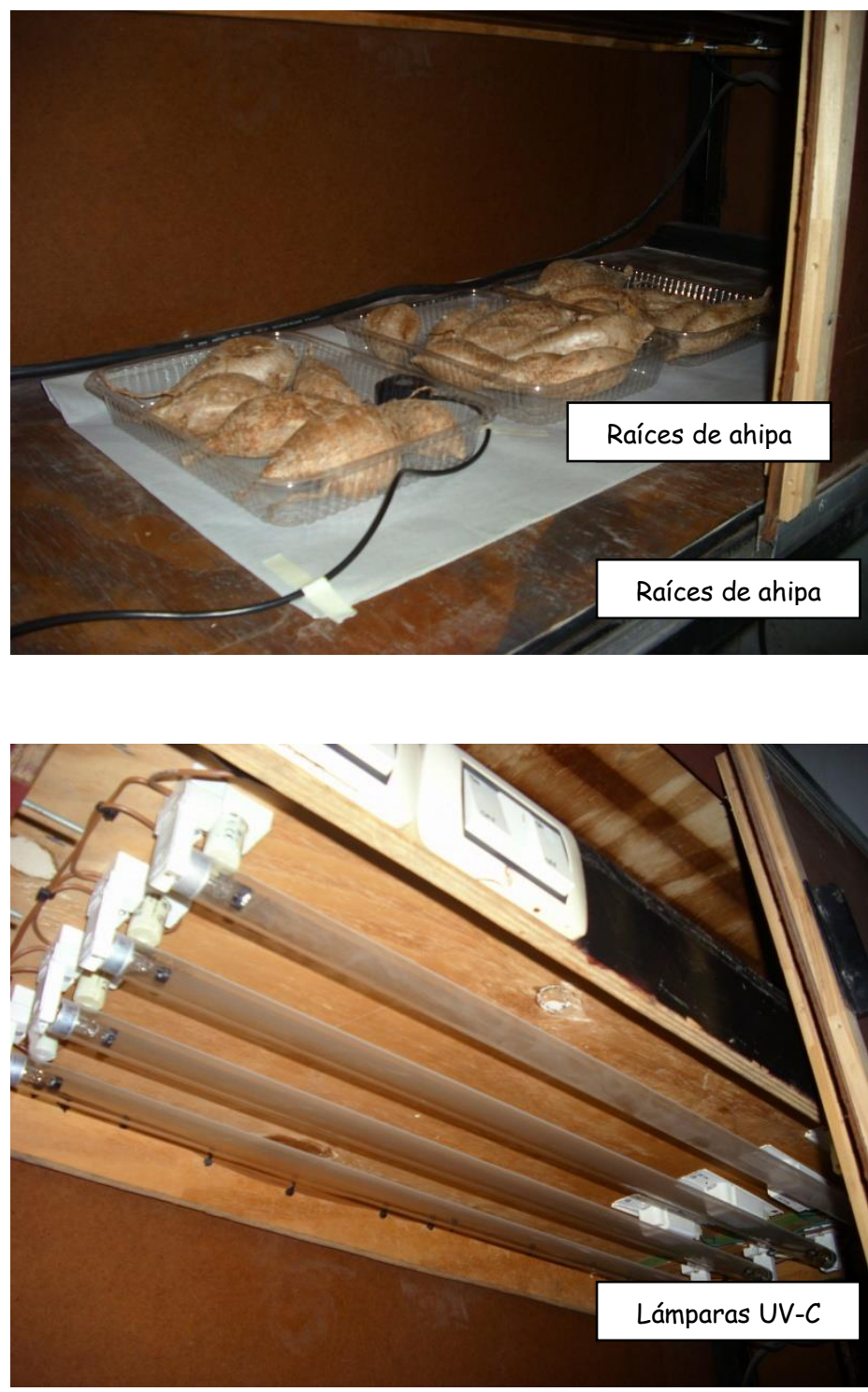

Figura 1.6. Modo de aplicación de los tratamientos UV-C en raíces de Pachyrhizus ahipa.

\subsection{Atributos de calidad en raíces almacenadas}

\subsubsection{Color}

La apariencia es muchas veces el único atributo en el cual basamos la decisión de compra o consumo de un producto. Una de las características de este atributo es el 
color, ya que el deterioro de un alimento es frecuentemente acompañado por cambios en el mismo.

Los atributos de la sensación visual son el color, la luminosidad y la saturación, los cuales se correlacionan con la longitud de onda, la luminancia y la pureza colorimétrica respectivamente.

Se caracterizó el color de las raíces empleando un colorímetro Konica Minolta CR-400 (Osaka, Japón) calibrado con una placa blanca estándar $(\mathrm{Y}=93,2, \mathrm{x}=0,3133, \mathrm{y}=$ 0,3192), utilizando el iluminante C. Se registraron las coordenadas de luminosidad L*, $a^{*}$ y $b^{*}$ de la escala CIE (Figura 1.7). En este sistema el parámetro a*, representa la variación rojo-verde, tomando valores positivos para el primero y negativos para el segundo, ya que el centro de coordenadas coincide con el blanco de referencia o con el iluminante. El parámetro b*, representa la variación amarillo-azul, siendo positivo para el primero y negativo para el segundo. Aquellos casos en los que $a^{*}=b^{*}=0$ son acromáticos y corresponden al color gris. El parámetro $L^{*}$ de luminosidad se asocia al brillo de la muestra y varía entre 0 para el negro mate a 100 para el blanco.

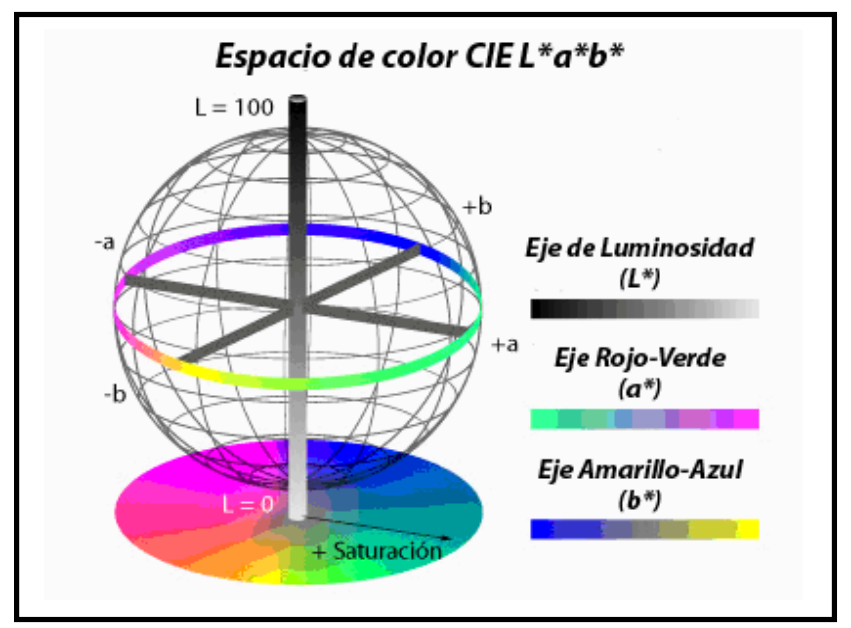

Figura 1.7. Parámetros de color superficial: luminosidad $L^{*}$ y de cromaticidad $a^{*}$ y $b^{*}$.

A partir de estos parámetros se calcularon los valores de hue $\left(h^{\circ}\right)$ y de Chroma $\left(C^{*}\right)$ con las ecuaciones 1.2 y 1.3 , respectivamente. La diferencia de color $(\Delta \mathrm{E})$ se calculó con respecto a los parámetros mencionados $\left(L^{*}, a^{*}\right.$ y $\left.b^{*}\right)$ medidos en las raíces al inicio del almacenamiento utilizando la ecuación 1.4. 


$$
\begin{aligned}
& \qquad \mathrm{h}^{\circ}=\arctan \left(\frac{\mathrm{b}^{*}}{\mathrm{a}^{*}}\right) \\
& \qquad \mathrm{C}^{*}=\sqrt{\left(\mathrm{a}^{* 2}+\mathrm{b}^{* 2}\right)} \\
& \qquad \Delta \mathrm{E}=\sqrt{\left(\left(\mathrm{a}^{*}-\mathrm{a}_{0} *\right)^{2}+\left(\mathrm{b}^{*}-\mathrm{b}_{0} *\right)^{2}+\left(\mathrm{L}^{*}-\mathrm{L}_{0}\right)^{2}\right)} \\
& \text { Donde los valores } \mathrm{a}_{0} * \text {, } \mathrm{b}_{0} * \text { y } \mathrm{L}_{0} * \text { son los parámetros } \mathrm{a}^{*}, \mathrm{~b}^{*} \text { y } \mathrm{L}^{*} \text { respectivamente, } \\
& \text { medidos al inicio del almacenamiento. } \\
& \text { Las medidas de color se llevaron a cabo mediante la aplicación directa del cabezal de } \\
& \text { lectura del colorímetro en la sección de corte a nivel ecuatorial de al menos quince } \\
& \text { raíces diferentes, para cada tratamiento y punto de muestreo (Figura 1.8). }
\end{aligned}
$$
medidos al inicio del almacenamiento.

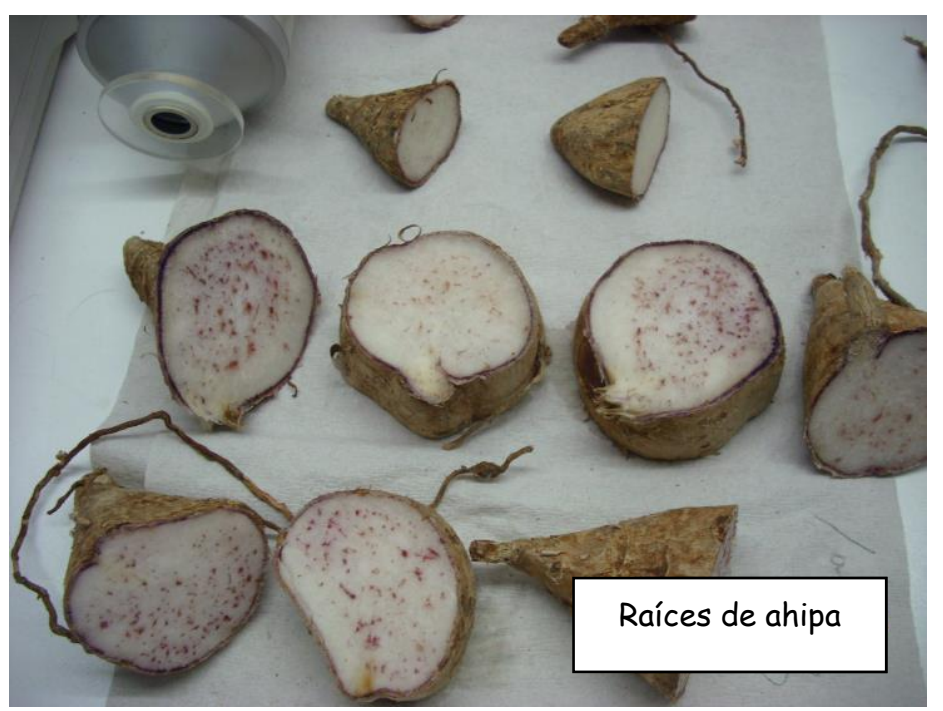




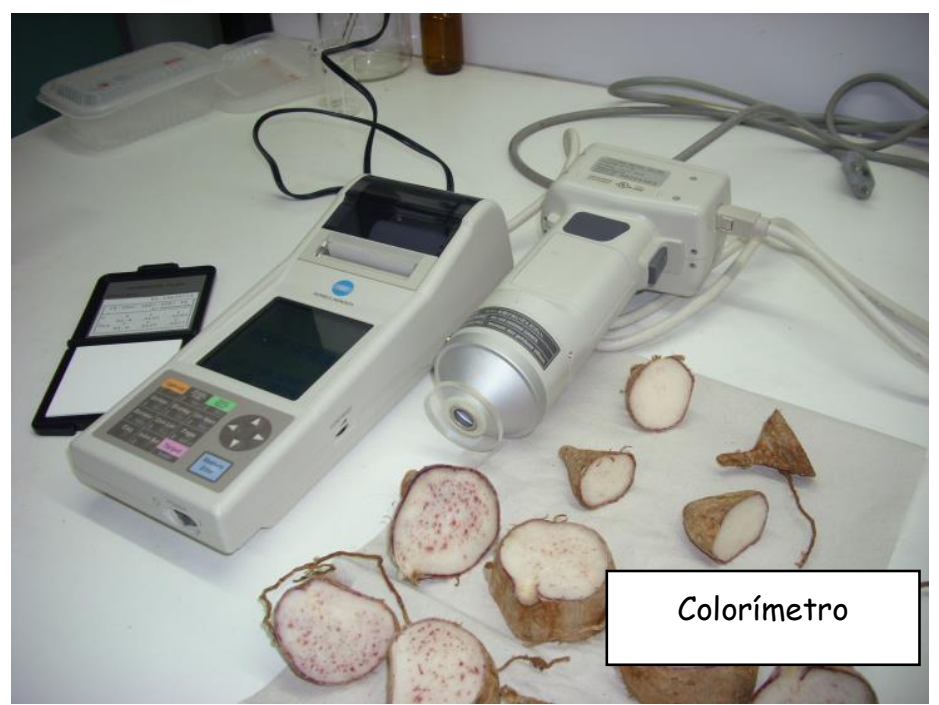

Figura 1.8. Raíces de Pachyrhizus ahipa (ahipa) cortadas transversalmente para la medición de color y colorímetro Konica Minolta CR-400.

\subsubsection{Textura}

La firmeza de los productos vegetales se cuantifica, generalmente, como la fuerza máxima producida durante la compresión de la muestra, ya que éste es uno de los parámetros que mejor se refieren a la percepción de la textura durante la masticación. En la Figura 1.9 se ejemplifica el patrón mecánico de una muestra en un ensayo típico de análisis de perfil de textura o en inglés Texture Profile Analysis (TPA).

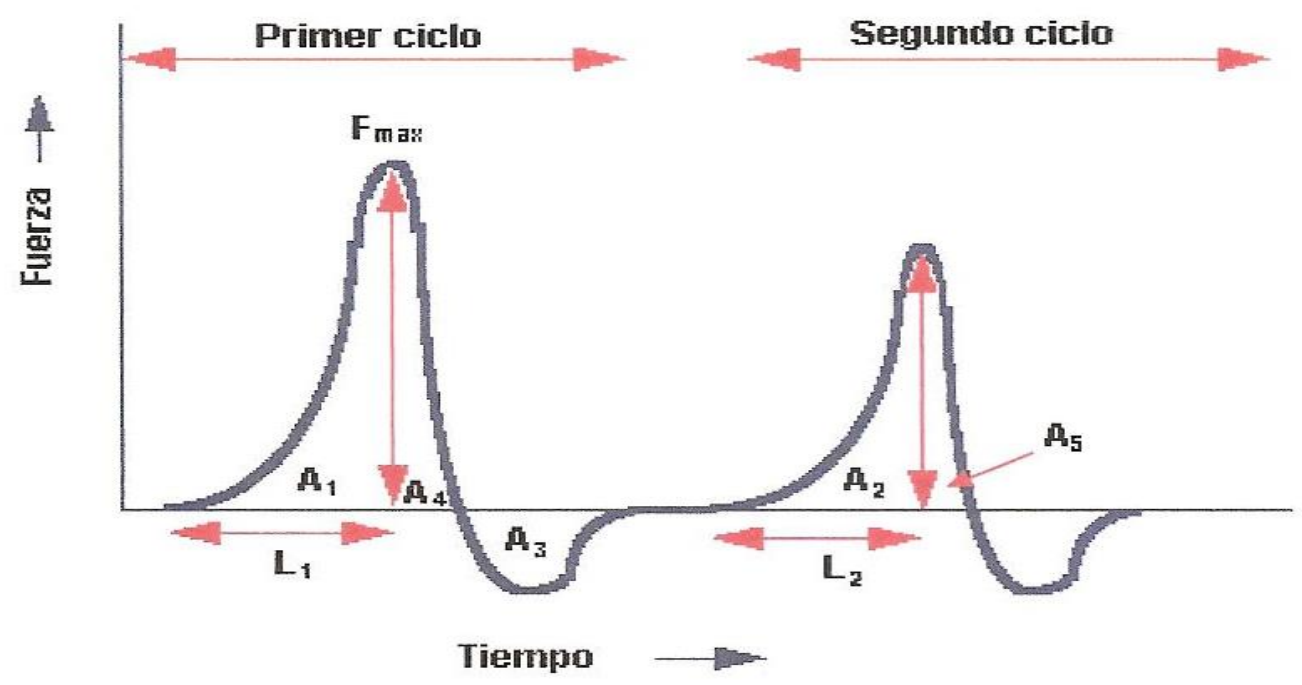

Figura 1.9. Patrón mecánico de una muestra en un ensayo típico de análisis de perfil de textura (TPA). Fuente: López, 2011. 
A partir de los patrones mecánicos observados en las muestras durante los ensayos correspondientes y empleando el programa Texture Expert para Windows (v.1.2), se calcularon los siguientes parámetros (Andrés y col., 2006):

Dureza $(\mathrm{N})$ : corresponde a la fuerza máxima en el primer pico, relacionada con la resistencia a la compresión.

Elasticidad (adimensional): se determina como el cociente entre L2 y L1 (Figura 1.9); es la capacidad de la muestra para recuperar su forma original y está relacionada con la altura que el material recupera entre el final de la primera compresión y el comienzo de la segunda.

Cohesividad (adimensional): es el cociente entre las áreas del pico positivo del segundo ciclo de compresión respecto al primero, $[(A 2+A 5) /(A 1+A 4)]$; indica el trabajo necesario para vencer las fuerzas internas del material.

Gomosidad (N): es el producto de la dureza por la cohesividad.

Adhesividad ( $\mathrm{N} \mathrm{mm}$ ): es el área del pico negativo (A3), si existiere.

Masticabilidad (N): es el producto de la gomosidad por la elasticidad.

Resiliencia (adimensional): es el cociente entre las áreas del primer pico (A4/A1). Esta magnitud cuantifica la cantidad de energía por unidad de volumen que almacena un material al deformarse elásticamente debido a una tensión aplicada.

Para llevar a cabo el análisis de perfil de textura de las raíces de ahipa se utilizaron muestras cilíndricas $(2,5 \mathrm{~cm}$ de altura y $1,7 \mathrm{~cm}$ de diámetro) cortadas desde el centro de las raíces, que se comprimieron $4 \mathrm{~mm}$ entre dos superficies planas utilizando un texturómetro TAXT2i (Stable Micro Systems Ltd., Godalming, Surrey, Reino Unido) (Figura 1.10). Se utilizó una celda de carga de $25 \mathrm{~kg}$. La sonda, una placa de aluminio de $75 \mathrm{~mm}$ de diámetro, fue operada en el modo compresión a una velocidad constante de $1,0 \mathrm{mms}^{-1}$. 


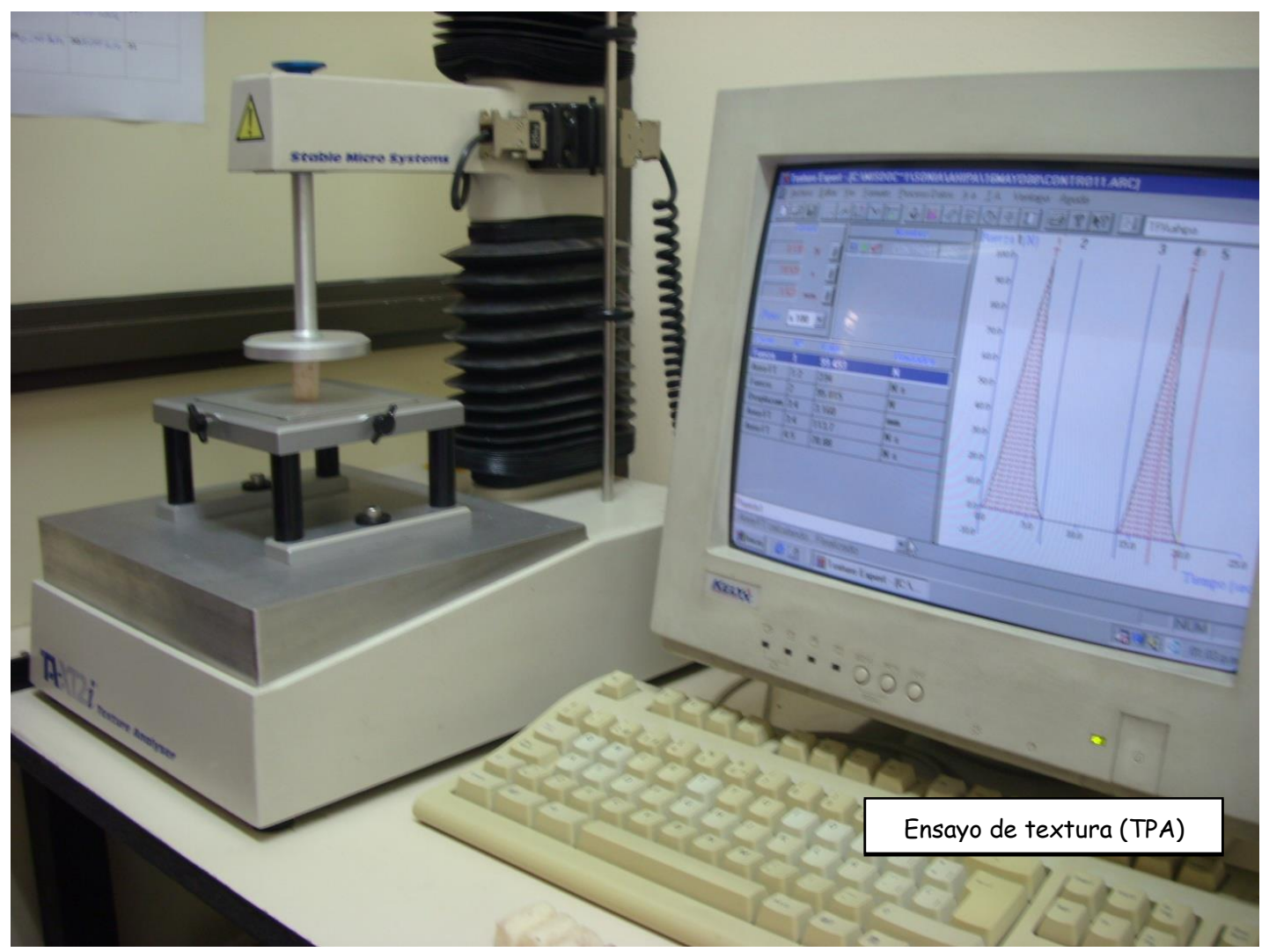

Figura 1.10. Muestras de raíces de Pachyrhizus ahipa (ahipa) analizadas en el texturómetro TAXT2i.

\subsection{Análisis de la población fúngica predominante}

Durante la conservación de raíces de ahipa se analizó la población fúngica presente en las mismas y su evolución durante el almacenamiento a 4,10 ó $25^{\circ} \mathrm{C}$. Las determinaciones fueron llevadas a cabo en el CIDEFI (Centro de Investigaciones de Fitopatología) de la Facultad de Ciencias Agrarias y Forestales de la Universidad Nacional de La Plata.

Para ello, se cortaron las raíces en trozos pequeños, se desinfectaron en solución de hipoclorito de sodio $(\mathrm{NaClO})$ al $10 \%$ durante 3 minutos, se lavaron en agua destilada estéril y se sembraron en cajas de Petri con ágar papa glucosado (APG) al $2 \%$. La incubación se efectuó en estufa a $25^{\circ} \mathrm{C}$, hasta observar la presencia de colonias fúngicas o bacterianas (entre 5 y 7 días). De cada tratamiento se realizaron 5 repeticiones de 5 cajas, con 5 trocitos cada una (125 trozos por tratamiento).

La cuantificación e identificación de la micoflora presente se realizó mediante el estudio de los caracteres morfobiométricos, el análisis de las características de las 
colonias en APG y de las estructuras conidiales, siguiendo la bibliografía de referencia (Booth, 1971; Ellis, 1971; Ellis, 1976; Nelson y col., 1983; Sivanesan, 1987; Barnett y Hunter, 1998). La incidencia del género predominante fue estimada como porcentaje del total de aislados.

\section{Análisis estadístico}

Se realizó el correspondiente análisis de varianza mediante el uso del software Systat (SYSTAT, Inc., Estados Unidos) versión 10.0. Las diferencias se compararon mediante el test de la diferencia mínima significativa de Fisher (LSD) usando un nivel de significación $p=0,05$. 


\section{RESULTADOS Y DISCUSIÓN \\ 1. Conservación de las raíces de ahipa a distintas temperaturas}

Las raíces almacenadas a $25^{\circ} \mathrm{C}$ fueron las que mostraron mayor vida útil. Como se puede observar en la Figura 1.11 las raíces conservadas a 4 y $10^{\circ} \mathrm{C}$ presentaron daño por frío, que se manifestó principalmente como una mayor susceptibilidad al ataque fúngico después de 30 días de almacenamiento.

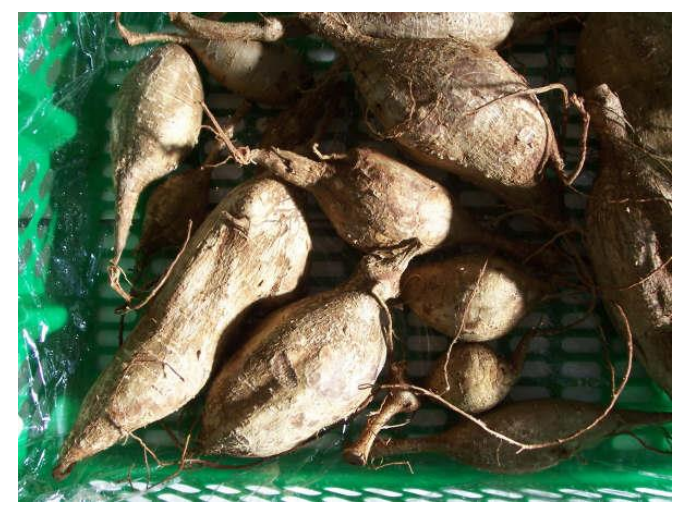

Raíces al inicio del almacenamiento

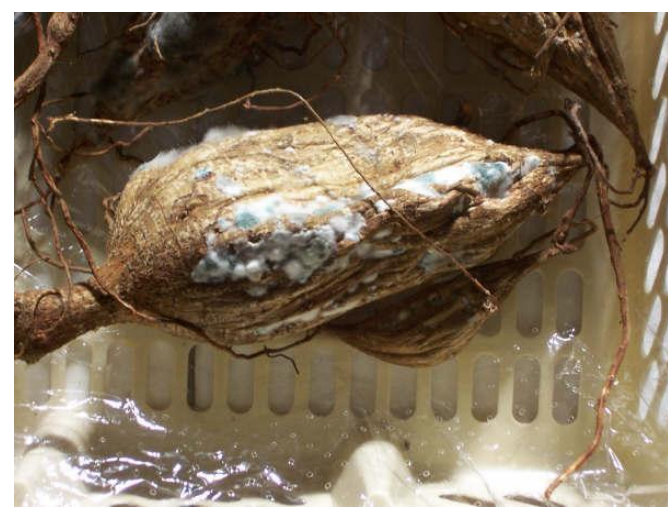

Raíces con signos y síntomas de ataque fúngico durante el almacenamiento refrigerado

Figura 1.11. Deterioro de raíces de Pachyrhizus ahipa (ahipa) almacenadas durante 30 días en condiciones de refrigeración.

\section{Parámetros fisiológicos asociados a la degradación de las reservas de almidón}

\subsection{Actividad respiratoria}

La respiración consiste en la degradación oxidativa de componentes orgánicos relativamente complejos, para producir dióxido de carbono, agua y energía. Las principales consecuencias de una actividad respiratoria elevada son la aceleración de la senescencia, la disminución del valor alimenticio, la pérdida del peso seco de venta, la producción de calor, con el consiguiente aumento de temperatura, y una conservación deficiente del producto.

La temperatura es el principal factor que afecta la calidad general de los productos hortícolas. Cuando la misma se incrementa desde 0 a $10^{\circ} \mathrm{C}$, la tasa respiratoria aumenta sustancialmente (Watada y col., 1996).

De acuerdo con Ravi y Aked (1996), para cultivos de R\&T luego de la cosecha y durante el almacenamiento subsiguiente han sido señalados tres desórdenes fisiológicos 
relevantes: incremento de la actividad respiratoria asociado con la pérdida de agua y carbohidratos, la ruptura de la dormancia y el daño inducido por bajas temperaturas. Para raíces maduras de jicama (Pachyrhizus erosus) se han informado los valores de la tasa respiratoria medida a distintas temperaturas de conservación, estando dichos valores comprendidos entre $2-4 ; 5-6 ; 5-10 ; 2-4$ y $3-4 \mathrm{~mL}$ de $\mathrm{CO}_{2} \mathrm{~kg}^{-1} \mathrm{~h}^{-1}$, para raíces mantenidas a $0,5,10,12,5$ y $20^{\circ} \mathrm{C}$ respectivamente (Cantwell, 2000). Para esta especie, en la respiración medida a 5 y $10^{\circ} \mathrm{C}$ se observó un incremento, mientras que la misma se redujo a temperaturas superiores a $10^{\circ} \mathrm{C}$.

En el caso de batatas, se ha señalado que una actividad respiratoria elevada contribuyó a la pérdida de peso y a alteraciones de los tejidos, tanto a nivel interno como externo (Ravi y Aked, 1996).

Los resultados obtenidos en el presente trabajo de Tesis, mostraron que la actividad respiratoria de raíces de ahipa medida a temperatura ambiente $\left(20^{\circ} \mathrm{C}\right)$ fue $25 \pm 5 \mathrm{~mL}$ $\mathrm{CO}_{2} \mathrm{~kg}^{-1} \mathrm{~h}^{-1}$. Picha (1986) informó que la tasa respiratoria de batatas recién cosechadas correspondió a $27 \mathrm{~mL}$ de $\mathrm{CO}_{2} \mathrm{~kg}^{-1} \mathrm{~h}^{-1}$, similar al valor hallado en ahipa. Mediciones de la actividad respiratoria llevadas a cabo por Coursey y Rusell (1969) en tubérculos de Dioscorea rotundata, tanto sanos como afectados por decaimiento, mostraron que la misma varió entre 5 y $20 \mathrm{~mL}$ de $\mathrm{CO}_{2} \mathrm{~kg}^{-1} \mathrm{~h}^{-1}$ para tubérculos sanos, dependiendo de la edad y el estado de dormición, mientras que en tubérculos dañados, la actividad respiratoria se incrementó por encima de $35 \mathrm{~mL} \mathrm{CO}_{2} \mathrm{~kg}^{-1} \mathrm{~h}^{-1}$. Teniendo en cuenta que en ciertas regiones tropicales y subtropicales los aroides comestibles son cultivados y consumidos en cantidades relevantes, Ravi y Aked (1996) han señalado que no existe demasiada información disponible sobre la actividad respiratoria de dichos productos durante la cosecha y el almacenamiento. Passam (1982) informó que en cormos de taro y tannia o malanga (Xanthosoma sagittifolium), las tasas respiratorias fueron $22 \pm 5$ y $41 \pm 11 \mathrm{~mL} \mathrm{CO}_{2} \mathrm{~kg}^{-1} \mathrm{~h}^{-1}$ a $27^{\circ} \mathrm{C}$ y $32^{\circ} \mathrm{C}$, respectivamente.

En las raíces de ahipa empleadas en los presentes ensayos se observó que la aplicación del tratamiento térmico incrementó 2,4 veces la actividad respiratoria inicial $(p<0,05)$ de forma inmediata, y que la producción de $\mathrm{CO}_{2}$ se retrotrajo a los valores de partida luego de 24 horas de aplicado el tratamiento. 
La irradiación UV-C también ocasionó un incremento significativo en la actividad respiratoria de las raíces (1,7 veces con respecto al control), en forma inmediata al tratamiento.

\subsection{Brotado}

Las raíces de ahipa, como otras raíces tuberosas, tienen un período natural de inactividad luego del cual comienzan a brotar. Este período varía según el tipo de cultivo, la especie y las condiciones de almacenamiento. Así, las raíces de ñame (Dioscorea spp.) pueden almacenarse a temperaturas entre 25 y $35^{\circ} \mathrm{C}$ durante 4 meses sin signos de brotado. Las papas, en cambio, presentan brotado luego de 5 semanas a $15^{\circ} \mathrm{C}$. En otros tubérculos andinos como oca (Oxalis tuberosa), ulluco (Ullucus tuberosus) y mashua (Tropaeolum tuberosum), se ha informado que el brotado y las consecuentes pérdidas por deshidratación y respiración son los principales factores que condicionan la vida útil de estos productos (Tupac Yupanqui, 2001).

Durante el almacenamiento a $25^{\circ} \mathrm{C}$, se observó brotado de las raíces de Pachyrhizus ahipa. En la Figura 1.12 se muestra, a modo de ejemplo, una bandeja conteniendo raíces de ahipa con distintos grados de brotado, hacia el final de la conservación.

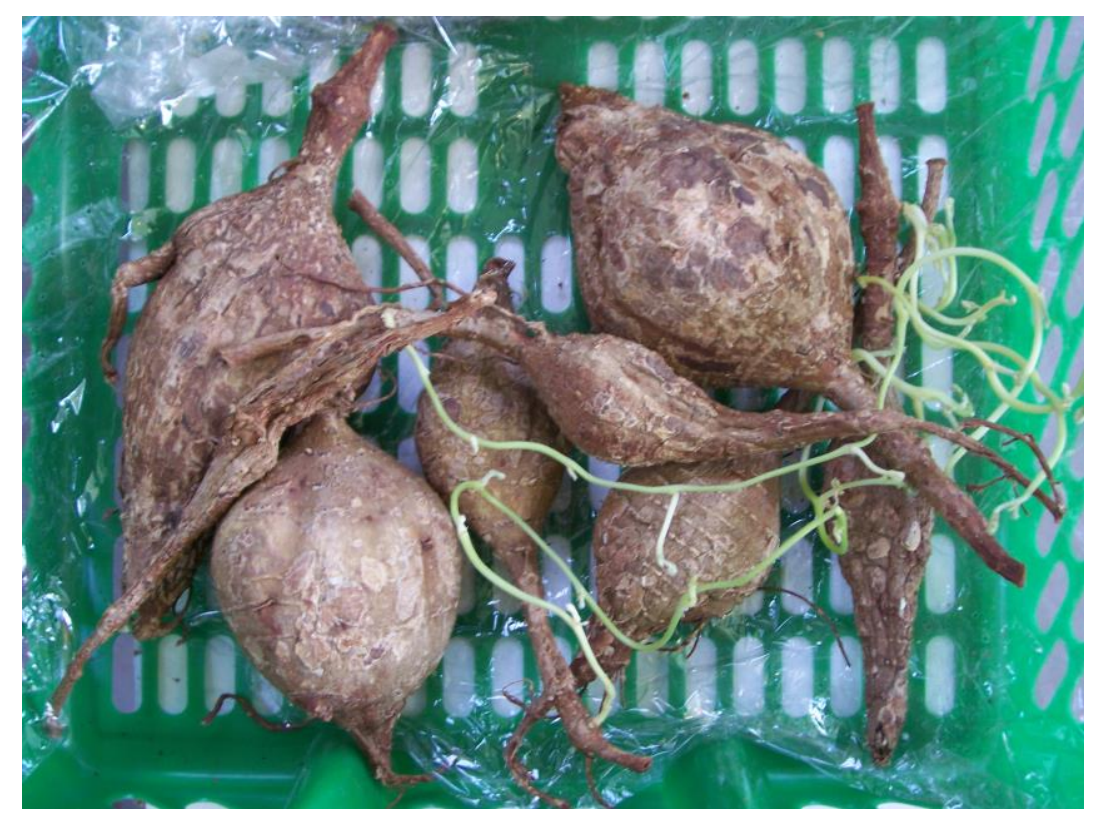

Figura 1.12. Bandejas conteniendo raíces brotadas de Pachyrhizus ahipa (ahipa). 
La cantidad relativa de raíces brotadas aumentó durante el almacenamiento a $25^{\circ} \mathrm{C}$ (Figura 1.13). La misma se incrementó significativamente durante los primeros tres meses y se estabilizó entre los 3 y 4 meses de conservación.

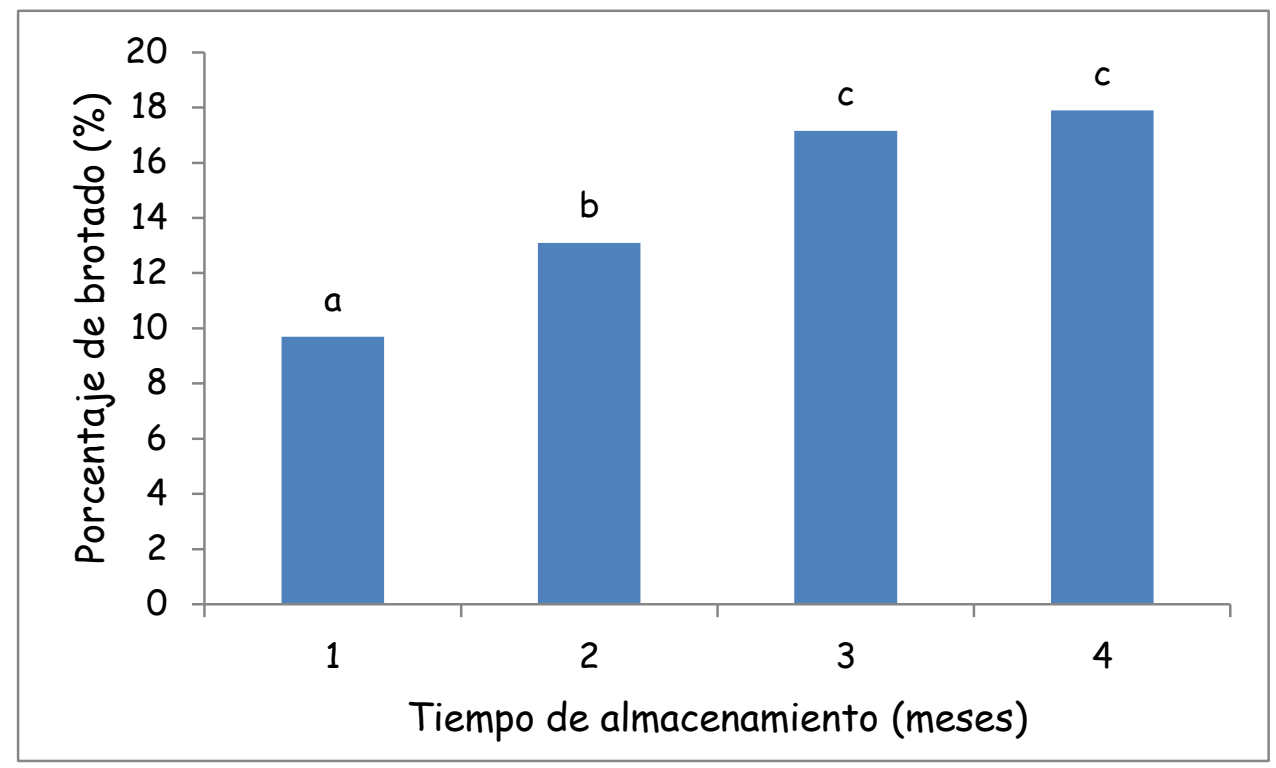

Figura 1.13. Porcentaje de raíces brotadas durante el almacenamiento ( 4 meses) a $25^{\circ} \mathrm{C}$.

En concordancia con el incremento en la incidencia de brotado se verificó una marcada reducción en el contenido de humedad de las raíces. La humedad inicial de las muestras (cuantificada a la temperatura de estabilización) $(76,3 \pm 0,5 \%)$ disminuyó significativamente $(p<0,05)$ luego de 4 meses a $25{ }^{\circ} \mathrm{C}(75,2 \pm 0,3 \%)$, al igual que la humedad residual $\left(\mathrm{a} 105^{\circ} \mathrm{C}\right)$.

\subsection{Contenido de almidón total y actividad $\alpha$-amilasa}

A pesar de las numerosas investigaciones dedicadas a los procesos industriales que implican la transformación enzimática del almidón, la naturaleza precisa de la degradación de este compuesto in situ en productos vegetales todavía presenta algunos aspectos por resolver. Es altamente posible que cada material amiláceo contenga su propia maquinaria para la hidrólisis de sus materiales de reserva (Okamoto y Akazawa, 1979).

La ruptura del almidón granular insoluble a maltodextrinas solubles en productos vegetales es llevada a cabo por endoamilasas ( $\alpha$-amilasa, EC 3.2.1.1) (Hagenimana y 
col., 1994). Éstas son las únicas enzimas consideradas generalmente capaces de atacar el almidón nativo, y su lenta acción es responsable de la erosión física de los gránulos de almidón. Se encuentran entre las principales enzimas sintetizadas durante la germinación de las semillas.

El rol fisiológico de las $\beta$-amilasas durante la degradación de almidón no está establecido tan claramente. A pesar de los altos niveles de $\beta$-amilasa en granos de cereales durante la germinación y su amplia distribución en plantas, esta enzima resulta más bien inefectiva durante el ataque de los gránulos de almidón intactos.

Dure (1960) encontró que la enzima $\alpha$-amilasa representa el $90 \%$ de la actividad amilolítica total en semillas de maíz durante la máxima actividad amilolítica en la germinación. Ni la $\beta$-amilasa ni la almidón-fosforilasa parecen ser esenciales para la movilización del almidón en granos de arvejas y otras legumbres.

El nivel endógeno de enzimas $\alpha$-amilasas en productos ricos en almidón afecta significativamente el uso industrial de los mismos. Dependiendo del destino final, puede resultar útil un nivel de $\alpha$-amilasa suficiente para producir azúcares que puedan ser utilizados por ejemplo, como fuente de energía por levaduras. Por otra parte, una actividad $\alpha$-amilasa demasiado elevada podría ocasionar una dextrinización excesiva (Doporto y col., 2011).

Por ejemplo en batatas, junto con un alto contenido de almidón, las raíces tienen un cierto contenido de amilasas. Estas enzimas nativas tienen una influencia importante en el almacenamiento y procesamiento de las raíces.

Las raíces frescas de batata contienen su actividad $\alpha$-amilasa concentrada en la periferia de la raíz, en un tejido que es removido durante el pelado.

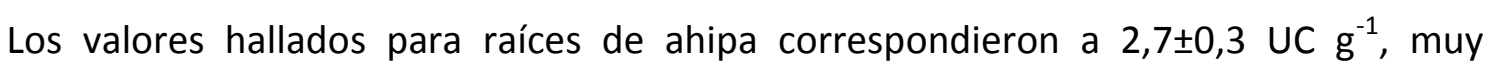
superiores a los obtenidos por Brandolini y col. (2010) para harina de trigo pan cultivar Blasco, aplicando el mismo método. La actividad $\alpha$-amilasa de las raíces de ahipa disminuyó hasta alcanzar $1,4 \pm 0,2 \cup \mathrm{C} \mathrm{g}^{-1}$ a los 4 meses de almacenamiento a $25{ }^{\circ} \mathrm{C}$ (Tabla 1.3).

Las raíces que fueron sometidas a irradiación UV-C mostraron una actividad $\alpha$-amilasa $32 \%$ menor que la correspondiente al control y a las raíces sometidas a tratamiento térmico (que no difirieron entre sí). 
Tabla 1.3. Contenido de almidón total y actividad $\alpha$-amilasa de raíces de Pachyrhizus ahipa (ahipa) controles, almacenadas durante 4 meses a $25^{\circ} \mathrm{C}$.

\begin{tabular}{c|c|c|} 
& Inicial (0 meses) & Final (4 meses) \\
\hline Almidón total (\%) & $37 \pm 3^{\text {a }}$ & $34 \pm 3^{\text {a }}$ \\
\hline Actividad $\alpha$-amilasa $\left(\mathrm{UC} \mathrm{g}^{-1}\right)$ & $2,7 \pm 0,3^{\mathrm{a}}$ & $1,4 \pm 0,2^{\mathrm{a}}$ \\
\hline
\end{tabular}

Nota: Los valores informados corresponden a las medias \pm las desviaciones estándar. Datos acompañados por una misma letra en la misma fila, no difieren significativamente $(p>0,05)$.

Como se observa en la Tabla 1.3 , de la misma manera que lo hizo la actividad $\alpha$ amilasa, el contenido de almidón total de las raíces también disminuyó al cabo de 4 meses de almacenamiento a $25^{\circ} \mathrm{C}$.

\section{Atributos de calidad: color y textura}

\subsection{Color}

La evaluación del color es un tema relevante dado que la aceptabilidad de los alimentos, en particular de los vegetales que se consumen frescos, normalmente se basa en la percepción del color por parte de los consumidores. Teniendo en cuenta otros cultivos de R\&T, Njie y Rumsey (1998) observaron visualmente que, inmediatamente después del pelado y corte, las raíces de ñame (Dioscorea dumetorum) sufrieron pardeamiento en la superficie expuesta cambiando su color de amarillo pálido a marrón oscuro. Por el contrario, en el caso de mandioca (Manihot esculenta) los mismos autores informaron que la raíz tuberosa resultaba muy blanca, con poca tendencia al pardeamiento enzimático luego del procesamiento mínimo (Njie y Rumsey, 1998).

Los resultados de las mediciones de color para las raíces de ahipa tratadas y almacenadas se muestran en la Tabla 1.4. La coordenada a* de cromaticidad que caracterizó al color interno de las raíces de ahipa comprendió valores entre $-1,49$ y 1,51 y la coordenada $b^{*}$, entre 2,96 y 11,56 . El grado de saturación o Chroma ( $\left.C^{*}\right)$ fue bajo, mientras que la luminosidad fue relativamente alta (Tabla 1.4). Estos valores resultaron inferiores a los informados por Sgroppo y col., (2010) para la batata variedad "Colorada Correntina" ( $L^{*}=91,5 \pm 2,7$ y $\left.C^{*}=31,3 \pm 2,3\right)$. El color de la pulpa de las raíces de ahipa puede describirse como pálido, blanco y escasamente saturado. La 
elevada desviación estándar de los valores de cromaticidad podría explicarse considerando que las secciones transversales de las raíces de ahipa exhiben puntuaciones de color violáceo, siendo altamente heterogéneas en cuanto a su coloración.

Tabla 1.4. Efecto del tratamiento y de las condiciones de almacenamiento en los parámetros luminosidad $\left(\mathrm{L}^{*}\right)$ y Chroma $\left(\mathrm{C}^{*}\right)$ de la sección de corte de raíces de Pachyrhizus ahipa (ahipa).

\begin{tabular}{ccc} 
Tratamiento y condiciones de almacenamiento & $L^{*}$ & $C^{*}$ \\
\hline Control (inicio del almacenamiento) & $81 \pm 5^{\mathrm{a}}$ & $8 \pm 4^{\mathrm{a}}$ \\
\hline Control 4 meses a $25^{\circ} \mathrm{C}$ & $83 \pm 3^{\mathrm{a}}$ & $12 \pm 1^{\mathrm{a}}$ \\
\hline Térmico 4 meses a $25^{\circ} \mathrm{C}$ & $83 \pm 4^{\mathrm{a}}$ & $12 \pm 1^{\mathrm{a}}$ \\
\hline UV-C 4 meses a $25^{\circ} \mathrm{C}$ & $81 \pm 2^{\mathrm{a}}$ & $12 \pm 1^{\mathrm{a}}$ \\
\hline Control 1 mes a $4^{\circ} \mathrm{C}$ & $83 \pm 3^{\mathrm{a}}$ & $11 \pm 2^{\mathrm{a}}$ \\
\hline Control 1 mes a $10^{\circ} \mathrm{C}$ & $77 \pm 7^{\mathrm{a}}$ & $13 \pm 6^{\mathrm{a}}$
\end{tabular}

Nota: Los valores informados corresponden a las medias \pm las desviaciones estándar. Letras diferentes en cada columna indican diferencias significativas $(p<0,05)$.

No se observaron diferencias significativas durante el almacenamiento a 4,10 o $25^{\circ} \mathrm{C}$, ni en los valores de luminosidad ( $\left.L^{*}\right)$ ni en los de Chroma $\left(C^{*}\right)$. Por lo tanto, las raíces de ahipa mantuvieron su color interno al menos durante 4 meses a $25^{\circ} \mathrm{C}$ o 1 mes a $4 \mathrm{y}$ $10^{\circ} \mathrm{C}$. Los tratamientos físicos ensayados no causaron diferencias significativas en las mediciones de color de las raíces de ahipa.

\subsection{Textura}

La Tabla 1.5 muestra los resultados de los ensayos de análisis de perfil de textura (TPA) realizados sobre muestras de raíces de ahipa. 
Tabla 1.5. Efecto del almacenamiento en los parámetros texturales de raíces de Pachyrhizus ahipa (ahipa) sometidas a diferentes tratamientos.

\begin{tabular}{|c|c|c|c|c|c|}
\hline Tratamiento & Dureza $(\mathrm{N})$ & Elasticidad & Cohesividad & Resiliencia & Masticabilidad (N) \\
\hline Control (inicial) & $135 \pm 22^{a}$ & $0,79 \pm 0,06^{a}$ & $0,5 \pm 0,2^{a}$ & $0,5 \pm 0,3^{a}$ & $48 \pm 28^{a}$ \\
\hline Control (4 meses a $\left.25^{\circ} \mathrm{C}\right)$ & $147 \pm 23^{a}$ & $0,72 \pm 0,08^{a}$ & $0,6 \pm 0,2^{a}$ & $0,4 \pm 0,2^{a}$ & $61 \pm 22^{a}$ \\
\hline Térmico ( 4 meses a $25^{\circ} \mathrm{C}$ ) & $152 \pm 36^{a}$ & $0,8 \pm 0,2^{a}$ & $0,72 \pm 0,05^{a}$ & $0,42 \pm 0,07^{\mathrm{a}}$ & $84 \pm 32^{a}$ \\
\hline UV-C ( 4 meses a $25^{\circ} \mathrm{C}$ ) & $151 \pm 18^{\mathrm{a}}$ & $0,74 \pm 0,03^{a}$ & $0,71 \pm 0,02^{\mathrm{a}}$ & $0,41 \pm 0,02^{a}$ & $79 \pm 10^{a}$ \\
\hline Control $\left(1\right.$ mes a $\left.4^{\circ} \mathrm{C}\right)$ & $122 \pm 31^{a}$ & $0,7 \pm 0,1^{\mathrm{a}}$ & $0,6 \pm 0,2 a$ & $0,5 \pm 0,1^{a}$ & $50 \pm 17^{a}$ \\
\hline Control $\left(1\right.$ mes a $\left.10^{\circ} \mathrm{C}\right)$ & $150 \pm 27^{a}$ & $0,8 \pm 0,2 a$ & $0,4 \pm 0,2^{a}$ & $0,5 \pm 0,2^{a}$ & $49 \pm 36^{a}$ \\
\hline
\end{tabular}

Nota: Los valores informados corresponden a las medias \pm las desviaciones estándar. Letras diferentes en cada columna indican diferencias significativas $(p<0,05)$.

En la Figura 1.14 se muestra el gráfico (fuerza versus tiempo) obtenido en el ensayo de análisis de perfil de textura realizado en las muestras de ahipa. En el mismo no se observa el pico de área negativa característico de las muestras adhesivas.

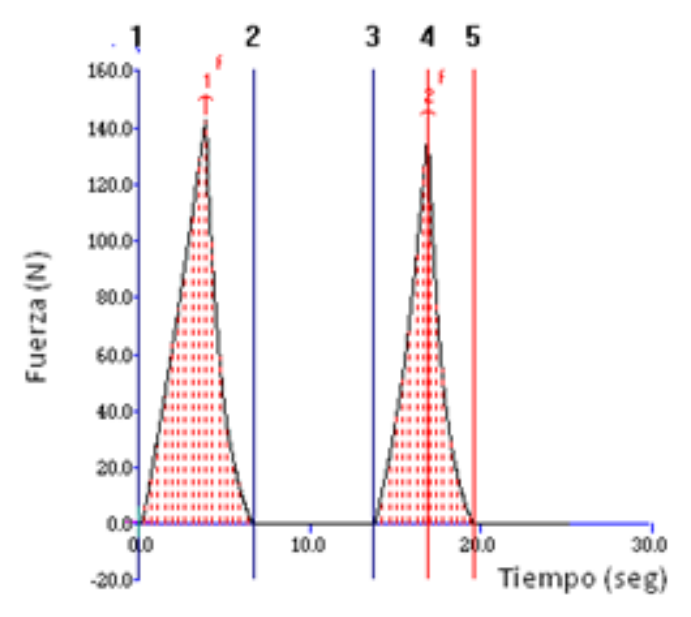

Figura 1.14. Perfil de textura describiendo el comportamiento mecánico de las muestras de raíces de Pachyrhizus ahipa (ahipa) durante el análisis.

En relación a otros cultivos de raíces, la fuerza máxima medida en compresión (hasta producir un $15 \%$ de deformación de la muestra) para mandioca fue $231,5 \mathrm{~N}$ (Menoli y Beleia, 2007). Los autores han señalado que las células turgentes de las raíces frescas presentaron una elevada fuerza de compresión, dado que los tejidos presentaron un contenido de agua igual a $65 \mathrm{~g} / 100 \mathrm{~g}$ de muestra. Las raíces de ahipa mostraron características similares. La dureza puede relacionarse con la fuerza necesaria para 
romper el producto con los incisivos durante la masticación. No se observaron diferencias significativas en la dureza de las muestras durante el almacenamiento de las muestras controles y tratadas (Tabla 1.5).

\section{Análisis de la población fúngica predominante}

La población fúngica aislada de las muestras al inicio del almacenamiento estuvo representada casi exclusivamente por el género Fusarium, proveniente del suelo (Figura 1.15). El contacto directo entre las raíces y el suelo sería la principal fuente de contaminación por este género (Gnonlonfin y col., 2008).

Se observó un predominio (77-100\%) de dicho género, identificándose las especies $F$. solani, F. oxysporum y F. equiseti.

En lo que respecta a población fúngica, no se observaron diferencias notorias entre los tratamientos ensayados.

Si bien los tratamientos físicos, tales como el calentamiento a temperaturas sub-letales (shock térmico) y la irradiación UV-C son utilizados para el control de microorganismos presentes en tejidos vegetales, en este caso no se observaron diferencias relevantes entre los tratamientos ensayados, con respecto al control.

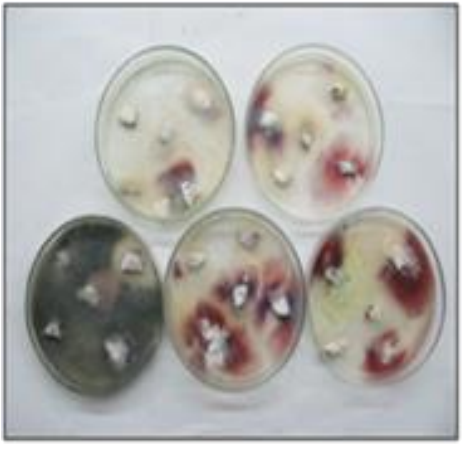

Tratamiento: control

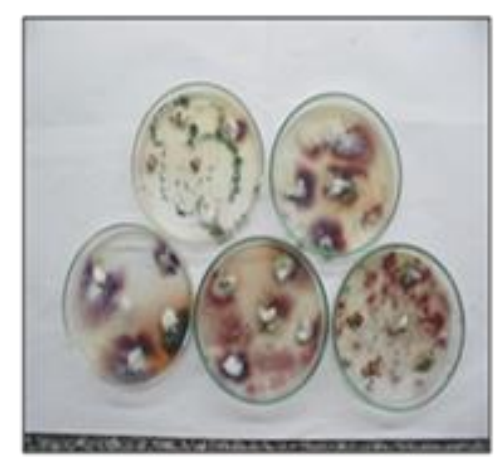

Tratamiento: térmico

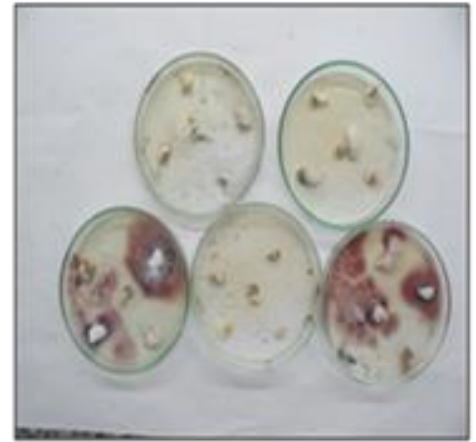

Irradiación UV-C

Figura 1.15. Población fúngica inicial de raíces de Pachyrhizus ahipa (ahipa) sometidas a diferentes tratamientos. 
En muestras almacenadas a baja temperatura, el género Fusarium representó el 72 y $75 \%$ de los recuentos, cuando las raíces fueron conservadas a 4 ó $10^{\circ} \mathrm{C}$, respectivamente (Tabla 1.6).

En estos casos, se identificaron representantes de otros géneros fúngicos tales como Alternaria, Bipolaris, Cladosporium, Curvularia, Penicillium y Trichoderma (Figura 1.16). Algunos de los géneros mencionados son característicos del almacenamiento.

La diversificación observada en cuanto a composición de la población fúngica puede haberse visto favorecida por la ocurrencia de daño por frío durante la conservación a bajas temperaturas.

Si bien son escasas las investigaciones específicas sobre los hongos que pueden afectar las raíces de ahipa, existe información disponible sobre las poblaciones fúngicas que afectan órganos vegetales subterráneos similares. Estudiando la micoflora de la superficie de la raíz de mandioca, Ikediugwu y Ejale (1980) han aislado a un pequeño grupo de hongos, que incluía Aspergillus niger, Botryodiplodia theobromae, Fusarium solani, Penicillium spp y Trichoderma spp. Con respecto al predominio de Fusarium, los resultados del presente trabajo concuerdan con los hallados en las raíces de mandioca por Lozano (1992), Msikita y col. (1997) y Bandyopadhyay y col. (2006).

Tabla 1.6. Efecto de los tratamientos aplicados y del almacenamiento en la incidencia de Fusarium en raíces de Pachyrhizus ahipa (ahipa).

\begin{tabular}{c|c|c|} 
Tratamientos y condiciones & Recuentos iniciales (\%) & Recuentos finales (\%) \\
\hline Control & $100 \pm 0^{\mathrm{a}}$ & $47 \pm 18^{\mathrm{b}}$ \\
\hline Tratadas térmicamente & $96 \pm 7^{\mathrm{a}}$ & $85 \pm 18^{\mathrm{a}}$ \\
\hline Tratadas con UV-C & $77 \pm 13^{\mathrm{a}}$ & $61 \pm 10^{\mathrm{a}}$ \\
\hline Almacenadas a $4^{\circ} \mathrm{C}$ & $100 \pm 0^{\mathrm{a}}$ & $72 \pm 16^{\mathrm{b}}$ \\
\hline Almacenadas a $10^{\circ} \mathrm{C}$ & $100 \pm 0^{\mathrm{a}}$ & $75 \pm 12^{\mathrm{b}}$
\end{tabular}

Nota: Los valores informados corresponden a las medias \pm las desviaciones estándar. Los datos dentro de cada fila seguidos por letras diferentes, indican diferencias significativas $(p<0,05)$.

Las muestras de ahipa almacenadas a 4 y $10^{\circ} \mathrm{C}$ mostraron un rápido deterioro y evidenciaron síntomas y signos de ataque de hongos, después de un mes de almacenamiento refrigerado (Figura 1.16). Por el contrario, las muestras control, las 
tratadas térmicamente y las irradiadas con UV-C pudieron conservarse durante al menos 4 meses a $25^{\circ} \mathrm{C}$. Estos resultados indican que las raíces de Pachyrhizus ahipa fueron afectadas por las bajas temperaturas, lo que posiblemente determinó que los tejidos fuesen más susceptibles al ataque de los agentes patológicos.

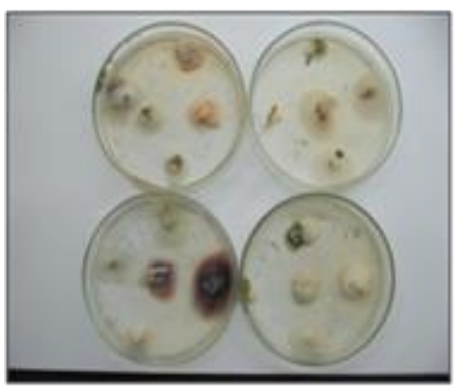

20 días a $4^{\circ} \mathrm{C}$

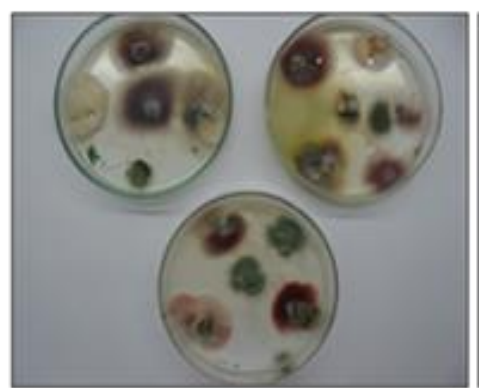

20 días a $10^{\circ} \mathrm{C}$

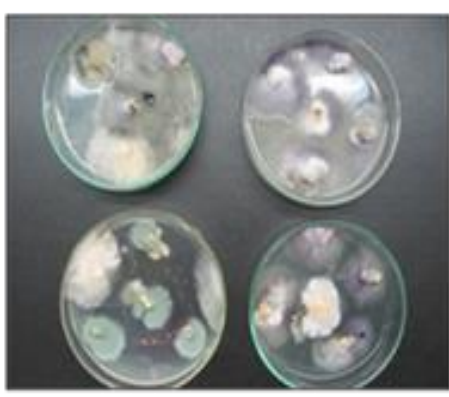

Figura 1.16. Población fúngica de raíces de Pachyrhizus ahipa (ahipa) almacenadas durante 20 días a 4 y a $10^{\circ} \mathrm{C}$.

Es sabido que las R\&T se pueden almacenar en forma subterránea (retrasando la cosecha), a temperatura ambiente o bajo refrigeración. La última alternativa no sería viable para las raíces de ahipa bajo las condiciones ensayadas, ya que sufrieron daño por frío. Dejar las raíces en el campo (una práctica común, por ejemplo, con raíces de mandioca) tiene la desventaja de no permitir el uso de las tierras para otra producción. Los resultados obtenidos en cuanto al efecto de los tratamientos físicos en la calidad y conservación de raíces de ahipa no mostraron ventajas notorias con respecto a la evolución de los controles. La aplicación de estas tecnologías demandará una optimización de las condiciones de aplicación de las mismas y la evaluación desde un punto de vista económico de los costos derivados de su implementación, en relación a la extensión de la vida útil lograda. 


\section{CAPÍTULO 1. SECCIÓN 3.}

\section{Composición química y propiedades}

funcionales de raíces de Pachyrhizus ahipa pertenecientes a diferentes accesiones 


\section{Material vegetal}

\section{MATERIALES Y MÉTODOS}

Como se indicó anteriormente, se utilizaron raíces de Pachyrhizus ahipa cultivadas en Misiones (EEA INTA-Montecarlo, Argentina), pertenecientes a cuatro accesiones, provenientes originariamente del IRNAS-CSIC (Instituto de Recursos Naturales y Agrobiología - Consejo Superior de Investigaciones Científicas, Sevilla, España). Dichas accesiones fueron designadas en la EEA Montecarlo de la siguiente manera: IRNAS 4, 5, 9 у 11.

Las raíces fueron recibidas en el CIDCA, lavadas exhaustivamente con agua corriente hasta eliminación de todo resto visible de tierra, secadas por oreo, cortadas manualmente en rodajas finas y deshidratadas hasta peso constante, a efecto de su estabilización como se describió en la Sección 1 del presente Capítulo.

Dada la variación de las condiciones agroclimáticas entre distintos ciclos de cultivo, en esta sección se incluyen también los datos correspondientes a la accesión Local, que fueron asimismo determinados junto con los de las accesiones IRNAS 4, 5, 9 y 11 (año 2010).

\section{Análisis químico de macro y microcomponentes}

Las raíces de las diferentes accesiones se acondicionaron tal como se mencionó anteriormente. Las muestras parcialmente deshidratadas de las cuatro accesiones fueron finamente molidas y conservadas hasta el momento de su análisis, al igual que las raíces pertenecientes a la accesión Local.

El contenido de materia seca, cenizas totales, lípidos, proteína cruda, almidón total y fibra detergente ácido se realizó según las técnicas descriptas en la Sección 1 del presente Capítulo.

\subsection{Cuantificación de sodio, potasio, calcio, hierro y magnesio}

Las determinaciones respectivas fueron llevadas a cabo en muestras de cenizas $(0,03-$ 0,05 g), remitidas al laboratorio del G.E.M.A. (Grupo de Estudios Medioambientales). Los análisis de hierro, calcio y magnesio fueron realizados por espectroscopía de absorción atómica, mientras que la cuantificación de sodio y potasio fue llevada a cabo 
por espectroscopía de emisión atómica. Las mediciones se efectuaron como se describió en la sección anterior. Los resultados finales se expresaron como mg/100g.

\subsection{Fibra dietaria total}

La fibra dietaria total (FDT) se determinó por duplicado en muestras secas de las raíces de ahipa, parcialmente deshidratadas, utilizando el kit enzimático K-TDFR 05/12 Megazyme (C) (Irlanda). Las muestras se trataron a $100^{\circ} \mathrm{C}$ con $\alpha$-amilasa (3000 Unidades Ceralpha/mL) para gelatinizar, hidrolizar y despolimerizar el almidón presente; luego se incubaron a $60^{\circ} \mathrm{C}$ con enzima proteasa (E-BSPRT, 350 Unidades tirosina/mL) para solubilizar y despolimerizar proteínas, y amiloglucosidasa (E-AMGDF, 200 p-NP- $\beta$ maltósido Unidades $/ \mathrm{mL}$ ) para hidrolizar fragmentos de almidón a glucosa. Posteriormente fueron tratadas con etanol $96 \%$ para precipitar la fibra soluble y eliminar la proteína despolimerizada y la glucosa (proveniente del almidón). Cada residuo se filtró; se lavó con etanol 78\%, etanol 95\% y acetona, se secó, y finalmente se pesó. Un duplicado se utilizó para analizar proteínas por el método de Kjeldahl y el otro se calcinó a $550^{\circ} \mathrm{C}$ en mufla para determinar el contenido de cenizas. El contenido de FDT es el peso del residuo filtrado y secado menos la suma del peso de proteínas y cenizas. Los resultados se expresaron como porcentaje (\%) sobre base seca.

\subsection{Contenido de azúcares}

La sacarosa, D-glucosa y D-fructosa se encuentran en la mayor parte de las plantas y productos alimenticios. Se analizó en raíces de ahipa, provenientes de diferentes accesiones, el contenido de los azúcares mencionados mediante el kit enzimático KSUFRG 12/05 Megazyme@ (Irlanda). Para determinar el contenido de D-glucosa, a pH 7,60 se agregó enzima hexoquinasa $(425 \mathrm{U} / \mathrm{mL}$ ) que catalizó la fosfoforilación de la Dglucosa y posteriormente en presencia de la enzima glucosa-6-fosfato deshidrogenasa (212 U/mL) se formó, entre otros productos de reacción, NADPH (nicotinamidaadenina dinucleótido fosfato reducido). Como la cantidad de NADPH que se formó en la reacción es estequiométrica con la cantidad de D-glucosa, se midió este producto espectrofotométricamente a $340 \mathrm{~nm}$. En cuanto al contenido de D-fructosa en la muestra, se determinó la cantidad de D-glucosa después de la isomerización catalizada por la fosfoglucosa isomerasa $(1000 \mathrm{U} / \mathrm{mL})$. La concentración de D-glucosa se 
determinó antes y después de la hidrólisis de la sacarosa por la enzima $\beta$-fructosidasa (4000 U). A un pH de 4,60 la sacarosa se hidroliza con $\beta$-fructosidasa en D-glucosa y Dfructosa. La concentración de D-glucosa total en la muestra es el producto de la hidrólisis de la sacarosa y se determinó según se describió anteriormente. El contenido de sacarosa se calculó a partir de la diferencia en concentraciones de D-glucosa antes y después de la hidrólisis con esta enzima. Los resultados se expresaron en $\mathrm{g} / 100 \mathrm{~g}$ de raíz.

\section{Factores antinutricionales}

Se investigó espectrofotométricamente la presencia de factores antinutricionales tales como fitatos, inhibidores de tripsina, taninos y compuestos fenólicos totales. Por otra parte se determinó el contenido de oxalatos por valoración redox (método analítico clásico). Además se evaluó cualitativamente la presencia de glicósidos cianogénicos, empleando tiras de papel de filtro embebidas en el reactivo de Guignard (ácido pícrico al $1 \%$ y carbonato de sodio al $10 \%)$, específico para tal fin.

\subsection{Fitatos}

El contenido de fitatos en las accesiones de ahipa se determinó siguiendo el protocolo descripto por Makkar y col., (2007). La separación se realizó en una columna de intercambio aniónico (CG-400 rellena con una resina Tipo I saturada con cloruro, 100200 mesh, Rohm \& Haas, Philadelphia B, PA, Estados Unidos) de 0,8 cm de diámetro y $9,5 \mathrm{~cm}$ de altura. La cuantificación de fitatos se realizó mediante la reacción con el reactivo de Wade $\left(\mathrm{FeCl}_{3} \cdot 6 \mathrm{H}_{2} \mathrm{O}\right.$ al $0,03 \%$ y ácido sulfosalicílico al $\left.3 \%\right)$ utilizando ácido fítico como estándar (Vaintraub y Lapteva, 1988). El contenido de fitatos se expresó como mg de ácido fítico/g de muestra.

\subsection{Compuestos fenólicos totales y taninos}

La cuantificación de taninos y compuestos fenólicos totales se realizó mediante el método de Folin-Ciocalteu, de acuerdo con Makkar y col., (2007). La extracción de ambos grupos de compuestos se realizó en las cinco accesiones de ahipa ( $1 \mathrm{~g}$ ) con una solución de acetona al 70\%. Para la determinación de los fenoles totales, a los diferentes extractos se les agregó una solución del reactivo comercial de Folin- 
Ciocalteu (1 N) y una solución de carbonato de sodio (20\%). Finalmente se midió la absorbancia a $725 \mathrm{~nm}$ y se calculó la cantidad de fenoles totales, como equivalente de ácido tánico, con una curva de calibración realizada previamente con una solución estándar de ácido tánico $(0,1 \mathrm{mg} / \mathrm{mL})$.

Los taninos se cuantificaron por diferencia entre fenoles totales y compuestos no taninos o fenoles simples. Estos últimos fueron determinados por precipitación de los taninos presentes en los extractos preparados anteriormente, con una solución de polivinilpolipirrolidona (PVPP) comercial (Sigma, St. Louis, MO, P 6755). El contenido de fenoles simples (no taninos) se determinó de igual forma que la cantidad de fenoles totales.

La concentración de taninos y compuestos fenólicos totales se expresó como mg de ácido tánico/g muestra.

\subsection{Inhibidores de tripsina}

La actividad inhibidora de la tripsina fue analizada espectrofotométricamente según Makkar y col., (2007), sobre la base de Kakade y col., (1969) y Smith y col., (1980). La muestra ( 1 g raíz estabilizada) fue tratada con $\mathrm{NaOH}(0,01 \mathrm{M})$ en agitación por 3 horas a temperatura ambiente, manteniendo el pH entre 9,5-9,8. La suspensión obtenida debió diluirse hasta que $1 \mathrm{~mL}$ de la misma inhibió la actividad de la tripsina entre un 40-60\%. Se utilizaron una solución patrón de tripsina (pepsina cristalizada libre de sales en $\mathrm{HCl}$ ) y como sustrato una solución de BAPNA (N-benzoil-arginina-p-nitroanilida). El producto de reacción de color amarillo se midió a través de la absorbancia a $410 \mathrm{~nm}$. La actividad de inhibición de la tripsina se calculó como mg de tripsina pura inhibida por g de muestra $(\mathrm{mg} / \mathrm{g})$.

\subsection{Oxalatos}

Se cuantificó el contenido de oxalatos según AOAC (1990). La extracción de los oxalatos presentes en la muestra $(2 \mathrm{~g})$, fue realizada con $\mathrm{HCl}(0,3 \mathrm{M})$ a $100^{\circ} \mathrm{C}$ durante una hora. Luego este contenido se precipitó con $\mathrm{CaCl}_{2}$ al $5 \%$ y finalmente se tituló con $\mathrm{KMnO}_{4}(0,01 \mathrm{~N})$. Los resultados se expresaron como mg oxalato/100g de muestra. 


\subsection{Glicósidos cianogénicos}

La presencia de glicósidos cianogénicos fue cualitativamente investigada por la reducción del picrato de sodio (reactivo de Guignard) de color amarillo a un compuesto de color rojo (Makkar y col., 2007) a partir de muestras maceradas de las raíces de ahipa. Las muestras se colocaron en un Erlenmeyer, cubriendo $1 / 3$ del volumen del mismo y se tapó suspendiendo del tapón la tira de papel picrosódico sin que toque la muestra ni las paredes. Luego de algunas horas se observan los cambios de coloración producidos en el papel picrosódico por el efecto de los gases cianhídricos. Un color rosa o rojo se considera positivo.

\section{Capacidad secuestrante de radicales libres (CSR)}

Se evaluó la CSR de las raíces de ahipa mediante los métodos que emplean los radicales $\mathrm{DPPH}^{\bullet}$ y $\mathrm{ABTS}^{\circ+}$. En ambos casos, las determinaciones se llevaron a cabo sobre tejidos de las raíces frescas congeladas de las accesiones IRNAS 11 y Local.

El primer análisis se realizó utilizando el radical estable 2,2-difenil-1-picrilhidracilo $\left(\mathrm{DPPH}^{\circ}\right)$, según lo informado por Brand-Williams y col. (1995). Se molieron raíces frescas congeladas de las mencionadas accesiones y con etanol al 96\% se realizó la correspondiente extracción. La cantidad de tejido necesaria para disminuir en un $50 \%$ la concentración de $\mathrm{DPPH}^{\bullet}$ inicial, fue calculada y definida como concentración efectiva media $\left(\mathrm{EC}_{50}\right)$. Los resultados se expresaron como $\mathrm{EC}_{50}{ }^{-1}\left(\mathrm{~g}^{-1}\right)$.

La capacidad antioxidante también se evaluó con el monocatión radical 2,2'-azinobis(3-etilbenzotiazolina-6-ácido sulfónico) $\left(\mathrm{ABTS}^{\bullet+}\right)$. El método se llevó a cabo siguiendo el protocolo de Re y col., (1999). La solución estándar utilizada fue Trolox (0-0,432 mg $\left.\mathrm{mL}^{-1}\right)$. Los resultados se expresaron como equivalentes de Trolox/100g de muestra.

\section{Propiedades funcionales asociadas a la composición química}

Los atributos sensoriales de un alimento son consecuencia del efecto neto de interacciones complejas entre varios ingredientes funcionales. Por lo tanto es importante conocer las propiedades funcionales de las raíces asociadas a su composición química, con el fin de evaluar a las mismas y a sus productos derivados desde el punto de vista de sus aplicaciones tecnológicas. 


\subsection{Capacidad de retención de solventes}

La capacidad de retención de solventes de muestras de las raíces de ahipa parcialmente deshidratadas fue analizada siguiendo el método 56-11 (Rosell y col., 2009). Los solventes utilizados fueron agua desionizada, sacarosa (50\% p/p), $\mathrm{Na}_{2} \mathrm{CO}_{3}$ $(5 \%$ p/p) y ácido láctico $(5 \%$ p/p). La capacidad de retención de solventes se calculó de la siguiente manera y se expresó como porcentaje (\%):

$$
\% \mathrm{CRS}=\left[\frac{\text { PesodelGel }}{\text { Pesodel amuestra }}-1\right] \times\left[\frac{86}{(100-\% \text { humeda del amues tra })}\right] \times 100
$$

\subsection{Propiedades térmicas}

La calorimetría diferencial de barrido o en inglés DSC (Differential Scanning Calorimetry) es la técnica más comúnmente utilizada en la determinación de las transiciones de fase en los materiales inorgánicos y orgánicos, y dentro de estos últimos los de origen alimenticio. Los calorímetros miden el flujo calórico diferencial requerido para mantener una muestra y una referencia inerte a la misma temperatura, sometidas a un programa de calentamiento o enfriamiento controlado. Los cambios entálpicos se registran como endotermas o exotermas, según el proceso que sufra la muestra.

En la Figura 1.17 se muestra un termograma típico y cada uno de los parámetros térmicos determinados a partir del mismo. Los parámetros térmicos que se encuentran asociados al pico endotérmico debido al proceso de gelatinización del almidón, son las temperaturas de inicio $\left(T_{0}\right)$ y de pico máximo $\left(T_{p}\right)$. El área del pico endotérmico mencionado, es proporcional a la entalpía $(\Delta \mathrm{H})$ del proceso. 


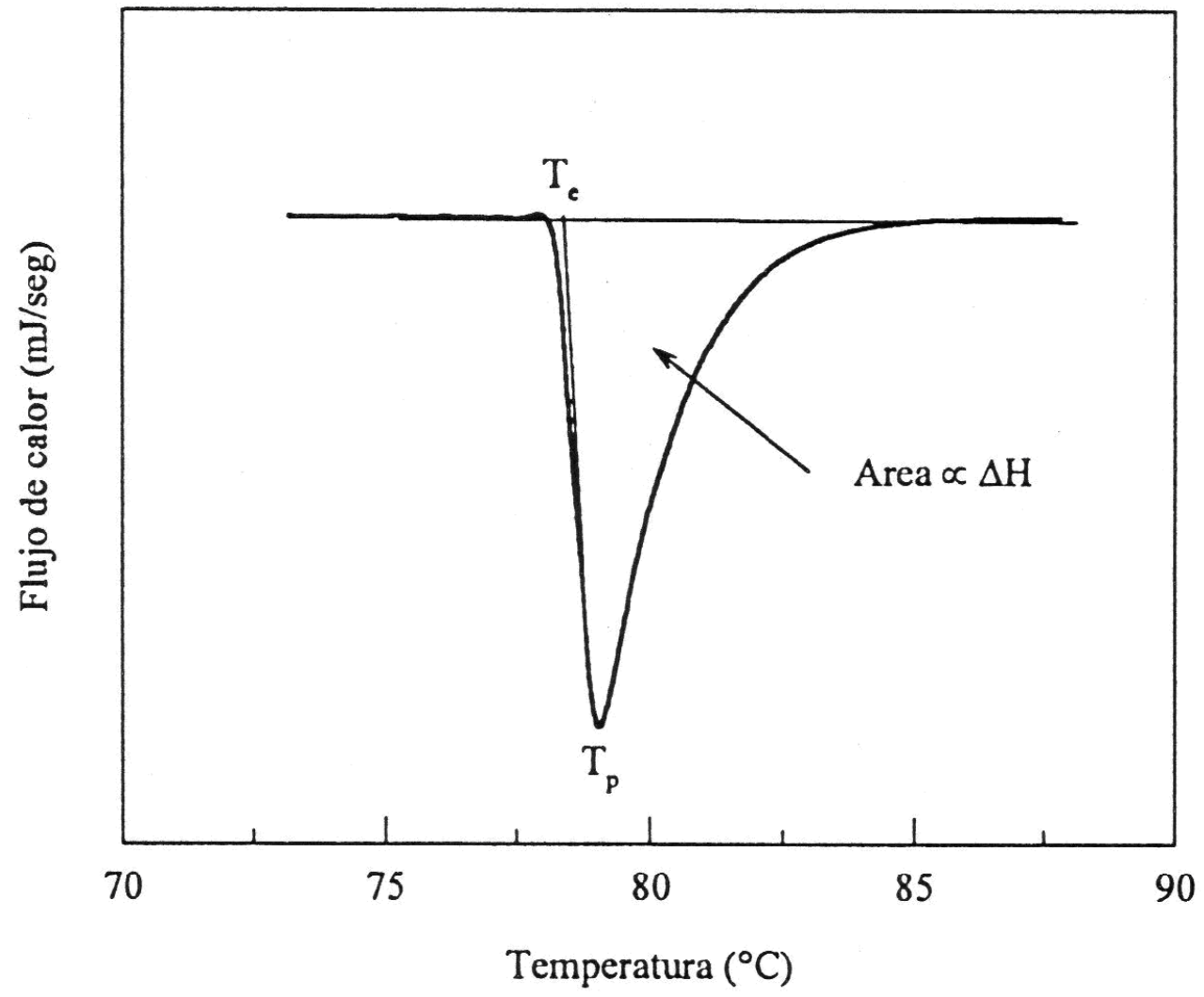

Figura 1.17. Termograma (flujo de calor versus temperatura) típico obtenido por DSC, donde se muestra el área del pico endotérmico, proporcional a la entalpía $(\Delta \mathrm{H})$ y las temperaturas de inicio $\left(T_{0}\right)$ y de pico máximo $\left(T_{p}\right)$. Fuente: López, 2011.

Para el análisis de las propiedades térmicas de las raíces de ahipa parcialmente deshidratadas se utilizó un calorímetro diferencial de barrido modelo Q100 controlado por el módulo TA 5000 (TA Instruments, Estados Unidos), con un accesorio de calentamiento-enfriamiento bajo atmósfera de $\mathrm{N}_{2}(20 \mathrm{~mL} / \mathrm{min})$. Se utilizó indio para la calibración de la temperatura y flujo de calor. Para la caracterización de las raíces de ahipa, se colocaron en las cápsulas alrededor de $7 \mathrm{mg}$ de muestra y $15 \mu \mathrm{L}$ de agua destilada. Las cápsulas se cerraron herméticamente. Se utilizó una cápsula vacía como referencia. La velocidad de barrido fue $10^{\circ} \mathrm{C} / \mathrm{min}$ y el rango de calentamiento varió entre $10-120^{\circ} \mathrm{C}$. Una vez analizadas las cápsulas se perforaron y se mantuvieron en estufa a $105^{\circ} \mathrm{C}$ hasta peso constante para determinar el peso seco de las muestras. A partir de los termogramas obtenidos se midieron las entalpías $(\Delta \mathrm{H}, \mathrm{J} / \mathrm{g}$ de muestra seca) y las temperaturas de la transición (temperatura de inicio $T_{0}$, de pico $T_{p}$ y final $T_{f}$, ${ }^{\circ} \mathrm{C}$ ) mediante el software Universal Analysis 2000 (Estados Unidos). 


\section{Análisis estadístico}

Se realizó el correspondiente análisis de varianza mediante el uso del software Systat (SYSTAT, Inc., Estados Unidos) versión 10.0. Las diferencias se compararon mediante el test de la diferencia mínima significativa de Fisher (LSD) usando un nivel de significación $p=0,05$. 


\section{RESULTADOS Y DISCUSIÓN}

\section{Composición química de raíces de ahipa pertenecientes a las diferentes accesiones}

Los valores obtenidos para las raíces de las diferentes accesiones se muestran en la Tabla 1.6.

Tabla 1.6. Composición química (\% p/p) de accesiones de raíces parcialmente deshidratadas de Pachyrhizus ahipa (ahipa).

\begin{tabular}{ccccccc} 
Accesión & Materia seca & $\begin{array}{c}\text { Cenizas } \\
\text { totales }\end{array}$ & $\begin{array}{c}\text { Lípidos } \\
\text { totales }\end{array}$ & Proteínas & Almidón total $\begin{array}{c}\text { Fibra dietaria } \\
\text { total }\end{array}$ \\
\hline Local $^{8}$ & $87,0 \pm 0,3^{\mathrm{c}}$ & $3,32 \pm 0,07^{\mathrm{a}}$ & $0,48 \pm 0,01^{\mathrm{a}}$ & $10,5 \pm 0,5^{\mathrm{b}, \mathrm{c}}$ & $56,8 \pm 0,9^{\mathrm{b}, \mathrm{c}}$ & $22,4 \pm 0,6^{\mathrm{b}}$ \\
\hline IRNAS N $^{\circ} 4$ & $82,9 \pm 0,3^{\mathrm{a}}$ & $3,82 \pm 0,00^{\mathrm{c}}$ & $0,43 \pm 0,07^{\mathrm{a}}$ & $12 \pm 1^{\mathrm{c}}$ & $54 \pm 6^{\mathrm{b}}$ & $24,4 \pm 0,8^{\mathrm{c}}$ \\
\hline IRNAS N $^{\circ} 5$ & $85,8 \pm 0,5^{\mathrm{b}}$ & $4,20 \pm 0,04^{\mathrm{d}}$ & $0,63 \pm 0,03^{\mathrm{b}}$ & $9,6 \pm 0,3^{\mathrm{b}}$ & $54 \pm 3^{\mathrm{b}}$ & $25,2 \pm 0,5^{\mathrm{c}, \mathrm{d}}$ \\
\hline IRNAS N $^{\circ} 9$ & $85,1 \pm 0,1^{\mathrm{b}}$ & $3,81 \pm 0,02^{\mathrm{b}, \mathrm{c}}$ & $0,62 \pm 0,00^{\mathrm{b}}$ & $7,9 \pm 0,5^{\mathrm{a}}$ & $44 \pm 2^{\mathrm{a}}$ & $25,9 \pm 0,2^{\mathrm{d}}$ \\
\hline IRNAS N $^{\circ} 11$ & $87,3 \pm 0,3^{\mathrm{c}}$ & $3,70 \pm 0,05^{\mathrm{b}}$ & $0,47 \pm 0,02^{\mathrm{a}}$ & $9,0 \pm 0,3^{\mathrm{a}, \mathrm{b}}$ & $65,0 \pm 0,6^{\mathrm{c}}$ & $20,8 \pm 0,2^{\mathrm{a}}$
\end{tabular}

Nota: Los valores informados corresponden a las medias \pm las desviaciones estándar. Los datos se encuentran expresados en base seca. Letras diferentes en cada columna indican diferencias significativas $(p<0,05)$.

El contenido de humedad residual de las muestras de ahipa estabilizadas (cuantificado mediante deshidratación a $105^{\circ} \mathrm{C}$ ) estuvo comprendido entre $12,7-17,2 \%$, mientras que las raíces enteras de ahipa presentaron un contenido de humedad (determinado a $60^{\circ} \mathrm{C}$ ) igual a $76,4 \%$ en promedio (Doporto y col., 2011).

El contenido de materia seca de las accesiones de raíces ahipa fue 78,4 a 83,5\% (Tabla 1.6), similar a los valores informados por $\emptyset$ rting y col., (1996) y Leonel y col., (2003). Estos niveles son comparables a los encontrados en papa (Solanum tuberosum, 7679\%), y más altos que los indicados para mandioca (Manihot esculenta, 63-65\%) (Dini y col., 2012).

La cantidad de cenizas totales en las diferentes accesiones de ahipa estuvo en el rango de 3,81 a 4,20\% (Tabla 1.6). Estos niveles fueron más altos que los presentes en otros cultivos de R\&T como el ñame (Dioscorea alata) (0,88-0,91\%), taro (Colocasia esculenta) (0,73-1,04\%), mandioca (Manihot esculenta) (1,15\%) (Leterme y col., 2006) y batata (Ipomoea batatas) (2,15-2,95\%) (Ahmed y col., 2010). La accesión IRNAS 5 se destacó por su alto contenido de cenizas totales. 
La Tabla 1.7 muestra el contenido mineral de las raíces de ahipa de distintas accesiones. En general, el contenido mineral varió significativamente con la accesión. Las muestras correspondientes a la accesión IRNAS 5 mostraron el mayor contenido de sodio, mientras que los de las accesiones Local y 11 presentaron los valores más bajos de este elemento.

La accesión Local mostró niveles de potasio y de hierro significativamente más bajos $(p<0,05)$ que los hallados para las cuatro accesiones restantes (IRNAS 4, 5, 9 y 11). Los tenores de calcio y magnesio para dicha accesión se ubicaron en valores intermedios dentro del rango correspondiente a las restantes accesiones (Tabla 1.7).

Tabla 1.7. Contenido mineral $(\mathrm{mg} / 100 \mathrm{~g})$ de raíces parcialmente deshidratadas de Pachyrhizus ahipa (ahipa) pertenecientes a distintas accesiones.

\begin{tabular}{cccccc} 
Accesión & Sodio & Potasio & Calcio & Magnesio & Hierro \\
\hline Local & $754 \pm 8^{\mathrm{b}}$ & $129 \pm 4^{\mathrm{a}}$ & $415 \pm 7^{\mathrm{b}}$ & $531 \pm 4^{\mathrm{c}}$ & $173 \pm 6^{\mathrm{b}}$ \\
\hline IRNAS N 4 & $917 \pm 9^{\mathrm{c}}$ & $172 \pm 4^{\mathrm{b}}$ & $573 \pm 8^{\mathrm{d}}$ & $164 \pm 4^{\mathrm{a}}$ & $630 \pm 7^{\mathrm{c}}$ \\
\hline IRNAS N 5 & $1302 \pm 10^{\mathrm{e}}$ & $172 \pm 5^{\mathrm{b}}$ & $546 \pm 9^{\mathrm{c}}$ & $227 \pm 5^{\mathrm{b}}$ & $756 \pm 8^{\mathrm{d}}$ \\
\hline IRNAS N $^{\circ} 9$ & $945 \pm 9^{\mathrm{d}}$ & $168 \pm 4^{\mathrm{b}}$ & $815 \pm 8^{\mathrm{e}}$ & $785 \pm 4^{\mathrm{e}}$ & $168 \pm 7^{\mathrm{b}}$ \\
\hline IRNAS N 11 & $207 \pm 9^{\mathrm{a}}$ & $192 \pm 4^{\mathrm{c}}$ & $181 \pm 8^{\mathrm{a}}$ & $592 \pm 4^{\mathrm{d}}$ & $126 \pm 7^{\mathrm{a}}$ \\
Nota: Los valores informados corresponden a la media \pm las desviaciones estándar. Letras diferentes en \\
\multicolumn{5}{c}{ cada columna indican diferencias significativas $(\mathrm{p}<0,05)}$.
\end{tabular}

La concentración de sodio en las accesiones de ahipa fue mayor que en el caso de mandioca (36-50 mg/100 g) (Charles y col., 2005) o taro (41,5-120,9 mg/100 g) (Lewu y col., 2010). Esto es importante, ya que es ampliamente reconocido que una alta ingesta de sodio está relacionada con la aparición de hipertensión, aumentando el riesgo de ataques cardíacos, apoplejías y daño a los riñones (Dini y col., 2012; Havas y col., 2004). Teniendo en cuenta esta consideración, la accesión IRNAS 5 no sería apropiada para la formulación de productos bajos en sodio.

Los valores de magnesio encontrados en ahipa (Tabla 1.7) fueron más altos que los hallados para mandioca por Charles y col., (2005) (31-43 mg/100g). Cabe señalar que una ingesta insuficiente de magnesio se ha asociado con el desarrollo de diabetes y resistencia a la insulina, así como también con determinadas complicaciones 
cardiovasculares (Ascherio y col., 1998; Saris y col., 2000). La ingesta de hierro diaria recomendada se encuentra en el rango de 25-50 mg (Gurzau y col., 2003). La contribución de hierro por parte de las raíces de ahipa (Tabla 1.7) varía con la accesión. La accesión IRNAS 5 exhibió el valor más alto respecto a las otras accesiones. El contenido de este mineral en la accesión IRNAS 4 (630 mg/100g materia seca) fue similar al de batata (Eluagu y Onimawo, 2010). El contenido de las accesiones restantes (126-173 mg/100g) fue considerablemente superior en comparación con otras raíces y tubérculos como mandioca (29-40 mg/100g) (Charles y col., 2005) o taro, cuyos valores estuvieron por debajo del límite de detección de la técnica en siete accesiones analizadas (Lewu y col., 2010).

Los niveles de lípidos totales se encontraron comprendidos dentro del rango 0,430,63\% (Tabla 1.6). Este contenido relativamente bajo de lípidos, similar al señalado para batata (Ahmed y col., 2010) y yacon (Choque Delgado y col., 2013), posicionaría a la ahipa como un posible ingrediente para la producción de alimentos bajos en grasa. Desde un punto de vista nutricional, la característica más relevante de la ahipa en comparación con otras R\&T es su relativamente alto contenido de proteínas. Las accesiones Local y 11 tienen un contenido de proteína similar siendo éste más alto que el de la accesión 9, pero inferior al encontrado en la accesión IRNAS 4 (Tabla 1.6). Estos valores de proteína son considerablemente más altos que los hallados en otras R\&T tales como mandioca (1-2\%), papa (3-6\%), batata (1-10\%), taro (0,6-2\%) o ñame (1-3\%) (Shewry, 2003) o yacon (2,45-6,48\%) (Choque Delgado y col., 2013). Aunque la ahipa sería en principio una fuente de proteínas, el estudio del perfil de aminoácidos de las mismas se vuelve crítico, con el fin de una mejor evaluación de la calidad nutricional.

Con respecto al contenido de almidón total de las raíces los valores hallados superaron el $44 \%$ (Tabla 1.6).

Las accesiones Local y 11 mostraron el mayor contenido de almidón respecto a las demás accesiones (Tabla 1.6).

Entre los macrocomponentes, también se cuantificó la fibra dietaria total (FDT). La fibra dietaria es el nombre colectivo dado a todos los componentes de las paredes celulares de las plantas que no son hidrolizados por las enzimas en el tracto digestivo humano. Es sabido que la fibra dietaria total se encuentra asociada a efectos beneficiosos en la regulación de la función intestinal, la prevención de los trastornos 
del colon y divertículos (Steinmetz y Potter, 1996). El contenido de fibra dietaria total en las raíces de ahipa se halló dentro del rango de 20,8 a 25,9 g/100 g (base seca). Las raíces de las accesiones IRNAS 11 y Local mostraron el menor contenido de este macrocomponente (Tabla 1.6). En cuanto a las accesiones IRNAS 5 y 9, éstas se destacaron por sus altos niveles de fibra. Estos resultados muestran que las raíces de ahipa pueden ser consideradas una buena fuente de fibra dietaria total en comparación con otras R\&T. Por ejemplo, Castro y col., (2013) informó 10,4 g FDT/100g en yacón. Teniendo en cuenta que el consumo de fibra dietaria debe oscilar entre los 20-35 gramos/día para alcanzar beneficios óptimos (Dreher, 2001), el consumo de $100 \mathrm{~g}$ de raíces de ahipa parcialmente deshidratadas cubriría las necesidades diarias de fibra.

Del mismo modo, las muestras de ahipa mostraron relativamente altas concentraciones de azúcares simples cuando se las comparan con otras R\&T. En las comunidades donde el cultivo y la comercialización de la ahipa es una práctica común, la raíz se consume principalmente cruda, ya que se asemeja a una fruta debido a su alto contenido de agua y sabor dulce. La Tabla 1.8 muestra el contenido de azúcares de las raíces de ahipa. La accesión IRNAS 4 presentó los valores más altos de sacarosa, mientras IRNAS 11 exhibió los niveles más bajos de glucosa, fructosa y sacarosa. Los valores medios encontrados para los azúcares simples en todas las accesiones ensayadas estuvieron comprendidos entre 14,1-25,1 g/100g (base seca). Estos valores son similares a los indicados para batata: 17,17-20,76\% (Ahmed y col., 2010), un producto que también tiene un sabor dulce característico. Entre los azúcares presentes en las raíces ahipa, la sacarosa fue el predominante (Tabla 1.8). 
Tabla 1.8. Contenido de azúcares simples $(\mathrm{g} / 100 \mathrm{~g})$ de raíces parcialmente deshidratadas de Pachyrhizus ahipa (ahipa).

\begin{tabular}{cccc} 
Accesión & Glucosa & Fructosa & Sacarosa \\
\hline Local & $1,7 \pm 0,2^{\mathrm{b}}$ & $5,4 \pm 0,3^{\mathrm{b}}$ & $11,44 \pm 0,07^{\mathrm{d}}$ \\
\hline IRNAS 4 & $1,77 \pm 0,07^{\mathrm{b}}$ & $6,29 \pm 0,07^{\mathrm{c}}$ & $17,0 \pm 0,4^{\mathrm{e}}$ \\
\hline IRNAS 5 & $1,6 \pm 0,1^{\mathrm{b}}$ & $5,34 \pm 0,03^{\mathrm{b}}$ & $7,8 \pm 0,2^{\mathrm{a}}$ \\
\hline IRNAS 9 & $2,8 \pm 0,1^{\mathrm{c}}$ & $6,3 \pm 0,2^{\mathrm{c}}$ & $10,2 \pm 0,4^{\mathrm{c}}$ \\
\hline IRNAS 11 & $0,74 \pm 0,03^{\mathrm{a}}$ & $4,51 \pm 0,01^{\mathrm{a}}$ & $8,9 \pm 0,1^{\mathrm{a}}$
\end{tabular}

Nota: Los valores informados corresponden a las medias \pm las desviaciones estándar. Letras diferentes en cada columna indican diferencias significativas $(p<0,05)$.

\section{Antinutrientes}

La Tabla 1.9 muestra los valores de los componentes antinutricionales y los compuestos fenólicos analizados.

Tabla 1.9. Componentes antinutrientes y compuestos fenólicos totales en raíces parcialmente deshidratadas de Pachyrhizus ahipa (ahipa).

\begin{tabular}{cccccc} 
Accesión & $\begin{array}{c}\text { Taninos (mg } \\
\text { ácido } \\
\text { tánico/g) }\end{array}$ & $\begin{array}{c}\text { Ácido fítico } \\
(\mathrm{mg} / \mathrm{g})\end{array}$ & $\begin{array}{c}\text { Actividad inhibidora } \\
\text { de tripsina }(\mathrm{UIT} / \mathrm{mg})\end{array}$ & $\begin{array}{c}\text { Oxalatos } \\
(\mathrm{mg} / 100 \mathrm{~g})\end{array}$ & $\begin{array}{c}\text { Compuestos } \\
\text { fenólicos totales } \\
(\mathrm{mg} / \mathrm{g})\end{array}$ \\
\hline Local & $1,70 \pm 0,06^{\mathrm{a}}$ & $1,03 \pm 0,01^{\mathrm{a}}$ & $2,73 \pm 0,02^{\mathrm{c}}$ & $74 \pm 7^{\mathrm{a}}$ & $3,2 \pm 0,4^{\mathrm{a}}$ \\
\hline IRNAS 4 & $1,92 \pm 0,02^{\mathrm{b}}$ & $1,27 \pm 0,00^{\mathrm{a}}$ & $1,05 \pm 0,03^{\mathrm{a}}$ & $217 \pm 8^{\mathrm{c}}$ & $3,8 \pm 0,2^{\mathrm{b}}$ \\
\hline IRNAS 5 & $2,03 \pm 0,05^{\mathrm{b}}$ & $1,3 \pm 0,3^{\mathrm{a}}$ & $1,02 \pm 0,01^{\mathrm{a}}$ & $176 \pm 6^{\mathrm{b}}$ & $3,8 \pm 0,3^{\mathrm{b}}$ \\
\hline IRNAS 9 & $1,94 \pm 0,00^{\mathrm{b}}$ & $1,73 \pm 0,02^{\mathrm{b}}$ & $1,0 \pm 0,1^{\mathrm{a}}$ & $210 \pm 4^{\mathrm{c}}$ & $3,73 \pm 0,06^{\mathrm{b}}$ \\
\hline IRNAS 11 & $1,59 \pm 0,01^{\mathrm{a}}$ & $1,05 \pm 0,02^{\mathrm{a}}$ & $2,3 \pm 0,1^{\mathrm{b}}$ & $58 \pm 8^{\mathrm{a}}$ & $3,03 \pm 0,06^{\mathrm{a}}$
\end{tabular}

Nota: Los valores informados corresponden a las medias \pm las desviaciones estándar. Letras diferentes en cada columna indican diferencias significativas $(p<0,05)$. UIT=Unidades de inhibidores de tripsina.

Las diferentes accesiones presentaron valores de taninos entre 1,6 y 2,0 mg de ácido tánico/g muestra. Estos valores son comparables a los informados en harina de mandioca (1-2 mg/g) (Oboh y Akindahunsi, 2003) y de batata (2,5 mg/g) (Eluagu y Onimawo, 2010), pero inferiores a los presentes normalmente en legumbres como poroto, cuyos valores oscilan entre 6,7 y 32,4 mg catequina/g muestra, según GuzmánMaldonado y col., (1996). 
La presencia de taninos cobra relevancia ya que actúan como inhibidores de enzimas digestivas y pueden reducir también la palatabilidad de un alimento por la astringencia que producen al combinarse con las proteínas salivales. Ha sido también señalado que interfieren en la asimilación de la vitamina B1 (tiamina) (Janssen, 1997). Por otra parte, ciertas clases de taninos han sido mencionadas como contribuyentes a la reducción del riesgo de enfermedades coronarias (Dell'Agli y col., 2004; Gresele y col., 2011).

En el análisis de antinutrientes, se detectó la presencia de fitina en todas las muestras analizadas. Los valores oscilaron entre 1,0 y $1,7 \mathrm{mg}$ ácido fítico/g muestra, similares a los mencionados para harina de mandioca $(0,9-1,4 \mathrm{mg} / \mathrm{g}$ ) (Charles y col., 2005) y para papa (1,1-2,7 mg fitato/g) (Phillippy y col., 2004) pero inferiores a los señalados en leguminosas como soja $(12,0-17,5 \mathrm{mg} / \mathrm{g})$ y arvejas $(7,2-12,3 \mathrm{mg} / \mathrm{g})$ (Hidvegi y Lasztity, 2002) y en cereales como trigo (9,6-22,2 mg/g) (García-Estepa y col., 1999); maíz (10,8 mg/g) (García-Estepa y col., 1999); centeno (4,5-5,7 mg/g) (Kikunaga y col., 1985; García-Estepa y col., 1999) y arroz (5,5-13,5 mg/g) (Kikunaga y col., 1985; GarcíaEstepa y col., 1999; Wu y col., 2009).

El anión fitato, liberado en la disociación del ácido fítico, se relaciona típicamente con la disminución de la disponibilidad de hierro, ya que forma un complejo insoluble con este mineral en el ambiente ácido del estómago. El hierro es liberado posteriormente como hidróxido férrico en las condiciones alcalinas del intestino, pero esta forma no disponible impide la absorción de este nutriente. El fitato produce también la precipitación de magnesio, zinc, cobre, calcio y manganeso. Contrariamente a estos efectos adversos descriptos, el fitato ha sido mencionado como agente anticarcinógeno (Harland y Morris, 1995).

La actividad de inhibición de la tripsina de las raíces de ahipa, expresada en unidades de inhibidores de tripsina (UIT), se encontró comprendida entre 1,0 y 2,7 UIT/mg (Tabla 1.9), comparable con los valores más bajos presentados por legumbres tales como los garbanzos, las lentejas y los lupines y cereales como el maíz, que corresponden en general a valores entre 1 y 20 UIT/mg. La soja puede tener concentraciones por encima de $40 \mathrm{UIT} / \mathrm{mg}$ (Dini y col., 2012). Además, es importante hacer hincapié en que, dado que los ensayos se llevaron a cabo en las raíces parcialmente deshidratadas, se determinó la actividad remanente de los inhibidores de tripsina en las muestras de ahipa. Las raíces de procedencia Local y la accesión IRNAS 
11 exhibieron los valores más altos, mientras que las accesiones IRNAS 4, 5 y 9 presentaron contenidos similares entre sí de inhibidores de tripsina.

Los inhibidores de tripsina pueden causar hipertrofia y/o hiperplasia pancreática. Sin embargo, se ha informado que los inhibidores de proteasas tienen efectos anticancerígenos (Makkar y col., 2007; Dragsted y col., 1993; Schelp y Pongpaew, 1988; Steinmetz y Potter, 1996). Del mismo modo, bajo un consumo controlado, la actividad antiproteína de estas sustancias se puede utilizar en alimentos destinados a la reducción de peso, ya que inducen una mayor sensación de saciedad. Según Noman y col. (2007) en su trabajo sobre Pachyrhizus erosus, esta especie junto a la batata y la papa podrían cumplir con estos requisitos ya que presentan actividades similares.

El contenido de oxalatos de las raíces ahipa varió entre 58 y 217 mg/100 g (Tabla 1.9). Huang y col., (2007) informó que en taro el contenido de oxalatos se encontró entre 234 y $411 \mathrm{mg} / 100 \mathrm{~g}$. Las raíces de las accesiones IRNAS 4 y 9 mostraron un contenido de oxalatos superior y estadísticamente $(p>0,05)$ comparable y, mientras que las accesiones 11 y Local mostraron los valores más bajos y no hubo diferencias significativas $(p>0,05)$ entre ellas.

Los oxalatos reducen la biodisponibilidad del calcio, y los complejos insolubles formados también pueden producir trastornos en el sistema de excreción (Dini y col., 2012; Hang y col., 2013; Sasaki y col., 2008).

Se encontró una correlación lineal $\left(R^{2}>0,75\right)$ entre el calcio y el contenido de oxalatos en las raíces ahipa.

En relación a la cuantificación de los compuestos fenólicos (Tabla 1.9), el contenido en la accesión IRNAS 11 fue significativamente menor $(p<0,05)$ respecto a las demás accesiones (IRNAS $4,5,9)$ y no hubo diferencia $(p>0,05)$ con respecto al registrado para la ahipa Local.

Los taninos representaron aproximadamente el $50 \%$ del total de los compuestos fenólicos en las accesiones de ahipa analizadas (Tabla 1.9).

Cabe destacar que las raíces de ahipa de las accesiones 11 y Local presentaron los contenidos más bajos de oxalatos, ácido fítico y taninos dentro de los rangos observados.

Por otra parte, la presencia de glicósidos cianogénicos fue cualitativamente investigada, no hallándose niveles detectables de los mismos en las raíces analizadas 
(Figura 1.18). A diferencia de la ahipa, la mandioca produce dos glicósidos cianogénicos, linamarina y una pequeña cantidad de lotaustralina (metil linamarina), además de la enzima linamarasa que cataliza la formación de glucosa y cianohidrinas. Las cianohidrinas se descomponen de forma espontánea por encima de $\mathrm{pH} 5$ produciendo cianuro de hidrógeno (Bradbury y Denton, 2010; Dini y col., 2012).

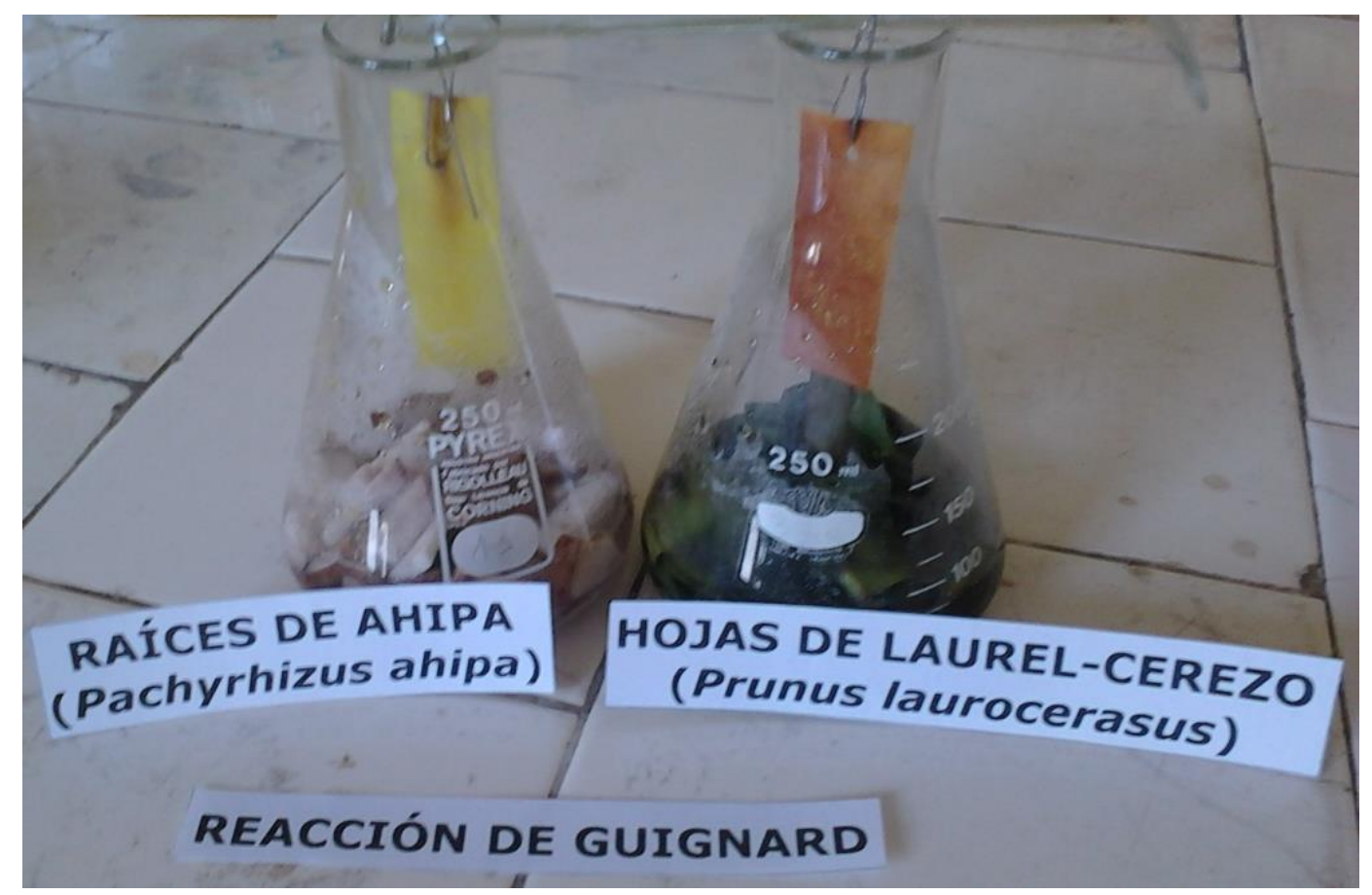

Figura 1.18. Ensayo cualitativo de glicósidos cianogénicos en raíces parcialmente deshidratadas de Pachyrhizus ahipa (ahipa).

Nota: Se observa a la derecha un testigo positivo (Prunus laurocerasus).

\section{Actividad secuestrante de radicales libres}

El análisis de antioxidantes fue realizado en las raíces con mayor contenido de almidón total: accesiones Local e IRNAS 11. La muestra de ahipa local mostró una actividad secuestrante de radicales libres (ASR) significativamente mayor $(42,5 \pm 0,7 \mathrm{mg}$ Trolox/100g) medido por el método de $\mathrm{ABTS}{ }^{+}$con respecto a la accesión IRNAS 11 $(28,6 \pm 0,9 \mathrm{mg}$ Trolox $/ 100 \mathrm{~g})$; estos valores fueron similares a los informados para batata $(25,03 \pm 4,07 \mathrm{mg}$ Trolox/100g) pero más bajos que los de mandioca $(51,07 \pm 7,10$ mg Trolox/100g) o el ñame ordinario (Typhonium trilobatum) $(74,05 \pm 10,20 \mathrm{mg}$ Trolox/100g) (Sreeramulu y Raghunath, 2010). 
En los ensayos de DPPH•, la reacción de inactivación requirió 6 horas para alcanzar el estado estacionario, de modo que los antioxidantes de la raíz de ahipa podrían ser incluidos en el grupo con cinética de reacción lenta (Brand-Williams y col., 1995). Esto indicaría una relativamente baja cantidad de ácido ascórbico, así como una contribución importante de compuestos fenólicos al poder antioxidante.

La ASR exhibida por las raíces de ahipa contra DPPH• fue $2,7 \pm 0,4 \mathrm{~g}^{-1}\left(E_{50^{-1}}\right)$ para IRNAS 11 y $2,5 \pm 0,4 \mathrm{~g}^{-1}$ para la accesión Local. Estos niveles de antioxidantes de las raíces de ahipa no difieren de los referidos para otras R\&T, por lo que la incorporación de esta raíz tuberosa en la dieta puede no representar una incorporación de antioxidante significativa, ya que otras hortalizas tales como pimientos rojos pueden proporcionar hasta 100 veces más antioxidantes que las raíces de ahipa.

\section{Capacidad de retención de solventes}

La Figura 1.19 muestra la capacidad de retención de solventes (CRS) de las raíces parcialmente deshidratadas de diferentes accesiones de ahipa. En general, la accesión IRNAS 4 exhibió la más alta capacidad de retención de los solventes ensayados, mientras que la accesión IRNAS 11 presentó los valores más bajos.

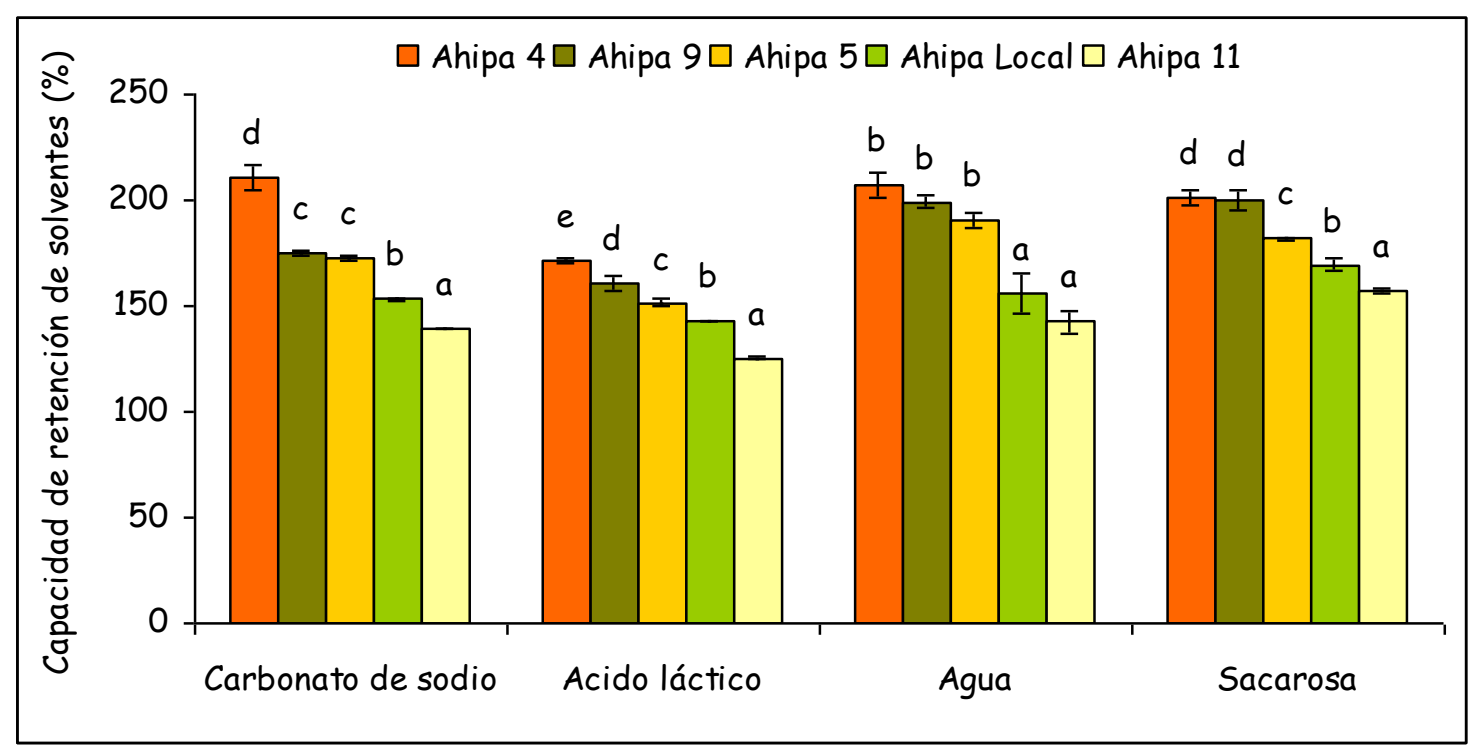

Figura 1.19. Capacidad de retención de solventes de raíces parcialmente deshidratadas de Pachyrhizus ahipa (ahipa). 
Se considera que la capacidad de retención del carbonato de sodio (CRCS) está relacionada con el contenido de almidón dañado, ya que una solución de carbonato de sodio al $5 \%(\mathrm{p} / \mathrm{p})$ eleva el pH por encima de 11, donde los grupos hidroxilo del almidón comienzan a ionizarse y por lo tanto el mismo se carga negativamente (Gaines, 2000; Duyvejonck y col., 2011; Dini y col., 2013). Las accesiones de raíces de ahipa IRNAS 9 y

5 podrían tener un contenido similar de almidón dañado, ya que su CRCS no fue significativamente diferente $(p>0,05)$ (Figura 1.19).

En general, la capacidad de retención del ácido láctico (CRAL) se asocia con la formación de la red de glutenina y la fuerza del gluten de una harina, debido a que un $\mathrm{pH}$ inferior a 7 favorece el entramado de la red por los polímeros de gluten relativos a los polisacáridos (Duyvejonck y col., 2011; Dini y col., 2013). Dado que la ahipa es un producto libre de gluten, la CRAL podría estar asociada a la capacidad de la proteína para desarrollar una red tridimensional. Por lo tanto, aunque las accesiones IRNAS 11 y Local exhibieron mayor contenido de proteína cuantificado por el método de Kjeldahl (Tabla 1.6), las proteínas presentes no mostrarían la capacidad de formación de una red.

Se observó una fuerte correlación lineal $\left(R^{2}>0,84\right)$ entre el contenido de fibra dietaria total (Tabla 1.6) y la capacidad de retención de agua (CRA). Una tendencia similar se informó para la harina de trigo (Colombo y col., 2008; Duyvejonck y col., 2012; Duyvejonck y col., 2011).

Las raíces parcialmente deshidratadas de las accesiones IRNAS 11 y Local mostraron la menor capacidad de retención de sacarosa (CRSA), asociada al contenido de pentosanos soluble en agua, que se cuantifica como fibra soluble. Estos hallazgos sugieren que estas muestras de ahipa contendrían una mayor proporción de fibra insoluble con los beneficios para la salud que esto conlleva. Además, la CRSA también se correlacionó con el contenido de FDT $\left(R^{2}>0,77\right)$.

\section{Propiedades térmicas}

En la Figura 1.20 se muestra el termograma de la raíz fresca de ahipa proveniente de la accesión Local. La temperatura de inicio registrada para la raíz fresca de ahipa fue de $62,2 \pm 0,3^{\circ} \mathrm{C}$ y la de gelatinización o pico endotérmico $66,6 \pm 0,6^{\circ} \mathrm{C}$. El proceso mostró una entalpía de 9,0 $\pm 0,8 \mathrm{~J} / \mathrm{g}$ en base seca. 


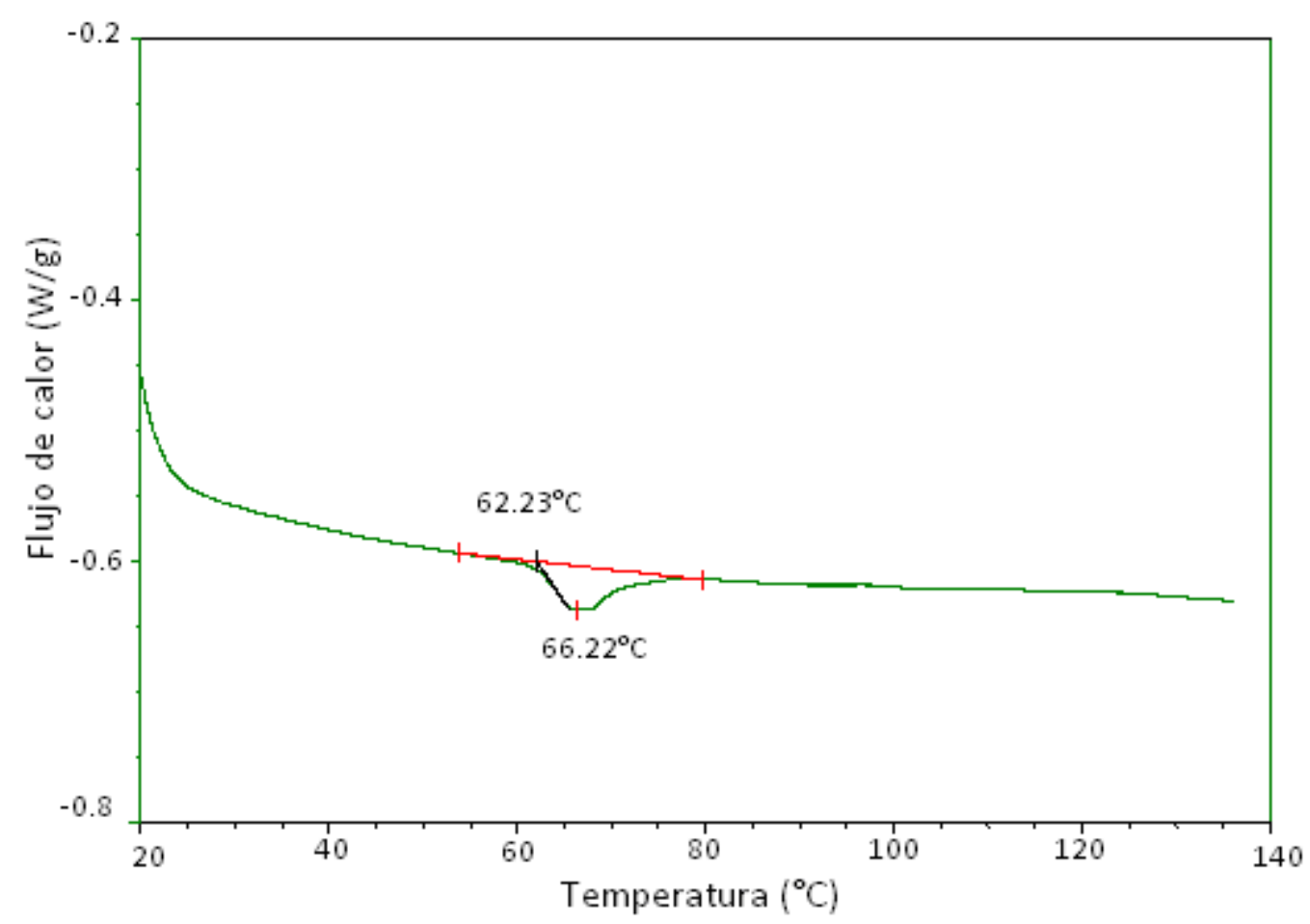

Figura 1.20. Termograma de la raíz fresca de Pachyrhizus ahipa (ahipa) accesión Local.

En la Figura 1.21 se muestran los termogramas correspondientes a raíces parcialmente deshidratadas provenientes de las cinco accesiones de ahipa estudiadas. En general, las suspensiones acuosas de muestras de raíces parcialmente deshidratadas de ahipa exhibieron una amplia transición térmica asociada principalmente a la gelatinización del almidón y a la desnaturalización de proteínas, siendo ambos procesos cooperativos (Figura 1.21). 


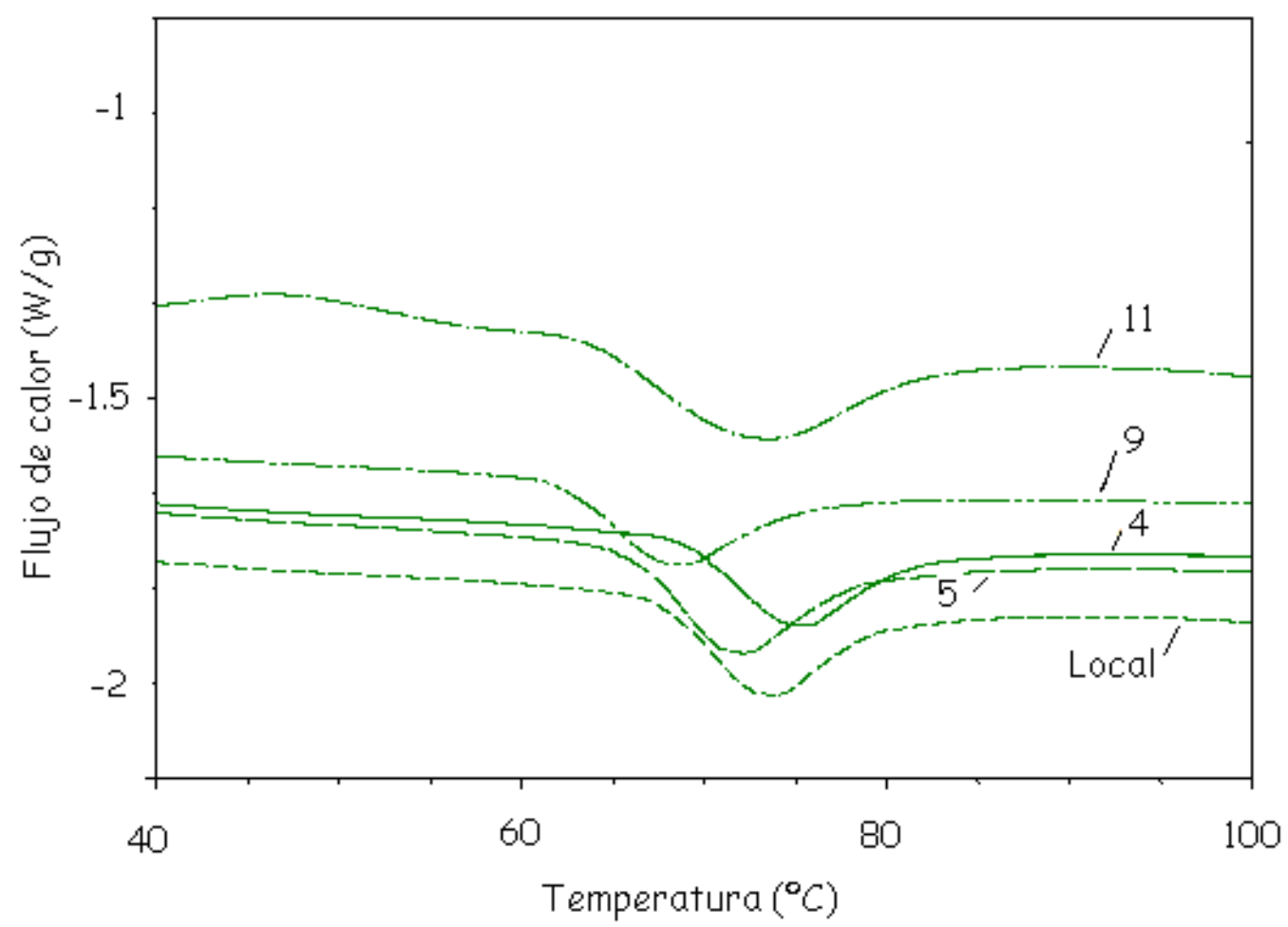

Figura 1.21. Termogramas (Flujo de calor en función de la temperatura) de las raíces parcialmente deshidratadas de diferentes accesiones de Pachyrhizus ahipa (ahipa).

La Tabla 1.10 resume los parámetros obtenidos a partir de los termogramas. Se observa que los mismos variaron dependiendo de la accesión analizada. Las raíces parcialmente deshidratadas de las accesiones IRNAS 11 y Local no difirieron estadísticamente $(p>0,05)$. Las accesiones 4 y 5 presentaron los mayores valores de temperatura de inicio y de pico mientras que para la accesión 11 se obtuvieron los valores más bajos, siendo en todos los casos las diferencias significativas $(p<0,05)$. 
Tabla 1.10. Parámetros térmicos de las raíces parcialmente deshidratadas de Pachyrhizus ahipa (ahipa) de diferentes accesiones.

\begin{tabular}{c|c|c|c|}
\hline Accesión & Temperatura de inicio $\left({ }^{\circ} \mathrm{C}\right)$ & Temperatura de pico $\left({ }^{\circ} \mathrm{C}\right)$ & Entalpía $(\mathrm{J} / \mathrm{g})$ \\
\hline Local & $66,1 \pm 0,1^{\mathrm{b}}$ & $71,3 \pm 0,4^{\mathrm{b}}$ & $25 \pm 3^{\mathrm{c}}$ \\
\hline IRNAS 4 & $69,7 \pm 0,7^{\mathrm{d}}$ & $75,3 \pm 0,5^{\mathrm{d}}$ & $17,5 \pm 0,5^{\mathrm{a}}$ \\
\hline IRNAS 5 & $68,0 \pm 0,4^{\mathrm{c}}$ & $73,5 \pm 0,2^{\mathrm{c}}$ & $23 \pm 3^{\mathrm{b}}$ \\
\hline IRNAS 9 & $62,2 \pm 0,4^{\mathrm{a}}$ & $68,2 \pm 0,2^{\mathrm{a}}$ & $20,6 \pm 0,4^{\mathrm{b}}$ \\
\hline IRNAS 11 & $66,1 \pm 0,4^{\mathrm{b}}$ & $71,9 \pm 0,5^{\mathrm{b}}$ & $25,4 \pm 0,9^{\mathrm{c}}$ \\
\hline
\end{tabular}

Nota: Los valores informados corresponden a las medias \pm las desviaciones estándar. Letras diferentes en cada columna indican diferencias significativas $(p<0,05)$. La entalpía se encuentra expresada en base seca.

Las diferencias observadas se correlacionan con la distinta composición de las raíces previamente descripta (Tabla 1.6). Como era de esperar, las muestras de ahipa Local e IRNAS 11, con alto contenido de almidón y proteínas (Tabla 1.6), presentaron los valores más altos de entalpía. Del mismo modo, la accesión IRNAS 4, con el más alto contenido de sacarosa (Tabla 1.8), presentó la temperatura más alta de pico, ya que es sabido que los azúcares desplazan el pico de temperatura de gelatinización del almidón y también afectan el proceso de desnaturalización de la proteína debido a la reducción de la disponibilidad de agua. Se observó una tendencia similar en otros trabajos realizados en mandiocas y ahipa (Aboubakar y col., 2008; Doporto y col., 2011, 2012; López y col., 2010; Dini y col., 2013). 


\section{CONCLUSIONES}

En comparación con otras R\&T tropicales y subtropicales, las raíces de ahipa mostraron una composición química más equilibrada desde el punto de vista nutricional, realizando un aporte significativo de proteínas, fibra y minerales tales como potasio, calcio, hierro, junto con el componente mayoritario (almidón).

Respecto de la poscosecha de las raíces, el daño por frío observado a 4 y $10^{\circ} \mathrm{C}$ no permitió prolongar el almacenamiento de las raíces de ahipa a estas temperaturas por más de un mes, en tanto que a $25^{\circ} \mathrm{C}$ la conservación se realizó durante cuatro meses. Las muestras conservadas a $25^{\circ} \mathrm{C}$ no evidenciaron cambios notorios en los atributos de color y textura. La aplicación de almacenamiento refrigerado para raíces de ahipa fue limitada por el desarrollo de daño por frío. Este trastorno fisiológico fue acompañado por ataque de hongos. Las tecnologías limpias poscosecha ensayadas (tratamiento térmico y tratamiento UV-C) podrían considerarse como instrumentos viables para extender la vida de almacenamiento de raíces de ahipa, dependiendo si los beneficios obtenidos justifican los costos derivados de su implementación.

Por otra parte, la composición química de las raíces ahipa varió con la accesión de origen. Aunque el contenido de agua de la ahipa es relativamente alto, las raíces se pueden considerar una buena fuente de hidratos de carbono (principalmente sacarosa y almidón) y fibra dietaria total. También pueden proporcionar una adecuada cantidad de minerales, en especial hierro y magnesio. Los niveles de proteína son considerablemente más altos que los señalados para otros cultivos de R\&T.

La ahipa Local e IRNAS 11 se destacaron por su alto contenido de almidón, y porque presentaron un nivel de proteína intermedio. El contenido de fibra dietaria total y de sodio de estas dos accesiones de ahipa fueron los más bajos. Del mismo modo, las accesiones Local e IRNAS 11 mostraron los niveles más reducidos de oxalatos, ácido fítico y taninos, lo que representa una ventaja desde el punto de vista nutricional.

La accesión IRNAS 11 tuvo los valores más bajos de CRS y en particular los valores de CRAL, indicando que las proteínas presentes en estos materiales no serían adecuadas para la formación de una red proteica. Al analizar las propiedades térmicas, las accesiones Local e IRNAS 11 mostraron los valores más altos de entalpía.

Por lo expuesto anteriormente, estas dos accesiones presentaron propiedades interesantes a tener en cuenta en un programa de mejoramiento genético. 


\section{REFERENCIAS BIBLIOGRÁFICAS}

Aboubakar, Njintang, Y. N., Scher, J., Mbofung, C. M. F. (2008). Physicochemical, thermal properties and microstructure of six varieties of taro (Colocasia esculenta $L$. Schott) flours and starches. Journal of Food Engineering, 86 (2), 294-305.

Afoakwa, E. O., Sefa-Dedeh, S. (2001). Chemical composition and quality changes occurring in Dioscorea dumetorum pax tubers after harvest. Food Chemistry, 75 (1), 85-91.

Agbor-Egbe, T.; Treche, S. (1995). Evaluation of the chemical composition of Cameroonian yam germplasm. J. Food Comp. Anal. 8, 274-283.

Ahmed, M., Sorifa, A. M., Eun, J. B. (2010). Effect of pretreatments and drying temperatures on sweet potato flour. International Journal of Food Science \& Technology, 45 (4), 726-732.

Allende, A., Artés, F. (2003). Combined ultraviolet-C and modified atmosphere packaging treatments for reducing microbial growth of fresh processed lettuce. Lebensm. Wiss. u.-Technol. 36: 779-786.

Andrés S. C., García, M. E., Zaritzky, N. E., Califano, A. N. 2006. Storage stability of lowfat chicken sausages. Journal of Food Engineering, 72, 311-319.

Ascherio, A., Rimm, E. B., Hernán, M. A., Giovannucci, E. L., Kawachi, I., Stampfer, M. J., \& Willett, W. C. (1998). Intake of potassium, magnesium, calcium, and fiber and risk of stroke among US men. Circulation, 98, 1198-1204.

AOAC. (1990). Official methods of analysis of the Association of Official Analytical Chemists (15th ed. / edited by Kenneth Helrich. ed.). Arlington, Va.: Association of Official Analytical Chemists. 
Bandyopadhyay, R., Mwangi, M., Aigbe, S. O., Leslie, J. F. (2006). Fusarium species from the cassava root rot complex in West Africa. Phytopathology, 96, 673-676.

Barnett, H. L., Hunter, B. B. (1998). Illustrated Genera of Imperfect Fungi. Fourth Edition. Pp 218. St. Paul, Minnesota, USA: The American Phytopathologycal Society.

Bongiovanni, R., Giletta, M. (2012). Calidad y competitividad de los cultivos industriales: algodón, caña de azúcar, mandioca, maní, tabaco, té y yerba mate. Competitividad y calidad de los cultivos industriales: caña de azúcar, mandioca, maní, tabaco, té y yerba mate. Bongiovanni, R., Morandi, J., Troilo, L. (Editores). Primera edición. Manfredi, Córdoba (AR): Ediciones INTA. Estación Experimental Agropecuaria Manfredi. 1-10.

Booth, C. (1971). The Genus Fusarium. Pp 237. Kew, Surrey, England: Commonwealth Mycological Institute.

Bradbury, J. H., Denton, I. C. (2010). Food Chem., 123, 840-845.

Brand-Williams, W., Cuvelier, M. E., Berset, C. (1995). Use of a free radical method to evaluate antioxidant activity. LWT - Food Science and Technology, 28 (1), 25-30.

Brandolini, A., Hidalgo, A., Plizzari, L. (2010). Storage-induced changes in einkorn (Triticum monococcum L.) and breadwheat (Triticum aestivum L. ssp. aestivum) flours. Journal of Cereal Science 51, 205-212.

Bridge, M. A., Klarman, W. L. (1973). Soybean phytoalexin, hydroxi-phaseolin, induced by ultraviolet irradiation. Phytopathology 63: 606-609. Citado en: Maharaj, R., Arul, J., Nadeau, P. 1999. Effect of photochemical treatment in the preservation of fresh tomato (Lycopersicon esculentum cv. Capello) by delaying senescence. Postharv. Biol. Technol. 15: 13-23. 
Calabrese, E. J., McCarthy, M. E., Kenyon, E. (1987). The ocurrence of chemically induced hormesis. Health Phys. 52: 531-541. Citado en: Maharaj, R., Arul, J., Nadeau, P. 1999. Effect of photochemical treatment in the preservation of fresh tomato (Lycopersicon esculentum cv. Capello) by delaying senescence. Postharv. Biol. Technol. 15: $13-23$.

Cammack, R. P. D. (2006). Oxford dictionary of biochemistry and molecular biology, Oxford University Press, Oxford.

Cantwell, M. (2000). Jicama: Recommendations for Maintaining Postharvest Quality. Perishables Handling, 103. Accedido el 25 de junio de 2012. Disponible en: http://postharvest.ucdavis.edu/pfvegetable/Jicama/.

Cantwell, M. I., Kasmire, R. F. (2002). Postharvest handling systems: underground vegetables (roots, tubers, and bulbs). En: Postharvest technology of horticultural crops. Third edition. Adel A. Kader (Technical Editor). University of California. Agricultural and Natural Resources Publication 3311. USA.

Castro, A., Céspedes, G., Carballo, S., Bergenståhl, B., Tornberg, E. (2013). Dietary fiber, fructooligosaccharides, and physicochemical properties of homogenized aqueous suspensions of yacon (Smallanthus sonchifolius). Food Research International, 50 (1), 392-400.

Colombo, A., Pérez, G. T., Ribotta, P. D., León, A. E. (2008). A comparative study of physicochemical tests for quality prediction of Argentine wheat flours used as corrector flours and for cookie production. Journal of Cereal Science, 48 (3), 775-780.

Charles, A. L., Sriroth, K., Huang, T.C. (2005). Proximate composition, mineral contents, hydrogen cyanide and phytic acid of 5 cassava genotypes. Food Chemistry, 92 (4), 615620. 
Choque Delgado, G., da Silva Cunha Tamashiro, W., Maróstica Junior, M., Pastore, G. (2013). Yacon (Smallanthus sonchifolius): A Functional Food. Plant Foods for Human Nutrition, 1-7.

Coursey, D. G., Rusell, J. D. (1969). A note on endogenous and bio-deteriorative factors in the respiration of dormant yam tubers. International Biodeterioration Bulletin, 5, 27.

Dell'Agli, M., Busciala, A., Bosisio, E. (2004). Vascular effects of wine polyphenols. Cardiovasc Res, 63 (4), 593-602.

Dini, C., Garcia, M. A., Viña, S. Z. (2012). Non-traditional flours: frontiers between ancestral heritage and innovation. Food \& Function, 3 (6), 606-620.

Dini, C., Doporto, M.C., García, M.A., Viña, S.Z. (2013). Nutritional profile and antinutrient analyses of Pachyrhizus ahipa roots from different accessions. Food Research International (54) 255-261.

Doporto, M. C., Mugridge, A., García, M. A., Viña, S. Z. (2011). Pachyrhizus ahipa (Wedd.) Parodi roots and flour: Biochemical and functional characteristics. Food Chemistry, 126 (4), 1670-1678.

Doporto, M. C., Dini, C., Mugridge, A., Viña, S. Z., García, M. A. (2012). Physicochemical, thermal and sorption properties of nutritionally differentiated flours and starches. Journal of Food Engineering (113) 569-576.

Dragsted, L. O., Strube, M., Larsen, J. C. (1993). Cancer-protective factors in fruits and vegetables: biochemical and biological background. Pharmacol Toxicol, 72 Suppl 1, 116-135.

Dreher, M. L. (2001). Chapter 1 Dietary Fiber Overview. In S. Sungsoo Cho, M. L. Dreher (Eds.), Handbook of Dietary Fiber. New York: Marcel Dekker, Inc. 
Dure, L.S. (1960). Site of origin and extent of activity of amylases in maize germination. Plant Physiol. 35:925-934.

Duyvejonck, A. E., Lagrain, B., Pareyt, B., Courtin, C. M., Delcour, J. A. (2011). Relative contribution of wheat flour constituents to Solvent Retention Capacity profiles of European wheats. Journal of Cereal Science, 53 (3), 312-318.

Duyvejonck, A. E., Lagrain, B., Dornez, E., Delcour, J. A., Courtin, C. M. (2012). Suitability of solvent retention capacity tests to assess the cookie and bread making quality of European wheat flours. LWT - Food Science and Technology, 47 (1), 56-63.

Ellis, M. B. (1971). Dematiaceous Hyphomycetes. Pp 608. Kew, Surrey, England: Commonwealth Mycological Institute.

Ellis, M. B. (1976). More Dematiaceous Hyphomycetes. Pp 507. Kew, Surrey, England: Commonwealth Mycological Institute.

Eluagu, E. N., Onimawo, I. A. (2010). Effect of processing on the mineral composition and Antinutritional factors of orange fleshed sweet Potato (ipomoea batatas I. Lam) flours. Electronic Journal of Environmental, Agricultural and Food Chemistry, 9 (6), 1000-1005.

FAOSTAT. (2013). FAO Statistics Division 2011.

Forsyth, J.L., Shewry, P.R. (2002). Characterization of the Major Proteins of Tubers of Yam Bean (Pachyrhizus ahipa). Journal of Agricultural and Food Chemistry, 50,19391944.

Gaines, C. S. (2000). Report of the AACC committee on soft wheat flour. Method 56-11, Solvent Retention Capacity Profile. Cereal Foods World, 45, 303-306. 
García-Estepa, R. M., Guerra-Hernández, E., García-Villanova, B. (1999). Phytic acid content in milled cereal products and breads. Food Research International, 32 (3), 217221.

Gnonlonfin, G. J .B., Hell, K., Fandohan, P., Siame, A. B. (2008). Mycoflora and natural occurrence of aflatoxins and fumonisin B1 in cassava and yam chips from Benin, West Africa. International Journal of Food Microbiology, 122, 140-147.

Gresele, P., Cerletti, C., Guglielmini, G., Pignatelli, P., de Gaetano, G., Violi, F. (2011). Effects of resveratrol and other wine polyphenols on vascular function: an update. J Nutr Biochem, 22 (3), 201-211.

Gurzau, E. S., Neagu, C., Gurzau, A. E. (2003). Essential metals-case study on iron. Ecotoxicology and Environmental Safety, 56 (1), 190-200.

Guzmán-Maldonado, H., Castellanos, J., De Mejía, E. G. (1996). Relationship between theoretical and experimentally detected tannin content of common beans (Phaseolus vulgaris L.). Food Chemistry, 55 (4), 333-335.

Hagenimana, V., Simard, R. E., Vézina, L. P. (1994). Amylolytic activity in germinating sweetpotato (Ipomoea batatas L.) roots. J. Amer. Soc. Hort. Sci. 119(2):313-320.

Hang, D. T., Vanhanen, L., Savage, G. (2013). Effect of simple processing methods on oxalate content of taro petioles and leaves grown in central Viet Nam. LWT - Food Science and Technology, 50 (1), 259-263.

Harland, B. F., Morris, E. R. (1995). Phytate: A good or a bad food component? Nutrition Research, 15 (5), 733-754.

Havas, S., Roccella, E. J., Lenfant, C. (2004). Reducing the Public Health Burden From Elevated Blood Pressure Levels in the United States by Lowering Intake of Dietary Sodium. American Journal of Public Health, 94 (1), 19-22. 
Heldt, H. W., Piechulla, B. (2011). Plant biochemistry, Academic, London.

Hidvegi, M., Lasztity, R. (2002). Phytic acid content of cereals and legumes and interaction with proteins. Periodica Polytechnica Series in Chemical Engineering, 46, $59-64$.

Hollósy, F. (2002). Effects of ultraviolet radiation on plant cells. Micron 33: 179-197.

Hoover, D. G. (1997). Minimally processed fruits and vegetables: reducing microbial load by nonthermal physical treatments. Food Technol. 51 (6): 66-71.

Huang, C. C., Chen, W. C., Wang, C. C. R. (2007). Comparison of Taiwan paddy-and upland-cultivated taro (Colocasia esculenta L.) cultivars for nutritive values. Food Chemistry, 102 (1), 250-256.

Ikediugwu, F. E. O., Ejale, A. U. (1980). Root-surface mycoflora of cassava (Manihot esculenta) and post harvest rot of the tubers. Mycopathologia, 71, 67-71.

Janssen, M. M. T. (1997). Food Safety and Toxicity, ed. J. D. Vries, CRC Press, Boca Raton; London, 2nd edn, ch. 3, p. 349.

Kakade, M. L., Simons, N., Liener, I. E. (1969). An evaluation of natural vs synthetic substrates for measuring the antitryptic activity of soybean samples. Cereal Chemistry, $46,518-526$.

Kikunaga, S., Takahashi, M., Huzisige, H. (1985). Accurate and Simple Measurement of Phytic Acid Contents in Cereal Grains. Plant and Cell Physiology, 26 (7), 1323-1330.

Langcake, P., Pryce, P. (1977). The production of resveratrol and viniferins by grapevines in response to ultraviolet irradiation. Phytochemistry 16: 1193-1196. Citado en: Maharaj, R., Arul, J., Nadeau, P. 1999. Effect of photochemical treatment in the 
preservation of fresh tomato (Lycopersicon esculentum cV. Capello) by delaying senescence. Postharv. Biol. Technol. 15: 13-23.

Lanza, G. (1997). Control del "moho verde" (Penicillium digitatum) mediante curación ("curing") a alta temperatura. Últimos ensayos en Italia. Phytoma España 90: 95-99.

Leonel, M., Sarmento, S. B. S., Cereda, M. P., Cãmara, F. L. A. (2003). Extração e caracterização de amido de jacatupé (Pachyrhizus ahipa). Ciência e Tecnologia de Alimentos, 23, 362-365.

Leterme, P., Buldgen, A., Estrada, F., Londoño, A. M. (2006). Mineral content of tropical fruits and unconventional foods of the Andes and the rain forest of Colombia. Food Chemistry, 95 (4), 644-652.

Lewu, M. N., Adebola, P. O., Afolayan, A. J. (2010). Effect of cooking on the mineral contents and anti-nutritional factors in seven accessions of Colocasia esculenta (L.) Schott growing in South Africa. Journal of Food Composition and Analysis, 23 (5), 389393.

López, O. V., Viña, S. Z., Pachas, A. N. A., Sisterna, M. N., Rohatsch, P. H., Mugridge, A., Fassola, H. E., García, M. A. (2010). Composition and food properties of Pachyrhizus ahipa roots and starch. International Journal of Food Science \& Technology, 45 (2), 223-233.

López, O. V. (2011). Tesis Doctoral “Desarrollo, caracterización y aplicación de envases biodegradables a partir de almidón".

Lozano, J. C. (1992). Overview of integrated cassava diseases. Fitopatologia Brasileira, $17,18-22$.

Lurie, S. (1998). Postharvest heat treatments. Postharv. Biol.Technol. 14: 257-269. 
Maharaj, R., Arul, J., Nadeau, P. (1999). Effect of photochemical treatment in the preservation of fresh tomato (Lycopersicon esculentum cV. Capello) by delaying senescence. Postharv. Biol. Technol. 15: 13-23.

Makkar, H. P., Siddhuraju, P., Becker, K. (2007). Plant secondary metabolites. Methods Mol Biol, 393, 1-122.

Meier, G., Vallejos, E., Vázquez, D. Cocco, M. (2004a). Control de podredumbres en mandarinas, con tratamientos alternativos a los fungicidas tradicionales: sales de sodio y tratamiento térmico. Congreso Internacional de Ciencia y Tecnología de los Alimentos. 24 al 26 de noviembre de 2004. Córdoba, Argentina.

Meier, G. E., Ponte, M., Vázquez, D. E. (2004b). Contenido de acetaldehído y etanol en naranjas y mandarinas durante la postcosecha. Revista de Investigaciones Agropecuarias 33(1):135-150.

Menoli, A. V., Beleia, A. (2007). Starch and pectin solubilization and texture modification during pre-cooking and cooking of cassava root (Manihot esculenta Crantz). LWT - Food Science and Technology, 40, 744-747.

Morandi, J., Pirker, E. (2012). La cadena de mandioca para industria en Misiones. Competitividad y calidad de los cultivos industriales: caña de azúcar, mandioca, maní, tabaco, té y yerba mate. Bongiovanni, R., Morandi, J., Troilo, L. (Editores). Primera edición. Manfredi, Córdoba (AR): Ediciones INTA. Estación Experimental Agropecuaria Manfredi. 51-64.

Msikita, W., Yaninek, J. S., Ahounou, M., Baimey, H., Fagbemisi, R. (1997). First report of Nattrassia mangiferae root and stem rot of cassava in West Africa. Plant Disease, 81, 1332. 
Mugridge, A., Sisterna, M. N., García, M.A., Viña, S. Z. (2012). Conservación poscosecha de raíces de Pachyrhizus ahipa. Pachyrhizus ahipa: revalorización de un cultivo ancestral. Ed. López, O. V., García M. A., Viña, S. Z.

Nelson, P. E., Toussoun, T. A., Marasas, W. F. O. (1983). Fusarium species. An illustrated manual for identification. Pp 193. London, UK: The Pennsylvania State University Press.

Noman, A.S.M, Hoque, M.A., Haque, M.M., Pervin, F., Karim, M.R. (2007). Nutritional and anti-nutritional components in Pachyrhizus erosus L. tuber. Food Chemistry 102, 1112-1118.

Njie, D. N., Rumsey, T. R. (1998). Solar absorptivity of peeled cassava root, yam tuber and unripe plantain fruit. Journal of Food Processing and Preservation, 21, 317-326.

Oboh, G., Akindahunsi, A. A. (2003). Biochemical changes in cassava products (flour \& gari) subjected to Saccharomyces cerevisae solid media fermentation. Food Chemistry, $82(4), 599-602$.

Ogbuagu, M. N. (2008). Nutritive and anti-nutritive composition of the wild (inedible) species of Dioscorea bulbifera (Potato Yam) and Dioscorea dumentorum (Bitter Yam). The Pacific Journal of Science and Technology, 9(1), 203-207.

Okamoto, K., T. Akazawa. (1979). Enzymic mechanisms of starch breakdown in germinating rice seeds. VII. Amylase formation in epithelium. Plant Physiol. 63:336340.

Opara, L. (2003). Postharvest technology of root and tuber crops. In R. Dris, R. Niskanen, S. Mohan Jain (Eds.), Crop Management and Postharvest Handling of Horticultural Products (Vol. II, pp. 381-406). Enfield, NH, USA: Science Publishers Inc. 
Ørting, B., Grüneberg, W. J., Sørensen, M. (1996). Ahipa (Pachyrhizus ahipa (Wedd.) Parodi) in Bolivia. Genetic Resources and Crop Evolution, 43 (5), 435-446.

Padonou, W., Mestres, C., Coffi Nago, M. (2005). The quality of boiled cassava roots: instrumental characterization and relationship with physicochemical properties and sensorial properties. Food Chemistry 89, 261-270.

Passam, H. C. (1982). Storage of some local and introduced mango cultivars grown in Trinidad. Scientia Horticulturae, 16 (2), 171-177.

Picha, D.H. (1986). Weight loss in sweet potatoes packaging of fresh-cut sweet potatoes during curing and storage. Contribution of transpiration and respiration. Journal of the American Society of Horticultural Science, 111(6): 889-892.

Piyachomkwan, K., Chotineeranat, S., Kijkhunasatian, C. (2002). Edible canna (Canna edulis) as a complementary starch source to cassava for the starch industry. Industrial Crops and Products, 16, 11-21.

Phillippy, B. Q., Lin, M., Rasco, B. (2004). Analysis of phytate in raw and cooked potatoes. Journal of Food Composition and Analysis, 17 (2), 217-226.

Ravi, V., Aked, J. (1996). Review on tropical root and tuber crops. II. Physiological isorders in freshly stored roots and tubers. Critical Reviews in Food Science and Nutrition, 36(7), 711-731.

Re, R., Pellegrini, N., Proteggente, A., Pannala, A., Yang, M., Rice-Evans, C. (1999). Antioxidant activity applying an improved ABTS radical cation decolorization assay. Free Radic Biol Med, 26 (9-10), 1231-1237.

Robertson, J. B., Van Soest, P. J. (1981). The detergent system of analysis and its application to human foods. In W. P. T. James, O. Theander (Eds.). The analysis of dietary fiber in food (pp. 123-158). New York: Marcell Dekker. 
Rosell, C. M., Santos, E., Collar, C. (2009). Physico-chemical properties of commercial fibres from different sources: A comparative approach. Food Research International, $42(1), 176-184$.

Saris, N. E., Mervaala, E., Karppanen, H., Khawaja, J. A., Lewenstam, A. (2000). Magnesium. An update on physiological, clinical and analytical aspects. Clin Chim Acta, 294 (1-2), 1-26.

Sasaki, M., Murakami, M., Matsuo, K., Matsuo, Y., Tanaka, S., Ono, T., Mori, N. (2008). Oxalate nephropathy with a granulomatous lesion due to excessive intake of peanuts. Clin Exp Nephrol, 12 (4), 305-308.

Schelp, F. P., Pongpaew, P. (1988). Protection against Cancer through NutritionallyInduced Increase of Endogenous Proteinase Inhibitors-A Hypothesis. International Journal of Epidemiology, 17 (2), 287-292.

Schirra, M., D’hallewin, G., Ben-Yehoshua, S., Fallik, E. (2000). Host-pathogen interactions modulated by heat treatment. Postharv. Biol. Technol. 21: 71-85.

Sgroppo, S. C., Vergara, L. E., Tenev, M. D. (2010). Effects of sodium metabisulphite and citric acid on the shelf life of fresh cut sweet potatoes. Span J Agric Res 8(3), 686693.

Shewry, P. R. (2003). Tuber Storage Proteins. Annals of Botany, 91 (7), 755-769.

Sivanesan, A. (1987). Graminicolous species of Bipolaris, Curvularia, Drechslera, Exserohilnm and their teleomorphs. Mycological Papers, 158, 1-261.

Smilanick, J. L., Mansour, M. F., Sorenson, D. (2006). Pre-and postharvest treatments to control green mold of citrus fruit during ethylene degreening. Plant Disease 90:8996. 
Smith, C., Van Megen, W., Twaalfhoven, L., Hitchcock, C. (1980). The determination of trypsin inhibitor levels in foodstuffs. J Sci Food Agric, 31 (4), 341-350.

Sreeramulu, D., Raghunath, M. (2010). Antioxidant activity and phenolic content of roots, tubers and vegetables commonly consumed in India. Food Research International, 43 (4), 1017-1020.

Stange, R. R. Jr, Eckert, J. W. (1994). Influence of postharvest handling and surfactants on control of green mold of lemons by curing. Phytopathology 84:612-616.

Steinmetz, K. A., Potter, J. D. (1996). Vegetables, Fruit, and Cancer Prevention: A Review. Journal of the American Dietetic Association, 96 (10), 1027-1039.

Tay, D. (2013). Chapter 12. Tropical and Subtropical Root and Tuber Crops. En: Conservation of Tropical Plant Species, M.N. Normah et al. (eds.), DOI 10.1007/978-14614-3776-5_12, Springer Science+Business Media. New York. USA.

Torres, R., Plaza, P., Usall, J., Lamarca, N., Asensio A., Viñas I. (2002). Efecto del curado sobre el control de las principales podredumbres en postcosecha de cítricos. NutriFitos., 17-122.

Tupac Yupanqui, A. (2001). Poscosecha y comercialización de tubérculos andinos con énfasis en papas nativas y ulluco. En: Perspectivas tecnológicas en el uso del germoplasma de papas nativas. Ministerio de Agricultura, Instituto Nacional de Investigación Agraria, Centro Internacional de la Papa. Lima, Perú. pp 29-34.

Tuset, J., Hinarejos, C., Mira, J. L. (1997). Enfermedades fúngicas de la postrecolección de los agrios actualmente en progreso. Phytoma 90:69-70, 74-76.

Vaintraub, I. A., Lapteva, N. A. (1988). Colorimetric determination of phytate in unpurified extracts of seeds and the products of their processing. Analytical Biochemistry, 175 (1), 227-230. 
Watada, A. E., Ko, N. P., Minott, D. A. (1996). Factors affecting quality of fresh-cut horticultural products. Postharv. Biol. Technol. 9: 115-125.

Wu, P., Tian, J. C., Walker, C. E., Wang, F. C. (2009). Determination of phytic acid in cereals - a brief review. International Journal of Food Science \& Technology, 44 (9), 1671-1676.

Zanklan, A. S., Ahouangonou, S., Becker, H. C., Pawelzik, E., Grüneberg, W. (2007). Evaluation of the storage root-forming legume yam bean (Pachyrhizus spp.) under West African conditions. Crop Science, 47, 1-14. 


\section{CAPÍTULO 2.}

Características físico-químicas,

morfológicas y funcionales del almidón de

Pachyrhizus ahipa 


\section{INTRODUCCIÓN}

El almidón es un polisacárido ampliamente utilizado en la industria de alimentos, textil, agroquímica y farmacéutica, entre otras. El estudio y la evaluación de sus características y propiedades funcionales son necesarios para comprender su rol en la formulación de alimentos, analizar su transformación durante el procesamiento y sugerir posibles usos y aplicaciones industriales del mismo.

\section{El almidón}

Es un polisacárido de reserva de carbono y energía en los vegetales y se localiza principalmente en raíces, tubérculos, frutos y semillas. A nivel celular se presenta en entidades discretas, semicristalinas, las cuales reciben el nombre de gránulos. El tamaño, forma y estructura de los gránulos difieren substancialmente con la fuente botánica. Su morfología es variada: esféricos o con forma de discos para los de trigo, poliédricos en arroz y maíz, con forma de "ostras" irregulares en papa, filamentosos en almidón de maíz de alto contenido de amilosa, entre otros (Whistler, 1984; Eliasson, 2004).

El almidón está compuesto fundamentalmente por dos polímeros de glucosa: amilosa y amilopectina. Los gránulos también contienen trazas de otros constituyentes como lípidos polares, principalmente fosfolípidos, que contienen nitrógeno y fósforo y que, en muchas ocasiones, juegan un rol importante en las propiedades funcionales del almidón (Belitz, 1997). La relación amilosa/amilopectina y su organización física dentro de la estructura granular, le confieren a los almidones propiedades fisicoquímicas y funcionales características (Bello-Pérez, 1995; Eliasson, 2004).

La amilosa (Figura 2.1) se compone principalmente de cadenas de residuos de $\alpha$-Dglucopiranosilo unidas por enlaces $\alpha-(1 \rightarrow 4)$. Aunque se admite que se trata de un polímero lineal, existe una pequeña proporción de ramificaciones por enlaces $\alpha-(1 \rightarrow 6)$ (Thomas y Atwell, 1999). El tamaño molecular varía entre $1 \times 10^{5}$ y $1 \times 10^{6} \mathrm{Da}$, conteniendo entre 500 y 6.000 unidades de glucosa. La naturaleza lineal y de gran longitud le confieren a la amilosa algunas propiedades únicas, como por ejemplo su capacidad para formar complejos con $\mathrm{I}_{2}$ de color azul, alcoholes o ácidos orgánicos y su tendencia a asociarse consigo misma, precipitando de la solución. Cuando se enfrían, 
las soluciones de amilosa presentan una fuerte tendencia a la retrogradación, donde cristaliza formando geles de almidón, aumentando así la viscosidad de la solución.

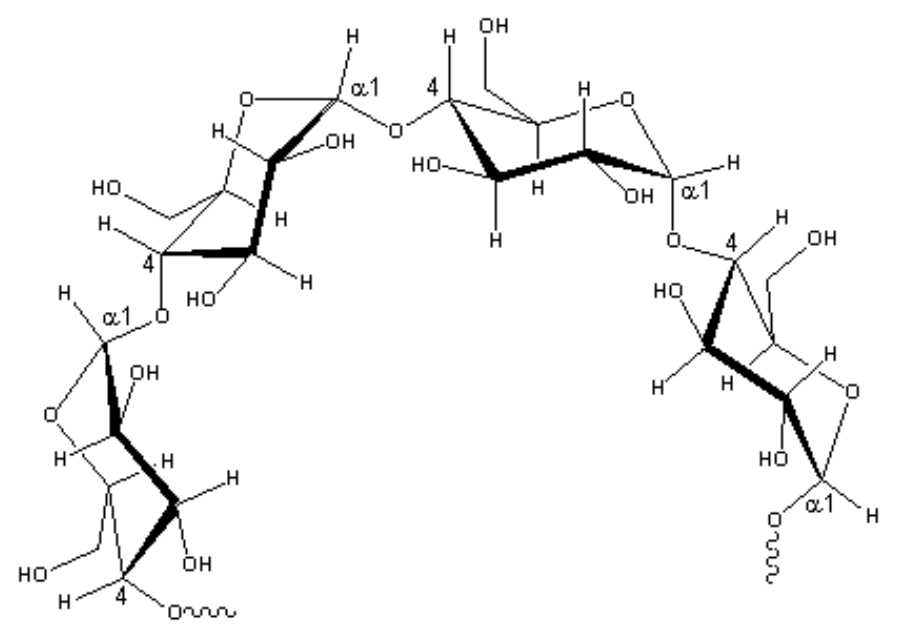

Figura 2.1. Estructura química de la amilosa.

La amilopectina (Figura 2.2) está formada por $\alpha$-D-glucosa, combinada principalmente por enlaces $\alpha-(1 \rightarrow 4)$. El grado de ramificación es mucho mayor que el de la amilosa, con un $4-5 \%$ de enlaces $\alpha-(1 \rightarrow 6)$. Representa entre un $70-80 \%$ y en ciertos casos alcanza niveles de hasta 98-99\%, dependiendo de la procedencia botánica del almidón (Zobel, 1988). Su estructura y proporción en el almidón contribuyen notablemente a las propiedades funcionales del mismo (Bello-Pérez y col., 2002). El peso molecular es del orden de $1 \times 10^{8} \mathrm{Da}$, con aproximadamente 600.000 residuos de glucosa y se encuentra ramificada al azar. En presencia de $I_{2}$ forma complejos de color púpura. Posee una alta viscosidad intrínseca debido a su estructura ramificada y su alto peso molecular. Por calentamiento en agua, proporciona soluciones claras y de alta viscosidad, que son además filamentosas y cohesivas. Sus soluciones no tienen casi tendencia a la retrogradación, tampoco presentan envejecimiento ni formación de gel, aunque la concentración de las mismas sea muy elevada. 


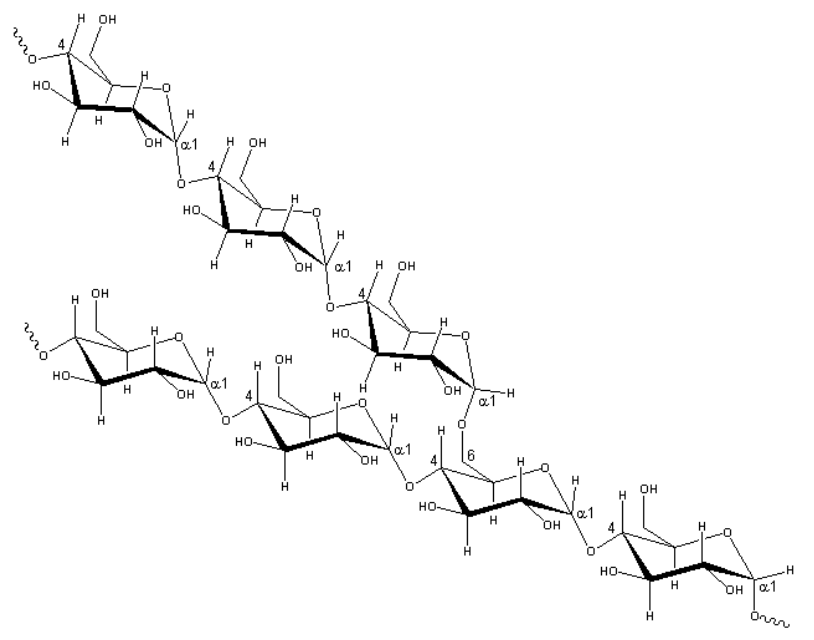

Figura 2.2. Estructura química de la amilopectina.

Los gránulos de almidón son anisotrópicos debido a la presencia de regiones cristalinas en una masa predominantemente amorfa, dando como resultado el fenómeno de doble refringencia o birrefringencia que se evidencia como una cruz de malta a la luz polarizada (Katz y col., 1993), (Figura 2.3).
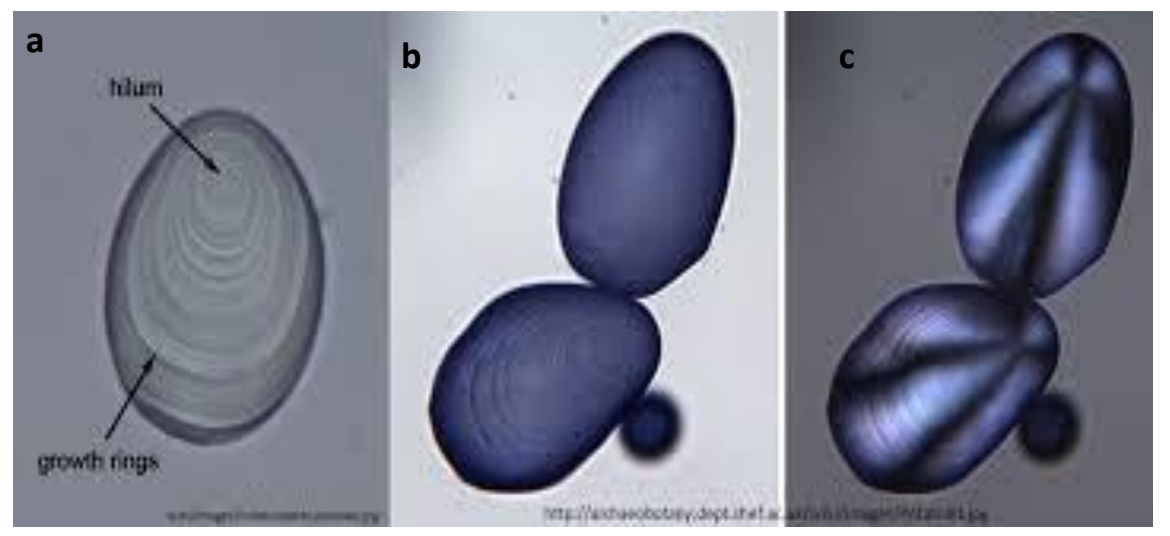

Figura 2.3. Gránulos de almidón de papa mostrando a) el hilium, los anillos de crecimiento, b) su tinción con $\mathrm{I}_{2}$ y c) las cruces de malta a la luz polarizada. Fuente: http://archaeobotany.dept.shef.ac.uk/wiki/index/Image

La región cristalina, que ha sido la más estudiada, está formada por cadenas de ramilletes o racimos de amilopectina mientras que la región amorfa por puntos ramificados de la amilopectina y por la amilosa (Zobel, 1988). Además, la estructura de los gránulos de almidón y el arreglo de sus componentes permiten explicar las 
propiedades fisicoquímicas y funcionales, como así también la digestibilidad de los diferentes almidones.

\subsection{Gelatinización}

Los gránulos de almidón son insolubles en agua fría, pero se hinchan cuando se calientan en un medio acuoso (Figura 2.4). Inicialmente el hinchamiento es reversible y los gránulos mantienen sus propiedades ópticas; sin embargo cuando se alcanza una cierta temperatura, el hinchamiento llega a ser irreversible afectando la estructura del gránulo. Este proceso es conocido como gelatinización y ocurre en un intervalo de temperatura, ya que los gránulos presentan diferente resistencia debido a su composición y grado de cristalinidad. La gelatinización es un proceso endotérmico que va acompañado de la lixiviación de la amilosa y pérdida de la birrefringencia del gránulo (Figura 2.4). Finalmente se genera una pasta en la que existen cadenas de amilosa de bajo peso molecular altamente hidratadas que rodean a los restos de los gránulos, también hidratados.

La temperatura de la gelatinización depende de la fuente botánica de la que proviene el almidón, del contenido de humedad de la muestra y de ciertas condiciones experimentales tales como pH, presencia de sólidos, etc. (Huang y Rooney, 2001).

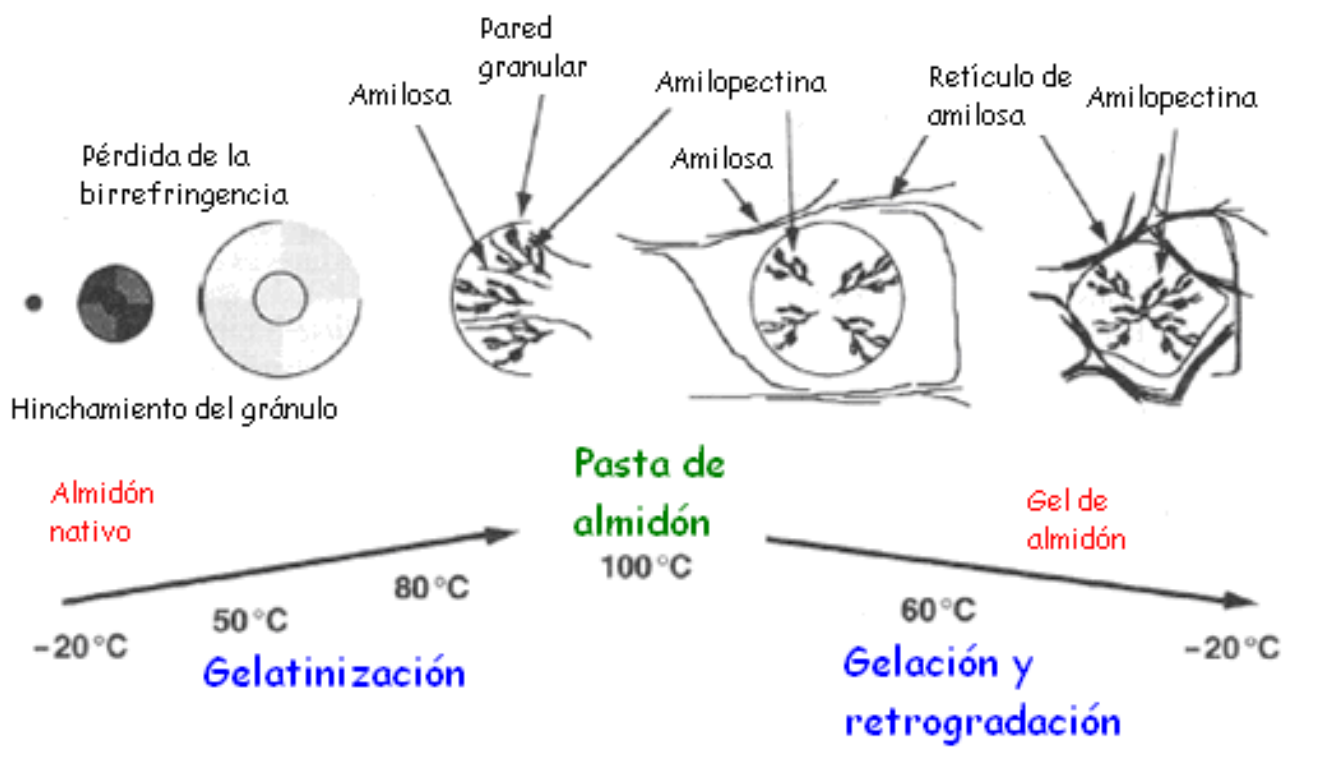

Figura 2.4. Efecto del procesamiento hidrotérmico sobre las características del almidón: hinchamiento, gelatinización, gelación y retrogradación. Adaptado de Eliasson (2004). 


\subsection{Retrogradación}

Varios autores consideran que los geles están compuestos por una matriz de amilosa que contiene gránulos gelatinizados compuestos mayoritariamente por amilopectina (Ring y col., 1987 y 1983; Miller y col., 1973; Ott y Hester, 1965). El desarrollo de la estructura y cristalinidad de los geles de almidón a corto tiempo está dominado por la gelación y cristalización de la amilosa (Figura 2.4). Los aumentos en el módulo de elasticidad de los geles durante el almacenamiento están ligados a la cristalización de la amilopectina, aumentando así la rigidez de los gránulos y reforzando la matriz de amilosa (Miles y col., 1985a). La formación de cristales va acompañada por un aumento gradual en la rigidez y la separación de las fases entre el polímero y el solvente (sinéresis). Estos procesos se agrupan bajo el término de retrogradación y afectan la textura, digestibilidad y aceptación por el consumidor de los productos a base de almidón. Dada su relevancia tecnológica estos fenómenos han sido ampliamente estudiados (Navarro y col., 1995; Ferrero y col., 1993; Biliaderis, 1992; Miles y col., 1985 a y b).

A nivel molecular se caracteriza por una asociación paralela mediante puentes de hidrógeno de las cadenas de amilosa lixiviadas, produciendo una red tridimensional donde quedan los gránulos hinchados, y dentro de éstos la amilopectina recristaliza, en un arreglo que dependerá del tipo de almidón y la temperatura a la que se almacenan los productos (Farhat y col., 2001). Finalmente se forman agregados cristalinos, acompañados por un incremento gradual en la rigidez, opacidad en la suspensión y sinéresis (Huang y Rooney, 2001; Biliaderis, 1992). Cada almidón tiene una tendencia diferente a la retrogradación que está relacionada principalmente con su contenido de amilosa, ya que la amilopectina está más limitada debido a que sus ramificaciones impiden la formación de puentes de hidrógeno entre cadenas adyacentes. Las fracciones de amilosa o las secciones lineales de amilopectina que retrogradan, forman zonas con una organización cristalina muy rígida, que requiere de una alta energía para fundir. 


\section{OBJETIVOS}

Los objetivos planteados para este capítulo son los siguientes:

1. Extraer almidón a partir de raíces tuberosas de ahipa (Pachyrhizus ahipa) y mandioca (Manihot esculenta) a escala de laboratorio, obteniendo muestras representativas.

2. Caracterizar fisicoquímica y microestructuralmente los almidones nativos extraídos analizando: contenido de amilosa y fósforo, morfología, distribución de tamaños de gránulos y estructura cristalina.

3. Estudiar las propiedades funcionales que determinan las aplicaciones tecnológicas de estos almidones, evaluando principalmente: la capacidad de hinchamiento de los gránulos y el proceso de gelatinización de las suspensiones de almidón.

4. Analizar las propiedades reológicas de las pastas de almidón y el proceso de retrogradación, evaluando el perfil de textura y el grado de sinéresis de las mismas. 


\section{MATERIALES Y MÉTODOS}

\section{Muestras}

Se utilizaron raíces tuberosas de ahipa (Pachyrhizus ahipa) pertenecientes a la denominada accesión Local, IRNAS 9 e IRNAS 11, cultivadas en la EEA Montecarlo como se describió en el Capítulo 1. Asimismo, las raíces de mandioca (Manihot esculenta) de diferentes cultivares fueron provistas por la misma Estación Experimental. En los ensayos donde se indique sólo "almidón de ahipa", los resultados obtenidos corresponden a la accesión Local y en el caso de "almidón de mandioca" al cultivar Pomberí. El material empleado en los presentes ensayos fue cosechado durante los años 2009-2012.

\section{Extracción del almidón de ahipa y mandioca}

El proceso de extracción de almidón de raíces y tubérculos es relativamente sencillo y consta de las siguientes etapas: lavado, pelado, rallado, filtración, decantación y secado. A continuación se describe el procedimiento propuesto por López y col., (2010) para la extracción de almidón a partir de raíces tuberosas de Pachyrhizus ahipa a escala de laboratorio (Figura 2.5), que fue el aplicado en el presente trabajo de Tesis. El proceso que a continuación se describe se adaptó tanto a la extracción de almidón de ahipa como de mandioca.

Se comenzó con la recepción de la materia prima y el lavado de las raíces para eliminar restos de tierra. Con el fin de reducir la carga microbiana de las raíces se incorporó una etapa de sanitización que consistió en la inmersión en solución de hipoclorito de sodio (250 ppm de $\mathrm{Cl}_{2}$ ) durante 10 minutos. Luego, las raíces se pelaron y se procesaron con un rallador de disco rotatorio especialmente adaptado para este fin. La pasta rallada se colocó en agua ( $2 \mathrm{~L} / \mathrm{kg}$ raíces), y se almacenó a $4^{\circ} \mathrm{C}$ durante 24 horas. Seguidamente, la mezcla se filtró a través de una tela muselina y se obtuvo el almidón en suspensión acuosa, denominada "lechada de almidón". El residuo retenido en la tela fue sometido a un nuevo proceso de extracción (Figura 2.5).

La suspensión se decantó a $4^{\circ} \mathrm{C}$ y se recuperó el material insoluble sedimentado constituido principalmente por almidón, que luego se secó a $40^{\circ} \mathrm{C}$. Finalmente, el material seco se sometió a molienda. Para el cálculo del rendimiento de la extracción 
se realizó el balance de masas del proceso, lo que permitió calcular la relación entre los pesos de las raíces y del almidón extraído.

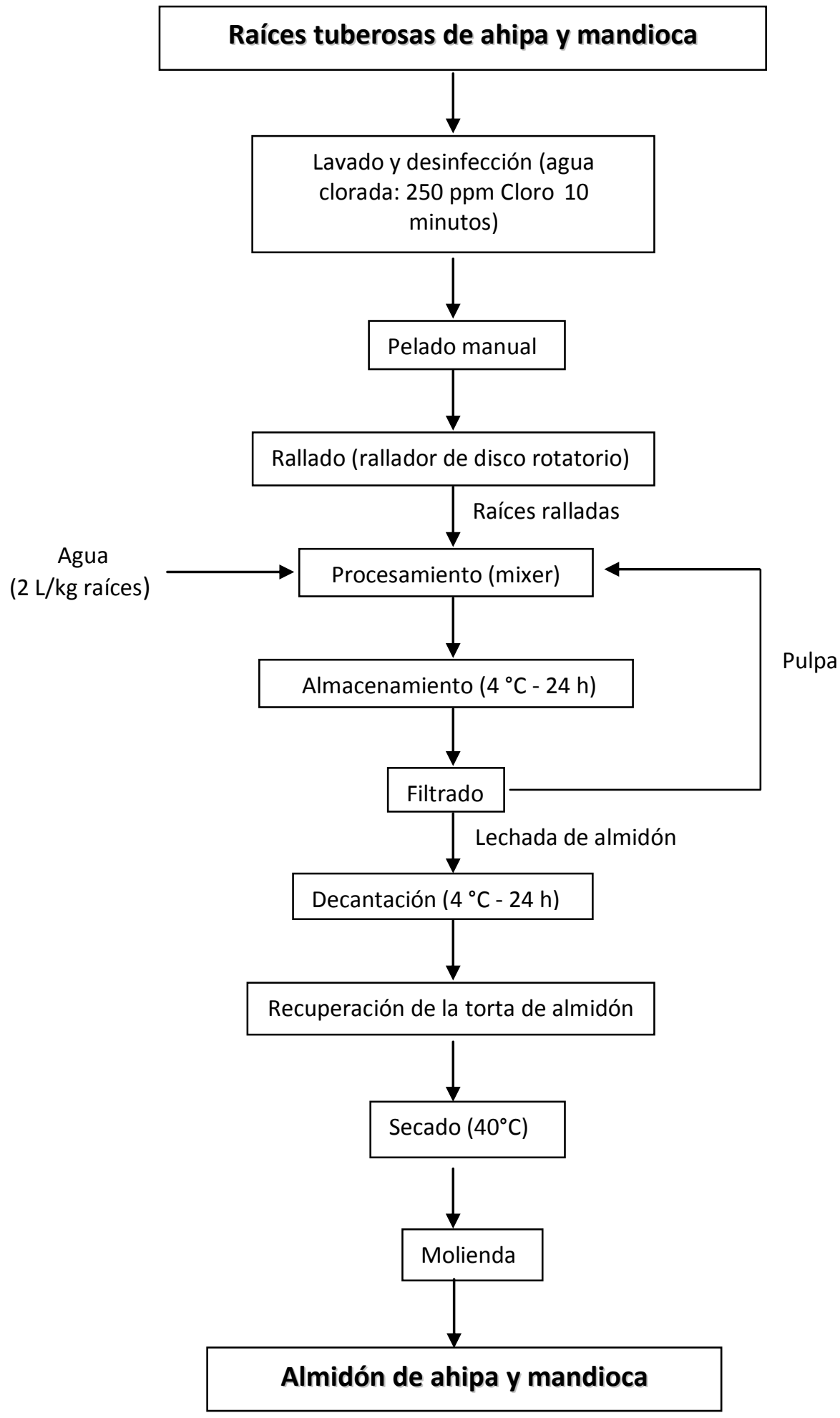

Figura 2.5. Diagrama de flujo del proceso de extracción de almidón de ahipa y mandioca. 


\section{Caracterización de los almidones extraídos}

El conocimiento de la composición química contribuye a una mejor utilización de estos almidones en programas de alimentación y nutrición. Las técnicas analíticas utilizadas para evaluar la composición química de los almidones de ahipa y mandioca se describen a continuación.

\subsection{Contenido de materia seca}

Se pesaron por duplicado las muestras de almidón y se secaron en una estufa (San Jor $\mathrm{H} 701 \mathrm{P}$, Argentina) a $105^{\circ} \mathrm{C}$ hasta peso constante. El procedimiento empleado se describió en el Capítulo 1. Los resultados se expresaron como porcentaje (\%) respecto al peso inicial.

\subsection{Determinación de cenizas totales}

Las muestras fueron colocadas en crisoles limpios, tratados con anterioridad a $900{ }^{\circ} \mathrm{C}$, con el fin de eliminar todo tipo de materia. Las muestras ( $2 \mathrm{~g})$ contenidas en los crisoles previamente tarados, fueron carbonizadas lentamente en la llama de un mechero Bunsen. Luego se realizó la determinación de cenizas según lo descripto en el Capítulo 1. Los crisoles conteniendo las cenizas se pesaron y con este valor se calculó el porcentaje (\%) de cenizas totales.

\subsection{Contenido de fósforo}

El contenido de fósforo se analizó por el método espectrofotométrico basado en la reacción con el complejo vanado-molibdato, según lo descripto en el Capítulo 1. Los resultados finales se expresaron como $\mathrm{mg} / 100 \mathrm{~g}$.

\subsection{Extracción y cuantificación de lípidos totales}

Para la determinación del contenido de lípidos, los almidones se pesaron por duplicado (12 g). Los mismos se dispusieron en un aparato Soxhlet durante 2 horas, tal como se describió en el Capítulo 1. El residuo sólido fue cuantificado gravimétricamente. Los resultados se expresaron como porcentaje (\%) sobre una base seca. 


\subsection{Determinación del contenido de nitrógeno total}

Se cuantificó el nitrógeno total de las muestras de almidón $(0,8 \mathrm{~g})$ mediante el método Kjeldahl. Se procedió tal como se describió en el Capítulo 1. Los resultados se expresaron como porcentaje (\%) sobre base seca.

\subsection{Actividad $\alpha$-amilasa}

Se midió empleando el kit enzimático Ceralpha (K-CERA 08/05 Megazyme@, Irlanda), empleando como sustrato el reactivo $p$-nitrofenil maltoheptaósido con su extremo no reductor bloqueado, en presencia de exceso de $\alpha$-glucosidasa termoestable que genera glucosa y $p$-nitrofenol. El procedimiento llevado a cabo fue descripto en el Capítulo 1. Los resultados se expresaron como Unidades Ceralpha $\mathrm{g}^{-1}$ de muestra seca.

\section{Caracterización fisicoquímica y microestructural de los almidones}

\subsection{Determinación de la concentración de amilosa en almidón de ahipa y mandioca}

El método seleccionado se basa en que la fracción de amilosa tiene afinidad para formar complejos con yodo, los que pueden ser cuantificados espectrofotométricamente (Morrison y Laignelet, 1983). Esta técnica incluye la remoción de los lípidos presentes en el almidón ya que éstos podrían interferir en la determinación (MacGregor y Fincher, 1993).

Se pesaron 70-80 mg de almidón en un tubo y se añadieron $10 \mathrm{~mL}$ de solución 1:9 de urea $6 \mathrm{M}$-dimetilsulfóxido (DMSO). El tubo se colocó en estufa a $100^{\circ} \mathrm{C}$ durante 1 hora, se retiró y se dejó enfriar. Se tomaron $0,5 \mathrm{~mL}$ de la solución, se transfirieron a un tubo de $10 \mathrm{~mL}$ y se pesaron; este paso se realizó por duplicado. Se adicionaron $5 \mathrm{~mL}$ de etanol 99,5\% v/v para remover los lípidos, se mezcló en un vórtex, se centrifugó 30 min a $5000 \times g$, descartándose el sobrenadante. Se adicionó $1 \mathrm{~mL}$ de la solución de urea-DMSO y se mezcló nuevamente en un vórtex, obteniéndose una solución clara. El contenido se transfirió a un matraz de $50 \mathrm{~mL}$ y se adicionaron aproximadamente $25 \mathrm{~mL}$ de agua destilada, $1 \mathrm{~mL}$ de solución de $\mathrm{I}_{2}\left(2 \mathrm{mg} \mathrm{I}_{2}\right.$ y $\left.20 \mathrm{mg} \mathrm{KI} / \mathrm{mL}\right)$, se llevó a volumen con agua destilada y se homogeneizó la solución. Se midió la absorbancia a $635 \mathrm{~nm}$ en un espectrofotómetro Beckman DU650 (Palo Alto, CA, Estados Unidos) y se calcularon el valor azul y el porcentaje de amilosa a partir de las siguientes ecuaciones: 
Valorazul $=\frac{\text { Absorbanci } \times 100}{2 \times \text { g soluciór } m \text { mgalmidó } r}$

Porcentajedeamilos $\approx 28,414 \times$ valorazul

La concentración de amilopectina se obtuvo por diferencia (100\% - porcentaje de amilosa). Los resultados informados corresponden al promedio de al menos cuatro determinaciones.

\subsection{Medidas de color superficial de los almidones}

Las medidas de color de los almidones de ahipa y mandioca se realizaron con un colorímetro CR-400 (Konica Minolta Sensing Inc., Japón). Los valores de la escala CIE empleada se expresan en términos de luminosidad $\left(L^{*}\right)$, coordenadas rojo-verde (parámetro de cromaticidad $\mathrm{a}^{*}$ ), y coordenadas azul-amarillo (parámetro de cromaticidad $b^{*}$ ). Asimismo, con estos parámetros fueron calculados el ángulo hue ( $h^{\circ}$ ) y la función Chroma $\left(C^{*}\right)$, como se describe en el Capítulo 1.

\subsection{Morfología y distribución de tamaño de los gránulos}

Una de las técnicas más empleadas para estudiar la morfología y distribución de tamaño de los gránulos es la microscopía electrónica de barrido o en inglés SEM (Scanning Electron Microscopy). A tal fin se utilizó un microscopio electrónico marca JEOL 35 CF (Japón) equipado con un detector secundario de electrones, con una resolución nominal de $60 \AA$, y se trabajó con un voltaje de aceleración de 15 kV. Las imágenes fueron obtenidas con el software IDX especialmente diseñado para adquirir imágenes digitales, con una resolución de 1024 x 800 píxeles. Para el procesamiento y el análisis de las imágenes se utilizó el software AnalySis Pro 3.0.

A partir de las imágenes SEM se pueden calcular diversos parámetros morfológicos, dentro de los cuales podemos citar los siguientes: diámetro medio, radio medio de Martins (se calcula teniendo en cuenta el centro de gravedad de la partícula), diámetro de círculo equivalente (DCE, diámetro correspondiente al círculo con igual área equivalente) y el factor de forma (relacionado con la forma del gránulo que varía entre 0 y 1 , correspondiendo este último a partículas esféricas). 


\subsection{Espectroscopía de difracción de rayos $\mathrm{X}$}

Un espectro de difracción de rayos $X$ de un material semicristalino, como el almidón, se caracteriza por la presencia de picos de absorción de la radiación y una zona de contribución amorfa. Cuanto mayor es esta zona, menor es el grado de cristalinidad de la muestra (Figura 2.6). Esta técnica permite obtener información sobre la estructura del material analizado ya que el diagrama de difracción es como una "huella dactilar" de las sustancias cristalinas.

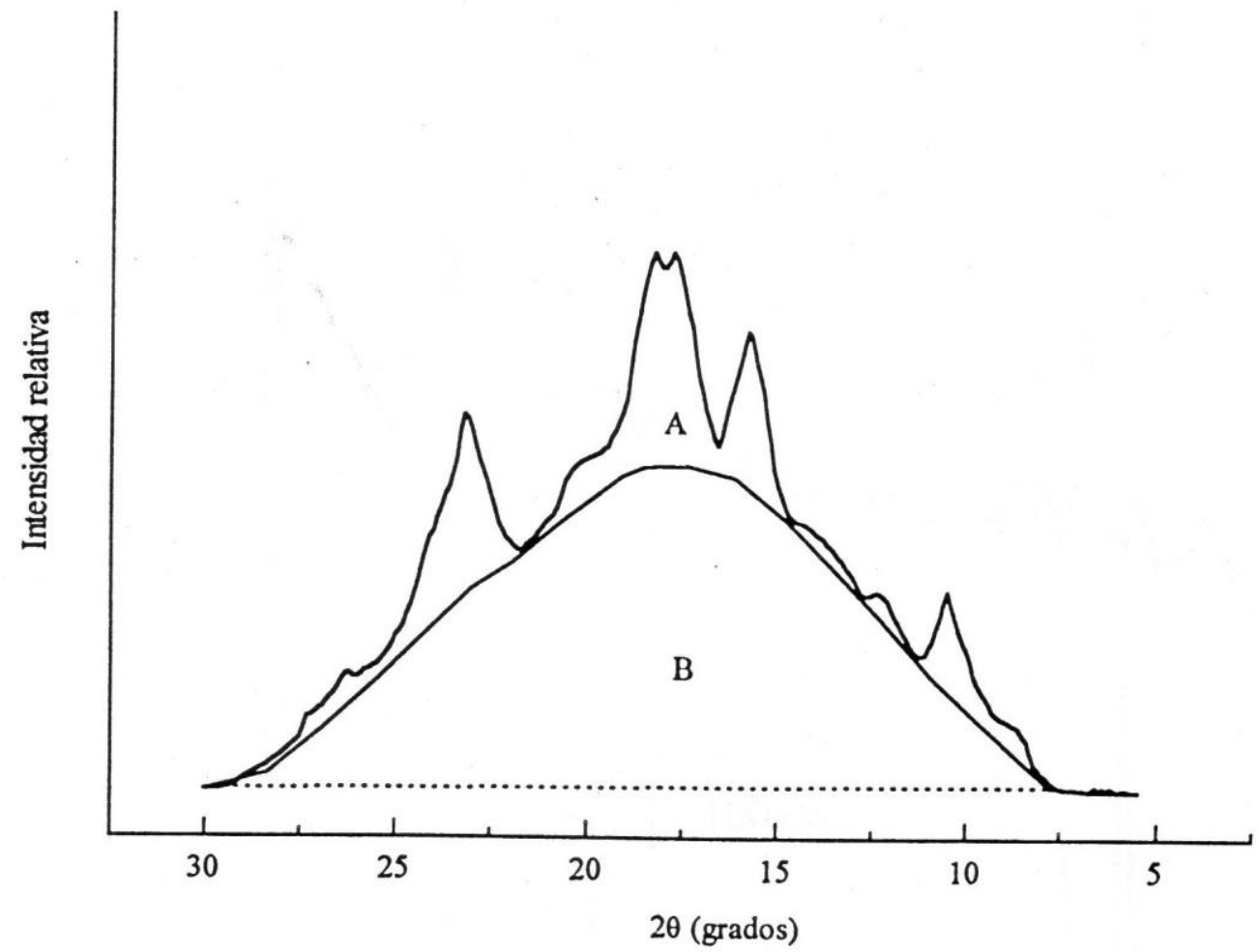

Figura 2.6. Difractograma típico de un material semicristalino.

Nota: La letra A corresponde al área de los picos de absorción o área cristalina, B es el área de la zona amorfa o de "background" y $(A+B)$ es el área total del difractograma.

Para el análisis de los almidones estudiados, se utilizó un difractómetro X'Pert Pro Analytical Model PW 3040/60 (Almelo, Holanda) provisto de un tubo con un ánodo de CuK, que emite radiación de $\lambda=1.543 \mathrm{~nm}$, y un detector que operó con un voltaje de 40 $\mathrm{kV}$ y una corriente de $40 \mathrm{~mA}$. Los difractogramas se obtuvieron desde $2 \theta=3^{\circ}$ hasta $2 \theta$ $=60^{\circ}$. Para cuantificar la cristalinidad, se utilizó una adaptación del método propuesto por Hermans y Weidinger (1948) para materiales semicristalinos, en el cual se estima, mediante una integración, la relación del área de los picos de absorción (que se 
atribuye a las regiones cristalinas) respecto al área total del difractograma (Ottenhoff, 2003). El grado de cristalinidad de una muestra puede calcularse como:

$$
\text { Grado de cristalindad }(\%)=\frac{A}{(A+B)} \times 100
$$

donde $A$ corresponde al área de los picos de absorción y $(A+B)$ es el área total del difractograma (Figura 2.6), determinadas mediante el procesamiento de los difractogramas con el programa Origin versión 7.0 (OriginLab Corporation, Estados Unidos).

\subsection{Análisis por Espectroscopía Infrarroja con Transformada de Fourier}

Los espectros IR con transformada de Fourier o en inglés FTIR (Fourier Transform InfraRed) de los almidones extraídos a partir de las raíces tuberosas de ahipa y mandioca fueron obtenidos con un espectrofotómetro Thermo Nicolet Nexus (Estados Unidos) perteneciente al PLAPIQUI (CCT Bahía Blanca - CONICET), trabajando en el rango de números de onda desde 4000 hasta $400 \mathrm{~cm}^{-1}$. Para cada muestra se colectaron 100 barridos con una resolución de $4 \mathrm{~cm}^{-1}$ que fueron acumulados y se generó el espectro promedio correspondiente a cada muestra utilizando el software asociado al equipo. Para la preparación de las muestras, los almidones de ahipa y mandioca se trituraron con bromuro de potasio (Sigma-Aldrich con pureza del 99\%) a una concentración del $3 \% \mathrm{p} / \mathrm{p}$, esta mezcla en polvo se comprimió formando una pastilla transparente a través de la cual se hizo incidir la radiación IR.

\subsection{Estudio de la estabilidad de los almidones: obtención de las isotermas de sorción}

La actividad acuosa $\left(a_{w}\right)$ es un parámetro muy usado como indicador para predecir la vida útil de un alimento.

Las isotermas son importantes para predecir los cambios en la estabilidad de los alimentos y en la elección del material de empaque adecuado. La isoterma de sorción se describe gráficamente como la cantidad de agua adsorbida en función de la humedad relativa de la atmósfera circundante al material o de la actividad de agua del 
mismo. Esta cantidad de agua es la captada luego de que se ha alcanzado el equilibrio a una temperatura constante. La actividad de agua y la humedad relativa son definidas por la ecuación:

$$
\mathrm{a}_{\mathrm{w}}=\frac{\mathrm{P}}{\mathrm{P}_{0}}=\frac{\text { \%humeda delativa }}{100}
$$

donde:

$\mathrm{P}=$ presión de vapor de agua del material a temperatura $\mathrm{T}_{0}$

$\mathrm{P}_{0}=$ presión de vapor del agua pura a temperatura $\mathrm{T}_{0}$

$\mathrm{T}_{0}=$ temperatura del sistema

Las isotermas pueden ser obtenidas en dos direcciones. La isoterma de adsorción se obtiene al colocar el material seco en varias atmósferas de humedad relativa creciente y midiendo el peso ganado debido al agua incorporada.

La isoterma de desorción se obtiene al dejar el material húmedo bajo atmósferas de humedades relativas decrecientes, pero en este caso midiendo la pérdida de peso asociada a la deshidratación de la muestra. Por causa del fenómeno de histéresis ambas isotermas no coinciden, encontrándose la de desorción por encima de la de adsorción.

Las isotermas de sorción se obtienen principalmente a través de dos grupos diferentes de métodos de medición: el gravimétrico y los basados en la determinación de la actividad de agua o presión de vapor de agua. En el método gravimétrico el cambio de peso de la muestra es medido en función de una determinada presión de vapor de agua de la atmósfera circundante. En el método basado en la determinación de la actividad de agua o la presión de vapor de agua, el $\mathrm{a}_{\mathrm{w}} \mathrm{o}$ la presión de vapor de agua es medida para un determinado contenido de agua de la muestra.

El método gravimétrico no determina directamente la presión de vapor de agua o $a_{w}$ del material. Se asume que en el equilibrio el material tiene la misma presión de vapor que la atmósfera circundante. El método gravimétrico estático es el más difundido, ha sido estandarizado por el "European Cooperative Project Cost 90" (Spiess y Wolf, 1983) y es el utilizado en el presente trabajo de Tesis. 
Las muestras $(0,15-0,20 \mathrm{~g})$ de los almidones de ahipa y mandioca fueron colocadas en recipientes de aluminio previamente pesados y se mantuvieron en un desecador con $\mathrm{CaCl}_{2}$ anhidro durante 7 días para deshidratarlas completamente. A continuación, las muestras se pesaron y se ubicaron en recipientes cerrados con soluciones saturadas de diferentes sales (Tabla 2.1). El intervalo de actividad acuosa de las mismas varió desde 0,11 hasta 0,91 (Thys y col., 2010). Cabe aclarar que a las soluciones de mayor valor de $\mathrm{a}_{\mathrm{w}}$ se les adicionó timol con el fin de evitar la proliferación de microorganismos.

Tabla 2.1. Soluciones saturadas salinas y sus valores de humedad relativa (\%) en función de la temperatura.

\begin{tabular}{ccccccc} 
& \multicolumn{6}{c}{ Temperatura $\left({ }^{\circ} \mathrm{C}\right)$} \\
\cline { 2 - 7 } Soluciones saturadas salinas & 10 & 20 & 25 & 30 & 35 & 40 \\
\hline Cloruro de litio & 11,30 & 11,31 & 11,30 & 11,28 & 11,25 & 11,21 \\
\hline Cloruro de magnesio & 33,50 & 33,07 & 32,78 & 32,44 & 32,05 & 31,60 \\
\hline Carbonato de potasio & 43,10 & 43,20 & - & 43,20 & - & - \\
\hline Nitrato de magnesio & 57,40 & 54,38 & 52,89 & 51,40 & 49,91 & 48,42 \\
\hline Nitrito de sodio & 67,30 & 65,00 & - & 63,50 & - & - \\
\hline Cloruro de sodio & 75,70 & 75,20 & 75,10 & 75,00 & 74,90 & 74,68 \\
\hline Cloruro de potasio & 86,80 & 85,05 & 84,20 & 83,60 & 82,70 & 81,80 \\
\hline Cloruro de bario & 91,00 & 90,65 & 90,30 & 90,00 & 89,50 & - \\
\hline Sulfato de potasio & 98,20 & 97,59 & 97,30 & 97,00 & 96,71 & 96,41 \\
\hline
\end{tabular}

Fuente: Robinson y Stokes, 1965; Greenspan, 1976; Kitic y col., 1986.

Las muestras se almacenaron a 10,20 y $30^{\circ} \mathrm{C}$ y se pesaron diariamente en balanza analítica hasta que dos medidas sucesivas de peso no difirieron, es decir, hasta alcanzar el equilibrio (7 días aproximadamente). Al cabo de ese tiempo las muestras se retiraron de los contenedores y se determinó el contenido de humedad de equilibrio de las mismas en estufa a $105^{\circ} \mathrm{C}$. Las isotermas de adsorción de los almidones de ahipa y mandioca se determinaron por triplicado. Los resultados se expresaron como $\mathrm{g}$ agua/g sólido en base seca. Las temperaturas elegidas se seleccionaron con el fin de simular almacenamientos del producto en condiciones de refrigeración doméstica $\left(10^{\circ} \mathrm{C}\right)$, ambiente $\left(20^{\circ} \mathrm{C}\right)$ y de abuso térmico $\left(30^{\circ} \mathrm{C}\right)$. 


\subsection{Modelado matemático de las isotermas de sorción de los almidones}

Los datos experimentales obtenidos para cada muestra fueron modelados matemáticamente con varias ecuaciones empíricas y semiempíricas propuestas para correlacionar el contenido de humedad de equilibrio con la actividad agua de un alimento. Los modelos de isotermas de adsorción empleados se muestran en la Tabla 2.2: BET (Brunauer-Emmett-Teller), GAB (Guggenheim-Anderson-de Boer), Halsey, Peleg, Oswin, Henderson, Chrife y Smith (Thys y col., 2010).

Para el modelo de $\mathrm{BET}$, se consideraron sólo los valores de $\mathrm{a}_{\mathrm{w}}<0,5$ para la regresión. La ecuación de GAB es de amplio uso en alimentos y es recomendada por el proyecto Europeo COST 90, ya que sus parámetros se relacionan con propiedades físicas de los alimentos. Este modelo está basado en la teoría de adsorción de BET, el cual da una explicación física a los parámetros involucrados en ella.

Tabla 2.2. Modelos matemáticos de isotermas de sorción utilizados.

\begin{tabular}{cc}
\hline Modelo & Ecuación matemática \\
\hline BET & $X=\frac{X_{m} C_{B} a_{w}}{\left(1-a_{w}\right)\left(1-a_{w}+C_{B} a_{w}\right)}$ \\
\hline GAB & $X=\frac{X_{m} K C_{G} a_{w}}{\left(1-K a_{w}\right)\left(1-K a_{w}+C_{G} K a_{w}\right)}$ \\
\hline Halsey & $a_{w}=\exp \left(\frac{-A}{X^{B}}\right)^{-}$ \\
\hline Peleg & $X=k_{1} a_{w}{ }^{n 1}+k_{2} a_{w}{ }^{n 2}$ \\
\hline Oswin & $X=A \times\left(\frac{a_{w}}{\left(1-a_{w}\right)}\right)^{B}$ \\
\hline Henderson & $\left(1-a_{w}\right)=\exp \left(A \times X^{B}\right)$ \\
\hline Chirife & $X=\exp \left(A+B \times \ln \left(C-\ln a_{w}\right)\right)$ \\
\hline Smith & $X=A+\left(B \times \log \left(1-a_{w}\right)\right)$
\end{tabular}

$\mathrm{X}$, contenido de humedad de equilibrio ( $\mathrm{g}$ agua/g sólido seco); $\mathrm{a}_{\mathrm{w}}$, actividad acuosa, $\mathrm{X}_{\mathrm{m}}$, contenido de humedad de equilibrio de la monocapa ( $g$ agua/g sólido seco); $A, B, C, K, k_{1}, k_{2}, n_{1}$ y $n_{2}$ son parámetros de ajuste de las diferentes ecuaciones.

Los datos se ajustaron matemáticamente con los modelos de isotermas de sorción propuestos (Tabla 2.2), utilizando el módulo de regresión no lineal del programa Systat 10.0 (SYSTAT, Inc., Evanston, IL, Estados Unidos). A través del análisis estadístico se estimó la bondad de ajuste de cada modelo a los datos experimentales así como 
también los valores de los parámetros de ajuste de cada modelo y su coeficiente de correlación $\left(\mathrm{R}^{2}\right)$.

\subsection{Parámetros termodinámicos derivados de las isotermas de sorción}

El calor isostérico es un parámetro de mucha utilidad en los procesos de adsorción y desorción de agua en alimentos. En los procesos de deshidratación representa la energía requerida para romper las fuerzas moleculares entre las moléculas de vapor de agua y la superficie del adsorbente y, cuando ocurren fenómenos de adsorción de agua, corresponde a la energía involucrada en el proceso inverso. La entalpía diferencial o calor isostérico $(\Delta \mathrm{h})$ y la entropía diferencial $(\Delta S)$ de sorción se determinaron de acuerdo con Cladera-Olivera y col., (2009) a partir de los datos de sorción de humedad utilizando la ecuación:

$$
(\operatorname{Ina})_{w}=-\frac{\Delta h}{R T}+\frac{\Delta S}{R}
$$

Donde:

$X=$ contenido de humedad en equilibrio ( $\mathrm{kg}$ agua / $\mathrm{kg}$ materia seca)

$\mathrm{R}=$ constante universal de los gases $\left(8,31 \mathrm{~J} \mathrm{~K}^{-1} \mathrm{~mol}^{-1}\right)$

$\mathrm{T}=$ temperatura absoluta $(\mathrm{K})$

Los valores de In $\left(a_{w}\right)$ se representaron versus $1 / T$ para un contenido de humedad dado $(X)$ y luego $\Delta \mathrm{h}\left(\mathrm{J} \mathrm{mol}^{-1}\right)$ se determinó a partir de la pendiente de la recta $(-\Delta \mathrm{h} / \mathrm{R})$ mientras que $\Delta S\left(\mathrm{~J} \mathrm{~mol}^{-1} \mathrm{~K}^{-1}\right)$ se obtuvo a partir del coeficiente lineal $(\Delta S / R)$ de la misma.

A partir de la teoría de la compensación de entalpía-entropía que propone una relación lineal entre $\Delta \mathrm{h}$ y $\Delta \mathrm{S}$, se calcularon la temperatura isocinética (K) y la energía libre $\left(\mathrm{J} \mathrm{mol}^{-1}\right.$ ) según la ecuación 2.6 (Al-Muhtaseb y col., 2002; Cladera-Olivera y col., 2008; Fasina, 2006):

$$
\Delta h=T_{\beta} \times \Delta S+\Delta G
$$


donde:

$\mathrm{T}_{\beta}=$ temperatura isocinética $(\mathrm{K})$

$\Delta G$ = energía libre $\left(\mathrm{J} \mathrm{mol}^{-1}\right)$

La temperatura isocinética representa la temperatura a la que todas las reacciones en serie proceden a la misma velocidad. Desde el punto de vista termodinámico, $\Delta \mathrm{G}$ se puede utilizar como un indicador de la afinidad del alimento por la adsorción del agua, proporcionando un criterio en cuanto a si la sorción de agua es un proceso espontáneo o no.

\section{Propiedades funcionales de los almidones}

\subsection{Determinación de la capacidad de retención de agua del almidón}

La capacidad de retención de agua de los almidones de ahipa y mandioca se midió de acuerdo con Szymonska y col., (2003). Se pesaron, por duplicado, muestras de almidón (1 g) y se colocaron en tubos de centrífuga. A continuación se añadieron $10 \mathrm{~mL}$ de agua destilada. Después de la homogeneización y posterior estabilización durante 15 minutos, se centrifugaron las suspensiones a $850 \times \mathrm{g}$ durante 15 minutos. Los sobrenadantes fueron descartados y los tubos se pesaron. La capacidad de retención de agua (CRA) se calculó de la siguiente manera:

$$
\operatorname{CRA}(\%)=\frac{(G-M)}{(M-T)} \times 100
$$

donde $\mathrm{G}$ es el peso del tubo que contiene la muestra húmeda luego de la decantación (g), $\mathrm{M}$ es el peso del tubo que contiene la muestra seca (g) y $\mathrm{T}$ es el peso del tubo de centrífuga vacío (g).

\subsection{Transiciones térmicas de los almidones de ahipa y mandioca. Estudio de la} gelatinización

La calorimetría diferencial de barrido o en inglés DSC (Differential Scanning Calorimetry) es la técnica más comúnmente utilizada en la determinación de las transiciones de fase en los materiales orgánicos, inorgánicos o de origen alimenticio. Los calorímetros miden el flujo calórico diferencial requerido para mantener una 
muestra y una referencia inerte a la misma temperatura, sometidas a un programa de calentamiento o enfriamiento controlado. Los cambios entálpicos se registran como endotermas o exotermas, según el proceso que sufra la muestra.

Se utilizó un calorímetro diferencial de barrido modelo Q100 controlado por el módulo TA 5000 (TA Instruments, Estados Unidos), con un accesorio de calentamientoenfriamiento bajo atmósfera de $\mathrm{N}_{2}(20 \mathrm{~mL} / \mathrm{min})$. Se utilizó indio para la calibración de la temperatura y del flujo de calor. Para la determinación, se colocaron en cápsulas de aluminio alrededor de $12 \mu \mathrm{L}$ de una suspensión acuosa al 20\% p/p de los almidones de ahipa o mandioca. Las cápsulas se cerraron herméticamente. Se utilizó una cápsula vacía como referencia. La velocidad de barrido fue de $10^{\circ} \mathrm{C} / \mathrm{min}$ y el rango de calentamiento varió entre $10-120^{\circ} \mathrm{C}$. Una vez analizadas las cápsulas se perforaron y se mantuvieron en estufa a $105^{\circ} \mathrm{C}$ hasta peso constante para determinar el peso seco de las muestras. Se determinaron como se describió en el Capítulo 1 las temperaturas de inicio, de pico y de finalización así como la entalpía asociada.

\subsection{Capacidad de hinchamiento de los gránulos de almidón}

Se determinó de acuerdo a una modificación del método propuesto por Tsai y col., (1997). Se prepararon suspensiones acuosas de almidón al 1\% p/p que se colocaron en tubos de centrífuga con tapa, los que se calentaron a $55,65,75,85,90$ y $95^{\circ} \mathrm{C}$ durante 1 hora. Luego las muestras se enfriaron a temperatura ambiente y se centrifugaron a $5000 \times g$ durante 15 minutos. El sobrenadante fue descartado. La capacidad de hinchamiento se determinó como la razón entre el peso del almidón hidratado (sedimento) y el peso inicial del almidón seco, los resultados se expresaron en porcentaje (\%).

En los sobrenadante del ensayo anterior obtenidos a cada temperatura se cuantificó por espectrofotometría, el contenido de amilosa y amilopectina. Se midieron las absorbancias a las longitudes de onda de $535 \mathrm{~nm}$ y $615 \mathrm{~nm}$, según García y col., (1995). Las concentraciones de amilosa y amilopectina fueron expresadas en $\mathrm{g} / \mathrm{L}$.

\subsection{Caracterización reológica de las pastas de almidón}

Las propiedades reológicas de un fluido se definen a partir de la relación existente entre un sistema de fuerzas externas y su respuesta. Todo fluido se va deformar en 
mayor o menor medida al someterse a fuerzas externas, representadas matemáticamente mediante el esfuerzo de corte o de cizalladura " $\tau$ "; la respuesta dinámica del fluido se cuantifica mediante la velocidad de deformación " $\gamma$ ”. Existen 3 tipos de fluidos:

a. Newtonianos: se caracterizan por cumplir la Ley de Newton, es decir, existe una relación lineal entre el esfuerzo de corte y la velocidad de deformación:

$$
\tau=\eta \dot{\gamma}
$$

donde $\eta$ : es la viscosidad dinámica o absoluta del fluido, la que puede calcularse como la pendiente de la recta de esfuerzo de corte versus velocidad de deformación (Figura 2.7).

Para este tipo de fluidos, la viscosidad es constante ya que no depende del esfuerzo de cizalladura ni del tiempo de aplicación del mismo, aunque sí puede depender de la temperatura y presión a la que se encuentre dicho fluido.

b. No Newtonianos: son aquellos en los que la relación entre el esfuerzo de corte y la velocidad de deformación no es lineal. Para este tipo de fluidos se calcula la viscosidad aparente definida para cada velocidad de deformación.

b.1 Independientes del tiempo de aplicación: se pueden clasificar según si requieren o no un mínimo valor de esfuerzo de corte (umbral) para que el fluido se ponga en movimiento.

\section{b.1.1 Sin esfuerzo umbral}

Pseudoplásticos: se caracterizan por una disminución de su viscosidad y del esfuerzo de corte con la velocidad de deformación (Figura 2.7). El comportamiento de un fluido pseudoplástico se puede modelar matemáticamente a partir de la Ley de la Potencia propuesta por Ostwald de Waele:

$$
\tau=\mathrm{k} \dot{\gamma}^{\mathrm{n}}
$$


donde k: es el coeficiente de consistencia $\left(\mathrm{Pa} / \mathrm{s}^{\mathrm{n}}\right)$ y sus dimensiones dependen del valor de la viscosidad aparente y $\mathrm{n}$ : es el índice de comportamiento de flujo (adimensional) que toma valores menores que uno.

Dilatantes: son fluidos en los que la viscosidad aumenta con la velocidad de deformación (Figura 2.7). Para describir matemáticamente este comportamiento también se puede utilizar la Ley de la Potencia anteriormente descripta, con valores de índice de flujo $n$ mayores que la unidad.

\section{b.1.2 Con esfuerzo umbral (plásticos o viscoplásticos)}

Este tipo de fluido se comporta como un sólido hasta que sobrepasa un esfuerzo de corte mínimo (umbral) y a partir de dicho valor se comporta como un líquido. Los fluidos plásticos, a su vez, se diferencian en la existencia o no de proporcionalidad entre el esfuerzo de corte y la velocidad de deformación, a partir de su esfuerzo umbral. Si existe proporcionalidad, se denominan fluidos plásticos de Bingham y si no la hay, se denominan solamente plásticos (Modelo de Herschel-Bulkey).

b.2 Dependientes del tiempo de aplicación: este tipo de fluidos pueden ser tixotrópicos, en los que su viscosidad disminuye al aumentar el tiempo de aplicación del esfuerzo de corte recuperando su estado inicial después de un reposo prolongado (Figura 2.7), o reopécticos, en los cuales su viscosidad aumenta con el tiempo de aplicación de la fuerza y vuelven a su estado anterior tras un tiempo de reposo.
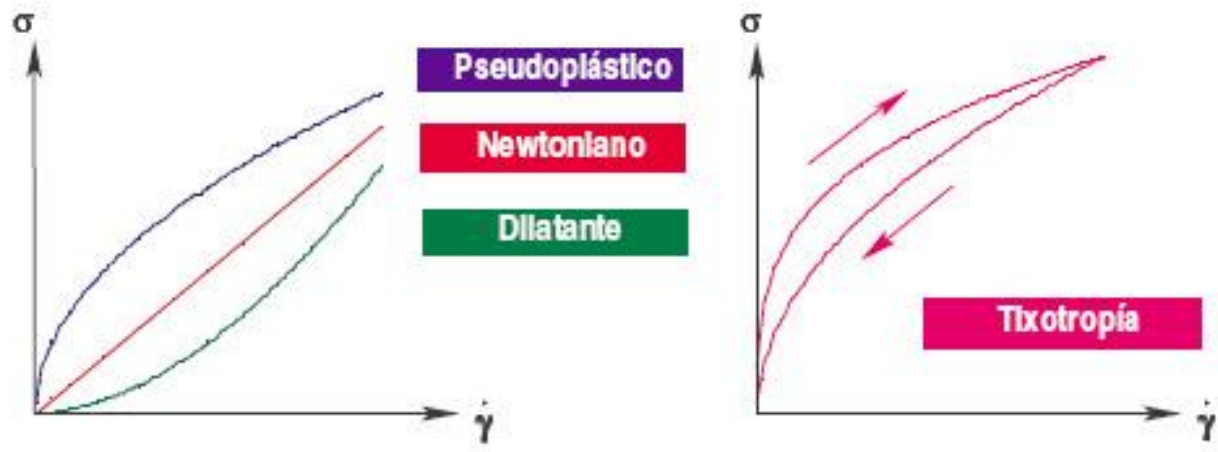

Figura 2.7. Diagrama ejemplificando diferentes comportamientos reológicos.

c. Sistemas viscoelásticos: se caracterizan por presentar a la vez tanto propiedades viscosas como elásticas. Este comportamiento, característico de las soluciones de moléculas muy largas y flexibles, de las suspensiones y de los materiales poliméricos, 
depende de la composición química y estructura física del material estudiado (Steffe, 1996).

La muestra se coloca entre un sistema de platos paralelos a temperatura controlada, donde el plato inferior se encuentra fijo y el superior oscila a una frecuencia controlada o fija $(\omega)$. Para un material perfectamente elástico (sólido ideal), la onda de deformación se encontrará en fase con el esfuerzo $(\sigma)$ aplicado, siendo el ángulo de desfasaje $(\delta)$ entre el esfuerzo aplicado y la deformación $0^{\circ}$. Para un material viscoso ideal, la deformación oscilatoria se encuentra completamente desfasada $\left(\delta=90^{\circ}\right)$ con respecto al esfuerzo aplicado (Steffe, 1996).

Los sistemas viscoelásticos presentan un comportamiento intermedio entre el viscoso ideal y al elástico ideal, variando el ángulo de desfasaje $\delta$ entre 0 y $90^{\circ}$ (Figura 2.8). La $\tan \delta$ se vincula con la relación entre la energía perdida por la muestra por ciclo respecto a la energía almacenada por ciclo (Steffe, 1996).

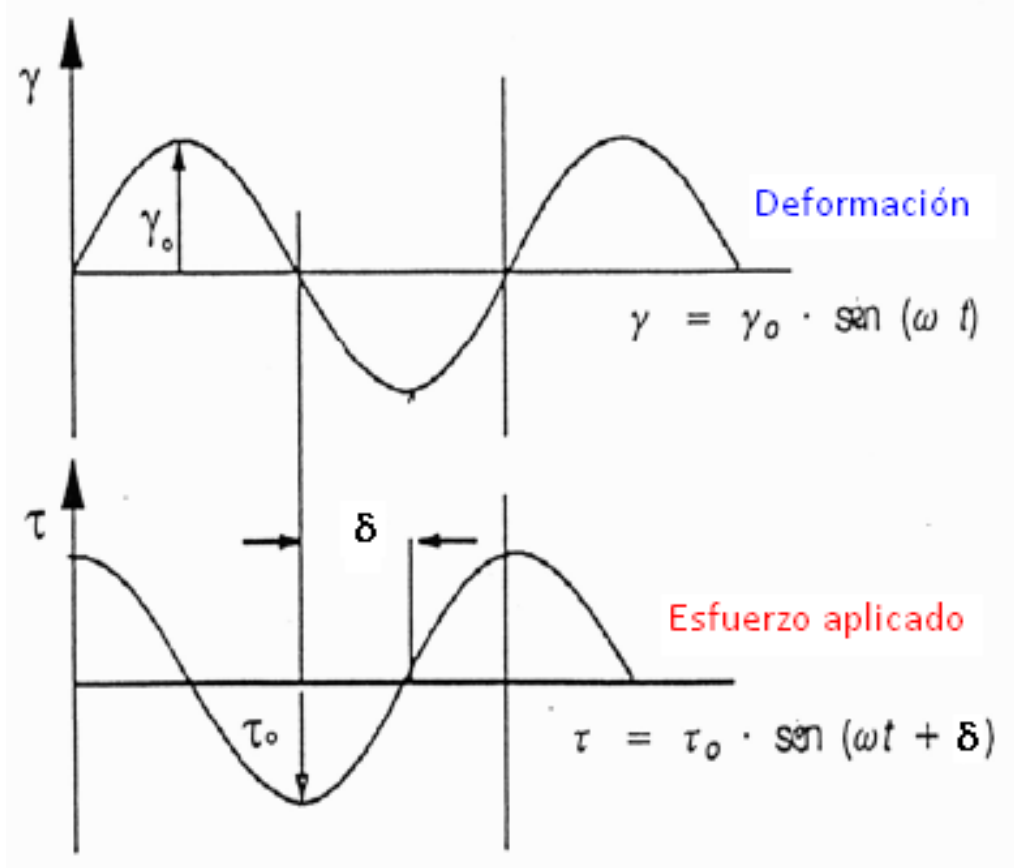

Figura 2.8. Relación entre el esfuerzo aplicado y la deformación de un sistema viscoelástico. Adaptado de Steffe, (1996).

Los ensayos reológicos se realizaron en un reómetro Rheo Stress 600 ThermoHaake (Haake, Alemania) usando un sistema plato-plato PP35 a temperatura controlada $\left(25^{\circ} \mathrm{C}\right)$. Se trabajó con suspensiones acuosas de almidón $(4 \% \mathrm{p} / \mathrm{p})$ las cuales fueron 
gelatinizadas a $90^{\circ} \mathrm{C}$ durante 20 minutos. La concentración utilizada corresponde a la mínima concentración que permite la formación de geles además de ser una de las más utilizadas en la formulación de alimentos.

Para investigar el comportamiento de flujo de las suspensiones de almidón se utilizó el modo rotacional. El mismo fue modelado matemáticamente con el modelo Newtoniano o el de Ostwald de Waele, calculándose para este último la viscosidad aparente a $500 \mathrm{~s}^{-1}$. Para evaluar la dependencia con el tiempo se determinaron los índices de tixotropía o reopexia, que corresponden al área de histéresis entre las curvas ascendente y descendente (Figura 2.7).

Para caracterizar el comportamiento viscoelástico de las suspensiones de almidón no Newtonianas se realizaron ensayos en modo dinámico. En primer lugar, se realizaron barridos de esfuerzo $(0-20 \mathrm{~Pa})$ a frecuencia constante $(1 \mathrm{~Hz})$ para determinar el rango de viscoelasticidad lineal (RVL). Luego se realizaron barridos de frecuencia (0,01 a 100 $\mathrm{Hz}$ ) a un valor de esfuerzo constante dentro del RVL. Los parámetros reológicos dinámicos registrados fueron el módulo de almacenamiento $\left(G^{\prime}\right)$, el módulo de pérdida $\left(G^{\prime \prime}\right)$, la tangente del ángulo de desfasaje ( $\left.\tan \delta=G^{\prime \prime} / G^{\prime}\right)$ y el módulo complejo del esfuerzo de corte $\left(G^{*}\right)$. También se obtuvieron los espectros mecánicos graficando $G^{\prime} y$ G" en función de la frecuencia.

Tanto en los ensayos dinámicos como en los rotacionales las muestras se colocaron en el sistema sensor plato-plato y se dejaron en reposo a la temperatura de ensayo durante 5 minutos, con el fin de permitir la relajación de las muestras. Los valores informados corresponden al promedio de al menos tres mediciones registradas.

\subsection{Retrogradación de las pastas de almidón de ahipa y mandioca bajo condiciones de refrigeración}

Se utilizaron tres técnicas complementarias: DSC y grado de sinéresis, para evaluar la retrogradación de amilopectina y amilosa respectivamente, y ensayos de análisis de perfil de textura o en inglés TPA (Texture Profile Analysis), para evaluar el proceso en general.

Se prepararon suspensiones acuosas al $10 \% \mathrm{p} / \mathrm{p}$ las que fueron gelatinizadas a $90^{\circ} \mathrm{C}$ durante 20 minutos en un baño termostático Haake (Alemania). La concentración utilizada corresponde a la mínima concentración a la cual se obtenía un gel 
autoportante que permitía realizar los ensayos de TPA. Para los ensayos de TPA y DSC, aproximadamente $5 \mathrm{~g}$ de las suspensiones gelatinizadas se colocaron dentro de contenedores plásticos (diámetro: 2,5 cm; altura: 1,5 cm) y se los cubrió con un film de cloruro de polivinilo (PVC). Para evaluar el grado de sinéresis de las pastas, aproximadamente $10 \mathrm{~g}$ de las suspensiones se colocaron en tubos de centrífuga previamente pesados. Los contenedores y los tubos se almacenaron a $4^{\circ} \mathrm{C}$ y a diferentes tiempos de ensayo $(1,3,7,9$ y 11 días) se tomaron muestras que fueron acondicionadas a temperatura ambiente durante 1 hora antes de ser analizadas.

Para determinar el grado de sinéresis los tubos se centrifugaron $(5000 \times \mathrm{g})$ durante 15 minutos, el líquido sobrenadante se removió cuidadosamente y el sedimento obtenido se pesó en una balanza analítica. El grado de sinéresis (\%) se determinó por diferencia entre el peso del tubo antes y después de la separación del sobrenadante.

Para los ensayos de TPA, las pastas se desmoldaron sobre la base del texturómetro TAXT2i Texture Analyzer (Stable Micro Systems Ltd, Reino Unido) equipado con una celda de carga de $25 \mathrm{~kg}$. Las mismas fueron comprimidas $4 \mathrm{~mm}$ con una sonda de aluminio de $75 \mathrm{~mm}$ de diámetro (P75), operada en modo de compresión. El programa consistió en dos ciclos de compresión y las condiciones de medida fueron las siguientes: velocidad de pre y post-ensayo $2 \mathrm{~mm} / \mathrm{s}$, velocidad de ensayo $1 \mathrm{~mm} / \mathrm{s}$ y tiempo entre ciclos $5 \mathrm{~s}$. Previamente se calibró la fuerza (con una pesa de $5 \mathrm{~kg}$ ) y la sonda; las medidas se realizaron sobre al menos 5 pastas de cada tipo de muestra para cada uno de los tiempos ensayados. Los datos se procesaron utilizando el software Texture Expert ${ }^{\circledR}$, para obtener el perfil de textura (curva de fuerza en función del tiempo o de la deformación).

A partir de los patrones mecánicos se calcularon los siguientes parámetros, según Andrés y col., (2006): dureza, elasticidad, cohesividad, gomosidad, adhesividad, y masticabilidad. Las expresiones para cada parámetro se encuentran especificadas en el Capítulo 1.

\section{Análisis estadístico}

Todas las determinaciones se realizaron al menos por triplicado. Para el análisis estadístico de resultados se utilizó el programa Systat ${ }^{\circledR}$ Software (Versión 10.0, Evanston, IL, Estados Unidos). Se efectuó el análisis de varianza (ANOVA) y se realizó la 
comparación de medias mediante el test de la diferencia mínima significativa de Fisher (LSD), con un nivel de significación $p=0,05$. Tal como se mencionó anteriormente, para el modelado matemático de los datos correspondientes a las isotermas de sorción, se aplicó el módulo de regresión no lineal del software. 


\section{RESULTADOS Y DISCUSION}

\section{Extracción de almidón}

Durante el proceso de extracción, se optimizó el volumen de agua utilizado como así también el número de veces que debían repetirse la obtención de la lechada y la posterior sedimentación del almidón suspendido en la misma, comprobándose que cuatro repeticiones eran suficientes. El lavado con agua clorada de las raíces y la elección de una baja temperatura $\left(4^{\circ} \mathrm{C}\right)$ fueron determinantes para evitar el desarrollo de microorganismos durante la extracción y posterior almacenamiento de las muestras. También se comprobó que no era necesario realizar una centrifugación de la lechada para recuperar el almidón ya que con una simple decantación durante 24 horas se obtenían resultados similares.

Se comprobó una adecuada eficiencia y desempeño del procedimiento de extracción ya que no se detectaron valores significativos de nitrógeno total en los almidones extraídos utilizando el método Kjeldhal.

En la Tabla 2.3 se presentan los rendimientos en base seca (\% p/p respecto de las raíces peladas) de la extracción de almidón de ahipa y mandioca según el año de cosecha de las raíces y accesión o cultivar.

Tabla 2.3. Rendimientos de extracción (\%) de los almidones extraídos.

\begin{tabular}{|c|c|c|c|}
\hline \multicolumn{2}{|c}{ Almidón } & Año & Rendimiento (\%) \\
\hline \multirow{4}{*}{ Ahipa } & Local & 2009 & 56,54 \\
\cline { 2 - 4 } & 11 & 2010 & 46,37 \\
\cline { 2 - 4 } & Local & 2010 & 48,03 \\
\cline { 2 - 4 } & 9 & 2011 & 39,81 \\
\cline { 2 - 4 } & 11 & 2011 & 39,13 \\
\cline { 2 - 4 } & Local & 2012 & 37,45 \\
\cline { 2 - 4 } Mandioca & Local & 2013 & 39,57 \\
\hline \multirow{5}{*}{} & Pomberí & 2010 & 80,60 \\
\cline { 2 - 4 } & Pomberí & 2011 & 80,12 \\
\cline { 2 - 4 } & IAPAR 989 & 2011 & 86,12 \\
\cline { 2 - 4 } & Verde Olivo & 2011 & 94,33 \\
\cline { 2 - 4 } & Pomberí Negra & 2011 & 83,44 \\
\cline { 2 - 4 } & Bahianinha & 2011 & 82,63 \\
\cline { 2 - 4 } & Pomberí & 2013 & \\
\cline { 2 - 4 } & & &
\end{tabular}


Las variaciones de rendimiento en ahipa verificadas se deben en parte al hecho de tratarse de un cultivo que no ha sido sometido a un proceso de mejoramiento sistemático, así como a diferencias atribuibles a las condiciones agroclimáticas de cada ciclo de cultivo.

Los resultados obtenidos se encuentran dentro del rango de valores señalados por Huang y col., (2007) para diferentes raíces y tubérculos no tradicionales (cará, taro y batata). Además, estos autores también indicaron que el proceso de extracción resultó eficaz y presentó un alto desempeño ya que el almidón extraído no contenía niveles detectables significativos de nitrógeno total, determinado por el método Kjeldhal.

En el caso de la extracción de almidón a partir de raíces, si bien éstas acumulan un alto contenido de almidón, su extracción puede ser baja ya que se encuentra la misma supeditada al tamaño del gránulo y la heterogeneidad en cuanto a la forma y tamaño de las raíces.

Asimismo, a pesar de que el rendimiento de almidón de mandioca fue mayor que el de ahipa, hay que tener en cuenta que esta última especie se propaga a través de sus semillas por lo que toda su producción podría destinarse a la obtención de almidón, no así la producción de mandioca, cuyo cultivo se propaga vegetativamente a través de estacas y en algunos casos requiere del uso de propágulos obtenidos de las raíces.

El proceso de extracción del almidón a partir de cereales requiere mayor tecnología y solamente se lleva a cabo a nivel industrial. Las ventajas del método de extracción utilizado en el presente trabajo de Tesis son su bajo costo y simplicidad, por lo que podría ser implementado por cooperativas rurales, contribuyendo de esta manera al desarrollo de regiones económicamente comprometidas.

\section{Caracterización de los almidones extraídos}

\subsection{Composición química}

En cuanto a la composición química del almidón de ahipa (2010), el contenido de cenizas y lípidos totales fue de $0,233 \pm 0,003 \%$ y $0,027 \pm 0,003 \%$, respectivamente. Estos valores son comparables con los informados por Maaran y col., (2014).

La pureza de los almidones se evaluó en base al bajo contenido de nitrógeno, siendo $0,08 \pm 0,02 \%$ para ahipa. Estos valores indicarían ausencia de lípidos no amiláceos (Maaran y col., 2014). Como se mencionó anteriormente, la eficiencia del proceso de 
extracción de almidón radica en el contenido de nitrógeno total y los resultados confirmaron el método utilizado.

\subsection{Contenido de fósforo}

Los resultados obtenidos para el almidón de ahipa (año 2010) fueron $6,7 \pm 0,8$ y 5,8 $\pm \pm 0,3$ $\mathrm{mg} / 100 \mathrm{~g}$ de muestra para las accesiones 11 y Local, respectivamente, no encontrándose diferencias significativas $(p>0,05)$ entre los valores obtenidos. Los resultados informados por Mélo y col., (2003) han revelado que el almidón de Pachyrhizus erosus tiene un contenido de fósforo superior (9 mg/100g) al de mandioca ( $5 \mathrm{mg} / 100 \mathrm{~g}$ ) y al de ahipa. El fósforo, aunque se halle presente en baja concentración, juega un papel importante en las propiedades funcionales del almidón (Jane y col., 1996).

\subsection{Actividad $\alpha$-amilasa}

La actividad $\alpha$-amilasa medida en el almidón de ahipa fue de $0,4 \mathrm{U} / \mathrm{g}$ de muestra, significativamente menor $(p<0,05)$ que en las raíces enteras de ahipa $(2,7 \mathrm{U} / \mathrm{g})$. Esta diferencia podría atribuirse a que posiblemente, durante el proceso de extracción, el almidón pierda algunas enzimas solubles, incluyendo en parte a la $\alpha$-amilasa.

\section{Caracterización fisicoquímica y microestructural de los almidones}

\subsection{Relación amilosa/amilopectina}

El contenido de amilosa total del almidón extraído de ahipa se muestra en la Tabla 2.4.

Tabla 2.4. Concentración de amilosa total (\%) del almidón de Pachyrhizus ahipa.

\begin{tabular}{|c|c|}
\hline Accesión & Concentración de amilosa total (\%) \\
\hline Local & $12,1 \pm 0,4^{\mathrm{a}, \mathrm{b}}$ \\
\hline 9 & $10,8 \pm 0,7^{\mathrm{a}}$ \\
\hline 11 & $13,7 \pm 0,3^{\mathrm{b}}$ \\
\hline
\end{tabular}

Nota: Los valores informados corresponden a las medias \pm las desviaciones estándar. Datos acompañados por una misma letra, no difieren significativamente $(p>0,05)$. 
Este almidón sería adecuado para el procesamiento de alimentos, ya que una baja tendencia a la retrogradación se asocia a un menor contenido de amilosa (Forsyth y col., 2002).

Estos resultados fueron obtenidos mediante el método espectrofotométrico propuesto por Morrison y Laignelet (1993) que cuantifica la fracción de amilosa que es capaz de formar complejos con el $\mathrm{I}_{2}$.

Estos valores se encuentran muy próximos a los señalados por otros autores. Forsyth y col., (2002) informaron que el contenido de amilosa en almidones de Pachyrhizus ahipa varió entre 11,6 y 16,8\% mientras que Leonel y col., (2003) hallaron un valor de $12,8 \pm 0,6 \%$. Hay que tener en cuenta que muchas veces las diferencias entre los datos proporcionados en la literatura se pueden atribuir a las variedades empleadas, las condiciones de crecimiento del cultivo, como así también al método de cuantificación utilizado (Mali y col., 2002). Los bajos valores de amilosa que presenta el almidón de ahipa podrían relacionarse con la alta digestibilidad y estabilidad de sus pastas (Skrabanja y col., 1999). Esta característica los hace muy interesantes como aditivos alternativos al almidón nativo de maíz con $25 \%$ de amilosa, ampliamente utilizado en la industria alimentaria, para la formulación de productos donde la retrogradación de las pastas de almidón es un problema crítico.

El contenido de amilosa del almidón de mandioca se presenta en la Tabla 2.5 y, como puede observarse, dependió del cultivar analizado.

Los valores obtenidos para el almidón de mandioca fueron significativamente mayores $(p<0,05)$ que los correspondientes a los almidones extraídos de las raíces tuberosas de ahipa. Estos resultados demuestran que, como era de esperar, el contenido de amilosa varía con el origen botánico. El contenido de amilosa informado por Mélo y col., (2003) para almidón de Pachyrhizus erosus (yam bean) fue 23\%, superior al cuantificado en promedio para los cultivares de mandioca. 
Tabla 2.5. Concentración de amilosa total (\%) del almidón de Manihot esculenta.

\begin{tabular}{|c|c|}
\hline Cultivar & Concentración de amilosa total (\%) \\
\hline Pombero & $16,4 \pm 0,7^{\mathrm{b}, \mathrm{c}}$ \\
\hline Corrientes 74 & $21,6 \pm 0,8^{\mathrm{c}}$ \\
\hline Coloradita & $17,4 \pm 0,2^{\mathrm{b}, \mathrm{c}}$ \\
\hline Rama Verde & $14,6 \pm 0,2^{\mathrm{a}, \mathrm{b}}$ \\
\hline Rocha & $14,1 \pm 0,6^{\mathrm{a}, \mathrm{b}}$ \\
\hline Concepción & $14,6 \pm 0,8^{\mathrm{a}, \mathrm{b}}$ \\
\hline Blanca de Santa Catarina & $13,7 \pm 0,8^{\mathrm{a}, \mathrm{b}}$ \\
\hline Tacuarita & $15,8 \pm 0,3^{\mathrm{a}, \mathrm{b}}$ \\
\hline CA 25-1 & $12 \pm 2^{\mathrm{a}, \mathrm{b}}$ \\
\hline CA 145 & $12 \pm 3^{\mathrm{a}, \mathrm{b}}$ \\
\hline IAC 90 & $13 \pm 5^{\mathrm{a}, \mathrm{b}}$ \\
\hline Rito B & $10 \pm 2^{\mathrm{a}}$ \\
\hline
\end{tabular}

Nota: Los valores informados corresponden a las medias \pm las desviaciones estándar. Datos acompañados por una misma letra, no difieren significativamente $(p>0,05)$.

\subsection{Color}

Haciendo referencia al color de los almidones extraídos, en los diferentes años y cultivos, se observó un alto grado de blancura (Tabla 2.6), especialmente para el almidón de mandioca. Boudries y col., (2009) han señalado que valores de luminosidad $\left(L^{*}\right)$ superiores a 90 dan un nivel de blancura satisfactorio, indicando la pureza del almidón.

Pérez Sira y Lares Amaiz (2004), caracterizaron almidones aislados de sorgo blanco y sorgo pigmentado, con valores de $L^{*}$ iguales a 91,3 y 78,4 , respectivamente.

Los valores tonales y cromáticos de los almidones de ahipa y mandioca (Tabla 2.6) fueron ligeramente superiores a los indicados para el almidón de semillas de piñón (Araucaria araucana) por Henríquez y col., (2008), (hue = 80,1 $\pm 0,4$; Chroma $=4,0 \pm 0,1$ ).

Tabla 2.6. Valores de $\mathrm{L}^{*}$, hue $\left(\mathrm{h}^{\circ}\right)$ y Chroma $\left(\mathrm{C}^{*}\right)$ de almidones de Pachyrhizus ahipa (ahipa) y de Manihot esculenta (mandioca).

\begin{tabular}{|c|c|c|c|}
\hline Almidón & $\mathrm{L}^{*}$ & $\mathrm{~h}^{\circ}$ & $\mathrm{C}^{*}$ \\
\hline Pachyrhizus ahipa (ahipa) & $93,5 \pm 0,7^{\mathrm{a}}$ & $85,8 \pm 0,5^{\mathrm{a}}$ & $4,4 \pm 0,2^{\mathrm{a}}$ \\
\hline Manihot esculenta (mandioca) & $96,2 \pm 0,7^{\mathrm{a}}$ & $91,9 \pm 0,4^{\mathrm{b}}$ & $4,9 \pm 0,2^{\mathrm{a}}$ \\
\hline
\end{tabular}

Nota: Los valores informados corresponden a las medias \pm las desviaciones estándar. Datos acompañados por una misma letra en la misma columna, no difieren significativamente $(p>0,05)$. 


\subsection{Morfología y distribución de tamaños de gránulos}

La Figura 2.9 muestra las micrografías electrónicas de barrido del almidón de ahipa (a) y mandioca (b) extraídos a escala de laboratorio.

Se observa que tanto los gránulos de almidón de ahipa como los de mandioca presentaron una morfología poligonal con bordes irregulares y que el proceso de extracción anteriormente descripto no causó daño en los gránulos, ya que mayormente no se observan grietas y sus superficies resultaron lisas. En ambos casos se hallaron partículas deformadas, truncadas o con poca esfericidad.
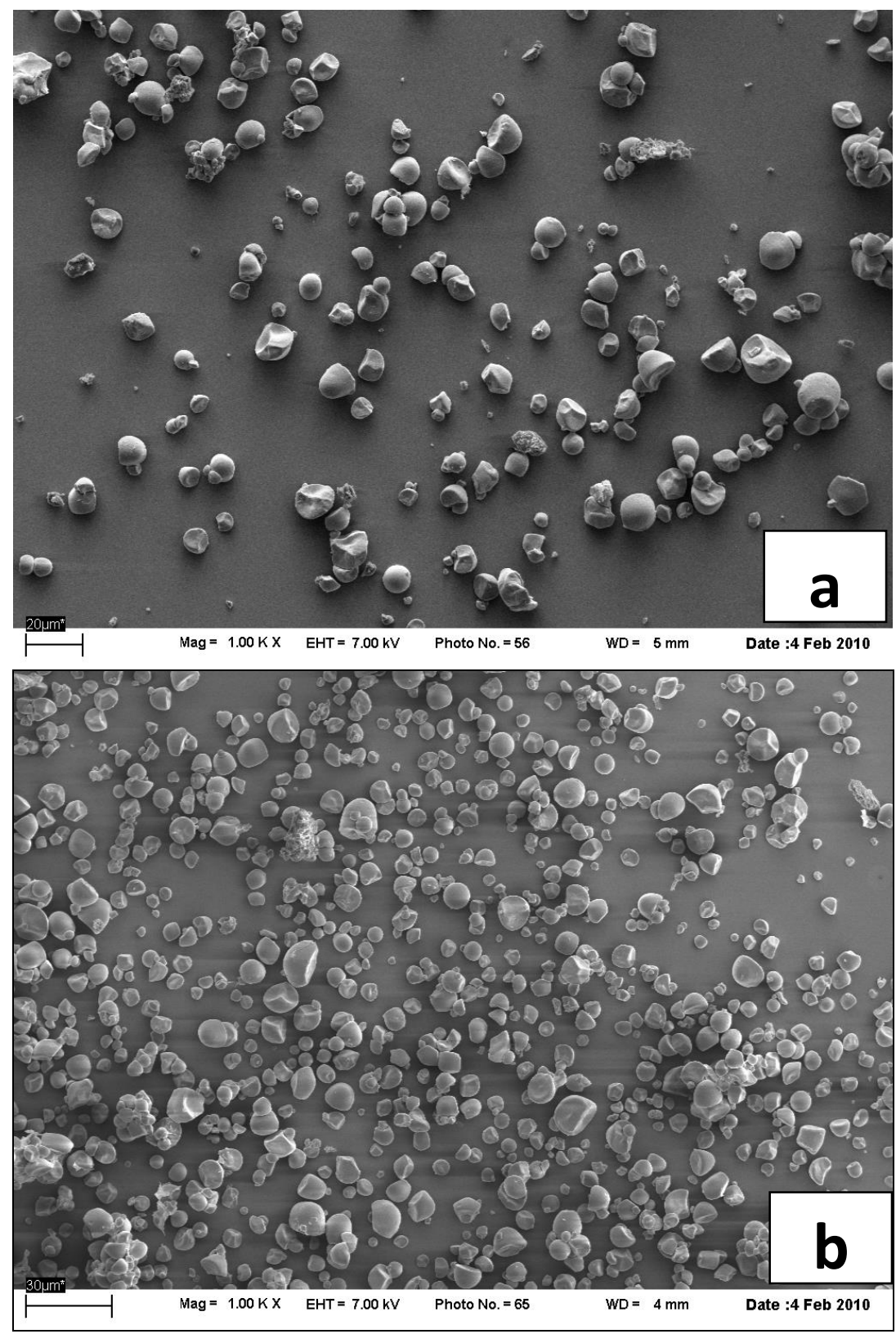

Figura 2.9. Micrografías electrónicas de barrido de almidones de (a) Pachyrhizus ahipa (ahipa) y de (b) Manihot esculenta (mandioca). 
En la Figura 2.10 se presentan los histogramas de distribución de tamaño de los gránulos de los almidones estudiados.
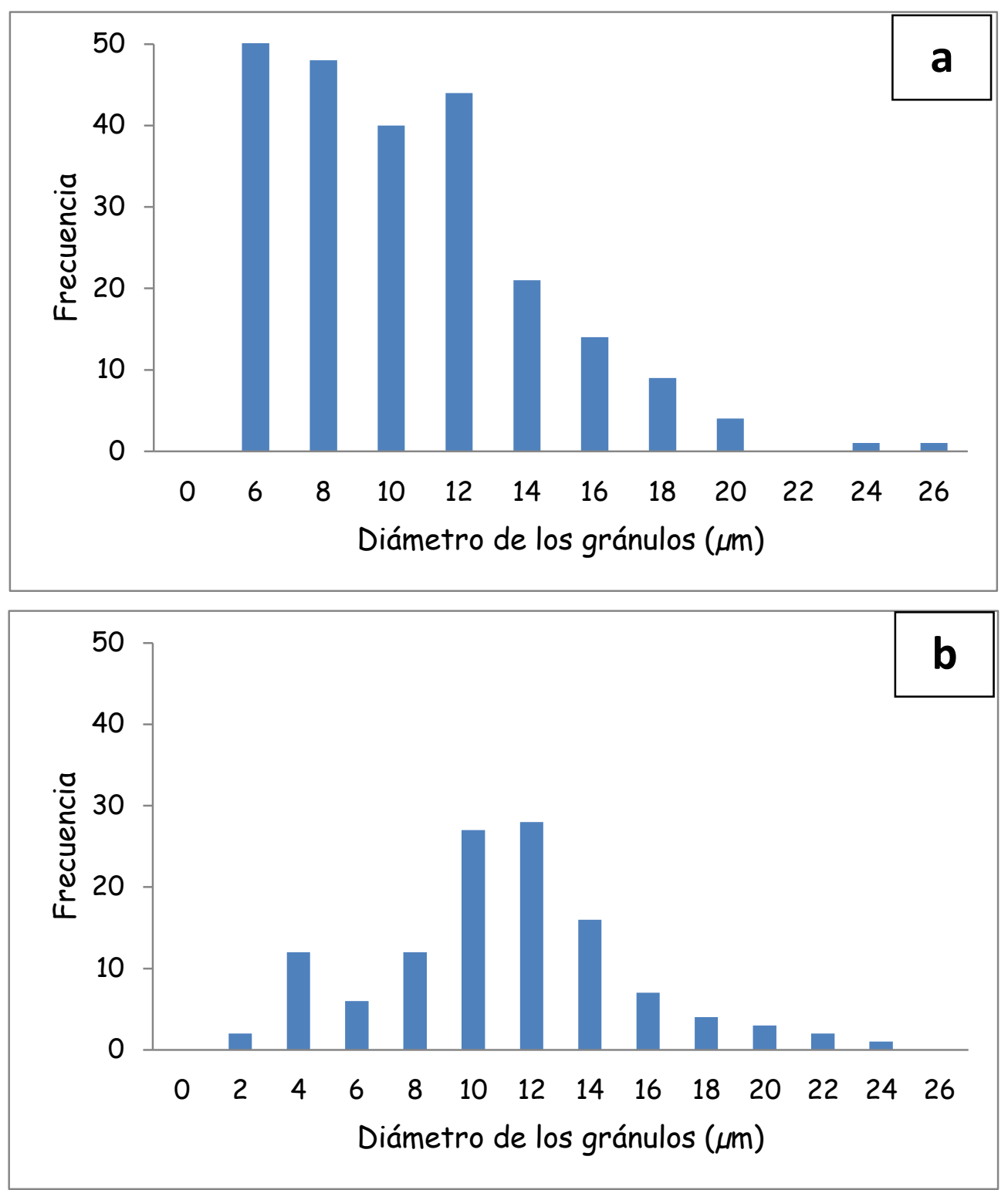

Figura 2.10. Histogramas de distribución de tamaño de gránulos de almidones de (a) Pachyrhizus ahipa (ahipa) y de (b) Manihot esculenta (mandioca).

Los gránulos de almidón de ahipa exhibieron una distribución de tamaño monomodal que varió entre 2 y $20 \mu \mathrm{m}$, con un valor medio de 8,9 $9 \pm 3,7 \mu \mathrm{m}$. Forsyth y col., (2002) informaron diámetros de gránulo cercanos al obtenido. En cambio, los gránulos de almidón de mandioca presentaron una distribución de tamaños bimodal, con dos grupos bien diferenciados centrados alrededor de 3 y $10 \mu \mathrm{m}$. Siroth y col., (1999) 
señalaron que la distribución de tamaño de los gránulos de almidón de algunos tubérculos depende de la fase que esté atravesando el cultivo al momento de cosecharse. La morfología, el tamaño y la superficie de los gránulos son características que influyen sobre la funcionalidad del almidón; además, son factores críticos para aplicaciones donde se requiere que el almidón sea una superficie portadora de materiales como pigmentos, saborizantes y condimentos.

En la Tabla 2.7 se resumen los parámetros morfológicos obtenidos a partir de los estudios de microscopía electrónica de barrido. No se observaron diferencias significativas $(p>0,05)$ en los parámetros morfológicos de los gránulos de almidones de ahipa y mandioca.

Tabla 2.7. Parámetros morfológicos de gránulos de almidón de Pachyrhizus ahipa (ahipa) y de Manihot esculenta (mandioca).

\begin{tabular}{ccccc} 
Almidón & $\begin{array}{c}\text { Diámetro } \\
\text { medio }(\mu \mathrm{m})\end{array}$ & $\begin{array}{c}\text { Radio medio de } \\
\text { Martins }(\mu \mathrm{m})\end{array}$ & $\begin{array}{c}\text { Diámetro de círculo } \\
\text { equivalente }(\mu \mathrm{m})\end{array}$ & $\begin{array}{c}\text { Factor de } \\
\text { forma }\end{array}$ \\
\hline Ahipa & $8,9 \pm 3,7$ & $4,0 \pm 1,7$ & $8,2 \pm 3,5$ & $0,90 \pm 0,05$ \\
\hline Mandioca & $9,4 \pm 3,7$ & $4,3 \pm 1,8$ & $8,8 \pm 3,6$ & $0,89 \pm 0,09$
\end{tabular}

Nota: Los valores informados corresponden a las medias \pm las desviaciones estándar.

\subsection{Espectroscopía de difracción de rayos $\mathrm{X}$}

Los almidones son materiales semicristalinos que tienen la capacidad de difractar los rayos $\mathrm{X}$, permitiendo así obtener información de su estructura (Bello-Pérez y col., 2002). El almidón produce diferentes respuestas frente a la incidencia de los rayos $X$ y en general pueden observarse cuatro patrones diferentes de difracción que se presentan en la Figura 2.11. 


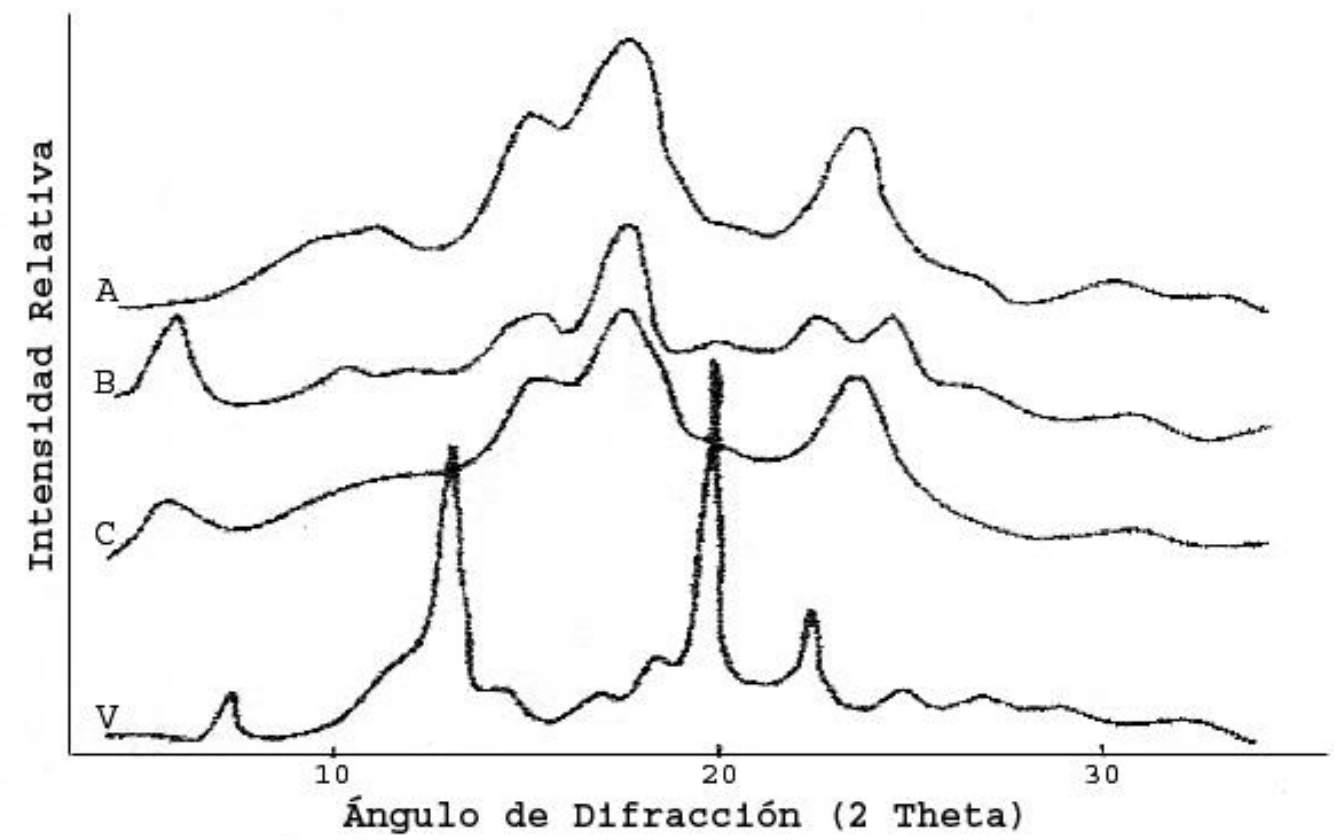

Figura 2.11. Espectros de difracción de rayos $X$ de almidones de diferente origen botánico (A: cereales, B: tubérculos, C: legumbres y V: complejos de inclusión helicoidal de la amilosa cristalina). Adaptado de Zobel, (1988).

El patrón A es típico de los cereales, el $B$ de los almidones de maíz de alto contenido de amilosa y de los tubérculos, el $\mathrm{C}$ de los almidones de legumbres y corresponde a una estructura intermedia entre A y B y el patrón $V$ se asocia a complejos de inclusión helicoidal de la amilosa cristalina (Zobel, 1988).

La parte amorfa del gránulo del almidón está formada esencialmente por la amilosa y los puntos de ramificación de la amilopectina, mientras que la región cristalina se debe a los planos formados por los cúmulos paralelos de cadenas cortas de la amilopectina (Rodríguez-Hernández y col., 2001).

La Figura 2.12 muestra los difractogramas de los almidones extraídos de raíces tuberosas. La asignación del patrón de difracción para los almidones no resultó sencilla; los difractogramas presentaron picos a $2 \theta=5.5,15.4,17.0,18.0,20.0$ y $23.5^{\circ}$, por lo que se les asignó un patrón Tipo C (Geng y col., 2007; Whistler y col., 1984). Este patrón es típico de almidones de legumbres (Zobel, 1988) y de almidones de frutas y tubérculos tropicales (Luengwilai y Beckles, 2009). En la literatura no hay homogeneidad respecto a la asignación de patrones de difracción de rayos $\mathrm{X}$ para 
almidones provenientes de raíces y tubérculos no tradicionales como taro, cará, batata y kudzu (Huang, 2009; Geng y col., 2007).

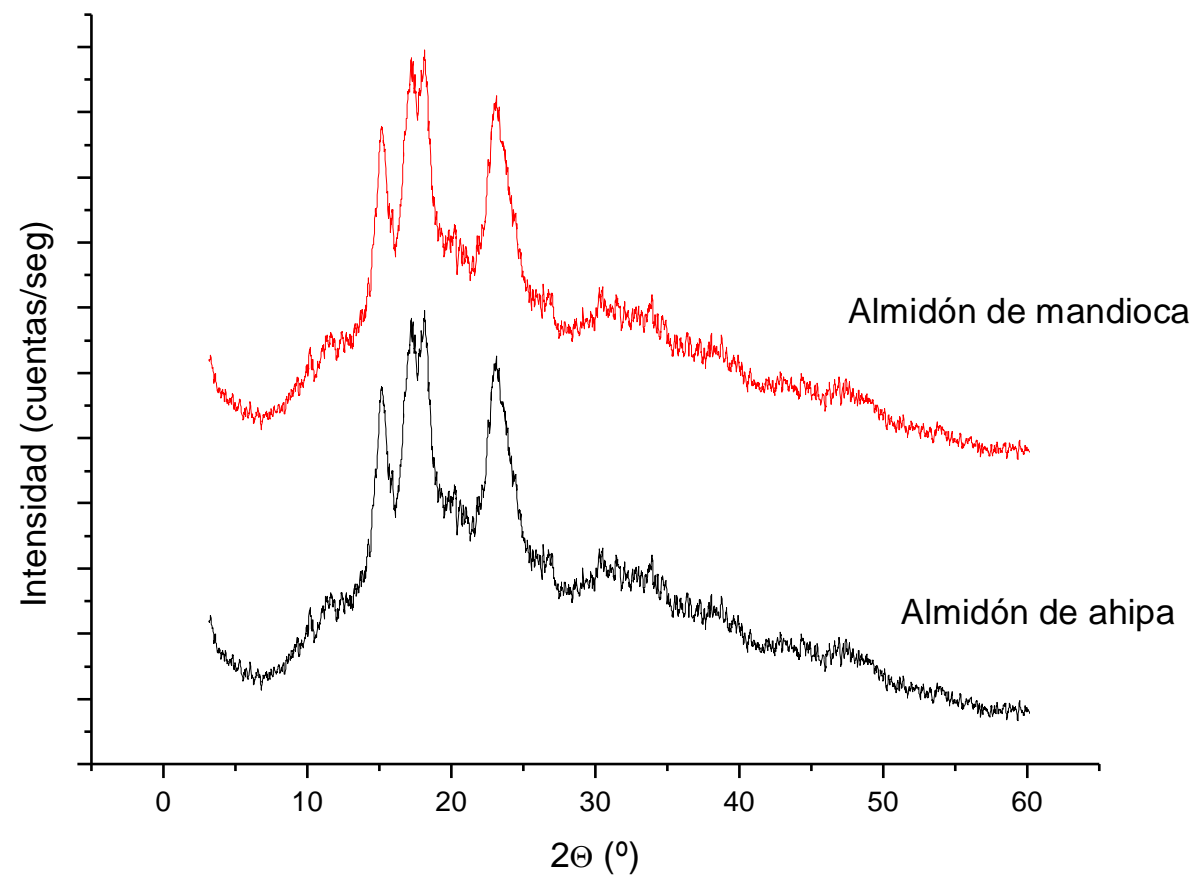

Figura 2.12. Espectros de difracción de rayos $X$ de almidones de Pachyrhizus ahipa (ahipa) y de Manihot esculenta (mandioca).

Los grados de cristalinidad fueron $10,6 \pm 0,4 \%$ para almidón de ahipa y $6,3 \pm 0,2 \%$ para almidón de mandioca. Así, el origen botánico del almidón afectó el grado de cristalinidad de los gránulos; esta variación podría relacionarse en forma inversa con el contenido de amilosa.

\subsection{Análisis por Espectroscopía Infrarroja con Transformada de Fourier}

La espectroscopía FTIR se utilizó para completar la caracterización de los almidones derivados de raíces tuberosas de ahipa y mandioca. Los espectros presentaron las señales típicas de estiramiento, flexión y deformación correspondientes a los principales grupos funcionales característicos del almidón (Figura 2.13). 


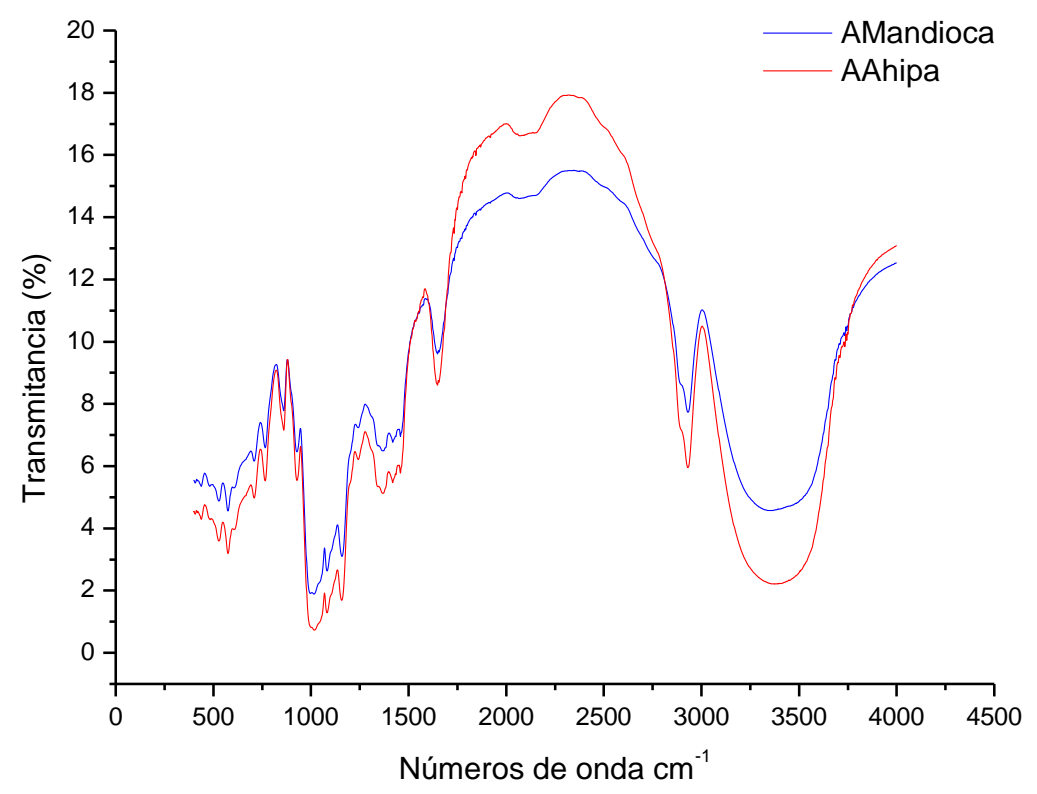

Figura 2.13. Espectros FTIR de almidones de Pachyrhizus ahipa (ahipa) y de Manihot esculenta (mandioca).

El origen botánico no afectó los espectros FTIR de ambos almidones, ya que como se observa en la Figura 2.13 ambos espectros resultaron similares y los picos identificados son coincidentes (Tabla 2.8).

En el presente trabajo de Tesis sólo se realizó la asignación de los picos más relevantes. Los picos localizados en $927,7,1081,9$ y $1157,1-1159 \mathrm{~cm}^{-1}$ corresponden al estiramiento del enlace C-O siendo el pico de $1081,9 \mathrm{~cm}^{-1}$ característico del estiramiento O-C en el anillo de anhidroglucosa (Zhang y Han, 2006; Pelissari y col., 2013). El pico que se observa en $1419 \mathrm{~cm}^{-1}$ se atribuye al modo de deformación simétrica del $-\mathrm{CH}_{3}$ (Salleh y col., 2009). Las bandas que aparecen a 1458 y $1649 \mathrm{~cm}^{-1} \mathrm{se}$ asignan a las flexiones $\delta$ del grupo $\mathrm{O}-\mathrm{H}$ del agua y del $-\mathrm{CH}_{3}$, respectivamente (Mano y col., 2003). Estos resultados son comparables con los informados por otros autores (Zhang y Han, 2006; Fang y col., 2002; Kacuráková y Wilson, 2001). El pico localizado a $2931 \mathrm{~cm}^{-1}$ es característico del estiramiento del enlace $\mathrm{C}-\mathrm{H}$. La banda extremadamente ancha que aparece con una intensidad máxima a $3365 \mathrm{~cm}^{-1}$ para almidón de mandioca y $3397 \mathrm{~cm}^{-1}$ para almidón de ahipa corresponde a los grupos hidroxilos enlazados por puente de hidrógeno. Esta banda se asocia al complejo vibracional de estiramiento relacionado con grupos hidroxilos libres, inter e intramolecularmente enlazados que 
forman parte de la estructura del almidón (Wu, 2003; Fang y col., 2002). A esta banda contribuyen también los estiramientos de los hidroxilos del agua asociada al almidón.

Tabla 2.8. Picos identificados en los espectros de FTIR de almidones de Pachyrhizus ahipa (ahipa) y de Manihot esculenta (mandioca).

\begin{tabular}{|c|c|}
\hline \multicolumn{2}{|c|}{ Picos en espectros de FTIR $\left(\mathrm{cm}^{-1}\right)$} \\
\hline Ahipa & Mandioca \\
\hline 526,5 & 526,5 \\
\hline 576,6 & 574,7 \\
\hline 612,4 & 612,3 \\
\hline 709,7 & 709,3 \\
\hline 765,6 & 765,6 \\
\hline 860,1 & 860,1 \\
\hline 927,7 & 927,6 \\
\hline 1018,2 & 1016,3 \\
\hline 1081,9 & 1081,9 \\
\hline 1157,1 & 1159 \\
\hline 1241,9 & 1240 \\
\hline 1367 & 1367,3 \\
\hline 1419,3 & 1419,4 \\
\hline 1457,9 & 1457,9 \\
\hline 1648,8 & 1648,8 \\
\hline 2931 & 2931,1 \\
\hline 3397 & 3365 \\
\hline
\end{tabular}

\subsection{Estudio de la estabilidad de los almidones extraídos (Isotermas de sorción)}

La Figura 2.14 muestra los valores experimentales del contenido de humedad de equilibrio en función de la actividad agua $\left(a_{w}\right)$ a 10,20 y $30{ }^{\circ} \mathrm{C}$ para los almidones de ahipa y mandioca. Las desviaciones estándar para el contenido de humedad de equilibrio fueron menores a 0,001 g de agua/g de sólido y por lo tanto no se muestran en la Figura 2.14, a efectos de una mayor claridad. 

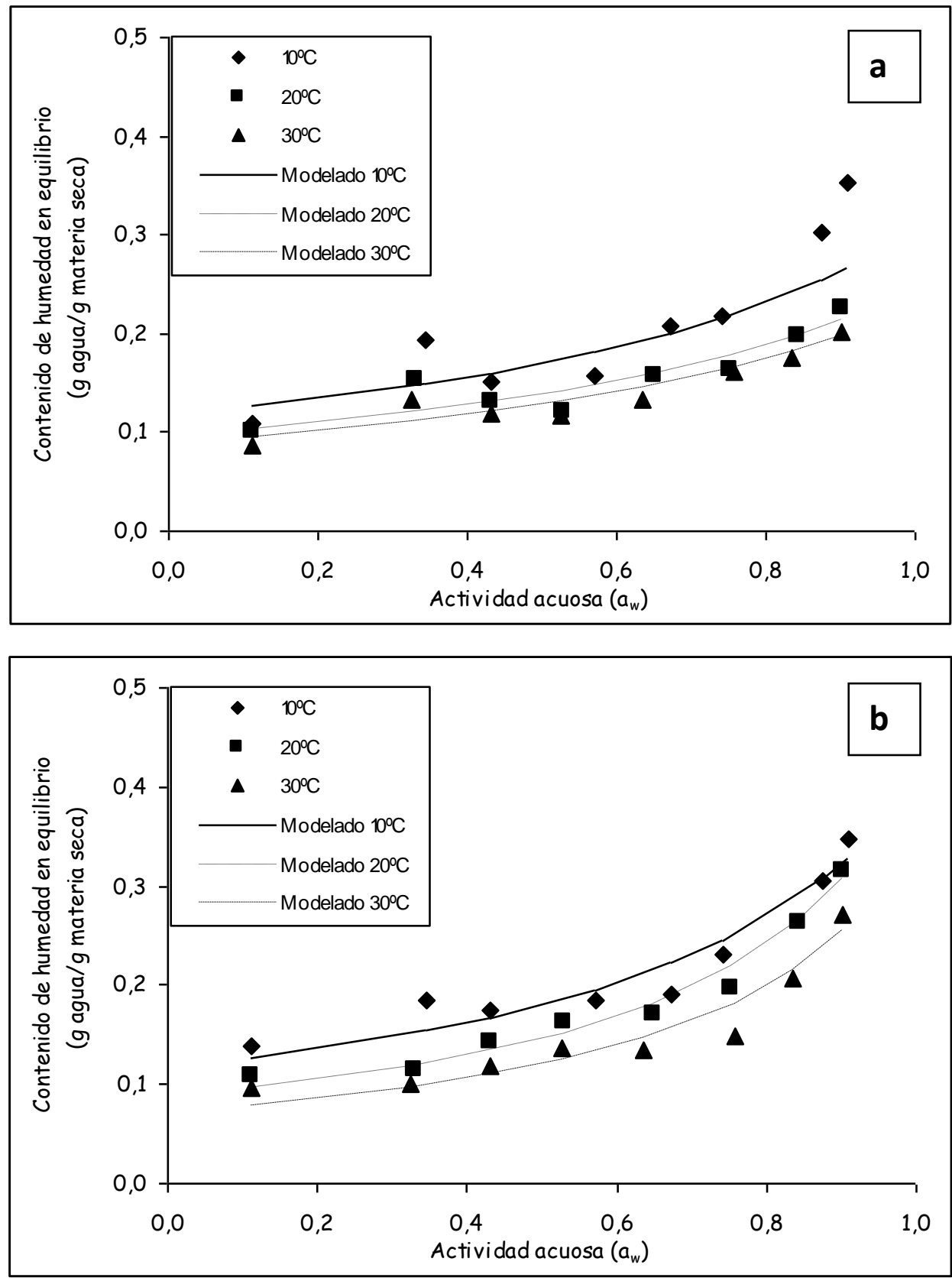

Figura 2.14. Isotermas de sorción de los almidones de (a) Pachyrhizus ahipa (ahipa) y de (b) Manihot esculenta (mandioca).

Nota: Los símbolos corresponden a los datos experimentales en tanto que las líneas señalan el ajuste del modelo de GAB.

Las isotermas de adsorción presentaron forma sigmoidea y correspondieron a isotermas tipo II de acuerdo con la clasificación de BET. Resultados similares fueron también descriptos para otros almidones de distinto origen botánico (Al-Muhtaseb y col., 2004). 
Las formas de las curvas y los datos experimentales concuerdan con la respuesta de la mayoría de los materiales biológicos, particularmente la de los alimentos en polvo (Fasina, 2006) indicando que a valores de $a_{w}$ constantes, la cantidad de agua que pueden retener los almidones disminuye a medida que aumenta la temperatura. Esto ocurre probablemente porque las moléculas de agua a bajas temperaturas tienen una energía cinética que no resulta suficiente para superar la energía de adsorción correspondiente (Polatoğlu y col., 2011). Al mismo tiempo, las moléculas de agua interactúan con los grupos funcionales hidrofílicos del producto. Esta interacción ocurre a través de puentes de hidrógeno, mediante una reacción exotérmica, que no se vería favorecida con los incrementos de temperatura.

Se observó para el almidón de ahipa que las curvas correspondientes a 20 y $30^{\circ} \mathrm{C}$ se cruzaban a valores de $a_{w}$ cercanos a 0,7 (Figura 2.14). Resultados similares fueron informados por Perdomo y col., (2009) quienes indicaron que este hecho podría ser atribuido a una mayor movilidad molecular del agua de la mayoría de los sitios activos, dado que a este valor relativamente alto de $a_{w}$, el agua podría ser liberada principalmente a partir de las regiones cristalinas del almidón.

Como se indicó previamente, los datos experimentales fueron modelados matemáticamente mediante los modelos indicados en la Tabla 2.2.

El modelo matemático de GAB fue el que mejor ajustó los datos experimentales para los almidones de ahipa y mandioca (Figura 2.14). Tanto este modelo como el de BET son los más usados en ciencias de los alimentos dado que sus parámetros tienen significado físico, como el calor de sorción y el contenido de humedad de la monocapa $\left(X_{m}\right)$, que es indicativo de la estabilidad del producto. La ecuación de dos parámetros del modelo de BET sólo describe adecuadamente los datos experimentales por debajo de $a_{w}=0,5$ mientras que el modelo $G A B$ de tres parámetros, considerado uno de los más apropiados para describir las isotermas de sorción de productos alimenticios, es aplicado en el rango completo de $\mathrm{a}_{\mathrm{w}}$. La Tabla 2.9 presenta los parámetros y coeficientes de correlación obtenidos en el ajuste de los datos experimentales con el modelo de GAB para los almidones de ahipa y mandioca.

Labuza (1984) ha señalado que el contenido de humedad máximo de la monocapa para productos alimenticios corresponde a $10 \%$ (en base seca), dado que cuando se supera dicho valor, se compromete la estabilidad del producto. El valor de $X_{m}$ para el 
almidón de mandioca fue menor que el mencionado por Perdomo y col., (2009), que correspondió a $0,0954 \mathrm{~g}$ de agua/g de sólidos secos a $20^{\circ} \mathrm{C}$. Por otra parte, la Tabla 2.9 muestra una tendencia de $\mathrm{X}_{\mathrm{m}}$ a disminuir a medida que aumentó la temperatura para el almidón de ahipa.

Además, cabe mencionar que no existen en la literatura informes referidos a isotermas de sorción para almidones de ahipa.

Tabla 2.9. Parámetros de ajuste del modelo de GAB para las isotermas de sorción de los almidones de Pachyrhizus ahipa (ahipa) y Manihot esculenta (mandioca).

\begin{tabular}{|c|c|c|c|}
\hline Temperatura $\left({ }^{\circ} \mathrm{C}\right)$ & Parámetros de GAB & Ahipa & Mandioca \\
\hline \multirow{4}{*}{10} & $X_{m}$ & 0,118 & 0,116 \\
\hline & $\mathrm{K}$ & 0,610 & 0,712 \\
\hline & C & 1,10 & 26,20 \\
\hline & $\mathrm{R}^{2}$ & 0,987 & 0,993 \\
\hline \multirow{4}{*}{20} & $X_{m}$ & 0,096 & 0,088 \\
\hline & $\mathrm{K}$ & 0,612 & 0,792 \\
\hline & C & 4,54 & 14,20 \\
\hline & $\mathrm{R}^{2}$ & 0,991 & 0,997 \\
\hline \multirow{4}{*}{30} & $X_{m}$ & 0,088 & 0,072 \\
\hline & $\mathrm{K}$ & 0,618 & 0,797 \\
\hline & C & 1,37 & 10,30 \\
\hline & $\mathrm{R}^{2}$ & 0,995 & 0,990 \\
\hline
\end{tabular}

Nota: $\mathrm{X}_{\mathrm{m}}$, contenido de agua de la monocapa ( $\mathrm{g}$ de agua/ $\mathrm{g}$ de sólido seco); $\mathrm{K}$ y C (valores $\times 10^{14}$ ) son parámetros de la ecuación de GAB y $\mathrm{R}^{2}$ es el coeficiente de correlación.

\subsection{Parámetros termodinámicos obtenidos a partir de las isotermas de sorción}

A partir del modelo de $G A B$, se pueden estimar los parámetros termodinámicos para los almidones de ahipa y mandioca.

En las Figuras 2.15 y 2.16 se observa la variación del calor isostérico (entalpía diferencial) y la entropía diferencial en función del contenido de humedad para el almidón de ahipa. Un comportamiento similar se obtuvo para el almidón de mandioca. 


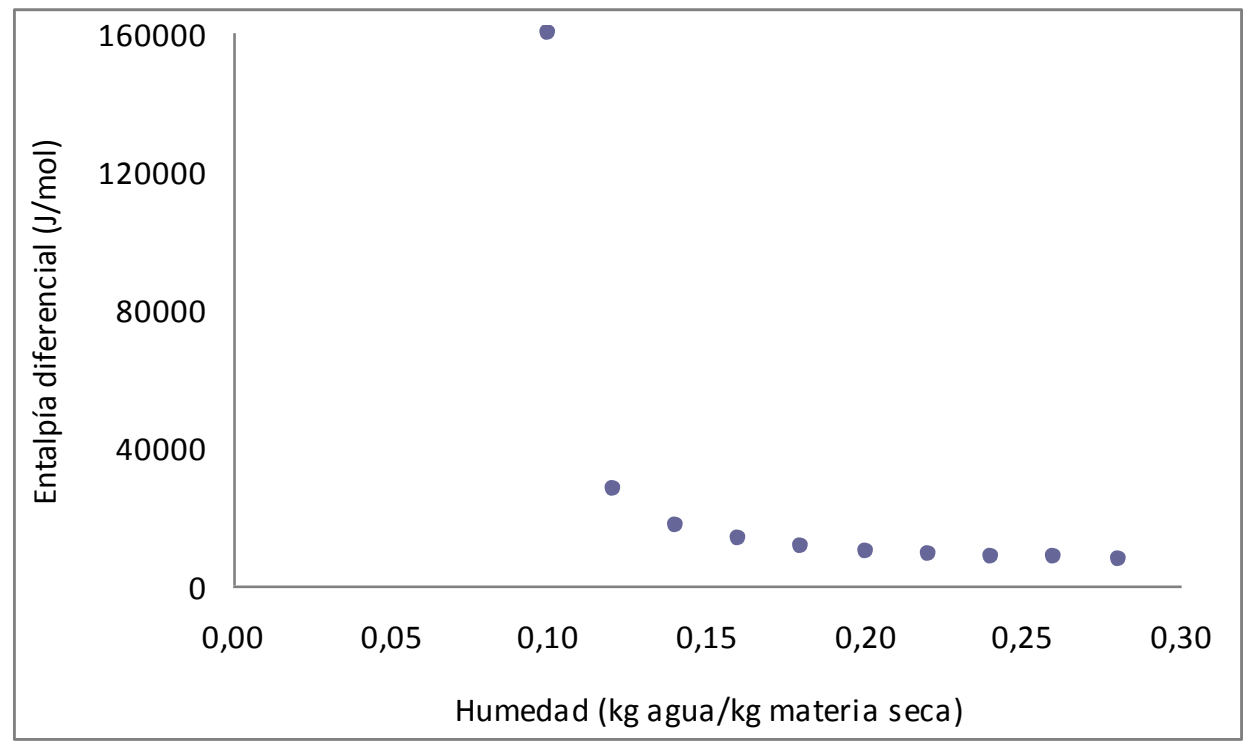

Figura 2.15. Entalpía diferencial en función del contenido de humedad del almidón de Pachyrhizus ahipa (ahipa).

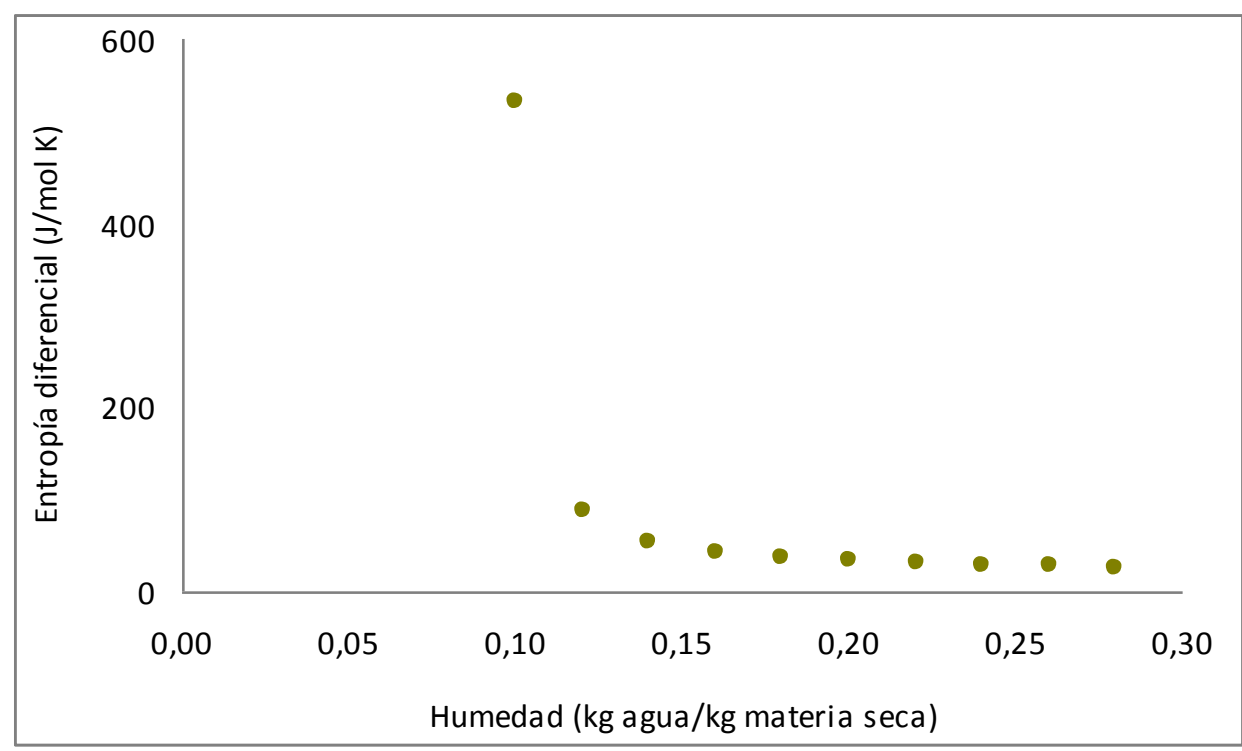

Figura 2.16. Entropía diferencial en función del contenido de humedad del almidón de Pachyrhizus ahipa (ahipa).

Las Figuras 2.15 y 2.16 muestran que tanto la entalpía como la entropía diferencial disminuyeron exponencialmente con el aumento del contenido de humedad, con una fuerte dependencia a bajos contenidos de humedad. Este comportamiento se puede atribuir a la ubicación del agua unida y al grado en que la interacción sólido-agua es mayor que la interacción de las moléculas de agua entre sí (Fasina, 2006; McMinn y 
Magee, 2003; Thys y col., 2010). Por lo tanto, a bajos contenidos de humedad, la energía requerida para producir la desorción de las moléculas de agua será mayor, ya que están fuertemente limitadas a los sitios disponibles de la matriz sólida.

La Figura 2.17 muestra que la entalpía diferencial varía linealmente con la entropía diferencial (con un coeficiente de regresión superior a 0,999 en todos los casos), lo que indica que la teoría de la compensación es aplicable en los sistemas estudiados.

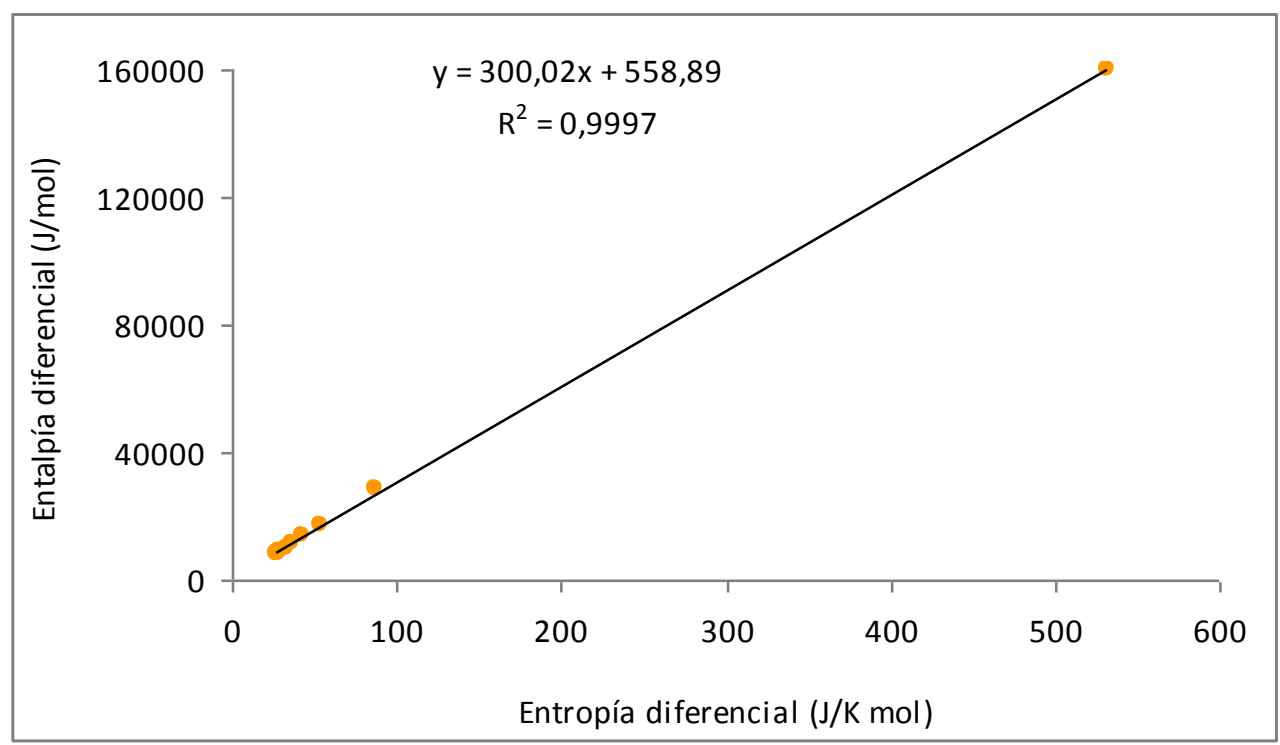

Figura 2.14. Entropía diferencial versus entalpía diferencial del almidón de Pachyrhizus ahipa (ahipa).

Esta correlación permite la estimación de la variación de energía libre de Gibbs $(\Delta \mathrm{G})$, así como la temperatura isocinética. $\Delta G$ es una medida del trabajo realizado por el sistema para llevar a cabo un proceso de adsorción o desorción. $\Delta G$ se puede utilizar como indicador del estado del agua adsorbida por las partículas sólidas, lo que determina la estabilidad física, química y microbiana de los materiales biológicos durante el almacenamiento (Aviara y Ajibola, 2002). Los valores obtenidos se resumen en la Tabla 2.10 para los almidones analizados y se observa que la temperatura isocinética para almidón de mandioca fue más alta que para el de ahipa.

Una tendencia similar observaron Thys y col. (2010) para la temperatura isocinética del almidón de piñón (pinhão, 428 K), y Cladera-Olivera y col. (2009) para su correspondiente harina (398 K). Del mismo modo, en el caso de la batata, Fasina (2006) ha destacado que la teoría de la compensación de entalpía-entropía se cumplía 
con una temperatura isocinética de $407,9 \mathrm{~K}$. Los valores de temperatura isocinética obtenidos están dentro del rango de los señalados para los granos de quínoa (361 K, Tolaba y col., 2004), ajo (348 K, Madamba y col., 1996), harina y copos de avena $(430,9$ y 443,4, respectivamente, McMinn y col., 2007), y sucuk un preparado alimenticio de origen turco (323,4 K, Polatoğlu y col., 2011).

Tabla 2.10. Parámetros termodinámicos calculados para los almidones de Pachyrhizus ahipa (ahipa) y Manihot esculenta (mandioca).

\begin{tabular}{ccc} 
Parámetro & Almidón de ahipa & Almidón de mandioca \\
\hline Temperatura isocinética (K) & 300 & 309 \\
\hline Energía libre de Gibbs $\left(\mathrm{J} \mathrm{mol}^{-1}\right)$ & 558,8 & 323,7
\end{tabular}

Cladera-Olivera y col. (2009) han señalado que la adsorción de agua de la harina de pinhao era un proceso no-espontáneo con un valor de $\Delta \mathrm{G}$ de $339 \mathrm{~J} \mathrm{~mol}^{-1}$, que es menor que los encontrados para los almidones estudiados. Además, teniendo en cuenta otros productos a base de almidón, McMinn y col. (2007) señalaron valores de $\Delta G$ de 280 y $325 \mathrm{~J} \mathrm{~mol}^{-1}$ para galletas de harina de avena y copos de avena, respectivamente.

\section{Propiedades funcionales de los almidones extraídos}

\subsection{Capacidad de retención de agua}

El almidón de ahipa mostró una capacidad de retención de agua $(81,6 \pm 3,5 \%)$ significativamente menor $(p<0,05)$ que el almidón de mandioca $(88,2 \pm 1,6 \%)$, (Figura 2.18).

Los resultados fueron relativamente bajos en comparación con otros ingredientes o aditivos alimentarios, tales como fibras dietarias de salvado de avena (2,10 g de agua / g de materia seca), salvado de arroz (4,89 g de agua / g de materia seca), harina de soja (4,79 a 6,75 g de agua / $g$ de materia seca) y salvado de trigo (5,03 g de agua / $g$ de materia seca), (Abdul-Hamid y Luan, 2000; Chen, 1988; Heywood y col., 2002). 


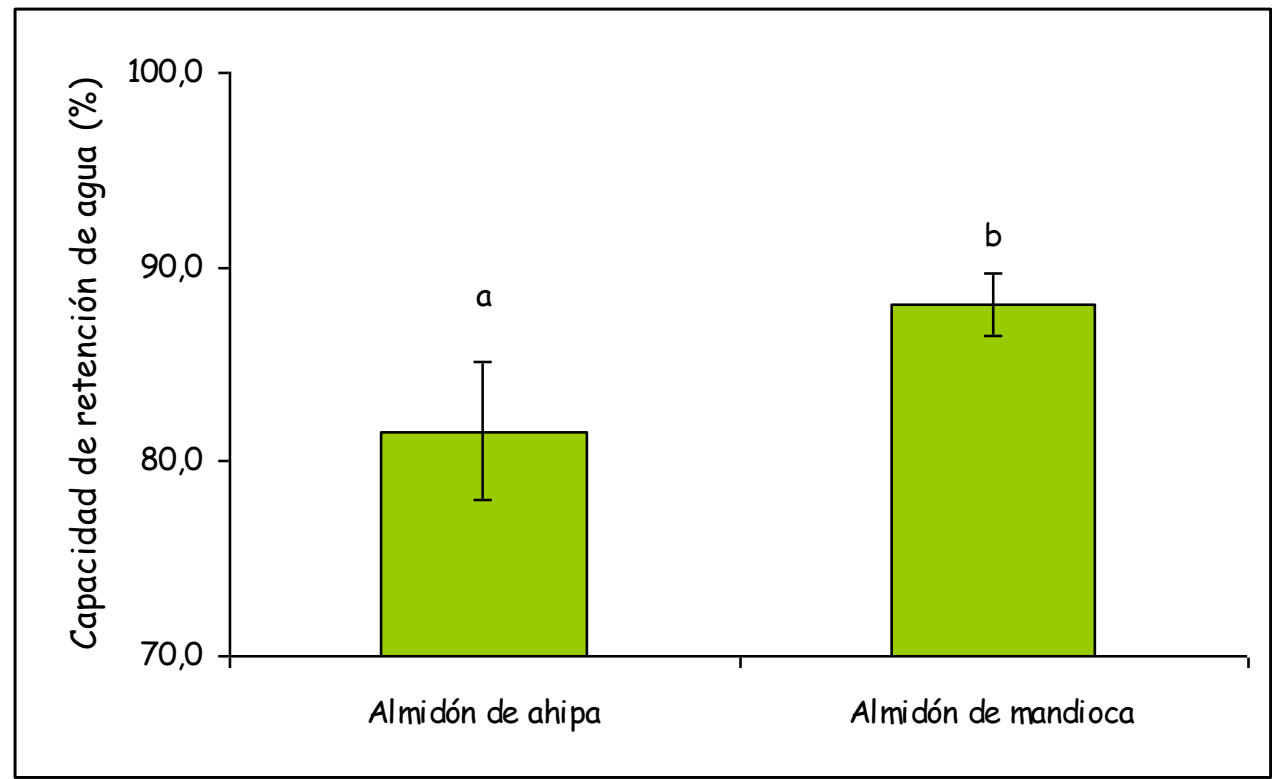

Figura 2.18. Capacidad de retención de agua del almidón de Pachyrhizus ahipa (ahipa) y de Manihot esculenta (mandioca).

\subsection{Gelatinización de las suspensiones de almidón. Transiciones térmicas}

Como ya ha sido mencionado anteriormente, la gelatinización es un proceso endotérmico que va acompañado de la lixiviación de amilosa y pérdida de la birrefringencia del gránulo. Al final de este fenómeno se genera una pasta en la que coexisten cadenas de amilosa de bajo peso molecular altamente hidratadas que rodean a los restos de los gránulos, también hidratados, en los que permanece mayoritariamente la amilopectina.

El proceso de gelatinización del almidón depende de varios factores como la arquitectura molecular de la región cristalina de los gránulos, la relación amilosa/amilopectina, la distribución de la longitud de las cadenas como así también de la fuente botánica, el contenido de humedad de la muestra y de ciertas condiciones experimentales tales como pH, presencia de sólidos, etc. (Huang y Rooney, 2001; López y col., 2010).

Las suspensiones de almidón de ahipa exhibieron termogramas (Figura 2.19) con una sola transición endotérmica, típica del proceso de gelatinización de suspensiones con elevado contenido de agua. Este proceso es de gran importancia para la industria de alimentos ya que la gelatinización del almidón se relaciona directamente con la textura de los productos cocidos que lo incluyan en su formulación. 


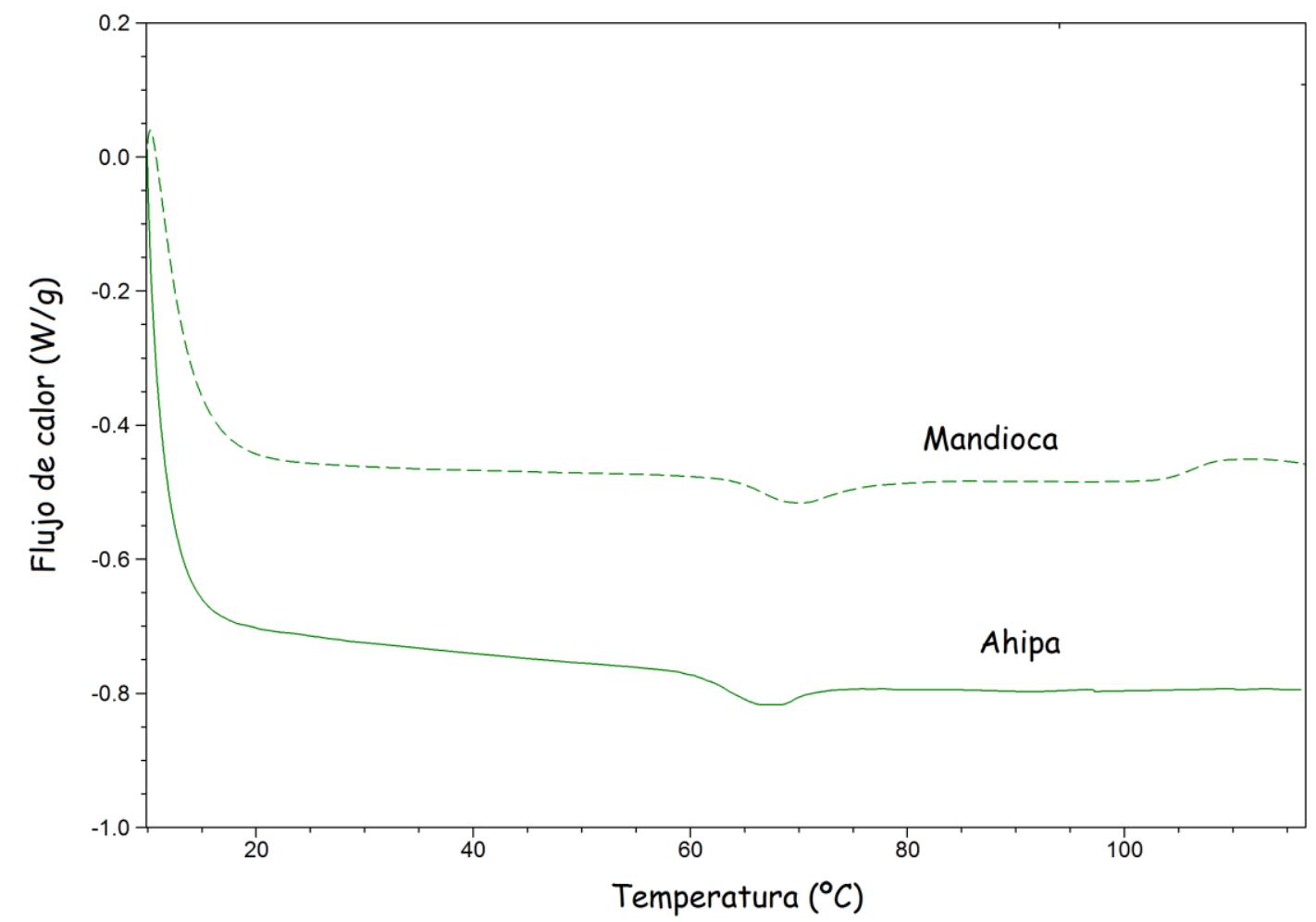

Figura 2.19. Termogramas de almidones de Pachyrhizus ahipa (ahipa) y de Manihot esculenta (mandioca).

La Tabla 2.11 muestra los parámetros térmicos de los almidones extraídos determinados por DSC.

El almidón de ahipa gelatinizó a temperaturas significativamente más bajas $(p<0,05)$ que el de mandioca, evidenciando la dependencia de ésta con el origen botánico del almidón, además de la variedad y de las condiciones de cultivo. Asimismo, los almidones extraídos de raíces tuberosas presentaron temperaturas de gelatinización más bajas que el almidón de maíz $\left(72,2 \pm 0,1^{\circ} \mathrm{C}\right)$, indicando una buena aptitud para la cocción y un menor costo energético asociado. Se espera además que sus pastas presenten elevada claridad y viscosidad (Mélo y col., 2003). El almidón de ahipa presentó un rango de gelatinización $\left(T_{f}-T_{i}\right)$ significativamente menor $(p<0,05)$ que el de mandioca, lo que podría relacionarse con un proceso altamente cooperativo (Huang, 2009) y una distribución de tamaño de las cadenas de amilosa y amilopectina más estrecho.

Los parámetros térmicos obtenidos para el almidón de mandioca se encuentran próximos a los señalados por otros autores para almidones de diferentes orígenes 
botánicos (Mélo y col., 2003; Pérez y col., 1998). La entalpía de gelatinización obtenida resultó similar a la informada por Betancur-Ancona y col., (2001).

Tabla 2.11. Temperaturas de inicio, de pico y final $\left(T_{i}, T_{p}\right.$ y $\left.T_{f}\right)$ y entalpía de gelatinización $(\Delta \mathrm{H})$ de almidones extraídos de raíces tuberosas.

\begin{tabular}{ccccc} 
Almidón & $\mathrm{Ti}\left({ }^{\circ} \mathrm{C}\right)$ & $\mathrm{Tp}\left({ }^{\circ} \mathrm{C}\right)$ & $\mathrm{Tf}\left({ }^{\circ} \mathrm{C}\right)$ & $\Delta \mathrm{H}(\mathrm{J} / \mathrm{g})$ \\
\hline Ahipa & $64,3 \pm 0,2^{\mathrm{b}}$ & $67,2 \pm 0,1^{\mathrm{a}}$ & $70,5 \pm 0,2^{\mathrm{a}}$ & $9,5 \pm 0,6^{\mathrm{a}}$ \\
\hline Mandioca & $51,7 \pm 0,8^{\mathrm{a}}$ & $69,9 \pm 0,0^{\mathrm{b}}$ & $85,0 \pm 0,5^{\mathrm{b}}$ & $9,7 \pm 0,4^{\mathrm{a}}$
\end{tabular}

Nota: Los valores informados corresponden a las medias \pm las desviaciones estándar. La entalpía se encuentra expresada en base seca. Letras diferentes en cada columna indican diferencias significativas $(p<0,05)$.

\subsection{Capacidad de hinchamiento de los gránulos}

Cuando una suspensión acuosa de almidón se calienta, los gránulos se hinchan y la estructura cristalina de los mismos se ve interrumpida (Huang y col., 2007).

La capacidad de hinchamiento de los gránulos cumple un rol muy importante en el comportamiento reológico de las suspensiones de almidón y se puede determinar de acuerdo a una modificación del método de Tsai y col. (1997).

La Figura 2.20 muestra la capacidad de hinchamiento de los gránulos de los almidones de ahipa y de mandioca en función de la temperatura de calentamiento, observándose un incremento del mismo con la temperatura. Este comportamiento se debe a que el agua absorbida permite que se reemplacen las interacciones entre cadenas por interacciones con el solvente por formación de puentes de hidrógeno (Eliasson, 2004). El alto poder de hinchamiento del almidón de papa puede ser explicado por su alto contenido de fosfatos, ya que la carga negativa puede facilitar el ingreso de agua a los gránulos (Mélo y col., 2003; Swinkels, 1985).

La capacidad de hinchamiento de los gránulos de almidón puede relacionarse también con los parámetros térmicos indicados con anterioridad (Tabla 2.11). El bajo grado de hinchamiento de los gránulos de ahipa que se observa a $55^{\circ} \mathrm{C}$ puede atribuirse a que a esa temperatura el proceso de gelatinización aún no comenzó. Cuando la suspensión alcanza los $65^{\circ} \mathrm{C}$ se produce un aumento significativo del hinchamiento de los gránulos debido al inicio del proceso de gelatinización $\left(T>T_{i}\right)$. Por último, a partir de los $85^{\circ} \mathrm{C}$ 
$\left(T>T_{f}\right)$ el aumento registrado podría atribuirse a que el agua se incorpora activamente mediante puentes de hidrógeno y se asocia a las cadenas de amilosa que forman la red y a las de amilopectina que permanecen aún en los gránulos.

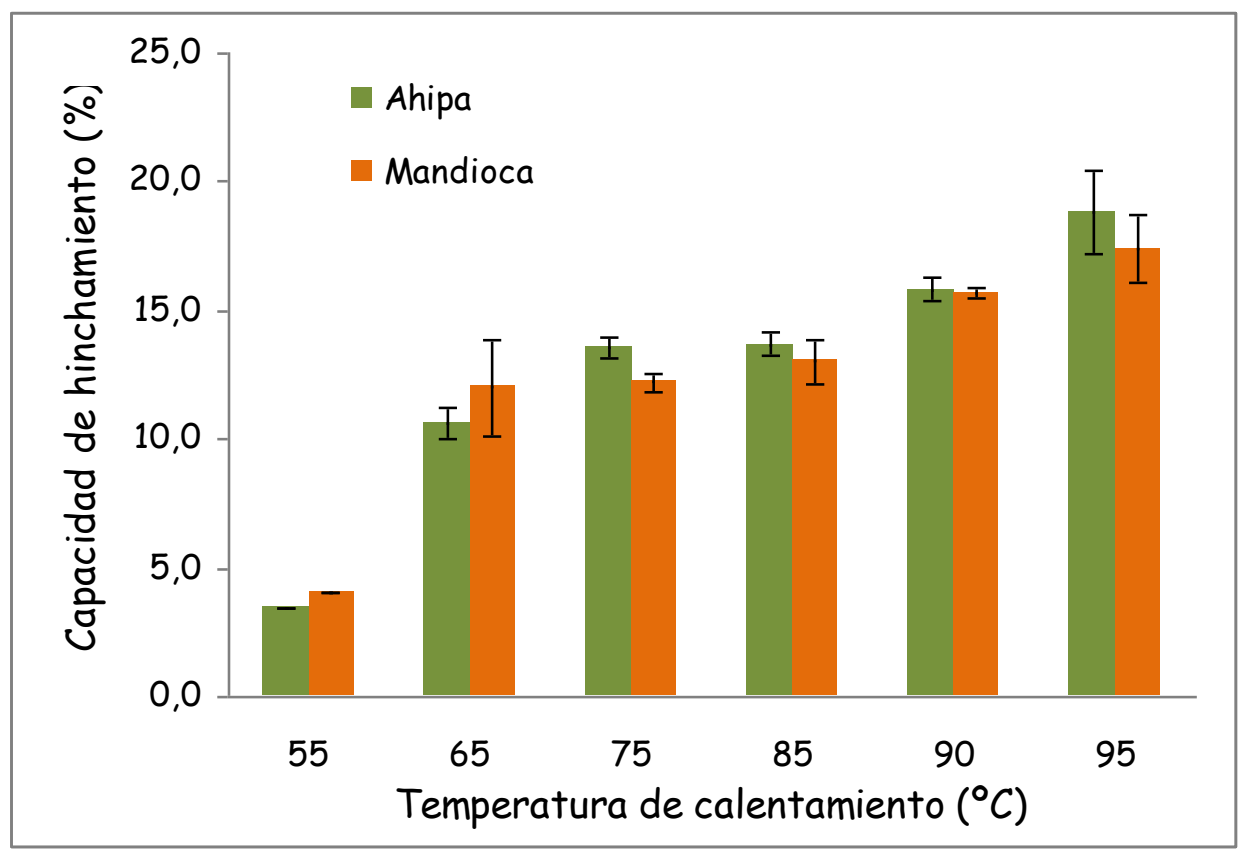

Figura 2.20. Capacidad de hinchamiento de gránulos de almidón de Pachyrhizus ahipa (ahipa) y de Manihot esculenta (mandioca) luego de una hora de calentamiento a diferentes temperaturas.

A $55^{\circ} \mathrm{C}$ el mayor grado de hinchamiento de los gránulos de mandioca se correlaciona con la menor temperatura de inicio del proceso de gelatinización $\left(51,7 \pm 0,8^{\circ} \mathrm{C}\right)$, (Figura 2.20).

Cuando la suspensión alcanza los $65^{\circ} \mathrm{C}$, el hinchamiento de los gránulos aumenta drásticamente ya que a esta temperatura los gránulos de los almidones de ambas raíces comenzaron el proceso de gelatinización $\left(T>T_{i}\right.$, Tabla 2.11).

A partir de los $85^{\circ} \mathrm{C}\left(T>T_{f}\right.$, Tabla 2.11$)$ no se hallaron diferencias significativas $(p>0,05)$ entre el hinchamiento de los gránulos de los almidones de diferente origen botánico. A temperaturas mayores el aumento registrado podría atribuirse a la mayor cantidad de agua asociada a la red de amilosa y a la amilopectina remanente en los gránulos. 
En general, el poder de hinchamiento del almidón de mandioca fue menor que el de ahipa. Según Mélo y col., (2003) la capacidad de hinchamiento correlaciona inversamente con el contenido de amilosa. Este resultado coincide con lo esperado.

\subsection{Comportamiento reológico de las pastas de almidón}

Las propiedades reológicas de las pastas de almidón tienen un alto impacto tecnológico en el desarrollo de alimentos ya que determinan las condiciones de procesamiento de los mismos.

Los ensayos rotacionales condujeron al análisis del comportamiento reológico de las pastas de almidón cuando éstas fueron sometidas a condiciones similares a las del procesamiento a escala industrial, como por ejemplo un alto esfuerzo de corte.

Las suspensiones acuosas al 4\% p/p de almidón de ahipa (accesiones 11 y Local) y mandioca, gelatinizadas a $90^{\circ} \mathrm{C}$ durante 20 minutos, presentaron un comportamiento pseudoplástico $(n<1)$ modelado satisfactoriamente por el modelo de Ostwald de Waele (Figura 2.21 y Tabla 2.12). Es importante destacar que $4 \% \mathrm{p} / \mathrm{p}$ corresponde a la mínima concentración que permite la formación de geles además de ser una de las más utilizadas en la formulación de alimentos, como ya se mencionó.

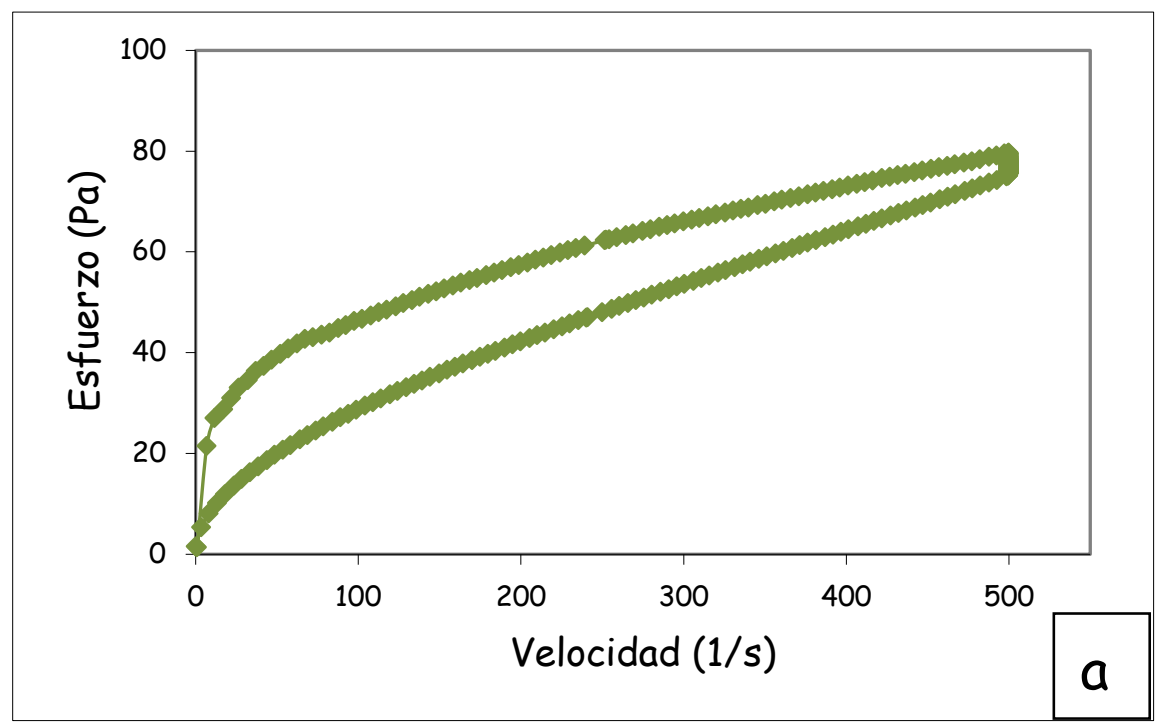



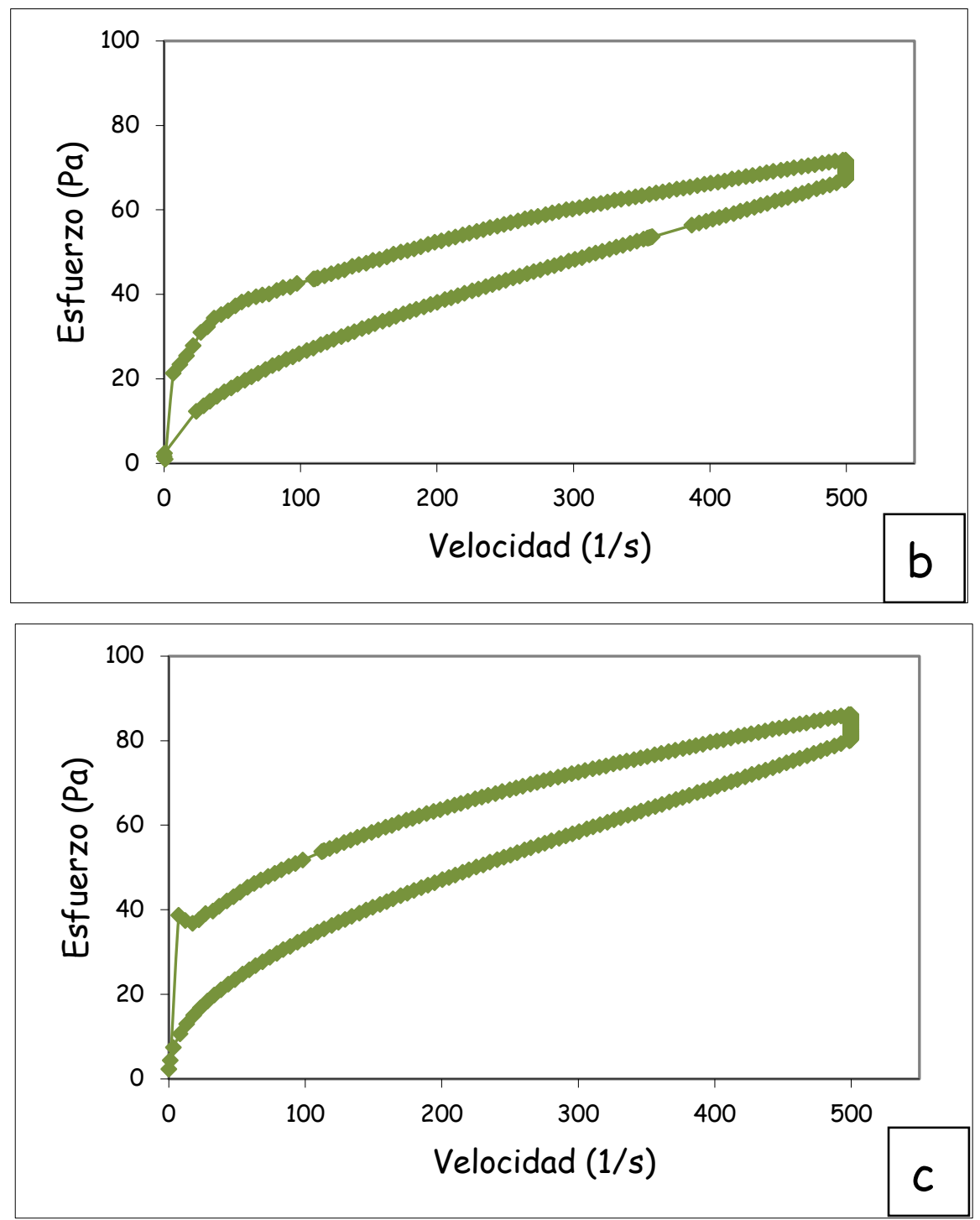

Figura 2.18. Curva de comportamiento de flujo (esfuerzo de corte versus velocidad de deformación) de suspensiones gelatinizadas de almidones de (a) Pachyrhizus ahipa

(ahipa) accesión Local, (b) Pachyrhizus ahipa (ahipa) accesión 11 y (c) Manihot esculenta (mandioca).

Además, las suspensiones de almidón gelatinizadas se caracterizaron como tixotrópicas, lo que indica que el comportamiento reológico de estos sistemas era dependiente del tiempo (Figura 2.21). Los sistemas tixotrópicos exhiben una disminución del esfuerzo de cizallamiento y de la viscosidad aparente con el tiempo a velocidad de deformación fija. Los índices tixotrópicos se calcularon como el área entre las curvas de flujo, como ya se mencionó. No se detectaron diferencias significativas $(p>0,05)$ entre las suspensiones de almidón de ahipa gelatinizadas (Tabla 2.12). Las 
suspensiones de almidón de mandioca gelatinizadas mostraron los valores más altos $(p<0,05)$ de tixotropía y viscosidad aparente (Tabla 2.12), lo que indica que la amilopectina remanente dentro de los gránulos de almidón refuerza más efectivamente la red de amilosa que en el caso de almidón de ahipa. Esto se atribuiría a las diferencias existentes en las distribuciones de los tamaños moleculares de las cadenas de amilosa y amilopectina de los almidones estudiados.

Tabla 2.12. Valores de tixotropía, viscosidad aparente y parámetros de ajuste del modelo de Ostwald de Waele de las suspensiones de almidones extraídos de raíces tuberosas.

\begin{tabular}{c|c|c|c|c|c|}
\multirow{2}{*}{ Almidón } & \multirow{2}{*}{ Tixotropía $(\mathrm{Pa} / \mathrm{s})$} & \multicolumn{3}{|c}{ Modelo de Ostwald de Waele } & \multirow{2}{*}{ N (mPa*s) } \\
\cline { 3 - 5 } & & $\mathrm{k}\left(\mathrm{Pa} / \mathrm{s}^{\mathrm{n}}\right)$ & $\mathrm{n}$ & $\mathrm{r}^{2}$ & \\
\hline Ahipa Local & 6564 & 11,227 & 0,314 & 0,9928 & $156,0 \pm 3,5^{\mathrm{a}, \mathrm{b}}$ \\
\hline Ahipa 11 & 6580 & 11,228 & 0,304 & 0,9938 & $145,6 \pm 10,7^{\mathrm{a}}$ \\
\hline Mandioca & 7672 & 14,570 & 0,281 & 0,99 & $166,5 \pm 5,7^{\mathrm{b}}$ \\
\hline
\end{tabular}

Nota: $\mathrm{k}$ (índice de consistencia) y $\mathrm{n}$ (índice de comportamiento de flujo) son parámetros del modelo de Ostwald de Waele y $\mathrm{r}^{2}$ es el coeficiente de correlación.

Los valores de viscosidad aparente $(\eta)$ informados corresponden a las medias \pm las desviaciones estándar. Letras diferentes en esta columna indican diferencias significativas $(p<0,05)$.

Los ensayos oscilatorios (dinámicos) evalúan el comportamiento reológico dentro del rango de viscoelasticidad lineal donde la muestra no sufre daño estructural. Para poder realizar estos ensayos previamente se realizaron barridos de esfuerzo a frecuencia constante para determinar dicho rango. Para el caso de las suspensiones gelatinizadas de los almidones de ahipa y de mandioca el rango de viscoelasticidad lineal se extiende hasta $2 \mathrm{~Pa}$, así para los barridos de frecuencia el esfuerzo se mantuvo a $1 \mathrm{~Pa}$.

La Figura 2.22 muestra el espectro mecánico correspondiente a la suspensión gelatinizada de almidón de ahipa Local, observándose que los valores del módulo de almacenamiento o elástico $\left(\mathrm{G}^{\prime}\right)$ resultan significativamente más altos $(p<0,05)$ que los del módulo de pérdida o viscoso $\left(G^{\prime \prime}\right)$, permaneciendo prácticamente constante en todo el rango de frecuencias analizado, lo que indica que las pastas se comportaron como geles débiles $\left(G^{\prime}>G^{\prime \prime}\right)$. Un comportamiento similar se observó para las pastas de 
almidón de mandioca. Además, Lee y Yoo (2009) también informaron un comportamiento similar de gel débil para pastas de almidón de batata.
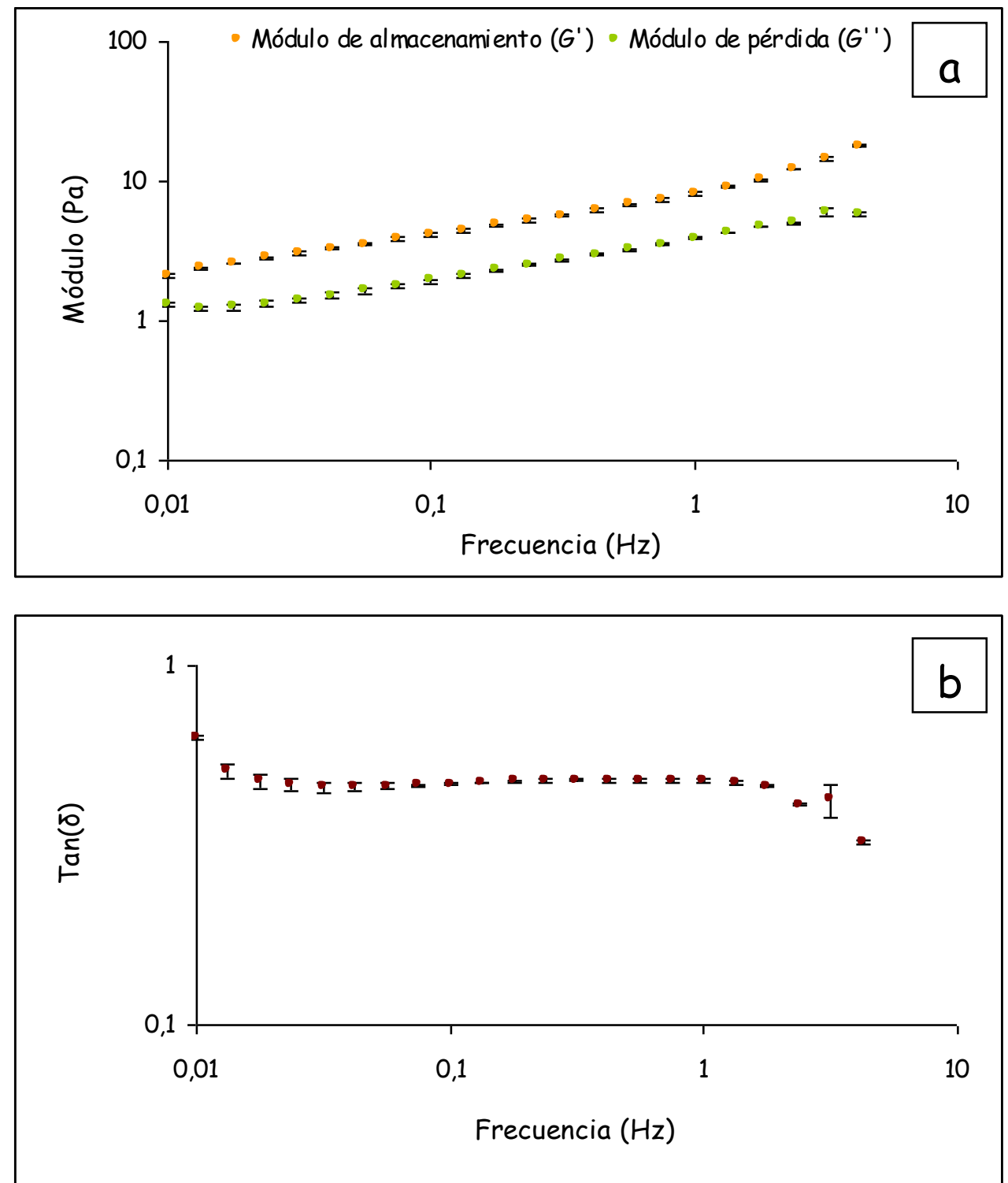

Figura 2.22. Espectro mecánico (a) módulo $\left(G^{\prime} \circ G^{\prime \prime}\right)$ versus frecuencia y (b) tangente del ángulo de desfasaje $(\bar{\delta})$ versus frecuencia, de una suspensión gelatinizada de almidón de Pachyrhizus ahipa (ahipa) accesión Local.

Del mismo modo, no se observaron diferencias significativas $(p>0,05)$ en los valores de los módulos G' y G" para las pastas de los almidones de ahipa de diferentes accesiones (Local y 11). Las suspensiones gelatinizadas de ahipa exhibieron valores de $\mathrm{G}^{\prime}$ significativamente menores $(p<0,05)$ que las correspondientes a mandioca. Por 
ejemplo, a $1 \mathrm{~Hz}$, los valores de los módulos G' y G" de las pastas de almidón de mandioca fueron 68 y $55 \%$ mayores, respectivamente, que los valores correspondientes a las pastas de almidón de ahipa (Figura 2.23).

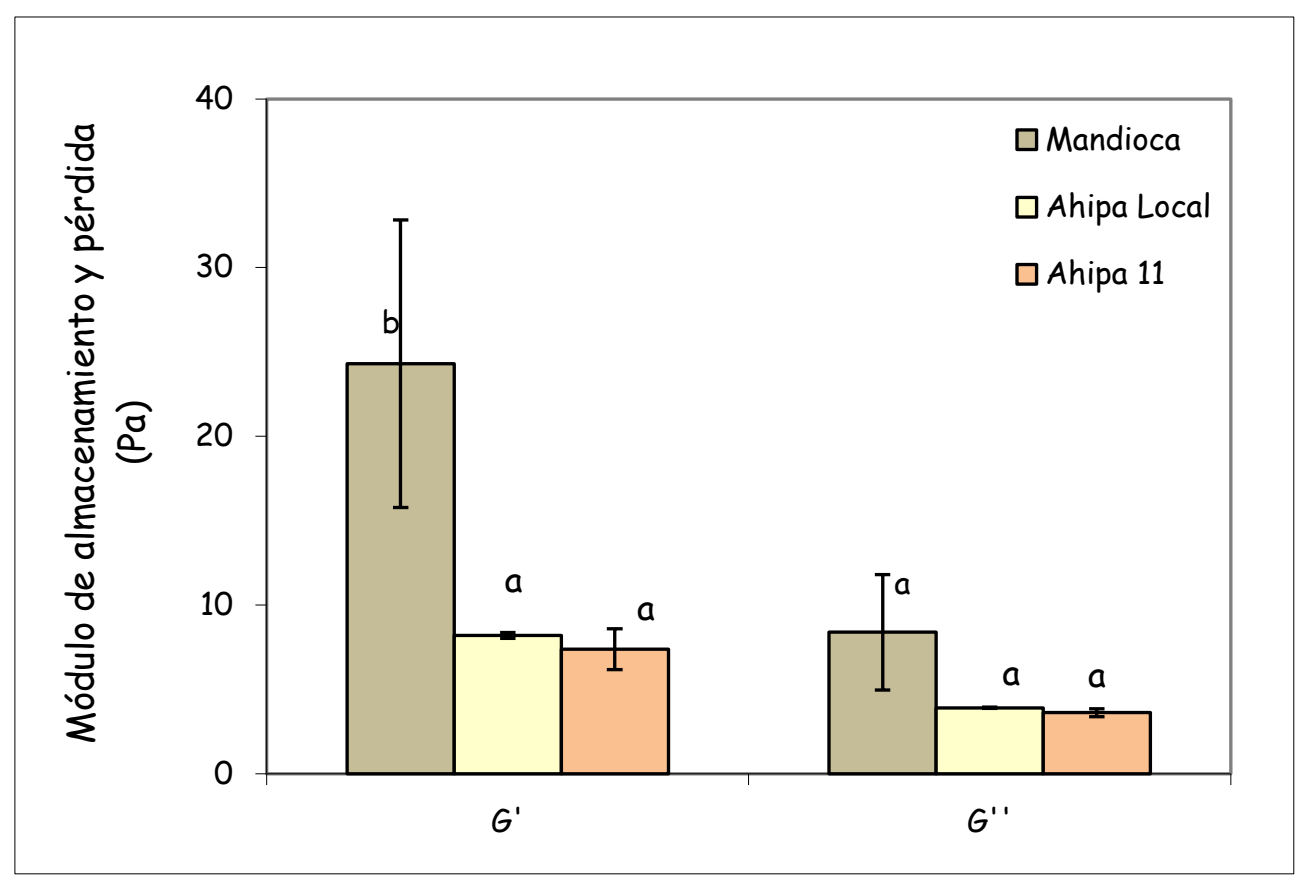

Figura 2.23. Módulos de almacenamiento (G') y de pérdida (G") a $1 \mathrm{~Hz}$ de las suspensiones gelatinizadas de almidones de Pachyrhizus ahipa (ahipa accesiones 11 y Local) y de Manihot esculenta (mandioca).

Nota: Los valores informados corresponden a las medias \pm las desviaciones estándar. Letras diferentes en cada módulo ( $\left.\mathrm{G}^{\prime} \circ \mathrm{G}^{\prime \prime}\right)$ indican diferencias significativas $(p<0,05)$.

Los resultados reológicos dinámicos se correlacionan con las viscosidades aparentes informadas previamente (Tabla 2.12). Las diferencias en las propiedades reológicas de las pastas de almidón de ahipa y mandioca se pueden atribuir a diferencias en el tamaño y forma de los gránulos (López y col., 2012), a la presencia de ésteres de fosfato, así como también a la relación amilosa/amilopectina y a la distribución de tamaño de las cadenas de ambos componentes. Se ha informado que la capacidad de hinchamiento de los gránulos y la temperatura gobiernan las propiedades viscoelásticas de la suspensiones de almidón gelatinizadas (Shon y Yoo, 2006).

Una tendencia similar fue observada por Che y col., (2008) en el estudio del comportamiento reológico de pastas de almidones de dos cultivares de mandioca. 
Los valores de la tangente del ángulo de desfasaje $(\delta)$ de las suspensiones de almidón gelatinizado fueron inferiores a 1 , lo que indica que las muestras son de naturaleza elástica, como se ejemplifica en la Figura 2.22, para el almidón de ahipa Local.

Los espectros mecánicos de las pastas de almidón se modelaron usando las ecuaciones correspondientes al modelo de la ley de potencia (Steffe, 1996):

$$
\begin{aligned}
& \mathrm{G}^{\prime}=\mathrm{a} \times \omega^{\mathrm{b}} \\
& \mathrm{G}^{\prime \prime}=\mathrm{c} \times \omega^{\mathrm{d}}
\end{aligned}
$$

Donde:

$\omega:$ es la frecuencia expresada en $\mathrm{Hz}$.

a, b, c y d: son los parámetros de ajuste del modelo.

Las ecuaciones propuestas ajustaron satisfactoriamente la variación de los módulos de almacenamiento y pérdida con la frecuencia, alcanzando las pastas de los almidones de ahipa los valores más altos de los coeficientes de correlación. Los valores de los parámetros de ajuste se muestran en la Tabla 2.13. No se detectaron diferencias significativas $(p>0,05)$ entre las pastas de los almidones de diferentes accesiones de ahipa mientras que, en general, los valores más altos de los parámetros del modelo matemático se obtuvieron para las pastas de almidón de mandioca.

Tabla 2.13. Parámetros correspondientes al modelado de los espectros mecánicos de suspensiones de almidones extraídos de raíces tuberosas.

Módulo de almacenamiento $\mathrm{G}^{\prime}(\mathrm{Pa}) \quad$ Módulo de pérdida $\mathrm{G}$ " $(\mathrm{Pa})$

\begin{tabular}{ccccccc} 
Almidón & \multicolumn{3}{c}{$\mathrm{G}^{\prime}=\mathrm{a} \omega^{\mathrm{b}}$} & $\mathrm{G}^{\prime \prime}=\mathrm{c} \omega^{\mathrm{d}}$ \\
\cline { 2 - 7 } & Parámetro a & Parámetro $\mathrm{b}$ & $\mathrm{r}^{2}$ & Parámetro c & Parámetro d & $\mathrm{r}^{2}$ \\
\hline Ahipa Local & $3,6 \pm 0,9^{\mathrm{a}}$ & $0,56 \pm 0,01^{\mathrm{a}}$ & 0,9779 & $4,2 \pm 1,1^{\mathrm{a}}$ & $0,41 \pm 0,06^{\mathrm{b}}$ & 0,9804 \\
\hline Ahipa 11 & $3,5 \pm 1,0^{\mathrm{a}}$ & $0,55 \pm 0,01^{\mathrm{a}}$ & 0,981 & $4,0 \pm 1,1^{\mathrm{a}}$ & $0,42 \pm 0,07^{\mathrm{b}}$ & 0,9723 \\
\hline Mandioca & $14,3 \pm 4,1^{\mathrm{b}}$ & $1,1 \pm 0,4^{\mathrm{b}}$ & 0,9681 & $15,9 \pm 4,7^{\mathrm{b}}$ & $0,25 \pm 0,02^{\mathrm{a}}$ & 0,9779
\end{tabular}

Nota: Los parámetros de ajuste $(a, b, c, d)$ corresponden al modelo de la ley de la potencia y $r^{2}$ es el coeficiente de correlación. Los valores informados corresponden a las medias \pm las desviaciones estándar. Letras diferentes en cada columna indican diferencias significativas $(p<0,05)$. 
La dependencia de los módulos con la frecuencia, también puede dar información valiosa sobre la estructura de las pastas. Un material que presenta módulos elásticos y viscosos independientes de la frecuencia tiene un comportamiento de gel, donde prevalece la contribución de la componente elástica $\left(G^{\prime}>G^{\prime \prime}\right)$. Por el contrario, una fuerte dependencia de la frecuencia sugiere un comportamiento de solución concentrada donde predomina la componente viscosa ( $\left.G^{\prime \prime}>G^{\prime}\right)$ (Ross-Murphy, 1994).

\subsection{Retrogradación de las pastas de almidón bajo condiciones de refrigeración}

La retrogradación es un proceso que ocurre cuando en las suspensiones de almidón gelatinizadas las cadenas de amilosa y amilopectina se reasocian formando una estructura más ordenada. Las pastas de los almidones estudiados se almacenaron durante 11 días bajo condiciones de refrigeración $\left(4^{\circ} \mathrm{C}\right)$, siendo éste el tiempo máximo de almacenamiento debido al desarrollo microbiano en los geles.

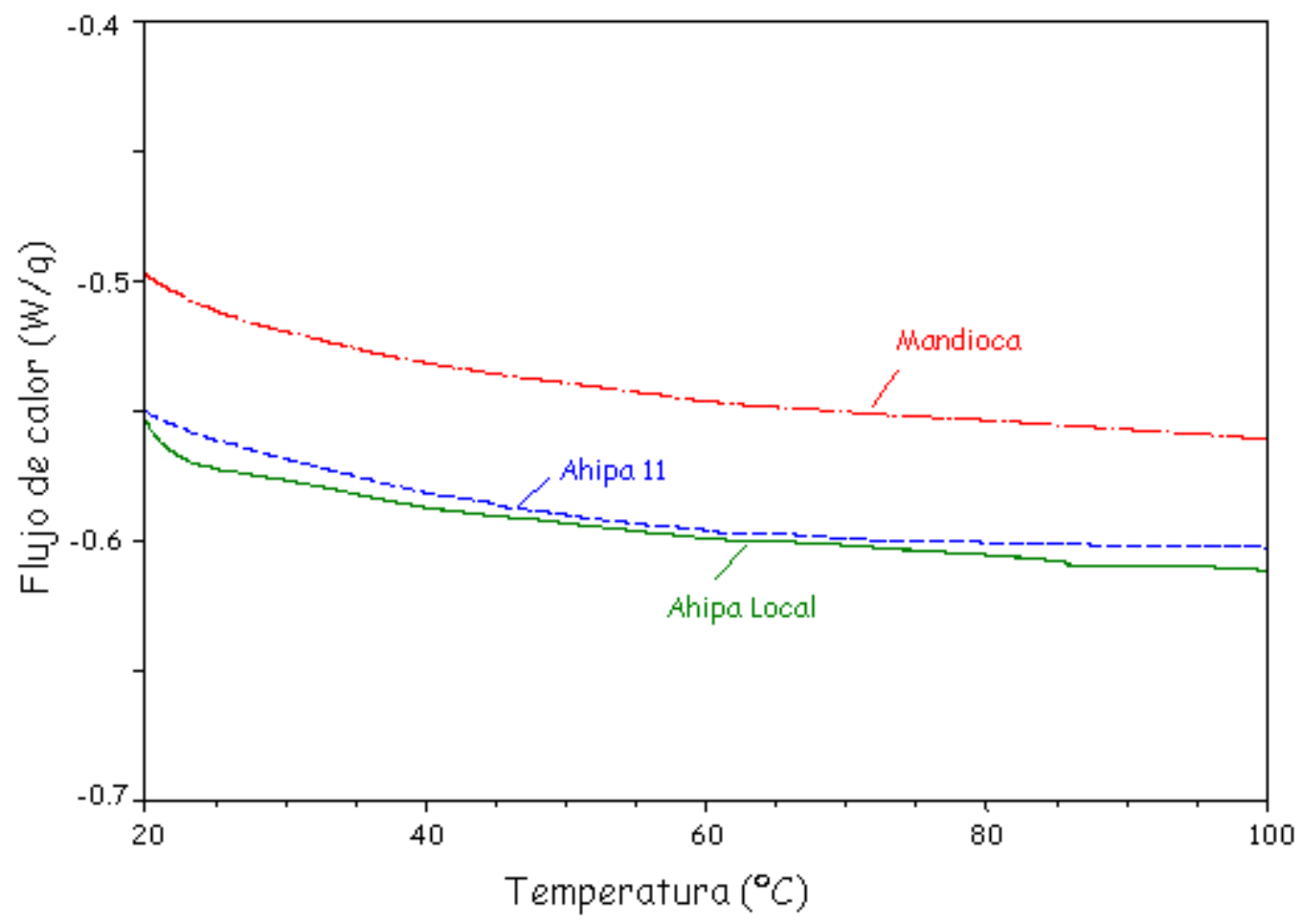

Figura 2.24. Termogramas de pastas de almidones de Pachyrhizus ahipa (ahipa) y Manihot esculenta (mandioca) almacenadas 11 días a $4{ }^{\circ} \mathrm{C}$.

Como se puede observar en el termograma, no se observó ningún pico endotérmico que indique cambios estructurales causados por la retrogradación de la amilopectina 
(Figura 2.24), típicamente localizado alrededor de los $45-55^{\circ} \mathrm{C}$. Este resultado indica que las cadenas de amilopectina en los almidones de ahipa y mandioca presentan un alto grado de ramificación, limitando así la asociación de las cadenas y la retrogradación de sus pastas. No se observaron diferencias entre las accesiones de ahipa.

Debido a que el proceso de retrogradación causa un incremento en la rigidez de las pastas induciendo una separación de fases, la presencia de exudado se utiliza como indicador de este proceso no deseado. La sinéresis se produce porque se reemplazan uniones amilosa- $\mathrm{H}_{2} \mathrm{O}$ por uniones amilosa-amilosa, con la consecuente pérdida de agua. Para las pastas de almidón de ahipa y mandioca, luego del almacenamiento, se observaron grados de sinéresis muy bajos $(0,21 \pm 0,01 \%$ y $4,07 \pm 0,77 \%$, respectivamente) (López, 2011).

Los cambios en la textura de las pastas de almidón durante su almacenamiento condicionan las aplicaciones de los almidones en la formulación de alimentos (Sandhu y Singh, 2007), por lo que su evaluación resulta importante. El ensayo se muestra en la Figura 2.25 .

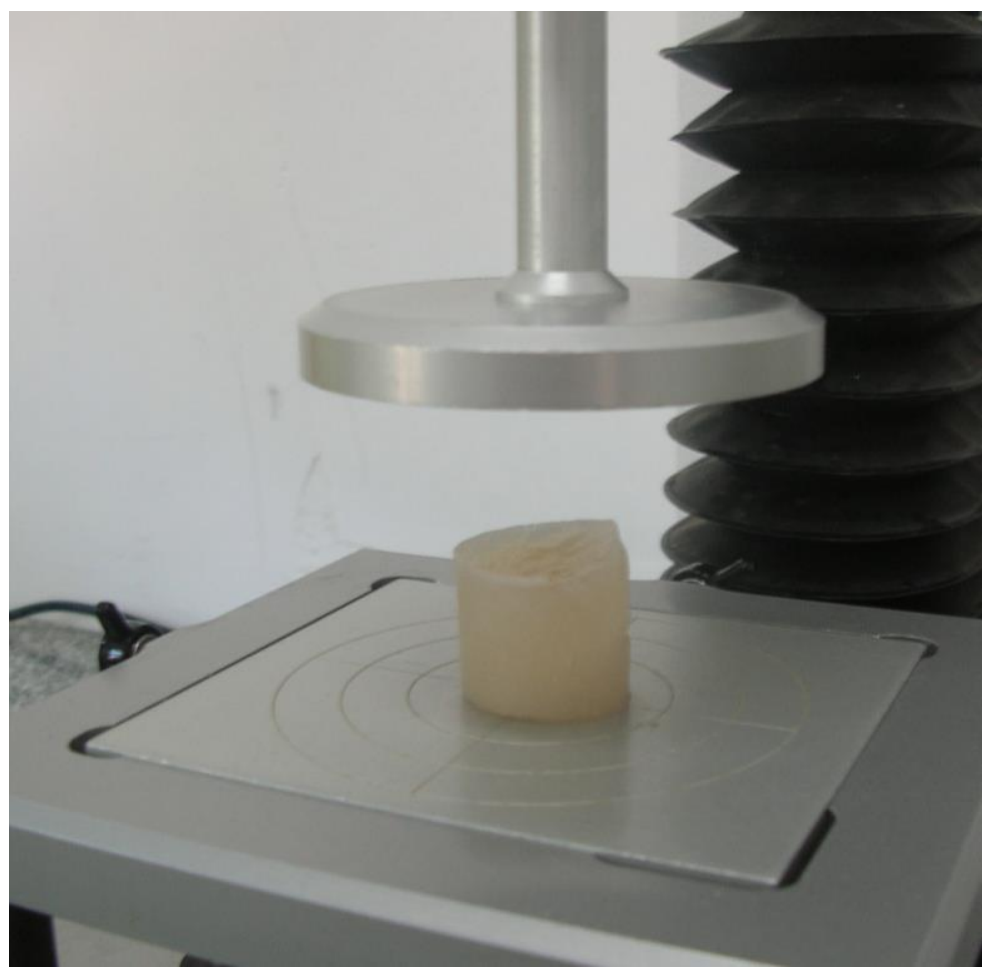

Figura 2.25. Ensayo de textura realizado en un cilindro de pasta o gel de almidón de Pachyrhizus ahipa (ahipa). 
En la Tabla 2.14 se muestran los parámetros del TPA obtenidos para las pastas de los almidones de ahipa (accesiones 11 y Local) y mandioca, al inicio y al final del almacenamiento refrigerado.

En los perfiles mecánicos no se observó el pico de fracturabilidad atribuible al aumento de la rigidez de la pasta debido a la retrogradación de la amilopectina. Así, los resultados del TPA se correlacionaron con los obtenidos a partir de los ensayos de DSC.

Tabla 2.14. Parámetros de TPA de pastas de almidón de Pachyrhizus ahipa (ahipa) y de Manihot esculenta (mandioca) almacenadas a $4{ }^{\circ} \mathrm{C}$ durante 1 y 11 días.

\begin{tabular}{|c|c|c|c|}
\hline Parámetro del TPA & Almidón & $\begin{array}{c}1 \text { día de } \\
\text { almacenamiento }\end{array}$ & $\begin{array}{c}11 \text { días de } \\
\text { almacenamiento }\end{array}$ \\
\hline \multirow{3}{*}{ Fracturabilidad (N) } & Ahipa 11 & nd & nd \\
\hline & Ahipa Local & nd & nd \\
\hline & Mandioca & nd & nd \\
\hline \multirow{3}{*}{ Dureza $(\mathrm{N})$} & Ahipa 11 & $0,22 \pm 0,03^{b}$ & $0,13 \pm 0,01^{\mathrm{a}}$ \\
\hline & Ahipa Local & $0,28 \pm 0,06^{c}$ & $0,14 \pm 0,01^{a}$ \\
\hline & Mandioca & $0,34 \pm 0,01^{d}$ & $0,28 \pm 0,02^{c}$ \\
\hline \multirow{3}{*}{ Elasticidad } & Ahipa 11 & $1,31 \pm 0,08^{b}$ & $1,04 \pm 0,06^{a}$ \\
\hline & Ahipa Local & $1,05 \pm 0,09^{a}$ & $1,02 \pm 0,04^{a}$ \\
\hline & Mandioca & $1,00 \pm 0,00^{\mathrm{a}}$ & $1,00 \pm 0,02^{\mathrm{a}}$ \\
\hline \multirow{3}{*}{ Cohesividad } & Ahipa 11 & $0,16 \pm 0,05^{\mathrm{a}}$ & $0,26 \pm 0,06^{b}$ \\
\hline & Ahipa Local & $0,33 \pm 0,07^{c}$ & $0,33 \pm 0,05^{c}$ \\
\hline & Mandioca & $0,70 \pm 0,01^{d}$ & $0,66 \pm 0,03^{d}$ \\
\hline \multirow{3}{*}{ Gomosidad (N) } & Ahipa 11 & $0,04 \pm 0,01^{a}$ & $0,03 \pm 0,01^{a}$ \\
\hline & Ahipa Local & $0,09 \pm 0,04^{b}$ & $0,05 \pm 0,01^{a}$ \\
\hline & Mandioca & $0,24 \pm 0,01^{d}$ & $0,19 \pm 0,02^{c}$ \\
\hline \multirow{3}{*}{ Adhesividad ( $\mathrm{N} \mathrm{mm}$ ) } & Ahipa 11 & $0,18 \pm 0,02^{\mathrm{a}}$ & $0,53 \pm 0,02^{b}$ \\
\hline & Ahipa Local & $0,20 \pm 0,04^{a}$ & $0,53 \pm 0,14^{b}$ \\
\hline & Mandioca & $0,52 \pm 0,18^{b}$ & $0,19 \pm 0,02^{\mathrm{a}}$ \\
\hline \multirow{3}{*}{ Masticabilidad (N) } & Ahipa 11 & $0,05 \pm 0,02^{a}$ & $0,04 \pm 0,01^{a}$ \\
\hline & Ahipa Local & $0,10 \pm 0,04^{b}$ & $0,05 \pm 0,01^{a}$ \\
\hline & Mandioca & $0,24 \pm 0,01^{d}$ & $0,19 \pm 0,02^{c}$ \\
\hline
\end{tabular}

Nota: Los valores informados corresponden a las medias \pm las desviaciones estándar. Letras diferentes indican diferencias significativas $(p<0,05)$; nd: no detectado. 
El tiempo de almacenamiento disminuyó significativamente $(p<0,05)$ la dureza, la gomosidad y la masticabilidad de las pastas almacenadas, mientras que los restantes parámetros del TPA no se vieron significativamente afectados $(p>0,05)$.

La adhesividad de las pastas es una propiedad de superficie y depende de las fuerzas adhesivas y cohesivas, como así también de la viscosidad y de las propiedades viscoelásticas (Huang y col., 2007; Adhikari y Jindal, 2001). La adhesividad de las pastas de almidón de mandioca al inicio fue mayor que las correspondientes a las pastas de ahipa (accesión 11 y Local), mientras que durante el almacenamiento la evolución dependió del origen botánico del almidón aumentando significativamente $(p<0,05)$ para las de ahipa (Tabla 2.14).

Luego de 1 día a $4^{\circ} \mathrm{C}$ las pastas de almidón de mandioca resultaron más cohesivas que las de ahipa. El tiempo de almacenamiento disminuyó $(p<0,05)$ la elasticidad de las pastas estudiadas (Tabla 2.14).

Por último, el almacenamiento afectó significativamente $(p<0,05)$ la masticabilidad de las pastas de almidón obteniéndose los valores más altos (Tabla 2.14) para las pastas de almidón de mandioca.

Es importante destacar que la comparación de los parámetros de textura de las pastas de almidón obtenidos con datos informados por otros autores es dificultosa ya que los mismos dependen de varios factores: concentración de la suspensión de almidón, tiempo y temperatura de almacenamiento, como así también de otras condiciones experimentales. 


\section{CONCLUSIONES}

El almidón de Pachyrhizus ahipa se puede obtener a escala de laboratorio empleando un proceso de extracción optimizado, simple y con un bajo costo asociado. Esta técnica resulta eficiente permitiendo conseguir muestras representativas, con buenos rendimientos y alta pureza. Por otra parte, las observaciones al SEM mostraron que este procedimiento no ocasionó daños en los gránulos del almidón extraído.

El almidón obtenido presentó bajo contenido de amilosa, por lo que podría considerarse un aditivo alternativo al almidón de maíz para la industria alimentaria. Además, sus pastas también presentan una mejor aptitud para la cocción que las del almidón de maíz ya que gelatinizan a una temperatura significativamente más baja. Sus gránulos exhiben buena capacidad de hinchamiento pudiendo emplearse así como agente espesante. Una de las principales ventajas de este almidón es la baja tendencia a la retrogradación de sus pastas cuando se almacenan bajo condiciones de refrigeración.

Las isotermas de sorción de los almidones obtenidos fueron modeladas satisfactoriamente, obteniendo el mejor ajuste de los datos experimentales con el modelo de GAB, el que permitió estimar el contenido de agua de la monocapa. Además, se calcularon los parámetros termodinámicos asociados al proceso de adsorción de agua. La variación de la energía libre de Gibbs correspondiente indicó que éste era un proceso no espontáneo.

Se caracterizó la microestructura de los almidones extraídos a través de ensayos morfológicos al SEM, estableciendo el patrón de difracción de rayos $\mathrm{X}$ y asignando los picos característicos de los espectros de FTIR.

Dado su bajo contenido de amilosa y las bajas temperaturas de la gelatinización, el almidón de ahipa podría constituirse en una alternativa frente a fuentes de almidón tradicionales. 


\section{REFERENCIAS BIBLIOGRÁFICAS}

Abdul-Hamid, A., Luan, Y. S. (2000). Functional properties of dietary fibre prepared from defatted rice bran. Food Chemistry, 68 (1), 15-19.

Al-Muhtaseb, A.H., McMinn, W.A.M., Magee, T.R.A. (2002). Moisture sorption isotherm characteristics of food products: a review. Food and Bioproducts Processing $80(2), 118-128$.

Al-Muhtaseb, A.H., McMinn, W.A.M., Magee, T.R.A. (2004). Water sorption isotherms of starch powders. Part 1: mathematical description of experimental data. Journal of Food Engineering 61 (3), 297-307.

Andrés, S. C., García, M. E., Zaritzky, N. E., Califano, A. N. (2006). Storage stability of low-fat chicken sausages. Journal of Food Engineering, 72, 311-319.

Aviara, N. A., Ajibola, O. O. (2002). Thermodynamics of moisture sorption in melon seed and cassava. Journal of Food Engineering, 55 (2), 107-113.

Belitz, H.D y Grosch, W. (1997). Cereales y Derivados. En: Química de los Alimentos, Belitz, H.D y Grosch, W. (eds). Acribia, Zaragosa.

Bello-Pérez, L.A. (1995). Amilopectina-Caracterización molecular y funcional. Tesis Doctoral. Centro de Investigación y de Estudios Avanzados del Instituto Politécnico Nacional, Unidad Irapuato, Guanajuato, México.

Bello-Pérez, L.A.; Osorio-Díaz, P.; Agama-Acevedo, E.; Nuñez-Santiago, C. y ParedesLópez, O. (2002). Chemica, physicochemical and rheological of masas and nixtamalized corn fluors. Agrociencia 2002, 36, 319-328.

Betancur, D. A., Ancona, L. A. C., Guerrero, R. I., Camelo Matos, G., Ortiz, D. (2001). Physicochemical and Functional Characterization of Baby Lima Bean (Phaseolus lunatus) Starch. Starch-Stärke 53, 219-226. 
Biliaderis, C. (1992). Structures and phase transitions of starch in food systems. Food Technolology, 98-109145.

Boudries, N., Belhaneche, N., Nadjemi, B., Deroanne, C., Mathlouthi, M., Roger, B., Sindic, M. (2009). Physicochemical and functional properties of starches from sorghum cultivated in the Sahara of Algeria. Carbohydrate Polymers 78 (3), 475-480.

Cladera-Olivera, F., Pettermann, A.C., Zapata Noreña, C.P., Wada, K., Ferreira Marczak, L.D. (2008). Thermodynamic properties of moisture desorption of raw pinhão (Araucaria angustifolia seeds). International Journal of Food Science \& Technology 43 (5), 900-907.

Cladera-Olivera, F., Ferreira Marczak, L.D.F., Zapata Noreña, C.P., Pettermann, A.C. (2009). Modeling water adsorption isotherms of pinhão (Araucaria angustifolia seeds) flour and thermodynamic analysis of the adsorption process. Journal of Food Process Engineering 34 (3), 826-843.

Che, L. M., Li, D., Wang, L. J., Özkan, N. (2008). Rheological properties of dilute aqueous solutions of cassava starch. Carbohydrate Polymers, 74, 385-389.

Chen, C. (1988). A study of equilibrium relative humidity for yellow dent corn kernels. Ph.D. thesis, University of Minnesota, St. Paul, MN.

Eliasson, A. (2004). Starch in food. Structure, function and applications.

Fang, J. M.; Fowler, P. A.; Tomkinson, J. y Hill, C. A. (2002). The preparation and characterization of a series of chemically modified potato starches. Carbohydrate Polymers, 47, 245-252.

Farhat, I.A.; Protzmann, J.; Becker, A.; Vallès-Pàmies, B.; Neale, R., Hill, S.E. (2001). Effect of the Extent of Conversion and Retrogradation on the Digestibility of Potato Starch. Starch/Stärke, 53(5), 431-436. 
Fasina, O. O. (2006). Thermodynamic properties of sweetpotato. Journal of Food Engineering 75 (2), 149-155.

Ferrero, C., Martino, M. N., Zaritzky, N. E. (1993). J. Food Process. Preserv. 17, 191211.

Forsyth, J. L., Ring, S. G., Noel, T. R., Parker, R., Cairns, P., Findlay, K., Shewry, P. R. (2002). Characterization of Starch from Tubers of Yam Bean (Pachyrhizus ahipa). Journal of Agricultural and Food Chemistry 50 (2), 361-367.

García, M. A., Martino, M. N., Zaritzky, N. E. (1995). Comparison of amylose enrichment procedures for the food applications. Cereal Chemistry, 72(6), 552-558.

Geng, Z., Zongdao, Ch., Yimin, W. (2007). Physicochemical properties of lotus (Nelumbo nucifera Gaertn.) and kudzu (Pueraria hirsute Matsum.) starches. International Journal of Food Science and Technology, 42, 1449-1455.

Henríquez, C., Escobar, B., Figuerola, F., Chiffelle, I., Speisky, H., Estévez, A. M. (2008). Characterization of piñon seed (Araucaria araucana (Mol) K. Koch) and the isolated starch from the seed. Food Chemistry, 107 (2), 592-601.

Hermans, P.H., Weidinger, A. (1948). Quantitative X-ray investigations on the crystallinity of cellulose fibres. A background analysis. Journal of Applied Physics, 19, 491-506.

Heywood, A., Myers, D., Bailey, T., Johnson, L. (2002). Functional properties of low-fat soy flour produced by an extrusion-expelling system. Journal of the American Oil Chemists' Society, 79 (12), 1249-1253.

Huang, D. P., Rooney, L. W. (2001). Starches for snack foods. En: Snack foods processing, Lusas, E.W. y Rooney, L.W. (eds). Lancaster, Pennsylvania. Technomic Publishing Company, Inc. 
Huang, C. C., Chen, W. C., Wang, C. C. R. (2007). Comparison of Taiwan paddy-and upland-cultivated taro (Colocasia esculenta L.) cultivars for nutritive values. Food Chemistry, 102 (1), 250-256.

Huang, C. C. (2009). Physicochemical, pasting and thermal properties of tuber starches as modified by guar gum and locust bean gum. International Journal of Food Science and Technology, 44, 50-57.

Jane, J., Kasemsuwan, T., Chen, J. F., Juliano, B. O. (1996). Phosphorus in rice and other starches. Cereal Foods World 41, 827-832.

Kacuráková, M., Wilson, R.H. (2001). Developments in mid-infrared FT-IR spectroscopy of selected carbohydrates. Carbohydrate Polymers, 44, 291-303.

Katz, F.R.; Furcsik, S.L.; Tenbarge, F.L.; Hauber, R.J. y Friedman, R.B. (1993). Behavior of starches derivied from varieties of maize containing different genetic mutations: effect of starch type on granular morphology. Carbohydrate Polymers, 21, 133-136.

Labuza, T. P. (1984). Moisture Sorption: Practical Aspects of Isotherm Measurement and Use. St. Paul, Minnesota: American Association of Cereal Chemists.

Lee, H. L., Yoo, B. (2009). Dynamic rheological and thermal properties of acetylated sweet potato starch. Starch - Stärke, 61, 407-413.

Leonel, M., Sarmiento, S. B. S., Cereda, M. P., Camara, F. L. A. (2003). Extraction and characterization of Pachyrhizus ahipa starch. Ciencia e Tecnologia de Alimentos, 23(3), 362-365.

López, O. V., Viña, S. Z., Pachas, A. N. A., Sisterna, M. N. (2010). Composition and food properties of Pachyrhizus ahipa roots and starch. International Journal of Food Science \& Technology 45, 223-233. 
López, O. V. (2011). Tesis Doctoral “Desarrollo, caracterización y aplicación de envases biodegradables a partir de almidón".

López, O. V., García, M. A. (2012). Starch films from a novel (Pachyrhizus ahipa) and conventional sources: Development and characterization. Materials Science and Engineering: C 32, 1931-1940.

Luengwilai, K., Beckles, D.M. (2009). Structural investigations and morphology of tomato fruit starch. Journal of Agricultural and Food Chemistry, 57, 282-291.

Madamba, P. S., Driscoll, R. H., Buckle, K. A. (1996). Enthalpy-entropy compensation models for sorption and browning of garlic. Journal of Food Engineering, 28 (2), 109119.

Mali, S., Grossmann, M., García, M., Martino, M., Zaritzky, N. (2002). Carbohydr. Polym. 50, 379-386.

Mano, J.F., Koniarova, D., Reis, R.L. (2003). Thermal Properties of Thermoplastic Starch/Synthetic Polymer Blends with Potential Biomedical Applicability. Journal of Materials Science: Materials in Medicine, 14, 127-135.

Maaran, S., Hoover, R., Donner, E., Liu, Q. (2014). Composition, structure, morphology and physicochemical properties of lablab bean, navy bean, rice bean, tepary bean and velvet bean starches. Food Chemistry 152, 491-499.

MacGregor, A.W., Fincher, G.B. (1993). Carbohydrates of the barley grain. En: Barley: Chemistry and Technology, MacGregor, A.W.; Bhatty, R.S. y St. Paul, M.N (eds.).

McMinn, W. A. M., Magee, T. R. A. (2003). Thermodynamic properties of moisture sorption of potato. Journal of Food Engineering, 60 (2), 157-165. 
McMinn, W. A. M., McKee, D. J., Magee, T. R. A. (2007). Moisture adsorption behaviour of oatmeal biscuit and oat flakes. Journal of Food Engineering, 79 (2), 481-493.

Mélo, E. A., Stamford, T. L., Silva, M. P., Krieger, N., Stamford, N. P. (2003). Functional properties of yam bean (Pachyrhizus erosus) starch. Bioresour Technol, 89, 103-106.

Miles, M.J.; Morris, V.J., Ring, S.G. (1985 b). Gelation of amylose. Carbohydrate Research, 135, 257-269.

Miles, M.J.; Morris, V.J.; Oxford, P.D., Ring, S.G. (1985 a). The roles of amylose and amylopectine in the gelation and retrogradation of starch. Carbohydrate Research, $135,271-281$.

Miller, B.S.; Derby, R.I. y Trimbo, H.B (1973). A pictorial explanation for the increase in viscosity of a heated wheat starch water suspension. Cereal Chemistry, 50, 271-275.

Morrison, W., Laignelet, B. (1983). J. Cereal Sci. 1 , 9-20.

Navarro, A. S., Martino, M. N., Zaritzky, N. E. (1995). J. Food Eng. 26, 481-495.

Ott, M., Hester, E.E. (1965). Gel formation as related to concentration of amylose and degree of starch swelling. Cereal Chemistry, 42, 476-484.

Ottenhof, M.A. (2003). A multi-techniquestudy of the retrogradation of concentrated starch system. PhD. Thesis. Division of Food Science. University of Nottingham, UK.

Pelissari, F.M., Andrade-Mahecha, M.M., do Amaral Sobral, P.J., Menegalli, F.C. (2013). Comparative study on the properties of flour and starch films of plantain bananas (Musa paradisiaca). Food Hydrocolloids 30, 681-690. 
Perdomo, J., Cova, A., Sandoval, A. J., García, L., Laredo, E., Müller, A. J. (2009). Glass transition temperatures and water sorption isotherms of cassava starch. Carbohydrate Polymers, 76 (2), 305-313.

Pérez, E., Breene, W., Bahanasey, Y. (1998). Starch-Stärke 50, 70-72.

Pérez Sira, E.E., Lares Amaiz, M. (2004). A laboratory scale method for isolation of starch from pigmented sorghum. Journal of Food Engineering 64 (4), 515-519.

Polatoğlu, B., Beşe, A. V., Kaya, M., \& Aktaş, N. (2011). Moisture adsorption isotherms and thermodynamics properties of sucuk (Turkish dry-fermented sausage). Food and Bioproducts Processing, 89 (4), 449-456.

Ring, S.G., Stainsby, G. (1983). Filler reinforcement of gels. Prog. Fd. Nutr. Sci., 6, 323329.

Ring, S.G.; Colonna, P.; lánson, K.J.; Kalichevsky, M.T.; Miles, M.J.; Morris, V.J., Oxford, P.D. (1987). The gelation and crystallization of amylopectin. Carbohyd. Res., 162: 277293.

Rodríguez-Hernández, A.I., Tecante, A., Doublier, J.L. (2001). Viscoelastic behavior of waxy maize starch-gellan mixtures under small amplitude oscillatory shear. En: Proceedings of the Eighth International Congress on Engineering and Food, (J. WeltyChanes, G.V. Barbosa-Cánovas y J.M. Aguilera, eds), 509-513.

Ross-Murphy, S. B. (1994). Rheological metodhs, Physical Techniques For The Study Of Food Biopolymers. Editado por Ross-Murphy. Blackie Academic \& Professional, London.

Salleh, E.; Muhamad, I.I. y Khairuddin, N. (2009). Structural Characterization and Physical Properties of Antimicrobial (AM) Starch-Based Films. WorldAcademy of Science, Engineering and Technology, 55, 432-440. 
Sandhu, S. K., Singh, N. (2007). Food Chem. 101, 1499-1507.

Shon, K.-J., Yoo, B. (2006). Effect of acetylation on rheological properties of rice starch. Starch - Stärke, 58, 177-185.

Siroth, K., Santisopasri, V., Petchalanuwat, C., Kurotjanawong, K., Piyachomkwan, K., Oates, C.G. (1999). Cassava starch granule structure-function properties: influence of time and conditions at harvest on four cultivars of cassava starch. Carbohydrate Polymers 38, 161-170.

Skrabanja, V., Liljerberg, H. G., Hedley, C. L., Kreft, I., Björck, I. M. (1999). J. Agric. Food Chem. 47, 2033-2039.

Spiess, W., Wolf, W.R. (1983). The result of the COST 90 project on water activity. In: Jowitt, R., Escher, F., Hallstrom, B., Meffert, M.S., Spiess, W., Vos, G. (Eds.), Physical Properties of Foods. Applied Science Publishers, London, 65-88.

Steffe, J. F. (2006). Rheological Methods in Food Process Engineering, Freeman Press.

Swinkels, J. J. M. (1985). Composition and properties of commercial native starch. Starch 37, 1-5.

Szymonska, J., Krok, F., Komorowska-Czepirska, E., Rebilas, K. (2003). Modification of granular potato starch by multiple deep-freezing and thawing. Carbohydrate Polymers $52(1), 1-10$.

Thomas, D. J., Atwell, W. (1999). Starch Modifications. En: Starches. Eagen Press Handbook. Estados Unidos.

Thys, R.C.S., Zapata Noreña, C.P., Ferreira Marczak, L.D., Gomes Aires, A., CladeraOlivera, F. (2010). Adsorption isotherms of pinhão (Araucaria angustifolia seeds) starch and thermodynamic analysis. Journal of Food Engineering 100 (3), 468-473. 
Tsai, M. L., Li, C. F., \& Lii, C. Y. (1997). Effects of granular structures on the pasting behaviors of starches. Cereal Chemistry, 74(6), 750-757.

Whistler, R.L. (1984). Starch, chemistry and tecnology (edited by R.L. Whistler, J.N. Be Miller, E.F. Paschall). Pp 718. Orlando, FL, Estados Unidos: Academic Press, Inc.

Wu, C. (2003). Physical properties and biodegradability of maleatedpolycaprolactone/starch composite. Polymer Degradation and Stability, 80, 127-134.

Zhang, Y. y Han, J. (2006). Mechanical and thermal characteristics of pea starch films plasticized with monosaccharides and polyols. Journal of Food Science, 71, 109-118.

Zobel, H.F. (1988). Starch crystal transformations and their industrial importance. Starch, 40, 1-7. 


\section{CAPÍTULO 3.}

\section{Digestibilidad del almidón de Pachyrhizus}

ahipa. Caracterización del residuo de la extracción de almidón 


\section{INTRODUCCIÓN}

\section{Digestibilidad de los almidones}

La digestión del almidón no es un proceso simple y único, comprende tanto reacciones de hidrólisis enzimáticas como químicas.

El proceso se puede cuantificar parcialmente a través de varios métodos que difieren entre sí en función de la/s enzima/s y las condiciones de reacción utilizadas para catalizar la hidrólisis. Estas medidas incluyen la velocidad de degradación de almidón, la tasa de aparición de la glucosa, y la tasa de aparición de diversos oligosacáridos.

La comprensión de los factores que influyen en la digestión del almidón podría ser analizada a través de un enfoque causal basado en el paradigma mostrado en la Figura 3.1:

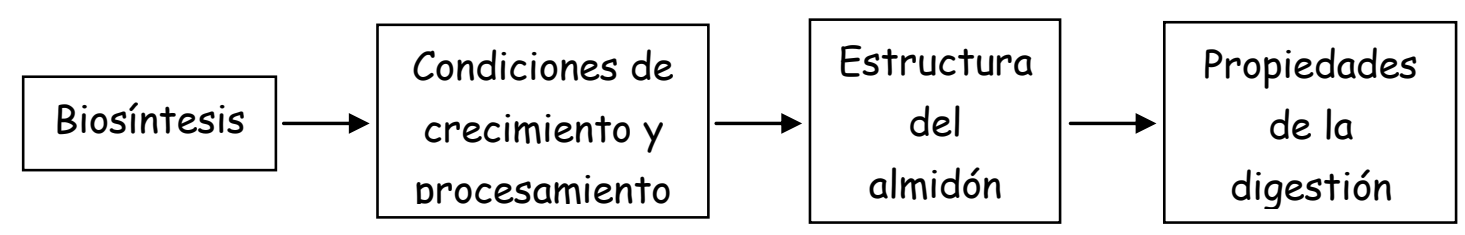

Figura 3.1. Diagrama del paradigma de la digestión del almidón.

En otras palabras, los eventos biosintéticos controlan la formación y por lo tanto, la estructura del almidón, que es dependiente de las condiciones de crecimiento del cultivo (Buleon y col., 1998; Copeland y col., 2009; Smith, 2007). Sin embargo se ha señalado que si bien puede haber una correlación entre, por ejemplo, la variedad del cultivo y la rápida digestibilidad del almidón, esto no es causal (Copeland y col., 2009). Además la digestión del almidón depende del procesamiento posterior, tal como las condiciones de cocción.

El almidón se organiza en los alimentos que lo contienen en diferentes escalas estructurales, como se ejemplifica en la Figura 3.2 para el grano de arroz. Se lo encuentra como cadenas individuales, las que pueden asociarse en el gránulo, dando lugar a las zonas cristalinas y amorfas, las que contribuyen a la estructura macroscópica del grano. Esta estructura incluye no sólo al almidón, sino también a proteínas, lípidos y polisacáridos no amiláceos que pueden estar presentes y con los cuales el almidón se asocia. Propiedades tales como la cinética de la digestión del 
almidón son controladas por los diversos niveles estructurales mencionados (Smith, 2007).

En general, el almidón consumido por los animales domésticos está en gran parte en estado nativo (no gelatinizado), mientras que en la mayoría de los alimentos consumidos por los humanos el almidón se encuentra gelatinizado, con algunas excepciones, como el muesli. Durante el proceso de cocción se destruye la estructura granular del almidón. La mayoría de las reacciones enzimáticas, entre ellas la digestión de almidón no gelatinizado, se controlan, en su mayor parte, por la estructura del sustrato (Dona y col., 2010).

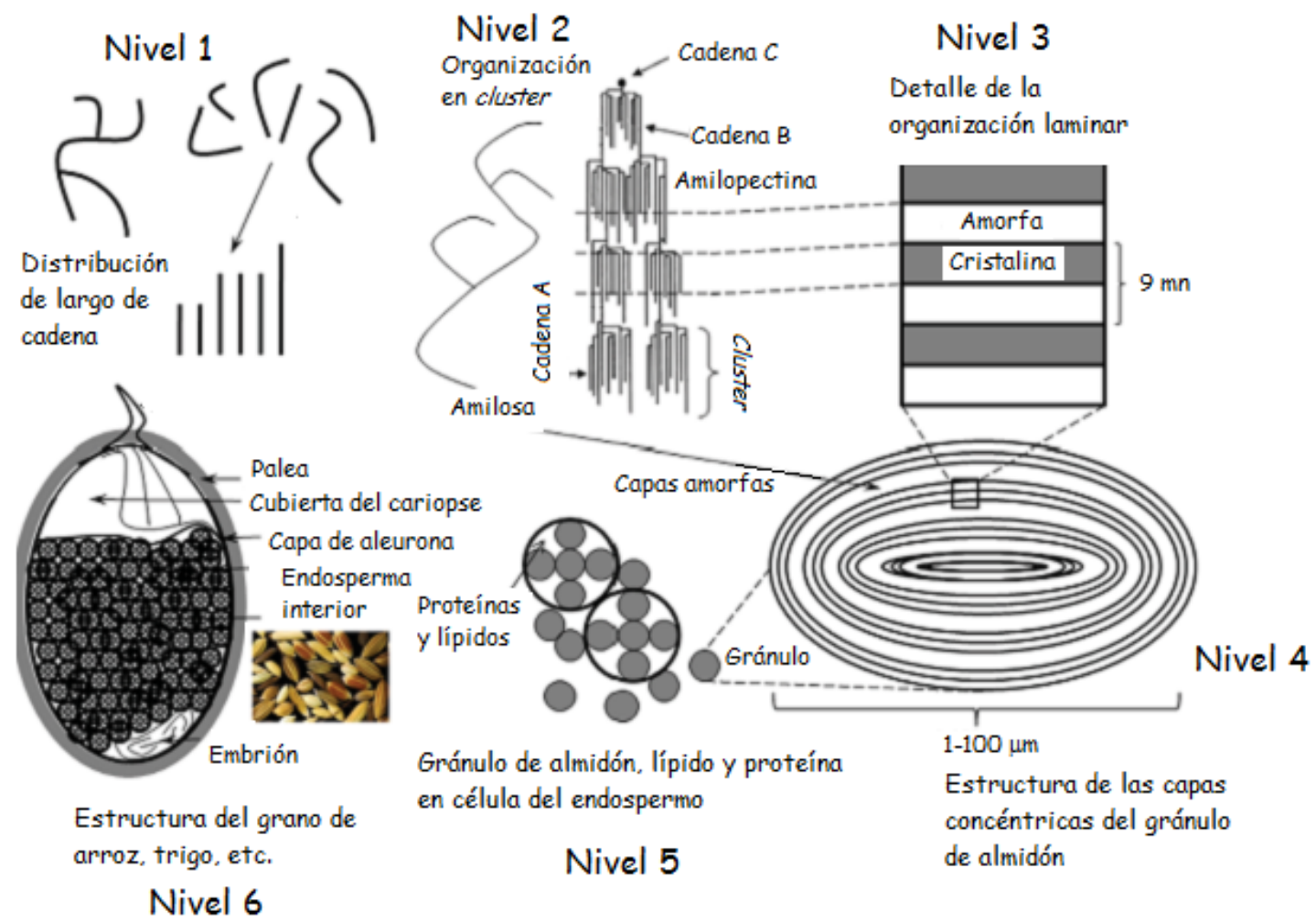

Figura 3.2. Niveles supramoleculares del grano de arroz, destacando la contribución estructural microscópica del almidón. Adaptado de Dona y col., (2010).

Como ya se mencionó, las condiciones de procesamiento y almacenamiento también afectan la digestibilidad del almidón (Noda y col., 2008; Lu y col., 2012). Por ejemplo, el almidón de papa nativo es altamente resistente a la hidrólisis por la enzima $\alpha$-amilasa pancreática, pero se vuelve rápidamente digerible después de su cocción mediante técnicas convencionales. Por otra parte, una pequeña proporción de almidón 
Capítulo 3. Digestibilidad del almidón de Pachyrhizus ahipa. Caracterización del residuo de la extracción de almidón

resistente se forma como resultado del proceso de retrogradación cuando las papas cocidas se someten a enfriamiento y se almacenan (Kingman y col., 1994).

En función de su susceptibilidad al ataque de las enzimas amilolíticas, el almidón puede clasificarse como digerible o resistente, siendo relevante esta distinción debido a los beneficios para la salud (Vieira Bezerra y col., 2013). Hasta hace algunos años el almidón era considerado un carbohidrato disponible que era completamente digerido y absorbido en el intestino delgado humano. Sin embargo, una fracción del mismo resiste la hidrólisis catalizada por las enzimas digestivas y se denomina almidón resistente.

\subsection{Digestión in vivo del almidón}

En los últimos 25 años, la digestibilidad in vivo de los alimentos ha sido caracterizada, entre otros, por el índice glicémico (IG) definido por Jenkins y col. (1981) como la respuesta glicémica total producida en sangre (área bajo la curva de la concentración de glucosa en función del tiempo) en un período inmediatamente posterior a 2 horas de consumir una cantidad fija de hidratos de carbono, referido a la glucosa liberada de un alimento estándar, como el pan (Roberts, 2000). Muchos factores intrínsecos y extrínsecos afectan a la naturaleza de almidón y por lo tanto al IG de un alimento, incluyendo la estructura del almidón en los seis niveles (Figura 3.2); estos factores son la motilidad gastrointestinal, el método de cocción, y la presencia de fibras, grasas y proteínas (Krezowski y col., 1986; Thorne y col., 1983).

\subsection{Digestión in vitro del almidón}

Según Englyst y col. (1992), desde el punto de vista nutricional el almidón puede ser clasificado en tres categorías, en función de su velocidad y extensión de la digestión, las cuales incluyen el almidón rápidamente digerido (ARD), el almidón que se digiere lentamente (ALD), y el almidón resistente (AR).

La fracción $A R D$ es la cantidad de almidón que causa un rápido incremento en la concentración de glucosa en sangre después de la ingestión de hidratos de carbono. Esta fracción in vitro se define como la cantidad de almidón digerido en los primeros 20 minutos de la mezcla de reacción (Englyst y col, 1992). 
La fracción de almidón que se digiere lentamente pero por completo en el intestino delgado humano se denomina ALD. Esta fracción se define como el almidón que se digiere en un tiempo mayor que el ARD pero en no más de 120 minutos en las condiciones estándar de concentración de sustrato y enzima utilizada (Englyst y col., 1992). Los beneficios potenciales para la salud del ALD in vivo incluye la estabilización del metabolismo de la glucosa, el control de la diabetes, el desempeño intelectual y la saciedad (Lehmann y Robin, 2007).

\subsection{Almidón resistente}

El término almidón resistente (AR) fue sugerido inicialmente por Englyst y col. (1982), cuando comprobaron que muchos alimentos procesados poseían mayor contenido aparente de polisacáridos distintos del almidón que los de la fuente originariamente empleada para su preparación. Análisis detallados revelaron que este aumento estaba relacionado con la presencia de $\beta$-glucanos, que podrían ser detectados como glucosa después de tratarse con hidróxido de potasio, y someterse a hidrólisis por enzimas amilolíticas.

La European Research Project on Resistant Starch (EURESTA) ha definido al AR como "la suma del almidón y sus productos de degradación que no son absorbidos en el intestino delgado de individuos saludables" (Asp, 1992).

El almidón resistente sigue su tránsito por el intestino delgado y llega al intestino grueso, donde es fermentado por las bacterias de la flora normal del colon. Como producto de la fermentación se generan ácidos grasos de cadena corta (AGCC) con una alta proporción de butirato. El butirato ha sido estudiado como factor trófico esencial en el mantenimiento de las funciones del intestino grueso y por su relación con la protección contra el cáncer colorrectal (Englyst y col., 1987; Cassidy y col., 1994). Los AGCC resultantes de la fermentación del almidón resistente, así como la velocidad y el nivel de digestión del almidón, afectan diversas funciones fisiológicas y tienen efectos benéficos en la salud, tales como la reducción de la respuesta glicémica e insulinémica al alimento, un efecto hipocolesterolémico, y un efecto protector contra el cáncer colorrectal (Cassidy y col., 1994). 
Por otra parte, el almidón resistente ha sido relacionado con la disponibilidad de sustratos para el crecimiento de probióticos, la inhibición de la acumulación de grasas y el incremento en la absorción de minerales (Sajilata y col., 2006).

El reconocimiento de la importancia nutricional del AR ha impulsado el desarrollo de métodos para establecer realmente la cantidad de AR en los alimentos, por medio de los cuales se permite estimar su actividad fisiológica (McClearly y Brown, 2004). En los últimos años, los dos subtipos de carbohidratos emergentes que han recibido particular interés son los oligosacáridos y el almidón resistente, debido a los efectos fisiológicos benéficos asociados (McClearly y Brown, 2004).

En general, los estudios sobre el origen y la composición del almidón resistente se han realizado mayoritariamente en almidón de cultivos tales como maíz, cebada y trigo.

La mayoría de los almidones han sido caracterizados como digeribles y su consumo ha sido asociado al aumento de la respuesta glicémica, y consecuentemente al aumento de la obesidad y la diabetes del tipo 2 en la población. Por el contrario, el almidón resistente puede contribuir de modo significativo a mejorar el perfil nutricional de alimentos en dietas de baja ingesta de carbohidratos, tanto en alimentos comunes como en especialidades.

\subsection{Tipos de almidón resistente}

La principal clasificación del almidón resistente (AR) propuesta por Englyst y col. (1992), se basa en la naturaleza del almidón y el alimento que lo contiene.

El almidón resistente se divide en cuatro subtipos designados como AR1 a AR4 (Brown, 2004). El almidón tipo AR1 es el que está protegido físicamente en el grano, en la semilla o en el tubérculo, atrapado en la matriz celular, y participa como almidón resistente en alimentos de granos integrales (Würsch y col., 1986; Asp 1992a).

El almidón designado tipo AR2 se refiere al almidón granular que resiste la digestión debido a su conformación o estructura. Varios autores han señalado que los gránulos nativos, por su naturaleza cristalina, son menos susceptibles a la hidrólisis (Englyst y Cummings, 1987; Faisant y col., 1995). La propiedad de estos gránulos de resistir la hidrólisis puede ser significativamente alterada por el proceso de cocción. El almidón de maíz con alto contenido de amilosa (amilomaíz) es el único que retiene su 
Capítulo 3. Digestibilidad del almidón de Pachyrhizus ahipa. Caracterización del residuo de la extracción de almidón

conformación granular (y en consecuencia su contenido de almidón resistente y fibra alimentaria) cuando se expone a condiciones aplicadas en la preparación de gran cantidad de alimentos. Se ha observado que existe correspondencia entre el aumento en el contenido de amilosa en el gránulo de almidón y el aumento de la fibra alimentaria y del almidón resistente (Brown, 2004). El AR2 puede ser un importante vehículo de almidón resistente en una amplia variedad de productos alimentarios y farmacéuticos.

El AR3 es el almidón retrogradado, que se forma en los alimentos que han sido cocidos y almacenados. Durante el enfriamiento las cadenas de amilosa se reasocian (proceso de retrogradación descripto en el Capítulo 2) formando estructuras semicristalinas resistentes a la hidrólisis enzimática (Englyst y Cummings, 1987). En alimentos como panes y cereales, las condiciones de preparación pueden alterar significativamente la cantidad del almidón AR3 formado.

El almidón tipo AR4 representa el grupo de almidón resistente (AR) químicamente modificado de forma tal que interfiere en la acción de las enzimas digestivas y por lo tanto en su capacidad de ser digerido.

Se propusieron diferentes métodos para la determinación de almidón resistente basados en la digestión enzimática in vitro, como los de Englyst y col. (1982), Berry (1986), Champ (1992), Faisant y col. (1995) y Goñi y col. (1996).

\subsection{Efectos fisiológicos del almidón resistente}

Como se ha expuesto anteriormente, un gran número de investigaciones se han llevado a cabo para dilucidar los efectos fisiológicos del almidón resistente consumido por las poblaciones occidentales, como la protección o tratamiento de la constipación (Asp, 1992), el cáncer colorrectal (Brown, 2004), el cólera (Ramakrishna y col., 2000), las enfermedades diarreicas (Bern y col., 1992) y la osteoporosis (McClearly y Brown, 2004).

El potencial fisiológico del almidón resistente, basado en estudios realizados en animales y humanos se detalla en la Tabla 3.1 (Brown, 2004). Asimismo, el AR es importante en la dieta en relación a la interacción con otros componentes 
Capítulo 3. Digestibilidad del almidón de Pachyrhizus ahipa. Caracterización del residuo de la extracción de almidón

alimentarios, incluyendo no solamente los macronutrientes, como grasas y proteínas, sino también micronutrientes como minerales y vitaminas.

Tabla 3.1. Efectos fisiológicos importantes del almidón resistente. Adaptado de Brown, (2004).

Evidencia fisiológica general Efecto fisiológico específico

\begin{tabular}{cc}
\hline \multirow{2}{*}{$\begin{array}{c}\text { Respuesta glicémica } \\
\text { reducida }\end{array}$} & $\begin{array}{c}\text { Respuesta glicémica post-prandial (concentración de glucosa en sangre 2hs } \\
\text { después de ingerir un alimento) más lenta }\end{array}$ \\
\cline { 2 - 2 } Energía reducida & \begin{tabular}{c} 
Respuesta insulínica post-prandial más lenta \\
\cline { 2 - 2 }
\end{tabular} \\
\hline & Menos calorías disponibles \\
\hline & Substrato fermentable (controlado) \\
\hline
\end{tabular}

Aumento de la producción de ácidos grasos de cadena corta en el colon

Mejora en la salud del intestino
Niveles reducidos de ácidos biliares secundarios

Niveles reducidos del amonio fecal

Aumento del bolo fecal

Reducción del tiempo de tránsito fecal

\begin{tabular}{|c|c|}
\hline \multirow{3}{*}{ Prebiótico } & Aumento de la población de bifidobacterias colónicas y lactobacilli \\
\hline & Disminución de la población de patógenos \\
\hline & Interacciones sinérgicas potenciadas con otros probióticos \\
\hline $\begin{array}{l}\text { Aumenta la viabilidad de } \\
\text { probióticos }\end{array}$ & $\begin{array}{l}\text { Ayuda a mantener la viabilidad de bacterias probióticas durante el } \\
\text { procesamiento y consumo del alimento }\end{array}$ \\
\hline $\begin{array}{c}\text { Aumento de absorción de } \\
\text { nutrientes }\end{array}$ & Absorción aumentada de minerales como calcio \\
\hline \multirow{3}{*}{$\begin{array}{l}\text { Potencial para la protección } \\
\text { del cáncer de intestino }\end{array}$} & Aumento de la producción de butirato \\
\hline & Aumento del índice apoptótico (muerte celular programada) \\
\hline & Disminución de los niveles de compuestos citotóxicos del colon \\
\hline \multirow{3}{*}{$\begin{array}{l}\text { Interacción sinérgica con } \\
\text { otros compuestos } \\
\text { alimentarios }\end{array}$} & Fibras alimentarias \\
\hline & Proteínas \\
\hline & Lípidos \\
\hline
\end{tabular}


Capítulo 3. Digestibilidad del almidón de Pachyrhizus ahipa. Caracterización del residuo de la extracción de almidón

\section{Fibra dietaria}

Hipsley (1953) utilizó por primera vez el término fibra dietaria para denominar a aquellos componentes no digeribles de las paredes celulares de las plantas.

Años más tarde, según la American Association of Cereal Chemists (AACC, 2001), “...fibra dietaria es la parte comestible de plantas o carbohidratos análogos que son resistentes a la digestión y absorción en el intestino delgado humano con completa o parcial fermentación en el intestino grueso. La fibra dietaria incluye polisacáridos, oligosacáridos, lignina y sustancias asociadas de origen vegetal". Los elementos constitutivos de la fibra dietaria, se presentan en la Tabla 3.2.

Tabla 3.2. Componentes de la fibra dietaria. Adaptado de la AACC (2001).

\begin{tabular}{|c|c|}
\hline Componentes & Tipo / Sub-tipo \\
\hline \multirow{7}{*}{$\begin{array}{c}\text { Polisacáridos } \\
\text { no-almidonosos y } \\
\text { oligosacáridos resistentes }\end{array}$} & Celulosa \\
\hline & Hemicelulosa / arabinoxilanos y arabinogalactanos \\
\hline & Polifructosas / inulina y oligofructanos \\
\hline & Galacto - oligosacáridos \\
\hline & Gomas \\
\hline & Mucílagos \\
\hline & Pectinas \\
\hline Dextrinas & $\begin{array}{l}\text { Dextrinas no digeribles / maltodextrinas resistentes (maíz y otras fuentes) y } \\
\text { dextrinas resistentes de la batata }\end{array}$ \\
\hline \multirow[t]{2}{*}{ Carbohidratos análogos } & $\begin{array}{l}\text { Componentes de carbohidratos sintéticos / polidextrosa, metilcelulosa e } \\
\text { hidroxipropilmetil celulosa }\end{array}$ \\
\hline & Almidones no digeribles (resistentes) \\
\hline Lignina & - \\
\hline \multirow{6}{*}{$\begin{array}{c}\text { Sustancias asociadas a } \\
\text { polisacáridos complejos no } \\
\text { almidonosos y lignina en } \\
\text { plantas }\end{array}$} & Ceras \\
\hline & Fitato \\
\hline & Cutina \\
\hline & Saponinas \\
\hline & Suberina \\
\hline & Taninos \\
\hline
\end{tabular}

En el año 2009, el organismo internacional Codex (Committee on Nutrition and Foods for Special Dietary Uses) define que la fibra dietaria se encuentra constituida por 
polímeros con 10 o más unidades monoméricas de carbohidratos no hidrolizados por enzimas endógenas en el intestino delgado de los seres humanos.

La nueva posición internacional se refleja actualmente en la siguiente definición, dada por Health Canada (2012): “la fibra dietaria consiste en: 1) carbohidratos con un grado de polimerización o número de unidades de monosacáridos de tres o más, que se presentan naturalmente en alimentos de origen vegetal y que no son digeridos $y$ absorbidos por el intestino delgado; y 2) nuevas fibras aceptadas".

Las "nuevas fibras" corresponden a ingredientes manufacturados que constituyen fuentes de fibra dietaria, producidos sintéticamente u obtenidos de fuentes naturales. Estos productos presentan al menos un efecto fisiológico demostrado mediante evidencia científica ampliamente aceptada.

La fibra dietaria promueve efectos fisiológicos benéficos incluyendo atenuación del nivel de colesterol y/o reducción de los niveles de glucosa en sangre" (AACC, 2001).

Los alimentos que contienen fibras traen beneficios a la salud, tales como la reducción del tiempo de retención del bolo fecal en el intestino grueso que conlleva a la reducción del tiempo de contacto del órgano con sustancias cancerígenas y consecuentemente la disminución del índice de cáncer colorrectal (Nutrinews, 2001; Waszczynskyj y col., 2001).

La American Dietetic Association (ADA, Estados Unidos) recomienda la ingesta mínima de 20 a 35 g por día de fibras para un individuo saludable, de acuerdo con su dieta (por ejemplo: en una dieta de $8400 \mathrm{~kJ}$, correspondiendo a aproximadamente $2000 \mathrm{kcal}$, se recomienda una ingesta de $25 \mathrm{~g}$ de fibra), mientras que la United States National Academy of Sciences, Institute of Medicine, sugiere una ingesta diaria de 25 a $35 \mathrm{~g}$ de fibra (FDA, 2008). 
Capítulo 3. Digestibilidad del almidón de Pachyrhizus ahipa. Caracterización del residuo de la extracción de almidón

\section{OBJETIVOS}

Los objetivos planteados para este capítulo son los siguientes:

1. Estudiar la digestibilidad de los almidones nativos y gelatinizados extraídos a partir de raíces tuberosas de ahipa y mandioca.

2. Cuantificar las fracciones de almidón resistente (AR), almidón lentamente digerible (ALD) y almidón rápidamente digerible (ARD) en los mencionados productos.

3. Estimar en base a los resultados obtenidos el índice glicémico (IG).

4. Analizar la composición química del remanente (o pulpa) de la extracción de almidón de las raíces de Pachyrhizus ahipa, evaluando los contenidos de macrocomponentes (humedad, cenizas totales, lípidos totales, nitrógeno total, fibra dietaria total, almidón total).

5. Evaluar ciertas propiedades funcionales del residuo (capacidad de retención de agua, de solventes y poder de hinchamiento). 


\section{MATERIALES Y METODOS}

\section{Material analizado}

Se utilizaron almidones extraídos de raíces tuberosas de ahipa (Pachyrhizus ahipa) y de mandioca (Manihot esculenta) cultivadas en el área de influencia de la EEA INTA Montecarlo (Misiones). Los almidones de ahipa estudiados en el presente capítulo correspondieron a las accesiones Local e IRNAS 11. El proceso de obtención de los almidones mencionados fue descripto en el Capítulo 2.

\section{Digestibilidad de los almidones}

Se realizaron ensayos destinados a evaluar la digestibilidad de los almidones de las accesiones 11 y Local de ahipa. Con fines comparativos se analizó el almidón de mandioca.

La digestibilidad de los almidones de ahipa y de mandioca fue estudiada en sus formas nativa y gelatinizada.

\subsection{Cuantificación de las fracciones de almidón digerible en forma rápida, lenta y almidón resistente en muestras gelatinizadas}

Se determinó en los almidones gelatinizados de ahipa (accesiones 11 y Local) y de mandioca, la proporción de las fracciones de almidón rápidamente digerible (ARD), almidón resistente (AR) y almidón lentamente digerible (ALD) según Juansang y col., (2012). Para ello se prepararon las suspensiones $(10 \% \mathrm{p} / \mathrm{p})$ en agua destilada de los almidones correspondientes y se gelatinizaron a $90^{\circ} \mathrm{C}$ durante 20 minutos. A cada tubo se le adicionó $5 \mathrm{~mL}$ de una solución reguladora de maleato de sodio (100 mM, pH 6) y $5 \mathrm{~mL}$ de una solución enzimática que contenía $\alpha$-amilasa pancreática $\left(20 \mathrm{U} \mathrm{mL}^{-1}\right)$ y amiloglucosidasa (15 $\mathrm{U} \mathrm{mL}^{-1}$ ) (Megazyme, K-RSTAR 05/2008). La mezcla se incubó en un agitador termostatizado por aire a $37^{\circ} \mathrm{C}$ con agitación constante (200 rpm). Luego se tomaron por duplicado alícuotas $(0,20 \mathrm{~mL})$ a los 20 y 120 minutos de reacción y se transfirieron a tubos de ensayo con $4 \mathrm{~mL}$ de etanol absoluto. Los tubos se centrifugaron (10 minutos a $2300 x g$ ). A continuación se tomaron por duplicado 0,10 $\mathrm{mL}$ del sobrenadante, que se colocaron en tubos de ensayo limpios, para medir la concentración de glucosa liberada en cada tiempo de reacción. El método para medir 
dicha concentración consistió en la determinación colorimétrica de la glucosa mediante una reacción enzimática específica acoplada a un sistema cromógeno (4amino antipirina), tal como se explicó en el Capítulo 1. Para ello a cada tubo se le adicionaron 2,0 $\mathrm{mL}$ de una solución enzimática GOPOD (reactivo conteniendo soluciones de glucosa oxidasa y peroxidasa, 4-aminofenazona en buffer Tris y fenol, provisto por el kit de reactivos para diagnóstico de Wiener lab, Rosario, Argentina) y se incubaron durante 10 minutos a $37^{\circ} \mathrm{C}$ en baño termostático. Luego se midió la absorbancia de las muestras y del patrón de glucosa (solución de 1,0 mg mL $\mathrm{mL}^{-1}$ ) a 505 $\mathrm{nm}$ contra el blanco $(20 \mu \mathrm{L}$ de solución reguladora de acetato de sodio $+2,0 \mathrm{~mL}$ de GOPOD) en un espectrofotómetro Shimadzu UV mini 1240 UV-VIS (Japón).

La fracción de almidón digerido a los 20 minutos, entre 20 y 120 minutos y el almidón remanente no digerido después de los 120 minutos de incubación se clasificaron como almidón rápidamente digerido ( $A R D)$, almidón de digestión lenta ( $A L D$ ) y almidón resistente (AR), respectivamente (Englyst y col., 1992; Juansang y col., 2012).

Los resultados se expresaron como porcentaje (\%) de almidón gelatinizado digerido.

\subsection{Digestibilidad de los almidones de ahipa y mandioca}

Para estudiar la digestibilidad de los almidones nativos, se pesaron $50 \mathrm{mg}$ de cada uno (almidón de mandioca y de ahipa, accesiones 11 y Local) en vasos de precipitado de 25 $\mathrm{mL}$ de capacidad. En el caso de los almidones gelatinizados, se colocaron $100 \mathrm{mg}$ de las suspensiones gelatinizadas en dichos vasos. A cada vaso se le adicionaron 10 perlas de vidrio, $5 \mathrm{~mL}$ de una solución reguladora de maleato de sodio $(100 \mathrm{mM}$; $\mathrm{pH} 6,0)$ y una solución enzimática cuya concentración final fue de $200 \mathrm{U} \mathrm{mL}^{-1}(670 \mu \mathrm{L}$ de $\alpha$-amilasa pancreática $3000 \mathrm{U} \mathrm{mL} \mathrm{mL}^{-1}$ provista por el kit Megazyme@ K-RSTAR 05/2008 y 4,330 mL de la solución reguladora antes mencionada). Las mezclas se incubaron en agitación continua $(150 \mathrm{rpm})$ a $37^{\circ} \mathrm{C}$ en un agitador termostatizado por aire. Se tomaron por duplicado $600 \mu \mathrm{L}$ de muestra en tubos Eppendorf a los siguientes tiempos de incubación: 5, 15, 30, 45, 60, 90, 120, 150 y 180 minutos. Luego se centrifugaron a temperatura ambiente durante 3 minutos a máxima velocidad en microfuga. Se tomaron $500 \mu \mathrm{L}$ del sobrenadante de cada muestra, se transfirieron a tubos de ensayo de vidrio y se les agregó a cada uno 3,50 mL de una solución reguladora de acetato de 
sodio (1,2 M; pH 3,80). Finalizado el muestreo se adicionaron a todos los tubos de reacción, en solución reguladora de acetato de sodio, $4 \mu \mathrm{L}$ de la enzima amiloglucosidasa $3300 \mathrm{U} \mathrm{mL}^{-1}$ (Megazyme@ K-RSTAR 05/2008). Se mezclaron en vórtex y se incubaron durante 30 minutos a $50^{\circ} \mathrm{C}$ en baño termostático. Luego se tomaron 20 $\mu \mathrm{L}$ de muestra y se pasaron a tubos de ensayo limpios para medir la concentración de glucosa liberada en cada punto. A continuación se adicionaron $2,0 \mathrm{~mL}$ de GOPOD y se incubaron los tubos durante 10 minutos a $37^{\circ} \mathrm{C}$ en baño de agua. Se midió la absorbancia de las muestras y del patrón de glucosa a $505 \mathrm{~nm}$ contra el blanco (20 $\mu \mathrm{L}$ de solución reguladora de acetato de sodio $+2,0 \mathrm{~mL}$ de GOPOD). Los resultados se expresaron como porcentaje de almidón hidrolizado (\%).

\section{3 Índice de hidrólisis e índice glicémico de los almidones de ahipa y mandioca}

El índice de hidrólisis $(\mathrm{IH})$ de los almidones nativos y gelatinizados se calculó siguiendo el protocolo descripto por Goñi y col. (1997), comparando el porcentaje del almidón total hidrolizado obtenido a partir de la curva de hidrólisis (área bajo la curva 0-180 minutos) de cada muestra y la glucosa liberada del pan blanco durante el mismo período de digestión. El porcentaje de almidón hidrolizado a cada uno de los tiempos de muestreo se calculó a partir de la glucosa total liberada. Las curvas de hidrólisis (de almidones nativos y gelatinizados) fueron modeladas según Goñi y col. (1997), empleando las herramientas estadísticas del programa SigmaPlot (versión 10.0, Estados Unidos). El cálculo fue realizado utilizando la ecuación 3.1.

$$
C=C_{\infty} *\left(1-e^{-k t}\right)
$$

donde: C: es la concentración de glucosa liberada en el tiempo $t$; $C_{\infty}$ : es la concentración de equilibrio; $\mathrm{K}$ : es la constante cinética y $\mathrm{t}$ : es el tiempo elegido.

De los valores obtenidos para el IH, se estimó el índice glicémico (IG) a través de la ecuación descripta por Goñi y col. (1997):

$$
I G=39,71+0,549 * I H
$$




\subsection{Cinética de hidrólisis a largo plazo de los almidones nativos de ahipa y mandioca}

Con el fin de estudiar la cinética de hidrólisis enzimática de los almidones nativos y determinar el tiempo requerido para alcanzar el porcentaje máximo de hidrólisis de los mismos, se siguió el método descripto por Hung y Morita (2005), con ligeras modificaciones.

Se prepararon suspensiones de almidón nativo $(1 \% \mathrm{p} / \mathrm{v})$ en una solución reguladora de maleato de sodio (100 mM, pH 6) y se añadieron $120 \mathrm{U} \mathrm{mL}^{-1}$ de la enzima $\alpha$-amilasa pancreática (Megazyme, K-RSTAR 05/2008). Las mezclas se incubaron con agitación continua $(100 \mathrm{rpm})$ a $37^{\circ} \mathrm{C}$ en un agitador termostatizado por aire. Se tomaron alícuotas a diferentes tiempos $(0,3,6,8,14,18$ y 20,5 horas) para medir la concentración de glucosa liberada mediante un método espectrofotométrico. Las alícuotas fueron centrifugadas durante 5 minutos a $5000 \times \mathrm{g}$. A partir de los sobrenadantes, $0,25 \mathrm{~mL}$ de muestra se dispusieron en dos tubos de ensayo por separado y se añadieron $2,25 \mathrm{~mL}$ de una solución reguladora de acetato de sodio (100 $\mathrm{mM}, \mathrm{pH} 4,50$ ). Las mezclas se incubaron con $25 \mu \mathrm{L}$ de amiloglucosidasa (Megazyme, $\mathrm{K}$ RSTAR 05/2008, $3300 \mathrm{U} \mathrm{mL}^{-1}$ ) durante 30 minutos a $50^{\circ} \mathrm{C}$. Para determinar la concentración de glucosa liberada en el sobrenadante, 0,1 $\mathrm{mL}$ de la mezcla fueron transferidos a tubos de ensayo con $3,0 \mathrm{~mL}$ del reactivo conteniendo glucosa oxidasa / peroxidasa (GOPOD). Las muestras se incubaron a $50^{\circ} \mathrm{C}$ durante 20 minutos. Las lecturas de absorbancia se realizaron a $505 \mathrm{~nm}$ frente al blanco de los reactivos. Los resultados se expresaron como porcentaje (\%) de almidón hidrolizado.

\section{Obtención del residuo sólido de la extracción del almidón de ahipa}

El residuo sólido o pulpa de ahipa es el producto remanente del proceso de extracción de almidón. La obtención de este residuo sólido o remanente se presenta en el diagrama de flujo de la Figura 3.3; este proceso fue detallado previamente en el Capítulo 2. El residuo sólido de ahipa húmedo fue secado en estufa a $50^{\circ} \mathrm{C}$, y almacenado a temperatura ambiente hasta su posterior análisis. 


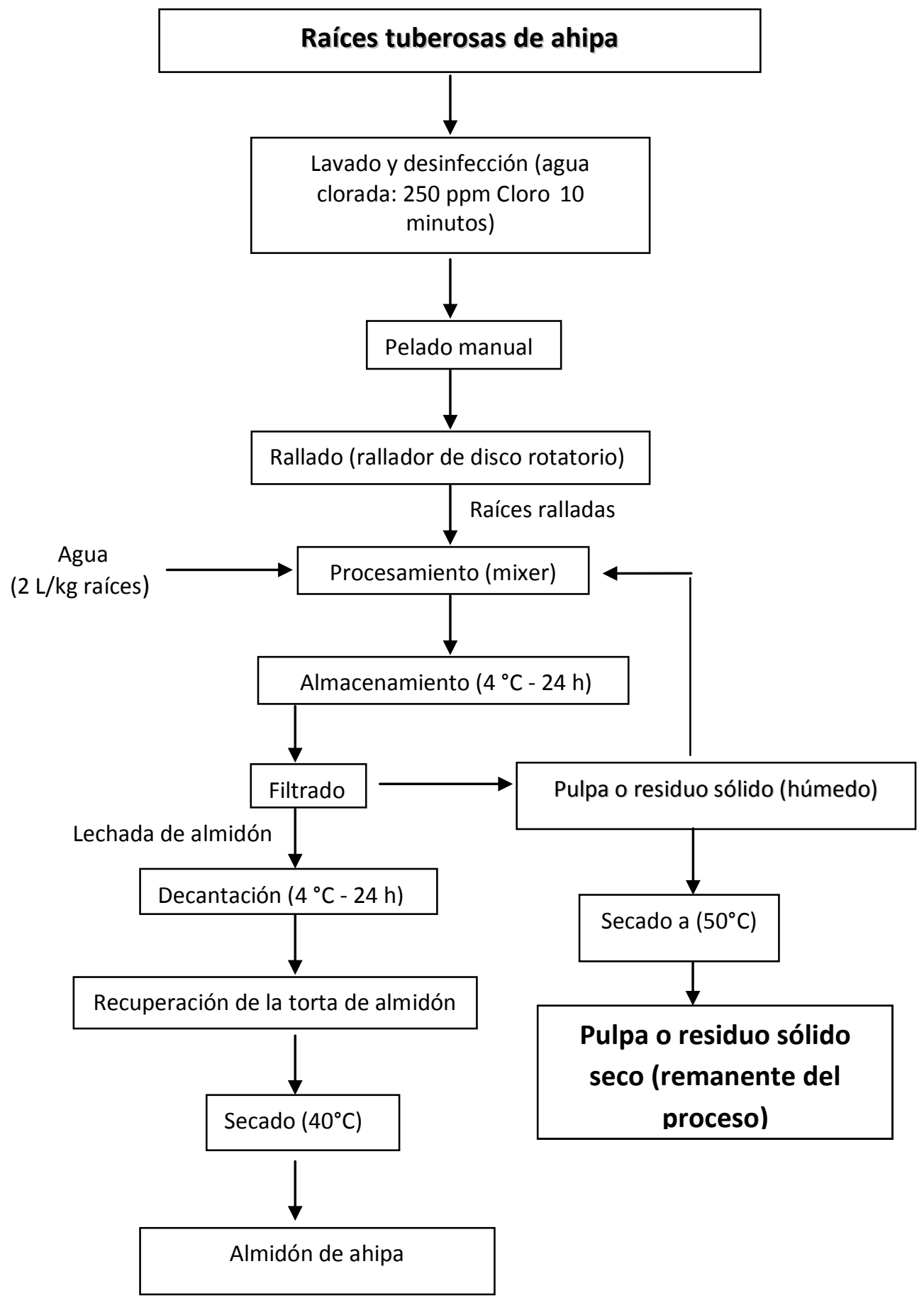

Figura 3.3. Diagrama de flujo del proceso de extracción de almidón y obtención del residuo sólido o pulpa de Pachyrhizus ahipa (ahipa).

\section{Composición química del residuo de la extracción del almidón de ahipa}

Se analizó la composición química del residuo sólido o pulpa de la obtención del almidón de ahipa. 


\subsection{Contenido de materia seca}

Se cuantificó el contenido de materia seca y humedad residual, por duplicado, siguiendo el método de referencia (AOAC, 1990). Las muestras se analizaron según el procedimiento descripto en el Capítulo 1. El resultado se expresó como porcentaje (\%) en relación al peso inicial de la muestra.

\subsection{Determinación de cenizas totales}

Se pesó por duplicado el residuo sólido de ahipa ( $2 \mathrm{~g})$. Las muestras se colocaron en los crisoles limpios y previamente tarados. Luego se realizó la determinación de cenizas según lo detallado en el Capítulo 1. Los crisoles conteniendo las cenizas se pesaron y con este valor se calculó el porcentaje (\%) de cenizas totales.

\subsection{Extracción y cuantificación de lípidos totales}

Se extrajeron y cuantificaron, en un equipo Soxhlet, utilizando $n$-hexano como solvente, los lípidos totales de las muestras (10 g) correspondientes al residuo sólido o remanente de la extracción del almidón de ahipa tal como se explicó en el Capítulo 1. Los resultados se expresaron como porcentaje (\%) sobre base seca.

\subsection{Determinación del contenido de nitrógeno total}

Se cuantificó el nitrógeno total del residuo de la extracción del almidón de ahipa (0,8 g) mediante el método Kjeldahl. El procedimiento se detalló en el Capítulo 1. Los resultados se expresaron como porcentaje (\%) sobre base seca.

\subsection{Contenido de almidón total}

Se determinó el contenido de almidón total a partir de 0,10-0,15 g de muestra, empleando el kit enzimático K-TSTA 05/06 (Megazyme@), Irlanda), según se describió en el Capítulo 1. Los resultados se expresaron en porcentaje (\%) sobre base seca. 


\subsection{Fibra dietaria total}

La cuantificación de fibra dietaria total se llevó a cabo utilizando el kit enzimático KTDFR 05/12 Megazyme@ (Irlanda). El procedimiento llevado a cabo se detalló en el Capítulo 1. Los resultados se expresaron como porcentaje (\%).

\section{Caracterización microestructural: morfología de las partículas del residuo}

La morfología de las partículas del residuo de la extracción del almidón de ahipa fue estudiada mediante microscopía electrónica de barrido (SEM, Scanning Electron Microscopy). Los procedimientos llevados a cabo para la obtención de micrografías SEM fueron descriptos en el Capítulo 2.

\section{Propiedades funcionales del residuo de la extracción del almidón de ahipa}

Las propiedades funcionales del residuo de la extracción del almidón de ahipa estudiadas se encuentran asociadas a su composición química, y han sido determinadas con el fin de caracterizar este subproducto obtenido a partir de las raíces tuberosas.

\subsection{Determinación de la capacidad de retención de agua}

La capacidad de retención de agua del residuo de la extracción del almidón de ahipa se midió de acuerdo con Szymonska y col. (2003), según el procedimiento descripto en el Capítulo 2. La capacidad ensayada se expresó como porcentaje (\%) sobre base seca.

\subsection{Determinación de la capacidad de hinchamiento}

Se determinó de acuerdo a una modificación del método propuesto por Tsai y col. (1997). Se prepararon suspensiones acuosas del residuo de la extracción del almidón de ahipa al $1 \% \mathrm{p} / \mathrm{p}$. Las temperaturas empleadas fueron $55,65,75,85,90$ y $95^{\circ} \mathrm{C}$. El ensayo se realizó tal como se especificó en el Capítulo 2. La capacidad de hinchamiento se determinó como la razón entre el peso del residuo del almidón hidratado (sedimento) y el peso inicial del residuo seco. 


\subsubsection{Contenido de amilosa y amilopectina}

En los sobrenadante del ensayo anterior obtenidos a cada temperatura se cuantificó por espectrofotometría, el contenido de amilosa y amilopectina. Se midieron las absorbancias a las longitudes de onda de 535 nm y 615 nm, según García y col. (1995). Las concentraciones de amilosa y amilopectina fueron expresadas en $\mathrm{g} / \mathrm{L}$.

\subsection{Capacidad de retención de solventes}

La capacidad de retención de solventes del residuo de la extracción del almidón de ahipa fue analizada siguiendo el método AACC 56-11 (Rosell y col., 2009). Los solventes utilizados fueron agua desionizada, sacarosa $(50 \% \mathrm{p} / \mathrm{p}), \mathrm{Na}_{2} \mathrm{CO}_{3}(5 \% \mathrm{p} / \mathrm{p})$ y ácido láctico ( $5 \%$ p/p). La capacidad de retención de solventes se calculó tal como se detalló en el Capítulo 1. El resultado se expresó como porcentaje (\%).

\section{Análisis estadístico}

Todas las determinaciones fueron llevadas a cabo al menos por triplicado. Para el análisis estadístico de resultados se utilizó el programa Systat Software (Versión 10.0). Se efectuó el análisis de varianza (ANOVA) y se realizó la comparación de medias mediante el test de la diferencia mínima significativa de Fisher (LSD), con un nivel de significación $p=0,05$. Como ya se describió, el modelado de las curvas de hidrólisis a la ecuación de Goñi y col. (1997) se realizó empleando las herramientas estadísticas del programa SigmaPlot (versión 10.0, Estados Unidos). 


\section{RESULTADOS Y DISCUSIÓN}

\section{Digestibilidad de los almidones de ahipa y mandioca}

Los valores correspondientes a las fracciones de almidón rápidamente digerible (ARD), lentamente digerible (ALD) y resistente (AR) obtenidos a partir de los almidones (mandioca y accesiones 11 y Local de ahipa) gelatinizados se muestran en la Figura 3.4. Como se mencionó anteriormente, estas fracciones son medidas in vitro asociadas con la velocidad de digestibilidad enzimática del almidón. Las fracciones ARD y ALD corresponden a la cantidad de almidón digerido a los 20 minutos y entre 20 y 120 minutos de efectuada la mezcla de reacción, respectivamente. El almidón no digerido luego de los 120 minutos de reacción se clasifica como AR (Englyst y col., 1992; Juansang y col., 2012).

El almidón de ahipa perteneciente a la accesión IRNAS 11 mostró mayores valores de ARD y $A R$ que el de mandioca $(p<0,05)$, mientras que ambas accesiones de ahipa exhibieron proporciones inferiores de $\operatorname{ALD}(p<0,05)$. La accesión 11 de ahipa presentó el valor más bajo de ALD de los tres almidones ensayados $(p<0,05)$.

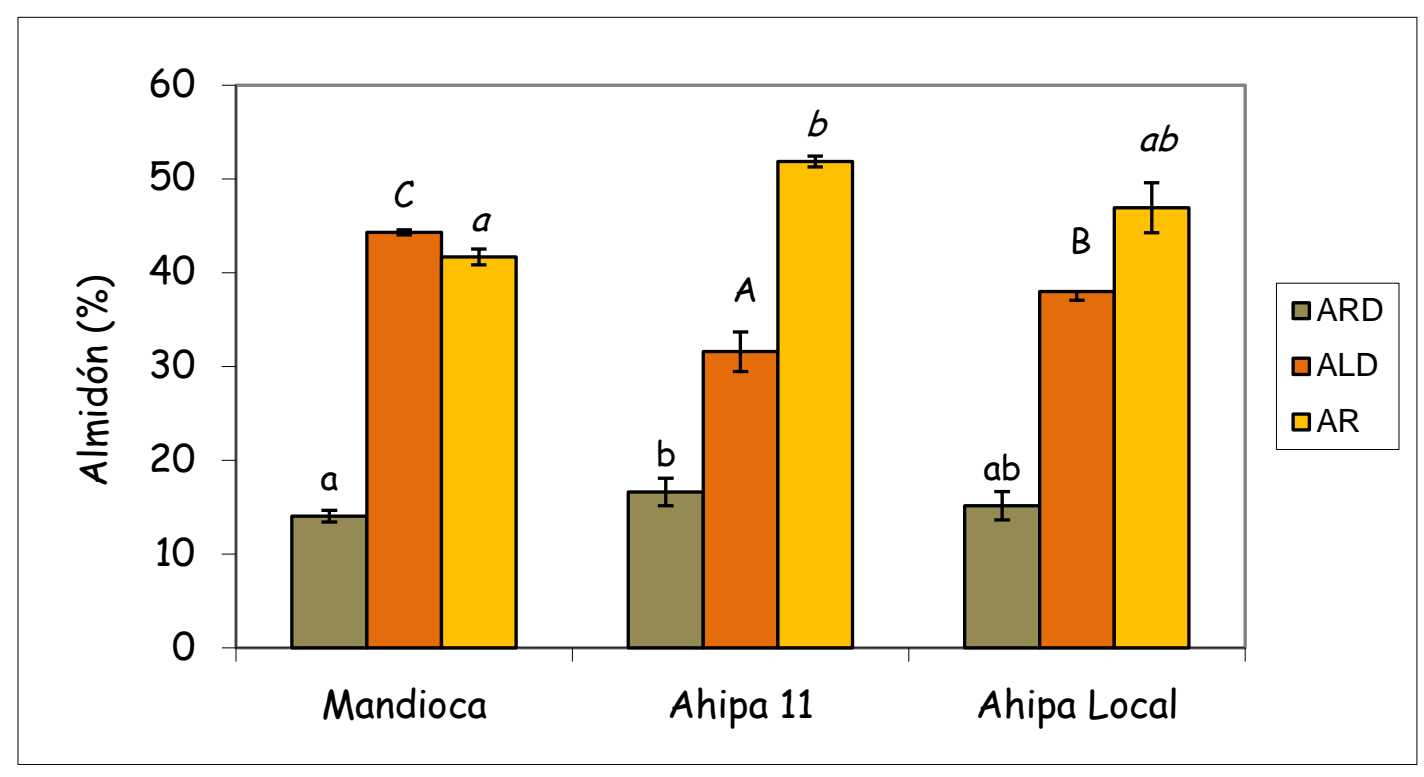

Figura 3.4. Porcentaje de almidón rápidamente digerible (ARD), lentamente digerible (ALD) y resistente (AR) de suspensiones de almidón de Pachyrhizus ahipa (ahipa) y Manihot esculenta (mandioca) gelatinizadas.

Nota: Se utilizó diferente formato de letra para comparar los resultados obtenidos entre los distintos almidones. Las medias acompañadas por una misma letra, no difieren significativamente $(p>0,05)$. 
Capítulo 3. Digestibilidad del almidón de Pachyrhizus ahipa. Caracterización del residuo de la extracción de almidón

El almidón resistente cuantificado en este caso se clasificaría como AR3 y correspondería a la fracción no hidrolizada compuesta principalmente de amilosa retrogradada formada durante el proceso de enfriamiento de las pastas de almidón gelatinizado (Brown, 2004).

La Figura 3.5 muestra las cinéticas de hidrólisis enzimática para las suspensiones de los almidones gelatinizados de ahipa y de mandioca en comparación con la de la digestión del pan blanco que se utiliza como referencia.

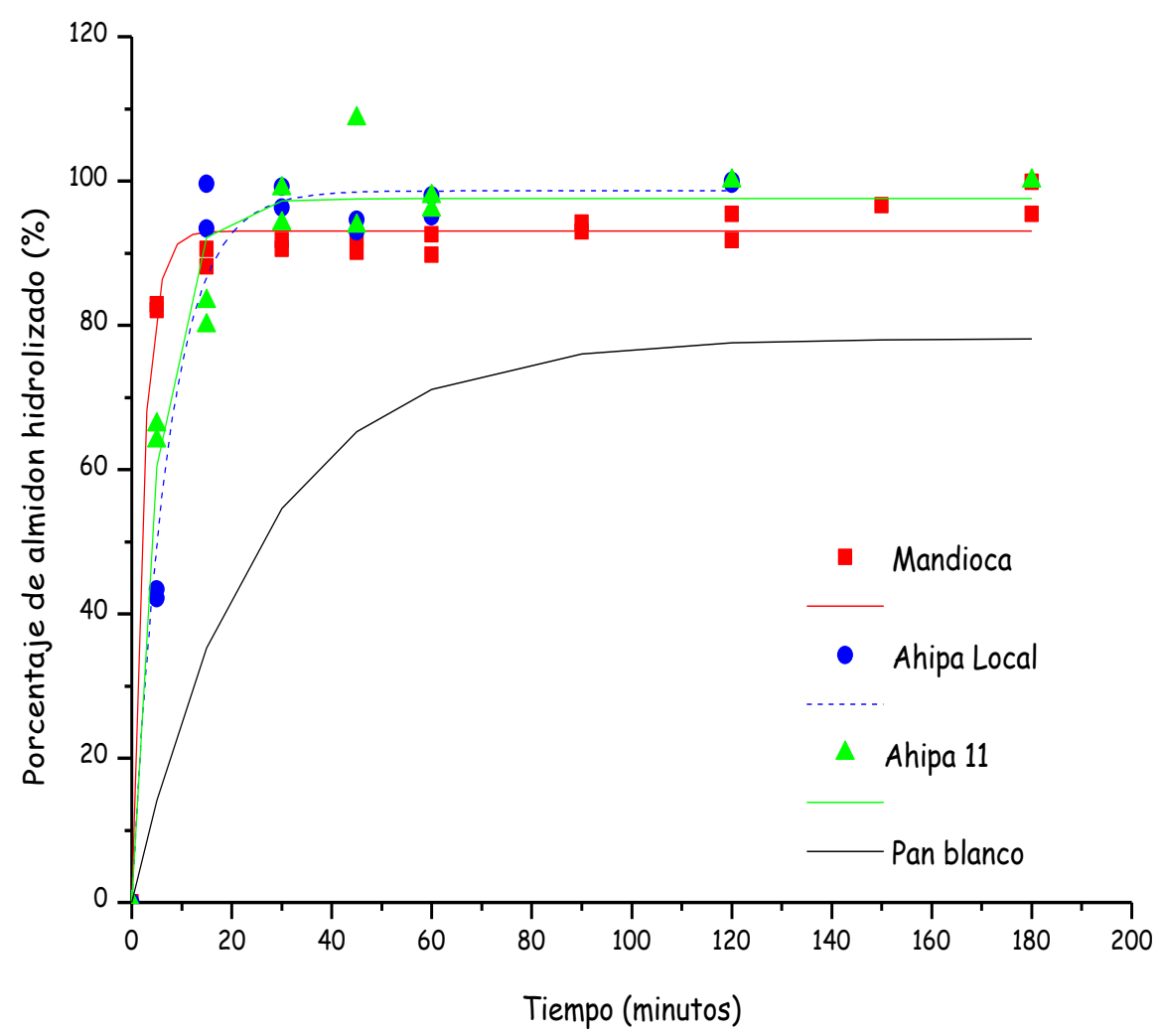

Figura 3.5. Cinética de hidrólisis enzimática (expresada como porcentaje de hidrólisis de almidón) de suspensiones de almidón gelatinizadas de Pachyrhizus ahipa (ahipa) de diferentes accesiones y de Manihot esculenta (mandioca).

Nota: Los datos experimentales corresponden a los símbolos y las líneas corresponden a las curvas de ajuste del modelo de Goñi y col. (1997); se muestra también la curva de referencia correspondiente al pan blanco.

Las curvas de la Figura 3.5 muestran una primera zona desde 0 hasta 30 minutos para las suspensiones del almidón gelatinizado de ahipa y desde 0 hasta 15 minutos para las 
Capítulo 3. Digestibilidad del almidón de Pachyrhizus ahipa. Caracterización del residuo de la extracción de almidón

suspensiones del almidón gelatinizado de mandioca donde la velocidad de hidrólisis aumenta linealmente y una segunda zona a partir de los tiempos mencionados donde se alcanza el plateau correspondiente al porcentaje de equilibrio. Comparando las curvas obtenidas con la correspondiente al sistema de referencia (pan blanco) se observa que la cinética de hidrólisis del pan blanco es más lenta ya que la primera zona de la curva se extiende hasta los 90 minutos.

Los parámetros del modelado de las curvas de hidrólisis al modelo de Goñi y col. (1997) se presentan en la Tabla 3.3.

Tabla 3.3. Parámetros del modelado de la cinética de hidrólisis según el modelo de Goñi y col. (1997), para almidones gelatinizados de Pachyrhizus ahipa (ahipa) y de Manihot esculenta (mandioca).

\begin{tabular}{cccc}
\multirow{2}{*}{ Fuente/almidón } & \multicolumn{3}{c}{ Modelado de la cinética de hidrólisis } \\
\cline { 2 - 4 } & $\begin{array}{c}\text { Coeficiente de } \\
\text { correlación }\left(\mathrm{r}^{2}\right)\end{array}$ & $\begin{array}{c}\text { Concentración de } \\
\text { equilibrio } \mathrm{C}_{\infty}(\%)\end{array}$ & $\begin{array}{c}\text { Constante cinética } \\
\mathrm{k}\left(\mathrm{min}^{-1}\right)\end{array}$ \\
\hline Referencia: Pan blanco* & -- & 78,2 & 0,04 \\
\hline Ahipa accesión 11 & 0,9792 & $99 \pm 2$ & $0,14 \pm 0,02$ \\
\hline Ahipa accesión Local & 0,9506 & $101 \pm 2$ & $0,17 \pm 0,03$ \\
\hline Mandioca & 0,9908 & $93,1 \pm 0,7$ & $0,43 \pm 0,04$
\end{tabular}
Nota: *Los datos de la referencia corresponden a Goñi y col. (1997).

El porcentaje de hidrólisis in vitro de los almidones es un parámetro que se puede relacionar directamente con el contenido de almidón disponible.

El índice glicémico (IG) es una característica de los carbohidratos consumidos en diferentes tipos de alimentos sobre la base del nivel postprandial de glucosa en sangre (Jenkins, 2007; Jenkins y col., 1982). Se ha informado que el consumo a largo plazo de alimentos con bajo IG se encuentra asociado a la reducción de la incidencia y prevalencia de ciertas enfermedades cardiovasculares, la diabetes, y también algunas de las formas de cáncer (Brand-Miller, 2007; Jenkins, 2007; Roberts, 2000; Wolever y Mehling, 2002).

La estimación del índice glicémico (IG) y la digestibilidad de los almidones se pueden vincular matemáticamente. Una de las funciones matemáticas utilizadas es la 
Capítulo 3. Digestibilidad del almidón de Pachyrhizus ahipa. Caracterización del residuo de la extracción de almidón

propuesta por Goñi y col. (1997) donde el IG in vivo se relaciona con la cantidad de almidón hidrolizado in vitro después de 180 minutos de incubación a $37^{\circ} \mathrm{C}$ (proceso normal de la digestión).

Los estudios de los almidones gelatinizados mostraron porcentajes de hidrólisis total del almidón por encima de los correspondientes al pan blanco en todos los puntos de muestreo analizados (Figura 3.5). En consecuencia, los valores del índice de hidrólisis (IH) de los tres almidones gelatinizados fueron superiores a 100 (Tabla 3.4). No se observaron diferencias significativas $(p>0,05)$ en el IG de los almidones gelatinizados ni entre las distintas especies vegetales ni entre las distintas accesiones de Pachyrhizus ahipa (Tabla 3.4).

Tabla 3.4. Índice de hidrólisis (IH) e índice glicémico estimado (IG) por el modelo de Goñi y col. (1997), para almidones gelatinizados de Pachyrhizus ahipa (ahipa) y de Manihot esculenta (mandioca).

\begin{tabular}{ccc} 
Fuente/almidón & Índice de hidrólisis (IH) & Índice glicémico (IG) \\
\hline Referencia: Pan blanco* $^{*}$ & 100 & 94 \\
\hline Ahipa accesión 11 & $136 \pm 3^{\text {a }}$ & $114 \pm 2^{\text {a }}$ \\
\hline Ahipa accesión Local & $136 \pm 4^{\text {a }}$ & $114 \pm 2^{\text {a }}$ \\
\hline Mandioca & $136,7 \pm 0,2^{\text {a }}$ & $114,8 \pm 0,1^{\text {a }}$ \\
$*$ Los datos de la referencia corresponden a Goñi y col. (1997).
\end{tabular}

Nota: Los valores informados corresponden a las medias \pm las desviaciones estándar. Datos acompañados por una misma letra en la misma columna, no difieren significativamente $(p>0,05)$

Para el caso de los almidones nativos (Figura 3.6) cabe aclarar que como no se alcanzó el plateau, no se pudo modelar matemáticamente los datos para obtener los parámetros de ajuste de la curva correspondiendo los mismos a la primera porción de la misma (zona lineal).

Como se esperaba, los almidones nativos presentaron valores de IG estimados inferiores a los de los almidones gelatinizados, siendo también más bajos que los valores del pan blanco (Tabla 3.5). El almidón de mandioca nativo mostró un valor de IG más bajo que los almidones de ahipa, siendo esta diferencia significativa $(p<0,05)$. 
En la Figura 3.6 se observa que después de 3 horas de incubación enzimática no se alcanzó el máximo porcentaje de hidrólisis de los almidones nativos analizados.

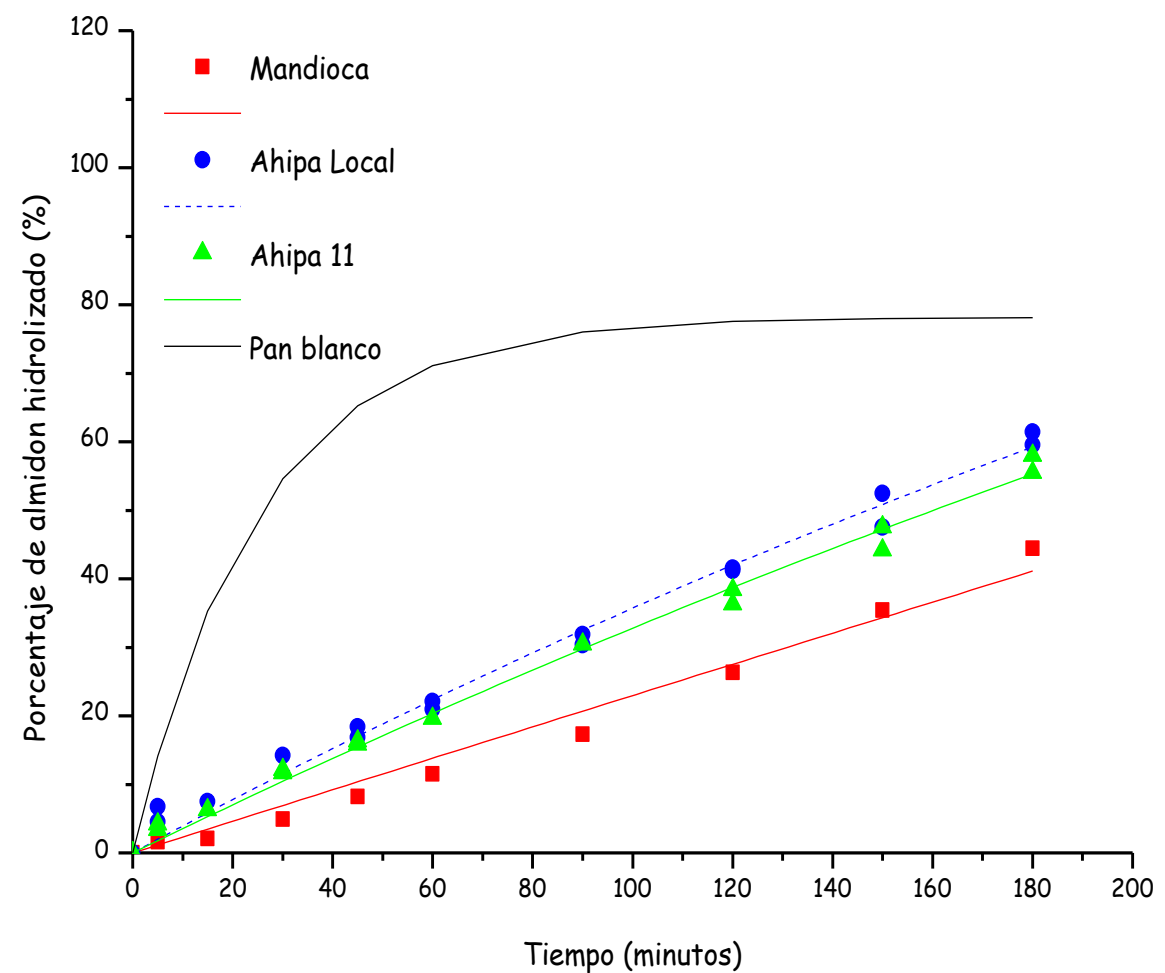

Figura 3.6. Cinética de hidrólisis enzimática (expresada como porcentaje de hidrólisis de almidón) de almidones nativos de Pachyrhizus ahipa (ahipa) de diferentes accesiones y de Manihot esculenta (mandioca).

Nota: Los datos experimentales corresponden a los símbolos y las líneas corresponden a las curvas de ajuste del modelo de Goñi y col. (1997); se muestra también la curva de referencia correspondiente al pan blanco.

En los almidones gelatinizados el IG fue mayor que el de los almidones nativos (Tabla 3.5), como era de esperar. Chung y col. (2006) atribuyeron este comportamiento a que durante el proceso de gelatinización del almidón, se interrumpen los enlaces de hidrógeno entre las cadenas de amilosa y amilopectina, debido a la interacción de las mismas con el agua, por lo que aumenta la exposición al ataque enzimático de dichas cadenas. 
Tabla 3.5. Índice de hidrólisis (IH) e índice glicémico estimado (IG) para almidones nativos de Pachyrhizus ahipa (ahipa) y Manihot esculenta (mandioca).

\begin{tabular}{ccc} 
Fuente/almidón & Índice de hidrólisis (IH) & Índice glicémico (IG) \\
\hline Referencia: Pan blanco* & 100 & 94 \\
\hline Ahipa accesión 11 & $43,2 \pm 0,1^{\text {a }}$ & $63,43 \pm 0,07^{\text {a }}$ \\
\hline Ahipa accesión Local & $47,2 \pm 0,5^{\text {a }}$ & $65,6 \pm 0,3^{\text {a }}$ \\
\hline Mandioca & $30 \pm 1^{\text {b }}$ & $56,2 \pm 0,6^{\text {b }}$ \\
Nota: * Los datos de la referencia corresponden a Goñi y col. (1997).
\end{tabular}

Los valores informados corresponden a las medias \pm las desviaciones estándar. Datos acompañados por una misma letra en la misma columna, no difieren significativamente $(p>0,05)$.

Ingredientes o componentes alimentarios con valores de IG estimados mayores que el del pan blanco, como por ejemplo el almidón de avena con tratamiento hidrotérmico (Ovando-Martínez y col., 2013), podrían ser útiles para la formulación de productos con alto contenido de energía, similares a varios alimentos feculentos naturales cocinados tales como el arroz del cultivar Karaya (Frei y col., 2003) y las papas pertenecientes a las variedades Russet Burbano (enteras o en trozos, cocidas al horno) y Desireed (enteras o en mitades hervidas) (Ek y col., 2012).

La cinética de hidrólisis a largo plazo (20,5 horas) de los almidones nativos con $\alpha$ amilasa pancreática se muestra en la Figura 3.7. El porcentaje máximo de la digestión enzimática se observó después de 8 horas de incubación para los tres almidones analizados, sin diferencias significativas entre ellos $(p>0,05)$.

Los valores máximos de porcentaje de hidrólisis de mandioca y ahipa fueron de 84,0 a $87,2 \%$, implicando que 12,8 y $16 \%$ corresponde a almidón resistente de tipo AR2, sobre la base de la clasificación derivada de las características nutricionales del almidón (Englyst y col., 1992). 


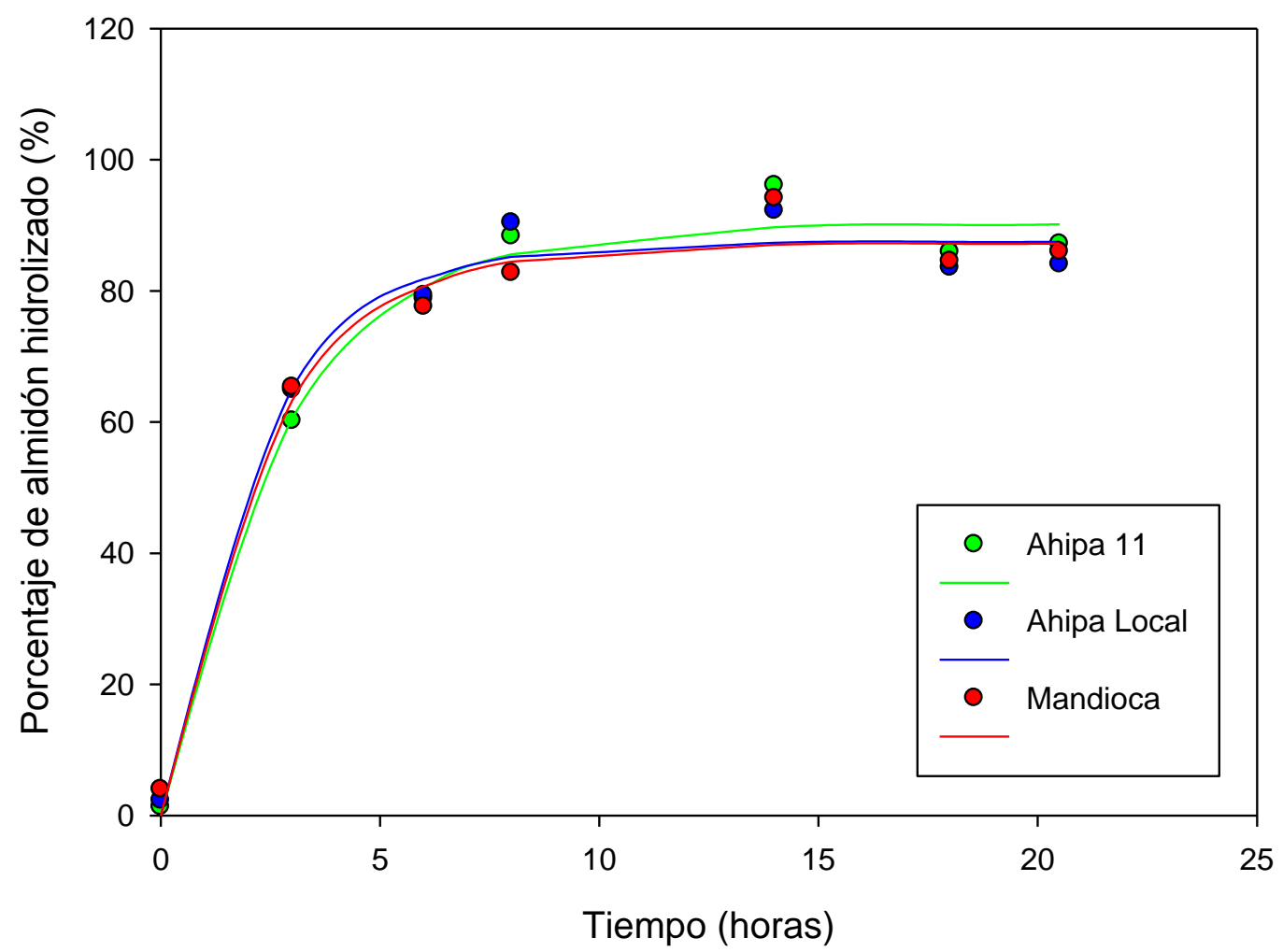

Figura 3.7. Cinética de la hidrólisis enzimática (expresada como porcentaje de hidrólisis de almidón) a largo plazo de los almidones nativos de Pachyrhizus ahipa (ahipa 11 y ahipa Local) y de Manihot esculenta (mandioca).

Nota: Los datos experimentales corresponden a los símbolos y las líneas corresponden a las curvas de ajuste del modelo de Goñi y col. (1997).

Para el almidón de mandioca, el porcentaje máximo digerido obtenido fue similar al valor indicado por Srichuwong y col. (2005), que informó una tasa de digestión máxima con enzima $\alpha$-amilasa del $88,4 \%$ para el almidón de mandioca de estructura cristalina tipo A. En general, los almidones tipo B exhiben baja digestibilidad in vitro (Annison y col., 1994). Como se mencionó en el Capítulo 2, el patrón de cristalinidad del almidón de ahipa fue asignado como tipo C (López y col., 2010), correspondiendo a una mezcla de los tipos cristalinos A y B. Los valores de digestibilidad del almidón de ahipa resultaron intermedios entre los informados para almidones con patrones de difracción tipos A y B (Srichuwong y col., 2005). Aunque la forma cristalina de los gránulos del almidón se ha citado como el factor más importante que afecta a la 
Capítulo 3. Digestibilidad del almidón de Pachyrhizus ahipa. Caracterización del residuo de la extracción de almidón

extensión de la hidrólisis enzimática (Srichuwong y col., 2005), otras características tales como el tamaño de los gránulos o la proporción de amilosa/amilopectina también han sido señalados como factores que afectan la actividad y accesibilidad de la enzima. Sin embargo, para almidones con el mismo tipo de patrón de difracción se ha señalado que la correlación con la actividad enzimática varió con la naturaleza del almidón analizado (Franco y col., 1992; Man y col., 2012).

Si bien se ha propuesto para otros cultivos comestibles de R\&T la existencia de una correlación entre el tamaño de los gránulos y la digestibilidad de los almidones, en el caso de ahipa y mandioca no se observó dicha correlación (Man y col., 2012). Para el almidón de ñame (Dioscorea esculenta), por ejemplo, que también presenta una estructura cristalina tipo C, el porcentaje máximo de digestión alcanzado fue cercano al $30 \%$, considerablemente menor que el hallado para los almidones de ahipa. Sin embargo, el almidón de ñame presenta un tamaño de gránulo medio de partícula que es aproximadamente la mitad que el de ahipa aunque su contenido de amilosa aparente es similar (14,2\%) (Srichuwong y col., 2005; Doporto y col., 2012).

Las leguminosas contienen altos niveles de fibra dietaria, relacionados con la presencia de paredes celulares, resistentes a la ruptura durante la cocción. Esto, aunado a la presencia de ciertos factores antinutricionales hace que el almidón de las leguminosas posea una digestibilidad baja. Por otra parte, las leguminosas procesadas contienen cantidades significativas de AR1, (además de AR2 y AR3) lo que las hace más interesantes desde el punto de vista nutricional (Tovar y col., 1992b; Velasco y col., 1997; Bravo y col., 1998). Así, la velocidad de digestión del almidón y la liberación de la glucosa al torrente sanguíneo, es un proceso lento después de ingerir leguminosas, lo cual causa bajas respuestas glicémicas e insulinémicas posprandiales en comparación con las asociadas al consumo de cereales o papas (Jenkins y col., 1982; Tovar y col., 1992b)

Teniendo en cuenta que la ahipa pertenece a la familia de las Leguminosas, la estructura del almidón y la digestibilidad resultan similares a los de otras plantas de la misma familia ya que la mayoría de ellos presentan patrón de difracción del tipo C (Sandhu y Lim, 2008). Los valores de almidón resistente mencionados para diversos almidones de plantas leguminosas obtenidos 120 minutos después de la ingestión 
Capítulo 3. Digestibilidad del almidón de Pachyrhizus ahipa. Caracterización del residuo de la extracción de almidón

están dentro del rango de 50-79\% (Sandhu y Lim, 2008), en el orden de los valores de AR observados para el almidón de ahipa (aproximadamente 54\%).

Por lo tanto, la ahipa puede ser considerada como una muy buena fuente de almidón y éste puede ser utilizado como un alimento funcional, lo que contribuye a aumentar la fracción rápidamente y lentamente digerible.

\section{Composición química del residuo de la extracción del almidón de ahipa}

La Tabla 3.6 muestra los resultados del análisis de macrocomponentes realizado sobre el residuo de la extracción del almidón de ahipa.

Tabla 3.6. Composición química (\% p/p) del residuo de la extracción del almidón de Pachyrhizus ahipa (ahipa).

\begin{tabular}{cccccc}
$\begin{array}{c}\text { Materia } \\
\text { seca }\end{array}$ & $\begin{array}{c}\text { Lípidos } \\
\text { totales }\end{array}$ & $\begin{array}{c}\text { Cenizas } \\
\text { totales }\end{array}$ & $\begin{array}{c}\text { Nitrógeno } \\
\text { total }\end{array}$ & $\begin{array}{c}\text { Fibra dietaria } \\
\text { total }\end{array}$ & $\begin{array}{c}\text { Almidón } \\
\text { total }\end{array}$ \\
\hline $87 \pm 2$ & $0,30 \pm 0,04$ & $2,15 \pm 0,01$ & $0,77 \pm 0,02$ & $45 \pm 2$ & $38 \pm 2$
\end{tabular}

Nota: Los valores informados corresponden a las medias \pm las desviaciones estándar. Los resultados se expresan en base seca.

El contenido de humedad del residuo sólido de ahipa (13\%) coincidió con el presentado por uno de los compuestos ricos en fibra de la calabaza (Cucurbita moschata Duchesne ex Poiret) informado por de Escalada Pla y col., (2007). El residuo remanente de la extracción está formado mayoritariamente por carbohidratos cuantificados como fibra (45\%) y almidón (38\%), todos de naturaleza hidrofílica, lo que afecta sus propiedades funcionales.

En cuanto al contenido de cenizas, el residuo de ahipa exhibió un valor similar al de la pulpa de calabaza (de Escalada Pla y col., 2007). La cantidad de proteína del residuo de ahipa, que se puede estimar multiplicando el contenido de nitrógeno total por el factor

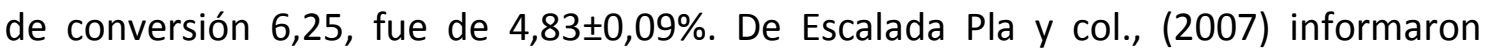
valores superiores al de ahipa para pulpa de calabaza. 


\section{Morfología del residuo remanente de la extracción del almidón de ahipa}

Las micrografías electrónicas (Figura 3.8) muestran aglomerados de componentes fibrosos, unidos entre sí muy posiblemente por el almidón remanente en el residuo. Las estructuras anatómicas que aportan a dichos componentes son fundamentalmente los restos de las paredes celulares que conforman el tejido parenquimático de la raíz (parénquima reservante, en el caso de la raíz de Pachyrhizus ahipa); a ellos se suman las paredes celulares del tejido de conducción, principalmente el xilema, conformado por los vasos leñosos o tráqueas. Normalmente, existe una cierta proporción de fibras que se encuentran asociadas al tejido de conducción, que actúan como elementos de refuerzo.

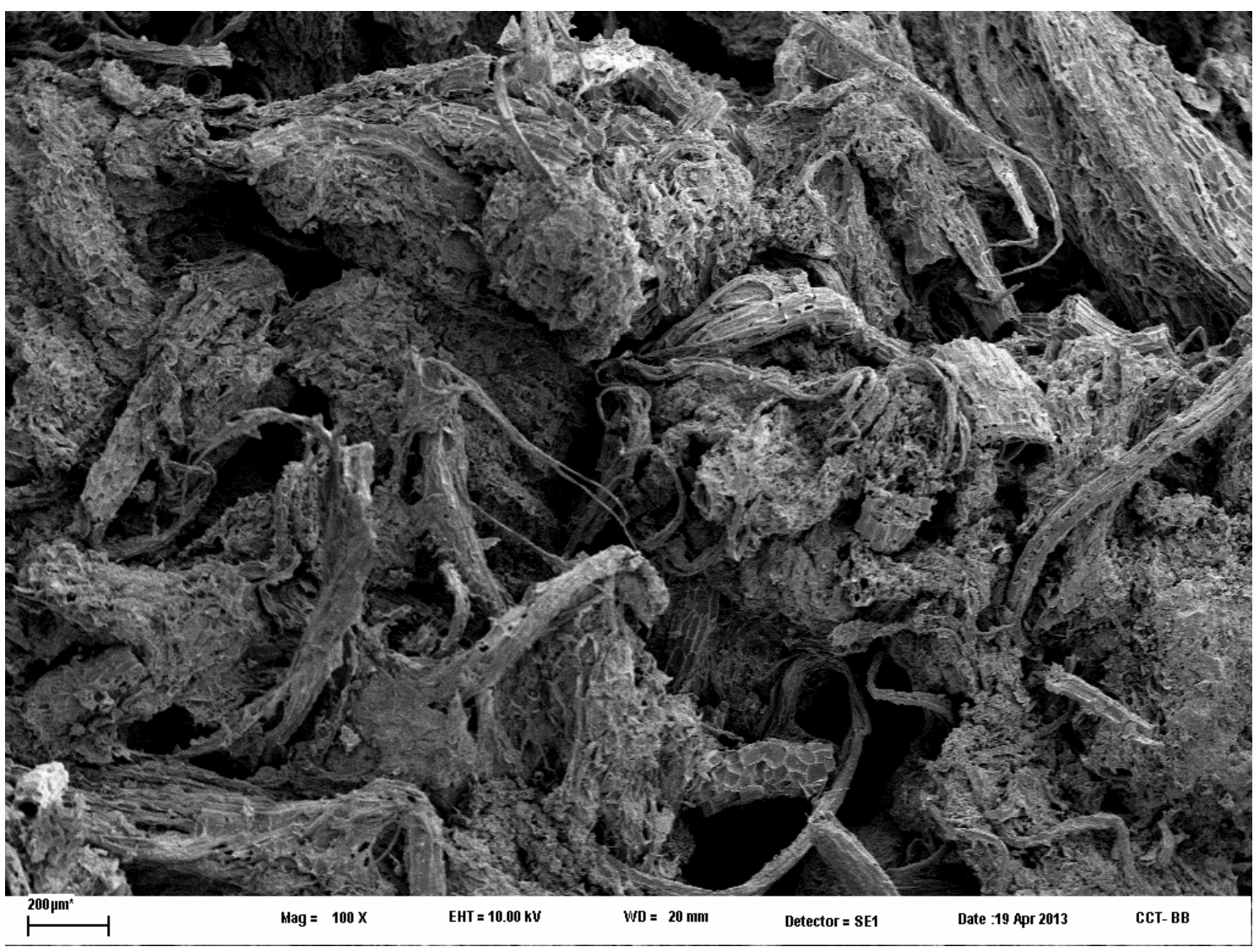

Figura 3.8. Micrografía electrónica obtenida en las observaciones mediante SEM del residuo remanente de la extracción de almidón de Pachyrhizus ahipa (ahipa).

Los vasos o tráqueas, que son abiertos, están formados por numerosos miembros de vasos superpuestos, comunicados entre sí por placas de perforación. Éstas pueden ser 
reticuladas, escalariformes o simples, mostrando en este caso una mayor evolución dada su adaptación a la conducción. Los miembros de vasos poseen pared secundaria reforzada (normalmente por deposición de lignina). Las paredes laterales de los elementos de conducción presentan distintos tipos de engrosamientos secundarios: anillados, espiralados, escalariformes, reticulados y punteados. La proporción de pared primaria es mayor en los vasos con engrosamientos anillados y espiralados, lo que les permite mayor adaptación al crecimiento.

En la Figura 3.9 se observa el detalle correspondiente a un miembro de vaso leñoso del tejido de conducción de la raíz de Pachyrhizus ahipa.

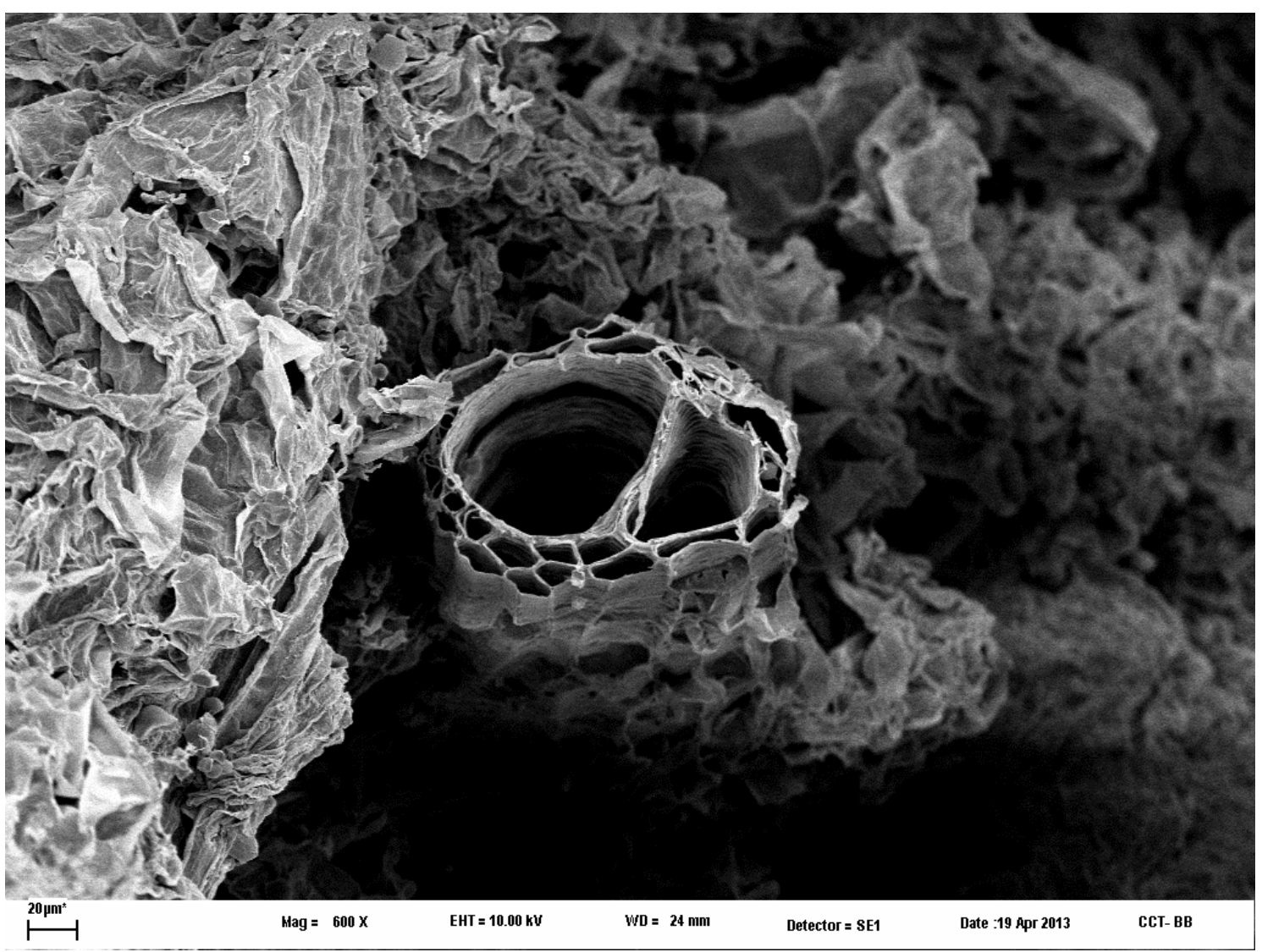

Figura 3.9. Micrografía electrónica (SEM) de un vaso leñoso del tejido de conducción de la raíz de Pachyrhizus ahipa (ahipa) en el residuo de la extracción.

La Figura 3.10 muestra una imagen en mayor detalle de los restos celulares que formaban en su origen el parénquima reservante de la raíz, mostrando gránulos de almidón contenidos en los mismos. 


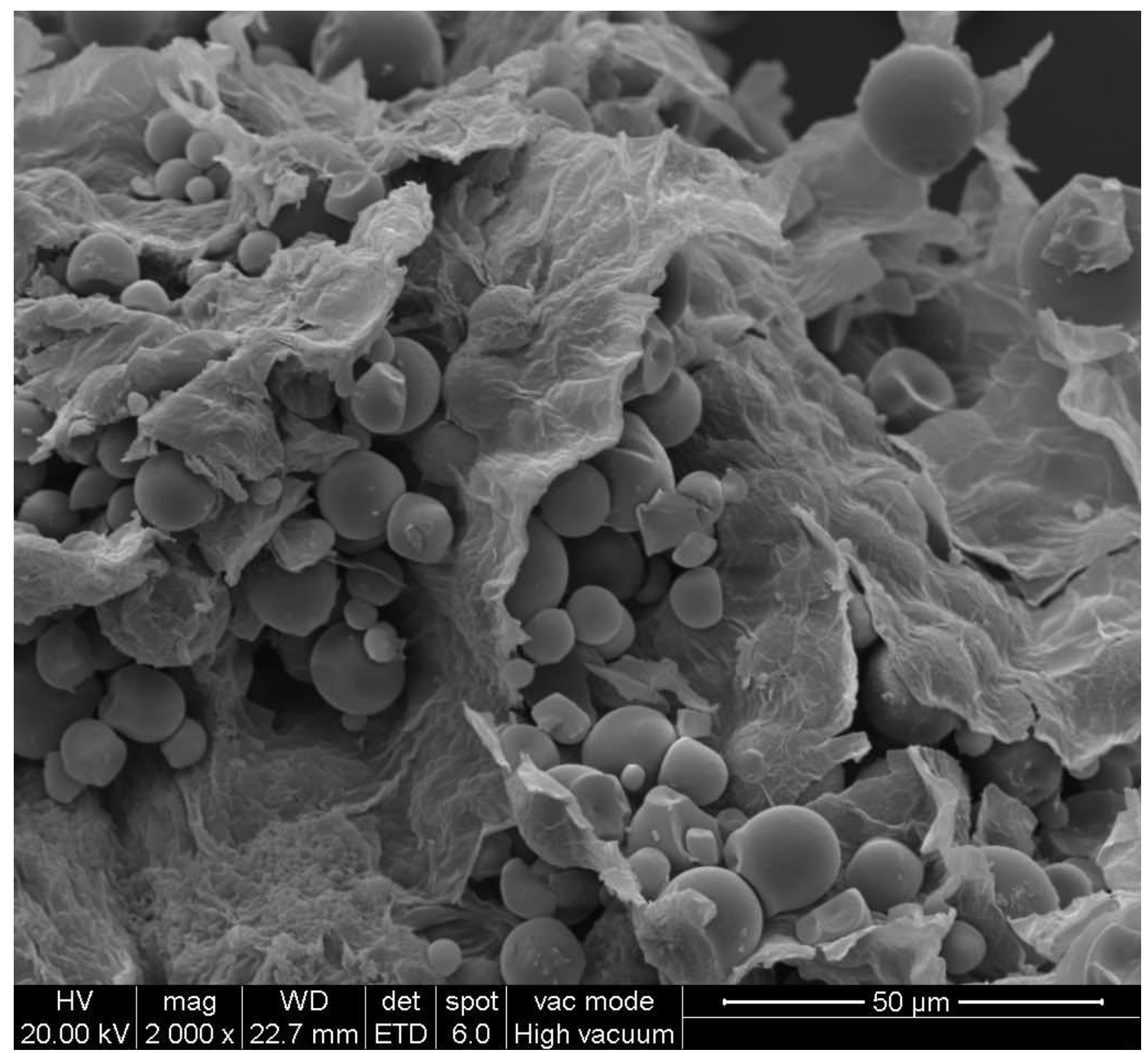

Figura 3.10. Micrografía electrónica (SEM) del parénquima y gránulos de almidón del residuo remanente de Pachyrhizus ahipa (ahipa).

\section{Propiedades funcionales del residuo de la extracción del almidón de ahipa}

\subsection{Capacidad de retención de agua}

La capacidad de retención de agua se define como la cantidad de agua retenida por la fibra sin la aplicación de cualquier fuerza externa, excepto la gravedad y la presión atmosférica (Raghavendra y col., 2004). Por lo tanto, este parámetro se encuentra relacionado con la proporción de agua débilmente asociada a la matriz de la fibra.

El resultado obtenido para el residuo estudiado de ahipa (Figura 3.11), fue cuatro veces mayor que para el almidón de ahipa (Capítulo 2). Es evidente que los componentes de este residuo, mayoritariamente celulosa y hemicelulosa, de 
naturaleza altamente hidrofílica retienen mayor cantidad de agua que el almidón correspondiente. Uno de los residuos rico en fibra de la Cucurbita moschata Duchesne ex Poiret, mostró un valor de 43 g / g de muestra seca (de Escalada Pla y col., 2007), considerablemente más bajo que el correspondiente al de ahipa.

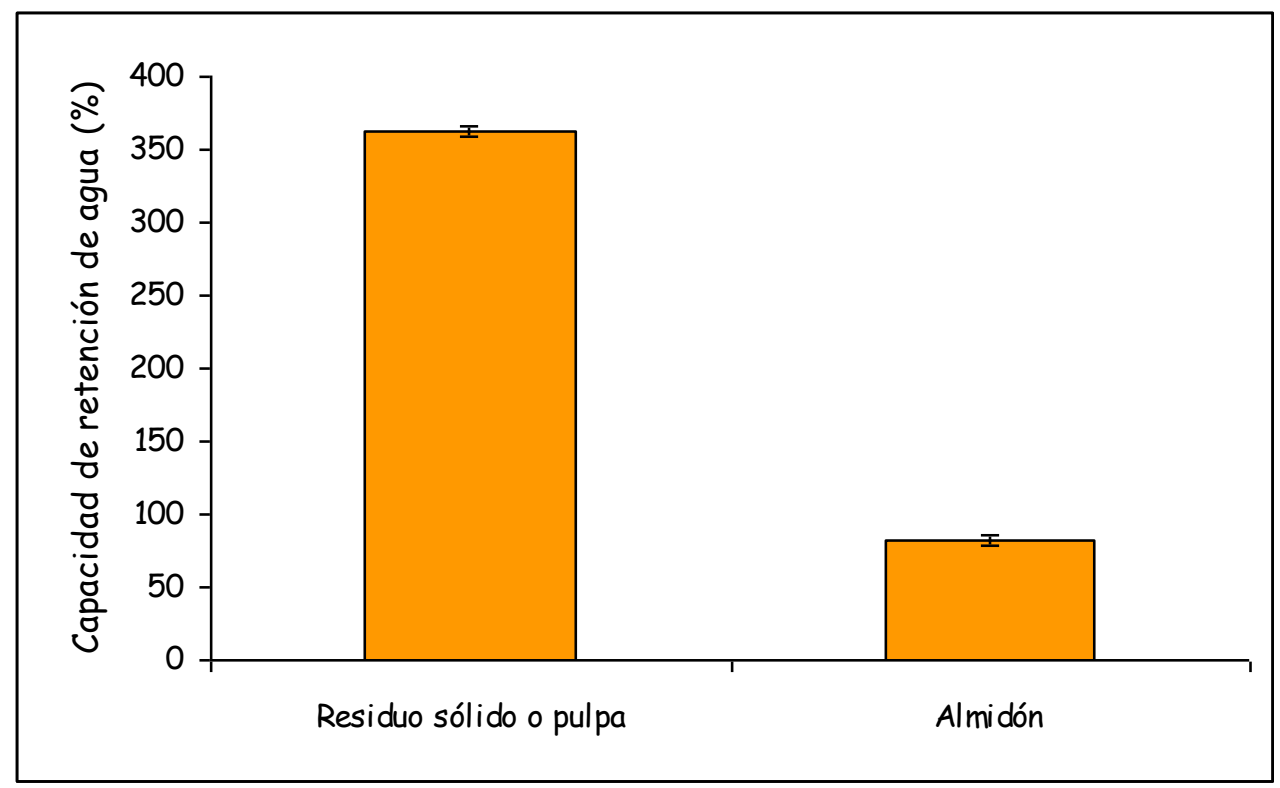

Figura 3.11. Capacidad de retención de agua del almidón y residuo sólido o pulpa de Pachyrhizus ahipa (ahipa).

\subsection{Capacidad de hinchamiento}

La Figura 3.12 muestra la capacidad de hinchamiento del residuo de almidón de ahipa en función de la temperatura de calentamiento, observándose un comportamiento diferencial en dos zonas, la primera entre $55-75^{\circ} \mathrm{C}$ y la segunda entre $85-95^{\circ} \mathrm{C}$. En ambas zonas la capacidad de hinchamiento aumenta con la temperatura, aunque el aumento relativo en la segunda zona fue menor que en la primera (Figura 3.12).

El aumento observado entre $85-95^{\circ} \mathrm{C}$ se correlaciona con el aumento registrado para el almidón. La capacidad de hinchamiento podría relacionarse con los parámetros térmicos indicados en el Capítulo 2 para el almidón de ahipa, ya que el 38\% del residuo contiene almidón (Tabla 3.6). En la primera zona $\left(55-75^{\circ} \mathrm{C}\right)$ el comportamiento podría atribuirse a los componentes no almidonosos de naturaleza altamente hidrofílica del residuo (celulosa y hemicelulosa, entre otros). 


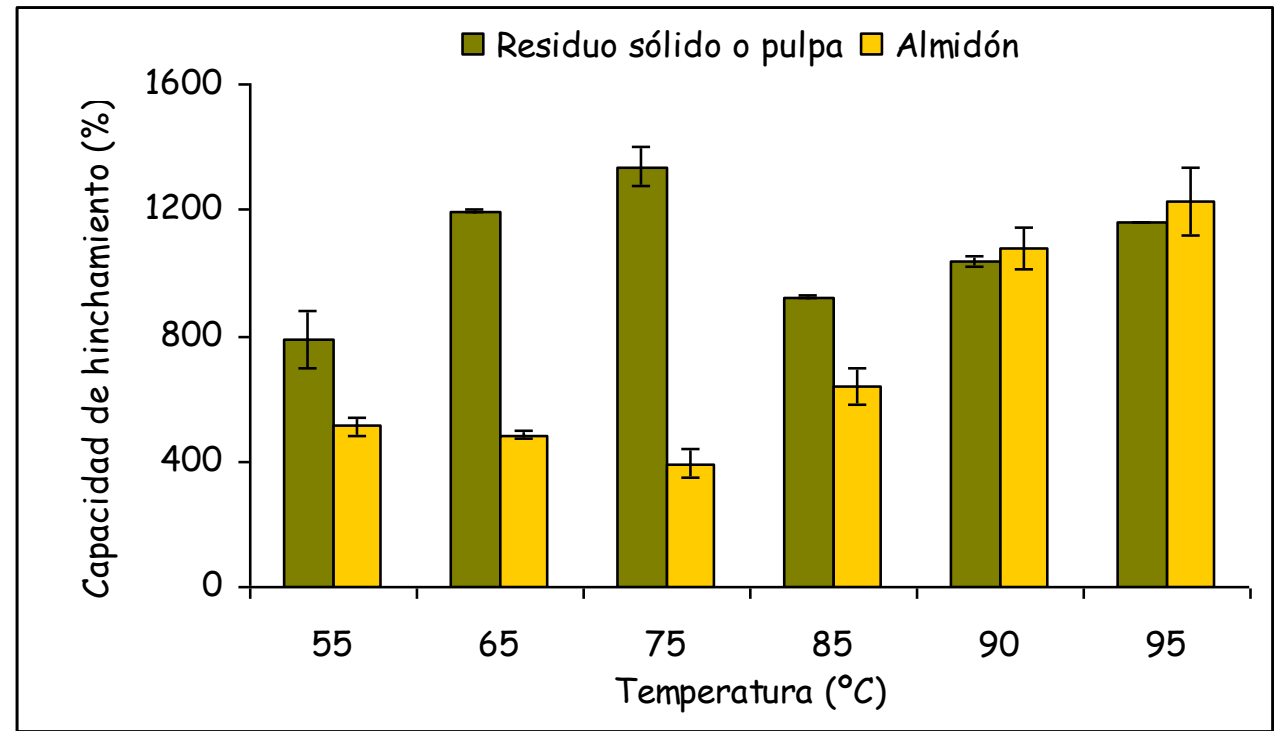

Figura 3.12. Capacidad de hinchamiento del almidón de Pachyrhizus ahipa (ahipa) y el residuo sólido o pulpa remanente de su extracción luego de 1 hora de calentamiento a diferentes temperaturas.

El bajo grado de hinchamiento del residuo que se observa a $55^{\circ} \mathrm{C}$ indica que el proceso de gelatinización del almidón presente aún no comenzó. Cuando la suspensión acuosa del residuo alcanza los $65^{\circ} \mathrm{C}$ se produce un aumento significativo de la capacidad de hinchamiento. En consecuencia, existiría una progresiva relajación de las fuerzas de enlace dentro del gránulo que justificarían este fenómeno.

A partir de los $85^{\circ} \mathrm{C}$ el incremento medido tanto en el residuo como en el almidón podría deberse al agua asociada a la red de amilosa y amilopectina remanente en los gránulos (Capítulo 2). Se observó, como en el almidón de ahipa, que a temperaturas por debajo de la de gelatinización, la cantidad de amilosa y amilopectina lixiviadas de los gránulos fue insignificante (Capítulo 2). En cambio, a temperaturas más elevadas, la lixiviación cobró relevancia y las concentraciones de ambos componentes en el sobrenadante se incrementaron con la temperatura; este fenómeno se muestra en la Figura 3.13. 


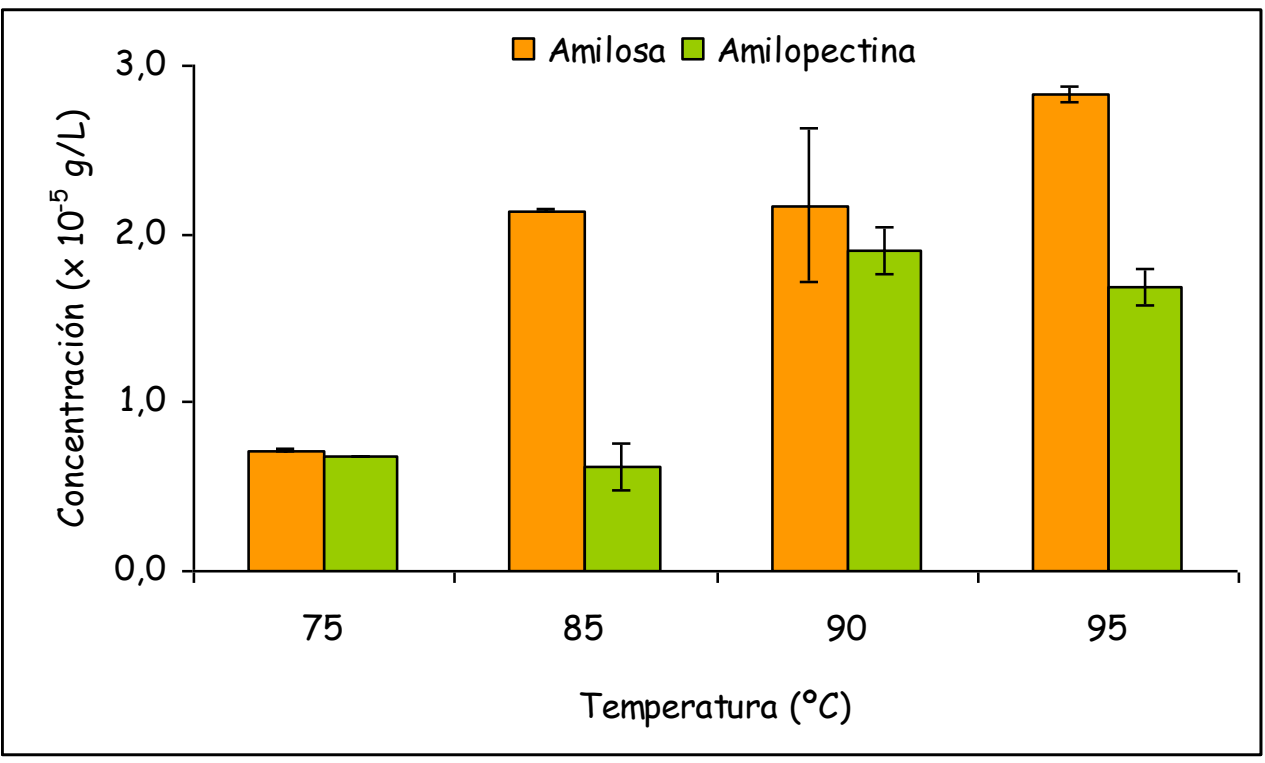

Figura 3.13. Contenido de amilosa y amilopectina lixiviadas en el sobrenadante correspondiente a la determinación de la capacidad de hinchamiento del residuo de la extracción del almidón de Pachyrhizus ahipa (ahipa) a 75, 85, 90 y $95^{\circ} \mathrm{C}$.

Las concentraciones de amilosa y amilopectina lixiviadas a partir de los gránulos de almidón remanente en el residuo durante el calentamiento a $75-95^{\circ} \mathrm{C}$ obtenidas correlacionaron con las encontradas en almidones, tal como fue descripto en el Capítulo 2.

\subsection{Capacidad de retención de solventes}

La Figura 3.14 muestra la capacidad de retención de solventes del residuo de extracción del almidón de ahipa y con fines comparativos se presentan los resultados obtenidos para la raíz tuberosa (Capítulo 1). El residuo sólido o pulpa de ahipa exhibió los porcentajes más altos de retención de los cuatro solventes empleados en el ensayo. La elevada capacidad de retención del carbonato de sodio en el residuo de ahipa, se correlaciona con el alto contenido de almidón dañado debido al procesamiento en la obtención de la muestra. 


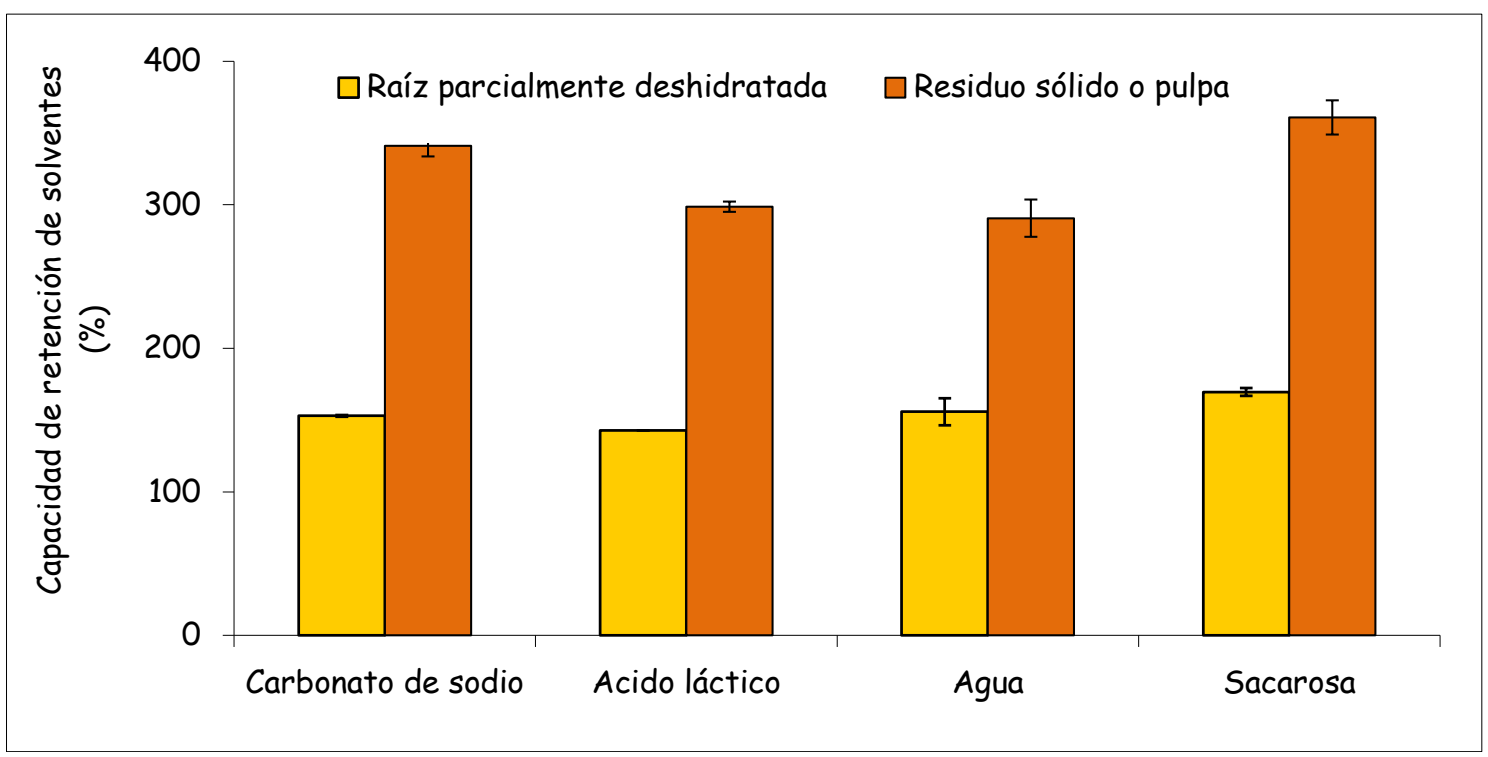

Figura 3.14. Capacidad de retención de solventes del residuo de la extracción del almidón de Pachyrhizus ahipa (ahipa) y de la raíz parcialmente deshidratada (accesión Local).

Como era de esperar, el elevado contenido de pentosanos se evidenció en la alta capacidad de retención de sacarosa (Figura 3.14).

Se ha observado que conforme la capacidad de retención de agua en la muestra aumenta, existe correspondencia con el incremento de la fibra dietaria total de la misma, siendo para el residuo sólido de $45 \pm 2 \mathrm{~g} / 100 \mathrm{~g}$ (Tabla 3.6) y para la raíz

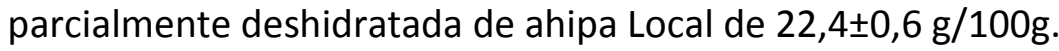


Capítulo 3. Digestibilidad del almidón de Pachyrhizus ahipa. Caracterización del residuo de la extracción de almidón

\section{CONCLUSIONES}

La digestibilidad del almidón de ahipa fue similar a la de otras plantas leguminosas. La accesión IRNAS 11 de ahipa mostró mayor proporción de almidón rápidamente digestible y resistente, mientras que el almidón de mandioca tuvo un contenido bajo de almidón lentamente digerible. El almidón de ahipa proveniente de la accesión Local presentó valores de estas fracciones intermedios entre la accesión 11 y mandioca. Desde un punto de vista nutricional, estos resultados podrían indicar cierta versatilidad del almidón de ahipa con el fin de ser utilizado como un ingrediente para alimentos con alto contenido de energía.

Por otra parte, se caracterizó el residuo remanente de la extracción de almidón de ahipa morfológicamente a través de SEM y se determinó su composición química, indicando que tanto la fibra como el almidón eran los componentes mayoritarios del mismo.

La capacidad de hinchamiento y de retención de solventes del residuo fue mayor que la del almidón y la raíz parcialmente deshidratada, respectivamente, debido al carácter altamente hidrofílico de sus componentes. 
Capítulo 3. Digestibilidad del almidón de Pachyrhizus ahipa. Caracterización del residuo de la extracción de almidón

\section{REFERENCIAS BIBLIOGRÁFICAS}

AACC: American Association of Cereal Chemists. (2001). AACC report: the definition of dietary fiber. Cereal Foods World, 46: 112-129.

Annison, G., Topping, D. L. (1994). Nutritional role of resistant starch: chemical structure vs physiological function. Annu Rev Nutr 14, 297-320.

AOAC. (1990). Official methods of analysis of the Association of Official Analytical Chemists, Association of Official Analytical Chemists, Arlington, Va.

Asp, N. G. (1992). Resistant starch. Proc. $2^{\text {nd }}$ Plenary Meeting of EURESTA. Eur. J. Clin. Nutr. 46 (Suppl. 2): SI.

Asp, N. G. (1992a). Incomplete digestion of legume starches in rats: A study of precooked flours containing retrograded and physically inaccessible starch fractions. J. Nutr. 122:1500-1507.

Bern, C., Martinez, J., de Zoysa, I., Glass, R. I. (1992). The magnitude of the global problem of diarrhoeal disease: a ten year update. Bulletin of the World Health Organization, 70: 705-714.

Berry, C. S. (1986). Resistant Starch: formation and measurement of starch that survives exhaustive digestion with amylolitic enzymes during the determination of dietary fibre. Journal of Cereal Science, 4: 301-314.

Brand Miller, J. C. (1994). Importance of glycemic index in diabetes. Am. J. Clin. Nutr. 59 (Suppl) 747S-52S.

Brand-Miller, J. (2007). The glycemic index as a measure of health and nutritional quality: An Australian perspective. Cereal Foods World 52, 41-44. 
Bravo, L., Siddhuraju, P., Saura-Calixto, F. (1998). Effect of various processing methodos on the in vitro starch digestibility and resistant starch content of indian pulses. J. Agr. Food Chem. 46, 4667-4674.

Brown, I. L. (2004). Applications and uses of resistant starch. Journal of AOAC International, 87: 727-732.

Buleon, A., Colonna, P., Planchot, V., Ball, S. (1998). Starch granules: Structure and biosynthesis. International Journal of Biological Macromolecules, 23, 85-112.

Cassidy, A., Bingham, S. A., Cummings, J. H. (1994). Starch intake and colorectal cancer risk: and international comparison. Brit. J. Cancer. 69: 937-942

Codex: Committee on Nutrition and Foods for Special Dietary Uses (2009). Thirty first session. Dusseldorf, Germany.

Copeland, L., Blazek, J., Salman, H., Tang, M. C. (2009). Form and functionality of starch. Food Hydrocolloids, 23, 1527-1534.

Champ, M. (1992). Determination of resistant starch in food products: interlaboratory study. European Journal of Clinical Nutrition, 46: 51-52.

Chung, H. J., Lim, H. S., Lim, S. T. (2006). Effect of partial gelatinization and retrogradation on the enzymatic digestion of waxy rice starch. Journal of Cereal Science 43, 353-359.

de Escalada Pla, M. F., Ponce, N. M., Stortzb, C. A., Gerschensona, L. N., Rojas, A. M. (2007). Composition and functional properties of enriched fiber products obtained from pumpkin (Cucurbita moschata Duchesne ex Poiret). LWT 40, 1176-1185. 
Doporto, M. C., Dini, C., Mugridge, A., Viña, S. Z., García, M. A. (2012). Physicochemical, thermal and sorption properties of nutritionally differentiated flours and starches. Journal of Food Engineering 113, 569-576.

Dona, A. C., Pages, G., Gilbert, R. G., Kuchel, P. W. (2010). Digestion of starch: In vivo and in vitro kinetic models used to characterise oligosaccharide or glucose release. Carbohydrate Polymers 80, 599-617.

Englyst, H. N., Kingman, S. M., Cummings, J. H. (1992). Classification and measurement of nutritionally important starch fractions. Eur J Clin Nutr 46 Suppl 2, S33-50.

Englyst, H. M., Cummings, J. H. (1987). Digestion of polysaccharides of potato in the small intestine of man. Am. J. Clin. Nutr. 45: 423-431.

Ek, K. L., Brand-Miller, J., Copeland, L. (2012). Glycemic effect of potatoes. Food Chemistry 133, 1230-1240.

Faisant, N., Planchot, V., Koziwski, F., Colonna, P., Champ, M. (1995). Resistant starch determination adapted to products containing high level of resistant starch. Science des Aliments, 15: 85-91.

FDA: Food and Drug Administration. (2008). Fiber health claims that meet significant scientific agreement.

Franco, C. M. L., do Rio Preto, S. J., Ciacco, C. F. (1992). Factors that affect the enzymatic degradation of natural starch granules -effect of the size of the granules. Starch - Stärke 44, 422-426.

Frei, M., Siddhuraju, P., Becker, K. (2003) Studies on the in vitro starch digestibility and the glycemic index of six different indigenous rice cultivars from the Philippines. Food Chemistry 83, 395-402. 
García, M. A., Martino, M. N., Zaritzky, N. E. (1995). Comparison of amylose enrichment procedures for the food applications. Cereal Chemistry, 72(6), 552-558.

Goñi, I., Garcia-Alonso, A., Saura-Calixto, F. (1997). A starch hydrolysis procedure to estimate glycemic index. Nutrition Research 17, 427-437.

Health Canada. (2012). Policy for labellingand advertising of dietary fibre-containing food products. Canada Bureau of Nutritional Sciences.

Hipsley, E.H. (1953). Dietary "fibre" and pregnancy toxaemia. British Medical Journal, $2,420-422$.

Hung, P. V., Morita, N. (2005). Physicochemical properties and enzymatic digestibility of starch from edible canna (Canna edulis) grown in Vietnam. Carbohydrate Polymers 61, 314-321.

Jenkins, D. J., Wolever, T. M., Taylor, R. H., Barker, H., Fielden, H., Baldwin, J. M., (1981). Glycemic index of foods: A physiological basis for carbohydrate exchange. American Journal of Clinical Nutrition, 34, 362-366.

Jenkins, D.J.A., Thorne, M.J., Camelon, K., Jenkins, A.L., Rao, A.V., Taylor, R.H., Thompson, L.U., Kalmusky, J., Reichert, R., Francis, T. (1982). Effect of processing in digestibility and the blood glucose response: study of lentils. Am. J. Clin. Nutr. 36:10931101.

Jenkins, D. J. A., Kendall, C. W. C., Augustin, L. S. A., Franceschi, S., Hamidi, M., Marchie, A., (2002). Glycemic index: Overview of implications in health and disease. American Journal of Clinical Nutrition 76, 266S-273S. 
Capítulo 3. Digestibilidad del almidón de Pachyrhizus ahipa. Caracterización del residuo de la extracción de almidón

Jenkins, A. L. (2007). The glycemic index: Looking back 25 years. Cereal Foods World, $52,50-53$.

Juansang, J., Puttanlek, C., Rungsardthong, V., Puncha-arnon, S., Uttapap, D. (2012). Effect of gelatinisation on slowly digestible starch and resistant starch of heat-moisture treated and chemically modified canna starches. Food Chemistry 131, 500-507.

Kingman, S. M., Englyst, H. N. (1994). The influence of food preparation methods on the in-vitro digestibility of starch in potatoes. Food Chemistry 49, 181-186.

Krezowski, P. A., Nuttall, F. Q., Gannon, M. C., Bartosh, N. H. (1986). The effect of protein ingestion on the metabolic response to oral glucose in normal individuals. American Journal of Clinical Nutrition, 44, 847-856.

Lehmann, U., Robin, F. (2007). Slowly digestible starch - its structure and health implications: A review. Trends in Food Science \& Technology, 18, 346-355.

López, O. V., Viña, S. Z., Pachas, A. N. A., Sisterna, M. N., Rohatsch, P. H., Mugridge, A., Fassola, H. E., García, M. A. (2010). Composition and food properties of Pachyrhizus ahipa roots and starch. International Journal of Food Science \& Technology 45, 223233.

Lu, Z. H., Donner, E., Yada, R. Y., Liu, Q. (2012). The synergistic effects of amylose and phosphorus on rheological, thermal and nutritional properties of potato starch and gel. Food Chemistry 133, 1214-1221.

Man, J., Yang, Y., Zhang, C., Zhou, X. (2012). Structural changes of high-amylose rice starch residues following in vitro and in vivo digestion. J Agric Food Chem 60, 93329341. 
McClearly, B. V., Brown, I. L. (2004). Novel dietary fibers: the importance of carbohydrates in the diet. Journal of AOAC International, 87: 681.

Noda, T., Takigawa, S., Matsuura-Endo, C., Suzuki, T. (2008). Factors affecting the digestibility of raw and gelatinized potato starches. Food Chemistry 110, 465-470. Nutrinews. (2001). Fibras: Necessárias para viver... bem.

Ovando-Martínez, M., Whitney, K., Reuhs, B. L., Doehlert, D. C., Simsek, S. (2013). Effect of hydrothermal treatment on physicochemical and digestibility properties of oat starch. Food Research International 52, 17-25.

Raghavendra, S. N., Rastogi, N. K., Raghavarao, K. S. M. S., Tharanathan, R. N. (2004). Dietary fiber from coconut residue: Effects of different treatments and particle size on the hydration properties. European Food Research Technology, 218, 563-567.

Ramakrishna, B. S., Venkataraman, S., Srinivasan, P., Dash, P., Young, G. P., Binder, H. J. (2000). Amylase-resistant starch plus oral rehydration solution for cholera. New England Journal of Medicine, 342: 308-313.

Roberts, S. B. (2000). High-glycemic index foods, hunger, and obesity: Is there a connection? Nutrition Reviews, 58, 163-169.

Rosell, C. M., Santos, E., Collar, C. (2009). Physico-chemical properties of commercial fibres from different sources: A comparative approach. Food Research International, 42 (1), 176-184.

Sajilata, M. G., Singhal, R. S., Kulkarni, P. R. (2006) Resistant starch -A review. Compr. Rev. Food Sci. Food Saf. 5, 48 1-17.

Sandhu, K. S., Lim, S. T. (2008). Digestibility of legume starches as influenced by their physical and structural properties. Carbohydrate Polymers 71, 245-252. 
Capítulo 3. Digestibilidad del almidón de Pachyrhizus ahipa. Caracterización del residuo de la extracción de almidón

Smith, A. M. (2007). Starch biosynthesis and degradation. Handbook of Plant Science, 2, 1159-1165.

Srichuwong, S., Sunarti, T. C., Mishima, T., Isono, N., Hisamatsu, M. (2005). Starches from different botanical sources I: Contribution of amylopectin fine structure to thermal properties and enzyme digestibility. Carbohydrate Polymers 60, 529-538.

Szymonska, J., Krok, F., Komorowska-Czepirska, E., Rebilas, K. (2003). Modification of granular potato starch by multiple deep-freezing and thawing. Carbohydrate Polymers $52(1), 1-10$.

Thorne, M. J., Thompson, L. U., Jenkins, D. J. A. (1983). Factors affecting starch digestibility and the glycemic response with special reference to legumes. American Journal of Clinical Nutrition, 38, 481-488

Tovar, J., Björck, I. M., Faisant, N., Buleon, A., Colonna, P., Molis, C., Lartigue, S., Galmiche, J. P., Cham, M. (1995). Digestion of raw banana starch in the small intestine of healthy humans: structural features of resistant starch. Br. J. Nutr. 73:111-123.

Tovar, J., Grandfeldt, Y., Björck, I. M. (1992b). Effect of processing on blood glucose and insulin responses to starch in legumes. J. Agr. Food Chem, 40:1846-1851.

Tsai, M. L., Li, C. F., Lii, C. Y. (1997). Effects of granular structures on the pasting behaviors of starches. Cereal Chemistry, 74(6), 750-757.

Velasco, Z. I., Rascón, A., Tovar, J. (1997). Enzymic availability of starch in cooked black beans (Phaseolus vulgaris L.) and cowpeas (Vigna spp) J. Agr. Food Chem, 45:15481551.

Vieira Bezerra, C., Amante, E. R., de Oliveira, D. C., Rodrigues, A. M. C., da Silva, L. H. M. (2013). Green banana (Musa cavendishii) flour obtained in spouted bed - Effect of 
Capítulo 3. Digestibilidad del almidón de Pachyrhizus ahipa. Caracterización del residuo de la extracción de almidón

drying on physico-chemical, functional and morphological characteristics of the starch. Industrial Crops and Products 41, 241-249.

Waszczynskyj, N., Wille, G. M. F. C., Protzek, E. C., de Freitas, R. J. S., Penteado, P. T. P. S. (2001). Tecnologia para obtenção de fibras alimentares a partir de matérias primas regionais. Experiência do Brasil. En: Lajolo FM, Saura-Calixto F, Penna EW, Menezes EW, editores. Fibra dietética en Iberoamérica: tecnología y salud: obtención, caracterización, efecto fisiológico y aplicación en alimentos. 1a ed. São Paulo: Livraria Varela. pag 237-243.

Wolever, T. M. S., Mehling, C. (2002). High-carbohydrate-low-glycaemic index dietary advice improves glucose disposition index in subjects with impaired glucose tolerance. British Journal of Nutrition, 87, 477-487.

Würsch, P., Del Vedovo, S., Koellreuter, B. (1986). Cell structure and starch nature as key determinants of the digestion rate of starch in legumes. Am. J. Clin. Nutr. 43: 2529. 
CAPÍTULO 4.

Obtención y caracterización de harinas de Pachyrhizus ahipa y Manihot esculenta 


\section{INTRODUCCIÓN}

\section{Harinas no tradicionales}

La harina es el polvo fino que se obtiene del cereal molido y de otros alimentos ricos en almidón. Aunque la más tradicional es la harina de trigo (cereal proveniente de Europa, ingrediente habitual en la elaboración del pan), también se produce harina de: centeno, cebada, avena, maíz (cereal proveniente del continente americano) o arroz (cereal proveniente de Asia). Existen asimismo en el mercado harinas de semillas de leguminosas, tales como garbanzos, porotos, lentejas, soja, etc. (Figura 4.1).

Si bien el Código Alimentario Argentino (Capítulo IX, artículo 661) señala que "con la denominación de harina, sin otro calificativo, se entiende el producto obtenido de la molienda del endosperma del grano de trigo que responda a las exigencias de éste", se admite la denominación de harina para la obtenida de otras materias primas, indicando en ese caso la procedencia de las mismas. Por ejemplo, el artículo 663 del mencionado Código indica que "las harinas de otros cereales o leguminosas deberán denominarse de acuerdo a la materia o materias primas empleadas (harina de maíz, harina de arvejas, etc.)", en tanto que el artículo 685 señala que "con la denominación de harina de papa o patata, se entiende el producto obtenido moliendo finamente los tubérculos pelados y desecados del Solanum tuberosum L., la que presentará como máximo un contenido en agua del $12 \%$ a $100-105^{\circ} \mathrm{C}^{\prime \prime}$.

El uso de la harina de trigo en la elaboración del pan, pilar de la alimentación en la cultura occidental, se debe en parte a la presencia de gluten, un complejo proteico que le otorga al pan elasticidad y consistencia.

Las harinas aportan carbohidratos complejos, principalmente almidón, que se transforman en glucosa al digerirse y proveen entre el 50 y el 60\% de la energía total de la dieta, por lo que brindan al cuerpo una fuente de energía rápida. El organismo humano posee las enzimas necesarias para digerir el almidón, la lactosa y la sacarosa provenientes de diversos alimentos que, junto a la D-glucosa y la D-fructosa, son fuentes energéticas para el hombre, proporcionando en todo el mundo el $70-80 \%$ de las calorías de la dieta (Doporto y col., 2012). 


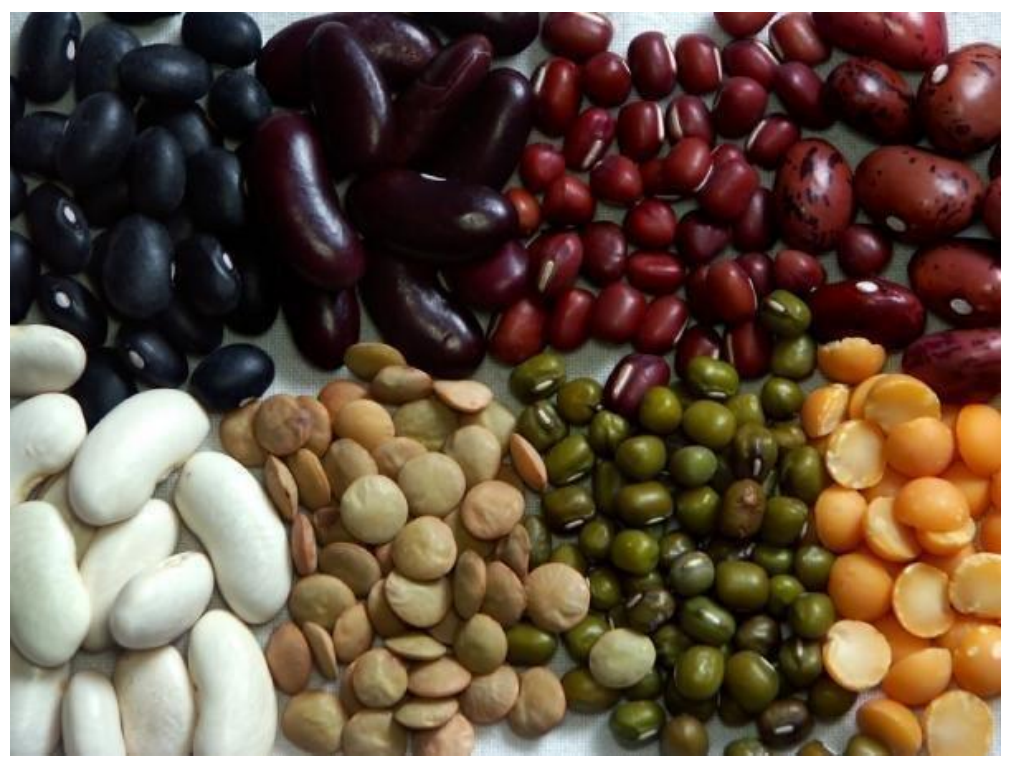

Figura 4.1. Diferentes granos de legumbres empleados para la obtención de harinas.

\subsection{Harina de Pachyrhizus ahipa}

Las raíces tuberosas de ahipa pueden destinarse a propósitos múltiples tales como obtención de harina, almidón y fibras naturales a escala industrial, además de su comercialización como hortaliza fresca. El rescate de este cultivo implicaría potenciales beneficios económicos y agroecológicos, relacionados con la diversificación productiva y la generación de materias primas y productos elaborados alternativos.

La harina de ahipa se presenta como un producto libre de gluten, por lo que serviría como ingrediente en la elaboración de mezclas para la obtención de productos panificados y horneados destinados a la población celíaca, al igual que las harinas de arroz, quínoa, soja y mandioca, entre otras.

\section{Celiaquía}

La celiaquía es la intolerancia permanente al gluten, conjunto de proteínas presentes en el trigo, avena, cebada y centeno (TACC) y productos derivados de estos cuatro cereales.

Las proteínas del gluten se clasifican en dos grupos, prolaminas y gluteninas. Las prolaminas reciben distintos nombres según el cereal de origen: en trigo, gliadina; en 
avena, avenina; en cebada, hordeína y en centeno, secalina (Gálvez y col., 2006). El gluten de los cereales mencionados es la forma más conocida de presentación de las prolaminas tóxicas para los celíacos. La gliadina constituye el mayor problema, por ser la harina de trigo la más utilizada en la industria alimenticia.

La avena pareciera no producir daño pero, en su proceso de industrialización, puede encontrarse contaminada con granos de trigo, cebada o centeno.

La celiaquía se presenta en personas que tienen predisposición genética a padecerla. Se sabe que aparece con más frecuencia entre miembros de la misma familia. Pueden manifestarla tanto niños como adultos, siendo la incidencia mayor en mujeres que en varones. Se estima que en Argentina, uno de cada cien habitantes puede ser celíaco (Asociación Celíaca Argentina, 2013).

Esta intolerancia produce una lesión característica de la mucosa intestinal provocando una atrofia de las vellosidades del intestino delgado (Figura 4.2), lo que altera o disminuye la absorción de los nutrientes de los alimentos (proteínas, grasas, hidratos de carbono, minerales y vitaminas), (Asociación Celíaca Argentina, 2013). La característica principal de esta atrofia vellositaria es que la mucosa intestinal se normaliza cuando el paciente inicia la dieta sin TACC. Otra particularidad de esta patología es que se presenta asociada a enfermedades autoinmunes y genéticas y se puede descubrir tardíamente en pacientes asintomáticos.

Se dice que la celiaquía es una condición autoinmune, es decir que el sistema de defensa de los celíacos reconocería como "extraño" o no perteneciente al organismo al gluten, y produciría anticuerpos o "defensas" contra el mismo. Estos anticuerpos provocarían la lesión del intestino con destrucción o atrofia de su mucosa (capa interior del intestino), produciéndose una alteración en la absorción de los alimentos. (Asociación Celíaca Argentina, 2013). 
Capítulo 4. Obtención y caracterización de harinas de Pachyrhizus ahipa y Manihot esculenta

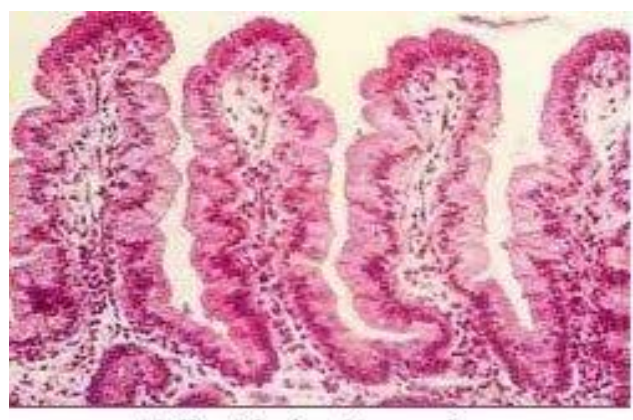

Vellosidades Normales

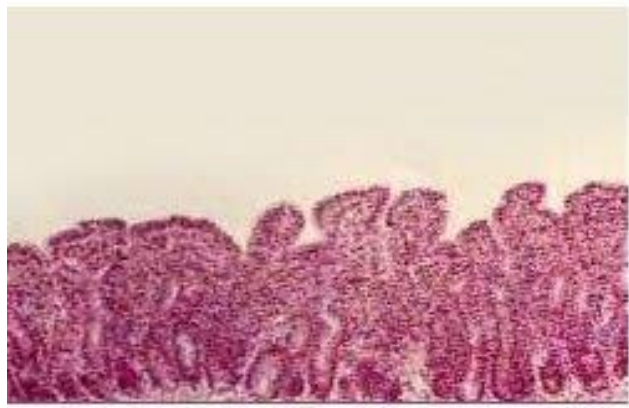

Vellosidades atrofiadas

Figura 4.2. Comparación de vellosidades del intestino delgado de un individuo sano y otro con atrofia total como consecuencia de la enfermedad celíaca. (Adaptado de la Asociación Celíaca Argentina, 2013). 
Capítulo 4. Obtención y caracterización de harinas de Pachyrhizus ahipa y Manihot esculenta

\section{OBJETIVOS}

Los objetivos planteados para este capítulo son los siguientes:

1. Optimizar la obtención y extracción de harina de Pachyrhizus ahipa (ahipa) y Manihot esculenta (mandioca) a escala de laboratorio.

2. Determinar la composición centesimal de los productos obtenidos (humedad, contenido de proteínas totales, tenor lipídico, cenizas totales, fibra dietaria). Analizar ciertos componentes minoritarios que guardan relevancia nutricional, principalmente elementos minerales.

3. Evaluar las propiedades físico-químicas y funcionales de las harinas obtenidas (granulometría, capacidad de retención de agua y de diferentes solventes, transiciones térmicas).

4. Caracterizar la microestructura y su relación con las propiedades funcionales de las harinas obtenidas.

5. Analizar la estabilidad de las harinas de ahipa y mandioca a través de la determinación de las isotermas de sorción. 


\section{MATERIALES Y MÉTODOS}

\section{Materias primas}

Se utilizaron raíces tuberosas de ahipa (Pachyrhizus ahipa) pertenecientes a la denominada "accesión Local" y de mandioca (Manihot esculenta). Las plantas de ahipa procedieron en su origen de semillas obtenidas en la Localidad Perico (Jujuy, Argentina) y, como ya se mencionó anteriormente, corresponden a la designada como accesión Local. Las mismas fueron cultivadas en la EEA Montecarlo INTA (Misiones). Asimismo, las raíces de mandioca "cultivar Pomberi" fueron provistas por dicha Estación Experimental. El material utilizado en los presentes ensayos fue cosechado durante los años 2009-2012.

\section{Procesamiento de las raíces y obtención de harina de Pachyrhizus ahipa y}

\section{Manihot esculenta}

Las raíces de Pachyrhizus ahipa (ahipa) fueron seleccionadas y acondicionadas para la obtención de la harina por diferentes métodos. Las mismas se trataron tal como se describió en el Capítulo 1. Las raíces peladas de ahipa fueron destinadas a los diferentes métodos de procesamiento: rallado (Figura 4.3), rallado y prensado, o cortado en rodajas (Figura 4.4).

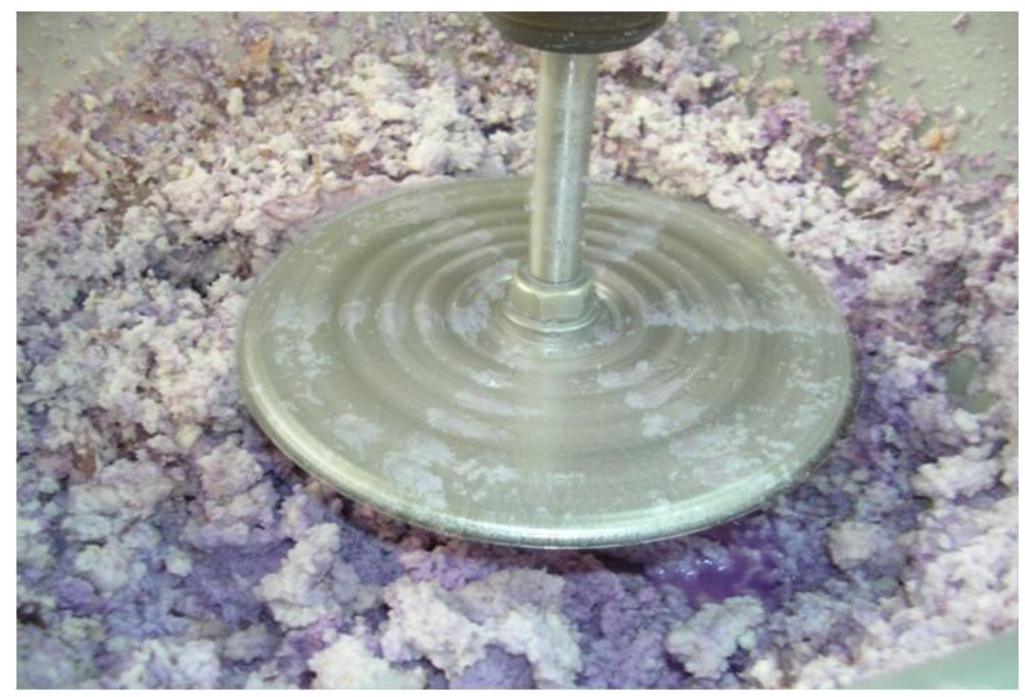

Figura 4.3. Rallado de raíces de Pachyrhizus ahipa para la obtención de harina. 


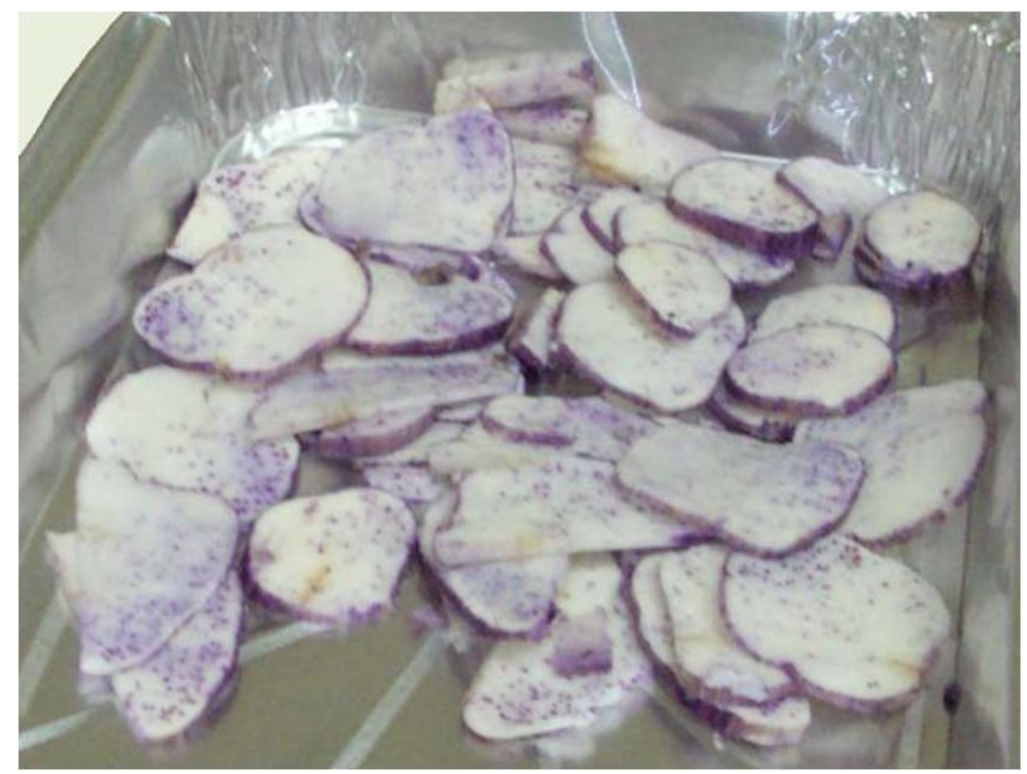

Figura 4.4. Rodajas de raíces de Pachyrhizus ahipa destinadas a la obtención de harina.

En la Figura 4.5 se detallan las diferentes alternativas de procesamiento de las raíces de ahipa con el fin de obtener las harinas antes mencionadas. En todos los casos, las raíces procesadas se secaron $50^{\circ} \mathrm{C}$ hasta peso constante, y finalmente fueron molidas.

A la harina de ahipa obtenida por rallado y posterior prensado, se le adicionó el almidón recuperado por decantación y secado a $40^{\circ} \mathrm{C}$ a partir de los líquidos obtenidos durante el proceso de prensado.

Así, los diferentes productos obtenidos fueron: harina de ahipa procedente de raíces peladas y ralladas, sin prensado (HARaSP); harina de ahipa a partir de raíces peladas y ralladas, prensadas y enriquecidas mediante la adición de los sólidos recuperados (HARaP) y harina de ahipa procedente de raíces peladas y cortadas en rodajas (HARo). 


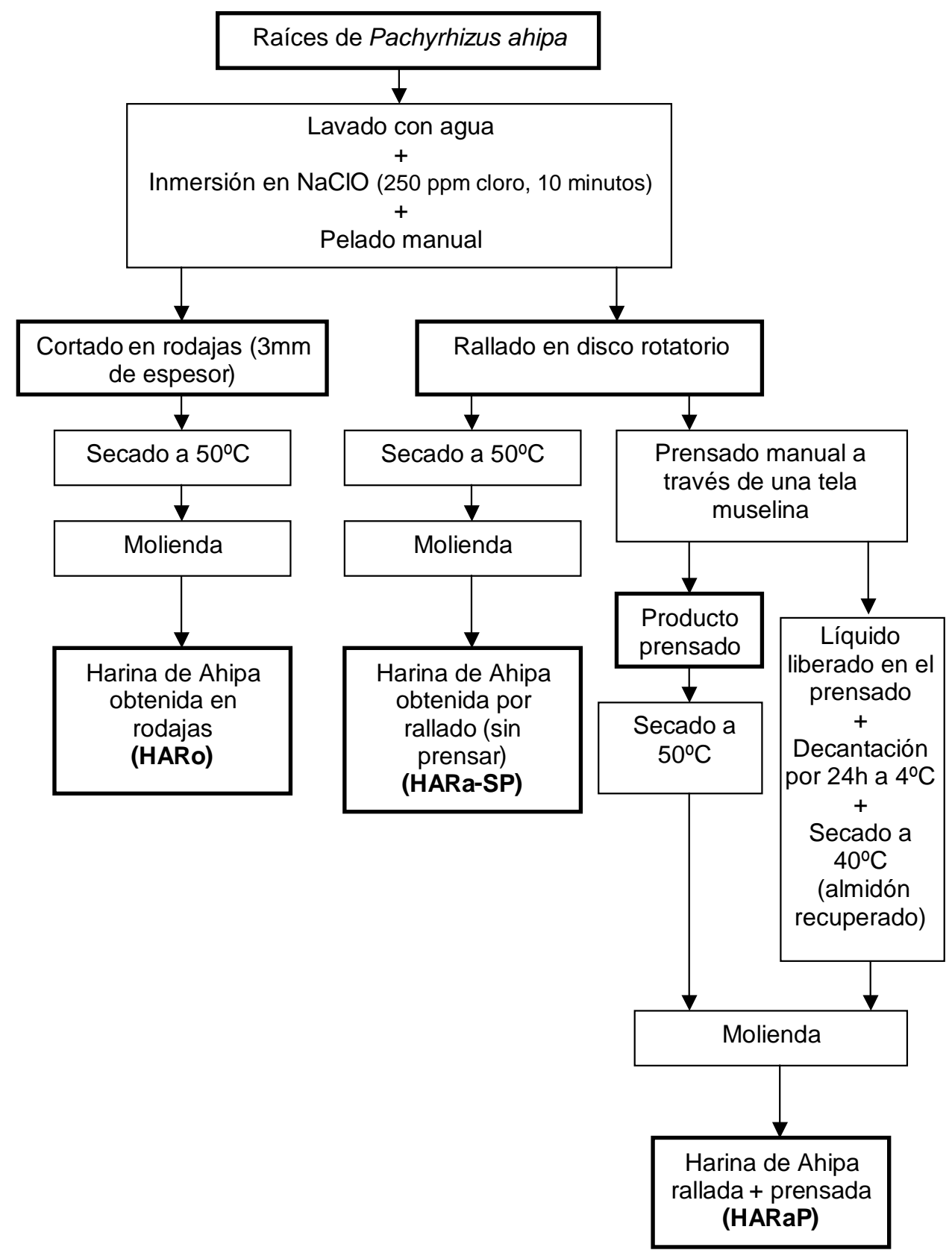

Figura 4.5. Diagrama de flujo mostrando el procesamiento realizado para la obtención de harina de Pachyrhizus ahipa a partir de sus raíces. 
El mismo procedimiento fue aplicado para la obtención de la harina de mandioca. Las raíces fueron acondicionadas de igual forma que las de ahipa y destinadas al rallado (sin prensado posterior) o bien fueron cortadas en rodajas. Los productos obtenidos se denominaron: harina de mandioca elaborada por rallado (HMRa) y harina de mandioca procesada en rodajas (HMRo).

\section{Caracterización de las harinas}

Desde el punto de vista de la calidad, es relevante conocer la relación que existe entre la composición de la materia prima y la del producto terminado. Se hace necesario estudiar la composición química de los alimentos, con el fin de elaborar productos saludables con alta aceptación por el consumidor.

Los análisis químicos se llevaron a cabo sobre muestras de las harinas HARo (harina de ahipa procesada en rodajas) y HARaP (harina de ahipa elaborada por rallado y prensado), ya que en la harina HARaSP (harina de ahipa elaborada por rallado sin prensado) se produjo el desarrollo de olores indeseables en un corto período de tiempo, mientras que HARo y HARaP mantuvieron su estado original y sus atributos de calidad, incluso después de nueve meses de almacenamiento.

La composición química de las harinas se evaluó cuantificando humedad, lípidos, minerales, cenizas y proteínas totales, mediante métodos oficiales (AOAC, 1990). Los minerales cuantificados fueron calcio, hierro, magnesio, sodio, potasio y fósforo. Además se determinó el contenido de almidón total y la actividad $\alpha$-amilasa.

\subsection{Contenido de materia seca}

El contenido de materia seca en las harinas se determinó gravimétricamente, deshidratando las muestras en estufa a $105^{\circ} \mathrm{C}$ hasta peso constante, como se detalló en el Capítulo 1. Los resultados se expresan como porcentaje (\%).

\subsection{Determinación de cenizas totales en harina de ahipa}

Se cuantificó el tenor de cenizas totales sobre muestras de harina (2 g) por calcinación en mufla a $500-550^{\circ} \mathrm{C}$ durante aproximadamente 5 horas, según lo descripto en el Capítulo 1. Los resultados se expresaron en porcentaje (\%). 
Capítulo 4. Obtención y caracterización de harinas de Pachyrhizus ahipa y Manihot esculenta

\subsection{Extracción y cuantificación de lípidos totales}

El contenido de compuestos liposolubles en las harinas se determinó luego de la extracción continua en un extractor Soxhlet. Para la determinación se pesaron por duplicado (15-18 g) de las muestras respectivas. Se ensayaron separadamente dos solventes diferentes: $\mathrm{n}$-hexano y una mezcla 1:1 de éter de petróleo y éter etílico, con el fin de evaluar diferencias en el poder extractivo debido a la polaridad de los lípidos presentes. El procedimiento general se llevó a cabo según lo descripto en el Capítulo 1. El residuo sólido se cuantificó gravimétricamente; los resultados se expresaron como porcentaje (\%).

\subsection{Determinación del contenido de nitrógeno total}

Se cuantificó el nitrógeno total de las muestras de harina $(0,8 \mathrm{~g})$ mediante el método Kjeldahl. Se procedió tal como se describió en el Capítulo 1. El contenido de proteína cruda se calculó usando el factor de conversión 6,25. Los resultados se expresaron como porcentaje (\%).

\subsection{Contenido de prolaminas en harina de ahipa}

Se determinó la presencia de prolaminas mediante una técnica de enzimoinmunoensayo competitivo, empleando anticuerpos policlonales, según Chirdo y col. (1995). Al efecto, las muestras fueron remitidas al Laboratorio de Investigación en el Sistema Inmune (LISIN) de la Facultad de Ciencias Exactas (UNLP). Para la caracterización de la harina de ahipa como producto libre de gluten se tuvo en cuenta el límite de detección del método (0,1 mg de gliadinas/100g de muestra).

\subsection{Determinación de fibra detergente ácido}

Para llevar a cabo esta determinación, se pesaron muestras de harina (1,0 g) por duplicado y las cuantificaciones de fibra detergente ácido (FDA) correspondientes fueron realizadas por el sistema de detergentes de Van Soest (Robertson y Van Soest, 1981), siguiendo el método 973.18c (AOAC, 1990). 


\subsection{Fibra dietaria total}

Se midió el contenido de fibra dietaria total en las harinas utilizando el kit enzimático K-TDFR 05/12 Megazyme @ (Irlanda). El método se encuentra detallado en el Capítulo 1. Los resultados se expresaron como porcentaje (\%).

\subsection{Contenido de carbohidratos totales}

El contenido de carbohidratos totales se calculó como la diferencia entre $100 \%$ y la suma de los porcentajes correspondientes a cenizas, lípidos y proteínas totales comprendidos en el análisis centesimal. Este valor se corresponde con el contenido de azúcares solubles, almidón y carbohidratos estructurales (celulosas, hemicelulosas), tomados conjuntamente.

\subsection{Análisis del perfil de aminoácidos}

Para la harina de ahipa, se realizó el análisis por cromatografía líquida de alta resolución en fase reversa (RPLC) de los siguientes aminoácidos: leucina, alanina, ácido aspártico, isoleucina, arginina, metionina, ácido glutámico, glutamina+serina, tirosina, histidina, valina, glicina+treonina y lisina. Al efecto, se enviaron muestras de harina al Laboratorio de Control de Calidad Melacrom (Mercedes, Bs. As., Argentina). El método analítico consiste en una derivatización de los aminoácidos presentes con un marcador fluorescente (OPA, o-ftalaldehído), una vez hidrolizadas las proteínas presentes en la muestra. Luego el extracto se analiza cromatográficamente en un HPLC con detector de fluorescencia, utilizando como fase móvil un gradiente de acetonitrilo - buffer fosfato de $\mathrm{pH} \mathrm{7,20.} \mathrm{La} \mathrm{columna} \mathrm{utilizada} \mathrm{es} \mathrm{una} \mathrm{ODS2} \mathrm{con} \mathrm{partículas} \mathrm{de} 5 \mu \mathrm{m}, 4,6 \mathrm{~mm}$ de diámetro interno y $250 \mathrm{~mm}$ de longitud.

Con este método es posible obtener simultáneamente un conjunto significativamente alto de picos cromatográficos, correspondientes a la mayoría de los aminoácidos presentes. Los que no quedan incluidos en este perfil de aminoácidos, es porque no logran ser derivatizados satisfactoriamente con OPA pues su grupo amino es secundario, o porque no tienen buena resolución cromatográfica.

La incertidumbre expandida del método $(U=2 u)$ es de $10 \%$, para un nivel de significación del 95\%. Los resultados fueron expresados en porcentaje (\%). 


\subsection{Cuantificación de sodio, potasio, calcio, hierro y magnesio en harina de ahipa}

Muestras de cenizas $(0,03-0,05 \mathrm{~g})$ obtenidas tal como se describió en la sección 3.2 se disolvieron en $50 \% \mathrm{v} / \mathrm{v}$ de $\mathrm{HNO}_{3}$. Para la determinación del contenido de calcio, las muestras se disolvieron y se les agregó óxido de lantano a una concentración final de 0,5\%, con el fin de evitar interferencias de radiación. Los análisis de hierro, calcio y magnesio se llevaron a cabo mediante espectroscopía de absorción atómica y la cuantificación de sodio y potasio por espectroscopía de emisión atómica. Al efecto, las muestras fueron remitidas al CINDEFI (Centro de Investigación y Desarrollo en Fermentaciones Industriales, Facultad de Ciencias Exactas UNLP - CONICET La Plata). EI procedimiento se encuentra descripto en el Capítulo 1. Los resultados se expresaron en $\mathrm{mg} / 100 \mathrm{~g}$.

\subsection{Contenido de fósforo en harina de ahipa}

El contenido de fósforo se analizó por el método colorimétrico 965.17 (AOAC, 1990) basado en la reacción con el complejo vanado-molibdato, según lo descripto en el Capítulo 1. Los resultados finales se expresaron en $\mathrm{mg} / 100 \mathrm{~g}$.

\subsection{Actividad $\alpha$-amilasa}

La actividad $\alpha$-amilasa en las harinas se midió por medio del kit enzimático Ceralpha (K-CERA 08/05 Megazyme (C, Irlanda). Este procedimiento se llevó a cabo tal como se describió en el Capítulo 1. Los resultados se expresaron como Unidades Ceralpha $\mathrm{g}^{-1} \mathrm{de}$ muestra.

\subsection{Contenido de almidón total}

Se determinó a partir de 0,10-0,15 g de muestra, empleando el kit enzimático K-TSTA 05/06 (Megazyme C), Irlanda). Los pasos implementados corresponden a los descriptos en el Capítulo 1. Los resultados se expresaron en porcentaje (\%).

\section{Caracterización fisicoquímica y microestructural de las harinas}

La determinación de la calidad de un alimento se lleva a cabo describiendo los diferentes parámetros fisicoquímicos y microestructurales. 
La caracterización de las harinas fue realizada en todos los casos en aquéllas procedentes de raíces de ahipa y en algunos, a modo comparativo, en harina de mandioca.

\subsection{Medidas de color de las harinas}

Se caracterizó el color de las harinas de ahipa y mandioca utilizando un colorímetro CR400 (Konica Minolta Sensing Inc., Japón). Los valores de la escala CIE empleada se expresaron en términos de luminosidad $\left(\mathrm{L}^{*}\right)$, coordenada rojo-verde (valor a*), y coordenada azul-amarillo (valor b*). Asimismo, con estos parámetros fueron calculados el ángulo hue $\left(\mathrm{h}^{\circ}\right)$ y la función Chroma $\left(\mathrm{C}^{*}\right)$ tal como fue descripto en el Capítulo 1.

\subsection{Estudio de la estabilidad de las harinas: obtención de las isotermas de sorción}

Las isotermas de adsorción de agua se determinaron utilizando el método estático gravimétrico estandarizado por "The European Cooperative Project COST 90" (Spiess y Wolf, 1983). Las muestras (0,15-0,20 g) de harina de ahipa (HARaP y HARo) y de mandioca (HMRa y HMRo), previamente pesadas en balanza analítica y deshidratadas en $\mathrm{CaCl}_{2}$, se colocaron en recipientes herméticos cerrados que contenían soluciones saturadas de diferentes sales (Capítulo 2; Tabla 2.1) y se procedió de modo descripto en el Capítulo 2. Las isotermas de adsorción de las harinas de ahipa y mandioca a las diferentes temperaturas se obtuvieron por triplicado. Los resultados se expresaron como g agua/g sólido en base seca.

\subsection{Modelado matemático de las isotermas de sorción de las harinas}

Los datos experimentales obtenidos para cada muestra fueron modelados matemáticamente con varias ecuaciones empíricas y semiempíricas para correlacionar el contenido de humedad de equilibrio con la actividad agua de un alimento. Los modelos de isotermas de adsorción empleados se presentaron en el Capítulo 2 (Tabla 2.2).

Los datos se ajustaron matemáticamente con los modelos de isotermas de sorción propuestos (Capítulo 2) utilizando el módulo de regresión no lineal del programa 
Systat 10.0 (SYSTAT, Inc., Evanston, IL, Estados Unidos). Se estimaron los valores de los parámetros de cada modelo y su bondad de ajuste a través del coeficiente de correlación $\left(\mathrm{R}^{2}\right)$.

\subsection{Parámetros termodinámicos estimados a través de las isotermas de sorción}

Los parámetros termodinámicos derivados de las isotermas de sorción, es decir, la entalpía diferencial $(\Delta h)$ y la entropía $(\Delta S)$ de sorción diferencial se determinaron de acuerdo con Cladera-Olivera y col., (2009) según lo detallado en el Capítulo 2.

Como ya se mencionó en dicho Capítulo, la teoría de la compensación de entalpíaentropía, que propone una relación lineal entre $\Delta \mathrm{h}$ y $\Delta S$, permitió calcular la temperatura isocinética $(\mathrm{K})$ y la energía libre $\left(\mathrm{J} \mathrm{mol}^{-1}\right)$ (Al-Muhtaseb y col., 2002; Cladera-Olivera y col., 2008; Fasina, 2006).

\subsection{Morfología y distribución de tamaño de partículas de las harinas}

La distribución del tamaño de partículas fue estudiada a nivel macroscópico, utilizando un tamiz de laboratorio y también a nivel microscópico por microscopía electrónica de barrido (SEM, Scanning Electron Microscopy).

Los procedimientos llevados a cabo para la obtención de micrografías SEM fueron descriptos en el Capítulo 2. Para el procesamiento y el análisis de las imágenes se utilizó el software AnalySis Pro 3.0 con el fin de obtener los histogramas correspondientes.

Para el estudio granulométrico, se empleó un cernidor de laboratorio Bühler MLU-300 con el siguiente conjunto de mallas: 32D (666 $\mu \mathrm{m}), 45 \mathrm{D}(472 \mu \mathrm{m}), 60 \mathrm{D}(341 \mu \mathrm{m}), 6 \mathrm{xx}$ $(230 \mu \mathrm{m})$ y un colector de fondo. El tamizado se realizó utilizando $100 \mathrm{~g}$ de cada harina durante $12 \mathrm{~min}$. Las fracciones retenidas en cada malla se separaron y se pesaron (Palacios-Fonseca y col., 2009).

\subsection{Espectroscopía de difracción de rayos $\mathrm{X}$ de las harinas}

Para la caracterización de las harinas de ahipa estudiadas, se utilizó un difractómetro X'Pert Pro PAnalytical Model PW 3040/60 (Almelo, Holanda) como se indicó en el 
Capítulo 2. Para cuantificar la cristalinidad de las harinas, se procedió como se detalló en el Capítulo 2.

\subsection{Análisis por Espectroscopía Infrarroja con Transformada de Fourier}

Se obtuvieron los espectros FTIR (Fourier Transform InfraRed) de las harinas obtenidas con un espectrofotómetro Thermo Nicolet Nexus (Estados Unidos), trabajando en el rango de números de onda desde 4000 hasta $400 \mathrm{~cm}^{-1}$ como se describió en el Capítulo 2. Las muestras se corrieron diluidas en pastillas de bromuro de potasio (Sigma-Aldrich con pureza del 99\%) a una concentración del 3\% p/p.

\section{Propiedades funcionales}

A partir de la interacción entre los constituyentes de un alimento, propiciada o acentuada por las condiciones de procesamiento, surgen las características, tanto organolépticas como nutricionales, adecuadas para satisfacer las demandas del consumidor. Los usos de las harinas dependen de sus propiedades funcionales.

\subsection{Determinación de la capacidad de retención de agua de las harinas}

La capacidad de retención de agua de las harinas de ahipa y mandioca se midió de acuerdo con Szymonska y col., (2003). Se pesaron, por duplicado, muestras de harina (1 g) y se colocaron en tubos de centrífuga. El procedimiento llevado a cabo fue descripto previamente, en el Capítulo 2. Los resultados fueron expresados en porcentaje (\%).

\subsection{Transiciones térmicas de las harinas de ahipa y mandioca}

Se utilizó el calorímetro diferencial de barrido modelo Q100 controlado por el módulo TA 5000 (TA Instruments, Estados Unidos) descripto en el Capítulo 1. Para la caracterización de las harinas de ahipa y mandioca, se pesaron aproximadamente $7 \mathrm{mg}$ de muestra y se le adicionaron $15 \mu \mathrm{L}$ de agua destilada en cápsulas de aluminio. Las cápsulas se cerraron herméticamente y se estabilizaron. Se utilizó una cápsula vacía como referencia. La velocidad de barrido fue $10^{\circ} \mathrm{C} / \mathrm{min}$. El rango de calentamiento varió entre $10-120^{\circ} \mathrm{C}$. Una vez analizadas, las cápsulas se perforaron y se mantuvieron 
en estufa a $105^{\circ} \mathrm{C}$ hasta peso constante para determinar el peso seco de las muestras. Este procedimiento fue descripto en el Capítulo 1. Se determinaron los parámetros térmicos según López y col., (2008).

\subsection{Capacidad de hinchamiento de la harina de ahipa}

Se determinó mediante una modificación del método propuesto por Tsai y col., (1997). Se prepararon suspensiones acuosas de harina de ahipa al $1 \% \mathrm{p} / \mathrm{p}$ que se colocaron en tubos de centrífuga con tapas; los tubos se calentaron a $55,65,75,85,90$ y $95{ }^{\circ} \mathrm{C}$ durante $1 \mathrm{~h}$. Las muestras se enfriaron a temperatura ambiente y se centrifugaron a 850xg durante 15 minutos. La capacidad de hinchamiento se determinó como la relación porcentual entre el peso de la harina hidratada (sedimento) y el peso inicial de la harina seca. Se recuperó el sobrenadante para la medición de la concentración de amilosa y amilopectina lixiviadas de acuerdo con el método espectrofotométrico propuesto por García y col., (1995). El ensayo se llevó a cabo tal como se detalla en el Capítulo 2.

\subsection{Capacidad de retención de solventes}

La capacidad de retención de solventes ensayada en harina de ahipa y de mandioca se realizó siguiendo el método AACC 56-11 (Rosell y col, 2009). Los solventes utilizados fueron agua desionizada, sacarosa $(50 \% \mathrm{p} / \mathrm{p}), \mathrm{Na}_{2} \mathrm{CO}_{3}(5 \% \mathrm{p} / \mathrm{p})$ y ácido láctico $(5 \% \mathrm{p} / \mathrm{p})$. La capacidad de retención de solventes se calculó como se explicó en el Capítulo 1. Los resultados se expresan en porcentaje (\%).

\section{Análisis estadístico}

Todas las determinaciones se llevaron a cabo al menos por triplicado. Para el análisis estadístico de resultados se utilizó el programa Systat ${ }^{\circledR}$ Software (Versión 10.0). Se efectuó el análisis de varianza (ANOVA) y se realizó la comparación de medias mediante el test de la diferencia mínima significativa de Fisher (LSD), con un nivel de significación $p=0,05$. Tal como se mencionó anteriormente, para el modelado matemático de los datos correspondientes a las isotermas de sorción, se aplicó el módulo de regresión no lineal de SYSTAT 10.0 (SYSTAT, Inc., Evanston, IL, USA). 


\section{RESULTADOS Y DISCUSIÓN}

\section{Procesamiento de las raíces y obtención de harinas}

El rendimiento de las diferentes harinas de ahipa (expresado en $\% \mathrm{p} / \mathrm{p}$ ), se calculó a través del balance de masas, considerando el peso inicial de las raíces frescas procesadas (con cáscara), y el peso del producto final. Para la harina obtenida por rallado y prensado fue de $14,83 \mathrm{~g}$ de harina/ $100 \mathrm{~g}$ de raíces frescas y para la harina obtenida por rodajas fue de 17,88 g de harina/ $100 \mathrm{~g}$ de raíces frescas de ahipa. En el caso de la harina de mandioca obtenida por rodaja y rallado, se obtuvieron rendimientos de 27,18 y $28,24 \mathrm{~g}$ de harina/ $100 \mathrm{~g}$ de raíces frescas, respectivamente. No se encontraron diferencias significativas $(p>0,05)$ entre los diferentes métodos propuestos (Tabla 4.1). Aunque los valores de rendimiento de las harinas no tradicionales en la literatura son más bien escasos, Bou Rached y col. (2006), han señalado que las variedades de ñame (Dioscorea trifida) Blanco y Morado de Mapuey produjeron 18,48 y $19,90 \mathrm{~g}$ de harina/100 g de pulpa, respectivamente. Estos valores son similares a los encontrados en el caso de harinas obtenidas a partir de raíces de ahipa.

Tabla 4.1. Rendimiento (\%p/p) de harina de Pachyrhizus ahipa (ahipa) y de Manihot esculenta (mandioca).

\begin{tabular}{ccc} 
& Harina & Rendimiento (\%) \\
\hline \multirow{2}{*}{ Ahipa } & Rodaja (HARo) & 17,88 \\
\cline { 2 - 3 } & Rallada sin prensar (HARaSP) & 13,14 \\
\cline { 2 - 3 } Mandioca & Rodaja (HMRo) & 14,83 \\
\cline { 2 - 3 } & Rallada sin prensar (HMRa) & 27,18 \\
\hline
\end{tabular}

Las harinas de ahipa elaboradas ya sea por rallado y prensado o por rodajas mantuvieron sus atributos de calidad originales, incluso después de nueve meses de 
almacenamiento, mientras que la harina de pasta rallada que no fue posteriormente prensada desarrolló aromas y sabores desagradables en un corto período de tiempo (una semana). Este hecho puede atribuirse a la fermentación, proceso que podría haber ocurrido durante el secado de la pulpa de ahipa rallada. El alto contenido de agua y de hidratos de carbono de las raíces y la temperatura de secado relativamente baja podrían haber favorecido el proceso de fermentación mencionado.

\section{Caracterización de las harinas}

\subsection{Composición química de las harinas}

Los resultados del análisis químico de macrocomponentes, tales como materia seca, cenizas totales, lípidos totales, proteínas, fibra detergente ácido (FDA) y carbohidratos totales, llevado a cabo en las muestras de harina de ahipa y mandioca se muestran en la Tabla 4.2.

Tabla 4.2. Composición química (\%p/p) de las harinas obtenidas a partir de Pachyrhizus ahipa (ahipa) y Manihot esculenta (mandioca).

\begin{tabular}{ccccccc} 
Harina & $\begin{array}{c}\text { Materia } \\
\text { seca }\end{array}$ & $\begin{array}{c}\text { Cenizas } \\
\text { totales }\end{array}$ & $\begin{array}{c}\text { Lípidos } \\
\text { totales }\end{array}$ & Proteínas & FDA & $\begin{array}{c}\text { Carbohidratos } \\
\text { totales }\end{array}$ \\
\hline $\begin{array}{c}\text { Ahipa Rallada } \\
\text { Prensada (HARaP) }\end{array}$ & $90,7 \pm 0,7^{\mathrm{c}}$ & $1,98 \pm 0,05^{\mathrm{a}}$ & $0,25 \pm 0,03^{\mathrm{a}}$ & $5,7 \pm 0,1^{\mathrm{c}}$ & $7,4 \pm 0,1^{\mathrm{c}}$ & $92,0 \pm 0,1^{\mathrm{b}}$ \\
\hline $\begin{array}{c}\text { Ahipa Rodaja } \\
\text { (HARo) }\end{array}$ & $88,8 \pm 0,2^{\mathrm{a}, \mathrm{b}}$ & $2,51 \pm 0,01^{\mathrm{b}}$ & $0,39 \pm 0,01^{\mathrm{b}}$ & $9,0 \pm 0,4^{\mathrm{d}}$ & $5,9 \pm 0,5^{\mathrm{b}}$ & $88,1 \pm 0,4^{\mathrm{a}}$ \\
\hline $\begin{array}{c}\text { Mandioca Rallada } \\
\text { (HMRa) }\end{array}$ & $88,4 \pm 0,2^{\mathrm{a}}$ & $3,28 \pm 0,05^{\mathrm{c}}$ & $0,39 \pm 0,01^{\mathrm{b}}$ & $2,8 \pm 0,2^{\mathrm{a}}$ & $\mathrm{s} / \mathrm{d}$ & $93,6 \pm 0,2^{\mathrm{c}}$ \\
\hline $\begin{array}{c}\text { Mandioca Rodaja } \\
\text { (HMRo) }\end{array}$ & $89,8 \pm 0,1^{\mathrm{b}, \mathrm{c}}$ & $3,45 \pm 0,04^{\mathrm{d}}$ & $0,48 \pm 0,02^{\mathrm{b}}$ & $3,7 \pm 0,7^{\mathrm{b}}$ & $1,9 \pm 0,2^{\mathrm{a}}$ & $92,5 \pm 0,9^{\mathrm{b}, \mathrm{c}}$
\end{tabular}

Nota: Los valores informados corresponden a las medias \pm las desviaciones estándar. Datos acompañados por una misma letra, no difieren significativamente $(p>0,05)$. $s / d$ : valor no determinado.

La humedad representa la cantidad de agua que posee un alimento. El contenido de agua residual, calculado a $105^{\circ} \mathrm{C}$, para la harina de ahipa obtenida por rallado y prensado fue de $9,3 \pm 0,7 \%$ y para la harina obtenida por rodaja $11,2 \pm 0,2 \%$, siendo esta diferencia significativa $(p>0,05)$.

La cantidad de cenizas en un alimento representa el contenido en minerales, sin especificar cada uno de los elementos. Como se esperaba, el contenido total de 
cenizas en la raíz entera con cáscara (dato presentado en el Capítulo 1), fue significativamente mayor que en la harina (Tabla 4.2), ya que el procesamiento para la obtención de harina comenzó con el pelado de las raíces. Las cáscaras de las raíces estarían realizando un cierto aporte de minerales.

El contenido total de cenizas hallado para las dos muestras de harina de ahipa estuvo comprendido dentro de los valores señalados por Lebot y col., (2009) para otras raíces y tubérculos tropicales, como yuca o mandioca (Manihot esculenta), camote o batata (Ipomoea batatas), taro (Colocasia esculenta) y ñame (Dioscorea spp.) El contenido de ceniza total para HARo fue significativamente mayor que para la harina HARaP, y esta observación se relaciona también con el método de procesamiento. Durante la preparación de la harina HARaP, parte de los componentes solubles se pierden en el sobrenadante liberado después del prensado. El contenido total de cenizas de los dos tipos de harina de ahipa fue superior a los mencionados en harinas tradicionales, como la harina de trigo pan $(0,50 \%)$, trigo duro $(0,80 \%)$, arroz $(0,48 \%)$ y maíz $(1,2 \%)$ (Sabanis y Tzia, 2009). Sin embargo, el contenido de cenizas de las harinas de ahipa y mandioca estuvo por debajo del informado en harina de soja $(4,1 \%)$.

Los lípidos constituyen un extenso grupo de compuestos químicamente heterogéneos que se caracterizan por ser solubles en solventes orgánicos. El contenido y la composición de lípidos en los alimentos pueden variar ampliamente y contribuyen a atributos como la textura, el sabor, la capacidad nutritiva y el valor calórico.

Se observó que el contenido de grasa cruda de las raíces enteras de ahipa (Capítulo 1) fue significativamente mayor $(p<0,05)$ que el de las harinas (Tabla 4.3). La mayor parte de los tejidos de la raíz corresponden a células parenquimáticas; por lo tanto, los lípidos presentes corresponderán mayoritariamente a los lípidos estructurales de las membranas celulares. Por otra parte, las cubiertas externas de la raíz (rizodermis), probablemente contienen células suberizadas y una cierta proporción de otras sustancias hidrofóbicas que actúan como una barrera de protección y de impermeabilización.

Las harinas de mandioca presentaron un contenido de lípidos igual o mayor que las de ahipa, no observándose diferencias entre los métodos de obtención ensayados (rallado y rodajas). El contenido lipídico de la harina de ahipa (HARo) determinado con la 
mezcla de solventes (éter de petróleo:éter etílico) fue ligeramente superior a la obtenida con $n$-hexano. Esto indicaría que los lípidos presentes son mayoritariamente no polares o de baja polaridad.

Los resultados del análisis químico mostraron que en el caso de las harinas de ahipa, HARo tuvo un nivel de proteína cruda $36 \%$ mayor que el de HARaP, siendo esta diferencia significativa $(p<0,05)$. Una posible explicación es la pérdida de proteínas solubles durante la etapa de prensado implementado en la obtención de HARaP. Según Forsyth y Shewry (2002), las proteínas solubles representan cerca del $60 \%$ del total de los compuestos nitrogenados presentes en las raíces de Pachyrhizus ahipa y presentan en general baja masa molecular. Estos compuestos comprenden un $30 \%$ de la materia seca. Los mencionados autores indicaron que el análisis electroforético de las proteínas solubles mostró que en seis diferentes accesiones de ahipa ninguno de los componentes estaba presente en cantidades suficientemente altas para sugerir que cumplan un papel como proteínas de almacenamiento. Forsyth y Shewry (2002) han concluido que las principales funciones de estas proteínas eran probablemente aquellas relacionadas con el proceso de engrosamiento y desarrollo de la raíz y con su metabolismo y que, en algunos casos, le confieren protección contra las plagas y diferentes patógenos. Dichos autores han señalado que no se encuentran presentes verdaderas proteínas de reserva y que la ausencia de las mismas es compatible con la función biológica de las raíces de ahipa como órganos de almacenamiento de hidratos de carbono.

En comparación con harinas tradicionales, el contenido de proteínas de la harina de ahipa HARo fue ligeramente inferior a los valores informados por Sabanis y Tzia (2009) para el trigo pan $(11,8 \%)$ y harina de trigo duro $(13,8 \%)$ y ligeramente superior a los valores encontrados en la harina de maíz $(7,5 \%)$ y arroz $(7,0 \%)$. Además, el contenido de proteínas de la harina de ahipa fue significativamente mayor $(p<0,05)$ que el de harina de mandioca (Tabla 4.2).

Los enzimoinmunoensayos llevados a cabo indicaron niveles de prolaminas inferiores al límite de detección de la técnica $(0,1 \mathrm{mg} / 100 \mathrm{~g})$, por lo que podría considerarse a las harinas extraídas de raíces de ahipa como productos naturalmente libres de gluten. 
Además, el aporte de proteínas (no gliadinas) de las raíces de ahipa resultaría relevante para el desarrollo de productos nutricionalmente equilibrados.

Con respecto al contenido de fibra (Tabla 4.2), el valor de fibra detergente ácido (FDA) para las raíces enteras de ahipa fue un $53,5 \%$ y $42,2 \%$ superior al hallado para la harina de ahipa, dependiendo del método de obtención. Esta diferencia es indicativa del contenido de fibra presente en la cáscara de la raíz. Al comparar el contenido de FDA de las harinas, la harina obtenida mediante rallado y prensado (HARaP) presentó un $19,6 \%$ más de fibra que la obtenida por rodajas (HARo). El contenido de FDA en harina de ahipa (HARo) fue significativamente mayor $(p<0,05)$ que en harina de mandioca (HMRo).

El contenido de fibra dietaria total de la harina de ahipa (HARo) fue $12,5 \pm 1,1 \mathrm{~g}$ por cada $100 \mathrm{~g}$ de muestra. Este valor resultó considerablemente mayor que el informado tanto para harina de trigo (2,9-3,1\%; Salinas, 2013) como de cebada $(7,52 \pm 0,09 \%$; Vasanthan y col., 2002).

En promedio, el contenido de carbohidratos totales de las harinas de ahipa fue ligeramente inferior a los valores indicados por Aboubakar y col., (2008) para la harina de taro (90,5-95,5\%). Respecto a las harinas obtenidas a partir de rodajas, el contenido de carbohidratos de la harina de mandioca fue mayor que el de la harina de ahipa.

\subsection{Análisis del perfil de aminoácidos de la harina de ahipa}

Los aminoácidos primarios unidos vía enlaces amida constituyentes de las proteínas son veinte: alanina, arginina, asparagina, ácido aspártico, cisteína, ácido glutámico, glutamina, glicina, histidina, isoleucina, leucina, lisina, metionina, fenilalanina, prolina, serina, treonina, triptófano, tirosina y valina. Existen diez aminoácidos, denominados esenciales, que el organismo es incapaz de sintetizar y que deben ser aportados por la alimentación. En la calidad de las proteínas influye el contenido en aminoácidos esenciales, y es importante señalar además la presencia de "limitantes". En efecto, se llama así al aminoácido esencial que en una proteína dada se encuentra en cantidad relativa más baja con respecto a la proteína patrón, porque limita el aprovechamiento de esa proteína a los fines biológicos (Fennema, 2008). Conocer el perfil de 
aminoácidos de la harina de ahipa permite establecer el valor de las proteínas que ésta posee y sus posibles usos alimenticios.

La Tabla 4.3 muestra el resultado del análisis del perfil de aminoácidos obtenidos por HPLC en harina de ahipa obtenida por rodajas (HARo). Con fines comparativos, en la misma Tabla se presentan los de la harina de trigo. Se han señalado además los aminoácidos esenciales.

Tabla 4.3. Análisis del perfil de aminoácidos en harinas de Pachyrhizus ahipa (ahipa) y de trigo.

\begin{tabular}{ccc} 
Aminoácido & Harina de ahipa (\%) & Harina de trigo (\%) \\
\hline Leucina* & 0,42 & 0,70 \\
\hline Alanina & 0,50 & 0,30 \\
\hline Ácido aspártico & 4,40 & 0,40 \\
\hline Isoleucina* & 0,80 & 0,37 \\
\hline Arginina* & 0,49 & 0,35 \\
\hline Metionina* & 0,56 & 0,15 \\
\hline Ácido Glutámico & 0,30 & 3,32 \\
\hline Glutamina + Serina & 0,11 & - \\
\hline Tirosina & 0,03 & 0,29 \\
\hline Histidina* & 0,76 & 0,18 \\
\hline Valina* & 0,00 & 0,42 \\
\hline Glicina + Treonina* & 0,50 & 0,68 \\
\hline Lisina* & 0,19 & 0,19 \\
\hline
\end{tabular}

* Aminoácidos esenciales.

Fuente de los datos informados para la harina de trigo: http://alimentos.org.es/aminoacidosharina-trigo

La harina de ahipa es mayoritariamente fuente de ácido aspártico, mientras que la de trigo es rica en ácido glutámico. Respecto a los aminoácidos esenciales, ambas harinas presentan el mismo contenido de lisina, mientras que la harina de ahipa aporta mayores contenidos de isoleucina, arginina, metionina e histidina. 
Como se ha señalado anteriormente, debido a que tanto fenilalanina, triptófano, cisteína y prolina no logran ser derivatizados satisfactoriamente con OPA no pudieron ser determinados por esta técnica.

\subsection{Contenido de minerales}

En el organismo humano los principales minerales son: calcio, fósforo, potasio, sodio, cloro, azufre, magnesio, manganeso, hierro, yodo, flúor, zinc, cobalto y selenio.

Algunos elementos minerales son necesarios en cantidades muy pequeñas en las dietas humanas pero son vitales para muchos procesos metabólicos; se denominan "elementos traza esenciales" (Medeiros y Wildman, 2012).

La Tabla 4.4 muestra el contenido de los minerales analizados en las harinas de ahipa y se incluyen además los valores informados para harina de mandioca por Oboh y col. (2002).

Tabla 4.4. Contenido de minerales $(\mathrm{mg} / 100 \mathrm{~g})$ de harinas.

\begin{tabular}{ccccccc} 
Harina & Sodio & Potasio & Calcio & Magnesio & Hierro & Fósforo \\
\hline HARaP & $16,4 \pm 0,3^{\mathrm{a}}$ & $459,0 \pm 5,6^{\mathrm{b}}$ & $97,0 \pm 2,8^{\mathrm{a}}$ & $31,1 \pm 0,6^{\mathrm{a}}$ & $4,0 \pm 1,1^{\mathrm{a}}$ & $329,0 \pm 21,5^{\mathrm{a}}$ \\
\hline HARo & $20,6 \pm 1,4^{\mathrm{b}}$ & $619,2 \pm 24,8^{\mathrm{c}}$ & $109,8 \pm 0,4^{\mathrm{b}}$ & $42,1 \pm 1,4^{\mathrm{b}}$ & $4,0 \pm 0,7^{\mathrm{a}}$ & $435,3 \pm 47,9^{\mathrm{a}}$ \\
\hline Mandioca* $^{*}$ & $43,8 \pm 0,3^{\mathrm{c}}$ & $49,8 \pm 0,4^{\mathrm{a}}$ & $61,6 \pm 0,7^{\mathrm{c}}$ & $43,4 \pm 0,2^{\mathrm{b}}$ & $26,0 \pm 0,4^{\mathrm{b}}$ & -
\end{tabular}

Nota: Los valores informados corresponden a la media \pm la desviación estándar. Los resultados se expresan en base seca. Valores seguidos por distintas letras dentro de una misma columna indican diferencias significativas $(p<0,05)$ * Oboh y col., (2002).

Los valores de sodio y potasio en la harina de ahipa obtenida por rodajas fueron significativamente mayores ( 1,25 y 1,35 veces respectivamente) que para la harina obtenida por rallado y prensado. El fósforo y el potasio son los elementos predominantes en ambas harinas. Se ha señalado que tanto el potasio como el sodio se absorben con facilidad y tienen la función fisiológica de mantener la presión osmótica (Medeiros y Wildman, 2012). Ogbuagu, (2008) también encontró que el potasio es uno de los principales elementos de la Dioscorea bulbifera (ñame de papa) y 
la Dioscorea dumentorum (ñame amargo). Sin embargo, la harina de mandioca es fuente de hierro y sodio, principalmente. Estos resultados indicarían que la harina de ahipa además de aportar proteínas y fibra contribuiría al desarrollo de alimentos de bajo contenido de sodio.

Los contenidos de magnesio y de calcio fueron mayores para la harina HARo que para HARaP. El contenido de calcio de la harina de ahipa se encuentra en el rango del informado por Aboubakar y col. (2008) para las harinas de taro de las variedades KW1 y CE. Además, la harina de ahipa aporta mayores contenidos de calcio que las harinas de mandioca (Tabla 4.4). El magnesio es un mineral esencial presente sobre todo en los huesos y en la mayor parte de los tejidos del cuerpo humano. Cuando hay pérdidas excesivas de magnesio corporal, se puede producir debilidad y en ocasiones se presentan convulsiones (Medeiros y Wildman, 2012). En los seres humanos y otros mamíferos, el calcio y el fósforo son los componentes principales del esqueleto. Además, son importantes en funciones metabólicas tales como la función muscular, el estímulo nervioso, las actividades enzimáticas y hormonales y el transporte del oxígeno (Medeiros y Wildman, 2012).

Entre los elementos esenciales analizados, el contenido de hierro es el más bajo con respecto a los otros minerales cuantificados, pero es necesario considerar que dicho elemento corresponde al grupo de los micronutrientes. No se observaron diferencias significativas $(p>0,05)$ en los niveles de hierro entre las diferentes harinas de ahipa analizadas, siendo éstos menores que los correspondientes al promedio de las harinas de mandioca (Tabla 4.4). La principal función biológica del hierro es el transporte de oxígeno a varios sitios del cuerpo. El hierro también está presente en las enzimas peroxidasa, catalasa y en transportadores electrónicos como los citocromos (Medeiros y Wildman, 2012).

Al comparar la harina de ahipa con las harinas tradicionales, los niveles de calcio fueron, en promedio, 4,77 veces más altos que los de harina de trigo (Peterson y col., 1986). Al mismo tiempo, las muestras de harina de ahipa mostraron un contenido de hierro 3,05 veces superior a las harinas de trigo. Este hallazgo indicaría que la harina de ahipa podría proporcionar una mayor cantidad de calcio y de hierro que la harina de trigo. A excepción del sodio, el contenido de los minerales analizados (hierro, calcio, 
magnesio, fósforo, potasio) fue mayor en las raíces enteras en comparación con las harinas (Capítulo 1 ).

\subsection{Actividad $\alpha$-amilasa y contenido de almidón total}

El nivel de amilasas endógenas en los productos que contienen almidón afecta de manera significativa a la utilización industrial de los mismos. Según la aplicación, puede ser útil disponer de un nivel de $\alpha$-amilasa suficiente para producir sacáridos disponibles, pero no tan alto como para causar una dextrinización excesiva.

En la Figura 4.6 se muestra la actividad $\alpha$-amilasa medida en la raíz entera de ahipa, sus harinas correspondientes (HARaP y HARo) y en las harinas de mandioca (HMRa y HMRo).

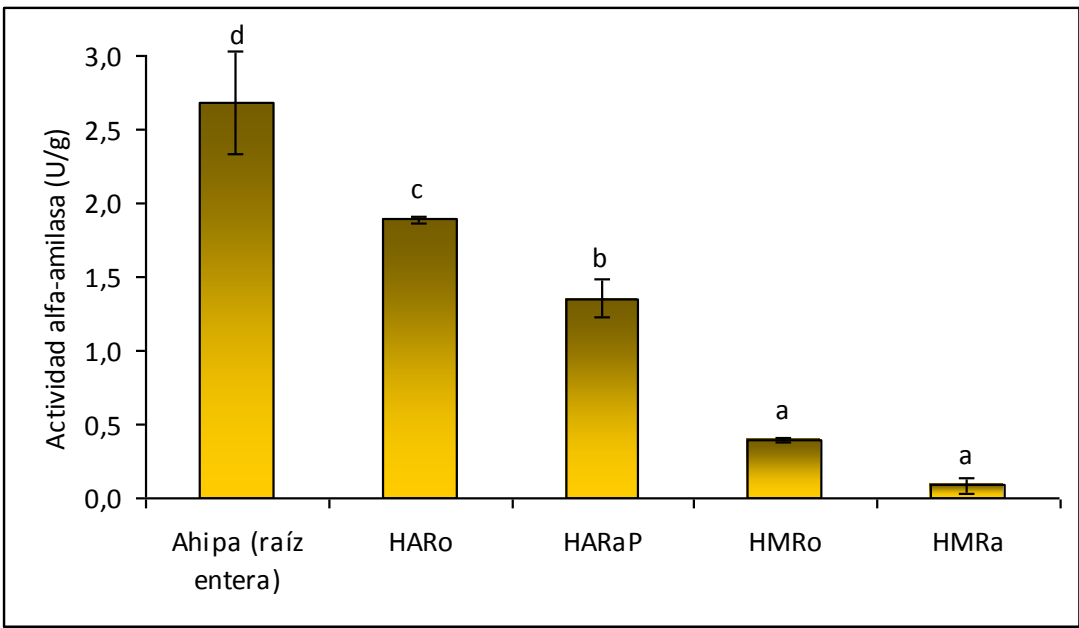

Figura 4.6. Actividad $\alpha$-amilasa medida en las raíces enteras de Pachyrhizus ahipa (ahipa), en las harinas obtenidas a partir de las mismas y en las harinas de Manihot esculenta (mandioca).

Nota: Los valores informados corresponden a las medias \pm las desviaciones estándar. Datos acompañados por una misma letra, no difieren significativamente $(p>0,05)$. Nomenclatura: HARo: harina de ahipa procedente de raíces cortadas en rodajas; HARaP: harina de ahipa obtenida por rallado, prensado y enriquecidas mediante la adición de los sólidos recuperados; HMRo: harina de mandioca procesada en rodajas; HMRa: harina de mandioca elaborada por rallado.

La actividad $\alpha$-amilasa, fue significativamente mayor $(p<0,05)$ en las raíces enteras de ahipa $(2,7 \pm 0,4 \mathrm{U} / \mathrm{g})$ que en las harinas $(1,9 \pm 0,0 \mathrm{U} / \mathrm{g}$ para HARo y $1,4 \pm 0,1 \mathrm{U} / \mathrm{g}$ para 
HARaP). Asimismo, en la harina obtenida por rodajas el valor determinado fue mayor que para la harina rallada y prensada. Posiblemente, el sobrenadante que se libera durante el prensado implementado en el procesamiento de la harina rallada contendría algunas enzimas solubles, incluyendo en parte a la $\alpha$-amilasa. La actividad de esta enzima resultó significativamente mayor $(p<0,05)$ en las harinas de ahipa que en las de mandioca (Figura 4.6).

El almidón es, fundamentalmente, un compuesto de reserva en los vegetales y proporciona un alto porcentaje de las calorías consumidas por los humanos en todo el mundo. El almidón y sus productos de hidrólisis constituyen la mayor parte de los carbohidratos digestibles de la dieta humana.

En la Figura 4.7 se presenta el contenido de almidón total medido en la raíz entera de ahipa, sus harinas correspondientes y en las harinas de mandioca.

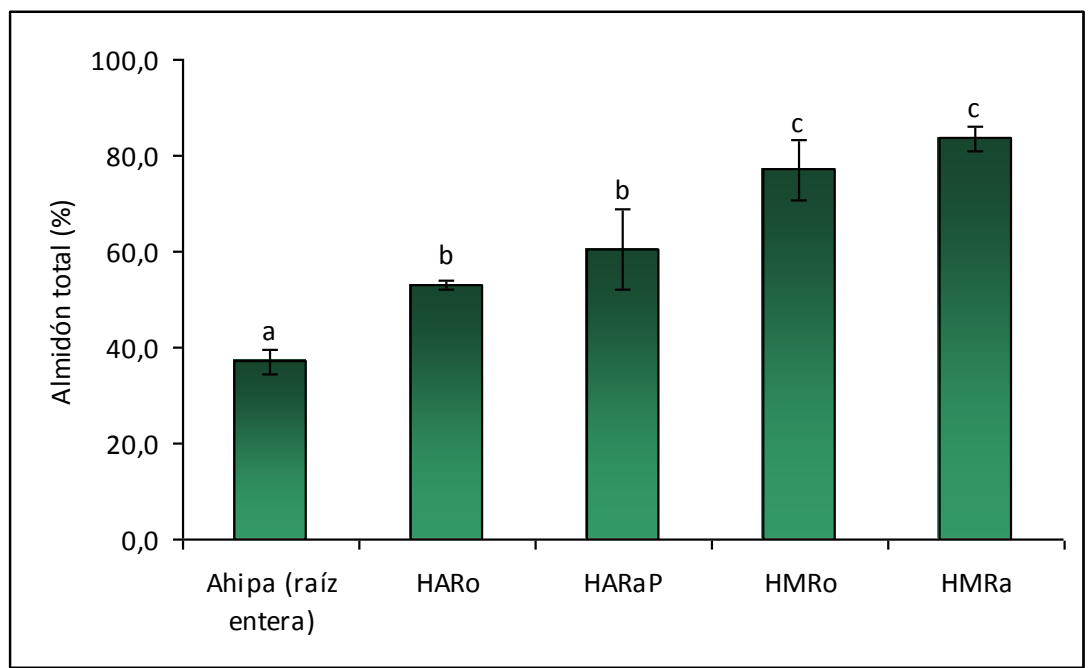

Figura 4.7. Contenido de almidón total medido en raíces enteras de Pachyrhizus ahipa

(ahipa), en las harinas obtenidas a partir de las mismas y en las harinas de Manihot

$$
\text { esculenta (mandioca). }
$$

Nota: Los valores informados corresponden a las medias \pm las desviaciones estándar. Datos acompañados por una misma letra, no difieren significativamente $(p>0,05)$. Nomenclatura: HARo: harina de ahipa procedente de raíces cortadas en rodajas; HARaP: harina de ahipa obtenida por rallado, prensado y enriquecidas mediante la adición de los sólidos recuperados; HMRo: harina de mandioca procesada en rodajas; HMRa: harina de mandioca elaborada por rallado. 
En las raíces enteras de ahipa, el contenido total de almidón resultó entre 18-27\% menor que en las harinas (Figura 4.7). No hubo diferencias significativas $(p>0,05)$ entre los niveles de almidón total de las harinas de ahipa obtenidas por ambos métodos. Así, el agregado de los sólidos recuperados luego del prensado de la pulpa a la harina rallada y prensada, resultó una estrategia eficaz de recuperación del almidón lixiviado. López y col. (2010) informaron que el rendimiento de almidón de ahipa obtenido a partir de sus raíces, a escala de laboratorio, fue $56,54 \%$ p/p sobre base seca. Este rendimiento es cercano al valor del contenido total del almidón encontrado en las harinas.

El contenido de almidón de la harina de ahipa rallada y prensada es inferior que el informado por Lebot y col., (2009) para mandioca, boniato, malanga y ñame. La harina de ahipa obtenida a partir de rodajas tiene un contenido de almidón similar al de la harina de batata (Krishnan y col., 2010; Lebot y col., 2009). Estos valores son inferiores al de las harinas de mandioca. El contenido de almidón total de las harinas de mandioca obtenidas por corte en rodajas (HMRo) y por rallado (HMRa) fue de $77,1 \pm 6,2 \%$ y $83,5 \pm 2,5 \%$, respectivamente (Figura 4.7).

\section{Caracterización fisicoquímica y microestructural de las harinas}

\subsection{Medidas de color de las harinas de ahipa y mandioca}

El color es uno de los atributos importantes para la aceptación de alimentos, siendo su evaluación una forma de garantizar la satisfacción del consumidor ante el producto final elaborado.

Los resultados de los análisis de color se muestran en la Tabla 4.5. Los valores de luminosidad $\left(L^{*}\right)$ no difirieron significativamente $(p>0,05)$ para las dos muestras de harina de ahipa. Contrariamente, dicho parámetro en la harina de mandioca obtenida por rallado (HMRa) tuvo valores significativamente más altos $(p<0,05)$ que la harina de mandioca obtenida por rodajas (HMRo). 
Tabla 4.5. Valores de $\mathrm{L}^{*}$, hue $\left(\mathrm{h}^{\circ}\right)$ y Chroma $\left(\mathrm{C}^{*}\right)$ de las harinas de Pachyrhizus ahipa (ahipa) y de Manihot esculenta (mandioca).

\begin{tabular}{cccc} 
Harina & $\mathrm{L}^{*}$ & $\mathrm{~h}^{\circ}$ & $\mathrm{C}^{*}$ \\
\hline Ahipa Rallada Prensada & $85,4 \pm 2,0^{\mathrm{a}}$ & $84,7 \pm 0,2^{\mathrm{a}}$ & $11,3 \pm 0,5^{\mathrm{a}}$ \\
\hline Ahipa Rodaja & $84,1 \pm 1,1^{\mathrm{a}}$ & $85,4 \pm 0,4^{\mathrm{b}}$ & $15,1 \pm 1,0^{\mathrm{b}}$ \\
\hline Mandioca Rallada & $92,9 \pm 0,8^{\mathrm{c}}$ & $92,3 \pm 0,3^{\mathrm{d}}$ & $10,9 \pm 0,5^{\mathrm{a}}$ \\
\hline Mandioca Rodaja & $90,9 \pm 0,9^{\mathrm{b}}$ & $91,3 \pm 0,3^{\mathrm{c}}$ & $11,9 \pm 0,5^{\mathrm{a}}$
\end{tabular}

Nota: Los valores informados corresponden a las medias \pm la desviación estándar. Letras diferentes en cada columna indican diferencias significativas $(p<0,05)$.

Los valores de $L^{*}$ de las harinas de ahipa estuvieron ligeramente por debajo de los de marama (Tylosema esculentum), harina de poroto $(92,2$ a 96,5) y superiores a los encontrados para la harina de soja desengrasada y tratada térmicamente $(72,2)$. Los valores de $L^{*}$ para la harina de ahipa fueron cercanos a los de la harina de soja desgrasada que no fue sometida a tratamiento térmico (89,1 según Maruatona y col., 2010). Las muestras de harina de ahipa presentaron valores de luminosidad similares a los hallados en la literatura para el maíz, el maíz nixtamalizado y la harina de taro (L*= $84,7,85,3$ y 81,2 , respectivamente de acuerdo con Rodríguez-Miranda y col., 2011).

La coordenada $a^{*}$ mostró valores similares, $1,04 \pm 0,08$ y $1,22 \pm 0,16$, para HARaP y HARo, respectivamente. Las principales diferencias se observaron en la coordenada b* $(11,2 \pm 0,5$ para HARaP y $15,0 \pm 0,9$ para HARo).

Analizando las coordenadas cromáticas, las muestras de harina de ahipa presentaron valores de $a^{*}$ cercanos a los de la harina de taro variedad RIE $(1,4 \pm 0,1)$; para la coordenada $b^{*}$, en harina de ahipa los valores fueron similares a los de las variedades de harina de taro KW1 y KW2 (Aboubakar y col., 2008).

El procedimiento de obtención de las harinas tendría incidencia significativa $(p<0,05)$ en los valores del ángulo hue, tanto en ahipa como en mandioca. En la harina de ahipa obtenida por rodajas se observaron valores significativamente más altos $(p<0,05)$ de Chroma que en la harina de ahipa obtenida por rallado (HARaP), por lo que el color de la primera fue más saturado, con una contribución menor de la tonalidad gris. No hubo diferencias significativas $(p>0,05)$ entre los valores de Chroma en ambas harinas de mandioca. 
En cuanto a los atributos de color, la harina de mandioca presentó valores de luminosidad y del parámetro hue significativamente mayores $(p<0,05)$ que los correspondientes a ahipa (Tabla 4.5). Con respecto al parámetro Chroma, las harinas presentaron valores mayores que su almidón debido posiblemente a ciertas reacciones de pardeamiento no enzimático o químico causadas por el relativamente alto nivel de azúcar y el contenido de proteínas (Doporto y col., 2011) y el tratamiento térmico que promueve estos fenómenos asociados a cierta disminución de la calidad. Específicamente en el caso de harina de ahipa, los altos valores de Chroma $(15,1 \pm 1,0)$ obtenidos se podrían relacionar con el mayor contenido de proteínas de la raíz tuberosa (Capítulo 1). En la harina de mandioca obtenida a partir de rodajas el valor de Chroma fue $11,9 \pm 0,5$, siendo éste significativamente menor $(p<0,05)$ que el correspondiente a la harina de ahipa obtenida por el mismo método. En la Figura 4.8 se presenta una fotografía evidenciando las diferencias de color observadas en ambas harinas.

\section{Harina de ahipa}

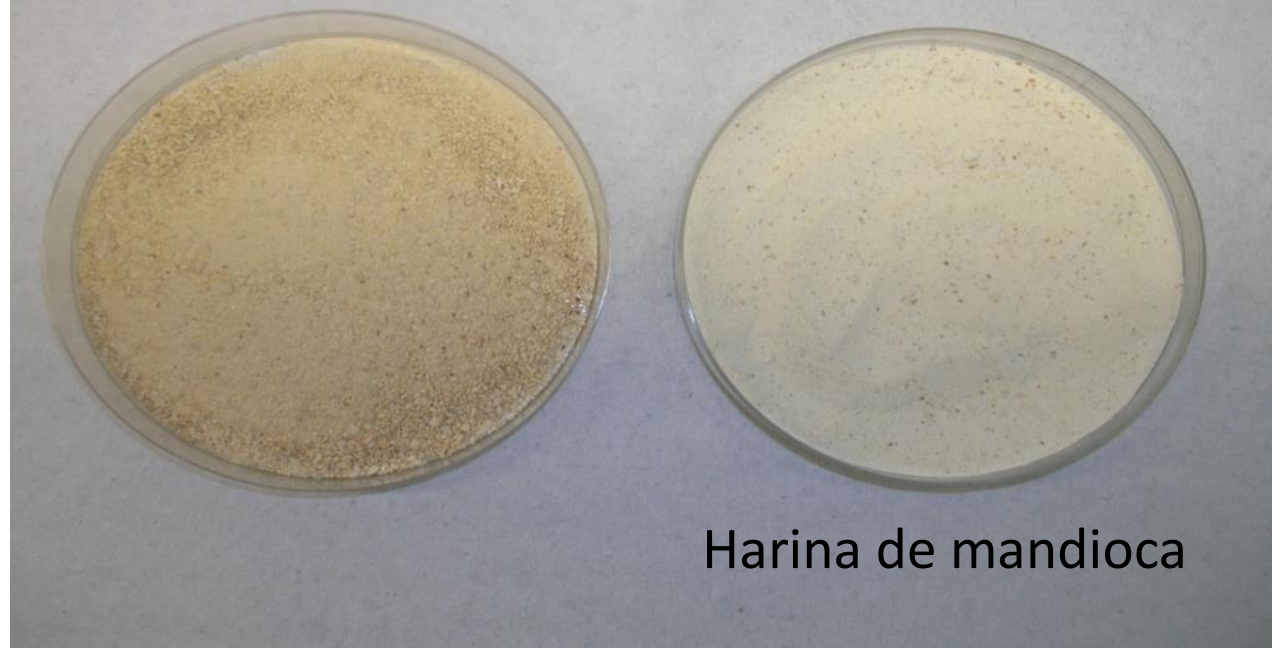

Figura 4.8. Diferencias de color observadas en las harinas de Pachyrhizus ahipa (ahipa) y Manihot esculenta (mandioca). 


\subsection{Granulometría}

Tal como se describió anteriormente, la distribución del tamaño de partículas fue estudiada a nivel macroscópico, utilizando un tamiz de laboratorio y también a nivel microscópico por microscopía electrónica de barrido (SEM).

La Figura 4.9 muestra los resultados del proceso de tamizado de las harinas de ahipa (HARaP y HARo) y la cuantificación de las distintas fracciones.

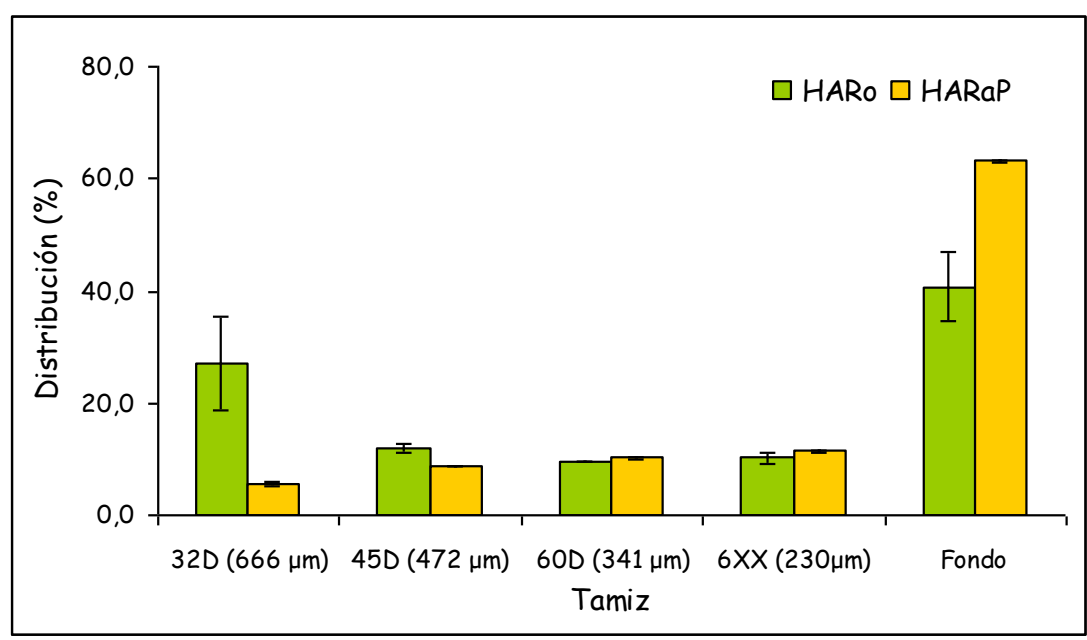

Figura 4.9. Distribución granulométrica $(\%, \mathrm{p} / \mathrm{p})$ de harina de Pachyrhizus ahipa

(ahipa), determinada por tamizado.

Nomenclatura: HARo: harina de ahipa obtenida por rodajas; HARaP: harina de ahipa obtenida por rallado y prensado.

Mediante este método macroscópico el $64 \%$ de las partículas para la harina rallada y prensada no pudo fraccionarse, ocurriendo lo mismo con el $41 \%$ de la harina procedente de rodajas, ya que su tamaño de partícula fue más reducido que el del menor tamiz disponible y por lo tanto se colectaron estas fracciones como "fondo". Con respecto a la distribución de las partículas retenidas, para la harina obtenida por rodajas (HARo), la mayor proporción de las partículas fue colectada en el primer tamiz 32D $(666 \mu \mathrm{m})$. Estos resultados se deben a que la harina obtenida por rodajas (HARo) presentó partículas de mayor tamaño respecto de la harina elaborada por rallado y prensado (HARaP). A pesar de haber obtenido las harinas de ahipa con el mismo tipo 
de molienda, la diferencia entre ellas radica en el agregado de almidón recuperado del prensado en la harina procesada por rallado de las raíces peladas de ahipa.

La Figura 4.10 muestra las micrografías SEM de harina de ahipa y mandioca. Las micrografías electrónicas de las harinas analizadas fueron tomadas a partir del material retenido en el reservorio del último tamiz (fondo) y las mismas muestran imágenes que se corresponden a los gránulos de almidón, así como otros componentes de las harinas, como complejos de fibra y proteínas. En todas las muestras, se observan partículas deformadas, truncadas y con poca esfericidad. En cuanto al método de procesamiento para la obtención de ambas harinas, se observaron diferencias en las micrografías analizadas. En general, las harinas obtenidas por rallado presentaron mayor proporción de partículas de menor tamaño.

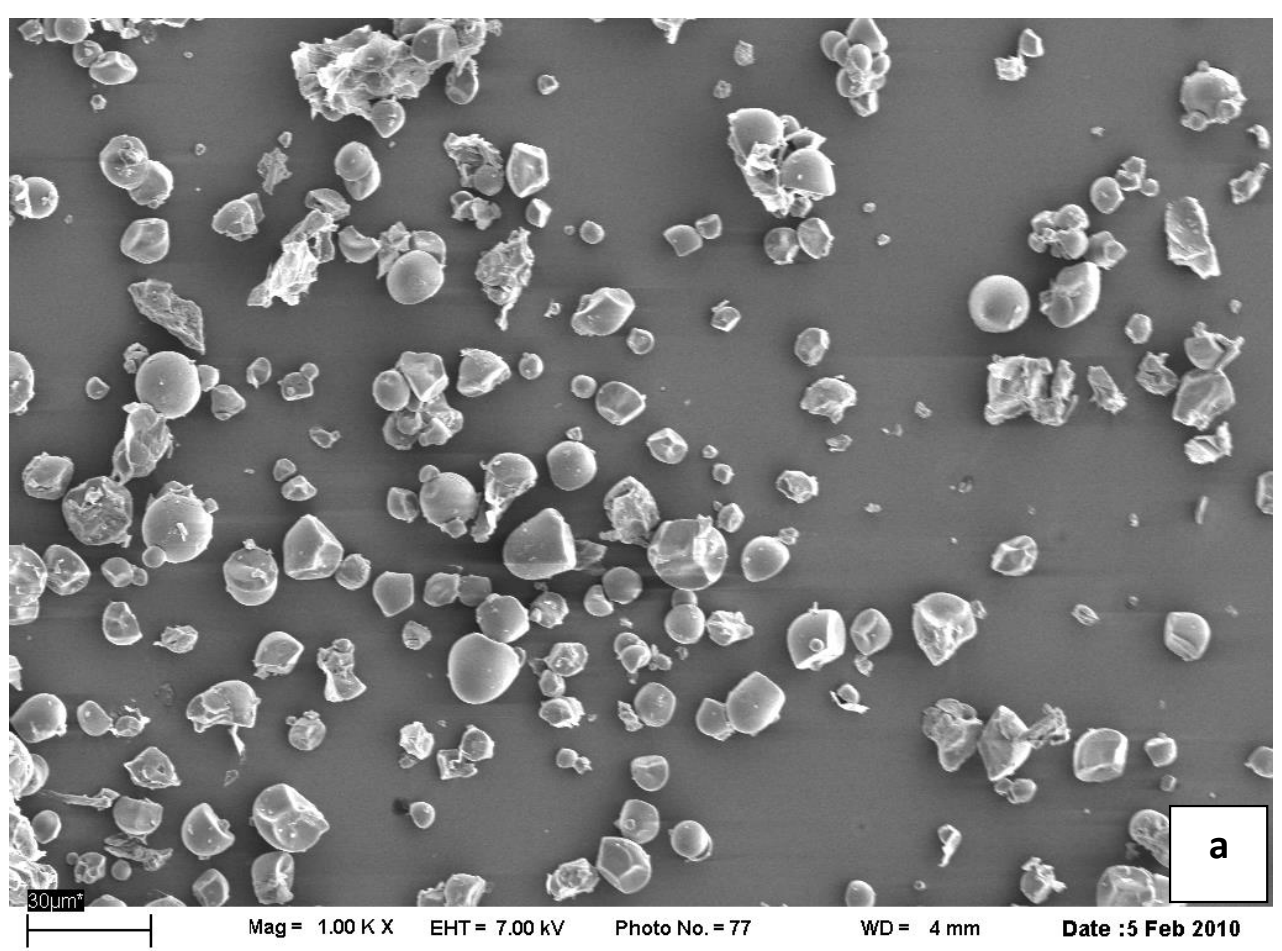


Capítulo 4. Obtención y caracterización de harinas de Pachyrhizus ahipa y Manihot esculenta
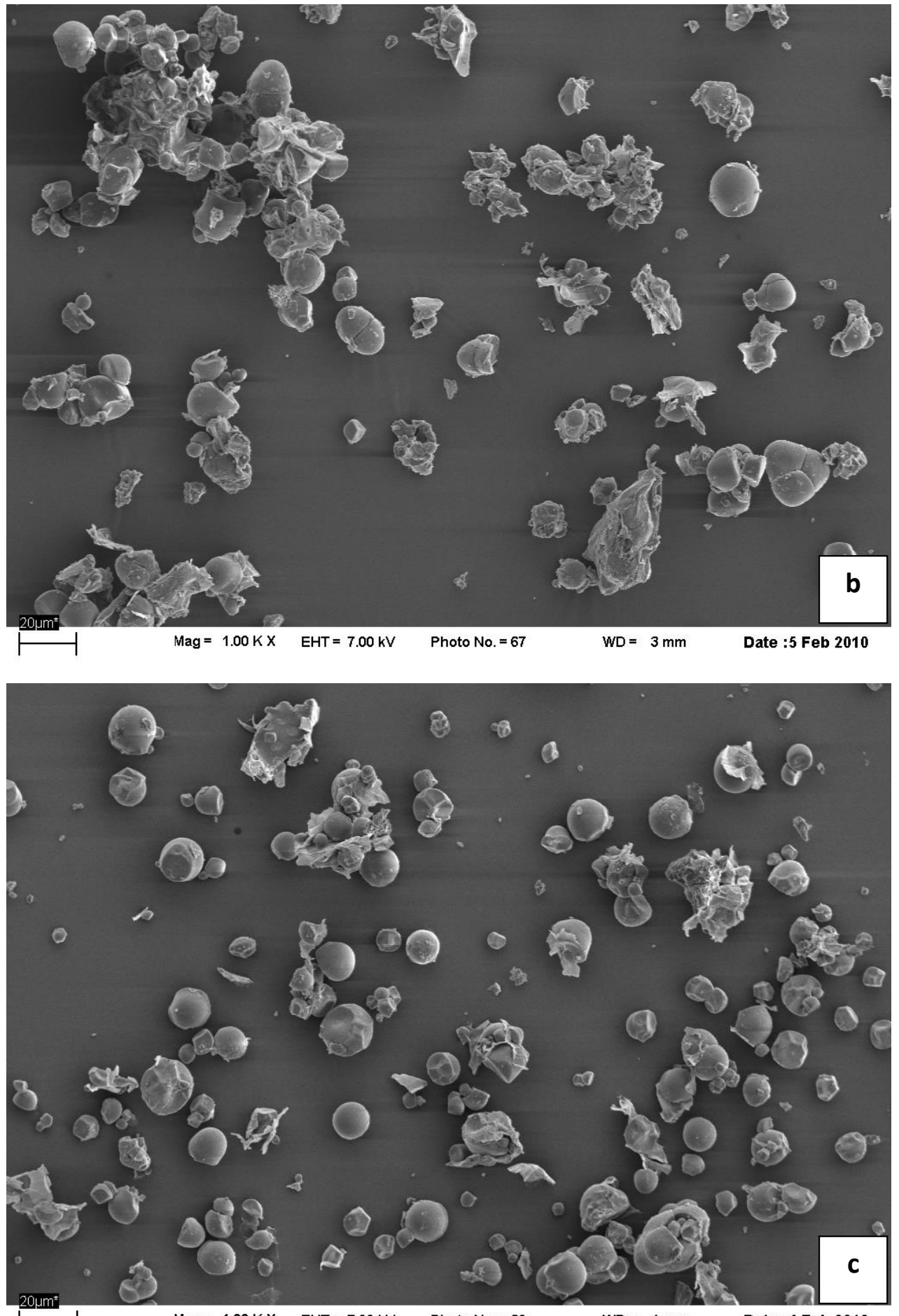

Date :4 Feb 2010 


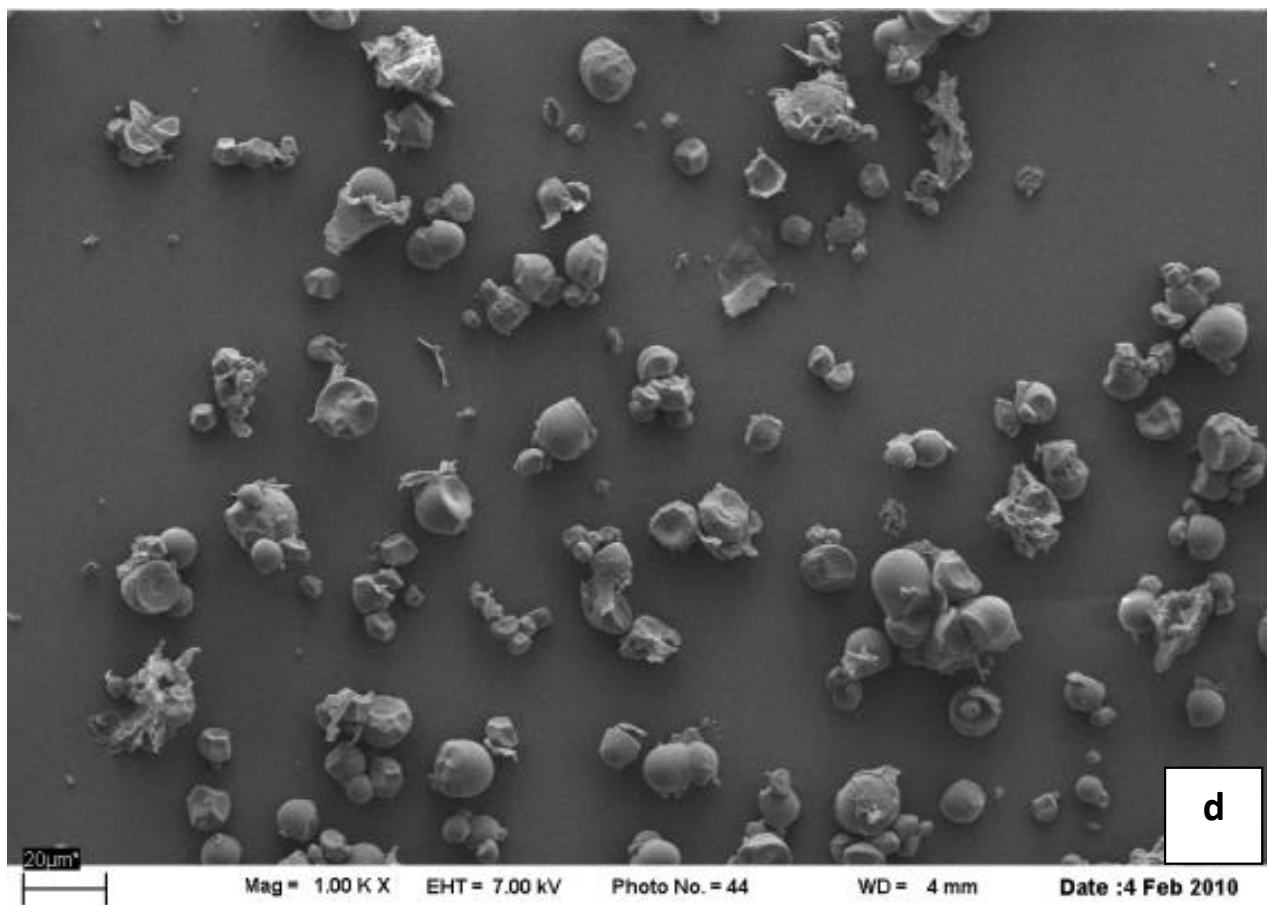

Figura 4.10. Micrografías electrónicas de barrido de las muestras de las harinas de Pachyrhizus ahipa (ahipa) y de Manihot esculenta (mandioca); (a) HARaP; (b) HARo; (c) HMRa; (d) HMRo. La magnificación se indica en la micrografía.

Nomenclatura: HARaP: harina de ahipa obtenida por rallado y prensado, HARo: harina de ahipa obtenida por corte (rodajas), HMRa: harina de mandioca obtenida por rallado, HMRo: harina de mandioca obtenida por rodajas.

En el histograma de la Figura 4.11 se puede apreciar que las muestras correspondientes a la harina HARaP presentaron una alta contribución de partículas pequeñas (con diámetros inferiores a $6 \mu \mathrm{m}$ ) que podría ser atribuido al agregado del sólido recuperado luego del proceso de prensado (constituido principalmente por almidón). Asimismo, partículas mayores a $18 \mu \mathrm{m}$ se observaron también para esta muestra, aunque en menor proporción que en la harina HARo. Se verificó en la harina HARo una contribución significativa de partículas con un tamaño inferior a $6 \mu \mathrm{m}$, si bien el tamaño medio de partículas fue similar al correspondiente a las otras muestras $(11 \mu \mathrm{m})$. 
Capítulo 4. Obtención y caracterización de harinas de Pachyrhizus ahipa y Manihot esculenta
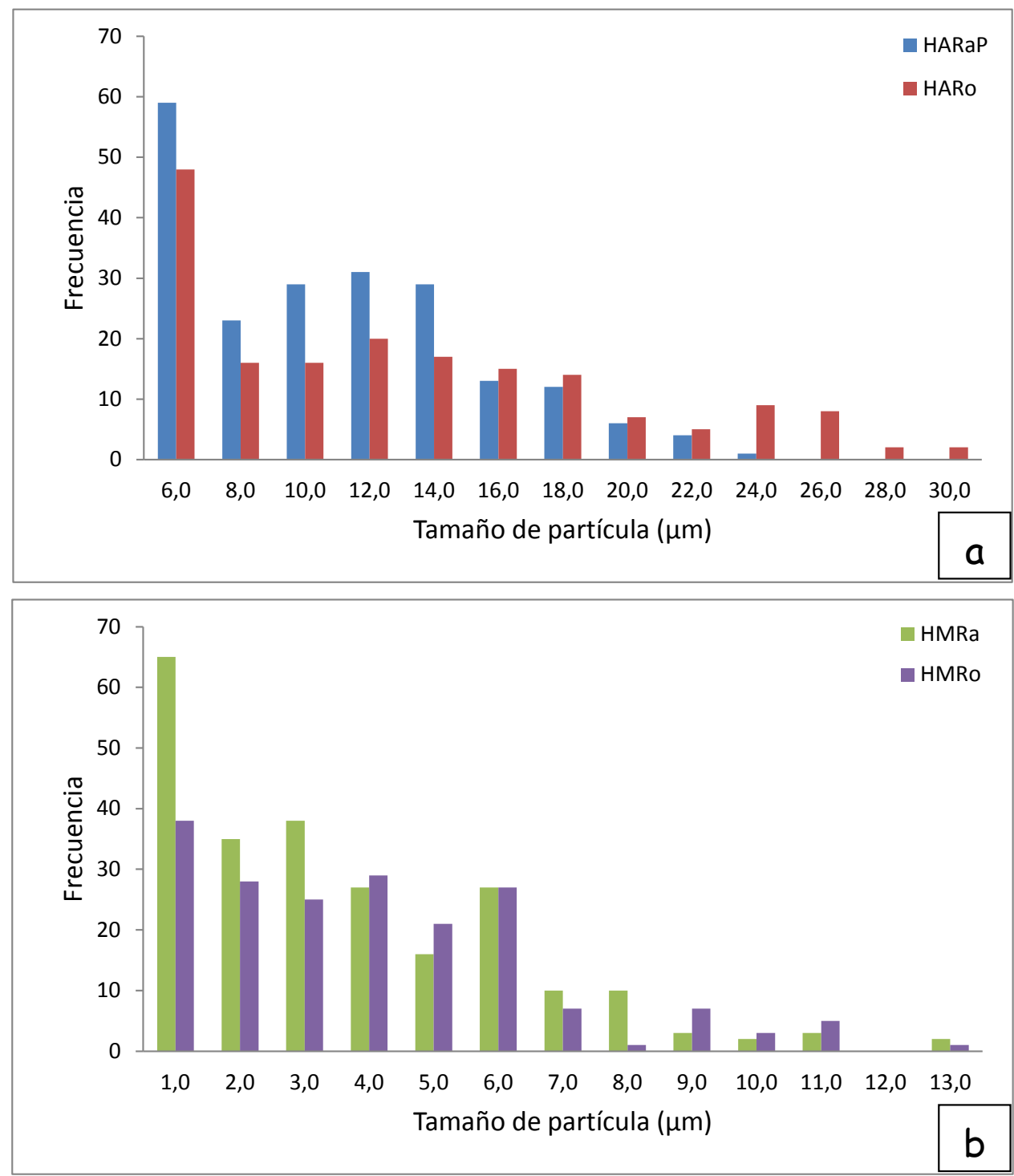

Figura 4.11. Histograma correspondiente a la distribución de tamaño de partícula de las muestras de las harinas de a) Pachyrhizus ahipa (ahipa) y b) Manihot esculenta (mandioca).

Nomenclatura: HARaP: harina de ahipa obtenida por rallado y prensado, HARo: harina de ahipa obtenida por corte (rodajas), HMRa: harina de mandioca obtenida por rallado, HMRo: harina de mandioca obtenida por rodajas.

Las harinas de ahipa y de mandioca se caracterizaron por la presencia de gránulos de almidón, así como de partículas irregulares, que podrían atribuirse principalmente a 
los agregados de proteínas y componentes de fibra. Además, estas partículas irregulares fueron más abundantes en las harinas de ahipa que en las de mandioca, correlacionándose con la composición química de ambas harinas (Tabla 4.2).

\subsection{Espectroscopía de difracción de rayos $\mathrm{X}$ de la harina de ahipa}

La Figura 4.12 muestra los difractogramas de las harinas y almidones de las raíces tuberosas estudiadas.
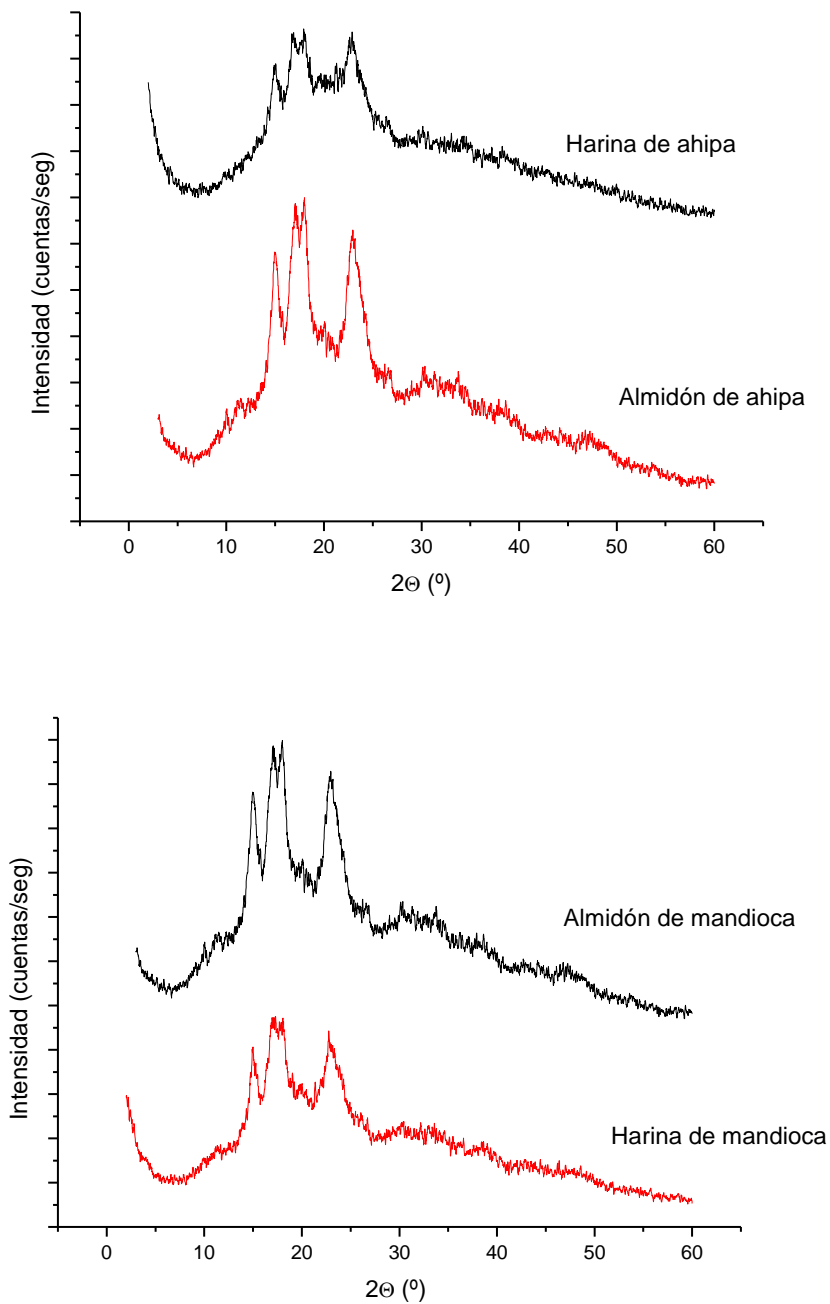

Figura 4.12. Espectros de difracción de rayos $X$ de harinas y almidones de Pachyrhizus ahipa (ahipa) y Manihot esculenta (mandioca). 
Dado que el componente mayoritario de las harinas es el almidón, la cristalinidad de las muestras de harina está determinada principalmente por este constituyente. La asignación del patrón de difracción no resultó sencilla; los difractogramas presentaron picos a $2 \theta=5.5,15.4,17.0,18.0,20.0$ y $23.5^{\circ}$, por lo que se les asignó un patrón Tipo $C$ (Geng y col., 2007; Whistler y col., 1984). Este patrón es típico de almidones de legumbres (Zobel, 1988) y de almidones de frutas y tubérculos tropicales (Luengwilai y Beckles, 2009). En la literatura no hay homogeneidad respecto a la asignación de patrones de difracción de rayos $X$ para almidones provenientes de raíces y tubérculos no tradicionales como taro, cará, batata y kudzu (Huang, 2009; Geng y col., 2007). Los grados de cristalinidad fueron: $7,5 \pm 0,3 \%$ para la harina de ahipa y $9,7 \pm 0,5 \%$ para la de mandioca. Se observó que el origen botánico de la muestra afectó el grado de cristalinidad de los gránulos; esta variación podría relacionarse inversamente con el contenido de amilosa (datos mostrados en el Capítulo 2).

\subsection{Espectroscopía infrarroja con transformada de Fourier}

Los espectros FTIR de ambas harinas fueron similares (Figura 4.13) y presentaron las señales típicas de estiramiento, flexión y deformación correspondientes a los principales grupos funcionales característicos del almidón (Figura 4.14).

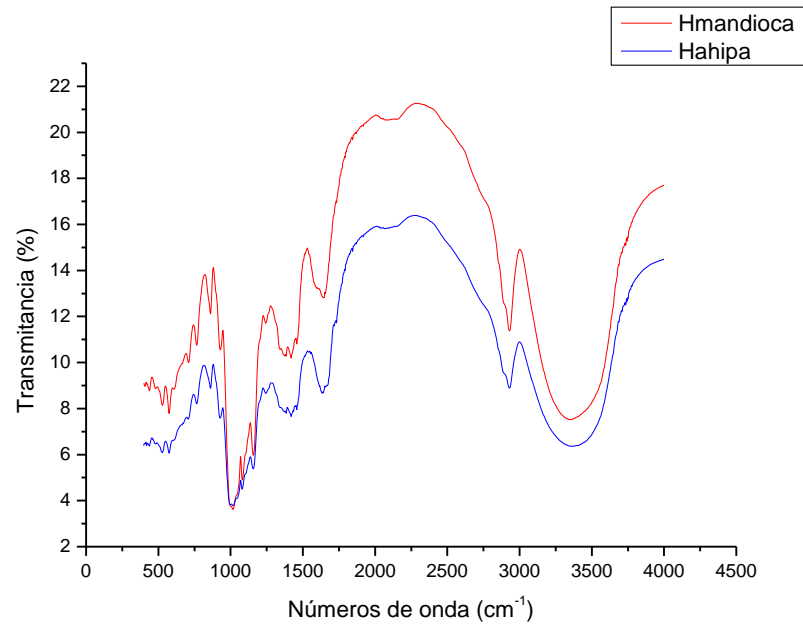

Figura 4.13. Espectros FTIR de harinas obtenidas a partir de raíces tuberosas de Pachyrhizus ahipa (ahipa) y Manihot esculenta (mandioca). 

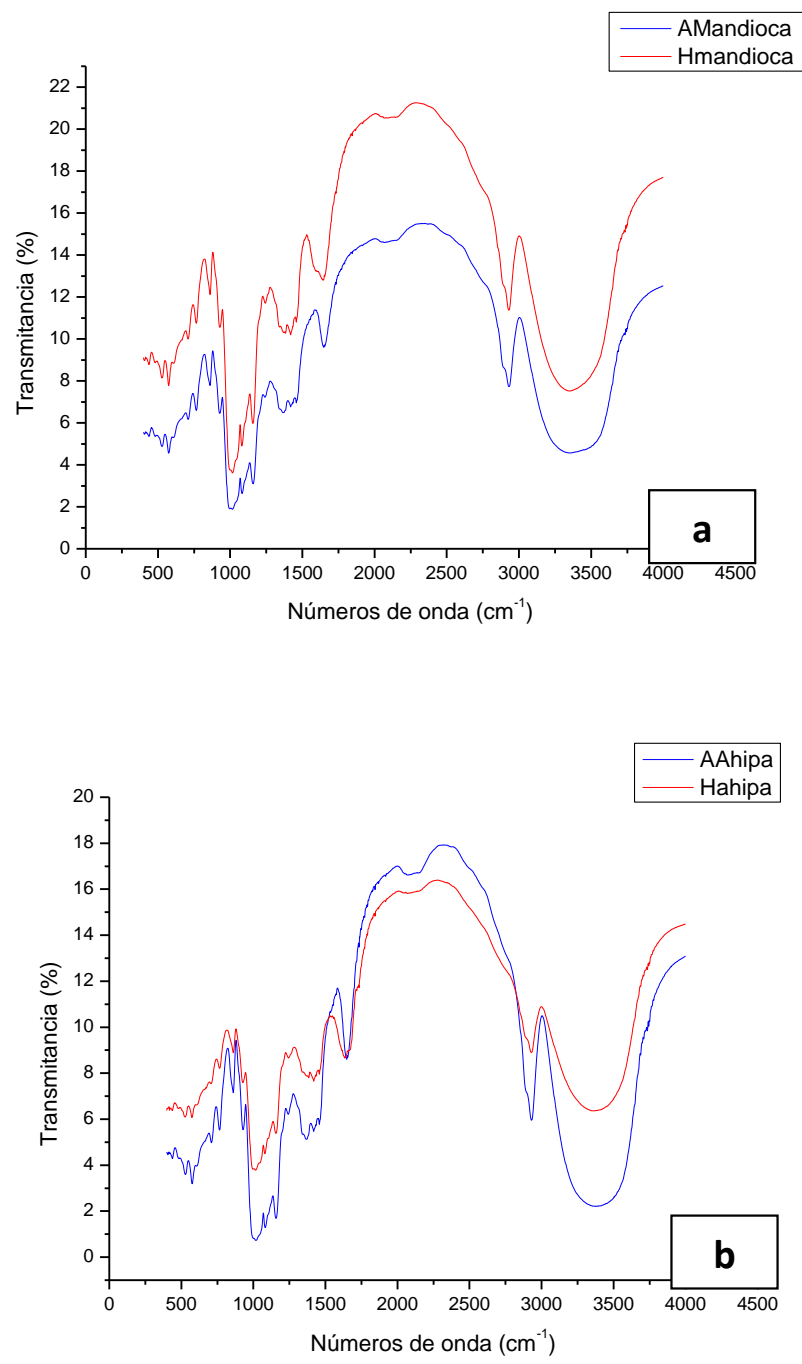

Figura 4.14. Comparación de los espectros FTIR obtenidos para la harina y el almidón derivado de raíces tuberosas de a) Manihot esculenta (mandioca) y b) Pachyrhizus ahipa (ahipa).

Nota: Las curvas en color azul corresponden a los almidones y las representadas en color rojo a las harinas.

El origen botánico no afectó los espectros FTIR de ambas harinas, ya que como se observa en la Figura 4.14 ambos espectros resultaron similares y los picos identificados son coincidentes (Tabla 4.6). 
Capítulo 4. Obtención y caracterización de harinas de Pachyrhizus ahipa y Manihot esculenta

Tabla 4.6. Picos identificados en los espectros de FTIR de almidones obtenidos de raíces tuberosas de Manihot esculenta (mandioca) y Pachyrhizus ahipa (ahipa).

\begin{tabular}{|c|c|c|c|}
\hline \multicolumn{4}{|c|}{ Picos identificados en los espectros de FTIR $\left(\mathrm{cm}^{-1}\right)$} \\
\hline \multicolumn{2}{|c|}{ Ahipa } & \multicolumn{2}{|c|}{ Mandioca } \\
\hline Almidón & Harina & Almidón & Harina \\
\hline 526,5 & 526,5 & 526,5 & 526 \\
\hline 576,6 & 574,7 & 574,7 & 574 \\
\hline 612,4 & 612,3 & 612,3 & 613 \\
\hline 709,7 & 705,8 & 709,3 & 709,7 \\
\hline 765,6 & 765,6 & 765,6 & 765,6 \\
\hline 860,1 & 862 & 860,1 & 860,1 \\
\hline 927,7 & 927,7 & 927,6 & 929,5 \\
\hline \multirow[t]{2}{*}{1018,2} & 1016,3 & 1016,3 & 1016,3 \\
\hline & 1049,4 & & 1045 \\
\hline \multirow[t]{2}{*}{1081,9} & 1079,9 & 1081,9 & 1079,9 \\
\hline & 1103,8 & & 1106 \\
\hline 1157,1 & 1155,1 & 1159 & 1157,1 \\
\hline \multirow[t]{2}{*}{1241,9} & 1243,9 & 1240 & 1243,1 \\
\hline & 1344,1 & & 1342 \\
\hline 1367 & 1382,7 & 1367,3 & $1372-1387$ \\
\hline 1419,3 & 1419,4 & 1419,4 & 1419 \\
\hline \multirow[t]{3}{*}{1457,9} & 1457,9 & 1457,9 & 1457,9 \\
\hline & 1542 & & 1588 \\
\hline & $1629,4-1640,9$ & & 1643 \\
\hline \multirow[t]{2}{*}{1648,8} & $1656,6-1675$ & 1648,8 & 1658 \\
\hline & $1718,2-1733,7$ & & 1733,9 \\
\hline 2931 & 2929,3 & 2931,1 & 2931 \\
\hline 3397 & 3360,1 & 3365 & 3355 \\
\hline
\end{tabular}

Como se describió en el Capítulo 2, sólo se identificaron los picos más relevantes del espectro y la asignación de los picos coincidentes entre las muestras de almidones y harinas corresponden a los descriptos en dicho Capítulo.

Ambas harinas presentan un pico característico localizado a $1342 \mathrm{~cm}^{-1}$ para harina de mandioca y $1344,1 \mathrm{~cm}^{-1}$ para la derivada de ahipa el que corresponde a la banda característica de la amida III que normalmente se localiza entre 1200 y $1350 \mathrm{~cm}^{-1}$ 
(Singh, 2000). Pelissari y col. (2013) trabajando con harina de banana también informaron la presencia de esta banda en los espectros de FTIR.

Las bandas que aparecen a 1458 y $1649 \mathrm{~cm}^{-1}$ se asignan a las flexiones $\delta$ del grupo O-H del agua y del $-\mathrm{CH}_{3}$, respectivamente (Mano y col., 2003, Zhang y Han, 2006; Fang y col., 2002; Kacuráková y Wilson, 2001).

Las principales diferencias entre los espectros de las harinas y de los almidones se observan en la región entre 1500 y $1800 \mathrm{~cm}^{-1}$. Para una mejor comprensión, esta región se presenta ampliada en la Figura 4.15.

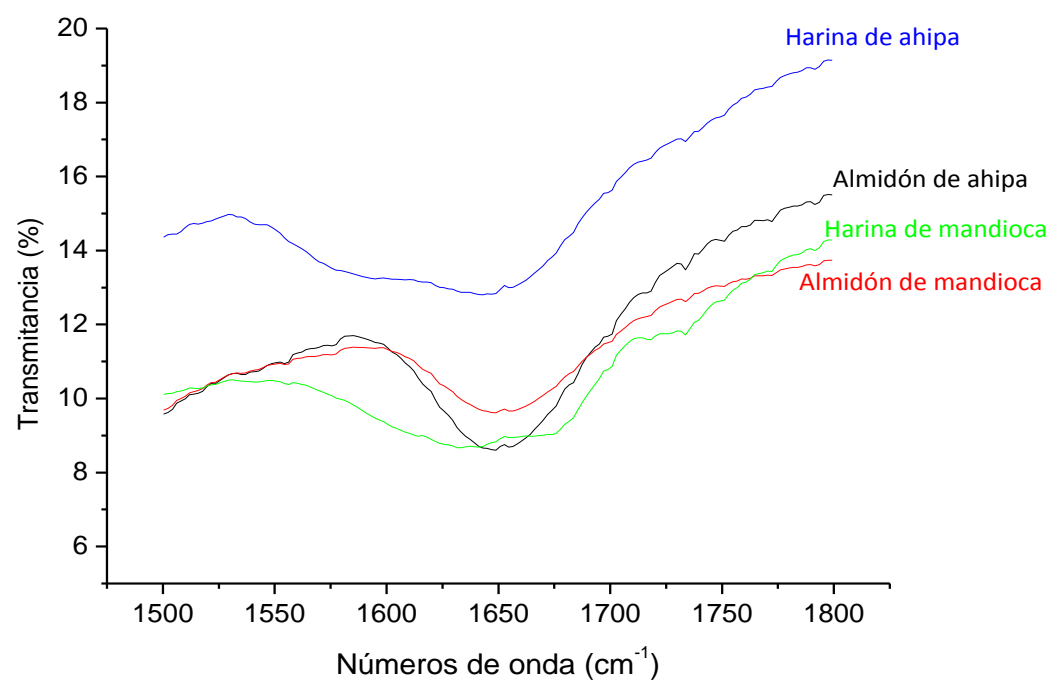

Figura 4.15. Comparación de los espectros de FTIR de harinas y almidones de raíces tuberosas en la región espectral de 1500 a $1800 \mathrm{~cm}^{-1}$.

Las proteínas y polipéptidos exhiben bandas características en los espectros FTIR. Uno de los modos más utilizados es la banda de la amida I. Este modo vibracional se origina en el estiramiento $\mathrm{V} C=\mathrm{O}$ perteneciente al grupo amida acoplado con el modo de flexión del grupo N-H y el estiramiento $\mathrm{VC}-\mathrm{N}$ dando bandas en la región $1600-1700 \mathrm{~cm}^{-1}$ que corresponden a una superposición de picos asociados a las diferentes conformaciones que pueden adoptar las cadenas polipeptídicas (Singh, 2000). La derivada segunda resultó ser una herramienta útil con el fin de individualizar las 
principales contribuciones a la banda de la amida I. En la Tabla 4.7 se muestran los picos individualizados a través de esta herramienta matemática.

Tabla 4.7. Asignación de picos en la región espectral correspondiente a la banda de la

\begin{tabular}{|c|c|c|}
\multicolumn{3}{|c}{ amida I $\left(1600-1700 \mathrm{~cm}^{-1}\right)$} \\
\hline Picos característicos & Picos detectados en los espectros de \\
\cline { 2 - 3 } & harina de mandioca & harina de ahipa \\
\hline hoja plegada $\beta$ paralela $1613-1625 \mathrm{~cm}^{-1}$ & 1621,8 & 1620,5 \\
\hline$\alpha$ hélice solvatada $1625-1637 \mathrm{~cm}^{-1}$ & 1631,5 & 1630,7 \\
\hline estructura al azar $1637-1645 \mathrm{~cm}^{-1}$ & 1639 & 1639,3 \\
\hline$\alpha$ hélice $1650-1658 \mathrm{~cm}^{-1}$ & 1654,6 & 1653,8 \\
\hline giros $\beta$ 1666-1673 $\mathrm{cm}^{-1}$ & & 1672 \\
\hline hoja plegada $\beta$ antiparalela $1675-1695 \mathrm{~cm}^{-1}$ & 1681,6 & 1682,2 \\
\hline
\end{tabular}

La mayor contribución en harina de ahipa corresponde al pico de $1653,8 \mathrm{~cm}^{-1}$ seguido por el de $1672 \mathrm{~cm}^{-1}$ asociados a la conformación de $\alpha$ hélice y giros $\beta$ respectivamente. Los giros- $\beta$ están definidos como regiones del polipéptido donde la cadena cambia de dirección, favoreciendo el plegamiento de la proteína (Marcelino y Gierasch, 2008). Con respecto al análisis por FTIR de otras harinas no tradicionales, Andrade-Mahecha y col. (2012) identificaron para harina de achira (Canna indica) una banda centrada en $1633 \mathrm{~cm}^{-1}$ mientras que Tapia-Blácido y col. (2007) informaron una banda en 1631$1634 \mathrm{~cm}^{-1}$ para películas a base de proteínas de harina de amaranto (Amaranthus cruentus). Harinas tradicionales como la de maíz (Zea maize) exhiben bandas características localizadas a 1635 y $1670 \mathrm{~cm}^{-1}$ (Gavicho Uarrotra y col., 2013)

Además, el pico localizado a $1733 \mathrm{~cm}^{-1}$ corresponde específicamente al estiramiento vibracional del enlace C-O de grupos acetilo (Demirgöz y col., 2000).

La banda extremadamente ancha que aparece con una intensidad máxima a $3440 \mathrm{~cm}^{-1}$ corresponde a la superposición de los modos vibracionales de estiramiento de los enlaces $\mathrm{O}-\mathrm{H}$ y $\mathrm{N}-\mathrm{H}$ de los grupos funcionales que participan en los enlaces de hidrógeno. Esta banda se atribuye al complejo vibracional de estiramiento asociado con grupos hidroxilos libres, e inter e intramolecularmente enlazados que forman 
parte de la estructura del almidón (Wu, 2003; Fang y col., 2002), los estiramientos de los $\mathrm{O}-\mathrm{H}$ del agua asociada al almidón y los correspondientes a los grupos $\mathrm{N}-\mathrm{H}$ de las proteínas presentes.

\subsection{Estabilidad de las harinas de ahipa y mandioca}

La actividad acuosa $\left(\mathrm{a}_{\mathrm{w}}\right)$ es un parámetro que indica la disponibilidad de agua en un alimento para que se produzcan reacciones químicas y bioquímicas (tales como oxidación de lípidos, reacciones enzimáticas, reacción de Maillard) y desarrollo microbiano (Gálvez y col., 2006). Por esto la actividad acuosa es un parámetro muy usado como indicador para predecir la vida útil de un alimento.

La isoterma de un producto relaciona gráficamente, a una temperatura constante, el contenido de humedad en equilibrio con la actividad termodinámica del agua del mismo, ya que en el equilibrio, este último parámetro es igual a la humedad relativa del aire que rodea al producto. Las isotermas son importantes para el análisis y diseño de varios procesos de transformación de alimentos, tales como secado, mezcla y envasado de los mismos. Además son útiles para predecir los cambios en la estabilidad de los alimentos y en la elección del material de empaque adecuado.

La Figura 4.16 muestra los valores experimentales del contenido de humedad de equilibrio en función de la actividad del agua $\left(a_{w}\right)$ a 10,20 y $30{ }^{\circ} \mathrm{C}$ para las harinas de ahipa y mandioca. Las desviaciones estándar para el contenido de humedad de equilibrio de cada punto experimental fueron inferiores a 0,001 ; las mismas no se incluyen en la figura para mayor claridad. 
Capítulo 4. Obtención y caracterización de harinas de Pachyrhizus ahipa y Manihot esculenta
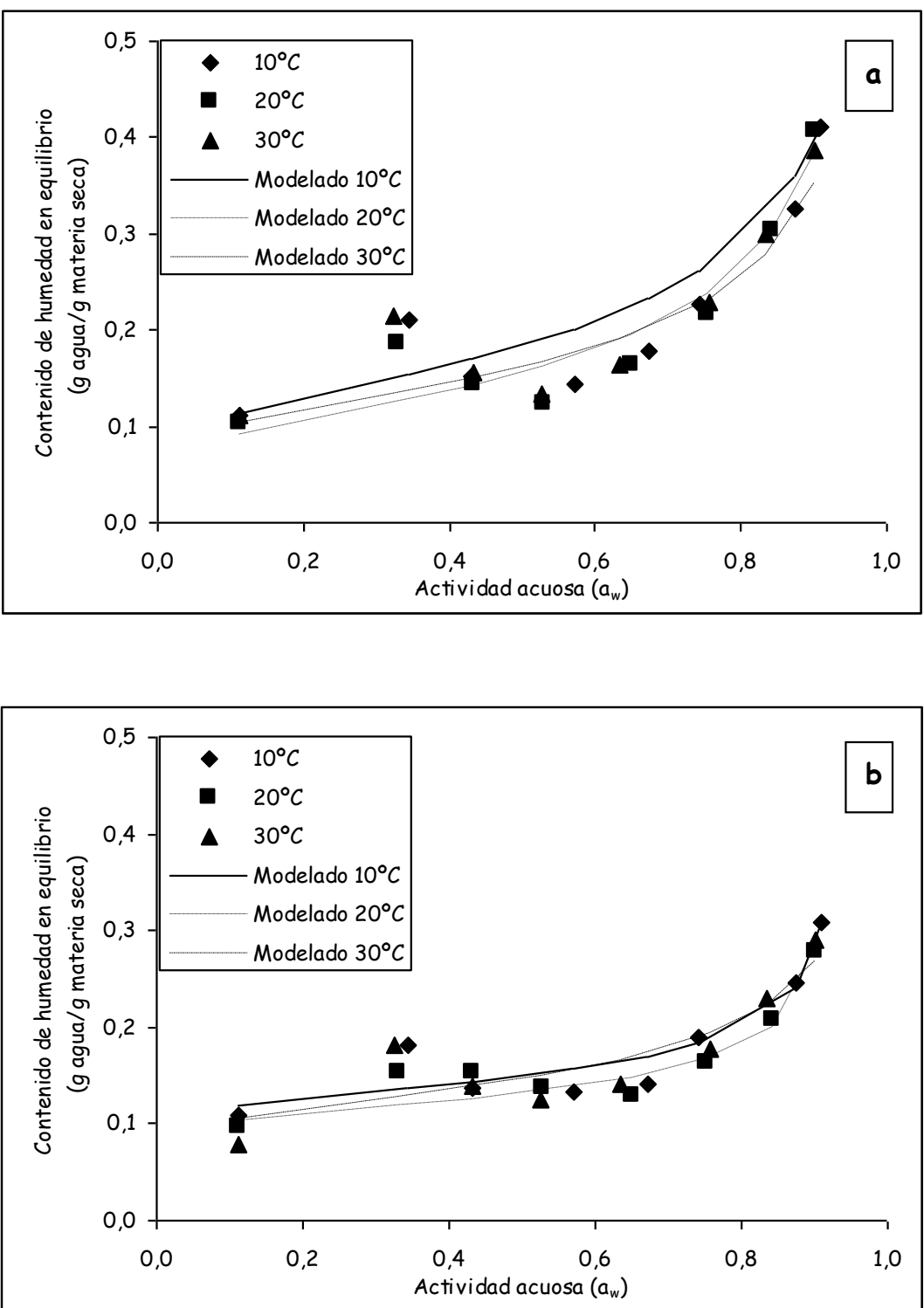

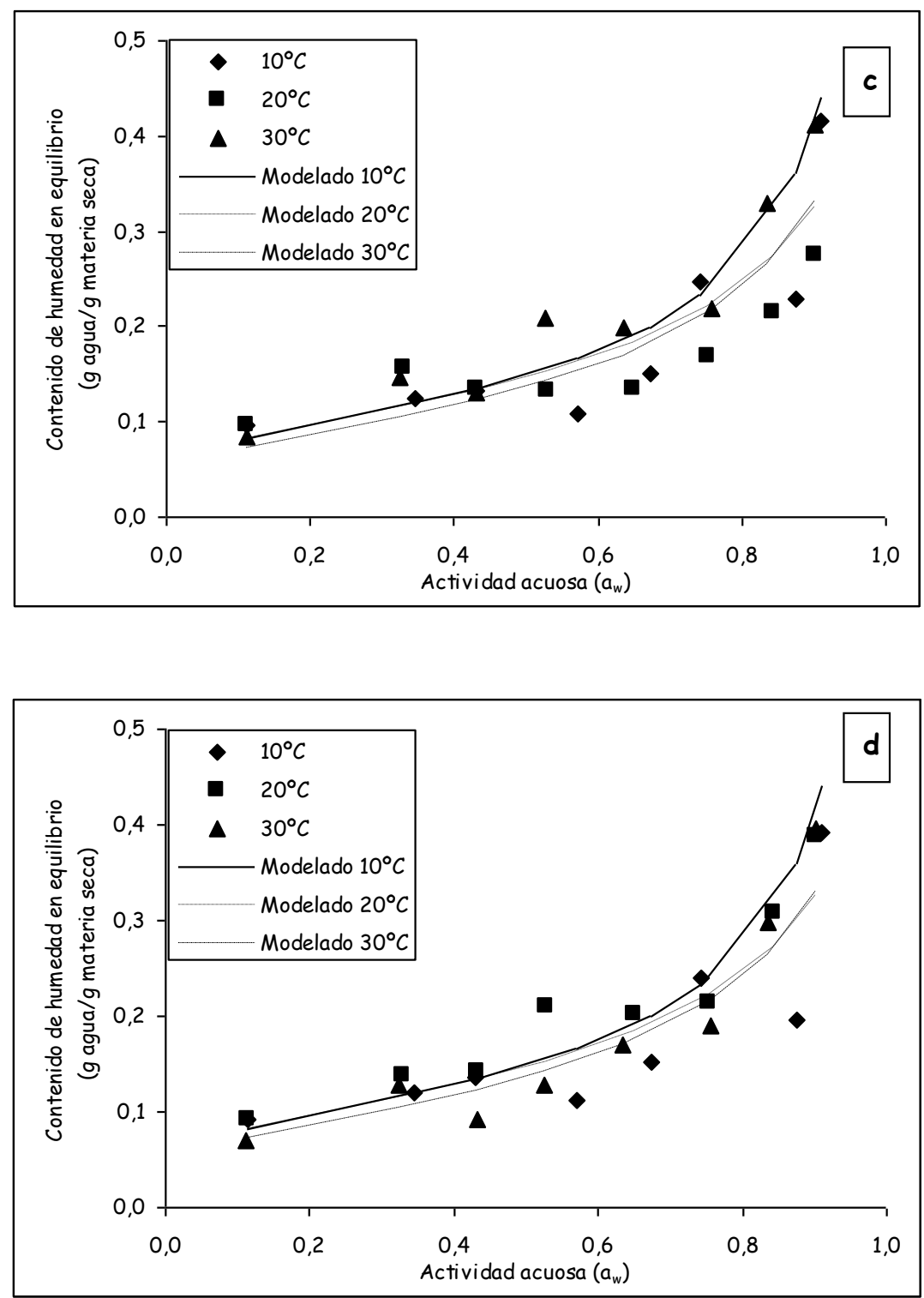

Figura 4.16. Isotermas de sorción de las harinas de Pachyrhizus ahipa obtenidas a) por rodaja, b) por rallado y prensado y de Manihot esculenta elaboradas c) por rodaja, d) por rallado. Los símbolos corresponden a los datos experimentales en tanto que las líneas señalan el ajuste del modelo de Chirife.

En las isotermas de sorción de las harinas de ahipa y mandioca (Figura 4.16) se observa, a temperatura constante, que el contenido de humedad de equilibrio aumenta a medida que aumenta el valor de $\mathrm{a}_{\mathrm{w}}$. Las isotermas de sorción de las harinas 
estudiadas presentaron una forma sigmoidea típica, correspondiendo a isotermas Tipo II, según la clasificación de BET. Resultados similares se describen para las isotermas de harina de papa (McMinn y Magee, 2003; Kaymak-Ertekin y Gedik, 2004), para la harina obtenida a partir de semillas de Araucaria angustifolia (Thys y col., 2010) y para almidones de diferente origen botánico (Al-Muhtaseb y col., 2004).

Además, se observó un entrecruzamiento de las curvas obtenidas a un valor de $a_{w}$ cercano a 0,70 para las muestras de harina de ahipa a 20 y $30^{\circ} \mathrm{C}$ (Figura 4.16 a y b). Resultados similares fueron informados por Perdomo y col., (2009); éste es un efecto común que se observa en los alimentos ricos en hidratos de carbono, tales como plátano, remolacha, pasas y malta cervecera entre otros (Barreiro y col., 2003; Perdomo y col., 2009).

De los modelos matemáticos utilizados, el de Chirife fue el que mejor ajustó los datos experimentales para las harinas de ahipa $\left(r^{2}>0,969\right)$ y mandioca $\left(r^{2}>0,959\right)$. CladeraOlivera y col., (2009) encontraron que este modelo fue también el más adecuado para describir las isotermas de sorción de harina de piñones de Araucaria angustifolia.

Las formas de las curvas de sorción y los valores experimentales obtenidos están de acuerdo con la respuesta de la mayoría de los materiales biológicos, en particular para alimentos en polvos (Fasina, 2006) lo que indica que a valores constantes de actividad acuosa, la cantidad de agua que tanto las harinas como los almidones (datos mostrados en el Capítulo 2) pueden mantener disminuye al aumentar la temperatura. Esto ocurre probablemente porque las moléculas de agua a bajas temperaturas tienen una energía cinética menor, que no es suficiente para superar la correspondiente energía de adsorción (Polatoğlu y col., 2011). Al mismo tiempo, las moléculas de agua interactúan con los componentes hidrofílicos del producto, tales como hidratos de carbono y proteínas. Esta interacción se produce a través de enlaces puente de hidrógeno, causando una reacción exotérmica, que no se ve favorecida con el aumento de temperatura. Para productos tales como harina de maíz, que es rica en carbohidratos y proteínas con grupos polares, Gálvez y col., (2006) han mencionado la disponibilidad de un alto número de centros activos de sorción.

Como ya se mencionó, los modelos de BET y de GAB son los más utilizados en ciencias de los alimentos debido a que sus parámetros tienen significado físico, ya que el calor 
de sorción y el contenido de humedad de la monocapa $\left(X_{m}\right)$, son indicativos de la estabilidad del producto. El modelo de GAB de tres parámetros, considerado uno de los más apropiados para describir las isotermas de adsorción de los productos alimenticios, se aplica a lo largo de todo el rango de $\mathrm{a}_{\mathrm{w}}$. La Tabla 4.8 presenta los parámetros y coeficientes de correlación obtenidos ajustando los datos experimentales con el modelo de GAB para harinas de ahipa y mandioca.

Tabla 4.8. Parámetros de ajuste del modelo de GAB para las isotermas de sorción de las harinas de Pachyrhizus ahipa (ahipa) y Manihot esculenta (mandioca).

\begin{tabular}{cccccc} 
Temperatura $\left({ }^{\circ} \mathrm{C}\right)$ & Parámetros de GAB & HARo & HARaP & HMRo & HMRa \\
\hline \multirow{3}{*}{10} & $\mathrm{X}_{\mathrm{m}}$ & 0,088 & 0,092 & 0,084 & 0,095 \\
& $\mathrm{~K}$ & 0,887 & 0,738 & 0,767 & 0,647 \\
& $\mathrm{C}$ & 9,368 & 13,758 & 2,711 & 2,731 \\
& $\mathrm{R}^{2}$ & 0,982 & 0,977 & 0,974 & 0,970 \\
\hline \multirow{3}{*}{20} & $\mathrm{X}_{\mathrm{m}}$ & 0,072 & 0,078 & 0,082 & 0,082 \\
& $\mathrm{~K}$ & 0,917 & 0,770 & 0,862 & 0,840 \\
& $\mathrm{C}$ & 2,727 & 11,058 & 1,810 & 2,376 \\
& $\mathrm{R}^{2}$ & 0,977 & 0,975 & 0,966 & 0,967 \\
\hline \multirow{3}{*}{30} & $\mathrm{X}_{\mathrm{m}}$ & 0,066 & 0,063 & 0,079 & 0,068 \\
& $\mathrm{~K}$ & 0,936 & 0,899 & 0,897 & 0,908 \\
& $\mathrm{C}$ & 6,343 & 9,779 & 0,755 & 0,253 \\
& $\mathrm{R}^{2}$ & 0,979 & 0,969 & 0,959 & 0,985
\end{tabular}

Nota: $\mathrm{X}_{\mathrm{m}}$, contenido de agua de la monocapa ( $\mathrm{g}$ de agua/ $\mathrm{g}$ de sólido seco); $\mathrm{K}$ y $\mathrm{C}$ (valores $\times 10^{14}$ ) son parámetros estimados de la ecuación de GAB y $R^{2}$ es el coeficiente de correlación. Nomenclatura: HARo: harina de ahipa obtenida por rodajas; HARaP: harina de ahipa obtenida por rallado y prensado; HMRo: harina de mandioca obtenida por rodajas; HMRa: harina de mandioca obtenida por rallado.

Los valores estimados del contenido de agua de la monocapa $\left(X_{m}\right)$ fueron, en general, menores en las harinas obtenidas a partir de rodajas (Tabla 4.8).

Sin embargo, independientemente del procedimiento de obtención de las harinas, los valores de $X_{m}$ de ambos productos son indicativos de una estabilidad aceptable para 
los mismos en el rango de valores de humedad relativa analizado. Según Labuza (1984), el máximo contenido de humedad de la monocapa para alimentos corresponde al 10\% (base seca); superando este valor, la estabilidad del producto frente a la humedad se ve comprometida. Aunque no hay referencias disponibles sobre harina de ahipa, los valores de $X_{m}$ encontrados fueron superiores a los de la harina de piñón, que estuvieron comprendidos entre 0,05 y 0,07 g de agua/g de sólidos secos (CladeraOlivera y col., 2009).

Las isotermas de sorción permitieron evaluar el contenido de humedad que garantiza la estabilidad de las harinas y almidones bajo diferentes condiciones de almacenamiento. La Tabla 4.8 también muestra la tendencia de $X_{m}$ a disminuir con el aumento de temperatura para las harinas de ahipa y mandioca. Este fenómeno puede atribuirse a la reducción de la disponibilidad de sitios activos para la adsorción de agua, teniendo en cuenta que el contenido de almidón (uno de los principales componentes hidrófilos) es menor en la harina de ahipa que en la de mandioca (Charoenkul y col., 2011; Doporto y col., 2011).

\subsection{Parámetros termodinámicos obtenidos a partir de las isotermas de sorción}

A partir del modelo de $G A B$, se pueden estimar diferentes parámetros termodinámicos. Las Figuras 4.17 y 4.18 muestran la variación del calor isostérico (entalpía diferencial) y la entropía diferencial en función del contenido de humedad de la harina de ahipa obtenida a partir de rodajas (HARo) y la correlación entre estos parámetros se presenta en la Figura 4.19. Esta correlación permite la estimación de la variación de energía libre de Gibbs $(\Delta G)$, así como la temperatura isocinética en la que todas las reacciones de sorción se llevarán a cabo en la misma proporción. $\Delta G$ es una medida del trabajo realizado por el sistema para llevar a cabo un proceso de adsorción o desorción. $\Delta \mathrm{G}$ se puede utilizar como indicador del estado de agua adsorbida por las partículas sólidas, lo que determina la estabilidad física, química y microbiana de los materiales biológicos durante el almacenamiento (Aviara y Ajibola, 2002).

Las Figuras 4.17 y 4.18 muestran que tanto la entalpía y la entropía diferencial disminuyeron exponencialmente con el aumento del contenido de humedad, con una fuerte dependencia a bajos contenidos de humedad. Este comportamiento se puede 
atribuir a la ubicación del agua ligada o estructural y al grado en que la interacción sólido-agua es mayor que la interacción de las moléculas de agua entre sí (Fasina, 2006; McMinn y Magee, 2003; Thys y col., 2010). Por lo tanto, a bajos contenidos de humedad, la energía requerida para la sorción de las moléculas de agua será mayor, ya que los sitios disponibles en la matriz sólida están fuertemente limitados.

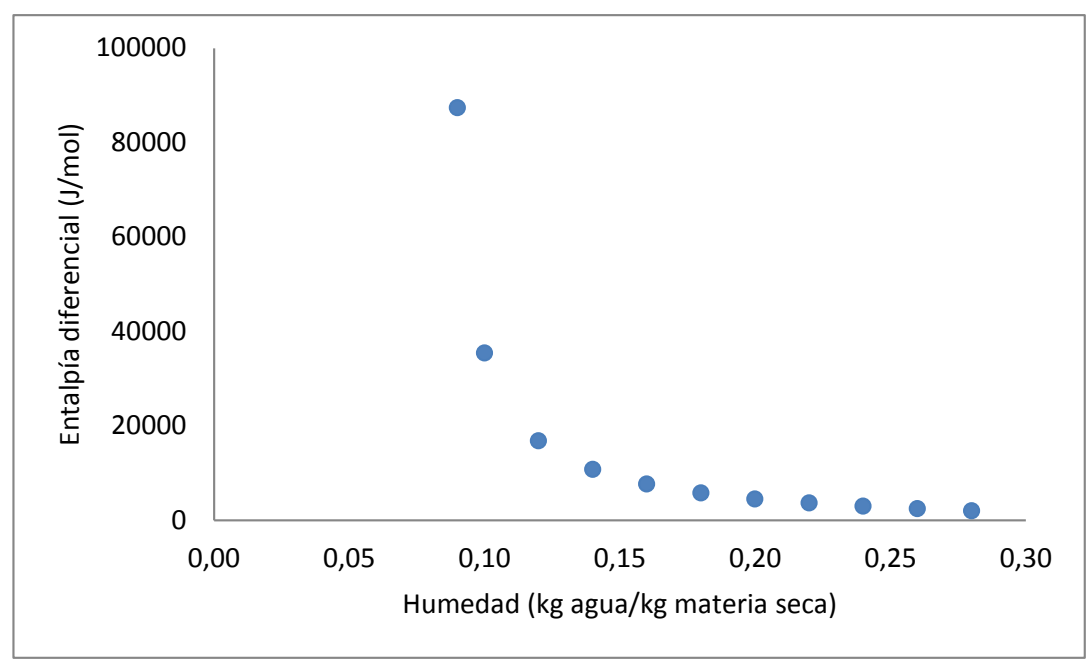

Figura 4.17. Entalpía diferencial de adsorción de la harina de Pachyrhizus ahipa (ahipa) elaborada a partir de rodajas (HARo) en función del contenido de humedad.

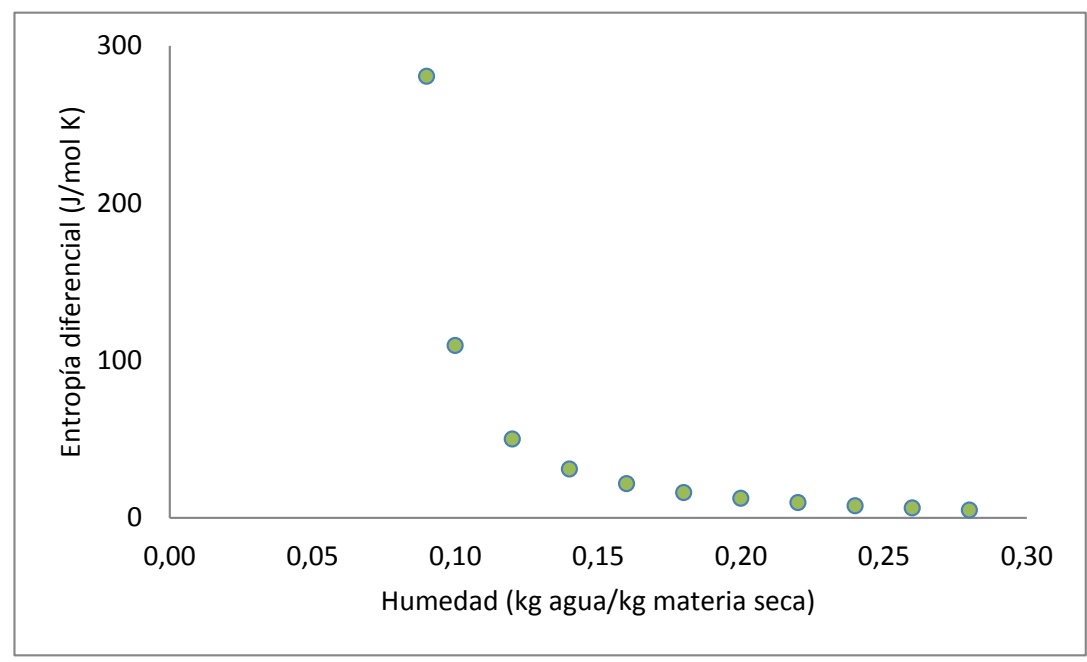

Figura 4.18. Entropía diferencial de adsorción de la harina de Pachyrhizus ahipa (ahipa) obtenida por rodajas (HARo) en función del contenido de humedad. 
La Figura 4.19 muestra que la entalpía diferencial varía linealmente con la entropía diferencial (con un coeficiente de regresión superior a 0,999 en todos los casos), lo que indica que la teoría de la compensación es aplicable en los sistemas analizados. Los valores obtenidos se resumen en la Tabla 4.9 para las harinas estudiadas.

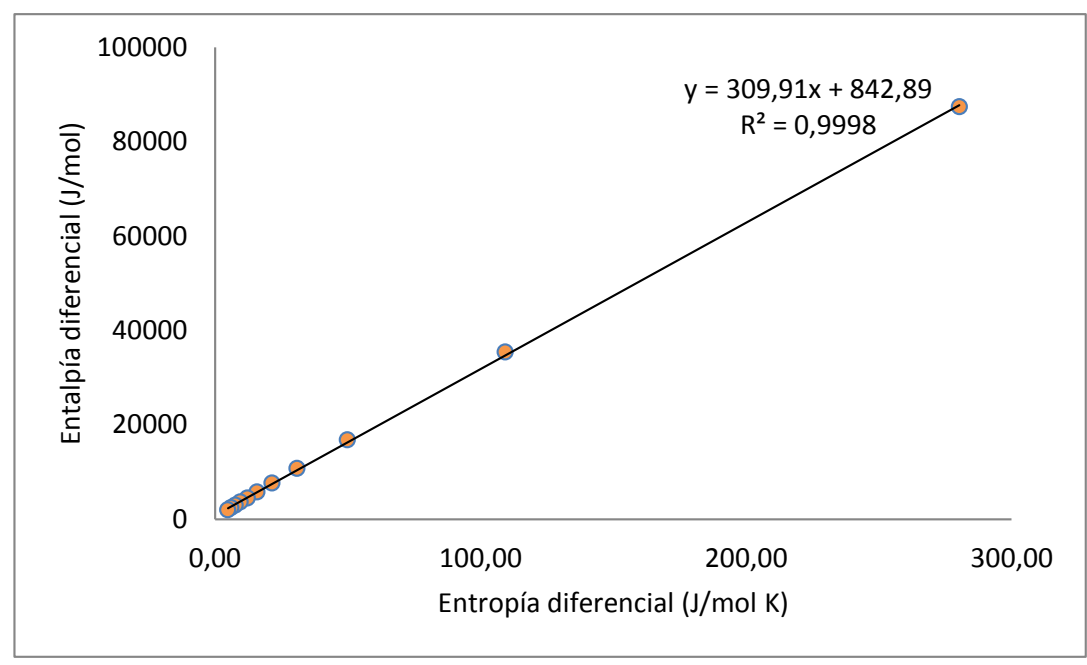

Figura 4.19. Entropía diferencial versus entalpía diferencial de la harina de Pachyrhizus ahipa (ahipa) procesada a partir de rodajas (HARo). Teoría de la compensación.

En general, la temperatura isocinética, así como el $\Delta G$ calculado para muestras de harina de mandioca fueron más altos que los de ahipa. Con respecto a la harina de ambas raíces tuberosas, el procedimiento de obtención afectó los valores de los parámetros termodinámicos, siendo los de las harinas obtenidas a partir de rodajas más altos que los correspondientes a las elaboradas mediante el proceso de rallado y prensado (Tabla 4.9). 
Tabla 4.9. Parámetros termodinámicos calculados para las harinas de Pachyrhizus ahipa (ahipa) y Manihot esculenta (mandioca).

\begin{tabular}{|c|c|c|c|c|}
\hline Parámetro termodinámico & HARo & HARaP & HMRo & HMRa \\
\hline Temperatura isocinética (K) & 309,9 & 305,6 & 389 & 310,3 \\
\hline Energía libre de Gibbs (J/mol) & 842,8 & 1009 & 2977 & 1504 \\
\hline
\end{tabular}

Nomenclatura: HARo: harina de ahipa obtenida por rodajas; HARaP: harina de ahipa obtenida por rallado y prensado; HMRo: harina de mandioca obtenida por rodajas; HMRa: harina de mandioca obtenida por rallado.

Además, tanto los almidones de ahipa como los de mandioca (Capítulo 2) presentaron menor $\Delta \mathrm{G}$ y temperatura isocinética que sus correspondientes harinas.

Una tendencia similar observaron Thys y col., (2010) para la temperatura isocinética del almidón de piñón (pinhao) (428 K), y Cladera-Olivera y col., (2009) para su correspondiente harina (398 K). Del mismo modo, en el caso de la batata, Fasina (2006) ha destacado que la teoría de la compensación de entalpía-entropía se cumple con una temperatura isocinética de 407,9 K. Los valores de temperatura isocinética obtenidos estuvieron dentro del rango de los informados para los granos de quinoa (361 K; Tolaba y col., 2004), el ajo (348 K; Madamba y col., 1996), harina y copos de avena (430,9 y 443,4, respectivamente; McMinn y col., 2007), y sucuk $(323,4 \mathrm{~K}$; Polatoğlu y col., 2011). Cladera-Olivera y col., (2009) han señalado que la adsorción de agua de la harina de pinhao es un proceso no-espontáneo con un valor de $\Delta \mathrm{G}$ de $339 \mathrm{~J}$ $\mathrm{mol}^{-1}$, siendo este valor menor que los encontrados para harinas de ahipa y de mandioca en el presente trabajo de Tesis. Además, teniendo en cuenta otros productos a base de almidón, McMinn y col., (2007) informaron valores de $\Delta \mathrm{G}$ de 280 y $325 \mathrm{~J} \mathrm{~mol}^{-1}$ para galletas de harina de avena y copos de avena, respectivamente.

\section{Propiedades funcionales}

\subsection{Determinación de la capacidad de retención de agua de las harinas de ahipa y mandioca}

Aunque la capacidad de retener agua y el poder de hinchamiento están relacionados, la primera de estas propiedades (determinada a temperatura ambiente) da 
información sobre las propiedades físicas que influyen en el comportamiento de la muestra.

Los valores de capacidad de retención de agua de la harina de ahipa $(191 \pm 0,8 \%$ y $132 \pm 0,6 \%$ para HARo y HARaP, respectivamente) fueron significativamente mayores $(p<0,05)$ que los valores encontrados para ambas muestras de harina de mandioca

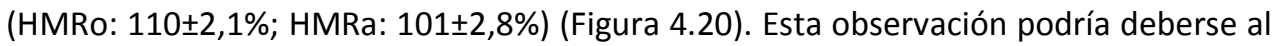
mayor contenido de proteína en la harina de ahipa que puede contribuir eficazmente a incrementar la capacidad de retención de agua.

El procedimiento de obtención afectó significativamente $(p<0,05)$ la capacidad de retención de agua de las harinas de ahipa y de mandioca: productos procedentes del procesamiento por corte en rodajas tuvieron valores significativamente más altos $(p<0,05)$ de capacidad de retención de agua que los productos obtenidos por rallado y prensado.

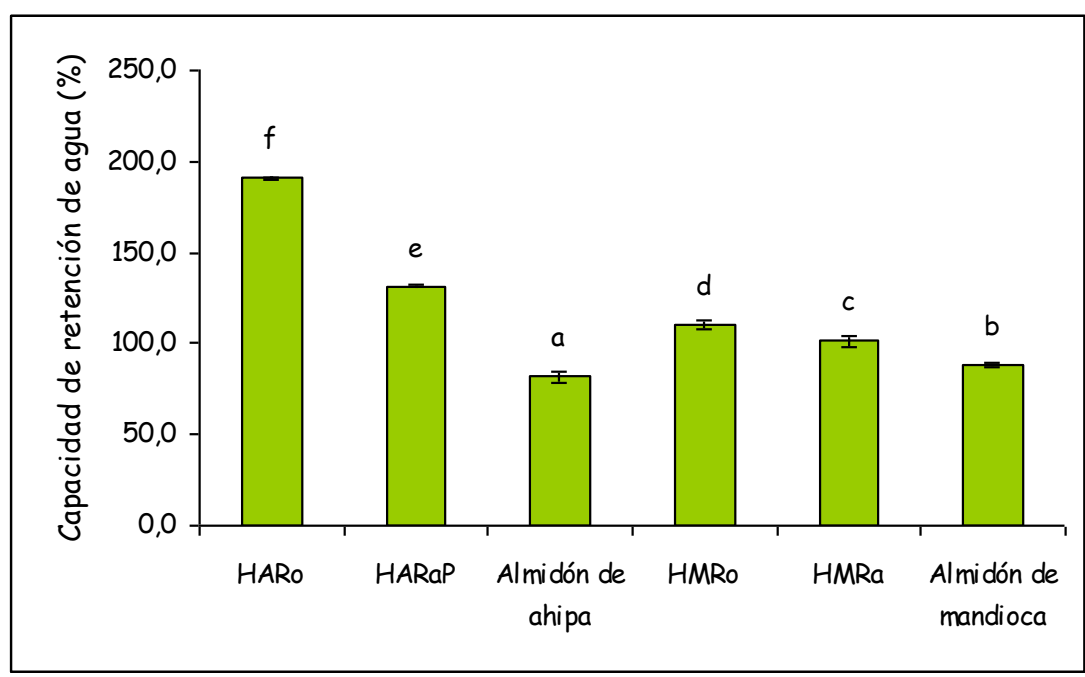

Figura 4.20. Capacidad de retención de agua en harinas y almidón de Pachyrhizus ahipa (ahipa) y Manihot esculenta (mandioca).

Nota: Letras diferentes en cada columna indican diferencias significativas $(p<0,05)$. Nomenclatura: HARaP: harina de ahipa obtenida por rallado y prensado, HARo: harina de ahipa obtenida por rodajas, HMRa: harina de mandioca obtenida por rallado, HMRo: harina de mandioca obtenida por rodajas. 
Los resultados indicaron que tanto las harinas como los almidones de ahipa y de mandioca mostraron valores relativamente bajos de capacidad de retención de agua en comparación con otros ingredientes o aditivos alimentarios, tales como fibras dietéticas de salvado de avena (2,10 g de agua/g de materia seca), salvado de arroz (4,89 g de agua/g de materia seca), harina de soja (4,79 a 6,75 g de agua/g de materia seca) y salvado de trigo (5,03 g de agua/g de materia seca) (Abdul-Hamid y Luan, 2000; Chen, 1988; Heywood y col., 2002). Del mismo modo, los valores hallados en las muestras de ahipa y de mandioca fueron inferiores a los indicados por Aziz y col. (2011) para harina obtenida a partir de plátano tratado con vapor o hervido $(10,66$ y $18,28 \mathrm{~g}$ de agua/g de materia seca, respectivamente).

\subsection{Transiciones térmicas de las harinas}

Las propiedades térmicas de las harinas se evaluaron por calorimetría diferencial de barrido. El análisis térmico permite identificar en la harina, un producto compuesto mayoritariamente por almidón, las transiciones y modificaciones de la estructura del gránulo e identificar los cambios asociados a la desnaturalización de las proteínas presentes como consecuencia de tratamientos combinados de humedad y calor.

La Figura 4.21 compara el comportamiento térmico de las raíces parcialmente deshidratadas con la harina derivada de ahipa Local; una tendencia similar se observó en todas las harinas analizadas. 


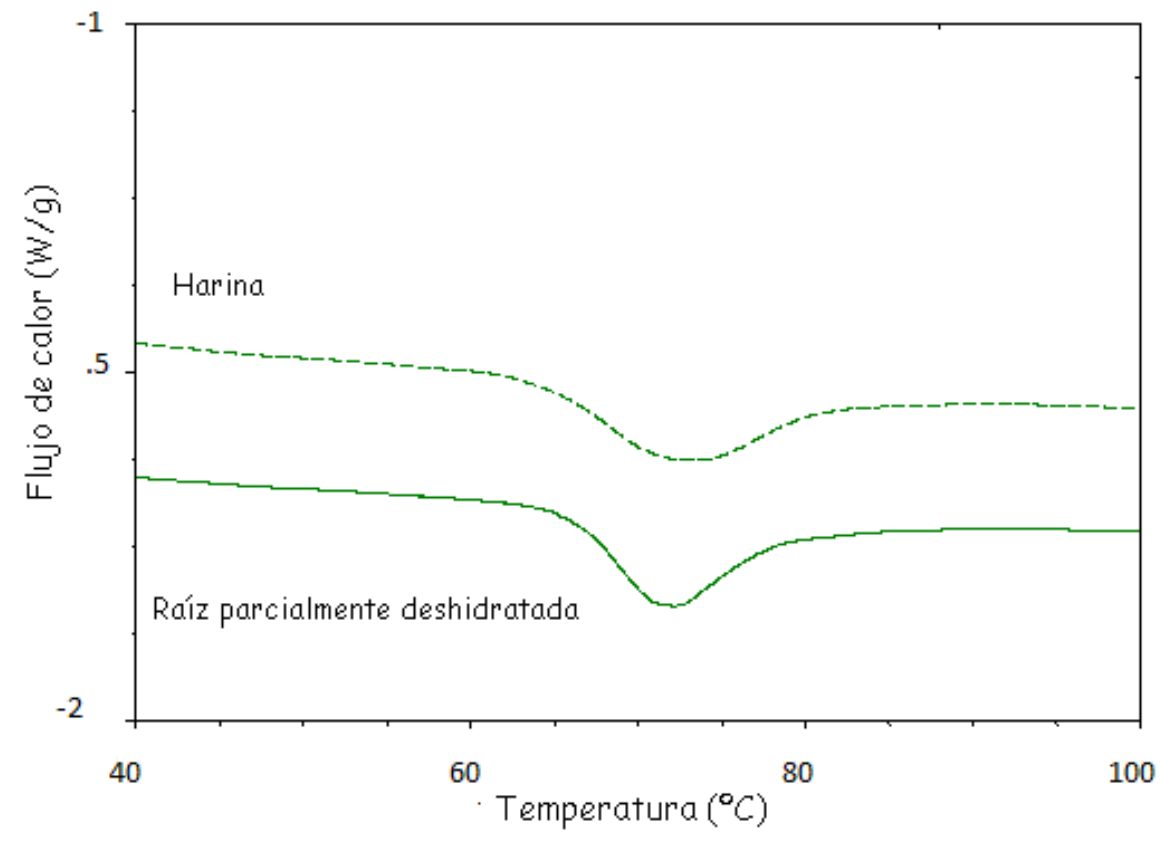

Figura 4.21 Termogramas correspondientes a la raíz parcialmente deshidratada de Pachyrhizus ahipa (ahipa) de la accesión Local y su harina (HARo).

En la Tabla 4.10 se muestra la comparación de los parámetros térmicos obtenidos para las raíces (presentados en el Capítulo 1), el almidón (analizados en el Capítulo 2) y la harina correspondiente.

Tabla 4.10. Parámetros térmicos de la raíz, harina y almidón de Pachyrhizus ahipa accesión Local.

\begin{tabular}{|c|c|c|c|}
\hline Muestra & $\begin{array}{c}\text { Temperatura de } \\
\text { inicio }\left({ }^{\circ} \mathrm{C}\right)\end{array}$ & $\begin{array}{c}\text { Temperatura de } \\
\text { pico }\left({ }^{\circ} \mathrm{C}\right)\end{array}$ & Entalpía $(\mathrm{J} / \mathrm{g})$ \\
\hline $\begin{array}{c}\text { Raíz parcialmente } \\
\text { deshidratada }\end{array}$ & $66,1 \pm 0,1^{\mathrm{b}}$ & $71,3 \pm 0,4^{\mathrm{b}}$ & $24,7 \pm 2,9^{\mathrm{b}}$ \\
\hline Harina de ahipa & $64,5 \pm 0,1^{\mathrm{a}}$ & $72,0 \pm 0,3^{\mathrm{b}}$ & $8,2 \pm 0,6^{\mathrm{a}}$ \\
\hline Almidón de ahipa & $64,3 \pm 0,2^{\mathrm{a}}$ & $67,2 \pm 0,1^{\mathrm{a}}$ & $9,6 \pm 0,6^{\mathrm{a}}$ \\
\hline
\end{tabular}

Nota: Los valores informados corresponden a las medias \pm las desviaciones estándar. La entalpía se encuentra expresada en base seca. Letras diferentes en cada columna indican diferencias significativas $(p<0,05)$. 
La temperatura de pico correspondiente a la harina fue más alta que la del almidón correspondiente (Tabla 4.10). Una tendencia similar se observó en otros trabajos realizados en mandioca y ahipa (Aboubakar y col., 2008; Doporto y col., 2011 y 2012; López y col., 2010).

Los termogramas (Figura 4.22) obtenidos por DSC mostraron un pico endotérmico asociado principalmente a la gelatinización del almidón presente en la harina. La harina de ahipa procesada en rodajas gelatinizó a una menor temperatura $(73,1 \pm 0,9$ ${ }^{\circ} \mathrm{C}$ ) que la de mandioca $\left(75,7 \pm 0,9^{\circ} \mathrm{C}\right)$, indicando una mayor aptitud para la cocción.

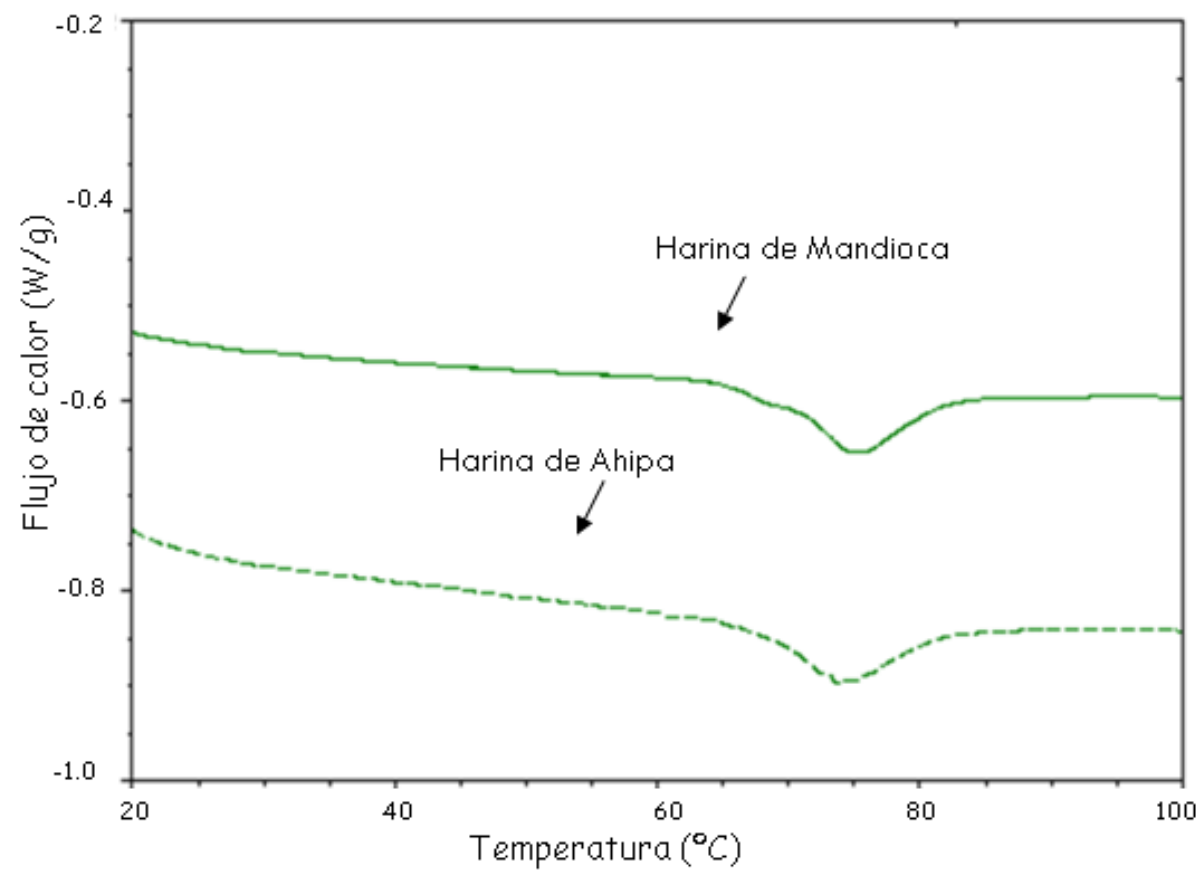

Figura 4.22. Termogramas de las harinas de Pachyrhizus ahipa (ahipa) y Manihot esculenta (mandioca) obtenidas por rodajas.

En la Tabla 4.11 se informan los valores de las propiedades térmicas medidas en harina de ahipa y mandioca obtenidas mediante un procesamiento similar. 
Tabla 4.11. Parámetros térmicos de las harinas de Pachyrhizus ahipa (ahipa) y de Manihot esculenta (mandioca).

\begin{tabular}{|c|c|c|c|}
\hline Harina & $\begin{array}{c}\text { Temperatura de } \\
\text { inicio }\left({ }^{\circ} \mathrm{C}\right)\end{array}$ & $\begin{array}{c}\text { Temperatura de } \\
\text { pico }\left({ }^{\circ} \mathrm{C}\right)\end{array}$ & Entalpía (J/g) \\
\hline $\begin{array}{c}\text { Ahipa Rallada } \\
\text { Prensada }\end{array}$ & $64,3 \pm 1,2^{\mathrm{a}}$ & $71,3 \pm 0,8^{\mathrm{a}}$ & $9,4 \pm 0,5^{\mathrm{a}}$ \\
\hline Ahipa Rodaja & $64,5 \pm 0,1^{\mathrm{a}}$ & $72,0 \pm 0,3^{\mathrm{a}}$ & $8,2 \pm 0,6^{\mathrm{a}}$ \\
\hline Mandioca Rallada & $67,1 \pm 0,2^{\mathrm{a}, \mathrm{b}}$ & $74,0 \pm 0,6^{\mathrm{a}, \mathrm{b}}$ & $11,4 \pm 2,3^{\mathrm{a}}$ \\
\hline Mandioca Rodaja & $70,1 \pm 0,8^{\mathrm{b}}$ & $75,7 \pm 0,9^{\mathrm{b}}$ & $10,5 \pm 0,9^{\mathrm{a}}$ \\
\hline
\end{tabular}

Nota: Los valores informados corresponden a las medias \pm las desviaciones estándar. La entalpía se encuentra expresada en base seca. Letras diferentes en cada columna indican diferencias significativas $(p<0,05)$.

Con respecto a otras harinas de diferentes orígenes botánicos, las de ahipa y mandioca presentaron temperaturas de pico mayores que la harina de taro, la cual varía entre $55,6-68,7^{\circ} \mathrm{C}$ (Aboubakar y col., 2008) y comparables a la de plátano verde (Tribess y col., 2009). Sin embargo, el análisis de las propiedades térmicas indicaría que tanto la harina de ahipa como la de mandioca tienen una adecuada aptitud para el proceso de cocción, relacionada con sus correspondientes temperaturas de gelatinización (temperatura de pico).

Se observó además que las harinas obtenidas a partir de rodajas presentaron valores de temperatura de gelatinización más altos que las obtenidas por el proceso de rallado, siendo estadísticamente significativa la diferencia $(p<0,05)$ en el caso de ahipa (Tabla 4.11).

En general, las temperaturas de gelatinización de las harinas de ahipa y mandioca fueron más altas que las de sus almidones. Esta tendencia también fue señalada por Jane y col. (1992) para harinas y almidones de diferentes orígenes botánicos. La diferencia mencionada fue mayor para las harinas obtenidas por cortado de la raíz en rodajas que las procesadas por rallado (aproximadamente 6 y $4{ }^{\circ} \mathrm{C}$, respectivamente). Los valores de temperatura de inicio, temperatura de gelatinización (temperatura de pico) y entalpía encontrados para la harina de mandioca fueron consistentes con los 
indicados por Charoenkul y col., (2011), en particular para las variedades de mandioca clasificadas por estos autores como pertenecientes al grupo "harinosas y firmes", según el tipo de textura de las raíces cocidas.

\subsection{Capacidad de hinchamiento de la harina de ahipa}

El poder de hinchamiento se relaciona con la capacidad que poseen tanto el almidón como las proteínas de absorber agua. Esta medida, determinada a diferentes temperaturas de calentamiento, es uno de los parámetros indicativos utilizados para estudiar el proceso de gelatinización. Los valores del poder de hinchamiento de las diferentes harinas de ahipa se obtuvieron a las siguientes temperaturas: $55,65,75,85$, 90 y $95^{\circ} \mathrm{C}$.

Hasta los $75^{\circ} \mathrm{C}$ (cerca de la temperatura de gelatinización), no se evidenciaron diferencias significativas $(p>0,05)$ en la capacidad de hinchamiento entre las harinas obtenidas por diferentes métodos de procesamiento (Figura 4.23). Una tendencia similar fue señalada por Aboubakar y col., (2008), trabajando en harinas y almidones de taro. Agunbiade y Longe (1999) también informaron que los almidones y harinas de diferentes fuentes exhibían un patrón de hinchamiento relativamente lento a bajas temperaturas. Cuando se alcanzó la temperatura de gelatinización, los gránulos de almidón se hincharon, aumentando varias veces su tamaño original debido a la hidratación. En cambio a temperaturas más altas, el poder de hinchamiento de la harina de ahipa, obtenida por rallado y prensado, fue mayor que la obtenida por el procedimiento de corte (rodajas). 


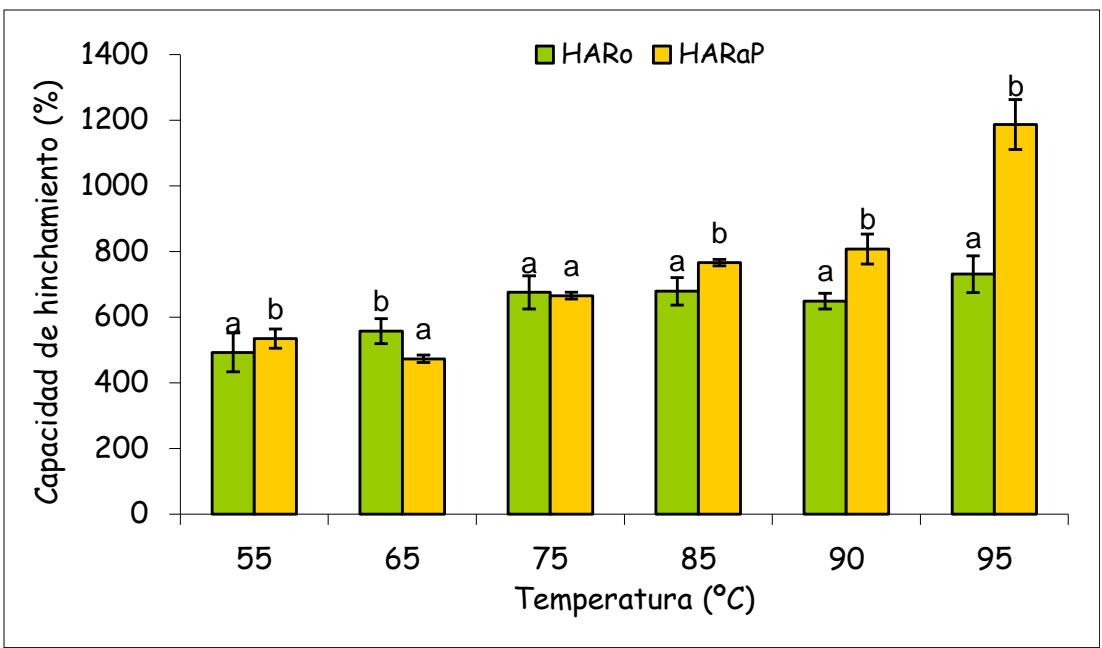

Figura 4.23. Capacidad o poder de hinchamiento (g harina hidratada/100 g muestra) de la harina de Pachyrhizus ahipa (ahipa) en función de la temperatura $\left({ }^{\circ} \mathrm{C}\right)$. Nomenclatura: HARo: harina de ahipa obtenida por rodajas; HARaP: harina de ahipa obtenida por rallado y prensado.

El hinchamiento se encuentra acompañado por la solubilización de los componentes de los gránulos de almidón. Nuevamente, a temperaturas inferiores a la de gelatinización, la cantidad de amilosa y amilopectina lixiviadas de los gránulos fue insignificante (Figura 4.23). A temperaturas más altas, la lixiviación cobró relevancia y las concentraciones de ambos componentes en el sobrenadante aumentaron con la temperatura. Este efecto se observa en la Figura 4.24, que muestra las concentraciones de amilosa y amilopectina lixiviadas a partir de los gránulos de almidón de la harina (rallada y prensada) durante el calentamiento a $95^{\circ} \mathrm{C}$. Los resultados obtenidos en harinas correlacionaron con los encontrados en almidones, tal como fueron descriptos en el Capítulo 2. 


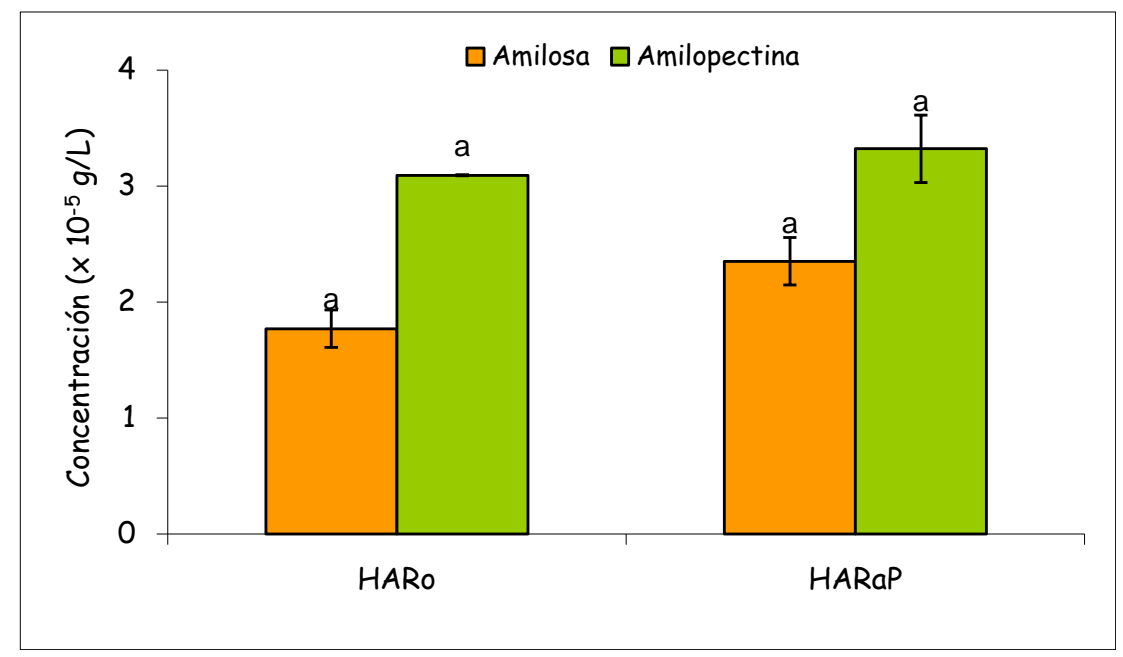

Figura 4.24. Concentración de amilosa y amilopectina lixiviada a partir de muestras de harina de Pachyrhizus ahipa durante el calentamiento a $95^{\circ} \mathrm{C}$.

Nomenclatura: HARo: harina de ahipa obtenida por rodajas; HARaP: harina de ahipa obtenida por rallado y prensado.

El procedimiento de obtención de la harina de ahipa no afectó significativamente $(p>0,05)$ ni a la concentración de amilosa ni de amilopectina lixiviada $\left(a 5^{\circ} \mathrm{C}\right)$ (Figura 4.24).

\subsection{Capacidad de retención de solventes}

Las pruebas de capacidad de retención de solventes (CRS) se usan comúnmente para establecer la calidad de la harina y el perfil de funcionalidad práctica que es útil para la predicción de su rendimiento en aplicaciones específicas, como por ejemplo en la formulación de productos horneados.

Por lo tanto, se llevaron a cabo estos ensayos en muestras de raíces parcialmente deshidratadas y en harina de ahipa. Los resultados mostraron que la CRS de las raíces de ahipa parcialmente deshidratadas fue más alta que para la harina correspondiente. La comparación se muestra en la Figura 4.25 para la ahipa Local como ejemplo. Dado que las muestras parcialmente deshidratadas contienen lo que comúnmente se denomina "cáscara" de la raíz, que contribuye al contenido de fibra dietaria total, la capacidad de retención de agua (CRA) fue significativamente mayor $(p<0,05)$ que para 
la harina correspondiente. Una tendencia similar se observó para la capacidad de retención de carbonato de sodio (CRCS), lo que indica un contenido de almidón dañado más bajo en la harina. La capacidad de retención de sacarosa (CRSA), se encuentra asociada al contenido de pentosanos solubles en agua. A todos los polisacáridos no almidonosos presentes en la harina se los denomina en forma genérica como pentosanos (arabinoxilanos y arabinogalactanos), ya que el $80 \%$ de los azúcares que los componen son pentosas: D-xilosa y D-arabinosa. Se los clasifica en base a su solubilidad en agua como pentosanos solubles e insolubles en agua, encontrándose en una relación 25:75 (Meuser y Suckow, 1986). El aumento en la capacidad de retención de sacarosa (CRSA) en las raíces parcialmente deshidratadas sugeriría una mayor proporción de componentes relacionados con la fibra dietaria soluble, lo que indica que la harina de ahipa presentaría un contenido mayor de fibra insoluble (Figura 4.25).

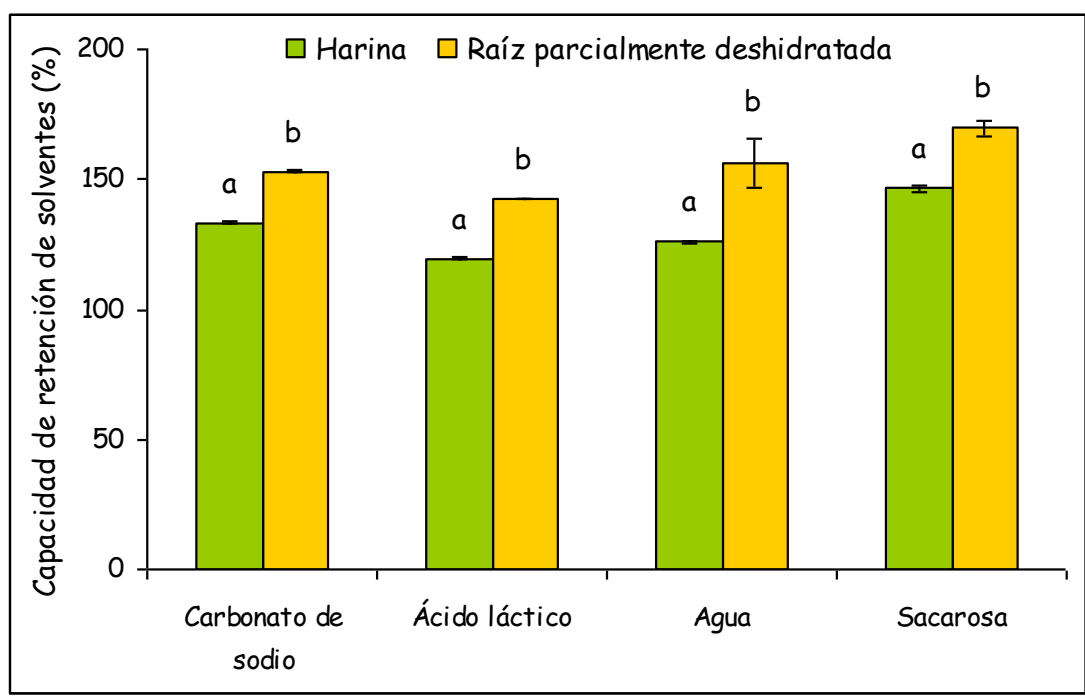

Figura 4.25. Capacidad de retención de solventes de raíces parcialmente deshidratadas y harina de Pachyrhizus ahipa (HARo) correspondientes a la accesión Local.

Nota: Letras diferentes en cada columna indican diferencias significativas $(p<0,05)$.

La Figura 4.26 muestra la capacidad de retención de solventes (CRS) de las harinas de ahipa y mandioca obtenidas por rodajas. 


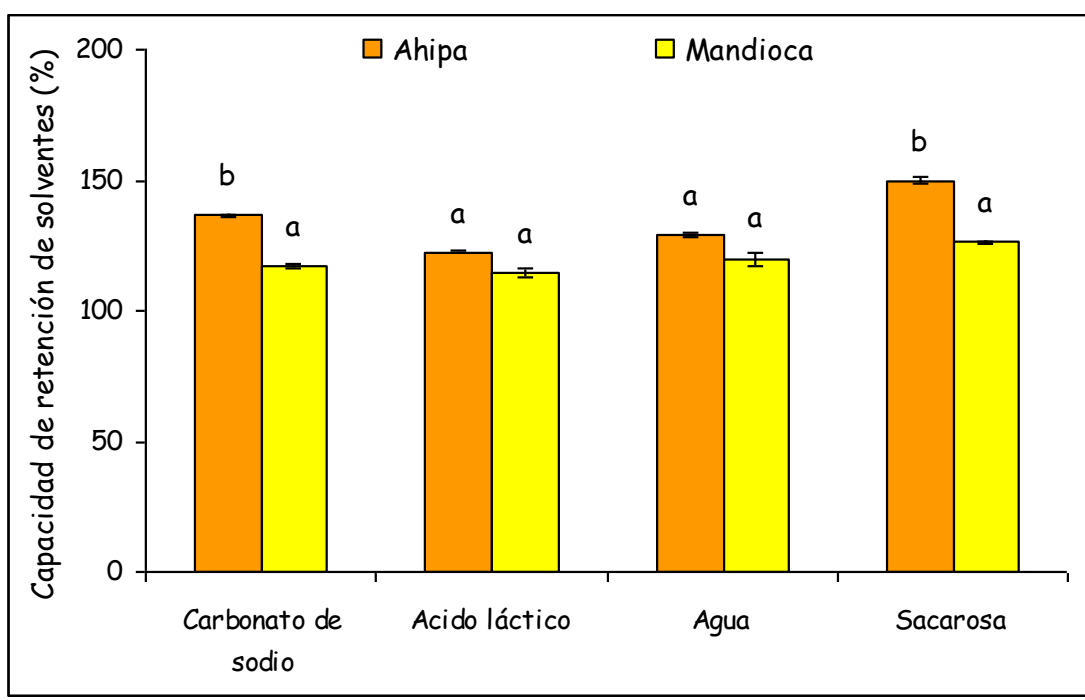

Figura 4.26. Capacidad de retención de solventes de harina de Pachyrhizus ahipa (ahipa) y de Manihot esculenta (mandioca) obtenidas por rodajas. Nota: Letras diferentes en cada columna indican diferencias significativas $(p<0,05)$.

Se cree que la capacidad de retención del carbonato de sodio (CRCS) está relacionada con el contenido de almidón dañado de la harina, (Gaines, 2000; Duyvejonck y col., 2011; Dini y col., 2013).

En general, la capacidad de retención de ácido láctico (CRAL) se asocia con la formación de la red de glutenina y la fuerza del gluten de la harina, (Duyvejonck y col., 2011; Dini y col., 2013). Tanto la harina de ahipa como la de mandioca son productos libres de gluten, y la CRAL puede estar asociada a la capacidad de las proteínas presentes para desarrollar una red, lo que constituye un indicativo de las aplicaciones tecnológicas de estos ingredientes.

Se observó que no hubo diferencias significativas $(p>0,05)$ en la capacidad de retención de agua (CRA) de las muestras. La harina de mandioca contendría una mayor proporción de fibra insoluble respecto de la harina de ahipa (Figura 4.26) por su menor capacidad de retención de sacarosa (CRS). 
Capítulo 4. Obtención y caracterización de harinas de Pachyrhizus ahipa y Manihot esculenta

\section{CONCLUSIONES}

Las harinas de ahipa y mandioca pueden obtenerse a través de procedimientos relativamente simples, tales como las alternativas analizadas en el presente trabajo de Tesis, lo que permite conservar un buen nivel de integridad de los gránulos de almidón. Ambas harinas presentan diferencias de color en términos de luminosidad y tinte básico, siendo mayores los valores de $L^{*}$ y hue medidos en la harina de mandioca. La técnica de rallado (sin prensado) ensayada no resultó adecuada, debido a la obtención de un producto fácilmente fermentable.

El procesamiento a partir de rodajas (HARo) fue más simple y la harina de ahipa resultante presentó la ventaja de un mayor contenido de potasio, magnesio, calcio y proteínas que la harina proveniente del rallado y prensado posterior, con agregado del almidón recuperado (HARaP). Esta última mostró menor contenido de sodio y mayor tenor de fibra, características nutricionales muy convenientes, junto con una baja temperatura de gelatinización.

La harina de ahipa es un producto que podría ser utilizado en la preparación alimentos para celíacos ya que por enzimoinmmuoensayos se verificó la ausencia de gliadinas. La característica diferencial de la harina de ahipa es su aporte de proteínas, fibra y minerales tales como potasio, hierro y calcio, reflejando una composición nutricionalmente más equilibrada que la correspondiente harina de mandioca y que otras harinas provenientes de raíces.

Se realizó la caracterización microestructural de las harinas obtenidas a través de difracción de rayos $X$ para evaluar el grado de cristalinidad y de FTIR para analizar la interacción entre los componentes principales de las harinas obtenidas. Las harinas presentaron un patrón de difracción Tipo C y el origen botánico de la muestra afectó el grado de cristalinidad de los gránulos. Los espectros FTIR de las harinas fueron similares, no afectando el origen botánico de las mismas.

Las isotermas de sorción permitieron evaluar el contenido de humedad que garantiza la estabilidad de las harinas bajo diferentes condiciones de almacenamiento. El modelo de GAB permitió estimar el contenido de agua de la monocapa y calcular los parámetros termodinámicos asociados a los procesos de adsorción de agua. En todos los casos se verificó la teoría de la compensación de entalpía-entropía y se obtuvieron 
la temperatura isocinética y la energía libre de Gibbs asociada, lo que indica que éste fue un proceso no espontáneo.

Independientemente del procedimiento de obtención, la harina de ahipa gelatinizó a temperatura más baja que la harina de mandioca, lo que indica una mejor aptitud para la cocción. En general, las temperaturas de gelatinización de las harinas (ahipa y mandioca) fueron más altas que las de sus almidones.

Las diferencias observadas en la capacidad de hinchamiento y de retención de solventes de ambas harinas deberán ser consideradas en relación a las aplicaciones específicas, tales como la incorporación de las mismas como ingredientes en alimentos funcionales libres de gluten. 


\section{REFERENCIAS BIBLIOGRÁFICAS}

AACC International. (2000). Approved Methods of the American Association of Cereal Chemists, 10th Ed. Methods 56-11. The Association: St. Paul, MN.

Abdul-Hamid, A., Luan, Y.S. (2000). Functional properties of dietary fibre prepared from defatted rice bran. Food Chemistry 68 (1), 15-19.

Aboubakar, Njintang, Y.N., Scher, J., Mbofung, C.M.F. (2008). Physicochemical, thermal properties and microstructure of six varieties of taro (Colocasia esculenta L. Schott) flours and starches. J. Food Eng., 86, 294-305.

Agunbiade, O. S., Longe, O. G. (1999). The physico-functional characteristics of starches from cowpea (Vigna unguiculata), pigeon pea (Cajanus cajan) and yambean (Sphenostylis stenocarpa). Food Chemistry, 65, 469-474.

Al-Muhtaseb, A.H., McMinn, W.A.M., Magee, T.R.A. (2002). Moisture sorption isotherm characteristics of food products: a review. Food and Bioproducts Processing 80 (2), 118-128.

Al-Muhtaseb, A.H., McMinn, W.A.M., Magee, T.R.A. (2004). Water sorption isotherms of starch powders. Part 1: mathematical description of experimental data. J. Food Eng., $61,297$.

AOAC (1990). Official Methods of Analysis. 15th edition. Edited by Kenneth Helrich. Arlington, Virginia, Estados Unidos.

Asociación Argentina de Celiaquía: sitio web http://www.celiaco.org.ar. Accedido en Marzo de 2013.

Aviara, N.A., Ajibola, O.O. (2002). Thermodynamics of moisture sorption in melon seed and cassava. Journal of Food Engineering 55 (2), 107-113. 
Aziz, N.A.A., Ho, L.-H., Azahari, B., Bhat, R., Cheng, L.-H., Ibrahim, M.N.M. (2011). Chemical and functional properties of the native banana (Musa acuminata balbisiana Colla cv. Awak) pseudo-stem and pseudo-stem tender core flours. Food Chemistry 128 (3), 748-753.

Barreiro, J.A., Fernández, S., Sandoval, A.J. (2003). Water sorption characteristics of six row barley malt (Hordeum vulgare). LWT - Food Science and Technology 36 (1), 37-42.

Bou Rached, L., de Vizcarrondo, C. A., Rincón, A. M., Padilla, F. (2006). Evaluation of the flour and starch from white and purple varieties of mapuey (Dioscorea trifida). Archivos Latinoamericanos de Nutrición, 56(4), 375-383.

Celíacos Argentinos: sitio web http://www.celiacosargentinos.com.ar. Accedido en Marzo de 2013.

Chirdo, F.G., Añón, M.C., Fossati, C.A. (1995). Optimization of a competitive ELISA with polyclonal antibodies for quantification of prolamins in foods. Food Agric Immunol 7(4), 333-343.

Cladera-Olivera, F., Pettermann, A.C., Zapata Noreña, C.P., Wada, K., Ferreira Marczak, L.D. (2008). Thermodynamic properties of moisture desorption of raw pinhão (Araucaria angustifolia seeds). International Journal of Food Science \& Technology 43 (5), 900-907.

Cladera-Olivera, F., Marczak, L.D.F., Noreña, C.P.Z., Pettermann, A.C. (2009). Modeling water adsorption isotherms of pinhão (Araucaria angustifolia seeds) flour and thermodynamic analysis of the adsorption process. J. Food Process Eng., 34, 3, 826843. 
Charoenkul, N., Uttapap, D., Pathipanawat, W., Takeda, Y. (2011). Physicochemical characteristics of starches and flours from cassava varieties having different cooked root textures. LWT - Food Science and Technology 44 (8), 1774-1781.

Chen, C. (1988). A study of equilibrium relative humidity for yellow dent corn kernels. Ph.D. thesis, University of Minnesota, St. Paul, MN.

Código Alimentario Argentino (CAA). (2013). Buenos Aires. Argentina. http://www.anmat.gov.ar/alimentos/normativas_alimentos_caa.asp. Accedido en Enero de 2014.

Demirgöz, D., Elvira, C., Mano, J., Cunha, A., Piskin, E., Reis, R. (2000). Chemical modification of starch based biodegradable polymeric blends: Effects on water uptake, degradation behavior and mechanical properties. Polymer Degradation and Stability, 70, 161-170.

Dini, C., Doporto, M.C., García, M.A., Viña, S.Z. (2013). Nutritional profile and antinutrient analyses of Pachyrhizus ahipa roots from different accessions. Food Research International (54) 255-261.

Doporto, M. C., Mugridge, A., García, M. A. Viña, S. Z. (2011). Pachyrhizus ahipa (Wedd.) Parodi roots and flour: Biochemical and functional characteristics. Food Chemistry 126, 1670-1678.

Doporto, M. C., Dini, C., Mugridge, A., Viña, S. Z., García, M. A. (2012). Physicochemical, thermal and sorption properties of nutritionally differentiated flours and starches. Journal of Food Engineering, 113 (4), 569-576.

Fang, J.M., Fowler, P.A., Tomkinson, J., Hill, C.A. (2002). The preparation and characterization of a series of chemically modified potato starches. Carbohydrate Polymers, 47, 245-252. 
Fasina, O.O. (2006). Thermodynamic properties of sweet potato. Journal of Food Engineering 75 (2), 149-155.

Fennema, O. (2008). Química de los Alimentos. Editores: Damodaran, S., Parkin, K. L., Fennema, $\mathrm{O}$.

Forsyth, J.L., Shewry, P.R. (2002). Characterization of the Major Proteins of Tubers of Yam Bean (Pachyrhizus ahipa). Journal of Agricultural and Food Chemistry, 50, 19391944.

Gálvez, A. V., Aravena, E. L., Mondaca, R. L. (2006). Isotermas de adsorción en harina de maíz (Zea mays L.). Cienc. Tecnol. Aliment. Campinas 26(4), 821-827.

García, M. A., Martino, M. N., Zaritzky, N. E. (1995). Comparison of amylose enrichment procedures for the food applications. Cereal Chemistry, 72(6), 552-558.

Gavicho Uarrota, V., Amante, E. R., Mottin Demiate, I., Vieira, F., Delgadillo, I., Maraschin, M. (2013). Physicochemical, thermal, and pasting properties of flours and starches of eight Brazilian maize landraces (Zea mays L.). Food Hydrocolloids 30, 614624.

Geng, Z., Zongdao, C., Yimin, W. (2007). Physicochemical properties of lotus (Nelumbo nucifera Gaertn.) and kudzu (pueraria hirsute matsum.) starches. International Journal of Food Science and Technology, 42(12), 1449-1455.

Heywood, A., Myers, D., Bailey, T., Johnson, L. (2002). Functional properties of low-fat soy flour produced by an extrusion-expelling system. Journal of the American Oil Chemists' Society 79 (12), 1249-1253. 
Huang C. (2009). Physicochemical, pasting and thermal properties of tuber starches as modified by guar gum and locust bean gum. International Journal of Food Science and Technology, 44, 50-57.

Jane, J., Shen, L., Chen, J., Lim, S., Kasemsuwan, T., Nip, W.K. (1992). Physical and chemical studies of taro starches and flours. Cereal Chemistry 69, 528-535.

Kaymak-Ertekin, F., Gedik, A. (2004). Sorption isotherms and isoteric heat of sorption for grapes, apricots, apples and potatoes. LWT, 37, 429.

Kacuráková, M., Wilson, R.H. (2001). Developments in mid-infrared FT-IR spectroscopy of selected carbohydrates. Carbohydrate Polymers, 44, 291-303.

Krishnan, J. G., Padmaja, G., Moorthy, S. N., Suja, G., Sajeev, M. S. (2010). Effect of presoaking treatments on the nutritional profile and browning index of sweet potato and yam flours. Innovative Food Science and Emerging Technologies, 11, 387-393.

Labuza, T.P., (1984). Moisture Sorption: Practical Aspects of Isotherm Measurement and Use. American Association of Cereal Chemists, American, St. Paul, MN.

Lebot, V., Champagne, A., Malapa, R., Shiley, D. (2009). NIR determination of major constituents in tropical root and tuber crop flours. Journal of Agricultural and Food Chemistry, 57, 10539-10547.

López, O.V., García, M.A., Zaritzky, N.E. (2008). Film forming capacity of chemically modified corn starches. Carbohydrate Polymers, 73, 573.

López, O.V., Viña, S. Z., Pachas, N.A., Sisterna, M.N., Rohatsch, P.H., Mugridge, A., Fassola, H.E., García, M.A. (2010). Composition and food properties of Pachyrhizus ahipa roots and starch. International Journal of Food Science and Technology, 45, 223233. 
Luengwilai, K., Beckles, D.M. (2009). Starch granules in tomato fruit show a complex pattern of degradation. Journal of Agricultural and Food Chemistry, 57(18), 8480-8487.

Madamba, P.S., Driscoll, R.H., Buckle, K.A. (1996). Enthalpy-entropy compensation models for sorption and browning of garlic. Journal of Food Engineering 28 (2), 109119.

Mano, J.F., Koniarova, D., Reis, R.L. (2003). Thermal Properties of Thermoplastic Starch/Synthetic Polymer Blends with Potential Biomedical Applicability. Journal of Materials Science: Materials in Medicine, 14, 127-135

Marcelino A.M., Gierasch L.M. (2008). Roles of $\beta$-turns in protein folding: from peptide models to protein engineering. Biopolymers, 89 (5): 380-391.

Maruatona, G. N., Duodu, K. G., Minnaar, A. (2010). Physicochemical, nutricional and functional properties of marama bean flour. Food Chemistry, 121, 400-405.

Meuser, F., Suckow, P. (1986). Chemistry and physics of baking. Ed. Blanshard Frazier, P. J., Gaillard, T. The Royal Society of Chemistry, Londres, Inglaterra, 42-61.

McMinn, W. A. M., Magee, T. R. A. (2003). Thermodynamics properties of moisture sorption of potato. J. Food Eng. 60, 157.

McMinn, W.A.M., McKee, D.J., Magee, T.R.A., (2007). Moisture adsorption behaviour of oatmeal biscuit and oat flakes. Journal of Food Engineering 79 (2), 481-493.

Medeiros, D. M., Wildman, R. E. C. (2012). Advanced Human Nutrition. Second Edition.

Oboh, G, Akindahunsi, A. A., Oshodiw, A. A. (2002). Nutrient and Anti-nutrient Contents of Aspergillus niger-fermented Cassava Products (Flour and Gari). Journal of Food Composition and Analysis 15, 617-622. 
Ogbuagu, M. N. (2008). Nutritive and anti-nutritive composition of the wild (inedible) species of Dioscorea bulbifera (Potato Yam) and Dioscorea dumentorum (Bitter Yam). The Pacific Journal of Science and Technology, 9(1), 203-207.

Palacios-Fonseca, A. J., Vázquez-Ramos, C., Rodríguez-García, M. E. (2009). Physicochemical characterizing of industrial and traditional nixtamalized corn flours. Journal of Food Engineering, 93, 45-51.

Pelissari, F. M., Andrade-Mahecha, M. M., do Amaral Sobral, P. J., Menegalli, F. C. (2013). Comparative study on the properties of flour and starch films of plantain bananas (Musa paradisiaca). Food Hydrocolloids 30, (2) 681-690.

Perdomo, J., Cova, A., Sandoval, A.J., García, L., Laredo, E., Müller, A.J. (2009). Glass transition temperatures and water sorption isotherms of cassava starch. Carbohydrate Polymers 76 (2), 305-313.

Peterson, C. J., Johnson, V. A., Mattern, P. J. (1986). Influence of cultivar and environment on mineral and protein concentration of wheat flour, bran and grain. Cereal Chemistry, 63(3), 183-186.

Polatoğlu, B., Beşe, A.V., Kaya, M., Aktaş, N. (2011). Moisture adsorption isotherms and thermodynamics properties of sucuk (Turkish dry-fermented sausage). Food and Bioproducts Processing 89 (4), 449-456.

Robertson, J. B., Van Soest, P. J. (1981). The detergent system of analysis and its application to human foods. In W. P. T. James \& O. Theander (Eds.), The analysis of dietary fiber in food (pp. 123-158). New York: Marcell Dekker.

Rodríguez-Miranda, J., Ruiz-López, I. I., Herman-Lara, E., Martínez-Sánchez, C. E., Delgado-Licon, E., Vivar-Vera, M. A. (2011). Development of extruded snacks using taro 
(Colocasia esculenta) and nixtamalized maize (Zea mays) flour blends. LWT Food Science and Technology 44, 673-680.

Rosell, C. M., Santos, E., Collar, C. (2009). Physico-chemical properties of commercial fibres from different sources: A comparative approach. Food Research International, $42(1), 176-184$.

Sabanis, D., Tzia, C. (2009). Effect of rice, corn and soy flour addition on characteristics of bread produced from different wheat cultivars. Food Bioprocess Technology, 2, 6879.

Salinas, V. (2013). "Estudio de la calidad panera, sensorial y nutricional de panes elaborados con harina de trigo fortificada con sales de calcio e inulina". Trabajo de Tesis Doctoral.

Singh, B. R. (2000). Infrared analysis of peptides and proteins e Principles and applications. Washington: American Chemical Society.

Spiess, W., Wolf, W.R. (1983). The result of the COST 90 project on water activity. In: Jowitt, R., Escher, F., Hallstrom, B., Meffert, M.S., Spiess, W., Vos, G. (Eds.), Physical Properties of Foods. Applied Science Publishers, London, pp. 65-88.

Szymonska, J., Krok, F., Komorowska-Czepirska, E., \& Rębilas, K. (2003). Modification of granular starch by multiple deep-freezing and thawing. Carbohydrate Polymers, 52, 110.

Tapia-Blácido, D. R., Mauri, A. N., Menegalli, F. C., Sobral, P. J. A., Añón, M. C. (2007). Contribution of the starch, protein, and lipid fractions to the physical, thermal, and structural properties of amaranth (Amaranthus caudatus) flour films. Journal of Food Science, 72(5), 293-300. 
Capítulo 4. Obtención y caracterización de harinas de Pachyrhizus ahipa y Manihot esculenta

Thys, R.C.S., Noreña, C.P.Z., Marczak, L.D.F., Gomes Aires, A., Cladera-Olivera, F. (2010). Adsorption isotherms of pinhão (Araucaria angustifolia seeds) starch and thermodynamic analysis. J. Food Eng. 100, 468.

Tolaba, M.P., Peltzer, M., Enriquez, N., Pollio, M.L. (2004). Grain sorption equilibria of quinoa grains. Journal of Food Engineering 61 (3), 365-371.

Tribess, T.B., Hernández-Uribe, J.P., Méndez-Montealvi, M.G.C., Menezes, E.W., BelloPérez, L.A., Tadini, C.C. (2009). Thermal properties and resistant starch content of green banana flour (Musa cavendishii) produced at different drying conditions. LWT, $42,022-1025$

Tsai, M. L., Li, C. F., Lii, C. Y. (1997). Effects of granular structures on the pasting behaviors of starches. Cereal Chemistry, 74(6), 750-757.

Vasanthan, T., Gaosong, J., Yeung, J., Li, J. J. (2002). Dietary fiber profile of barley flour as affected by extrusion cooking. Food Chemistry, 77, 35-40.

Whistler, R.L., BeMiller, J.N., Paschall, E.F. (1984). Starch: chemistry and technology. Academic Press, Inc.

Wu, P. Tian, J. C., Walker, C. E., Wang, F. C. (2009). Determination of phytic acid in cereals - a brief review. International Journal of Food Sciencie \& Technology, 44 (9) 1671-1676.

Zhang, Y., Han, J. (2006). Mechanical and thermal characteristics of pea starch films plasticized with monosaccharides and polyols. Journal of Food Science, 71, 109-118.

Zobel, H.F. (1988). Starch crystal transformations and their industrial importance. Starch/Stärke, 40, 1-7. 


\section{CAPÍTULO 5.}

Aplicaciones tecnológicas: productos horneados elaborados con harina de

Pachyrhizus ahipa 


\section{INTRODUCCIÓN}

\section{Alimentos para celíacos}

Como ya se mencionó previamente, el único tratamiento eficaz de la celiaquía es el cambio a una dieta libre de gluten de por vida, lo que permite la regeneración de las vellosidades intestinales y la disminución de los síntomas asociados a la enfermedad. Una dieta sin gluten exige eliminar las principales fuentes de prolaminas, como el pan y los granos, así como leer meticulosamente las etiquetas de los productos para evitar fuentes ocultas de harina principalmente de trigo, aunque también se incluyen avena, cebada y centeno (productos rotulados "sin TACC").

Comúnmente la harina de trigo se utiliza como espesante y para mantener la fluidez de productos secos en polvo; se la incluye en la formulación de alimentos procesados tales como aderezos para ensaladas, azúcar morena, café instantáneo, salchichas, salsas para carnes, canela, cacao, margarinas, papas fritas, té instantáneo, yogurt con fruta, cereales secos, cubos de caldo, helados, mostaza, queso para untar y salsa de tomate, entre otros (Gómez-González, 2007).

Por lo tanto, los anteriores son productos que pueden contener gluten así como alguno de estos ingredientes que a continuación se mencionan y, de ser así, se deben evitar: fibra, harina, sémola, almidón, harina enriquecida, fécula, amiláceos, espesantes, almidón de trigo, malta, proteína enriquecida, hidrolizados, levadura, emulsificantes, proteína vegetal, cereales, extracto de malta, glutamato monosódico (conservador) (GómezGonzález, 2007).

Por esto puede ser difícil atenerse a una dieta estricta libre de gluten, ya que la mayoría de los alimentos procesados lo contienen y en muchos casos la dieta no es bien aceptada dado que se suprimen alimentos básicos cotidianos.

Las recomendaciones en la alimentación son para toda la vida. Durante la adolescencia es cuando suelen producirse las desviaciones más importantes de la dieta debido a la "rebelión juvenil". Por todo ello es necesaria una constante y esmerada educación nutricional del niño y de la familia para facilitar una adhesión estricta a la dieta. Deben cuidarse los aspectos culinarios para que la alimentación del celíaco sea segura y a la vez apetecible.

Un inconveniente importante reside en que, tal como señala Ramón (2013), la base tecnológica de la oferta de alimentos aptos para celíacos se sustenta casi exclusivamente 
en la generación de productos libres de dicha proteína o sus trazas, sin aportar ningún otro beneficio desde el punto de vista nutricional.

El mercado mundial de alimentos libres de gluten se encuentra en expansión, y su crecimiento supera las estimaciones de los estudios de mercado de comienzos de esta década. Se calcula que en el año 2012 sólo en Estados Unidos se generaron ventas por más de 4.200 millones de dólares, y se espera que esta cifra aumente hasta más de 6.500 millones a fines del año 2017 (Ramón, 2013). A pesar de ello, es importante remarcar que la base de esta oferta dietaria es la "ausencia de gluten" y que en muy pocos casos se han lanzado al mercado productos que, cumpliendo con este requisito primordial, presenten alguna característica nutricional o funcional adicional que sea de interés y/o relevancia para los enfermos celíacos.

Teniendo en cuenta que los cambios en la alimentación requeridos por los pacientes celíacos para ajustarse y mantener una dieta libre de gluten estricta son considerables y tienen un impacto significativo en sus vidas diarias, se ha incrementado la preocupación sobre los hábitos alimenticios a largo plazo y las elecciones alimentarias de dichos pacientes.

Los resultados de un número de estudios indican un consumo desequilibrado de carbohidratos, proteínas y lípidos, como así también una ingesta limitada de ciertos nutrientes esenciales en los sujetos celíacos, en relación a los controles (Álvarez-Jubete y col., 2010).

Una investigación llevada a cabo en los Estados Unidos (Thompson y col., 2005) señaló que el consumo de hierro, calcio y fibra en pacientes celíacos que llevaban una dieta libre de gluten no resultó adecuado (Álvarez-Jubete y col., 2010).

Esta situación conduce a un interés creciente en el estudio y desarrollo de productos libres de gluten que puedan suministrar, al mismo tiempo, cantidades significativas de fibra, almidón y minerales.

\section{Legislación en la Argentina}

El Código Alimentario Argentino, en su Capítulo XVII, Artículo 1339 - (Resolución Conjunta SPRel - Secretaría de Políticas, Regulación e Institutos - N 94/08 y SAGPyA N 357/08), señala que "se entiende por 'Alimentos dietéticos' o 'Alimentos para regímenes especiales' a los alimentos envasados preparados especialmente que se diferencian de 
los alimentos ya definidos por el presente Código por su composición y/o por sus modificaciones físicas, químicas, biológicas o de otra índole resultantes de su proceso de fabricación o de la adición, sustracción o sustitución de determinadas substancias componentes. Están destinados a satisfacer necesidades particulares de nutrición y alimentación de determinados grupos poblacionales".

Dentro de este grupo se encuentran comprendidos los "Alimentos libres de gluten", siendo clasificados como "Alimentos para satisfacer necesidades alimentarias de personas que presentan estados fisiológicos particulares".

A continuación se indican los artículos específicos del CAA que hacen referencia a los productos libres de gluten:

- Artículo 1383 - (Resolución Conjunta SPRel N 131/2011 y SAGyP N 414/2011):

Se entiende por "alimento libre de gluten" el que está preparado únicamente con ingredientes que por su origen natural y por la aplicación de buenas prácticas de elaboración -que impidan la contaminación cruzada- no contiene prolaminas procedentes del trigo, de todas las especies de Triticum, como la escaña común (Triticum spelta L.), kamut (Triticum polonicum L.), de trigo duro, centeno, cebada, avena ni de sus variedades cruzadas. El contenido de gluten no podrá superar el máximo de $10 \mathrm{mg} / \mathrm{kg}$. Para comprobar la condición de libre de gluten deberá utilizarse metodología analítica basada en la Norma Codex STAN 118-79 (adoptada en 1979, enmendada en 1983; revisada en 2008) enzimoinmunoensayo ELISA R5 Méndez y toda aquella que la Autoridad Sanitaria Nacional evalúe y acepte.

Estos productos se rotularán con la denominación del producto que se trate seguido de la indicación "libre de gluten" debiendo incluir además la leyenda "Sin TACC" en las proximidades de la denominación del producto, con caracteres de buen realce, tamaño y visibilidad.

A los efectos de la inclusión en el rótulo de la leyenda "Sin TACC", la elaboración de los productos deberá cumplir con las exigencias del presente Código para alimentos libres de gluten.

Para la aprobación de los alimentos libres de gluten, los elaboradores y/o importadores deberán presentar ante la Autoridad Sanitaria de su jurisdicción: análisis que avalen la condición de "libre de gluten" otorgado por un organismo oficial o entidad con reconocimiento oficial y un programa de buenas prácticas de fabricación, con el fin de 
asegurar la no contaminación con derivados de trigo, avena, cebada y centeno en los procesos, desde la recepción de las materias primas hasta la comercialización del producto final".

- Artículo 1383 bis - (Resolución Conjunta SPRel N²01/2011 y SAGyP Nº 649/2011) Los productos alimenticios 'Libres de Gluten' que se comercialicen en el país deben llevar, obligatoriamente impreso en sus envases o envoltorios, de modo claramente visible, el símbolo que figura a continuación (Figura 5.1) y que consiste en un círculo con una barra cruzada sobre tres espigas y la leyenda "Sin T.A.C.C." en la barra, admitiendo dos variantes:

a) A color: círculo con una barra cruzada rojos (pantone - RGB255-0-0) sobre tres espigas dibujadas en negro con granos amarillos (pantone - RGB255-255) en un fondo blanco y la leyenda "Sin T.A.C.C.".

b) En blanco y negro: círculo y barra cruzada negros sobre tres espigas dibujadas en negro con granos blancos en un fondo blanco y la leyenda "Sin T.A.C.C.".
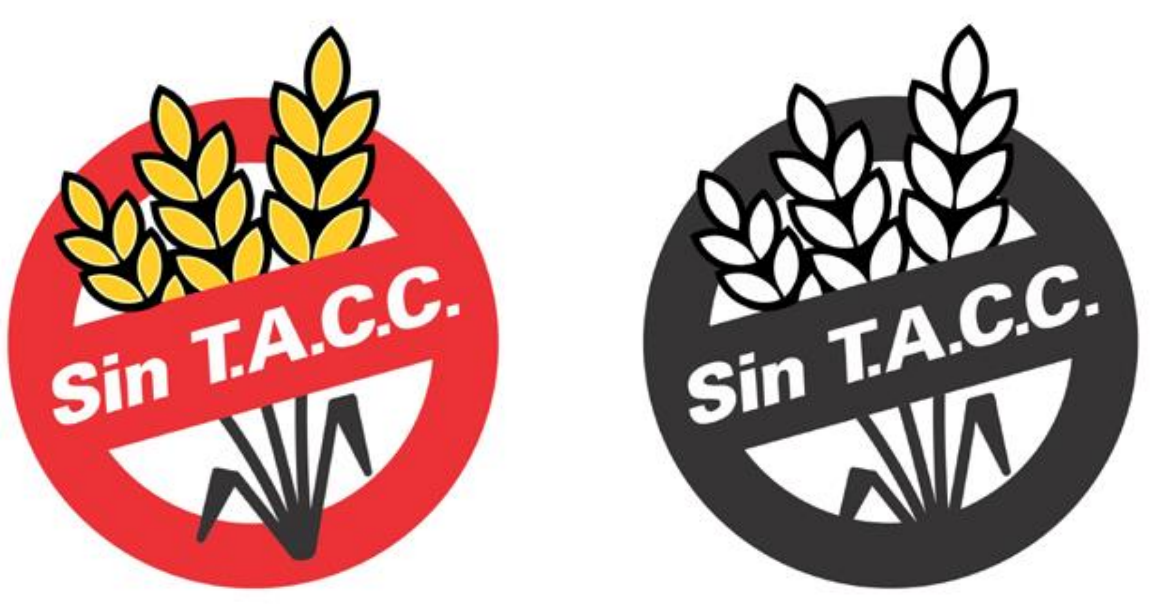

Figura 5.1. Símbolo que identifica a los productos libres de gluten.

La Ley Nacional № 26.588 sancionada y promulgada en diciembre de 2009, declara de “interés nacional la atención médica, la investigación clínica y epidemiológica, la capacitación profesional en la detección temprana, diagnóstico y tratamiento de la enfermedad celíaca". También señala su "difusión y el acceso a los alimentos libres de 
gluten con la incorporación de la respectiva leyenda y el símbolo que establezca la autoridad de aplicación".

En el 2007, por medio de la Resolución 1560 del Ministerio de Salud de la Nación, se creó el Programa Nacional de Detección y Control de la Enfermedad Celíaca, con el fin de "contribuir a la detección temprana de la enfermedad y al fortalecimiento del Sistema Nacional de Control de Alimentos".

\section{Incidencia de la enfermedad celíaca en nuestro país}

Se estima que en la actualidad existen alrededor de 500.000 pacientes celíacos en la Argentina. No obstante, el Primer Estudio Multicéntrico Poblacional de Prevalencia de la Enfermedad Celíaca en la población pediátrica (Mora y col., 2010) determinó que la presencia de la patología en niños es mayor: 1 de cada 79 chicos es celíaco, lo que representa una prevalencia del 1,27\%, mientras que en adultos es de 1 celíaco cada 167 personas. El estudio fue realizado a niños y adolescentes de todo el país, de entre 3 y 16 años, durante los años 2008 y 2009.

La investigación de la Comisión Nacional "Salud Investiga", dependiente de la cartera sanitaria, reveló además que esta enfermedad está presente de manera más significativa en las mujeres y que el 90\% de los casos se halló en niños mayores de 6 años.

\section{Galletitas aptas para celíacos}

El Código Alimentario Argentino (CAA), en su Capítulo IX, Artículo 760 (Dec. 112, 12.1.76), define con los términos genéricos de Galletitas y Bizcochos (Cakes, Crackers, Biscuits, etc.), a “... productos a los que se les da formas variadas antes del horneado de una masa elaborada a base de harina de trigo u otras o sus mezclas, con o sin agentes químicos y/o biológicos autorizados."

Estos productos son consumidos tanto por niños como por adultos, se pueden utilizar en el desayuno, en la merienda, como colación, en el hogar o fuera de él. Las galletitas pueden ser saladas o dulces (Figura 5.2). Estas últimas pueden elaborarse rellenas, como alfajores. Se entiende por alfajor, según el CAA (Artículo 761 bis, Resolución Conjunta 196/2001 y 1020/2001), “... el producto constituido por dos o más galletitas, galletas o masas horneadas, adheridas entre sí por productos tales como, mermeladas, 
jaleas, dulces u otras sustancias o mezclas de sustancias alimenticias de uso permitido." Además, siendo la galletita un producto horneado y seco, presenta la ventaja de poder conservarse durante varios días.

Existen en el mercado galletitas dulces (cookies) sin gluten, aptas para el consumo de personas celíacas, aunque son, en general, productos de baja calidad debido a su textura arenosa y seca. En ellas se reemplaza la harina de trigo por mezclas de almidones o harinas libres de gluten. La ventaja de este producto con respecto al pan es que, al no incluir un leudado, el desarrollo de la red de gluten tiene menor relevancia.

Las galletitas elaboradas a base de una harina libre de gluten, como la harina obtenida de la raíz tuberosa de Pachyrhizus ahipa (ahipa), serían aptas para aquellas personas con Celiaquía.

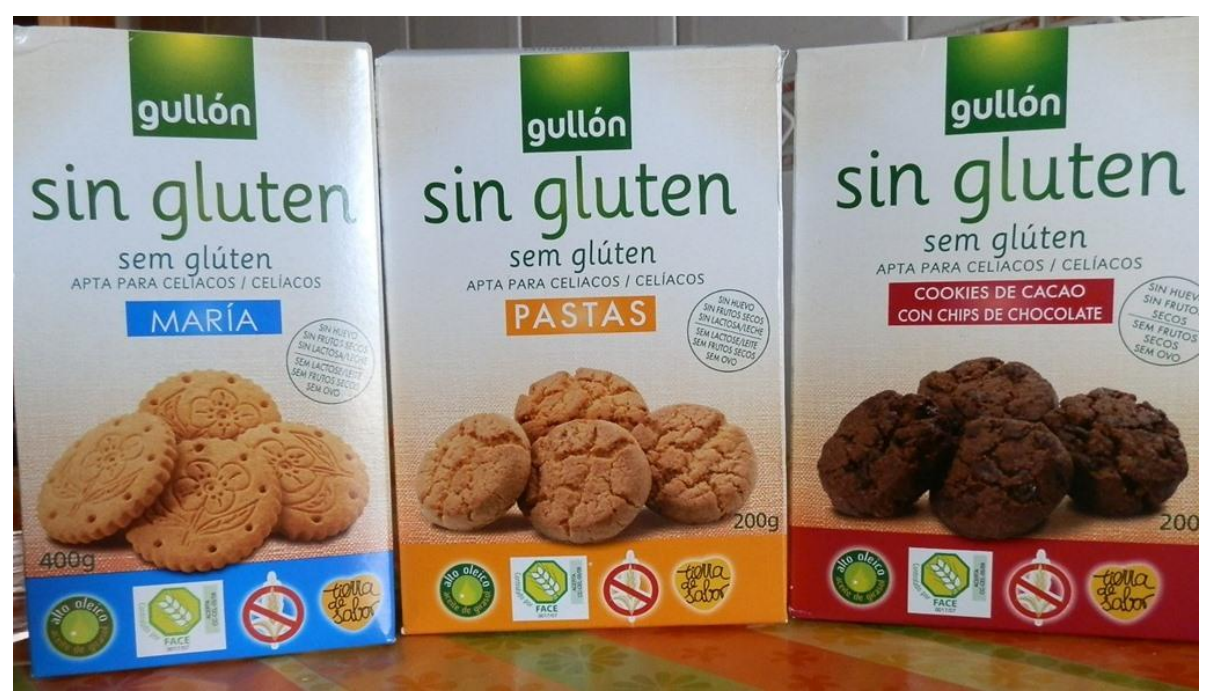

Figura 5.2. Galletitas dulces libres de gluten. 


\section{OBJETIVOS}

Los objetivos planteados para este capítulo son los siguientes:

1. Formular y elaborar galletitas libres de gluten conteniendo harina obtenida a partir de raíces de Pachyrhizus ahipa.

2. Analizar la composición química de las galletitas elaboradas con harina de Pachyrhizus ahipa, evaluando los contenidos de macrocomponentes (humedad, cenizas totales, lípidos totales, proteína cruda, fibra dietaria total) que guardan relevancia nutricional.

3. Estudiar aquellas propiedades físico-químicas tanto de las mezclas secas, de las masas crudas y de los productos elaborados que se relacionan con su calidad y aptitud para la conservación.

4. Evaluar desde el punto de vista de su aceptabilidad sensorial a los productos terminados. 


\section{MATERIALES Y MÉTODOS}

\section{Elaboración de las galletitas}

Para la elaboración de las galletitas se trabajó en base a una de las recetas difundidas por el sitio web de Celíacos Argentinos (2013), para alfajores de maizena. Asimismo, la Asociación Argentina de Celiaquía (2013) en su sitio web presenta una receta similar.

En la Figura 5.3 se encuentra la receta original de alfajores de maizena.

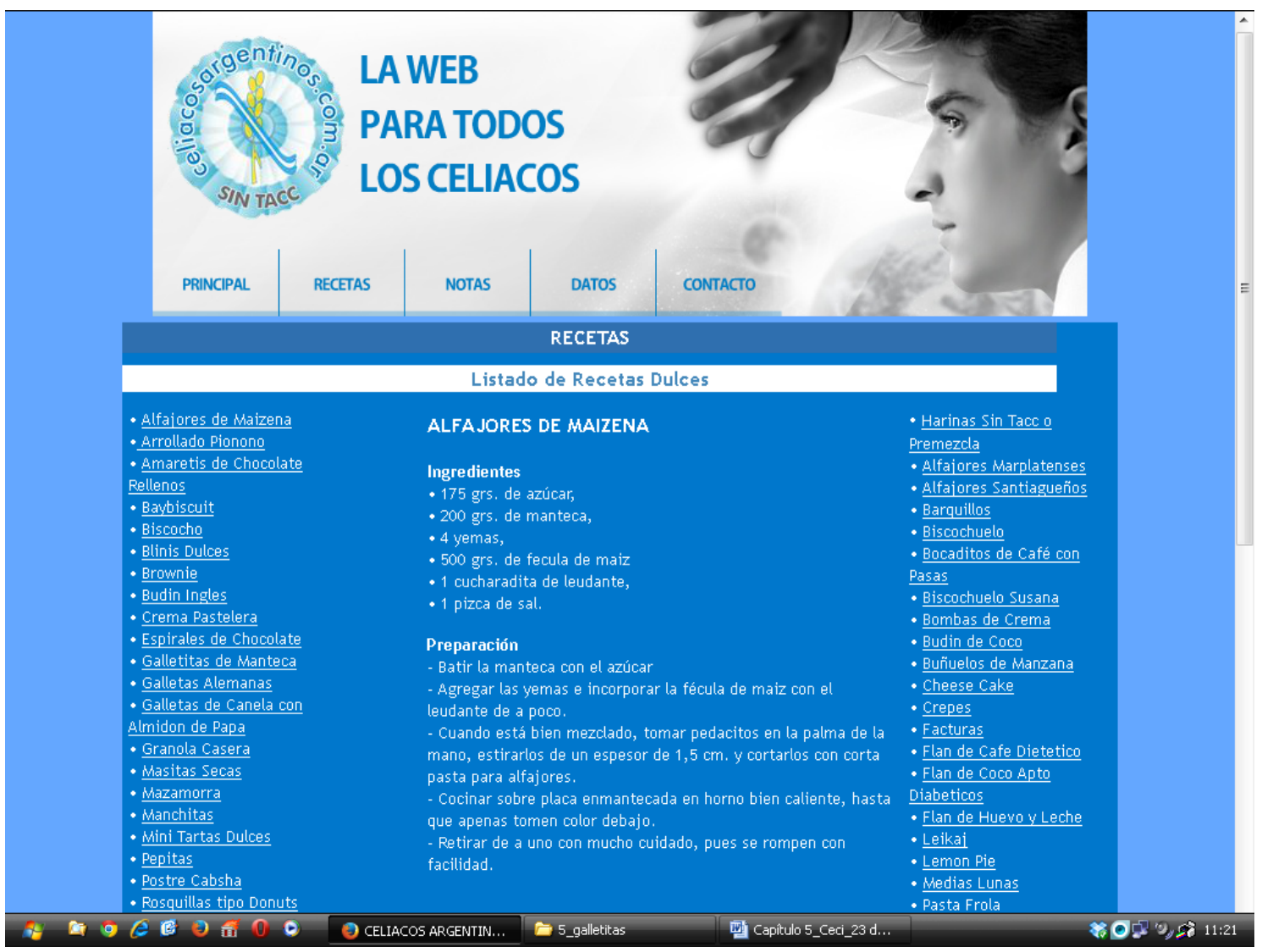

Figura 5.3. Receta de alfajores de maizena extraída del sitio web de Celíacos

Argentinos (2013).

El leudante se preparó mezclando una parte de bicarbonato de sodio (Royal, Argentina) con una parte de crémor tártaro y media parte de fécula de maíz o almidón de maíz (Maizena, elaborado por R.N.E. para Unilever Argentina), como se propone en el sitio web de Celíacos Argentinos.

Durante la preparación se realizaron modificaciones sobre la receta original (Figura 5.3) con el fin de obtener un producto tipo galletita. Las modificaciones realizadas consistieron en reducir las cantidades a la mitad de todos los ingredientes para 
trabajar con una masa más reducida, reemplazar una yema por un huevo entero incorporando así los nutrientes de la clara y por último, se eliminó la sal, haciendo al producto más saludable.

En la Figura 5.4 se puede observar la receta modificada que contiene fécula de maíz (Maizena), el leudante previamente descripto, azúcar blanca refinada (Real Ledesma, Argentina), huevo, yema y manteca (Sancor, Argentina).

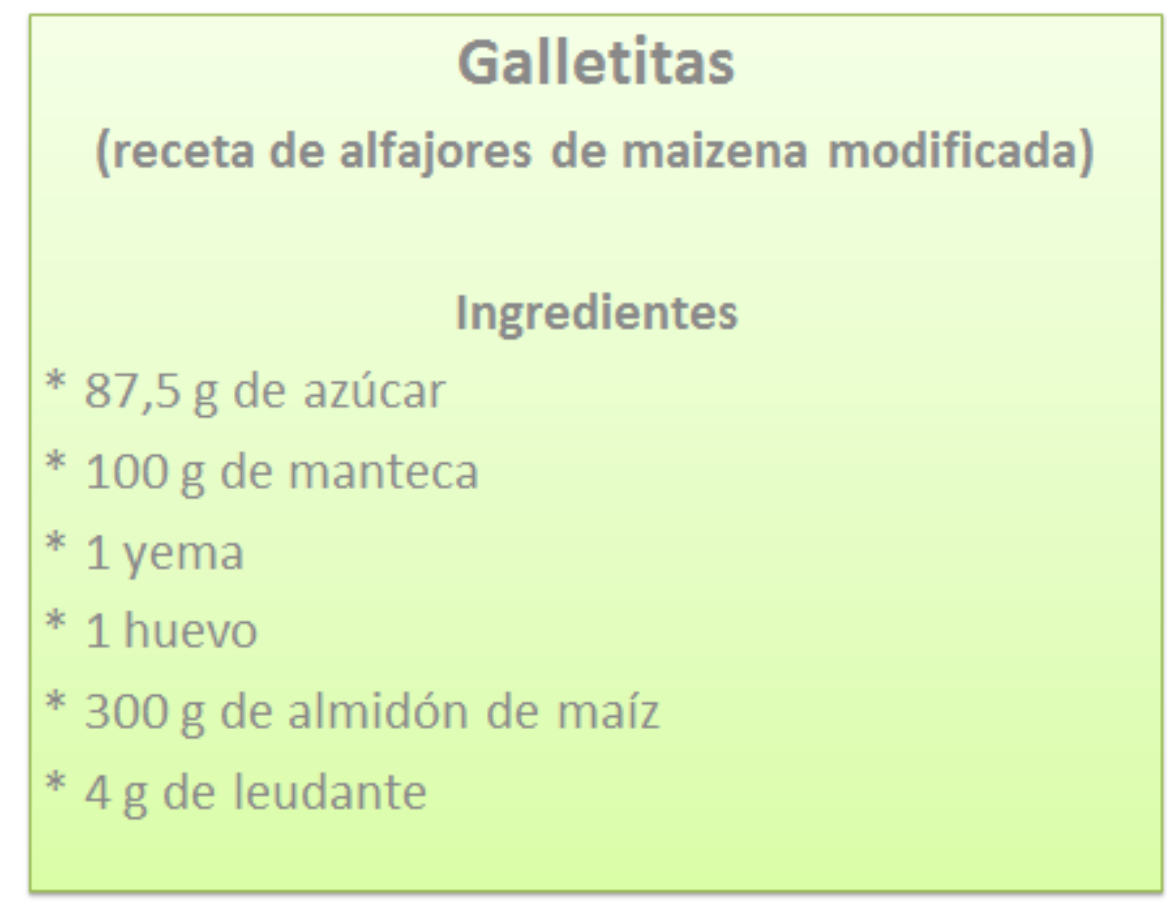

Figura 5.4. Receta de alfajores de maizena modificada.

\section{Formulaciones ensayadas}

Se ensayaron seis formulaciones reemplazando, en la receta indicada en la Figura 5.4, parte del almidón de maíz por las harinas obtenidas a partir de las raíces de ahipa y mandioca. Se consideró también utilizar harina de trigo integral comercial (Pureza, Molino Cañuelas SACIFIA, Argentina) en una de las formulaciones.

Se propusieron formulaciones conteniendo diferentes proporciones de harina de ahipa (12,5-35\%). Con fines comparativos, en el caso de las harinas de mandioca y trigo integral, sólo se trabajó con el porcentaje de sustitución seleccionado para ahipa.

En la Tabla 5.1 se muestran las formulaciones ensayadas a partir de la receta de alfajores de maizena modificada indicada con el número cero. Las recetas numeradas 
del uno al seis corresponden a las distintas formulaciones con los diferentes reemplazos de almidón de maíz realizados.

Tabla 5.1. Reemplazos de almidón de maíz evaluados correspondientes a las diferentes formulaciones o recetas ensayadas.

\begin{tabular}{c|c|c|c|c}
\hline Formulación & Almidón de maíz & Harina de ahipa & Harina de mandioca & Harina integral \\
\hline 0 & $100 \%(300 \mathrm{~g})$ & - & - & - \\
\hline 1 & $87,5 \%(262,5 \mathrm{~g})$ & $12,5 \%(37,5 \mathrm{~g})$ & - & - \\
\hline 2 & $82 \%(246 \mathrm{~g})$ & $18 \%(54 \mathrm{~g})$ & - & - \\
\hline 3 & $75 \%(225 \mathrm{~g})$ & $25 \%(75 \mathrm{~g})$ & - & - \\
\hline 4 & $65 \%(195 \mathrm{~g})$ & $35 \%(105 \mathrm{~g})$ & - & - \\
\hline 5 & $75 \%(225 \mathrm{~g})$ & - & $25 \%(75 \mathrm{~g})$ & - \\
\hline 6 & $75 \%(225 \mathrm{~g})$ & - & - & $25 \%(75 \mathrm{~g})$
\end{tabular}

\section{Preparación}

Para la preparación de la masa se empleó una procesadora Philips Cucina HR 7633 (Brasil) de 600 watt de potencia utilizando el accesorio amasador para mezclar los ingredientes y trabajar la masa resultante.

Para cada formulación se prepararon las mezclas o premezclas secas en un recipiente. Las mismas resultaron de reunir el almidón de maíz con el leudante y la harina correspondiente para cada receta (ver Tabla 5.1). Con respecto a la harina de trigo integral comercial, previamente a ser utilizada se la tamizó para eliminar restos de fibra de gran tamaño y obtener una harina más homogénea.

En el recipiente de la procesadora se mezclaron el azúcar con la manteca cortada en cubos de $2 \mathrm{~cm}$, hasta que la mezcla quedó suave y cremosa. A continuación se incorporaron el huevo y la yema. Finalmente se añadió de a poco la mezcla o premezcla seca correspondiente y se procesó hasta integrar completamente los ingredientes.

La masa obtenida se estiró en una placa de acrílico cuyo espesor era de $8 \mathrm{~mm}$ y se cortó con un molde circular de $2 \mathrm{~cm}$ de diámetro para obtener las galletitas.

Las galletitas crudas se colocaron sobre una lámina de silicona colocada en una placa metálica (ver Figura 5.5) y se llevaron al horno. 


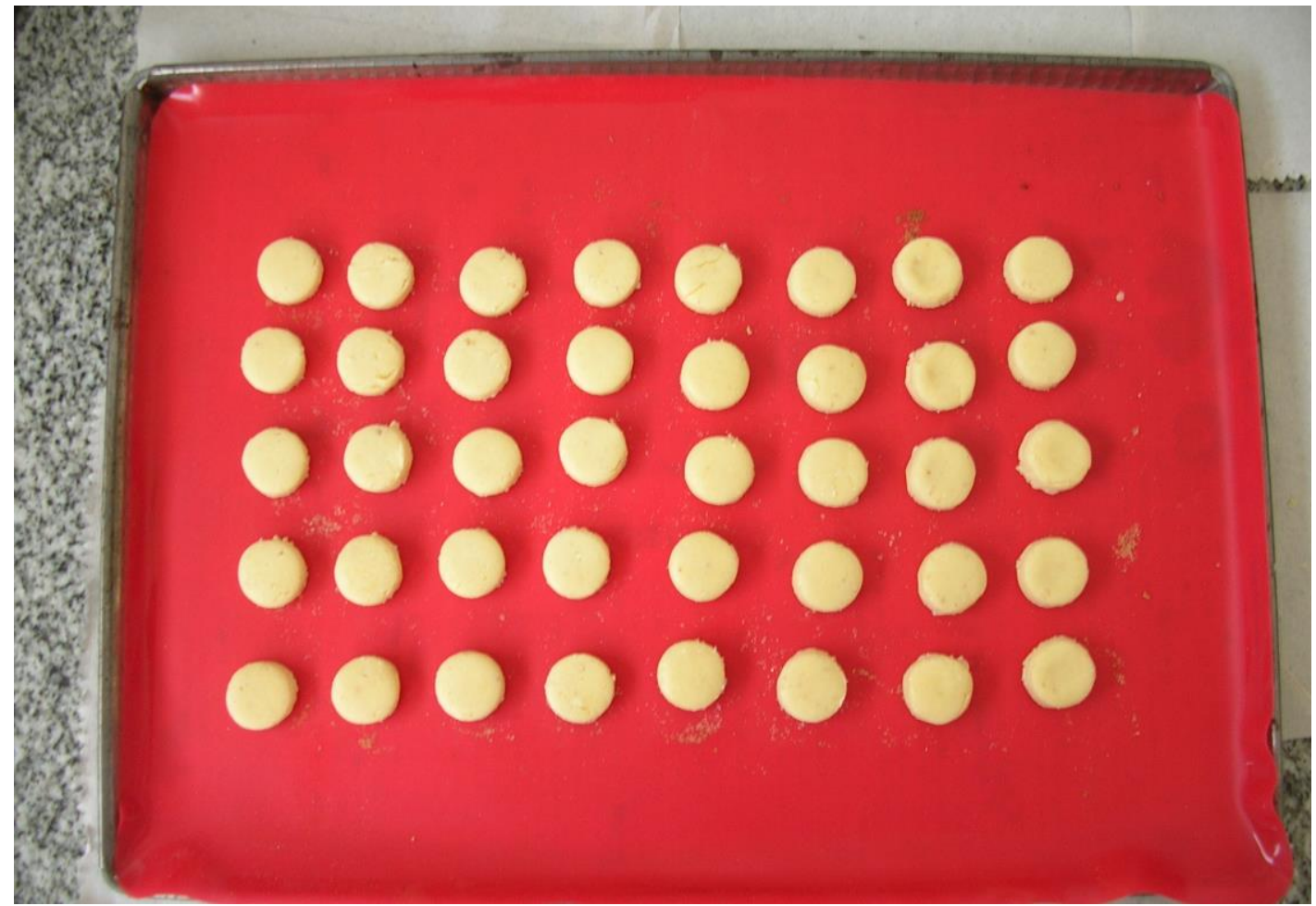

Figura 5.5. Galletitas crudas dispuestas en lámina de silicona.

El horneado de las galletitas se realizó en un horno eléctrico doméstico, Ariston FM87FC (Italia), cuyas dimensiones útiles son $0,4 \mathrm{~m}$ de largo, 0,39 $\mathrm{m}$ de profundidad y 0,34 m de altura, con un volumen útil de 53 L. Para los ensayos de horneado se utilizó el modo convencional del horno, encendiendo las resistencias superior e inferior, con convección natural del mismo. En este procedimiento se probaron diferentes condiciones de horneado, ya que la receta original indicaba que: "la cocción de la masa debe realizarse en horno bien caliente, hasta que apenas tome color la parte inferior del producto" (Celíacos Argentinos, 2013). 
La temperatura máxima de un horno comercial en promedio alcanza los $200^{\circ} \mathrm{C}$. Como el tiempo también es un factor de relevancia industrial, se consideraron dos temperaturas $\left(180\right.$ y $\left.200^{\circ} \mathrm{C}\right)$ y los correspondientes tiempos necesarios para obtener un producto bien horneado. En la Tabla 5.2 se muestran las diferentes condiciones ensayadas para hornear las galletitas.

Tabla 5.2. Condiciones de horneado ensayadas.

\begin{tabular}{|c|c|}
\hline Temperatura $\left({ }^{\circ} \mathrm{C}\right)$ & Tiempo (minutos) \\
\hline 180 & 10 \\
\hline 180 & 15 \\
\hline 200 & 7,5 \\
\hline 200 & 10 \\
\hline 200 & 15
\end{tabular}

Con el fin de seleccionar las mejores condiciones de cocción se llevaron a cabo ensayos de evaluación organoléptica en forma interna o preliminar: las galletitas elaboradas fueron sometidas a la degustación por parte del equipo de trabajo asociado al tema con el fin de caracterizar el producto obtenido. En base a los resultados obtenidos, las temperaturas y los tiempos preseleccionados fueron los que se encuentran en la Tabla 5.3 .

Tabla 5.3. Condiciones de horneado ensayadas en las diferentes formulaciones.

\begin{tabular}{c|c|}
\hline Temperatura $\left({ }^{\circ} \mathrm{C}\right)$ & Tiempo (minutos) \\
\hline 180 & 10 \\
\hline 200 & 7,5 \\
\hline 200 & 10 \\
\hline
\end{tabular}


La Figura 5.6 muestra el esquema o diagrama de flujo empleado para la elaboración de las galletitas dulces.

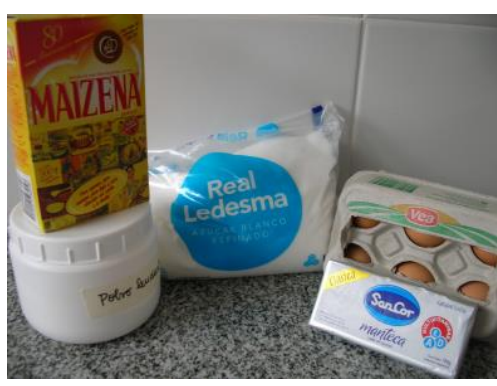

Preparación de la mezcla
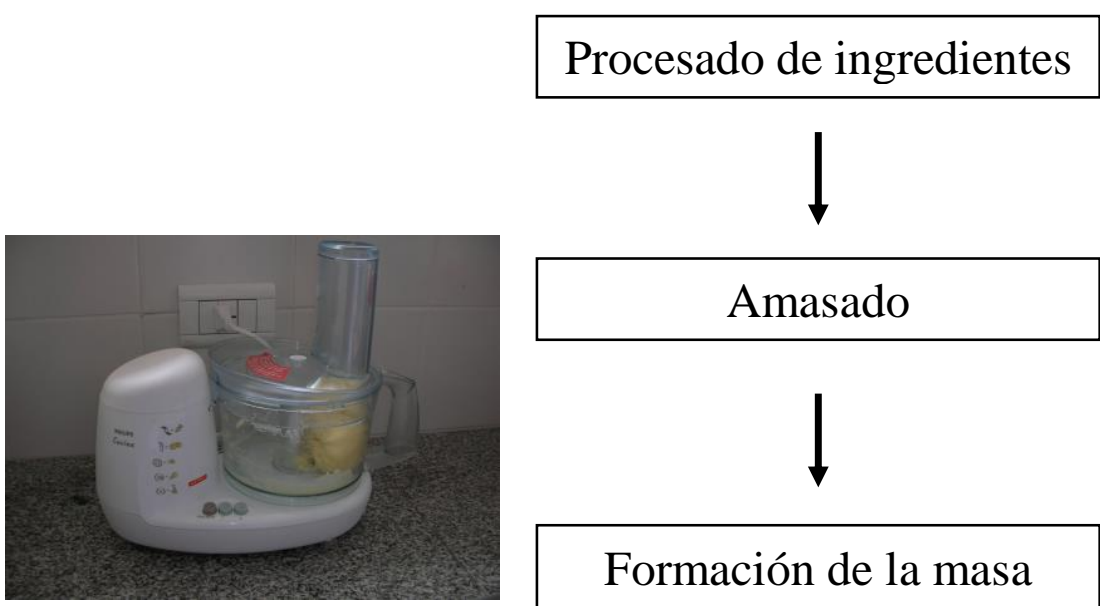

$\downarrow$
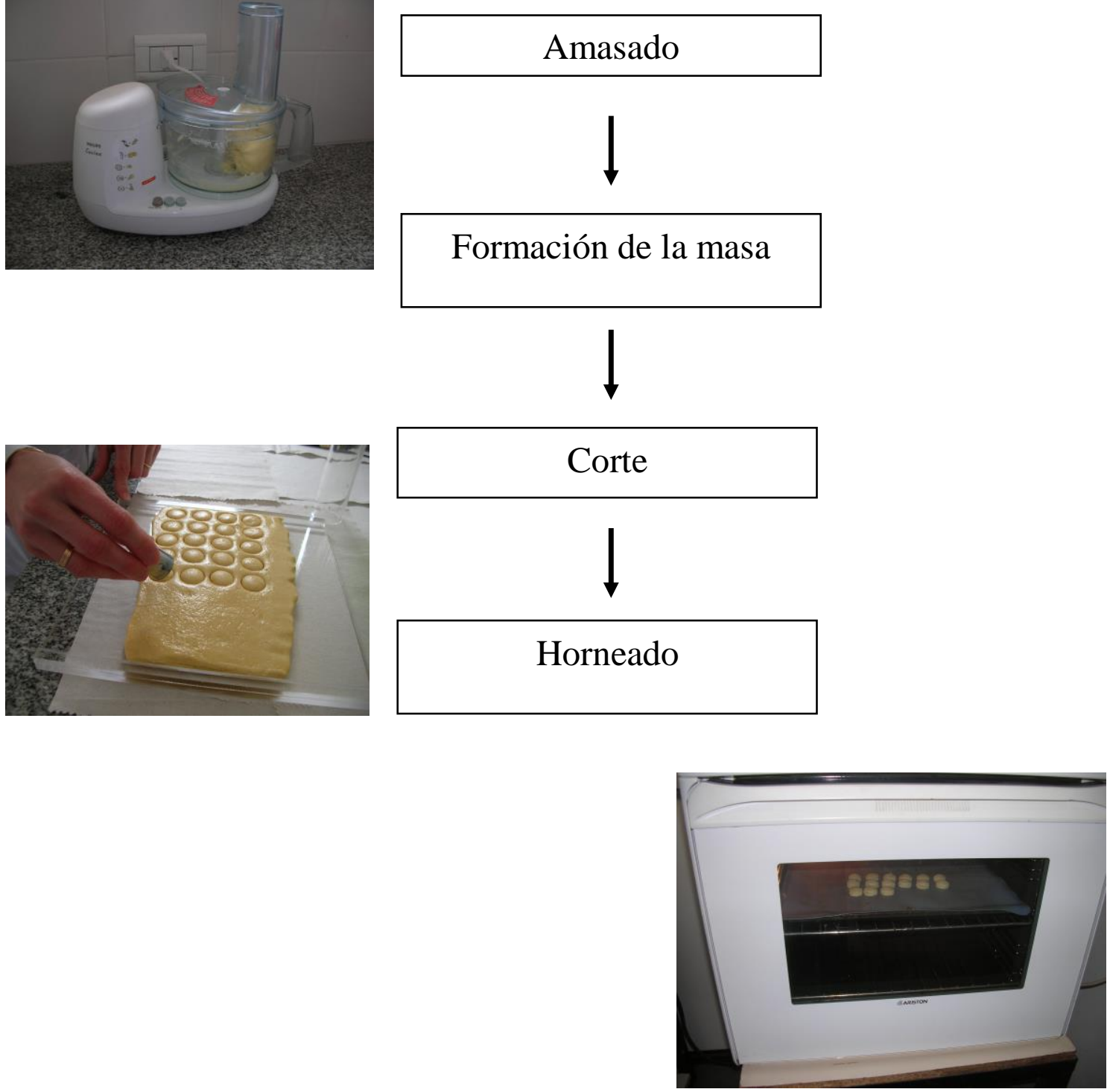

Figura 5.6. Diagrama del proceso de producción de galletitas dulces elaboradas a base almidón de maíz. 


\section{Caracterización de las mezclas secas}

Se caracterizaron el color y la capacidad de retención de solventes de las mezclas o premezclas secas sin leudante de las formulaciones 0 (100\% almidón de maíz o mezcla base), 3 (75\% almidón de maíz y 25\% harina de ahipa), 5 (75\% almidón de maíz y 25\% harina de mandioca) y 6 (75\% almidón de maíz y 25\% harina de trigo integral comercial) (ver Tabla 5.1) según la metodología descripta en el Capítulo 1.

\subsection{Color superficial de las mezclas secas}

La apariencia es muchas veces el único atributo en el cual basamos la decisión de compra o consumo de un producto. El color del producto final está determinado además de la formulación y de las condiciones de horneado por el color de las mezclas secas. Así, para la determinación de color, se realizaron 10 medidas sobre cada mezcla seca; los valores de luminosidad $\left(\mathrm{L}^{*}\right)$, hue $\left(\mathrm{h}^{\circ}\right)$ y Chroma $\left(\mathrm{C}^{*}\right)$ informados corresponden al promedio de las determinaciones. Los cálculos se realizaron como se indicó en el Capítulo 1.

\subsection{Capacidad de retención de solventes}

La capacidad de retención de solventes se cuantificó en las cuatro mezclas secas indicadas siguiendo el método AACC 56-11 (Rosell y col., 2009). Los solventes utilizados fueron agua desionizada, sacarosa $50 \% \mathrm{p} / \mathrm{p}$, carbonato de sodio $5 \% \mathrm{p} / \mathrm{p}$ y ácido láctico $5 \% \mathrm{p} / \mathrm{p}$. La capacidad de retención de solventes se calculó como se explicó en el Capítulo 1. Los resultados se expresaron en porcentaje (\%).

\section{Caracterización de las masas crudas}

Con el fin de caracterizar las masas elaboradas se analizó el perfil de textura, el color superficial, la actividad acuosa y el contenido de humedad de las masas crudas de todas las formulaciones ensayadas.

\subsection{Análisis de perfil de textura}

El término textura puede ser definido como la manifestación sensorial de la estructura o composición inherente en términos de su reacción a la fuerza, medida como propiedad mecánica (dureza/firmeza, adhesividad, cohesividad, gomosidad, 
viscosidad) y/o por el sentido quinestésico en los músculos de la mano, dedos, lengua, mandíbula o labios.

La evaluación de las propiedades mecánicas se realiza comúnmente utilizando ensayos de compresión para simular el proceso de la masticación y determinar la textura de los productos.

El análisis del perfil de textura se llevó a cabo de la misma forma que se describe en el Capítulo 1 sobre discos de masa cruda de $3 \mathrm{~cm}$ de diámetro y $8 \mathrm{~mm}$ de espesor acondicionados a $4^{\circ} \mathrm{C}$ durante 30 minutos. Los parámetros fueron analizados según Andrés y col. (2006) y Bourne y col. (1978).

\subsection{Color superficial de las masas crudas}

Para la determinación de color, se utilizaron 10 muestras (masa cruda), de cada formulación, procediendo como se indica en el Capítulo 1. Los resultados informados corresponden al promedio de las determinaciones.

\subsection{Actividad acuosa}

La actividad acuosa $\left(a_{w}\right)$ es un parámetro que indica la disponibilidad de agua en un alimento para que existan reacciones químicas, bioquímicas (tales como oxidación de lípidos, reacciones enzimáticas, reacción de Maillard) y desarrollo microbiano (Gálvez y col., 2006). Por esto la actividad acuosa es un parámetro comúnmente usado como uno de los indicadores para predecir la vida útil de un alimento.

Para medir la actividad acuosa de la masa cruda de todas las muestras se utilizó el equipo Meter Aqualab serie 3 (Decagon Devices, Inc., Washington, Estados Unidos) tal como se muestra en la Figura 5.6.a, que emplea el método de determinación de punto de rocío. El rango de medición de $a_{w}$ del equipo se encuentra entre 0,03 y 1 , con una resolución de $\pm 0,001$.

La actividad acuosa de las muestras se midió por triplicado a $25^{\circ} \mathrm{C}$. Se utilizó una solución de sulfato de potasio saturada como estándar de calibración $\left(25^{\circ} \mathrm{C}\right)$. 

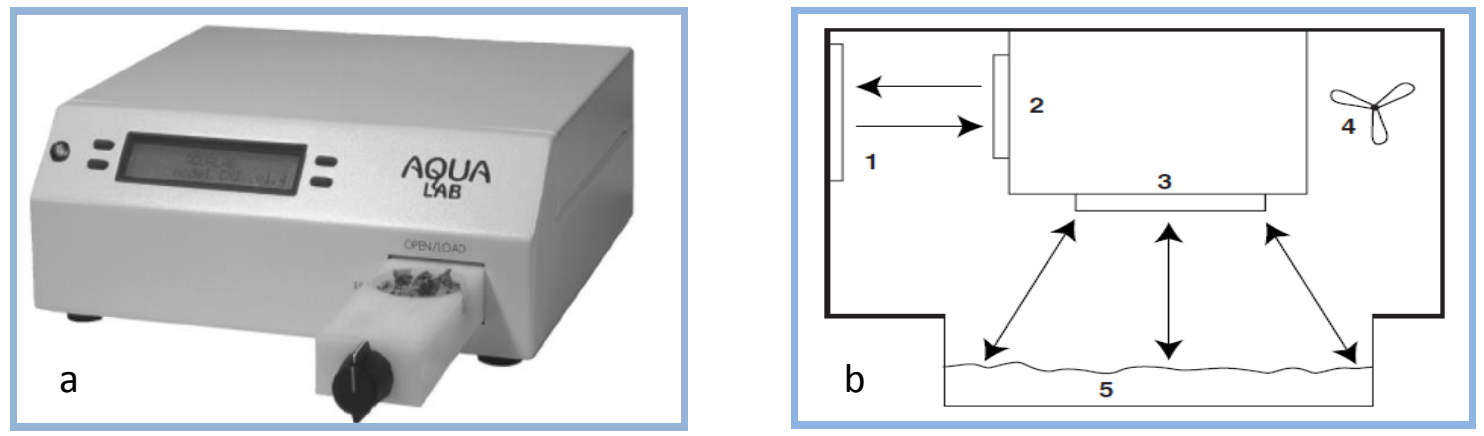

Figura 5.6. (a) Equipo AQUALAB Serie 3 empleado para las determinaciones de $a_{w}$, (b) modelo del funcionamiento interno del AQUALAB (1-espejo, 2-sensor óptico, 3termómetro infrarrojo, 4-micro ventilador, 5-porta muestra cargado)

\subsection{Contenido de humedad}

El contenido de humedad de las muestras se determinó según norma AOAC (1990), por secado en estufa a $105^{\circ} \mathrm{C}$ hasta peso constante, tal como se describió en el Capítulo 1.

\section{Atributos de calidad y composición química de las galletitas}

Las galletitas elaboradas fueron analizadas con el fin de evaluar su estabilidad y valor nutritivo. Para ello se realizaron medidas de parámetros fisicoquímicos y funcionales.

\subsection{Contenido de materia seca}

Se evaluó gravimétricamente el contenido de materia seca y humedad remanente de todas las galletitas elaboradas con las diferentes formulaciones, por deshidratación en estufa a $105^{\circ} \mathrm{C}$ hasta peso constante, tal como se describió en el Capítulo 1 . Los resultados fueron expresados en porcentaje (\%).

\subsection{Determinación de cenizas totales}

Las galletitas de las formulaciones 0 (100\% almidón de maíz), 3 (75\% almidón de maíz y $25 \%$ harina de ahipa), 5 (75\% almidón de maíz y 25\% harina de mandioca) y 6 (75\% almidón de maíz y $25 \%$ harina de trigo integral comercial) fueron molidas previamente en un mortero y colocadas en crisoles previamente tarados. A continuación se 
procedió de la misma forma que en el Capítulo 1 para la cuantificación de cenizas totales. Los resultados finales se expresaron en porcentaje (\%).

\subsection{Extracción y cuantificación de lípidos totales}

Las galletitas molidas de las formulaciones $0,3,5$ y 6 , se pesaron por duplicado (10 g) y se colocaron en cartuchos realizados con papel de filtro. Los mismos se dispusieron en un equipo Soxhlet tal como se explicó en el Capítulo 1. Los resultados se expresaron como porcentaje (\%).

\subsection{Cuantificación de proteína cruda}

Se cuantificó el nitrógeno total de las galletitas dulces elaboradas con las formulaciones $0,3,5$ y 6 mediante el método Kjeldahl. Se procedió tal como se describió en el Capítulo 1. El contenido de proteína cruda se calculó usando el factor de conversión 6,25. Los resultados se expresaron como porcentaje (\%).

\subsection{Contenido de carbohidratos totales}

El contenido de carbohidratos totales se calculó por diferencia, después de la cuantificación de todos los otros componentes del análisis centesimal (humedad, cenizas, proteínas y lípidos totales) como se detalló en el Capítulo 1. Los resultados se expresaron como porcentaje (\%).

\subsection{Fibra dietaria total}

Se midió en las galletitas preparadas con las formulaciones 0, 3, 5 y 6 el contenido de fibra dietaria total utilizando el kit enzimático K-TDFR 05/12 Megazyme@ (Irlanda). El procedimiento llevado a cabo se detalló en el Capítulo 1. Los resultados se expresaron como porcentaje (\%).

\section{Caracterización fisicoquímica}

La determinación de la calidad de un alimento se lleva a cabo caracterizando los diferentes parámetros fisicoquímicos. 


\subsection{Actividad acuosa de las galletitas}

La medida de actividad acuosa se realizó en las galletitas dulces estudiadas utilizando el equipo que se detalla en el apartado 5.3, efectuando las mediciones a $25^{\circ} \mathrm{C}$. El ensayo se llevó a cabo por triplicado.

\subsection{Propiedades ópticas: color superficial de las galletitas}

Para la determinación de color, se utilizaron 10 muestras (galletitas) de cada formulación, horneadas a las diferentes condiciones. El ensayo se llevó a cabo tal como se describió en el ítem 4.1. Los resultados fueron expresados como diferencias de color $(\Delta E)$ calculadas respecto de la masa cruda correspondiente a cada formulación y también en relación a las coordenadas que caracterizaron el color de la galletita horneada de la formulación 0 (con 100\% de almidón de maíz). La ecuación utilizada es la presentada en el Capítulo 1.

Asimismo, a partir de las medidas de color superficial se calculó el índice de pardeamiento (IP) que estima la pureza del color marrón (Buera y col., 1985). Este parámetro presenta una correlación lineal con la concentración de pigmento marrón, resultando de utilidad en la evaluación de los cambios de color en aquellos alimentos que experimentan reacciones de pardeamiento enzimático y no enzimático, como es el caso de los productos horneados. El índice de pardeamiento se calculó utilizando las ecuaciones 5.1 y 5.2 .

$$
x=\frac{a^{*}+1,75 L^{*}}{5,645 L^{*}+a^{*}-3,012 b^{*}}
$$

Donde:

$$
I P=\frac{100(x-0,31)}{0,172}
$$

a*: parámetro de cromaticidad que indica la variación o posición entre verde y rojo

b*: parámetro de cromaticidad que indica la variación o posición entre azul y amarillo

$L^{*}$ : parámetro de luminosidad 


\subsection{Ensayos de textura en el producto horneado}

Se utilizaron diferentes sondas del texturómetro TA-XT2i Stable Micro System (Surrey, Reino Unido) mencionado en el Capítulo 1, empleando el programa Texture Expert para Windows (v.1.2) para estudiar la textura de las galletitas y con el fin de encontrar la medida más representativa del proceso de masticación del producto elaborado. Se probaron los siguientes ensayos de compresión: de punción con sonda SMS de $3 \mathrm{~mm}$, TPA con sonda SMS de $75 \mathrm{~mm}$, con cuchilla de hoja lisa y por último compresión con la sonda Volodkevich Bite Jaws (ver Figura 5.8) que simula la acción de morder y cortar la muestra con los dientes incisivos, siendo éste el ensayo seleccionado en base a los resultados obtenidos. Los parámetros registrados fueron la fuerza máxima que se relaciona con la firmeza de la muestra, y el área debajo de la curva, que se asocia directamente con la energía requerida para cortar la muestra (Olivera y Salvadori, 2012). Se analizaron doce repeticiones para cada muestra.

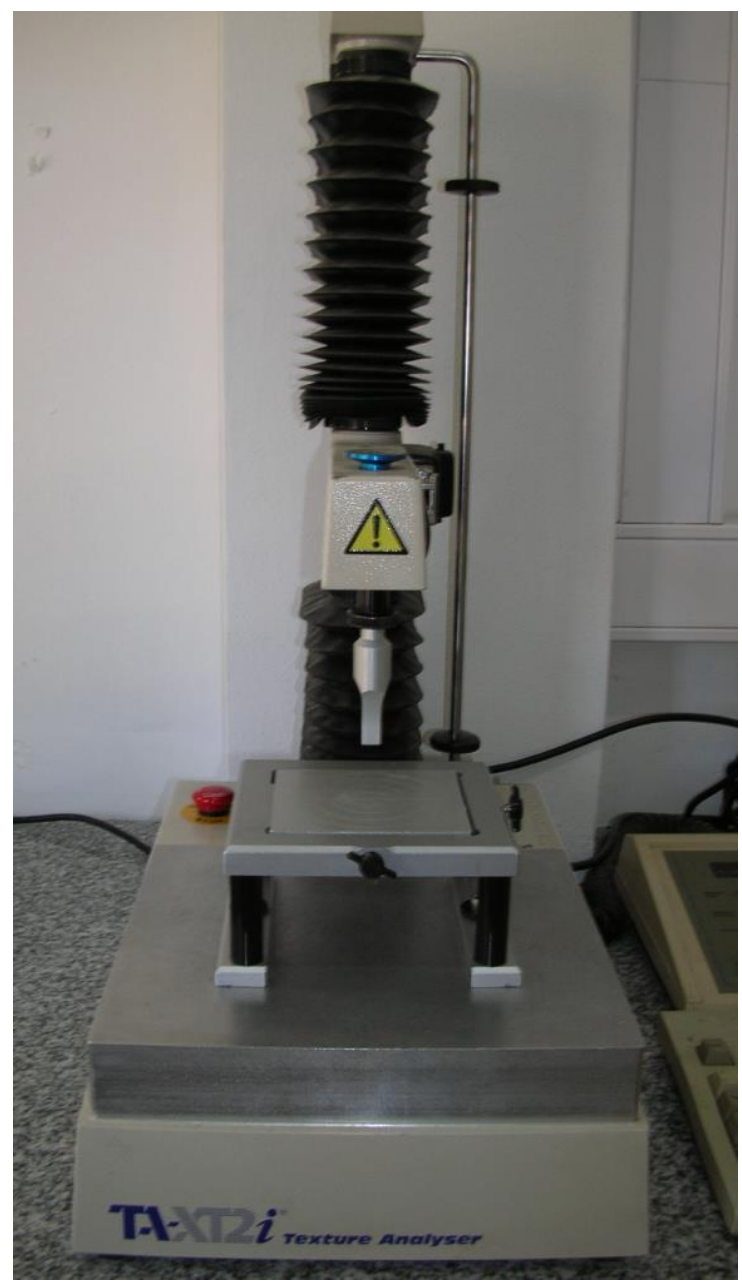

Figura 5.8. Sonda Volodkevich Bite Jaws. 


\subsection{Medida del volumen del producto horneado}

Se midió el volumen de las galletitas utilizando una probeta $(250 \mathrm{~mL})$ y semillas de colza. El procedimiento consistió en agregar $200 \mathrm{~mL}$ de semillas de colza en la probeta y luego cada muestra (por quintuplicado) en la misma. Luego se invirtió el sistema tres veces y se leyó el volumen de semillas desplazadas por la muestra $(\mathrm{mL})$. El volumen es directamente proporcional al desplazamiento medido y se expresó en $\mathrm{cm}^{3}$.

\section{Evaluación de la aceptabilidad del producto mediante panel sensorial}

La División de Evaluación Sensorial del Instituto de Tecnólogos de Alimentos de los Estados Unidos (IFT), define la evaluación sensorial como: "la disciplina científica utilizada para evocar, medir, analizar e interpretar las reacciones a aquellas características de alimentos y otras sustancias, que son percibidas por los sentidos de la vista, olfato, gusto, tacto y oído". Esta definición implica que:

- La evaluación sensorial involucra a todos los sentidos.

- Cubre una variedad de disciplinas científicas: psicología, estadística, tecnología de alimentos y sociología.

- En la interpretación de los resultados, el análisis sensorial es el puente entre el mundo interno de una empresa y el mundo externo o sea el mercado. Para una empresa orientada al consumidor, el valor más importante es su reputación en proveer productos de calidad. Productos de calidad constante son esenciales en la aceptación del consumidor y son la base para conseguir la lealtad a la marca.

El sabor (flavor) es la sensación que causa un alimento en la boca al ser percibido por los sentidos químicos (olfato, gusto y sentido químico común). El término "aromáticos" se emplea para indicar los constituyentes volátiles que se originan de un alimento en la boca y son percibidos por el sistema olfatorio a través de las coanas posteriores.

La calidad organoléptica cobra cada vez más importancia ya que los consumidores demandan una apariencia "impecable" del producto final y resulta necesaria su evaluación.

Se diseñaron los ensayos sensoriales teniendo en cuenta las siguientes condiciones generales: 
Evaluadores: Los evaluadores deben dar juicios independientes, por lo tanto, para prevenir posible comunicación entre ellos, se realiza el ensayo en grupos de 6 u 8 personas en un mismo espacio físico.

Horario: La hora del día en que se desarrollan las pruebas puede influir en los resultados. Los mejores momentos para llevar a cabo el ensayo serían al finalizar la mañana y la media tarde. En este caso los ensayos se realizaron alrededor de las 11:00 horas.

Temperatura de las muestras: Para ensayos de aceptabilidad, lo mejor es servir las muestras a la temperatura que normalmente se consumen. En este caso las galletitas se presentaron a temperatura ambiente.

Codificación y orden de presentación: Se ha demostrado que en algunos casos existe un efecto del orden de presentación sobre los resultados. La presentación de una muestra de muy buena calidad antes de otra más pobre, hace que esta última reciba un puntaje menor del que recibiría si el orden fuera inverso. Para evitar éste y otros problemas, el orden de presentación debe ser al azar. Los códigos con que se identifican las muestras no deben dar ningún indicio sobre los tratamientos. En general se utilizan códigos numéricos de tres dígitos. Los códigos empleados en el análisis sensorial se encuentran en la Figura 5.9.

Neutralizante: Los evaluadores reciben algún agente para el enjuague de la boca entre las muestras. En general se utiliza agua de la zona a temperatura ambiente. Para alimentos grasos, es mejor que el agua esté tibia. Para casos específicos se han utilizado distintos agentes como apio, manzana o galletita. Otro buen neutralizante es el tiempo entre muestra y muestra: evaluadores entrenados en evaluación de quesos esperan 5 minutos antes de probar la siguiente muestra. En nuestro caso se empleó agua corriente.

Existen numerosos métodos para medir aceptabilidad sensorial entre los que se destacan: comparación de a pares; ordenamiento de preferencia y escala hedónica. Para evaluar la aceptabilidad del producto elaborado se empleó el método de Escala Hedónica valorando los atributos de color, sabor, textura y aceptabilidad general. Cada atributo se presentó con una escala estructurada del 1 al 9. Además se incorporaron 
las leyendas "me disgusta mucho", "me es indiferente" y "me gusta mucho" correspondientes a los valores 1,5 y 9 de la escala citada (Figuras 5.9 y 5.10).

Un total de 60 consumidores o evaluadores participaron del análisis de aceptabilidad conformando un panel no entrenado. En estos ensayos se tuvieron en cuenta la edad y el sexo de los panelistas.

Las muestras, codificadas con tres dígitos y dispuestas al azar, fueron presentadas a los evaluadores en bandejas.

Se evaluaron las características sensoriales de las galletitas mediante dos ensayos de aceptabilidad sensorial. El primer ensayo consistió en analizar las galletitas elaboradas con un $25 \%$ de harina de ahipa y horneadas a $200^{\circ} \mathrm{C}$, en dos tiempos: 7,5 y 10 minutos. Debido a que ésta fue la formulación con mejor desempeño, el objetivo de este ensayo sensorial fue seleccionar el tiempo de cocción preferido por los consumidores o evaluadores del panel mediante el uso de la escala hedónica. Además, con el fin de estimar los mejores descriptores del producto se les solicitó a los consumidores comentar observaciones de los mismos y responder la pregunta de preferencia. En esta sesión los panelistas recibieron dos muestras.

Los casilleros marcados por el consumidor se transformaron en puntajes para el análisis de los resultados. A partir de los puntajes relativos obtenidos para las distintas muestras, se pudo inferir la muestra preferida.

Además de la formulación seleccionada de la harina de ahipa, en el segundo ensayo se incluyeron galletitas elaboradas con harina de mandioca (25\%) y almidón de maíz (100\%), en la condición de horneado seleccionada en el ensayo anterior. El objetivo fue comparar el grado de aceptabilidad sensorial del producto desarrollado.

Los casilleros señalados por el evaluador se convirtieron en puntajes para el análisis de los resultados de las distintas muestras. De esta manera se pudo cuantificar la aceptabilidad de las muestras y obtener el histograma que evidencia la distribución de las preferencias de los consumidores. 


\section{ACEPTABILIDAD DE GALLETITAS POR ATRIBUTOS}

Nombre:

Edad:

Consumidor №

Ud. recibirá dos muestras de galletitas, utilizando la siguiente escala, por favor evalúe la aceptabilidad de cada atributo.

Comience con el producto que se ubica a su izquierda y luego con el de su derecha.

$\begin{array}{ccc} & \text { MUESTRA № 467 } & \\ \text { Me } & \text { Me } & \text { Me } \\ \text { disgusta } & \text { es } & \text { gusta } \\ \text { mucho } & \text { indiferente } & \text { mucho }\end{array}$

Color

Sabor

Textura

Aceptabilidad general

\begin{tabular}{|c|c|c|c|c|c|c|c|c|c|}
\hline & & & & ES & $A \cap$ & 803 & & & \\
\hline & $\begin{array}{c}\text { Me } \\
\text { disgusta } \\
\text { mucho }\end{array}$ & & & & $\begin{array}{l}\text { Me } \\
\text { es } \\
\text { fere }\end{array}$ & & & & $\begin{array}{l}\text { Me } \\
\text { gusta } \\
\text { much }\end{array}$ \\
\hline Color & $\square$ & $\square$ & $\square$ & $\square$ & $\square$ & $\square$ & $\square$ & $\square$ & $\square$ \\
\hline Sabor & $\square$ & $\square$ & $\square$ & $\square$ & $\square$ & $\square$ & $\square$ & $\square$ & $\square$ \\
\hline Textura & $\square$ & $\square$ & $\square$ & $\square$ & $\square$ & $\square$ & $\square$ & $\square$ & $\square$ \\
\hline
\end{tabular}

Aceptabilidad general

Si tuviera que elegir una de las muestras, cuál preferiría?.

Por favor, comente las razones de su elección.

Observaciones

Figura 5.9. Planilla utilizada en el primer ensayo sensorial de aceptabilidad por atributos de las galletitas. 


\section{ACEPTABILIDAD DE GALLETITAS POR ATRIBUTOS}

Nombre:

Edad:

Consumidor №

Ud. recibirá tres muestras de galletitas, utilizando la siguiente escala, por favor evalúe la aceptabilidad de cada atributo.

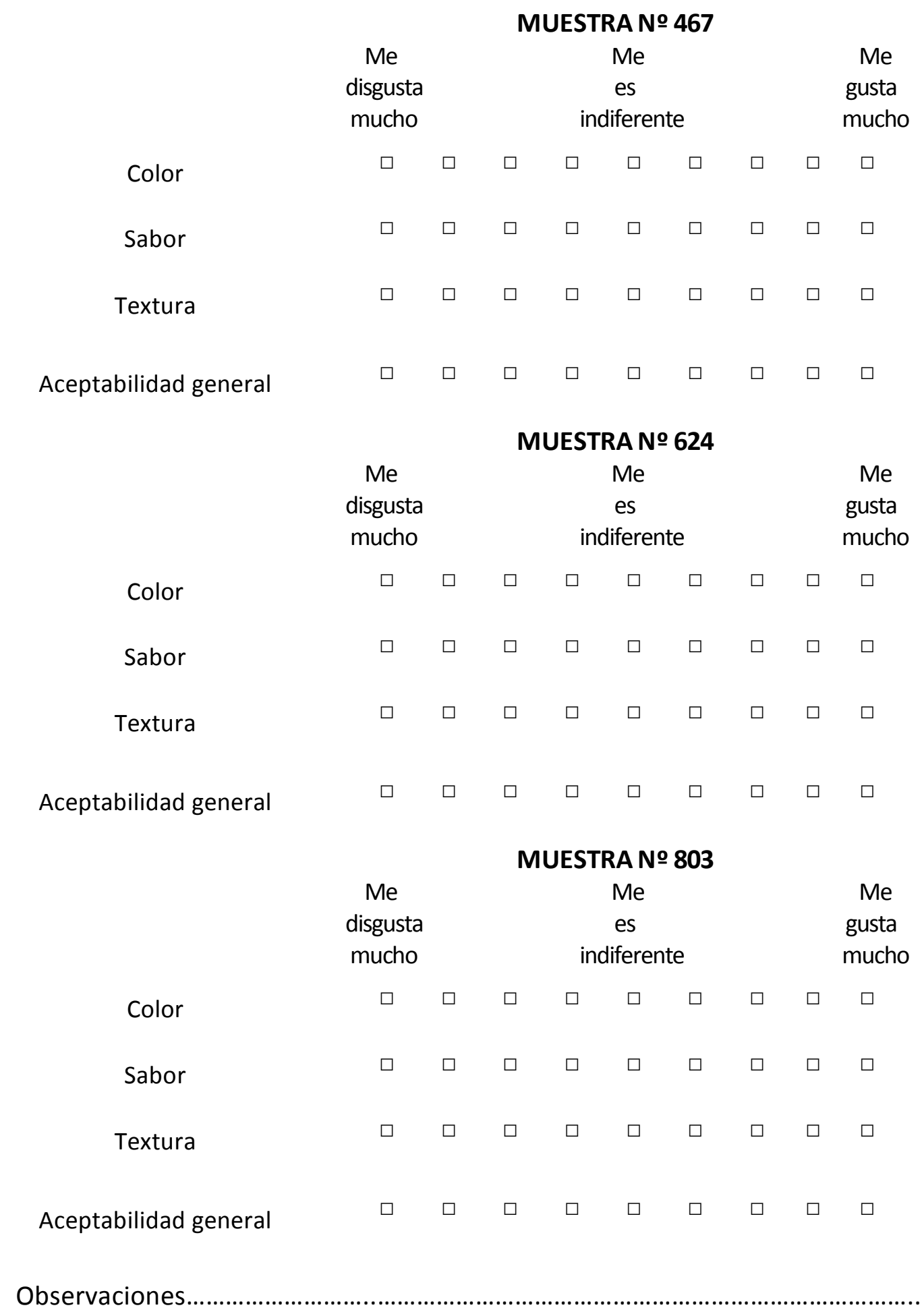

Figura 5.10. Planilla utilizada en el segundo ensayo sensorial de aceptabilidad por atributos de las galletitas. 
Cuando se compara un producto con otros comerciales se puede analizar la diferencia que existe entre los mismos. El ensayo es de dos colas ya que de antemano no es posible predecir el sentido de la diferencia. Para comparar los promedios se utilizó el test de Student para ensayos dependientes ya que cada consumidor prueba en un caso dos y en otro tres de las galletitas dulces. La fórmula a utilizar para hallar el estadístico t-Student experimental ( $t_{\exp }$ ) es la ecuación 5.3. (Meilgaard y col., 2007)

$$
t_{\exp }=\frac{\bar{d}}{S_{d} / \sqrt{N}}
$$

Donde:

$\overline{\mathrm{d}}=\frac{\sum d_{i}}{\mathrm{~N}}$

$\mathrm{S}_{\mathrm{d}}={\sqrt{\frac{\sum\left(d_{i}-\bar{d}\right)}{N-1}}}^{2}$

Siendo:

$\mathrm{N}=$ número de evaluadores/consumidores

$\overline{\mathrm{d}}=$ diferencia promedio

$\mathrm{d}_{\mathrm{i}}=$ diferencia evaluada por cada consumidor

$\mathrm{S}_{\mathrm{d}}=$ desviación estándar de la diferencia

\section{Análisis estadístico}

Se realizaron análisis multifactoriales de varianza mediante el uso del software InfoStat versión 2013. Las diferencias se determinaron mediante el test de la diferencia mínima significativa de Fisher (LSD) usando un nivel de significación $p=0,05$. Como ya se mencionó, para el análisis estadístico de los ensayos sensoriales se empleó además el test de Student. 


\section{RESULTADOS Y DISCUSIÓN}

\section{Elaboración de las galletitas}

Se optimizaron las condiciones de obtención de las galletitas formuladas en base a almidón de maíz.

Con el objetivo de lograr una masa flexible, fácil de cortar y manipular, se probaron los tiempos de amasado y reposo de la misma en la formulación 0. La masa obtenida, luego de procesar e integrar todos sus ingredientes (hasta completa homogeneización de los mismos) se dejó reposar a $4^{\circ} \mathrm{C}$ durante 30 minutos. La masa cruda refrigerada mostró una mejor aptitud al amasado y posterior corte.

Además se ensayaron los distintos reemplazos de almidón de maíz por harina obtenida de la raíz tuberosa de ahipa, con el fin de encontrar un producto nutritivo y agradable al consumidor.

Finalmente se probaron los diferentes tiempos y temperaturas de horneado (Tabla 5.2) en las galletitas elaboradas con 100\% almidón de maíz (formulación 0) para finalmente utilizar las condiciones de cocción citadas en la Tabla 5.3.

\section{Caracterización de las mezclas secas}

Las mezclas secas caracterizadas fueron las correspondientes a las formulaciones que se encuentran en la Tabla 5.4.

Tabla 5.4. Mezclas secas de las formulaciones ensayadas.

\begin{tabular}{|c|c|c|c|c}
\hline Mezcla seca & Almidón de maíz & Harina de ahipa & Harina de mandioca & Harina integral \\
\hline 0 & $100 \%(300 \mathrm{~g})$ & - & - & - \\
\hline 3 & $75 \%(225 \mathrm{~g})$ & $25 \%(75 \mathrm{~g})$ & - & - \\
\hline 5 & $75 \%(225 \mathrm{~g})$ & - & $25 \%(75 \mathrm{~g})$ & - \\
\hline 6 & $75 \%(225 \mathrm{~g})$ & - & - & $25 \%(75 \mathrm{~g})$
\end{tabular}

\subsection{Color}

En cuanto a los atributos de color, en la Tabla 5.5 se muestran los valores promedio de hue $\left(\mathrm{h}^{\circ}\right)$, Chroma $\left(\mathrm{C}^{*}\right)$ y luminosidad $\left(\mathrm{L}^{*}\right)$ para las cuatro mezclas secas $(0,3,5$ y 6$)$. 
Tabla 5.5. Valores luminosidad $\left(\mathrm{L}^{*}\right)$, hue $\left(\mathrm{h}^{\circ}\right)$ y Chroma $\left(\mathrm{C}^{*}\right)$, de las mezclas secas.

\begin{tabular}{c|c|c|c}
\hline Formulación & $\mathrm{L}^{*}$ & $\mathrm{~h}^{\circ}$ & $\mathrm{C}^{*}$ \\
\hline 0 & $96,9 \pm 0,5^{\mathrm{c}}$ & $94,2 \pm 0,5^{\mathrm{c}}$ & $5,5 \pm 0,6^{\mathrm{a}}$ \\
\hline 3 & $93,4 \pm 0,5^{\mathrm{a}}$ & $85,7 \pm 0,6^{\mathrm{a}}$ & $7,7 \pm 0,2^{\mathrm{b}}$ \\
\hline 5 & $95,5 \pm 0,3^{\mathrm{b}}$ & $90,5 \pm 0,2^{\mathrm{b}}$ & $7,7 \pm 0,2^{\mathrm{b}}$ \\
\hline 6 & $94,9 \pm 0,6^{\mathrm{b}}$ & $95,2 \pm 0,6^{\mathrm{d}}$ & $5,5 \pm 0,5^{\mathrm{a}}$
\end{tabular}

Nota: Los valores informados corresponden a las medias \pm las desviaciones estándar. Datos acompañados por una misma letra en la misma columna, no difieren significativamente $(p>0,05)$.

Como era de esperar, los valores de Chroma más altos se observaron en las mezclas secas 3 y 5 , en correspondencia con sus ingredientes (harinas de ahipa y mandioca, respectivamente), debido a que ambas harinas presentaron los mayores valores de este atributo (Capítulo 4) respecto de la harina de trigo integral tamizada $\left(C^{*}=8,3\right.$ ).

La mezcla 3 que contiene harina de ahipa obtuvo el valor más bajo de hue en concordancia con el menor tinte básico de la harina de ahipa $\left(h^{\circ}=85,4\right)$ respecto de la harina de mandioca $\left(h^{\circ}=91,3\right)$, como se describió en el Capítulo 4 . Los valores más altos de este atributo correspondieron a las mezclas secas 0 y 6 donde el color del almidón de maíz fue el responsable, ya que el valor de hue de la harina de trigo integral tamizada fue de $86,2^{\circ}$.

El parámetro $L^{*}$ más elevado se correspondió con la mezcla 0 (100\% almidón de maíz). La harina de trigo integral, previamente tamizada, presentó un valor de $L^{*}(92,5)$ superior al de las harinas de mandioca y ahipa (84,1 y 90,9 , respectivamente).

\subsection{Capacidad de retención de solventes}

La capacidad de retención de solventes es una prueba que analiza la capacidad que posee la harina o mezcla seca para retener una amplia gama de solventes como un medio para evaluar múltiples aspectos de la calidad de la materia prima asociados al contenido de pentosanos, de almidón dañado, la fuerza del gluten (si estuviera presente), y la retención de agua en general. Estas pruebas se usan comúnmente para establecer la calidad de la harina o mezcla seca y el perfil de funcionalidad práctica necesario para predecir su rendimiento en aplicaciones específicas, como en la formulación de productos horneados. La Figura 5.11 muestra los resultados del ensayo realizado sobre las cuatro mezclas secas evaluadas. 


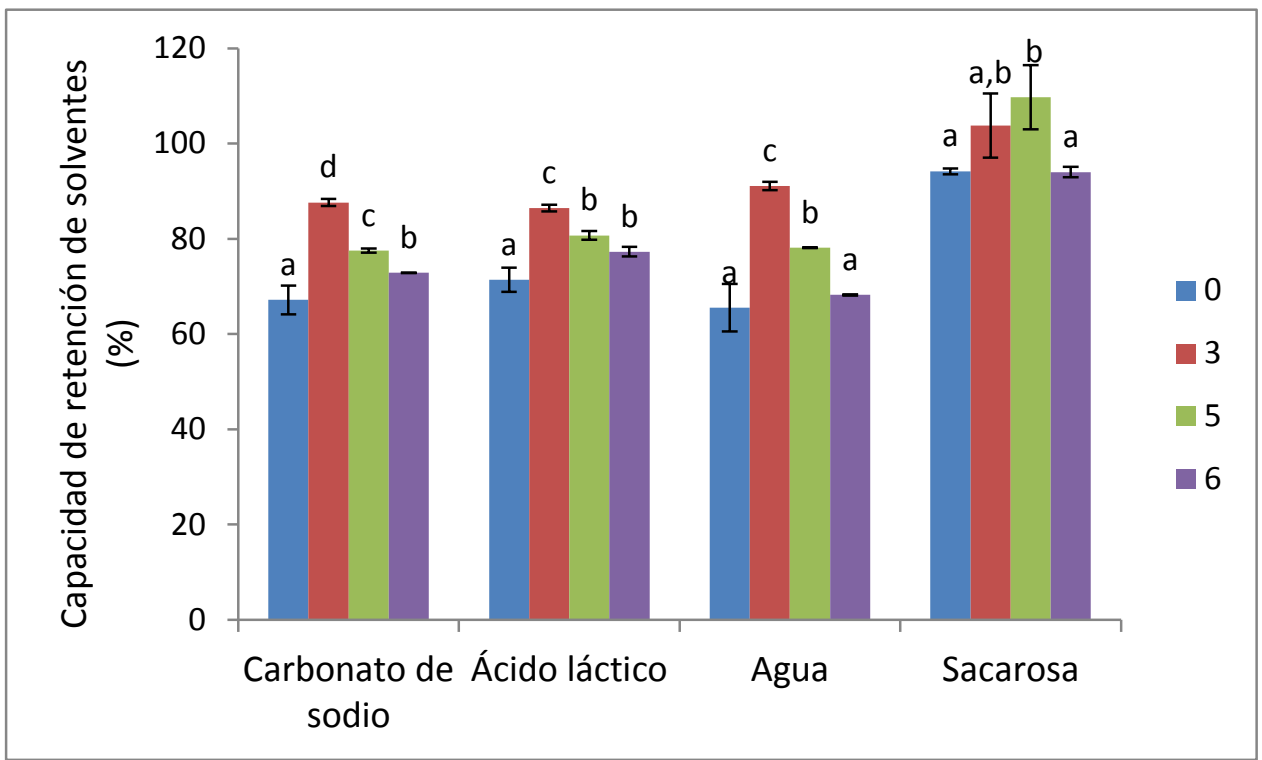

Figura 5.11. Capacidad de retención de solventes de las mezclas secas.

Nota: Los valores informados corresponden a las medias \pm las desviaciones estándar. Datos acompañados por una misma letra para cada uno de los cuatro solventes ensayados, no difieren significativamente $(p>0,05)$.

En general, la mezcla 3 correspondiente a la preparación con harina de ahipa exhibió la más alta capacidad de retención de los solventes ensayados, mientras que la mezcla 0 (100\% almidón de maíz) presentó los valores más bajos. Este comportamiento era de esperar debido al aporte de proteínas de la harina de ahipa (9\%) como se indicó en el Capítulo 4.

Se considera que la capacidad de retención del carbonato de sodio (CRCS) está relacionada con el contenido de almidón dañado de la muestra (Gaines, 2000; Duyvejonck y col., 2011; Dini y col., 2013). El valor más bajo fue hallado en la mezcla 0 (100\% almidón de maíz). Se evidenciaron diferencias significativas $(p<0,05)$ entre las mezclas preparadas con harina de ahipa, mandioca y de trigo integral comercial (Figura 5.11).

En general, la capacidad de retención del ácido láctico (CRAL) se asocia con la formación de la red de glutenina y la fuerza del gluten de una harina (Duyvejonck y col., 2011; Dini y col., 2013). Tanto el almidón de maíz como las harinas de ahipa y mandioca son productos libres de gluten, y la CRAL puede estar asociada a la capacidad de la proteína para desarrollar una red, lo que constituye un indicativo de 
las aplicaciones tecnológicas de estos ingredientes. En este caso la mezcla 3 (harina de ahipa) exhibió el valor más alto de CRAL.

En general, se observa una fuerte correlación lineal $\left(R^{2}>0,903\right)$ entre el contenido de fibra dietaria total y la capacidad de retención de agua (CRA). Una tendencia similar se informó para la harina de trigo (Colombo y col., 2008; Duyvejonck y col., 2012; Duyvejonck y col., 2011).

Los valores relativamente bajos de capacidad de retención de agua (CRA) en la mezcla seca de la formulación 6 pueden deberse al proceso de tamizado realizado sobre la harina de trigo integral.

Las mezclas secas 0, 3 y 6 (100\% almidón de maíz, 25\% harina de ahipa y $25 \%$ harina de trigo integral, respectivamente) mostraron la menor capacidad de retención de sacarosa (CRSA), asociada al contenido de pentosanos solubles en agua, cuantificado como fibra soluble, lo que sugiere que estas preparaciones contendrían una mayor proporción de fibra insoluble respecto de la mezcla con harina de mandioca, con los beneficios para la salud que esto conlleva.

\section{Caracterización de las masas}

\subsection{Perfil de textura}

El comportamiento de una masa sometida a una deformación depende principalmente de su composición. El estudio sobre la textura de la masa permite el control de calidad del producto final (Rodríguez-Sandoval y col., 2005).

En la cadena de producción, industrialización, distribución y preparación culinaria, las manipulaciones modifican la estructura de los productos antes de llegar a la boca del consumidor, condicionando la textura, viscosidad y consistencia de las preparaciones (Bjorck y col., 1994, Gustafsson y col., 1995).

En el presente trabajo de Tesis, se analizó el perfil de textura (curva de fuerza en función del tiempo) de las masas crudas de todas las formulaciones ensayadas. En la Figura 5.12 se pueden observar sólo cuatro perfiles correspondientes a las formulaciones $0,3,5$ y 6 (Tabla 5.1). 

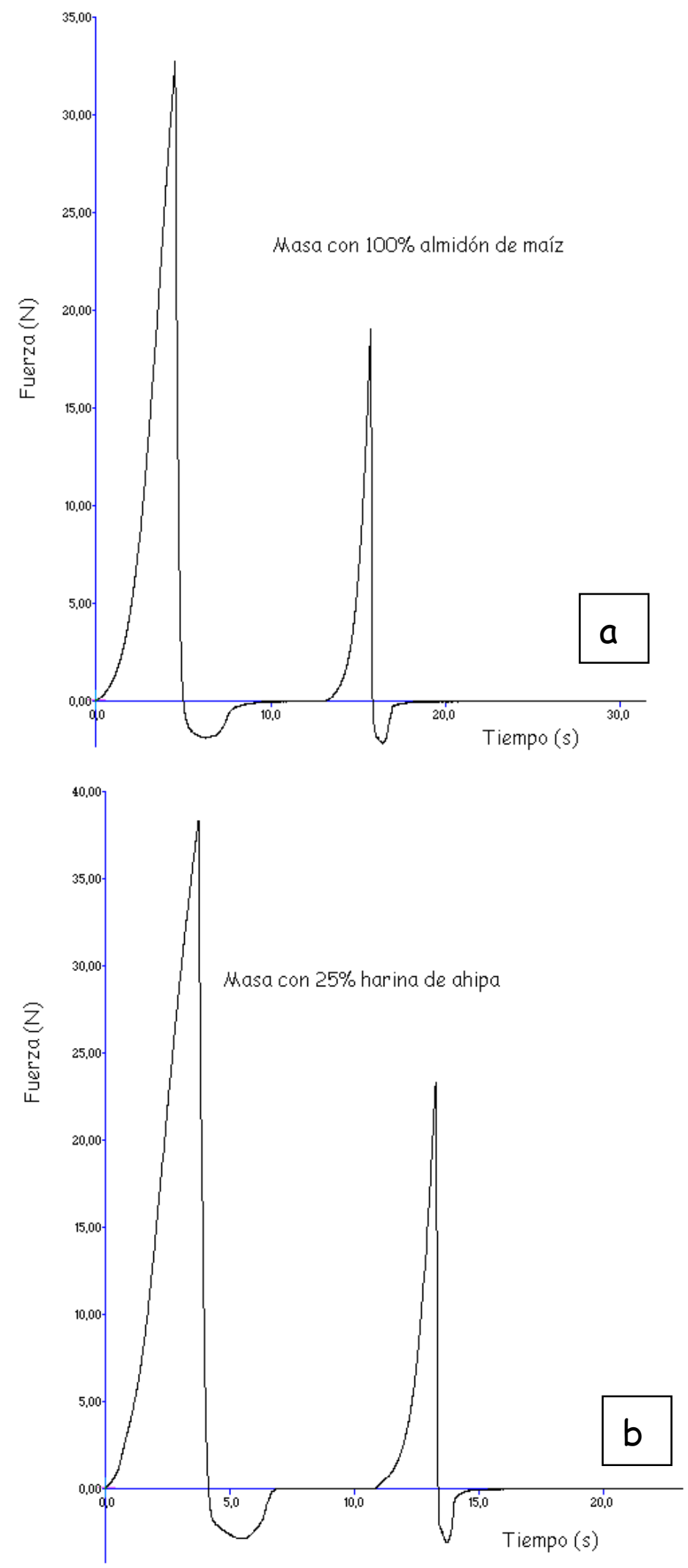

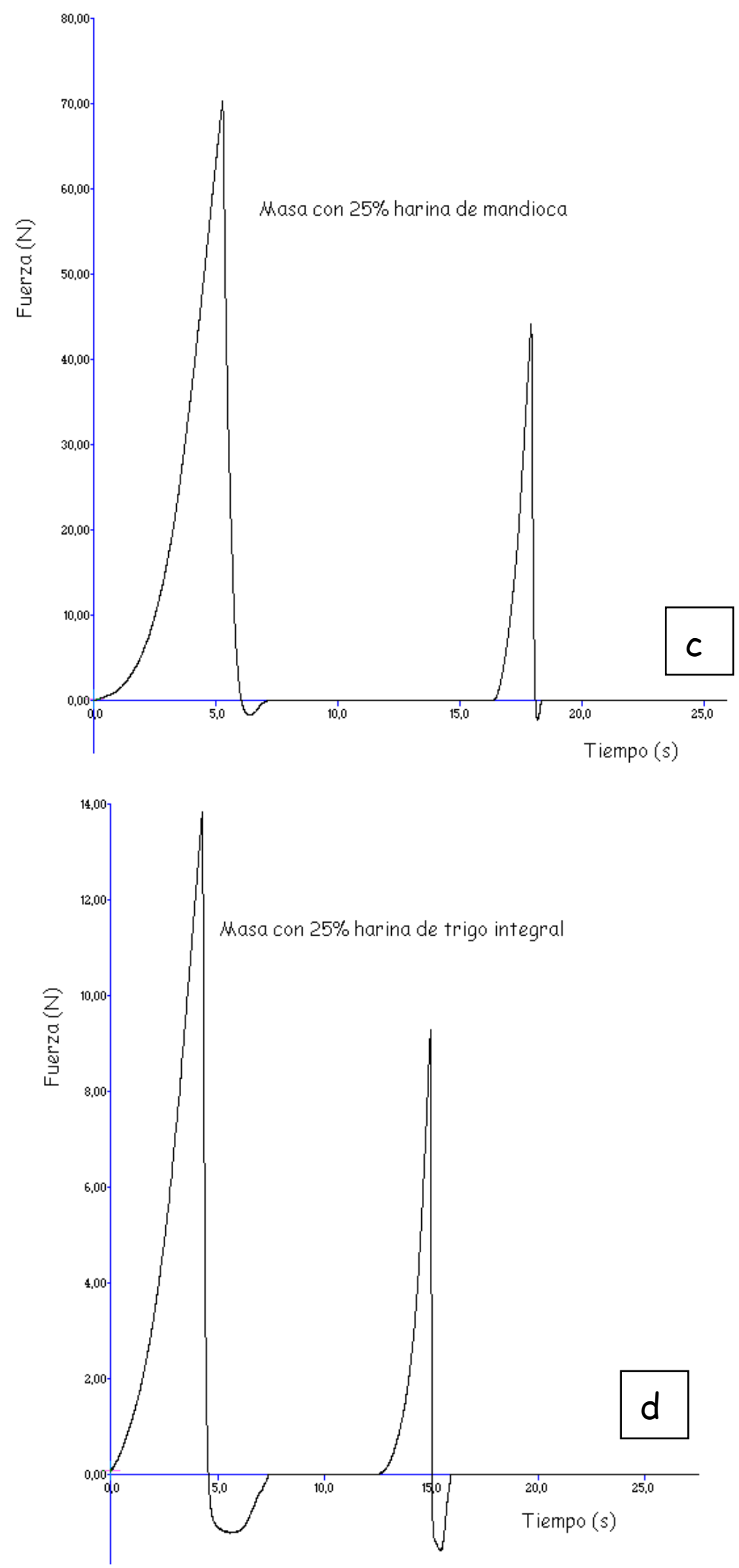

Figura 5.12. Perfil de textura de masa cruda elaborada con a) $100 \%$ almidón de maíz, b) $25 \%$ harina de ahipa, c) $25 \%$ harina de mandioca y d) $25 \%$ harina de trigo integral. 
En la Tabla 5.6 se muestran los parámetros calculados del análisis de perfil de textura para las masas de las formulaciones ensayadas.

Tabla 5.6. Parámetros del análisis de perfil de textura de las masas.

\begin{tabular}{|c|c|c|c|c|c|c|c|}
\hline Masa & $\begin{array}{l}\text { Dureza } \\
(\mathrm{N})\end{array}$ & Elasticidad & Cohesividad & $\begin{array}{c}\text { Gomosidad } \\
(\mathrm{N})\end{array}$ & $\begin{array}{c}\text { Adhesividad } \\
\text { ( } \mathrm{N} \mathrm{mm})\end{array}$ & $\begin{array}{c}\text { Masticabilidad } \\
(\mathrm{N})\end{array}$ & $\begin{array}{c}\text { Consistencia } \\
(\mathrm{N} \mathrm{mm})\end{array}$ \\
\hline 0 & $31,9 \pm 1,9^{b}$ & $1,00 \pm 0,01^{a}$ & $0,23 \pm 0,02^{b}$ & $7,3 \pm 0,7^{c}$ & $4,1 \pm 0,6^{a}$ & $7,3 \pm 0,6^{d}$ & $64,6 \pm 4,3^{b}$ \\
\hline 1 & $29,7 \pm 1,8^{b}$ & $1,00 \pm 0,00^{a}$ & $0,19 \pm 0,03^{a}$ & $5,7 \pm 0,9^{b}$ & $3,6 \pm 0,9^{a, b}$ & $5,7 \pm 0,8^{c}$ & $59,2 \pm 7,6^{b}$ \\
\hline 2 & $13,9 \pm 2,0^{a}$ & $1,00 \pm 0,01^{a}$ & $0,29 \pm 0,03^{c}$ & $4,1 \pm 0,5^{a}$ & $3,3 \pm 0,9^{a, b}$ & $4,1 \pm 0,5^{b}$ & $25,5 \pm 4,6^{\mathrm{a}}$ \\
\hline 3 & $38,5 \pm 1,3^{c}$ & $1,00 \pm 0,01^{a}$ & $0,24 \pm 0,01^{b}$ & $9,2 \pm 0,3^{d}$ & $4,1 \pm 1,3^{a, b}$ & $1,4 \pm 0,1^{a}$ & $76,1 \pm 9,0^{c}$ \\
\hline 4 & $80,4 \pm 0,5^{\mathrm{e}}$ & $1,00 \pm 0,00^{a}$ & $0,22 \pm 0,02^{a, b}$ & $17,9 \pm 1,3^{f}$ & $2,6 \pm 0,8^{b}$ & $17,9 \pm 1,3^{f}$ & $164,2 \pm 5,6^{\mathrm{e}}$ \\
\hline 5 & $68,2 \pm 4,3^{d}$ & $1,00 \pm 0,00^{\mathrm{a}}$ & $0,22 \pm 0,01^{a, b}$ & $14,9 \pm 1,2^{\mathrm{e}}$ & $0,23 \pm 0,01^{c}$ & $14,9 \pm 1,2^{\mathrm{e}}$ & $140,6 \pm 14,3^{d}$ \\
\hline 6 & $13,8 \pm 1,1^{a}$ & $1,00 \pm 0,01^{a}$ & $0,31 \pm 0,03^{c}$ & $4,2 \pm 0,3^{a}$ & $2,8 \pm 0,4^{b}$ & $4,2 \pm 0,3^{b}$ & $28,1 \pm 2,2^{\mathrm{a}}$ \\
\hline
\end{tabular}

La mayor dureza fue registrada para la masa de la formulación 4 (35\% harina de ahipa) respecto del control y demás formulaciones. Las masas correspondientes a las formulaciones 2 y 6 (con $18 \%$ harina de ahipa y $25 \%$ harina de trigo integral, respectivamente) mostraron la menor dureza. Si bien la formulación 6 incluye harina integral a base de trigo y contiene gluten, probablemente el contenido de este ingrediente y las condiciones de amasado no hayan sido suficientes para la formación de la red proteica. Asimismo, la consistencia varió en el mismo sentido que la dureza. Las masas más adhesivas fueron las correspondientes a las formulaciones $0(100 \%$ almidón de maíz) y 3 (con $25 \%$ harina de ahipa).

La cohesividad es un parámetro relacionado con las fuerzas que vinculan entre sí los componentes de la matriz, por lo tanto valores bajos de este parámetro se asocian a una menor integración de los componentes en la masa (Roopa y Bhattacharya, 2008). La masa con $12,5 \%$ harina de ahipa (formulación 1) presentó el menor valor de cohesividad indicando baja integración de los componentes en la misma. La masa de formulación 3 (con $25 \%$ harina de ahipa) no mostró diferencias significativas con el control $(p>0,05)$.

Las masas 2 (con 18\% harina de ahipa) y 6 (con $25 \%$ harina de trigo integral) resultaron las más blandas y cohesivas de todas las formulaciones. 
Las masas 4 (con 35\% harina de ahipa) y 5 (25\% harina de mandioca) de mayor consistencia presentaron menor cohesividad, por lo tanto son masas más estructuradas debido a la interacción de sus componentes. El primer parámetro podría estar relacionado con el alto contenido de almidón de diferente origen botánico presente en la masa de ahipa y mandioca, respectivamente.

La gomosidad de la masa con $35 \%$ harina de ahipa (formulación 4) podría relacionarse con su mayor dureza $(80,4 \mathrm{~N})$ y masticabilidad $(17,9 \mathrm{~N})$.

\subsection{Color de las masas crudas}

Los parámetros $L^{*}$, hue $\left(h^{\circ}\right)$ y Chroma $\left(C^{*}\right)$ de las masas se presentan en la Tabla 5.7, para cada formulación. Los valores más altos de estos atributos de color se hallaron en la formulación que contiene $100 \%$ de almidón de maíz.

Tabla 5.7. Valores de $L^{*}$, hue $\left(h^{\circ}\right)$ y Chroma $\left(C^{*}\right)$ de las masas crudas.

\begin{tabular}{c|c|c|c|}
\hline Masa & $\mathrm{L}^{*}$ & $\mathrm{~h}^{\circ}$ & $\mathrm{C}^{*}$ \\
\hline 0 & $88,7 \pm 1,3^{\mathrm{d}}$ & $98,4 \pm 0,3^{\mathrm{e}}$ & $31,4 \pm 1,0^{\mathrm{d}}$ \\
\hline 1 & $80,7 \pm 2,0^{\mathrm{c}}$ & $90,2 \pm 0,5^{\mathrm{d}}$ & $24,1 \pm 1,6^{\mathrm{a}}$ \\
\hline 2 & $80,4 \pm 0,9^{\mathrm{c}}$ & $89,2 \pm 0,4^{\mathrm{c}}$ & $24,7 \pm 1,3^{\mathrm{a}, \mathrm{b}}$ \\
\hline 3 & $77,5 \pm 0,7^{\mathrm{b}}$ & $87,7 \pm 0,3^{\mathrm{b}}$ & $25,4 \pm 1,0^{\mathrm{b}}$ \\
\hline 4 & $74,1 \pm 1,2^{\mathrm{a}}$ & $87,4 \pm 0,4^{\mathrm{b}}$ & $29,6 \pm 1,8^{\mathrm{c}}$ \\
\hline 5 & $73,6 \pm 2,1^{\mathrm{a}}$ & $84,7 \pm 0,5^{\mathrm{a}}$ & $28,6 \pm 1,1^{\mathrm{c}}$ \\
\hline 6 & $72,6 \pm 2,2^{\mathrm{a}}$ & $89,7 \pm 2,7^{\mathrm{c}, \mathrm{d}}$ & $23,4 \pm 1,9^{\mathrm{a}}$ \\
\hline
\end{tabular}

Nota: Los valores informados corresponden a las medias \pm las desviaciones estándar. Datos acompañados por una misma letra en la misma columna, no difieren significativamente $(p>0,05)$.

Las masas cuyas formulaciones poseen harina de ahipa, mandioca y trigo integral presentaron el valor de L* más bajo respecto del control (formulación 0 ).

Según la Tabla 5.5 los parámetros $L^{*}$ y hue disminuyeron con el aumento de la proporción de harina de ahipa incorporada en las preparaciones correspondientes a las formulaciones 1, 2, 3 y 4 (12,5\%, 18\%, 25\% y $35 \%$ respectivamente). En cuanto a los valores de Chroma, la tendencia observada se invirtió.

La formulación que contiene $25 \%$ de harina de mandioca (formulación 5) presentó el valor más bajo de hue $\left(84,7^{\circ}\right)$. 
La masa de la formulación 6, con $25 \%$ de harina de trigo integral comercial, mostró el valor de Chroma más bajo $(23,4)$, es decir un color superficial menos saturado. En cambio la masa preparada con $100 \%$ almidón de maíz (formulación 0) exhibió el color más saturado (Chroma=31,4), como era de esperar.

\subsection{Actividad acuosa y contenido de humedad de las masas crudas}

La actividad de agua, como se mencionó antes, se define como "agua libre", "agua sin consolidar", o "agua disponible" en un sistema y este parámetro mide la disponibilidad de agua para los cambios asociados al deterioro y al crecimiento microbiano.

En la Tabla 5.8 se presenta la actividad acuosa de las masas crudas ensayadas. Los menores valores se registraron para la masa que contiene $25 \%$ de harina de ahipa (formulación 3). Mientras que las masas cuyo principal ingrediente fue el almidón de maíz (formulaciones 0,1 y 2) o que contienen harina de mandioca (formulación 5) presentaron los valores más altos de $\mathrm{a}_{\mathrm{w}}$. Cabe recordar que la harina de ahipa presentó un 53\% de almidón total, mientras que la harina de mandioca un 77\% (Capítulo 4), por lo tanto, en las formulaciones $0,1,2$ y 5 con un mayor contenido total de almidón, éste se encontraría interaccionando con el agua aumentando su disponibilidad y en consecuencia el $a_{w}$. También existiría una correlación inversa con el contenido de proteínas de las harinas, ya que en promedio, según el Capítulo 4, este valor para la harina de ahipa ( $9 \%$ de proteína bruta) es mayor al de la harina de mandioca ( $4 \%$ de proteína bruta). La naturaleza hidrofóbica de los aminoácidos esenciales isoleucina y metionina presentes en la harina de ahipa podrían estar asociados con este resultado.

Tabla 5.8. Actividad acuosa y contenido de humedad de las masas crudas.

\begin{tabular}{|c|c|c|}
\hline Masa & $a_{w}$ & $\%$ Humedad \\
\hline 0 & $0,855 \pm 0,001^{d}$ & $21,4 \pm 1,3^{e}$ \\
\hline 1 & $0,837 \pm 0,000^{c, d}$ & $17,4 \pm 0,2^{b}$ \\
\hline 2 & $0,846 \pm 0,003^{d}$ & $20,2 \pm 0,2^{d}$ \\
\hline 3 & $0,774 \pm 0,003^{a}$ & $18,6 \pm 0,2^{c}$ \\
\hline 4 & $0,807 \pm 0,005^{b}$ & $19,1 \pm 0,3^{c}$ \\
\hline 5 & $0,842 \pm 0,001^{d}$ & $18,7 \pm 0,1^{c}$ \\
\hline 6 & $0,814 \pm 0,038^{b, c}$ & $15,0 \pm 0,1^{a}$ \\
\hline
\end{tabular}

Nota: Los valores informados corresponden a las medias \pm las desviaciones estándar. Datos acompañados por una misma letra en la misma columna, no difieren significativamente $(p>0,05)$. 
La masa preparada con $100 \%$ almidón de maíz exhibió los valores más altos de $a_{w} y$ contenido de humedad (Tabla 5.8).

En la Tabla 5.8 se observa que en general, el contenido de humedad de las masas con harina de ahipa aumentó con el porcentaje incorporado en las formulaciones respectivas (formulaciones 1, 2, 3 y 4). En cambio, a grandes rasgos, el $\mathrm{a}_{\mathrm{w}}$ registró una tendencia contraria.

Los valores de actividad acuosa de todas masas estudiadas, resultaron superiores a los informados por Mundt y Wedzicha (2007) en masas de galletitas elaboradas con harina comercial de trigo $\left(a_{w}\right.$ menores a 0,40$)$.

\section{Composición química de las galletitas}

Se analizó la composición química de las galletitas elaboradas con $25 \%$ de harina de ahipa en base a los ensayos anteriores (formulación 3) y las galletitas elaboradas con $100 \%$ almidón de maíz, 25\% harina de mandioca y $25 \%$ harina de trigo integral comercial (formulaciones 0,5 y 6 , respectivamente) con fines comparativos. En todos los casos las condiciones de horneado ensayadas (tiempo de cocción y temperatura del horno) no fueron factores de influencia en los resultados. En la Tabla 5.9 se encuentra la composición química porcentual de las galletitas mencionadas (formulaciones 0, 3, 5 y 6, ver Tabla 5.1).

Tabla 5.9. Composición química de las galletitas seleccionadas por cada $100 \mathrm{~g}$ de producto.

\begin{tabular}{|c|c|c|c|c|c|c|}
\hline $\begin{array}{c}\text { Galletita } \\
\text { (formulación) }\end{array}$ & $\begin{array}{c}\% \text { Materia } \\
\text { seca }\end{array}$ & $\begin{array}{c}\% \text { Cenizas } \\
\text { totales }\end{array}$ & $\begin{array}{c}\% \text { Proteína } \\
\text { cruda }\end{array}$ & $\begin{array}{c}\text { \% Lípidos } \\
\text { totales }\end{array}$ & \% FDT & $\begin{array}{c}\% \text { Carbohidratos } \\
\text { totales }\end{array}$ \\
\hline 0 & $87,44 \pm 0,07^{\mathrm{b}}$ & $0,67 \pm 0,04^{\mathrm{a}}$ & $1,3 \pm 0,1^{\mathrm{a}}$ & $17,2 \pm 1,0^{\mathrm{a}}$ & $1,9 \pm 0,8^{\mathrm{a}}$ & $81 \pm 2^{\mathrm{a}}$ \\
\hline 3 & $87,28 \pm 0,08^{\mathrm{a}}$ & $0,84 \pm 0,02^{\mathrm{b}}$ & $2,6 \pm 0,1^{\mathrm{b}}$ & $17,2 \pm 0,5^{\mathrm{a}}$ & $5,0 \pm 1,4^{\mathrm{b}}$ & $79,3 \pm 0,8^{\mathrm{a}}$ \\
\hline 5 & $87,99 \pm 0,03^{\mathrm{d}}$ & $0,77 \pm 0,01^{\mathrm{b}}$ & $1,57 \pm 0,01^{\mathrm{a}}$ & $18,2 \pm 0,5^{\mathrm{a}}$ & $3,2 \pm 0,1^{\mathrm{a}}$ & $79,5 \pm 0,7^{\mathrm{a}}$ \\
\hline 6 & $87,66 \pm 0,00^{\mathrm{c}}$ & $0,68 \pm 0,02^{\mathrm{a}}$ & $2,77 \pm 0,01^{\mathrm{b}}$ & $18,3 \pm 0,2^{\mathrm{a}}$ & sd & $78,3 \pm 0,3^{\mathrm{a}}$ \\
\hline
\end{tabular}

Nota: Los valores informados corresponden a las medias \pm las desviaciones estándar. Datos acompañados por una misma letra en la misma columna, no difieren significativamente $(p>0,05)$. Sd: $\sin$ determinar debido a valores anómalos.

El contenido de materia seca de la galletita elaborada con harina de ahipa (formulación 3) presentó el valor más bajo $(87,28 \pm 0,08 \%)$, mientras que aquélla conteniendo harina 
de mandioca (formulación 5) exhibió el mayor tenor de materia seca $(87,99 \pm 0,03 \%)$. Estos resultados se corresponden con el contenido de materia seca de las respectivas harinas (Capítulo 4).

Las galletitas elaboradas con $100 \%$ de almidón de maíz (formulación 0) y harina de trigo integral (formulación 6) presentaron los menores porcentajes de cenizas totales. En cambio las galletitas conteniendo harina de ahipa y mandioca, mostraron valores superiores en correspondencia con sus ingredientes ya que el contenido de esta fracción en la harina de trigo integral (1,65\%; Salinas, 2013) es inferior al de las harinas de ahipa (2,51\%) y de mandioca (3,45\%) (Capítulo 4$)$.

En cuanto al contenido de proteínas, las galletitas con harina de ahipa $(2,6 \pm 0,1 \%)$ y harina de trigo integral $(2,8 \pm 0,0 \%)$, como era de esperar, presentaron los valores más altos. En promedio, la harina de trigo tiene 10-12\% (De la Vega, 2009), la harina de trigo integral comercial un $11 \%$, la harina de ahipa un $9 \%$ y la harina de mandioca un 4\% de proteínas (Capítulo 4).

El porcentaje de lípidos totales no mostró diferencias significativas entre las muestras $(p>0,05)$ dado que el ingrediente que aporta mayoritariamente este componente es la manteca (100 g por formulación). Asimismo, en la Tabla 5.9 se observa que el valor más alto observado para las galletitas elaboradas con harina de mandioca se correspondería con el mayor contenido lipídico de este ingrediente $(0,50 \%)$, como se informó en el Capítulo 4, aunque las diferencias no son estadísticamente significativas. Estos valores son inferiores a los hallados por Rodrigues Ferreira y col. (2009) en galletitas de chocolate elaboradas a partir de harina de sorgo y Granato y Ellendersen (2009) para galletitas libres de gluten formuladas con harina de maní.

El mayor contenido de fibra dietaria total (FDT) fue hallado en la galletita con harina de ahipa (formulación 3). La FDT de la harina de trigo, determinada con el mismo método que el utilizado en el presente trabajo de Tesis, fue de 2,9-3,1\% (Salinas, 2013), mientras que el de la harina de ahipa es cuatro veces superior (12,5\%). Por su parte la harina de mandioca presenta un $1 \%$ de FDT y la harina de trigo integral un contenido que varía entre $9-12 \%$.

El contenido de FDT de la galletita elaborada con harina de ahipa (formulación 3) fue superior al valor informado por de Oliveira y col. (2009) para galletitas formuladas a 
partir de plantas medicinales (Guaraná - Paullinea cupana y Catuaba - Anemopaegma mirandum) libres de gluten, suplementadas con cobre, hierro y zinc.

El contenido de hidratos de carbono fue calculado por diferencia como se explicó en la sección 6.5. No hubo diferencias significativas entre las distintas galletitas.

\section{Caracterización fisicoquímica del producto horneado}

\subsection{Actividad acuosa y contenido de humedad}

En los alimentos el agua se puede encontrar libre, ligada o interaccionando con los macrocomponentes de los mismos. Cuanto mayor sea la disponibilidad del agua, la cantidad de agua libre se incrementará y en consecuencia menor será la interacción de ésta con los componentes del sistema. Este valor es muy importante ya que en el desarrollo de un producto, es un análisis de control de calidad que se puede utilizar para la determinación de la vida útil del mismo (Pham, 2001). La actividad de agua también es considerada un buen indicador del proceso de cocción, por lo que muchas industrias de galletitas lo utilizan como un parámetro de calidad (Cheftel y Cheftel, 1977).

La actividad acuosa $\left(\mathrm{a}_{\mathrm{w}}\right)$ y el contenido de humedad de las galletitas horneadas en las condiciones ensayadas se pueden observar en las Figuras 5.13 y 5.14 respectivamente. Para mayor claridad de los resultados obtenidos, en la Figura 5.13.a y 5.14.a se encuentran los valores de estos parámetros medidos en todas las formulaciones ensayadas ( 0 a 6 ); en las Figuras 5.13.b y 5.14.b, aquellos correspondientes a las formulaciones $0,3,5$ y 6 ; mientras que los correspondientes a las galletitas elaboradas con distintas proporciones de harina de ahipa (formulaciones 1, 2, 3 y 4) se muestran en las Figuras 5.13.c y 5.14.c.

Como puede observarse en la Figura 5.13.a, la condición de horneado correspondiente a $200^{\circ} \mathrm{C} 10$ minutos presentó los valores más bajos de $a_{w}$ en todas las galletitas preparadas excepto aquellas elaboradas con harina de trigo integral comercial (formulación 6). Asimismo la menor $a_{w}(0,304 \pm 0,006)$ se encontró en las galletitas elaboradas con la formulación 4 (35\% harina de ahipa) y horneada a $200^{\circ} \mathrm{C}$ durante 10 minutos. En cambio la mayor actividad acuosa se observó en las galletitas preparadas con las formulaciones 0 (100\% almidón de maíz) y 2 (18\% harina de ahipa) a $200^{\circ} \mathrm{C} 7,5$ minutos y $180^{\circ} \mathrm{C} 10$ minutos, respectivamente. Estos resultados sugieren que en estas 
últimas condiciones, el agua se encontraría más disponible en el sistema. Además del análisis surge que las condiciones de horneado afectaron significativamente $(p<0,05)$ el $a_{w}$ de las muestras.

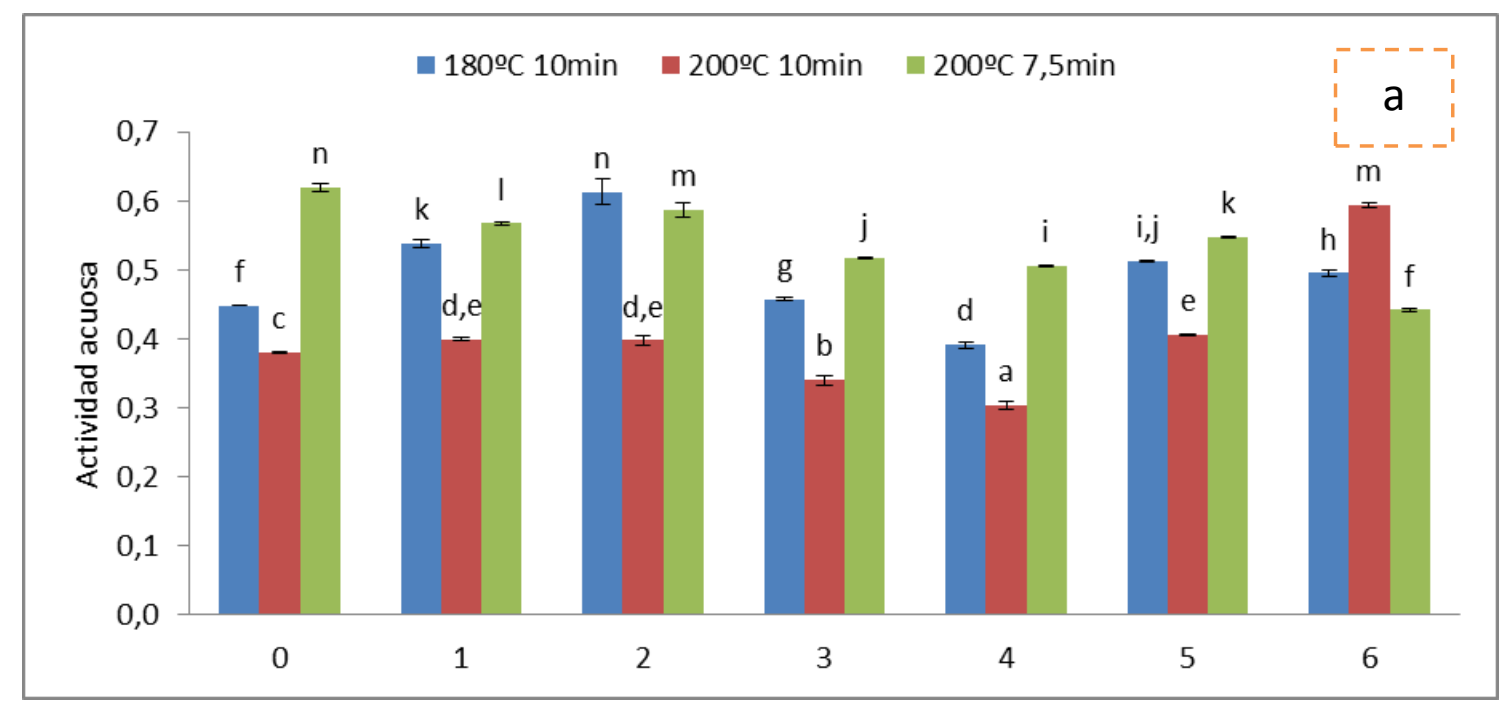

Figura 5.13.a. Actividad acuosa de las galletitas horneadas en las tres condiciones de tiempo y temperatura ensayadas.

Nota: Los valores informados corresponden a las medias \pm las desviaciones estándar. Datos acompañados por una misma letra, no difieren significativamente $(p>0,05)$.

Analizando los valores de $a_{w}$ de las galletitas elaboradas con las formulaciones $0,3,5$ y 6 (Figura 5.13.b), aquéllas preparadas con harina de ahipa (formulación 3) presentaron los valores más bajos en las tres condiciones de horneado, por lo tanto la harina estaría interactuando favorablemente con el agua disponible del producto. 


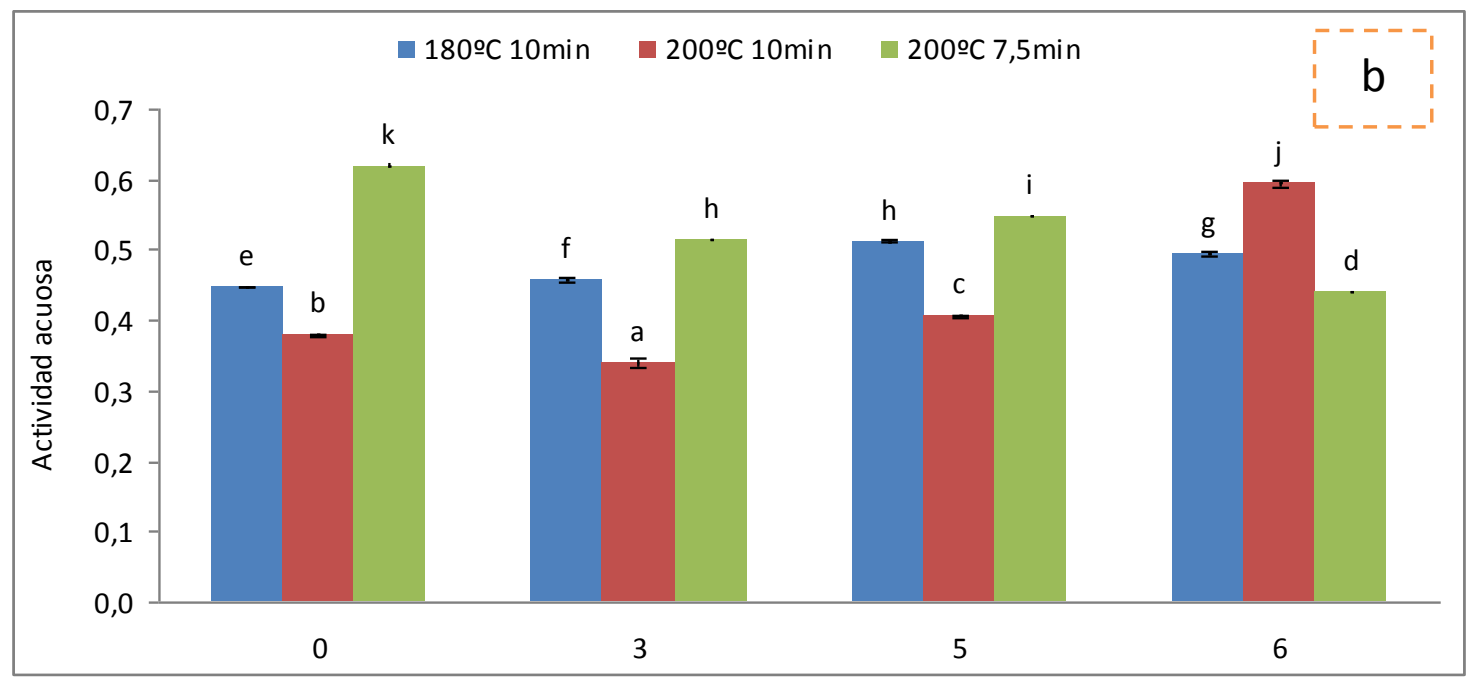

Figura 5.13.b. Actividad acuosa de las galletitas elaboradas con las formulaciones 0,3 , 5 y 6 , horneadas en las tres condiciones de tiempo y temperatura ensayadas. Nota: Los valores informados corresponden a las medias \pm las desviaciones estándar. Datos acompañados por una misma letra, no difieren significativamente $(p>0,05)$.

En general, la actividad acuosa de las galletitas conteniendo harina de ahipa (formulaciones 1, 2, 3 y 4) disminuyó a medida que aumentó la cantidad de este ingrediente en la elaboración del producto dulce (Figura 5.14.c).

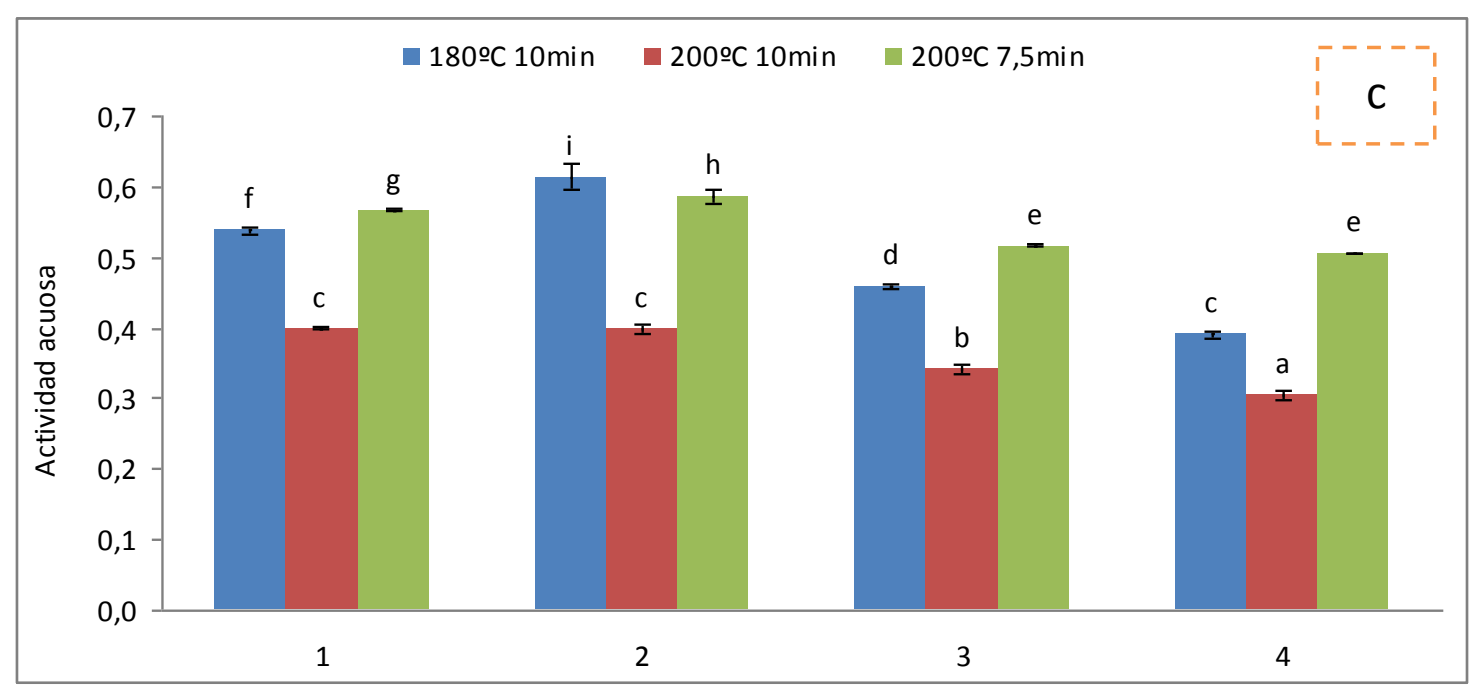

Figura 5.13.c. Actividad acuosa de las galletitas elaboradas con las formulaciones 1, 2, 3, y 4 , horneadas en las tres condiciones de tiempo y temperatura ensayadas. Nota: Los valores informados corresponden a las medias \pm las desviaciones estándar. Datos acompañados por una misma letra, no difieren significativamente $(p>0,05)$. 
Los valores de humedad están asociados con la absorción de agua o capacidad de retención de la misma. El contenido de humedad de las galletitas horneadas, varió con el tiempo y la temperatura de cocción. La condición de horneado correspondiente a $200^{\circ} \mathrm{C} 10$ minutos presentó los valores más bajos de humedad en todas las galletitas preparadas, excepto aquella elaborada con harina de trigo integral comercial (formulación 6). En cambio las galletitas horneadas en las otras condiciones de tiempo y temperatura ensayadas $\left(180^{\circ} \mathrm{C} 10\right.$ minutos y $200^{\circ} \mathrm{C} 7,5$ minutos) mostraron el mayor contenido de humedad. Este mismo comportamiento también fue observado para la actividad acuosa.

La actividad acuosa y el contenido de humedad brindan información complementaria acerca de un sistema. En general el comportamiento de estos parámetros medidos en los productos de las formulaciones 0, 4 y 5 (100\% almidón de maíz, 35\% harina de ahipa y $25 \%$ harina de mandioca, respectivamente) fueron coincidentes. Estas formulaciones presentaron los mayores contenidos de almidón de diferente fuente botánica (maíz, ahipa y mandioca, respectivamente) lo que sugiere una mayor interacción de este polisacárido con el agua y su mayor capacidad de retención en las mezclas secas (Figura 5.11).

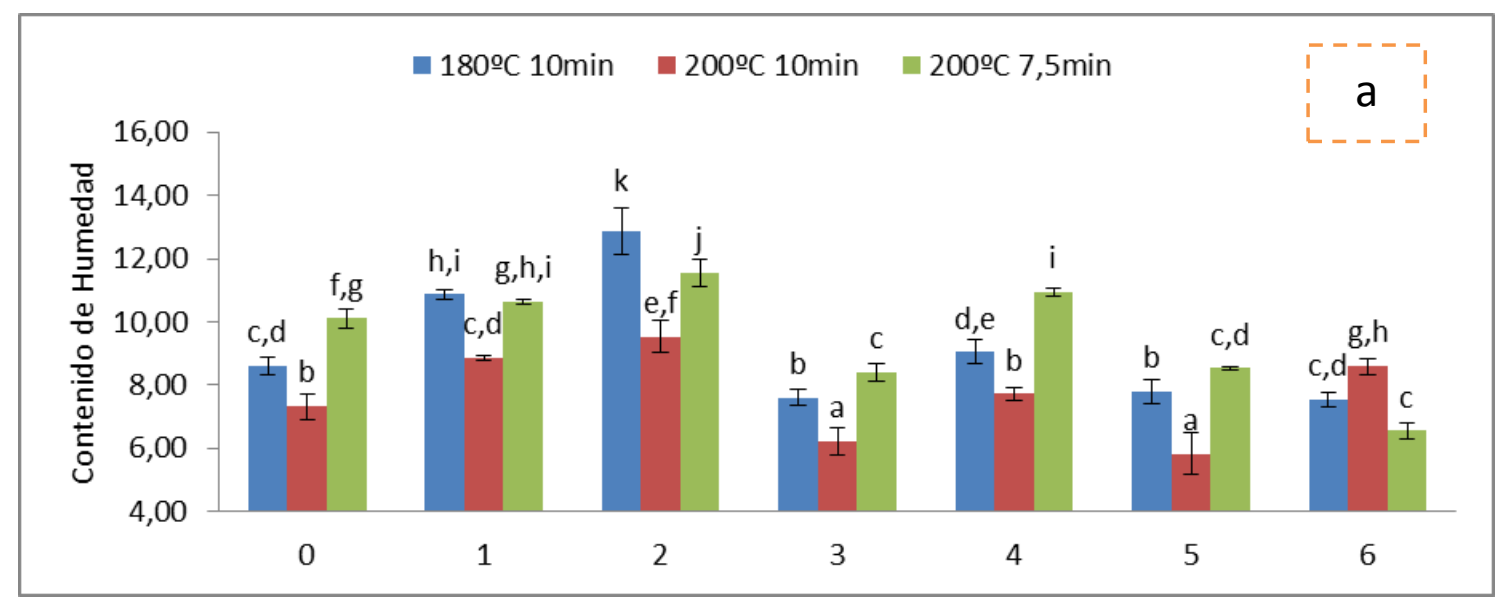

Figura 5.14.a. Contenido de humedad (\%) de las galletitas horneadas en las tres condiciones de tiempo y temperatura ensayadas.

Nota: Los valores informados corresponden a las medias \pm las desviaciones estándar. Datos acompañados por una misma letra, no difieren significativamente $(p>0,05)$. 
En la Figura 5.14.b se observa el menor contenido de humedad de los productos de las formulaciones 3 y 5 ( $25 \%$ harina de ahipa y de harina de mandioca, respectivamente) respecto del control (formulación 0$)$, sin diferir significativamente entre ellos $(p>0,05)$. Las galletitas elaboradas con la formulación 6 (25\% harina de trigo integral comercial), en comparación con las formulaciones 0, 3 y 5 (100\% almidón de maíz, 25\% harina de ahipa y mandioca, respectivamente) no mostraron la tendencia esperada, es decir, valores más altos asociados al contenido de proteína y fibra.

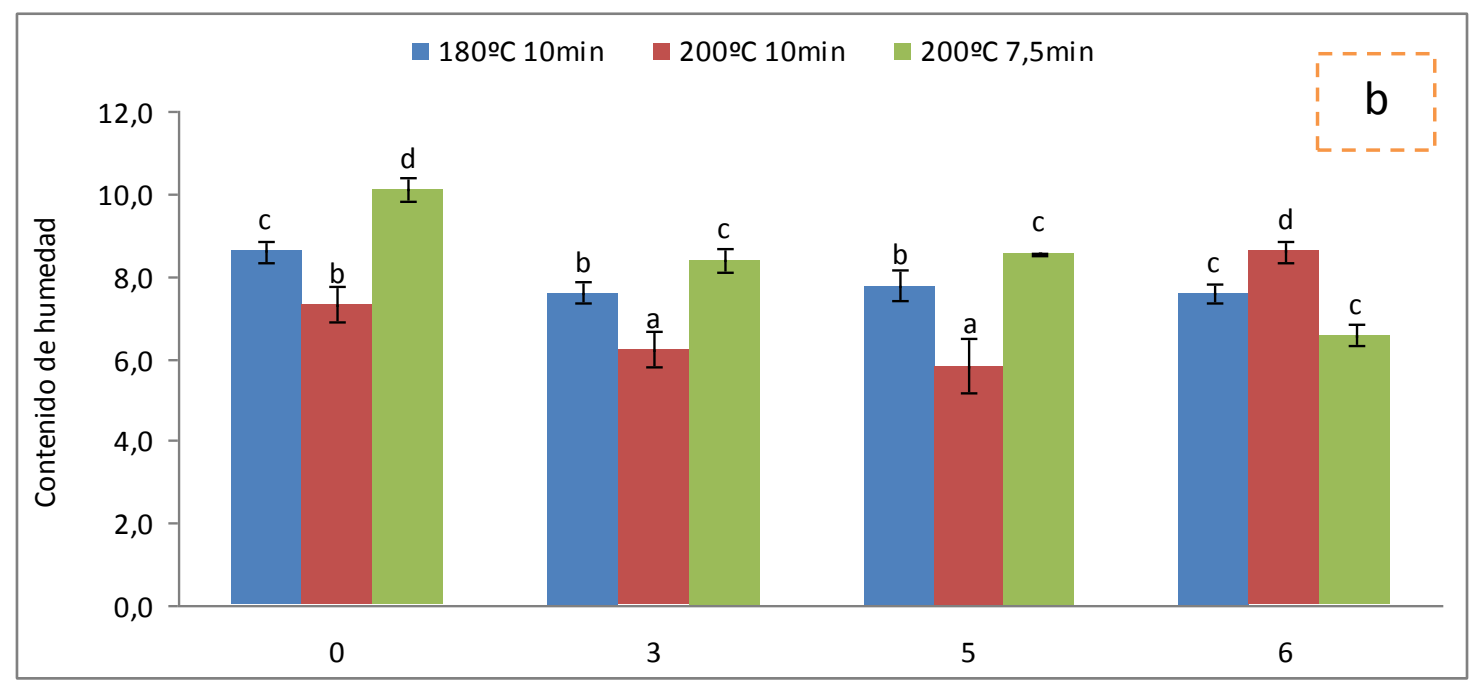

Figura 5.14.b. Contenido de humedad (\%) de las galletitas elaboradas con las formulaciones $0,3,5$ y 6 , horneadas en las tres condiciones de tiempo y temperatura ensayadas.

Nota: Los valores informados corresponden a las medias \pm las desviaciones estándar. Datos acompañados por una misma letra, no difieren significativamente $(p>0,05)$.

Según la Figura 5.14.c, de las galletitas preparadas con harina de ahipa, aquélla cuya formulación contiene un $25 \%$ de la misma (formulación 3), presentó el menor contenido de humedad, en sus tres condiciones de horneado. La galletita preparada con la formulación 2 (18\% harina de ahipa) exhibió los valores más altos de humedad. 


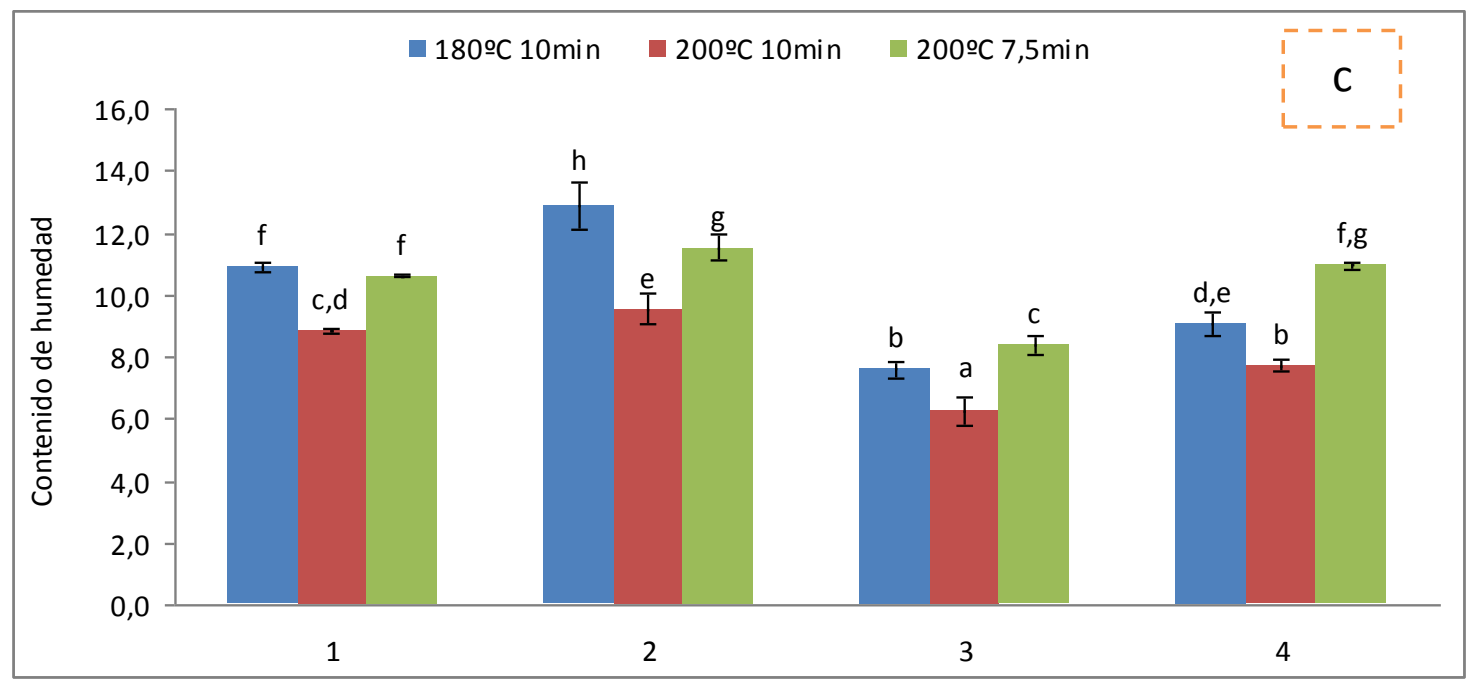

Figura 5.14.c. Contenido de humedad (\%) de las galletitas elaboradas con las formulaciones 1, 2, 3 y 4, horneadas en las tres condiciones de tiempo y temperatura ensayadas.

Nota: Los valores informados corresponden a las medias \pm las desviaciones estándar. Datos acompañados por una misma letra, no difieren significativamente $(p>0,05)$.

La actividad acuosa de las galletitas no tiene un valor establecido debido a la relación existente entre los diferentes ingredientes de la misma. Ameur y col. (2007) informaron valores de $a_{w}$ desde $0,34 \pm 0,02$ hasta $0,45 \pm 0,03$ en galletitas elaboradas con harina de trigo. Datos similares se obtuvieron en el trabajo de Granato y Ellendersen (2009). Esto demuestra que, en general, las galletitas preparadas con harina de ahipa pueden considerarse microbiológicamente seguras ya que por debajo de $a_{w}=0,40$ no hay agua libre disponible para el crecimiento microbiano, según Pham (2001).

\subsection{Color superficial de las galletitas}

Se realizó una comparación fotográfica de los productos horneados para evaluar el aspecto y complementar las mediciones de color superficial de las galletitas. En la Figura 5.15 se pueden observar las galletitas preparadas con las diferentes formulaciones ensayadas $(12,5 \%, 18 \%, 25 \%$ y $35 \%$ harina de ahipa, $25 \%$ harina de mandioca, $25 \%$ harina de trigo integral y $100 \%$ almidón de maíz) y horneadas en las tres condiciones $\left(180^{\circ} \mathrm{C}-10 \mathrm{~min}, 200^{\circ} \mathrm{C}-10 \mathrm{~min}\right.$ y $\left.200^{\circ} \mathrm{C}-7,5 \mathrm{~min}\right)$. 
Galletitas elaboradas con $12,5 \%$ de harina de ahipa

180 으 $10 \mathrm{~min}$

$200 \div \mathrm{C} 10 \mathrm{~min}$

$200 \circ \mathrm{C} 7,5 \mathrm{~min}$

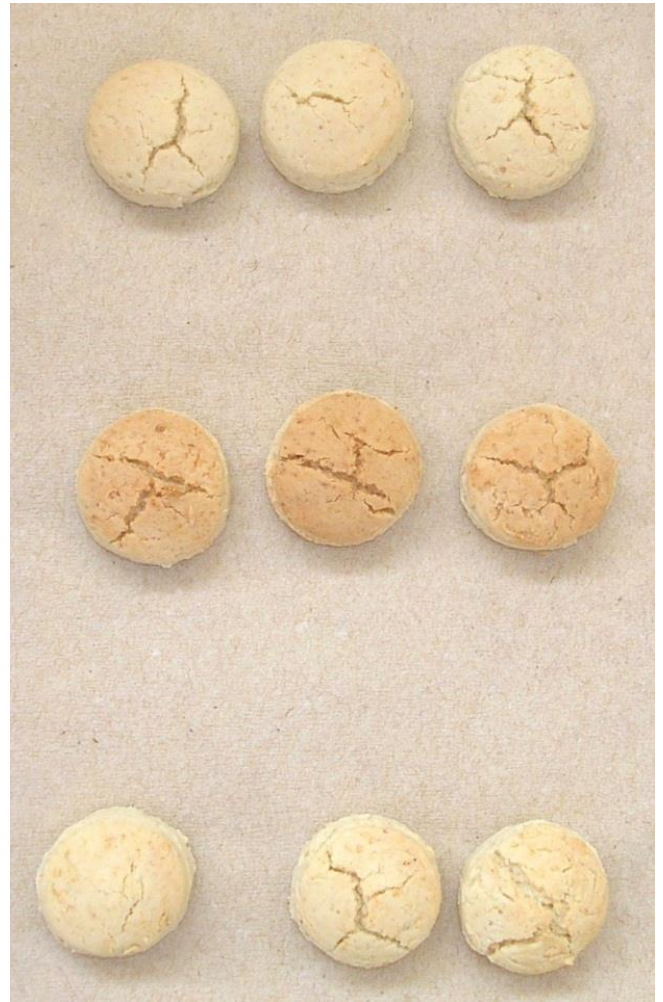

Galletitas elaboradas con $18 \%$ de harina de ahipa

180 ㅇ $10 \mathrm{~min}$

$200 \div \mathrm{C} 10 \mathrm{~min}$

$200 \circ \mathrm{C} 7,5 \mathrm{~min}$ 
Galletitas elaboradas con $25 \%$ de harina de ahipa

$180 \div \mathrm{C} 10 \mathrm{~min}$

$200 \div \mathrm{C} 10 \mathrm{~min}$

$200 \circ \mathrm{C} 7,5 \mathrm{~min}$

Galletitas elaboradas con $35 \%$ de harina de ahipa

$200 \div \mathrm{C} 10 \mathrm{~min}$

$200 \circ \mathrm{C} 7.5 \mathrm{~min}$ 


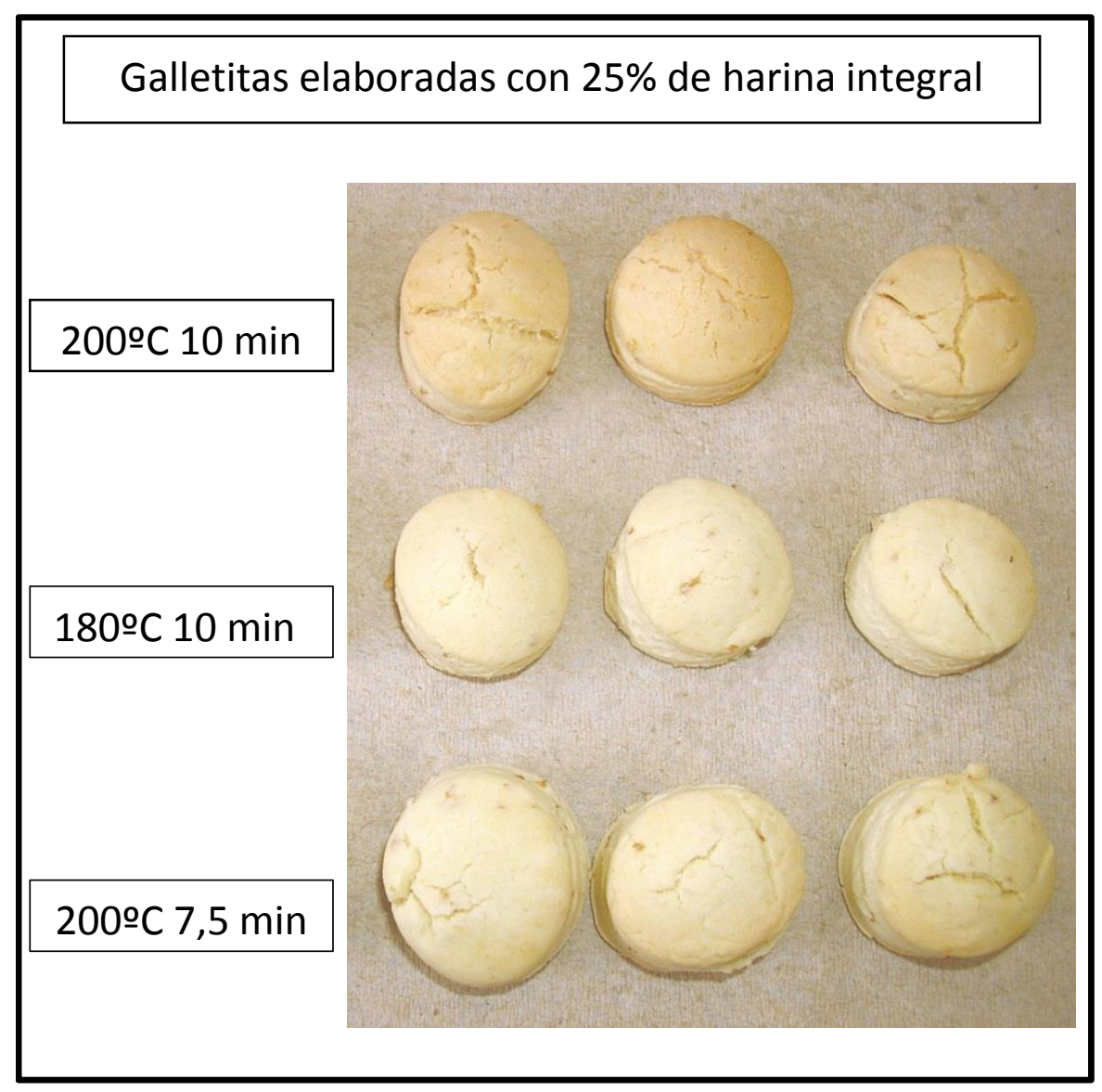

Galletitas elaboradas con $25 \%$ de harina de mandioca

$180 \circ \mathrm{C} 10 \mathrm{~min}$

$200 \circ \mathrm{C} 7,5 \mathrm{~min}$

$200 \circ \mathrm{C} 10 \mathrm{~min}$ 


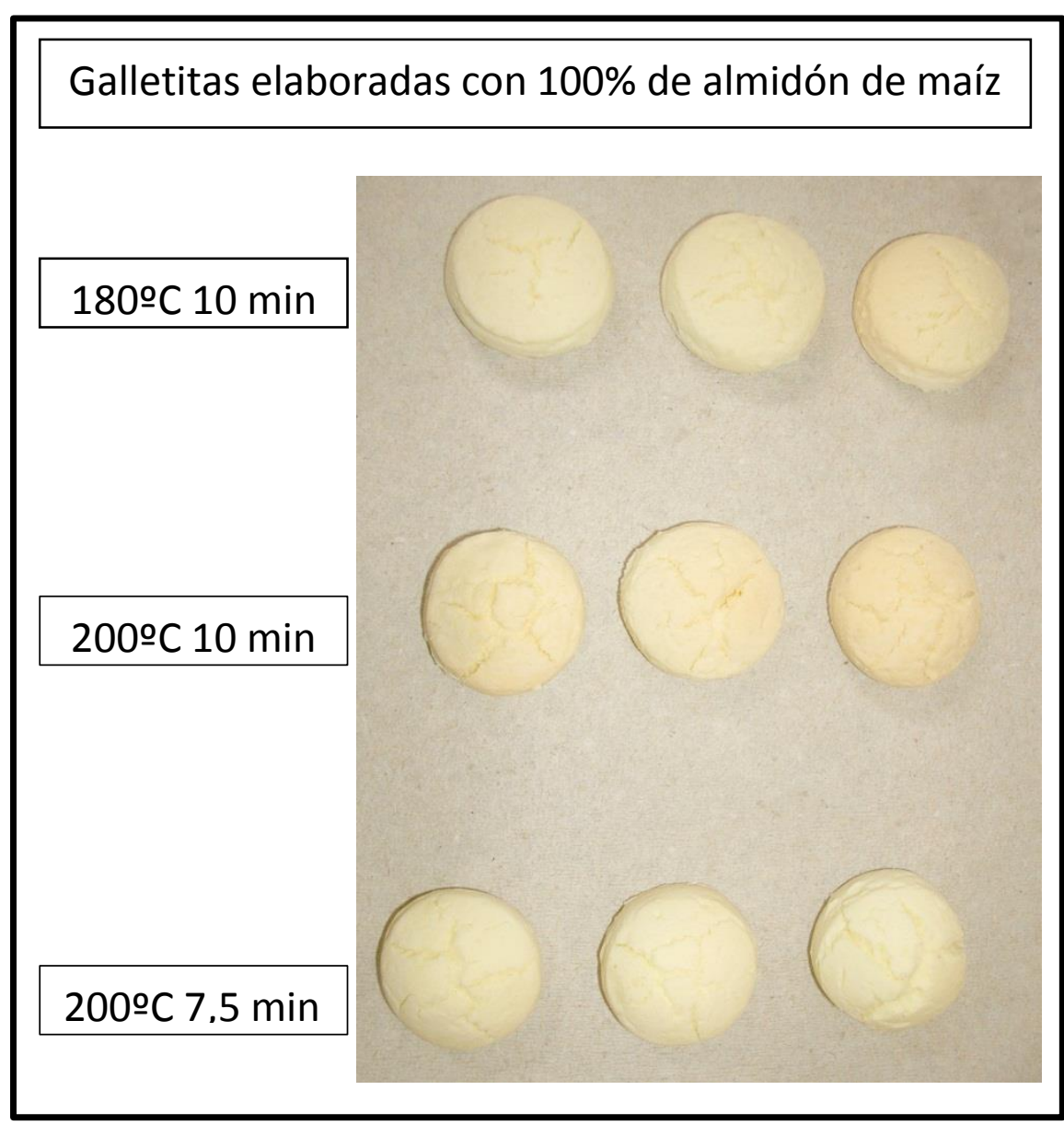

Figura 5.15. Fotografías de las galletitas elaboradas y horneadas en las condiciones ensayadas.

A partir de los parámetros $L^{*}, a^{*}$ y $b^{*}$ medidos en las galletitas, se calcularon las diferencias de color $(\Delta \mathrm{E})$ con el fin de observar los cambios respecto de la masa cruda (para cada formulación) y de la galletita elaborada con $100 \%$ de almidón de maíz (formulación 0). En las Tablas 5.10 y 5.11 se muestran las diferencias de color calculadas para las formulaciones ensayadas, en las tres condiciones de horneado. 
Tabla 5.10. Diferencias de color $(\Delta \mathrm{E})$ respecto de la masa cruda para cada galletita (formulación) horneada en las diferentes condiciones.

\begin{tabular}{c|c|c|c|}
\hline Formulación & $180^{\circ} \mathrm{C} 10 \mathrm{~min}$ & $200^{\circ} \mathrm{C} 10 \mathrm{~min}$ & $200^{\circ} \mathrm{C} 7,5 \mathrm{~min}$ \\
\hline 0 & $16,0 \pm 3,3^{\mathrm{h}}$ & $21,7 \pm 4,8^{\mathrm{i}}$ & $14,4 \pm 2,8^{\mathrm{f}, \mathrm{g}}$ \\
\hline 1 & $4,6 \pm 0,9^{\mathrm{a}}$ & $11,5 \pm 1,4^{\mathrm{d}, \mathrm{e}}$ & $4,5 \pm 0,8^{\mathrm{a}}$ \\
\hline 2 & $4,1 \pm 0,7^{\mathrm{a}}$ & $13,0 \pm 1,6^{\mathrm{e}, \mathrm{f}}$ & $4,9 \pm 0,7^{\mathrm{a}, \mathrm{b}}$ \\
\hline 3 & $5,0 \pm 0,4^{\mathrm{a}, \mathrm{b}}$ & $8,8 \pm 1,4^{\mathrm{c}}$ & $4,8 \pm 0,7^{\mathrm{a}}$ \\
\hline 4 & $6,1 \pm 0,4^{\mathrm{b}}$ & $12,3 \pm 0,9^{\mathrm{d}, \mathrm{e}}$ & $5,3 \pm 0,8^{\mathrm{a}, \mathrm{b}}$ \\
\hline 5 & $11,0 \pm 1,4^{\mathrm{d}}$ & $8,8 \pm 1,0^{\mathrm{c}}$ & $11,8 \pm 1,0^{\mathrm{d}, \mathrm{e}}$ \\
\hline 6 & $15,9 \pm 0,9^{\mathrm{h}}$ & $12,4 \pm 0,5^{\mathrm{e}}$ & $15,8 \pm 0,9^{\mathrm{g}, \mathrm{h}}$ \\
\hline
\end{tabular}

Nota: Los valores informados corresponden a las medias \pm las desviaciones estándar. Datos acompañados por una misma letra, no difieren significativamente $(p>0,05)$.

Como puede observarse en la Tabla 5.10, la mayor diferencia de color entre la masa cruda y el producto horneado corresponde a la galletita elaborada con $100 \%$ almidón de maíz (formulación 0). Esto se debe a que la masa cruda de referencia presentó los parámetros de color más altos (Tabla 5.7).

En general, a medida que aumenta el porcentaje de harina de ahipa en la formulación (recetas 1, 2, 3 y 4) en las tres condiciones de horneado, las diferencias de color tienden a incrementarse, como era de esperar. Esto es una consecuencia de la reacción de Maillard o pardeamiento no enzimático, entre azúcares reductores (principalmente D-glucosa) y un grupo amino primario (aminoácido libre o un grupo amino lateral de una molécula proteica). Por lo tanto los resultados se deben al contenido de azúcares y proteínas presentes en la harina de ahipa (Capítulo 4). Además, Fennema (2008) ha señalado que asociado a las reacciones de Maillard hay pérdidas de lisina y arginina, aminoácidos esenciales presentes en la harina de ahipa, tal como se mencionó en el Capítulo 4. La descomposición de los mencionados aminoácidos esenciales conlleva a una pérdida de la calidad nutricional del alimento.

La galletita elaborada con $25 \%$ de harina de ahipa (formulación 3) mostró relativamente bajas diferencias de color, en sus tres condiciones de horneado.

El pardeamiento no enzimático surge de los tratamientos térmicos o del almacenamiento prolongado de alimentos que contienen azúcares reductores. 
Analizando estadísticamente los valores de $\Delta \mathrm{E}$ de los productos horneados en función de las condiciones de cocción, las combinaciones de $180^{\circ} \mathrm{C}-10$ minutos y $200^{\circ} \mathrm{C}-7,5$ minutos no presentaron diferencias significativas $(p>0,05)$, observándose los valores más bajos respecto de la condición $200^{\circ} \mathrm{C}$ - 10 minutos.

La Tabla 5.11 muestra las diferencias de color halladas respecto de la galletita elaborada con $100 \%$ de almidón de maíz (formulación 0).

Tabla 5.11. Diferencias de color $(\Delta \mathrm{E})$ respecto de la galletita elaborada con $100 \%$ almidón de maíz (formulación 0) en las diferentes condiciones de horneado.

\begin{tabular}{c|c|c|c|}
\hline Formulación & $180^{\circ} \mathrm{C} 10 \mathrm{~min}$ & $200^{\circ} \mathrm{C} 10 \mathrm{~min}$ & $200^{\circ} \mathrm{C} 7,5 \mathrm{~min}$ \\
\hline 0 & $0,00 \pm 0,00$ & $0,00 \pm 0,00$ & $0,00 \pm 0,00$ \\
\hline 1 & $13,1 \pm 0,6^{\mathrm{d}, \mathrm{e}}$ & $21,8 \pm 1,6^{\mathrm{h}}$ & $14,8 \pm 0,9^{\mathrm{f}}$ \\
\hline 2 & $13,4 \pm 0,6^{\mathrm{e}}$ & $23,9 \pm 1,7^{\mathrm{i}}$ & $13,1 \pm 0,5^{\mathrm{d}, \mathrm{e}}$ \\
\hline 3 & $13,4 \pm 0,7^{\mathrm{e}}$ & $21,9 \pm 1,6^{\mathrm{h}}$ & $14,8 \pm 0,9^{\mathrm{f}}$ \\
\hline 4 & $17,8 \pm 1,0^{\mathrm{g}}$ & $27,4 \pm 1,1^{\mathrm{j}}$ & $15,4 \pm 1,1^{\mathrm{f}}$ \\
\hline 5 & $12,4 \pm 1,4^{\mathrm{b}, \mathrm{c}}$ & $12,9 \pm 0,5^{\mathrm{d}, \mathrm{e}}$ & $12,0 \pm 0,8^{\mathrm{c}, \mathrm{d}}$ \\
\hline 6 & $10,2 \pm 0,7^{\mathrm{a}}$ & $9,7 \pm 0,3^{\mathrm{a}}$ & $11,2 \pm 0,8^{\mathrm{b}}$
\end{tabular}

Nota: Los valores informados corresponden a las medias \pm las desviaciones estándar. Datos acompañados por una misma letra, no difieren significativamente $(p>0,05)$.

La galletita elaborada con $25 \%$ harina de trigo integral (formulación 6) presentó los menores valores de $\Delta \mathrm{E}$ respecto de la galletita control (formulación 0 ), ya que dicho ingrediente previamente fue tamizado.

En general, con el incremento de la proporción de harina de ahipa (formulaciones 1, 2, 3 y 4), en los tiempos y temperaturas de cocción ensayados, las diferencias de color aumentaron y se atribuyeron al desarrollo de la reacción de Maillard. La galletita elaborada con $35 \%$ harina de ahipa (formulación 4) mostró el mayor valor de $\Delta \mathrm{E}$ respecto de todos los productos horneados.

Nuevamente, el análisis estadístico en función de las condiciones de horneado, indicó que las combinaciones $180^{\circ} \mathrm{C}-10$ minutos y $200^{\circ} \mathrm{C}-7,5$ minutos no presentaron diferencias significativas $(p>0,05)$ siendo los valores obtenidos más bajos que los correspondientes a la condición restante $\left(200^{\circ} \mathrm{C}-10\right.$ minutos $)$. 
Las galletitas elaboradas a partir de las mezclas secas ensayadas (0, 3, 5 y 6), presentaron un color más intenso y valores de luminosidad superiores a los encontrados en las preparaciones (mezclas secas). Este resultado concuerda con lo informado por von Atzingen y col. (2005).

El índice de pardeamiento (IP) es un parámetro relacionado con la coloración marrón del producto, tal como se describió en la sección 7.3. Este color es consecuencia de la reacción de pardeamiento no enzimático o reacción de Maillard. En la Tabla 5.12 se presentan los diferentes índices de pardeamiento (IP) de los productos horneados estudiados, observándose que en general a medida que aumenta el porcentaje de sustitución de almidón de maíz por harina de ahipa (formulaciones 1, 2, 3 y 4) los valores del IP son mayores respecto del control (formulación 0) para todas las condiciones de horneado. Esto puede relacionarse, como ya se mencionó, con el incremento en el contenido de azúcares y proteínas presentes en la harina de ahipa (Capítulo 4).

Tabla 5.12. Índice de pardeamiento de la superficie de las galletitas estudiadas.

\begin{tabular}{c|c|c|c|} 
Formulación & $180^{\circ} \mathrm{C} 10 \mathrm{~min}$ & $200^{\circ} \mathrm{C} 10 \mathrm{~min}$ & $200^{\circ} \mathrm{C} 7,5 \mathrm{~min}$ \\
\hline 0 & $27,0 \pm 2,4^{\mathrm{c}}$ & $30,4 \pm 3,1^{\mathrm{d}}$ & $21,1 \pm 1,5^{\mathrm{a}}$ \\
\hline 1 & $30,6 \pm 2,0^{\mathrm{d}}$ & $46,6 \pm 2,3^{\mathrm{h}}$ & $36,7 \pm 1,8^{\mathrm{f}}$ \\
\hline 2 & $33,0 \pm 2,3^{\mathrm{e}}$ & $46,6 \pm 1,5^{\mathrm{h}}$ & $31,2 \pm 2,1^{\mathrm{d}}$ \\
\hline 3 & $36,9 \pm 0,9^{\mathrm{f}}$ & $48,3 \pm 2,3^{\mathrm{h}}$ & $36,2 \pm 2,2^{\mathrm{f}}$ \\
\hline 4 & $44,3 \pm 1,2^{\mathrm{g}}$ & $52,8 \pm 2,2^{\mathrm{i}}$ & $44,1 \pm 1,7^{\mathrm{g}}$ \\
\hline 5 & $32,3 \pm 1,5^{\mathrm{d}, \mathrm{e}}$ & $36,5 \pm 1,6^{\mathrm{f}}$ & $30,7 \pm 0,7^{\mathrm{d}}$ \\
\hline 6 & $26,1 \pm 1,4^{\mathrm{c}}$ & $36,3 \pm 2,0^{\mathrm{f}}$ & $24,3 \pm 1,3^{\mathrm{b}}$
\end{tabular}

Nota: Los valores informados corresponden a las medias \pm las desviaciones estándar. Datos acompañados por una misma letra, no difieren significativamente $(p>0,05)$.

Como era de esperar los IP más altos corresponden a la condición de horneado de mayor exposición a la temperatura más alta $\left(200^{\circ} \mathrm{C} 10\right.$ minutos), en la que pueden producirse incluso reacciones de caramelización. 


\subsection{Textura del producto horneado}

En las galletitas, los snacks y los productos rebozados, la crocancia, fragilidad, y textura están relacionados en general con el contenido acuoso y condicionan la aceptabilidad por parte de los consumidores (Abbas y col., 2010). Con respecto a la dureza o firmeza de las galletitas, Hoseney y Rogers (1994) y McWatters y col. (2003) informaron que la misma se debe a la interacción de las proteínas y el almidón, por enlaces de hidrógeno, durante el desarrollo y horneado de la masa que contiene estos componentes.

La elaboración de los productos sin gluten, como panes y pastas, es difícil porque el gluten contribuye a la retención de gas y el desarrollo de una red de proteína fuerte que produce panes de buena calidad y evita la disolución de la pasta durante la cocción (Gallagher y col., 2004). La textura de las galletitas sin gluten es principalmente atribuible a la gelatinización del almidón y fusión del azúcar, ingredientes presentes en la formulación (Gallagher, 2002).

Se analizaron los perfiles de textura (fuerza en función del tiempo) de las galletitas elaboradas con las seis formulaciones y horneadas en las tres condiciones ensayadas, utilizando la sonda Volodkevich Bite Jaws. Tal como se mencionó anteriormente, los parámetros registrados fueron la fuerza máxima $(\mathrm{N})$, que se relaciona con la firmeza de la muestra y el área bajo la curva ( $\mathrm{N} \mathrm{mm}$ ), que se asocia con la energía requerida para cortar la misma.

A modo de ejemplo, en la Figura 5.16 se muestran las curvas obtenidas para las galletitas elaboradas con $25 \%$ harina de ahipa (formulación 3 ) y horneadas en las condiciones estudiadas. 


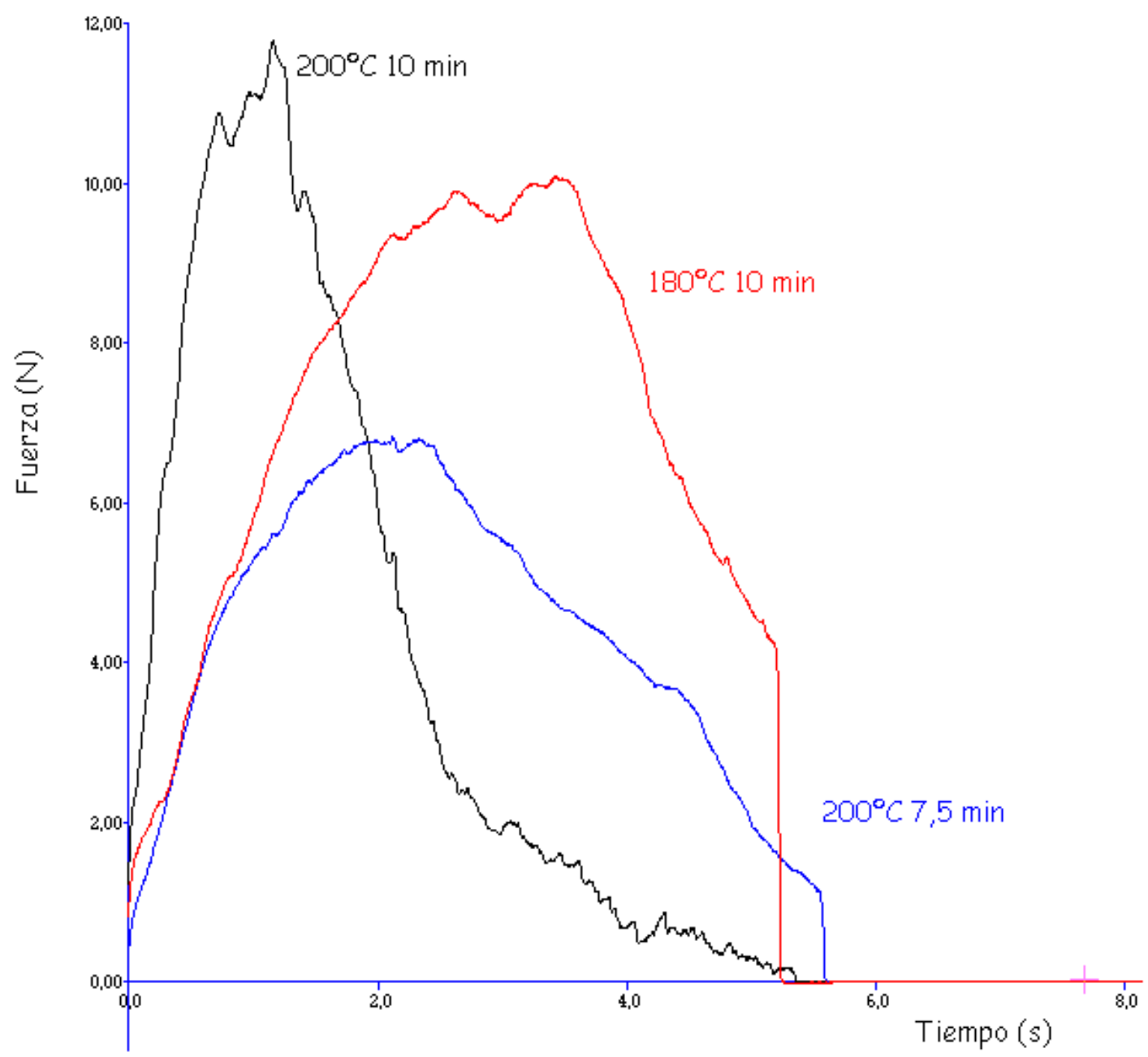

Figura 5.16. Perfil de textura de las galletitas elaboradas con $25 \%$ harina de ahipa (formulación 3) y horneadas en las diferentes condiciones.

En la Tabla 5.13 se presentan los parámetros de texturales obtenidos, observándose que en general a medida que aumenta el porcentaje de sustitución de almidón de maíz por harina de ahipa (formulaciones 1, 2, 3 y 4) los valores del área bajo la curva son mayores respecto del control (formulación 0 ) en todas las condiciones de horneado. Todas las formulaciones, presentaron los valores más altos de fuerza máxima en la condición de horneado $200^{\circ} \mathrm{C}-10$ minutos, lo que estaría indicando una muestra de mayor firmeza respecto de las demás condiciones y una sobre-cocción del producto. Estos resultados concuerdan con el menor contenido de humedad de las muestras (Figura 5.14.c) y podría relacionarse con la contracción de volumen observado (Tabla 5.14). 
En la Tabla 5.13 se puede apreciar que los parámetros de textura analizados de las galletitas elaboradas con las formulaciones 3 y 5 (25\% harina de ahipa y de mandioca, respectivamente), en las condiciones de horneado $180^{\circ} \mathrm{C}-10$ minutos y $200^{\circ} \mathrm{C}-7,5$ minutos, son similares. Además, los valores de $a_{w}$ de estas galletitas son comparables (Figura 5.13.b).

La galletita preparada con 35\% de harina de ahipa (formulación 4) exhibió los valores más altos de fuerza máxima y área bajo la curva en sus tres condiciones de horneado. Al respecto, la muestra de mayor firmeza correspondió a la horneada a $200^{\circ} \mathrm{C}-10$ minutos (fuerza máxima de $22,2 \pm 1,3 \mathrm{~N}$ ), posiblemente asociada con su menor actividad acuosa y contenido de humedad (ver Figuras 5.13.a, 5.13.c, 5.14.a y 5.14.c). Así, la disminución en el contenido de humedad podría ser la responsable de la mayor firmeza de la muestra.

Estos resultados concuerdan con una textura "más áspera" al paladar, evaluada informalmente.

Tabla 5.13. Fuerza máxima $(\mathrm{N})$ y área $(\mathrm{N} \mathrm{mm})$ de las galletitas estudiadas horneadas en las tres condiciones.

\begin{tabular}{c|ccccc|c|}
\hline \multirow{2}{*}{ Formulación } & \multicolumn{2}{|c}{$180^{\circ} \mathrm{C} 10 \mathrm{~min}$} & \multicolumn{2}{c}{$200^{\circ} \mathrm{C} 10 \mathrm{~min}$} & \multicolumn{2}{c|}{$200^{\circ} \mathrm{C} 7,5 \mathrm{~min}$} \\
\cline { 2 - 7 } & $\mathrm{F}$ máx & Área & $\mathrm{F} \mathrm{máx}$ & Área & $\mathrm{F}$ máx & Área \\
\hline 0 & $6,8 \pm 0,5^{\mathrm{d}}$ & $15,6 \pm 1,1^{\mathrm{b}}$ & $7,0 \pm 1,4^{\mathrm{d}}$ & $7,5 \pm 2,8^{\mathrm{a}}$ & $3,5 \pm 0,7^{\mathrm{a}}$ & $8,8 \pm 1,3^{\mathrm{a}}$ \\
\hline 1 & $4,7 \pm 0,5^{\mathrm{b}, \mathrm{c}}$ & $18,9 \pm 1,2^{\mathrm{c}}$ & $21,9 \pm 1,6^{\mathrm{f}}$ & $31,0 \pm 2,7^{\mathrm{h}}$ & $14,8 \pm 0,9^{\mathrm{a}, \mathrm{b}}$ & $15,7 \pm 0,9^{\mathrm{b}}$ \\
\hline 2 & $3,6 \pm 0,4^{\mathrm{a}, \mathrm{b}}$ & $15,4 \pm 1,5^{\mathrm{b}}$ & $12,3 \pm 1,6^{\mathrm{h}}$ & $42,7 \pm 3,7^{\mathrm{i}}$ & $3,9 \pm 0,5^{\mathrm{a}, \mathrm{b}}$ & $14,4 \pm 1,6^{\mathrm{b}}$ \\
\hline 3 & $9,4 \pm 1,8^{\mathrm{f}, \mathrm{g}}$ & $30,6 \pm 2,5^{\mathrm{g}, \mathrm{h}}$ & $11,6 \pm 1,6^{\mathrm{h}}$ & $19,9 \pm 1,8^{\mathrm{c}}$ & $7,1 \pm 0,6^{\mathrm{d}, \mathrm{e}}$ & $28,3 \pm 2,9^{\mathrm{f}, \mathrm{g}}$ \\
\hline 4 & $21,4 \pm 1,8^{\mathrm{j}}$ & $54,2 \pm 2,9^{\mathrm{j}}$ & $22,2 \pm 1,3^{\mathrm{j}}$ & $40,0 \pm 3,6^{\mathrm{i}}$ & $15,0 \pm 1,0^{\mathrm{i}}$ & $58,7 \pm 2,6^{\mathrm{k}}$ \\
\hline 5 & $8,3 \pm 0,8^{\mathrm{e}, \mathrm{f}}$ & $30,6 \pm 2,9^{\mathrm{g}, \mathrm{h}}$ & $8,7 \pm 1,4^{\mathrm{f}, \mathrm{g}}$ & $25,7 \pm 3,5^{\mathrm{e}, \mathrm{f}}$ & $7,2 \pm 0,6^{\mathrm{d}, \mathrm{e}}$ & $27,1 \pm 2,3^{\mathrm{f}}$ \\
\hline 6 & $8,7 \pm 0,8^{\mathrm{f}, \mathrm{g}}$ & $23,8 \pm 3,1^{\mathrm{d}, \mathrm{e}}$ & $9,9 \pm 2,0^{\mathrm{g}}$ & $23,7 \pm 2,3^{\mathrm{d}, \mathrm{e}}$ & $5,5 \pm 0,9^{\mathrm{c}}$ & $22,8 \pm 3,1^{\mathrm{d}}$ \\
\hline
\end{tabular}

Nota: Los valores informados corresponden a las medias \pm las desviaciones estándar. Datos acompañados por una misma letra, no difieren significativamente $(p>0,05)$.

\subsection{Volumen de las galletitas}

El volumen de las galletitas horneadas en las condiciones ensayadas, se muestra en la Tabla 5.14 siendo, en general, los valores más altos los correspondientes al producto elaborado con $100 \%$ de almidón de maíz (formulación 0). Este comportamiento puede deberse a una masa más blanda y cohesiva como se describió previamente (Tabla 5.4) 
lo que le permitió que la misma se expanda más durante el horneado, por ser más blanda, y que, al ser cohesiva, retenga más el $\mathrm{CO}_{2}$ generado por el leudante durante la cocción.

Tabla 5.14. Volumen de las galletitas horneadas en las diferentes condiciones $\left(\mathrm{cm}^{3}\right)$.

\begin{tabular}{c|c|c|c|} 
Formulación & $180^{\circ} \mathrm{C} 10 \min 200^{\circ} \mathrm{C} 10 \mathrm{~min} 200^{\circ} \mathrm{C} 7,5 \mathrm{~min}$ \\
\hline 0 & $11,6 \pm 2,2^{\mathrm{k}}$ & $9,8 \pm 0,8^{\mathrm{j}, \mathrm{k}}$ & $13,8 \pm 1,5^{\mathrm{l}}$ \\
\hline 1 & $9,0 \pm 0,7^{\mathrm{g}, \mathrm{h}, \mathrm{i}}$ & $8,4 \pm 0,5^{\mathrm{f}, \mathrm{g}, \mathrm{h}}$ & $8,0 \pm 1,2^{\mathrm{e}, \mathrm{f}, \mathrm{g}}$ \\
\hline 2 & $9,8 \pm 1,1^{\mathrm{h}, \mathrm{i}}$ & $9,8 \pm 1,3^{\mathrm{h}, \mathrm{i}}$ & $10,0 \pm 0,7^{\mathrm{i}, \mathrm{j}}$ \\
\hline 3 & $6,2 \pm 0,8^{\mathrm{b}, \mathrm{c}, \mathrm{d}}$ & $4,4 \pm 0,5^{\mathrm{a}}$ & $7,6 \pm 0,9^{\mathrm{d}, \mathrm{e}, \mathrm{f}}$ \\
\hline 4 & $7,0 \pm 1,0^{\mathrm{c}, \mathrm{d}, \mathrm{e}, \mathrm{f}}$ & $6,8 \pm 0,8^{\mathrm{c}, \mathrm{d}, \mathrm{e}}$ & $9,6 \pm 1,8^{\mathrm{h}, \mathrm{i}}$ \\
\hline 5 & $7,6 \pm 0,9^{\mathrm{d}, \mathrm{e}, \mathrm{f}}$ & $5,2 \pm 1,5^{\mathrm{a}, \mathrm{b}}$ & $5,0 \pm 1,2^{\mathrm{a}, \mathrm{b}}$ \\
\hline 6 & $5,0 \pm 1,6^{\mathrm{a}, \mathrm{b}}$ & $6,8 \pm 0,8^{\mathrm{c}, \mathrm{d}, \mathrm{e}}$ & $5,6 \pm 1,1^{\mathrm{a}, \mathrm{b}, \mathrm{c}}$ \\
\hline
\end{tabular}

Nota: Los valores informados corresponden a las medias \pm las desviaciones estándar. Datos acompañados por una misma letra, no difieren significativamente $(p>0,05)$.

La columna de la Tabla 5.14 correspondiente a la condición de horneado $200^{\circ} \mathrm{C}-10$ minutos muestra valores de volumen relativamente bajos, indicando una excesiva cocción y en consecuencia una contracción de volumen de los productos estudiados. Asimismo el volumen de la galletita elaborada con $25 \%$ harina de ahipa (formulación 3 ) horneada en la condición citada fue el más bajo. Este resultado podría estar asociado a una baja interacción con el leudante, aunque los atributos texturales evaluados en la masa cruda correspondiente no se relacionaron con este comportamiento.

\section{Evaluación sensorial del producto}

De los ensayos anteriores, y con el fin de obtener un producto nutricionalmente balanceado se seleccionó la formulación con $25 \%$ de harina de ahipa. La formulación 4 con $35 \%$ de harina de ahipa se descartó debido a los resultados obtenidos respecto al color superficial (mayor índice de pardeamiento, Tabla 5.12) y de textura (mayores valores de los parámetros texturales, Tabla 5.13). Además, de los productos preparados con harina de ahipa, aquéllos obtenidos a partir de la formulación 3 presentaron el menor contenido de humedad y por consiguiente de actividad acuosa, 
en sus tres condiciones de horneado (ver Figuras 5.13 y 5.14 ), factor favorable en lo que respecta a la conservación.

Dado que, considerando solamente los valores de los parámetros instrumentales de color y textura previamente descriptos resultaba difícil seleccionar la condición de horneado más adecuada, se realizó un ensayo sensorial empleando una escala hedónica de 9 valores. Además, como se describió previamente, no se observaron diferencias significativas $(p>0,05)$ en la mayoría de los resultados obtenidos para los productos horneados a $180^{\circ} \mathrm{C}-10$ minutos o a $200^{\circ} \mathrm{C}-7,5$ minutos. En este caso se optó por la última condición, teniendo en cuenta una potencial ventaja a nivel de producción a gran escala representada en un menor tiempo de la operación.

Así, se analizaron los atributos color, sabor y textura junto con la aceptabilidad general de las galletitas elaboradas con $25 \%$ de harina de ahipa (formulación 3 ) y horneadas a $200^{\circ} \mathrm{C}$ en dos tiempos: 7,5 y 10 minutos.

En la Figura 5.17 se pueden observar los porcentajes obtenidos para las diferentes puntuaciones, a partir de la evaluación sensorial de las galletitas elaboradas con 25\% de harina de ahipa. Para mayor claridad de los resultados se agruparon los valores de la escala hedónica utilizada en tres rangos: 1-3 (me disgusta), 4-6 (me es indiferente) y 7-9 (me gusta mucho). Los gráficos correspondientes a las galletitas horneadas a $200^{\circ} \mathrm{C}$ durante 7,5 y 10 minutos se indican con la letra a y $b$ respectivamente.
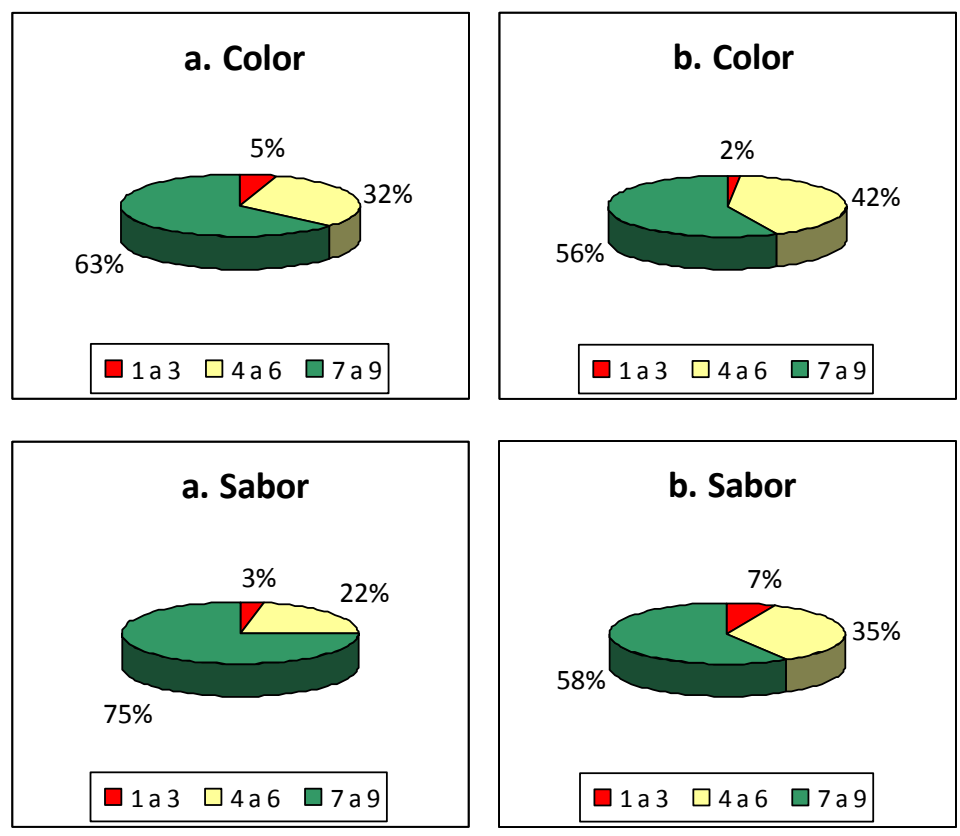

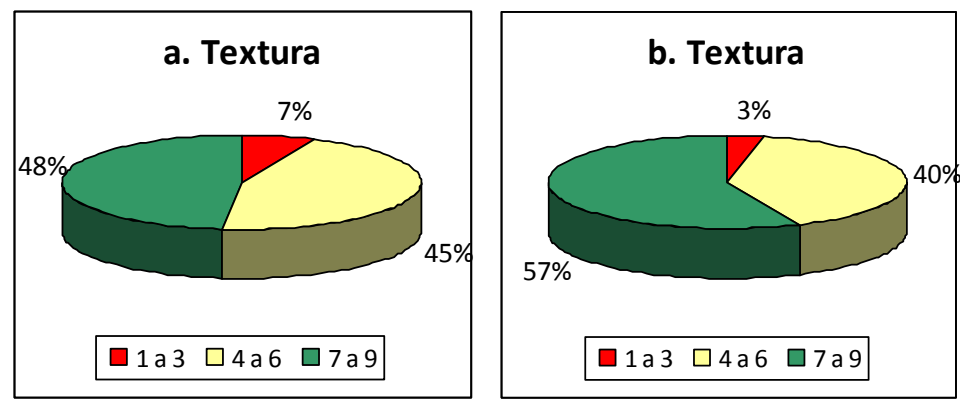

Figura 5.17. Porcentajes obtenidos a partir de la evaluación sensorial de galletitas elaboradas con $25 \%$ de harina de ahipa y horneadas a $200^{\circ} \mathrm{C}$ a) 7,5 minutos y b) 10 minutos.

Los resultados fueron clasificados en tres rangos: 1-3 (rojo), 4-6 (amarillo) y 7-9 (verde) de la escala hedónica.

En cuanto al color, el 63\% de los consumidores le otorgó la mayor puntuación (7-9) a la galletita horneada durante 7,5 minutos (a.Color). Mientras que el 57\% prefirió la galletita de color más oscuro (b.Color), debido a la caramelización de la sacarosa y otros azúcares reductores presentes por su mayor tiempo de exposición al calor (10 minutos). Por lo tanto, este atributo, según los consumidores, no estaría indicando una diferencia entre los productos analizados.

El sabor de las galletitas, según la Figura 5.17, presentó la misma tendencia que el descriptor anterior, observándose que el $75 \%$ de los panelistas prefirió la galletita horneada a $200^{\circ} \mathrm{C}-7,5$ minutos. Los valores más bajos para la condición $200^{\circ} \mathrm{C}-10$ minutos (b.Sabor) se podrían relacionar con los productos de la reacción de Maillard que otorgan sabor amargo, en este caso no deseable.

En la Figura 5.17, la textura de la galletita horneada durante 10 minutos (b.Textura) presentó el mayor porcentaje (57\%) para la puntuación más alta (7-9) en concordancia con la menor energía requerida para cortar la galletita (ver parámetro área de la Tabla 5.12), respecto del otro producto evaluado.

Teniendo en cuenta todos los atributos, el $60 \%$ de los evaluadores prefirió la galletita horneada durante 7,5 minutos. En su mayoría coincidieron en que les agradó el sabor (promedio 7,08 puntos) a pesar del color más pálido (promedio 6,62 puntos).

La aceptabilidad general para la galletita seleccionada $\left(200^{\circ} \mathrm{C}-7,5\right.$ minutos) fue en promedio de 7 puntos, mientras que la otra condición obtuvo 6,60 puntos.

A continuación, en la Figura 5.18 se presentan los histogramas para la aceptabilidad general de las galletitas evaluadas durante el primer ensayo sensorial. 

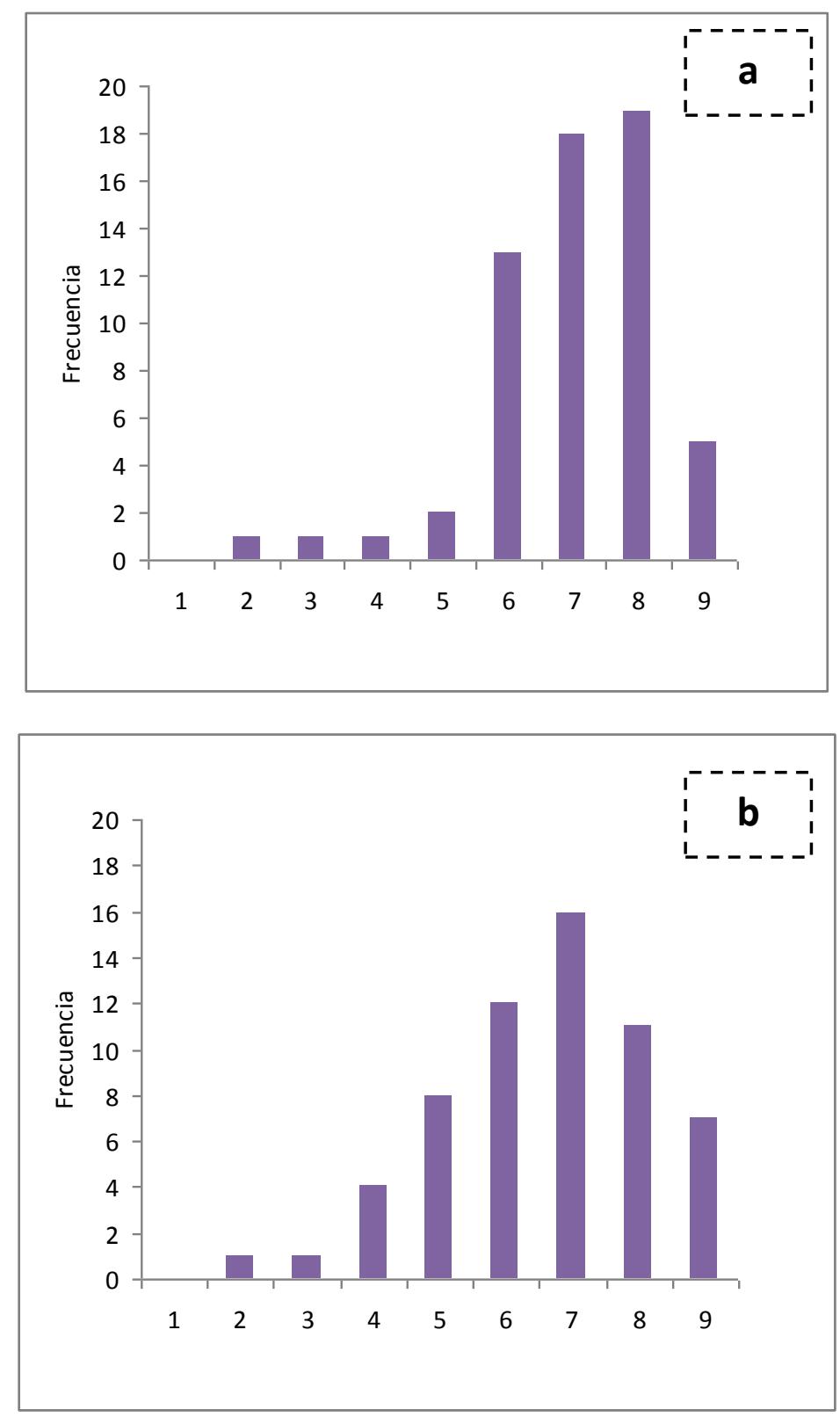

Figura 5.18. Histogramas obtenidos a partir de la aceptabilidad general evaluada en forma sensorial de galletitas elaboradas con $25 \%$ de harina de ahipa (formulación 3) y horneadas a $200^{\circ} \mathrm{C}$ durante a) 7,5 minutos y b) 10 minutos.

En cuanto a la aceptabilidad general, ambos histogramas son similares en el primer rango (1-3) de la escala hedónica. La distribución en la Figura 5.18.a, tiene un sesgo hacia los valores de mayor puntuación de la escala hedónica (7 y 8) mientras que en la Figura 5.18.b se observa una distribución más simétrica. Esto indicaría que la galletita horneada durante 7,5 minutos sería la preferida por la mayoría de los evaluadores. Sin 
embargo, ambos histogramas muestran que la galletita elaborada con $25 \%$ de harina de ahipa (formulación 3) tuvo buena aceptación por parte de los consumidores, independientemente de la condición de horneado.

Para analizar la diferencia existente entre los productos estudiados se utilizó el test de Student aplicando la ecuación 5.3., indicada previamente. La hipótesis nula del problema es que no hay diferencias entre las galletitas evaluadas. En la Tabla 5.15 se presentan los resultados de aceptabilidad obtenidos para ambas galletitas y las diferencias calculadas entre ellas. Teniendo en cuenta estos valores y que en este caso el número de evaluadores $(\mathrm{N})$ es de 60 , el promedio de la diferencia, calculada con la ecuación 5.4 es:

$\overline{\mathrm{d}}=\frac{\sum d_{i}}{\mathrm{~N}}=\frac{24}{60}=0,40$

Con este valor se estimó la desviación estándar empleando la ecuación 5.5:

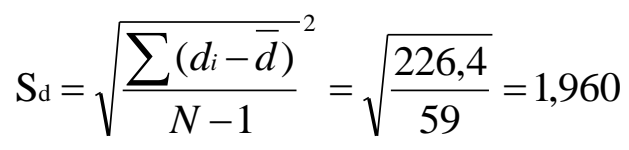

Con ambos parámetros estadísticos se calculó el valor experimental del estadístico tStudent $\left(t_{\exp }\right)$ con la ecuación 5.3:

$t_{\exp }=\frac{\bar{d}}{S_{d} / \sqrt{N}}=\frac{0,40}{1,96 / \sqrt{60}}=1,581$ 
Tabla 5.15. Valores de aceptabilidad de las galletitas analizadas utilizando escala hedónica y diferencia entre las mismas.

\begin{tabular}{|c|c|c|c|}
\hline \multirow{2}{*}{ Evaluador (N) } & \multicolumn{2}{|c|}{ Galletita } & \multirow{2}{*}{ Diferencia (d) } \\
\hline & $a$ & $\mathrm{~b}$ & \\
\hline 1 & 8 & 7 & 1 \\
\hline 2 & 8 & 8 & 0 \\
\hline 3 & 6 & 8 & -2 \\
\hline 4 & 7 & 6 & 1 \\
\hline 5 & 6 & 4 & 2 \\
\hline 6 & 6 & 8 & -2 \\
\hline 7 & 6 & 4 & 2 \\
\hline 8 & 2 & 8 & -6 \\
\hline 9 & 7 & 5 & 2 \\
\hline 10 & 7 & 6 & 1 \\
\hline 11 & 6 & 5 & 1 \\
\hline 12 & 7 & 9 & -2 \\
\hline 13 & 8 & 7 & 1 \\
\hline 14 & 6 & 6 & 0 \\
\hline 15 & 6 & 6 & 0 \\
\hline 16 & 7 & 7 & 0 \\
\hline 17 & 9 & 8 & 1 \\
\hline 18 & 7 & 7 & 0 \\
\hline 19 & 4 & 3 & 1 \\
\hline 20 & 8 & 8 & 0 \\
\hline 21 & 8 & 7 & 1 \\
\hline 22 & 8 & 6 & 2 \\
\hline 23 & 8 & 7 & 1 \\
\hline 24 & 6 & 8 & -2 \\
\hline 25 & 8 & 8 & 0 \\
\hline 26 & 9 & 8 & 1 \\
\hline 27 & 8 & 6 & 2 \\
\hline 28 & 3 & 5 & -2 \\
\hline 29 & 7 & 4 & 3 \\
\hline 30 & 7 & 6 & 1 \\
\hline 31 & 7 & 7 & 0 \\
\hline 32 & 6 & 4 & 2 \\
\hline 33 & 8 & 9 & -1 \\
\hline 34 & 8 & 5 & 3 \\
\hline 35 & 5 & 7 & -2 \\
\hline 36 & 8 & 7 & 1 \\
\hline 37 & 5 & 7 & -2 \\
\hline 38 & 7 & 8 & -1 \\
\hline 39 & 9 & 6 & 3 \\
\hline 40 & 6 & 9 & -3 \\
\hline 41 & 7 & 9 & -2 \\
\hline 42 & 8 & 9 & -1 \\
\hline 43 & 7 & 6 & 1 \\
\hline 44 & 6 & 6 & 0 \\
\hline 45 & 7 & 9 & -2 \\
\hline 46 & 6 & 7 & -1 \\
\hline 47 & 8 & 5 & 3 \\
\hline 48 & 8 & 9 & -1 \\
\hline 49 & 7 & 6 & 1 \\
\hline 50 & 9 & 2 & 7 \\
\hline 51 & 6 & 5 & 1 \\
\hline 52 & 8 & 5 & 3 \\
\hline 53 & 8 & 7 & 1 \\
\hline 54 & 7 & 7 & 0 \\
\hline 55 & 8 & 7 & 1 \\
\hline 56 & 7 & 5 & 2 \\
\hline 57 & 7 & 7 & 0 \\
\hline 58 & 8 & 7 & 1 \\
\hline 59 & 9 & 6 & 3 \\
\hline 60 & 7 & 8 & -1 \\
\hline
\end{tabular}

En la Tabla 5.16, se observa que para 59 grados de libertad y un nivel de significación (NS) de $0,05 t=2,000$, mientras que para $N S=0,1 \mathrm{t}=1,671$ (para un ensayo de dos colas). 
Como el valor de $t_{\text {exp }}=1,581$ es menor que el teórico obtenido de la Tabla 5.16 se aceptó la hipótesis nula. Por lo tanto, con ambos niveles de significación no habría diferencia significativa entre las galletitas evaluadas mediante el ensayo sensorial. Sin embargo, considerando que la formulación 3 con menor tiempo de cocción (7,5 minutos) obtuvo el mayor puntaje en cuanto a la aceptabilidad general, y atributos sabor y color, y teniendo en cuenta el menor requerimiento energético para la elaboración del producto, ésta fue la condición seleccionada.

Tabla 5.16.Valores de la distribución t de Student para ensayos de una y dos colas.

\begin{tabular}{|c|c|c|c|c|c|c|}
\hline \multirow[b]{4}{*}{ di } & \multicolumn{6}{|c|}{ Nvel de sicnĭcosoión para onsayo de una coda } \\
\hline & 0,1 & 0,05 & 0,025 & 0,01 & 0,005 & 0,0005 \\
\hline & \multicolumn{6}{|c|}{ Nivel do significación pera eresypo de dos colses } \\
\hline & 0,2 & 0,1 & 0,05 & 0,02 & 0,01 & 0.001 \\
\hline 1 & $3, \mathrm{Cr} 8$ & 6,314 & 12,706 & 31,821 & 63,656 & 636,578 \\
\hline 2 & 1,886 & 2,920 & 4,303 & 6,965 & 9,225 & 31,600 \\
\hline 3 & 1,638 & 2,353 & 3,182 & 4,541 & 5,841 & 12,924 \\
\hline 4 & 1,533 & 2,132 & 2,776 & 3,747 & 4,604 & 8,610 \\
\hline 5 & 1,476 & 2,015 & 2,571 & 3,365 & 4,032 & 6,869 \\
\hline 6 & 1,440 & 1,923 & 2,447 & 3,143 & $3,70 \mathrm{r}$ & 5,860 \\
\hline 7 & 1,415 & 1,805 & 2,365 & 2,2086 & 3,400 & 5,408 \\
\hline 8 & $1,39 \pi$ & 1,860 & 2,306 & 2,856 & 3,356 & 5,041 \\
\hline 2 & 1,383 & 1,833 & 2,262 & 2,821 & 3,250 & 4,781 \\
\hline 10 & $1,3 / 2$ & 1,812 & 2,228 & 2,754 & 3,160 & 4,587 \\
\hline 11 & 1,363 & 1,796 & 2,201 & 2,718 & 3,106 & 4,437 \\
\hline 12 & 1,356 & 1,782 & 2,179 & 2,681 & 3,056 & 4,318 \\
\hline 13 & 1,350 & 1,771 & 2,160 & 2,650 & 3,012 & 4221 \\
\hline 14 & 1,345 & 1,761 & 2,145 & 2,624 & 2,977 & 4,140 \\
\hline 15 & 1,341 & 1,753 & 2,131 & 2,600 & $2,9 \mathrm{TT}$ & 4,073 \\
\hline 16 & $1,3 \mathrm{JI}$ & 1,746 & 2,120 & 2,583 & 2,921 & 4,015 \\
\hline 17 & 1,333 & $1,7<0$ & 2,110 & 2,567 & 2,898 & 3,965 \\
\hline 18 & 1,330 & 1,734 & 2,101 & 2,552 & 2,878 & 3,022 \\
\hline 19 & 1,328 & 1,720 & 2,093 & 2,530 & 2,851 & 3,883 \\
\hline 20 & 1,325 & 1,725 & 2,086 & 2,528 & 2,845 & 3,850 \\
\hline 21 & 1,323 & 1,721 & 2,080 & 2,518 & 2,839 & 3,819 \\
\hline 22 & 1,321 & 1,717 & 2,074 & 2,508 & 2,819 & 3,792 \\
\hline 23 & 1,319 & 1,714 & 2,060 & 2,500 & $2,90 \mathrm{~T}$ & 3,768 \\
\hline 24 & 1,318 & 1,711 & 2,064 & 2,450 & $2,7 \mathbb{W}$ & 3,745 \\
\hline 25 & 1,316 & 1,708 & 2,060 & 2,485 & $2,78 \mathrm{I}$ & 3,725 \\
\hline 26 & 1,315 & 1,706 & 2,056 & 2,479 & 2,770 & $3, \pi 07$ \\
\hline 27 & 1,314 & 1,703 & 2,052 & 2,473 & 2,771 & 3,689 \\
\hline 28 & 1,313 & 1,701 & 2,048 & $2,46 \pi$ & 2,763 & $3, \sqrt{ } 4$ \\
\hline 20 & 1,311 & $1, \in D$ & 2,045 & 2,462 & 2,756 & 3,660 \\
\hline 30 & 1,310 & 1,607 & 2,042 & 2,457 & 2,750 & 3,646 \\
\hline 40 & 1,303 & 1,684 & 2,021 & 2,423 & 2,704 & 3,551 \\
\hline 60 & 1,206 & 1,671 & 2,000 & 2,380 & 2,060 & 3,460 \\
\hline 120 & 1,289 & 1,658 & 1,980 & 2,358 & 2,617 & 3,373 \\
\hline$=$ & 1,282 & 1,645 & 1,96 & 2.376 & 2,576 & 3.201 \\
\hline
\end{tabular}

En un segundo ensayo sensorial, una vez definido el porcentaje de sustitución y el tiempo de cocción, se evaluaron tres de los productos libres de gluten elaborados. Mediante una escala hedónica estructurada se analizaron los mismos atributos del 
ensayo anterior (color, sabor, textura) y la aceptabilidad general, de las galletitas elaboradas con las formulaciones 0 (100\% almidón de maíz), 3 (25\% harina de ahipa) y 5 ( $25 \%$ harina de mandioca), horneadas en las condiciones dadas por el primer sensorial $\left(200^{\circ} \mathrm{C}-7,5\right.$ minutos). No se consideró la formulación 6 que contenía harina de trigo integral por no corresponder a un producto libre de gluten.

Los resultados obtenidos en este ensayo se encuentran representados en las Figuras 5.19 y 5.20. Los atributos color, sabor y textura se presentan en la Figura 5.19 con los códigos 0 para la galletita preparada con 100\% de almidón de maíz, 3 y 5 para aquellas con $25 \%$ de harina de ahipa y mandioca, respectivamente.
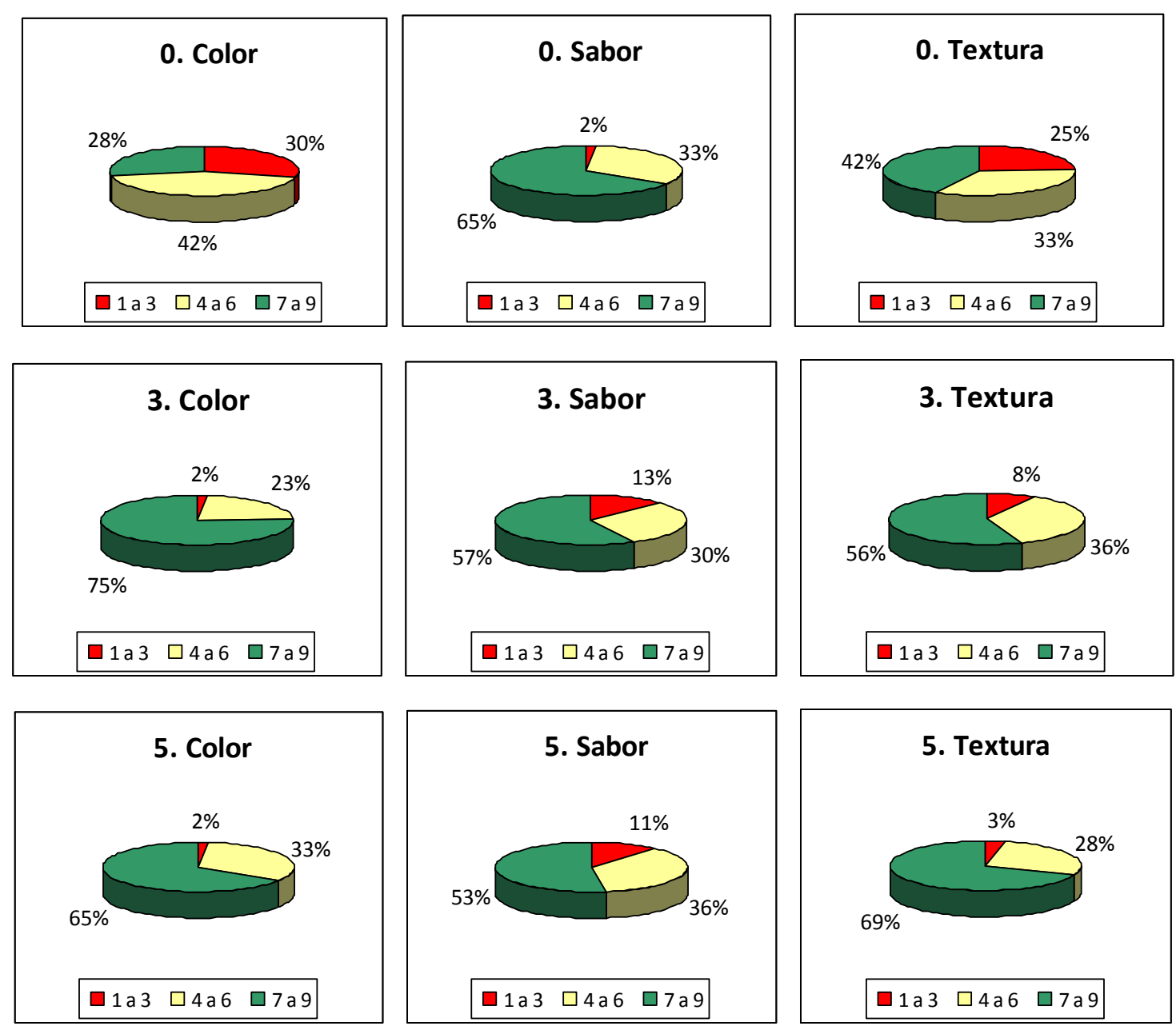

Figura 5.19. Porcentajes obtenidos para las diferentes puntuaciones, a partir de la evaluación sensorial de galletitas horneadas a $200^{\circ} \mathrm{C} 7,5$ minutos, elaboradas con las formulaciones 0,3 y 5 .

Los resultados fueron clasificados en tres rangos: 1-3 (rojo), 4-6 (amarillo) y 7-9 (verde) de la escala hedónica. 
El color de la galletita elaborada con harina de ahipa (formulación 3) presentó el mayor porcentaje (75\%) en el rango de puntuación 7-9 (3.Color). En este ensayo los consumidores prefirieron el mismo producto que en la evaluación sensorial anterior. La galletita de almidón de maíz (formulación 0) mostró los porcentajes más altos en el rango 1-3 (0.Color) que indican una mayor proporción de rechazo del producto, mientras que recibió la mayor puntuación en sabor (0.Sabor). Este comportamiento puede encontrarse relacionado al sabor más familiar y tradicional que los panelistas describieron como "asociado al alfajor de maicena".

La textura de la galletita elaborada con harina de mandioca (5.Textura) obtuvo el 69\% de aceptación por parte de los consumidores siendo el valor más alto para el rango 79. En segundo lugar se ubicó la galletita con harina de ahipa (3.Textura), mientras que el 36\% le otorgó puntuación en el rango 4-6 respecto de los otros productos evaluados. La galletita con $100 \%$ almidón de maíz (formulación 0) mostró los porcentajes más altos en el rango 1-3 (0.Textura) que como ya se mencionó indican un mayor rechazo del producto, dentro de la muestra de consumidores participantes.

En cuanto a los valores promedio obtenidos para los productos evaluados de todos los atributos, las galletitas elaboradas con harina de ahipa (6,64 puntos) y con harina de mandioca (6,68 puntos) recibieron el mayor puntaje en comparación con la galletita preparada con $100 \%$ almidón de maíz (5,91 puntos). En promedio, el color de la galletita elaborada con ahipa fue evaluado con mayor puntaje $(7,26$ puntos) respecto de las otras galletitas.

Los histogramas de los productos evaluados (Figura 5.20) muestran los resultados del ensayo sensorial para la aceptabilidad general de la galletita preparada con harina de ahipa (formulación 3) en comparación con las galletitas "convencionales" libres de gluten (formulaciones 0 y 5 ). 

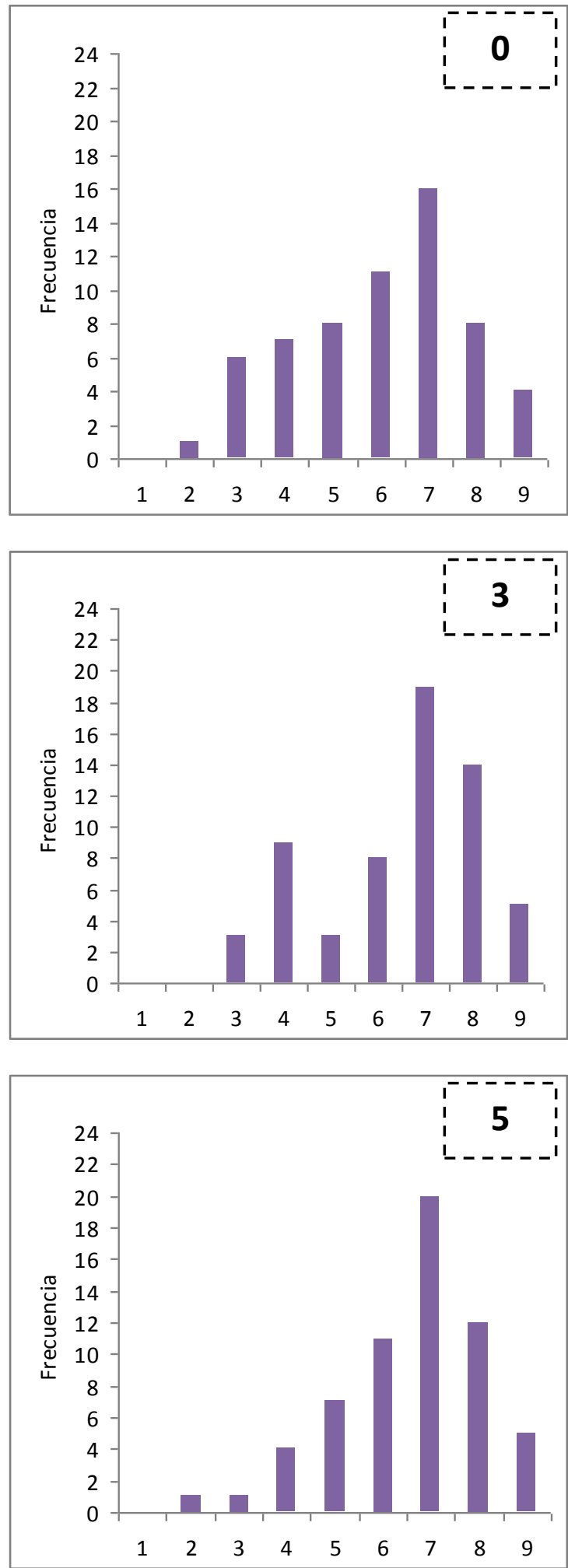

Figura 5.20. Histogramas obtenidos para los valores de aceptabilidad general de las galletitas elaboradas a partir de las recetas 0,3 y 5 , horneadas a $200^{\circ} \mathrm{C}$ durante 7,5 minutos. 
Los tres histogramas son diferentes; la distribución en la Figura 5.20.3, tiene un sesgo hacia los valores de mayor puntuación de la escala hedónica ( 7 y 8 ) mientras que en las Figuras 5.20 .5 y 5.20 .0 se observa una distribución más simétrica.

La aceptabilidad general para la galletita con harina de ahipa (6,52 puntos) fue menor que para el producto con harina de mandioca (6,61 puntos). Estos resultados sugieren que ambos productos fueron aceptados respecto de la galletita elaborada con $100 \%$ almidón de maíz (6 puntos).

La harina de ahipa podría sustituir al almidón de maíz en futuras formulaciones para la preparación de productos libres de gluten, lo que contribuiría a obtener un producto nutricionalmente balanceado y con buena aceptación por parte de los consumidores. 


\section{CONCLUSIONES}

Se demostró la factibilidad de elaborar una galletita de muy buena calidad sensorial a base de harina de ahipa y almidón de maíz (ambas materias primas exentas de gluten) destinada a la población celíaca por su baja concentración de prolaminas, inferior al límite indicado en la legislación.

Las galletitas elaboradas a partir de las mezclas secas ensayadas, presentaron un color más intenso y valores de luminosidad superiores a los encontrados en las preparaciones.

En general, la mezcla o premezcla seca 3 correspondiente a la preparación con 25\% harina de ahipa exhibió la más alta capacidad de retención de los solventes ensayados, mientras que la mezcla 0 (100\% almidón de maíz) presentó los valores más bajos. Este comportamiento era de esperar debido al aporte de proteínas de la harina de ahipa (9\%).

El análisis del perfil de textura de las masas crudas ensayadas mostró diferencias respecto de los ingredientes presentes en las mismas. La masa preparada con $35 \%$ de harina de ahipa (formulación 4) presentó el valor más alto de dureza respecto del control y demás formulaciones. La menor cohesividad fue registrada en la masa elaborada con 12,5\% harina de ahipa (formulación 1), indicando así una baja integración de los componentes en la misma. En cambio la masa de formulación 3 (con $25 \%$ harina de ahipa) no mostró diferencias significativas con el control $(p>0,05)$.

En cuanto a la composición química, las galletitas elaboradas con $25 \%$ de harina de ahipa (formulación 3) presentaron un contenido de materia seca más bajo y un mayor porcentaje de proteínas, cenizas y fibra dietaria total.

El análisis estadístico realizado para las diferencias de color de las galletitas evaluadas, en función de las condiciones de horneado, indicó que las combinaciones $180^{\circ} \mathrm{C}-10$ minutos y $200^{\circ} \mathrm{C}-7,5$ minutos no presentaron diferencias significativas $(p>0,05)$ siendo los valores obtenidos más bajos que los correspondientes a la condición restante (200 $\mathrm{C}-10$ minutos).

El índice de pardeamiento (IP) de los productos horneados estudiados, se incrementó en general a medida que aumentó el porcentaje de sustitución de almidón de maíz por harina de ahipa (formulaciones 1, 2, 3 y 4). Además estos valores fueron mayores al control (formulación 0) para todas las condiciones de horneado. Esto se relacionó con 
el incremento en el contenido de azúcares y proteínas presentes en la harina de ahipa (Capítulo 4).

En general, las galletitas preparadas con harina de ahipa pueden considerarse microbiológicamente seguras ya que las medidas de actividad acuosa se encontraron por debajo de $\mathrm{a}_{\mathrm{w}}=0,40$.

Todas las formulaciones presentaron los valores más altos de fuerza máxima en la condición de horneado $200^{\circ} \mathrm{C}-10$ minutos, lo que estaría indicando una muestra de mayor firmeza respecto de las demás condiciones y una sobre-cocción del producto.

La galletita elaborada con $25 \%$ de harina de ahipa y horneada a $200^{\circ} \mathrm{C}$ durante 7,5 minutos obtuvo el mayor puntaje en cuanto a aceptabilidad general, sabor y color. Teniendo en cuenta el menor requerimiento energético para la preparación del producto, ésta fue la condición seleccionada.

La harina obtenida de la raíz tuberosa de Pachyrhizus ahipa podría sustituir al almidón de maíz en futuras formulaciones de galletitas para la preparación de productos libres de gluten, lo que contribuiría a obtener un producto nutricionalmente balanceado y con buena aceptación de los consumidores. 


\section{REFERENCIAS BIBLIOGRÁFICAS}

AACC International. (2000). Approved Methods of the American Association of Cereal Chemists, 10th Ed. Methods 56-11. The Association: St. Paul, MN.

Abbas, K. A., Khalily, S. K., Shobirin Meor Hussin, A. (2010). Modified Starches and Their Usages in Selected Food Products: A Review Study. Journal of Agricultural Science Vol. 2, No. 2.

Álvarez-Jubete, L., Arendt, E. K., Gallagher, E. (2010). Nutritive value of pseudocereals and their increasing use as functional gluten free ingredients. Trends Food Sci. Technol. 21, 106-113.

Ameur, L. A., Mathieu, O., Lalanne, V., Trystram, G., Birlouez-Aragon, I. (2007). Comparison of the effects of sucrose and hexose on furfural formation and browning in cookies baked at different temperatures. Food Chemistry 101 (4) 1407-1416.

Andrés, S.C., García, M.E., Zaritzky, N.E. Califano, A.N. (2006). Storage stability of lowfat chicken sausages. Journal of Food Engineering, 72, 311-319.

AOAC (1990). Official methods of analysis of the Association off Official Analytical Chemists. Arlington, Va.

Asociación Argentina de Celiaquía: sitio web http://www.celiaco.org.ar. Accedido en Marzo de 2013.

Bjorck, I., Grandfeldt, Y., Liljeberg, H., Tovar, J., Asp, N. G. (1994). Food properties affecting the digestion and absorption of carbohydrates. Am J Clin Nutr, 59 (suppl): 699S-705S.

Bourne, M. C. (1978). Texture profile analysis. Food Technology, 32 (7) 62-66,72. 
Buera, M. P., Retriella, C., Lozano, R. D. (1985). Definition of colour in the nonenzymatic browning process. Die Farbe 33, 316-326.

Celíacos Argentinos: sitio web http://www.celiacosargentinos.com.ar. Accedido en Marzo de 2013.

Cheftel, J. C.; Cheftel, H. (1977). Introduction à la biochimie et à la technologie des aliments. Paris: Lavoisier, 420 p.

Código Alimentario Argentino (CAA). (2013). Buenos Aires. Argentina. http://www.anmat.gov.ar/alimentos/normativas alimentos caa.asp. Accedido en Enero de 2014.

Colombo, A., Pérez, G. T., Ribotta, P. D., León, A. E. (2008). A comparative study of physicochemical tests for quality prediction of Argentine wheat flours used as corrector flours and for cookie production. Journal of Cereal Science, 48(3), 775-780.

De la Vega, M. C. G. (2009). Proteínas de la harina de trigo: clasificación y propiedades funcionales. Temas de Ciencia y Tecnología, 13 (38) 27-32.

de Oliveira, K. E., Takase, I., de Andrade Gonçalves, E. C. B. (2009). Development of gluten-free cookie from medicinal plants (Guaraná - Paullinea cupana and Catuaba Anemopaegma mirandum) aiming at copper, iron, and zinc supplementation. Ciênc. Tecnol. Aliment., Campinas, 29(3): 631-635.

Dini, C., Doporto, M.C., García, M.A., Viña, S.Z. (2013). Nutritional profile and antinutrient analyses of Pachyrhizus ahipa roots from different accessions. Food Research International (54) 255-261.

Duyvejonck, A. E., Lagrain, B., Pareyt, B., Courtin, C.M., Delcour, J. A. (2011). Relative contribution of wheat flour constituents to Solvent Retention Capacity profiles of European wheats. Journal of Cereal Science, 53(3), 312-318. 
Duyvejonck, A. E., Lagrain, B., Dornez, E., Delcour, J. A., Courtin, C. M. (2012). Suitability of solvent retention capacity tests to assess the cookie and bread making quality of European wheat flours. LWT - Food Science and Technology, 47(1), 56-63.

Fennema, O. (2008). Química de los Alimentos. Editores: Damodaran, S., Parkin, K. L., Fennema, $\mathrm{O}$.

Gaines, C. S. (2000). Report of the AACC committee on soft wheat flour. Method 56-11, Solvent Retention Capacity Profile. Cereal Foods World, 45, 303-306.

Gálvez, A.V., Aravena, E.L., Mondaca, R.L. (2006). Isotermas de adsorción en harina de maíz (Zea mays L.). Ciência e Tecnologia de Alimentos 26, 821-827.

Gallagher, E. (2002). The Application of Functional Ingredients in Short Dough Biscuits. MSc Thesis. Cork, Ireland: Department of Food Technology, University College Cork.

Gallagher, E., Gormley, T.R., Arendt, E.K. (2004). Recent advances in the formulation of gluten-free cereal-based products. Trends in Food Science \& Technology, 15, 143-152.

Gómez-González, A. (2007). Notas Breves Sobre Alimentación en la Enfermedad Celiaca. Bol Clin Hosp Infant Edo Son 24(2): 81-83.

Granato, D., Ellendersen, L. de S. N. (2009). Almond and peanut flours suppelmented with iron as potential ingredients to develop gluten-free cookies. Ciênc. Tecnol. Aliment., Campinas, 29(2): 395-400.

Gustafsson, K., Asp, N. G., Hagander, B., Nyman, M., Schweizer, T. (1995). Influence of processing and cooking of carrots in mixed meals on satiety, glucose and hormonal response. Int J Food Sci Nutr, 46: 3-12.

Hoseney, R.C., Rogers, D.E. (1994). Mechanism of sugar functionality in cookies: the science of cookie and cracker production. In: The science of cookie and cracker 
production (edited by H. Faridi). Pp. 203-225. St. Paul, MN: American Association of Cereal Chemists.

InfoStat versión 2013. Di Rienzo J.A., Casanoves F., Balzarini M.G., Gonzalez L., Tablada M., Robledo C.W. Grupo InfoStat, FCA, Universidad Nacional de Córdoba, Argentina. URL http://www.infostat.com.ar.

McWatters, K.H., Ouedraogo, J.B., Resurrection, A.V.A., Hung, Y.C., Philips, R.D. (2003). Physical and sensory characteristics of sugar cookies containing mixtures of wheat, fonio (Digitaria exilis) and cowpea (Vigna unguiculata) flours. International Journal of Food Science and Technology, 38, 403-410.

Meilgaard, M., Civille, G. V., Carr, B. T. (2007). Sensory Evaluation Techniques. Ch. 12. CRC Press, Florida, Estados Unidos.

Mora, M., Litwin, N., Tocca, M. D. C. (2010). Prevalencia de enfermedad celíaca: estudio multicéntrico en población pediátrica en cinco distritos urbanos de Argentina. Rev Argent Salud Pública, 1(4): 26-31.

Mundt, S., Wedzicha, S. M. (2007). A kinetic model for browning in the baking of biscuits: effects of water activity and temperature. LWT - Food Science and Technology 40, (6) 1078-1082.

Olivera, D.F., Salvadori, V. O. (2012). Kinetic modeling of quality changes of chilled ready to serve lasagna. Journal of Food Engineering, 110 (3) 487-492.

Pham, Q. T. (2001). Modelling thermal process: cooling and freezing. In: Tijskens, L. M. M.; Hertog, M. L. A. T. A.; Nicolai, B. M. (Eds.). Food process modeling. Cambridge: Woodhead Publishing Limited, 312-339. 
Ramón, D. (2013). Diseño científico de un producto lácteo para celíacos. Editores Rodrigo, L., Pena, A. S. Enfermedad celíaca y sensibilidad al gluten no celíaco. Barcelona, España: Omnia Science, 497-506.

Rodrigues Ferreira, S. M. Cordeiro Luparelli, P., Madalozzo Schieferdecker, M. E., Vilela, R. M. (2009). Cookies sem glúten a partir da farinha de sorgo. Archivos Latinoamericanos de Nutrición. Órgano Oficial de la Sociedad Latinoamericana de Nutrición. Departamento de Nutrição da Universidade Federal do Paraná, Brasil. Vol. 59 № 4.

Rodríguez-Sandoval, E., Fernández-Quintero, A., Alaya-Aponte, A. (2005). Reología y textura de masas: aplicaciones en trigo y maíz. Ingeniería e Investigación, 57: 72-78.

Rosell, C. M., Santos, E., Collar, C. (2009). Physico-chemical properties of commercial fibres from different sources: A comparative approach. Food Research International, $42(1), 176-184$.

Salinas, V. (2013). "Estudio de la calidad panera, sensorial y nutricional de panes elaborados con harina de trigo fortificada con sales de calcio e inulina". Trabajo de Tesis Doctoral.

Thompson, T., Dennis, M., Higgins, L. A., Lee, A. R., Sharrett, M. K. (2005). Gluten-free diet survey: are Americans with coeliac disease consuming recommended amounts of fibre, iron calcium and grain foods? Journal of Human Nutrition and Dietetics, 18, 163169.

von Atzingen, M. C., Machado Pinto, M. E. (2005). Evaluación de la textura y color de almidones y harinas en preparaciones sin gluten. Ciencia y Tecnología Alimentaria 4 (5), 319-323. Sociedad Mexicana de Nutrición y Tecnología de Alimentos, México. 
CONCLUSIONES GENERALES 


\section{CONCLUSIONES GENERALES}

- La incorporación de raíces de Pachyrhizus ahipa a la dieta constituiría una alternativa nutricionalmente relevante, debido a su aporte de proteínas, fibra y minerales esenciales. La composición química de las raíces varió con la accesión de origen. Las accesiones Local e IRNAS 11 se destacaron por su alto contenido de almidón, un nivel de proteína intermedio y los niveles más reducidos de antinutrientes (oxalatos, ácido fítico y taninos), características interesantes a tener en cuenta en un programa de mejoramiento genético, junto con sus propiedades tecno-funcionales.

- Respecto a la poscosecha de las raíces de ahipa, el almacenamiento refrigerado no resultó viable en las condiciones ensayadas debido al desarrollo de daño por frío, en tanto que a $25^{\circ} \mathrm{C}$ la conservación se realizó durante cuatro meses sin cambios notorios en los atributos de color y textura. Optimizando las condiciones de aplicación, el tratamiento térmico y la irradiación UV-C podrían ser alternativas viables para prolongar la vida útil de las raíces, aunque deben considerarse los costos derivados de su implementación.

- Es factible obtener a escala de laboratorio almidón de Pachyrhizus ahipa empleando un proceso de extracción optimizado, simple y con un bajo costo asociado. Dado su bajo contenido de amilosa y las bajas temperaturas de gelatinización, el almidón de ahipa podría constituirse en una alternativa frente a fuentes de almidón tradicionales. Las propiedades reológicas de sus pastas indican que podría emplearse como agente espesante, con la ventaja adicional de su baja tendencia a la retrogradación en condiciones de refrigeración.

- Se determinó la digestibilidad del almidón de ahipa, la que resultó similar a la de los almidones de otras leguminosas. Como ingrediente, podría ser utilizado en alimentos con alto contenido de energía debido a su alta proporción de almidón rápidamente digestible, especialmente el almidón proveniente de la accesión IRNAS 11. El almidón de mandioca tuvo un contenido bajo de almidón lentamente digerible y el derivado de la accesión Local de ahipa presentó valores intermedios para las fracciones analizadas.

- Se caracterizó el residuo remanente de la extracción de almidón morfológicamente a través de SEM y se determinó que tanto la fibra dietaria como el almidón eran los componentes mayoritarios del mismo. 
- Fue factible obtener harinas de Pachyrhizus ahipa y Manihot esculenta (mandioca) siendo el procesamiento a partir de rodajas la alternativa más simple. La harina de ahipa es un producto que podría ser utilizado en la preparación de alimentos para celíacos ya que se verificó la ausencia de gliadinas, mediante métodos sensibles actualmente en uso. La característica diferencial de esta harina es su aporte de proteínas, fibra y minerales tales como potasio, hierro y calcio, reflejando una composición nutricionalmente más equilibrada que otras harinas provenientes de R\&T.

- Las isotermas de sorción permitieron evaluar el contenido de humedad que garantiza la estabilidad de las harinas bajo diferentes condiciones de almacenamiento. La harina de ahipa presentó menor temperatura de gelatinización que la de mandioca, indicando una mejor aptitud para la cocción. Las diferencias observadas en la capacidad de hinchamiento y de retención de solventes de ambas harinas condicionan sus aplicaciones específicas, tales como su incorporación en alimentos libres de gluten.

- Se demostró la factibilidad de elaborar una galletita de alta calidad sensorial a base de harina de ahipa y almidón de maíz, ambas materias primas exentas de gluten destinadas a la población celíaca.

- El índice de pardeamiento de los productos horneados aumentó con el porcentaje de sustitución con harina de ahipa. La galletita elaborada con $25 \%$ de harina de ahipa y horneada a $200^{\circ} \mathrm{C}$ durante 7,5 minutos obtuvo el mayor puntaje en cuanto a aceptabilidad general, sabor y color, siendo ésta la condición seleccionada, considerando además el menor requerimiento energético para su proceso de elaboración.

- La harina obtenida de la raíz tuberosa de Pachyrhizus ahipa podría sustituir al almidón de maíz en futuras formulaciones de alimentos libres de gluten, lo que contribuiría a obtener un producto nutricionalmente balanceado y con buena aceptación por parte de los consumidores. 